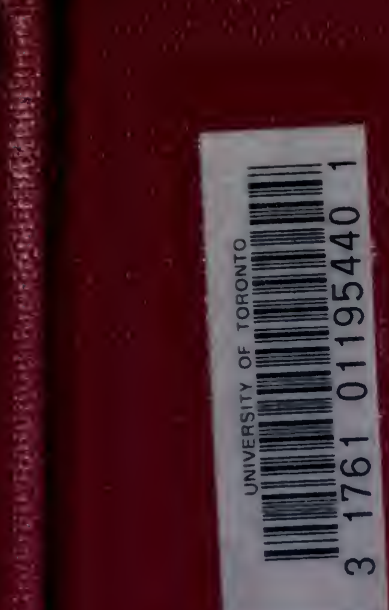







\section{THE POTATO}






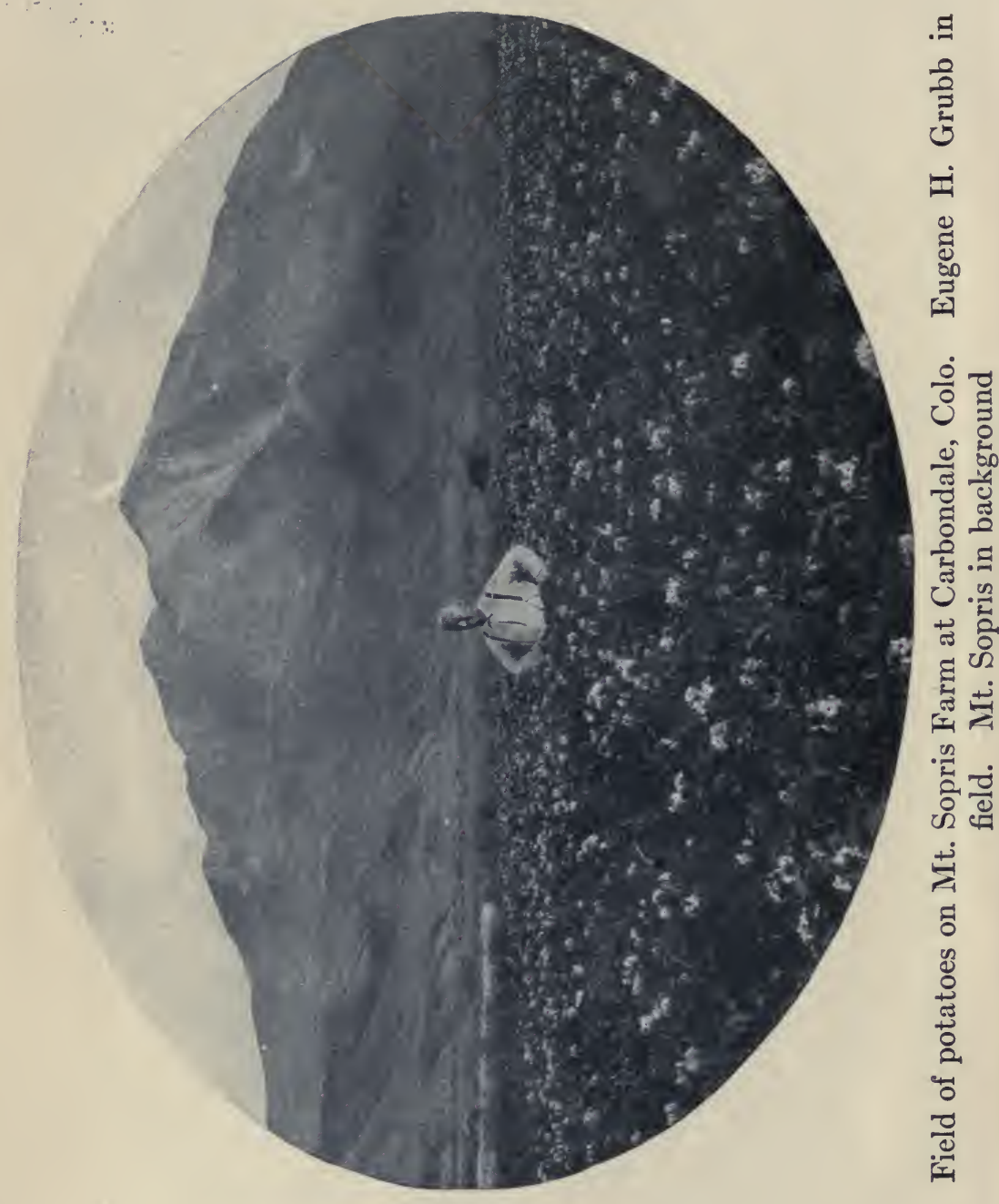




\section{The Jarm librare}

\section{THE POTATO}

A Compilation of Information from Every Available Source

\section{BY \\ EUGENE H. GRUBB}

Mt. Sopris Farm, Carbondale, Colorado; Consulting Agriculturist for the Twin Falls North Side Land and Water Company, Idaho, and the

Sacramento Valley Irrigation Company, California; Special

Commissioner to Europe in Potato Investigations for

the United States Government; author of

"The Modern Delicacy", "Orchard

Heating," "Farmers' Bulle-

tin 886 on Potatoes."

\section{AND \\ W. S. GUILFORD}

Jerome, Idaho, and Willows, California ; Director of Agriculture, Sacramento Valley Irrigation Company, California.

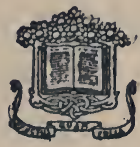

Garden City New York

DOUBLEDAY, PAGE \& COMPANY

1912 
Copyright, 1912, by

Doubleday, Page \& Company

All rights reserved, including that of translation into foreign languages, including the Scandinavian.
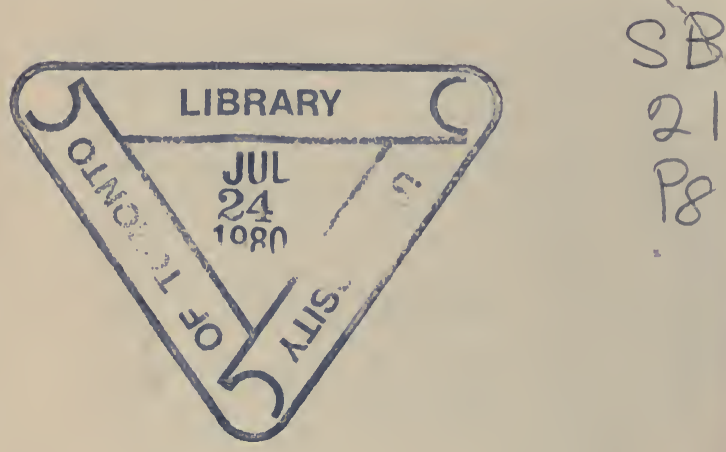

211 


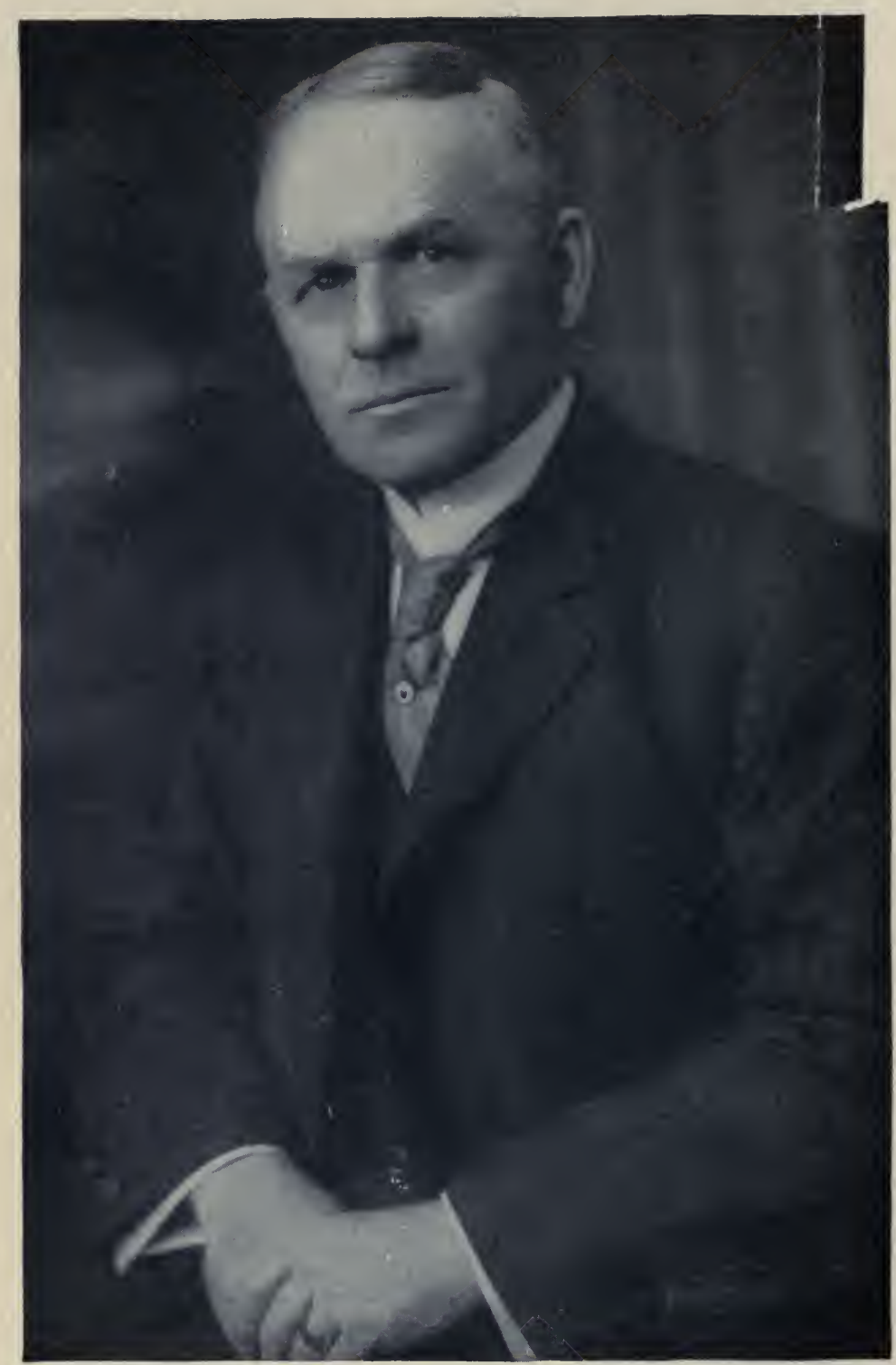

W. C. Brown, president New York Central Lines - a leader in agricultural progress 



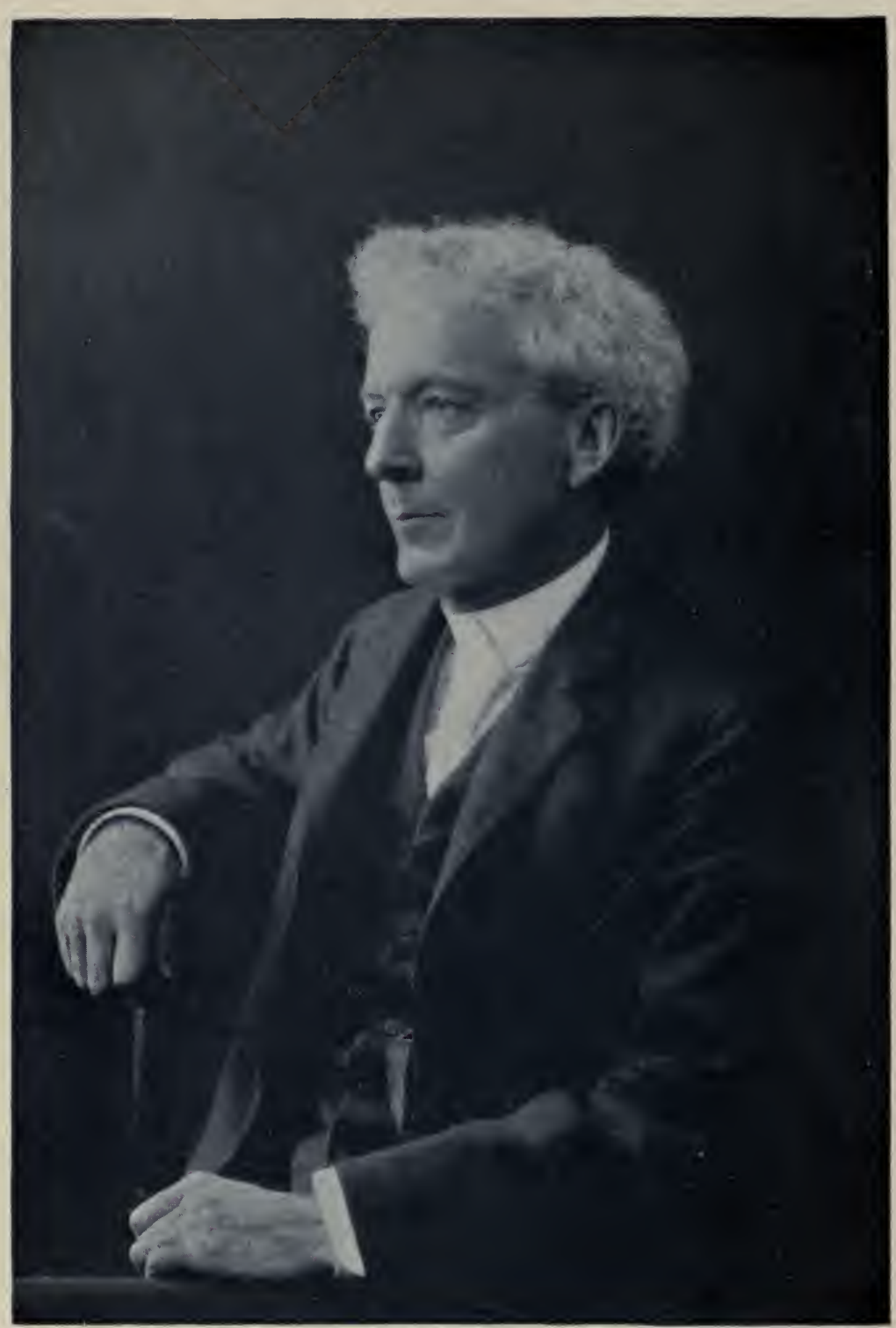

Luther Burbank, the world's greatest plant breeder 



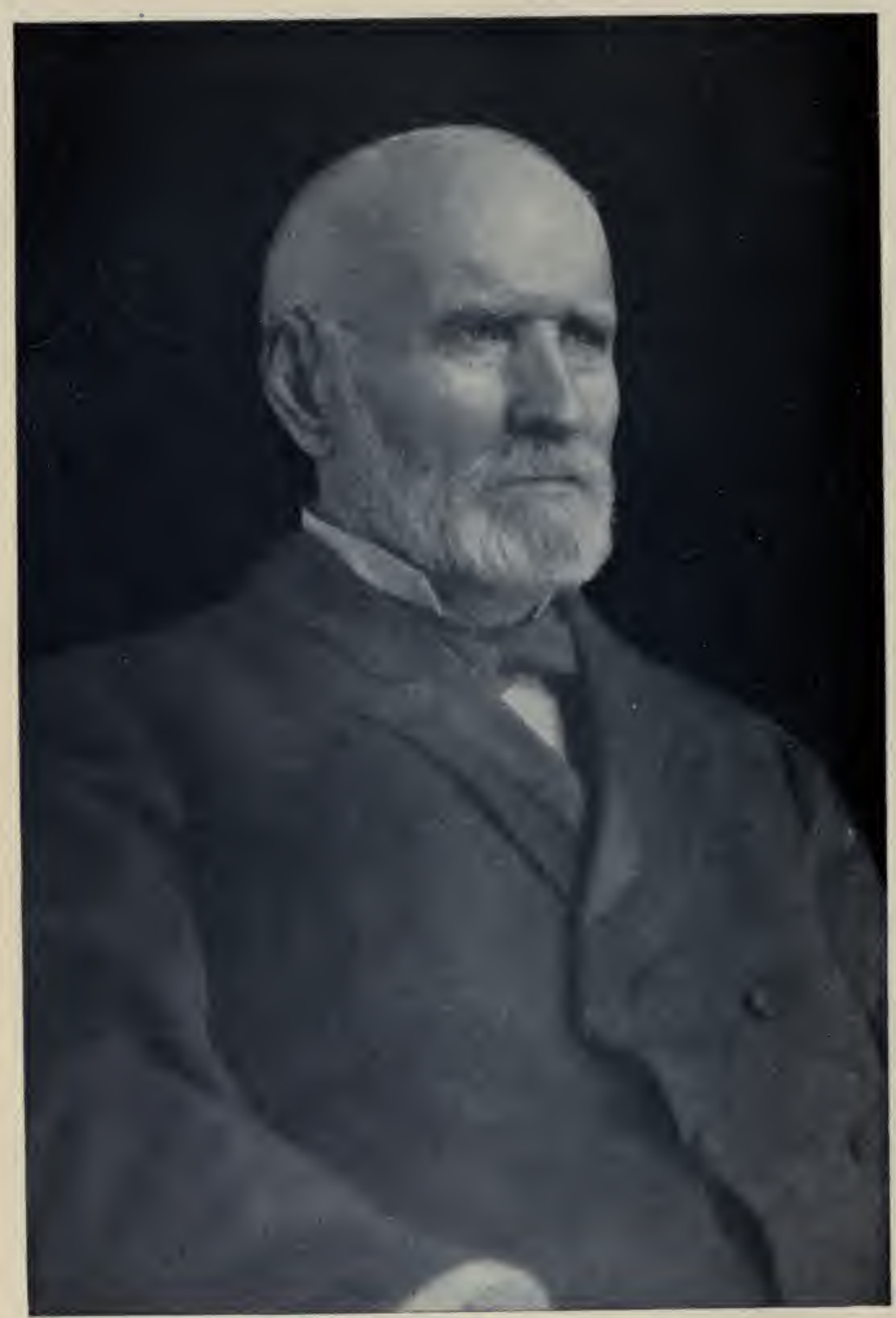

James Wilson, Secretary of Agriculture 


\title{
DEDICATION
}

Recognizing their valuable, lasting and unselfish work for American Agriculture in different fields, for the common good, this book is respectfully dedicated to

\author{
James Wilson \\ Secretary of Agriculture. \\ Luther Burbank \\ The World's Greatest Plant Breeder. \\ W. C. Brown \\ President, New York Central Lines.
}

Three men whose past work, present achievement, and plans for the future place them high in the list of those whose names live through all time. 



\section{ACKNOWLEDGMENTS}

The authors desire to acknowledge courtesies so numerous that to enumerate them is not possible, from potato growers, government and state agricultural authorities, dealers, officials of transportation companies and others interested in agricultural uplift, both in America and Europe. Every source of information has been drawn on, and credit has been given in the text of the book where quotations occur.

They also desire to thank Mr. Cassius K. Michael, with Doubleday, Page \& Company, for many valuable suggestions as to the compilation of the matter for this book and his careful and conscientious work in editing and preparing the copy for same. 



\section{AUTHORS' PREFACE}

It is with the hope that a compilation of information in regard to one of the world's greatest food plants - the potato - will be of service to the increasing thousands of people now interested and becoming interested in practical, scientific agriculture, that this work is published.

Never before in the history of the world has the production of human food received as great attention as at the present time. Population is increasing with alarming rapidity, while the supply of land on which it is possible to grow food is limited. The one solution of the problem is the production of more and better food on every acre of land on which crops are grown.

The working out of this problem calls for broad, liberal education, not the least factor of which is to benefit by the experience of others. This has been made a keynote in this work, and while growers may not see fit to adopt wholly some of the methods described, it is believed that they will find the suggestions helpful.

The senior author has grown a large acreage of potatoes at Mt. Sopris Farm for years, and has made a careful study of the practical side of potato growing all over the world. The discussion of problems, and the suggestions made, are from the standpoint of the practical grower.

E. H. Grubb.

W. S. GuILFORd.

March, 1912. 



\section{GONTENTS}

CHAPTER

$\checkmark$ Importance of the Potato !. ' .

PAGE

II The Potato as Food . . . . 7

III Climatic Requirements . . $\quad 17$

IV Potato Soils . . . . . 21

V Drainage . • . . . . 28

VI Soed Stocks and Varieties . . . $\quad 37$

VII Seod-bed Preparation and Planting . $\quad 76$

VIII Cultivation . $\quad$ • $\quad$ • $\quad$ • $\quad$ • 95

IX Irrigation . $\quad . \quad$. $\quad$. 101

X Harvesting • • . . . . 111

XI Potato Machinery $\quad$ • $\quad$ • 119

XII Selling and Storage . • • • 127

XIII Cost of Growing Potatoes - Yield Prices - Profits . . . . 141

XIV Markets and Marketing . . . 154

XV Enemies of the Potato . . . . 167

XVI Dining Cars, Hotels, and Restaurants . 208

XVII Fertilizers . . . . . . 210

XVIII The Farm Rotation . . . . 221

XIX Early Potatoes - Specialties . . . 224

XX The Burbank Potato . . . . 237

XXI The Sweet Potato . . . . 241

XXII Legislation . . . . . . 254

XXIII Cooking the Potato . . . $\quad 261$

XXIV Manufactures . . . . . 277

XXV Potatoes and Potato Products as Stock

Feed . . . . . . 303 


\section{CONTENTS}

CHAPTER

PAGE

XXVI Potatoes for Exhibition - Score Cards

and Standards . . . . . 311

XXVII Potato Superstitions and Prejudices • 319

XXVIII Recent Development in New and Old Dis-

tricts

XXIX North Atlantic States . . . $\quad$ • 328

XXX South Atlantic and Gulf States . . 347

XXXI The Middle West . . . . 354

XXXII Colorado . • . • • • 363

XXXIII Idaho - Twin Falls County - Upper

Snake River . . . . . 382

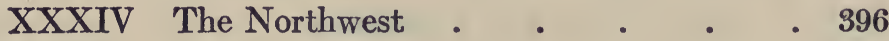

XXXV California . . . . . . 409

XXXVI The Island of Chiloe, Chile . . . 434

XXXVII Great Britain • • • • • 437

XXXVIII The Channel Islands . . . . 477

XXXIX Ireland . . • • • • 486

XL Continent of Europe $\quad$ • $\quad$ • $\quad$ • 489

XLI History . $\quad$ • $\quad$ • $\quad$ • $\quad$ • 512

XLII Botany, Physical and Chemical Composition of the Potato . . 521

APPENDIX

The Worlds Food Problem . . . . 535

Potato Statistics . . . . . . . 540

Acreage, Production, Value, Prices, etc. - $\quad$ - 542 


\section{LIST OF ILLUSTRATIONS}

Field of potatoes on Mt. Sopris Farm at Carbondale, Colo.

Frontispiece

James Wilson, Secretary of Agriculture . - ) Preceding

Luther Burbank .

W. C. Brown, President N. Y. Central Lines $\}$ Page

Map showing production of potatoes in the world

FACING PAGE

Graphic map showing production of potatoes in the

United States . . . . . . . . . 5

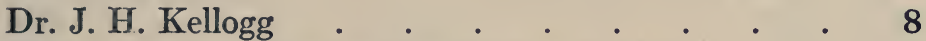

Battle Creek Sanitarium, Battle Creek, Mich. . $\quad 8$

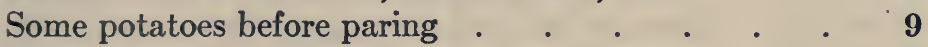

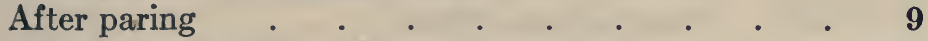

Chart showing origin of potato varieties $\quad$. $\quad$. 38

A Burbank potato . . . . . . . . . . $\quad$. 39

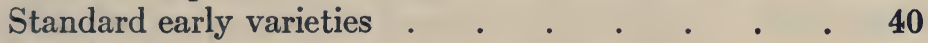

Standard late varieties $\quad . \quad$. $\quad . \quad$. $\quad . \quad$. $\quad . \quad 41$

Two views of Iron Age cultivator at work $\quad 96$

Potato field at Mt. Sopris Farm . . . . $\quad$. 97

Iron Age potato hoe or ridger . . . . . . 120

" " riding cultivator . . . . . . . 120

“ “

" " traction sprayer . . . . . . 120

“ “ (Improved Robbins) potato planter . . 121

Seed pieces in place of furrows . . . . . . 121

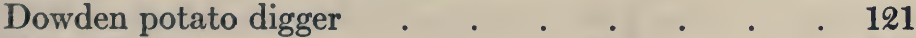

Deere disk harrow . . . . . . . . 122

" cultivator . . . . . . . . . 122

“ potato digger . . . . . . . . . . . 122

" two-way plow . . . . . . . . 122

" double-action disk harrow . . . . . 122

“ shaker potato digger . . . . . . . . . 122 


\section{LIST OF ILLUSTRATIONS}

"Picker" in Aspinwall planter . . . . . 123

Aspinwall two-row planter . . . . . . 123

" planter with fertilizer attachment . . 123

" potato sorter . . . . . . . . 123

" potato planter. . . . . . . . 124

“ sprayer . . . . . . . . 124

Thompson's Greeley potato sorter . . . . 125

Dowden potato digger at work on Mt. Sopris Farm . 126

Iron Age digger at work . . . . . . . 126

Hauling potatoes to storehouse in "half-sacks" - Mt.

Sopris Farm . . . . . . . . 126

Iron Age planter at work . $\quad . \quad$. $\quad . \quad$. 127

New potato cellar of Commissioner of Agriculture, A.

W. Gilman . . . . . . . • . 130

Potato storage cellar plan . . . . . . . 131

Wart disease of potatoes . . . . . . . 172

Early blight . . . . . . . . . 173

Potato Scab . . . . . . . . . 173

Late blight - diseased leaf and tuber of potato . . 178

Late blight - last stages of disease _ . . . . 179

Hill of potatoes partly diseased by dry-rot (Fusarium) 194

Various stages in destruction of potatoes by Fusarium 195

Rhizoctonia - showing development of "little potatoes" 198

" - showing stem of young potato plant affected from the seed

The potato eelworm, showing eggs, worm and infected potato . . . . . . . . 206

Iron Age sprayer in operation . . . . . . 207

E. L. Cleveland, Houlton, Maine . . . . . 226

E. L. Cleveland Co. potato storehouse . . . . 227

Carbondale Peachblow potatoes on exhibition . . 312

An attractive English exhibit of potatoes . . . 313

Map showing some potato districts in the United States 322

D. E. Burley and C. H. Schlaacks . . . . . 323

James J. Hill . . . . . . . . . 324

Eugene H. Grubb . . . . . . . . 325

Mt. Sopris and a part of the Carbondale district, Colo. . 374

Lord Ogilvy, agricultural editor of Denver Post,

Denver, Colo. . 


\section{LIST OF ILLUSTRATIONS}

Potato digging near Twin Falls

Planet Jr. furrower or ridger for hilling potatoes . . 384

Potatoes near Jerome $\quad$ • • • • • . . 385

Irrigating potatoes near Wendell . . . . . . 385

I. B. Perrine and H. L. Hollister . . . . . 386

Map showing districts in Great Britain where there are prominent potato farms . . . . . . 438

Sir Matthew Wallace . . . . . . . . 442

Potato digging in Scotland . . . . . . 443

Potato field on the farm of Matthew G. Wallace . 443

Mr. Hannah and Mr. Grubb in potato field . . . 450

Potato field on Girvan Mains farms . . . 450

Digging potatoes at Girvan Mains . . . . . 450

Garden on Girvan Mains farms . . . . 450

Buildings on Little Pinmore farm, Scotland . . . 451

House on Little Pinmore farm . . . . . 451

Farm buildings, Girvan Mains farms . . . . 451

Laborer's house, Girvan Mains . . . . . 451

A party of leading British farmers . . . . . 456

Sutton's Windsor Castle . . . . . . . 457

Intensive British agriculture illustrated . . . 458

W. Dennis \& Sons . . . . . . . . 464

Potato storage house on farm of W. Dennis \& Sons . 465

Titus Kime . . . . . . . . . . 470

Northern Star potatoes grown by Titus Kime . . 470

Half acre challenge plot of Northern Star potatoes . 4771

Harvesting early potatoes on the Island of Jersey . 478

Oats on the Island of Jersey . . . . . . 478

Plow for very deep plowing used in the Island of Jersey 478

Sutton's Ninety-fold potatoes . . . . . . 4479

Composition of the potato . . . . . . 524

Transverse and longitudinal sections of the potato $\quad 525$ 

THE POTATO 



\section{CHAPTER I}

IMPORTANCE OF THE POTATO

D

URING the season of 1911-1912 the United States has imported large quantities of potatoes from Europe. The crop of 1911 was a good many million bushels short of the needs of the nation.

This situation causes the thoughtful student of the food problem to ask why we do not grow more potatoes. Have we not a sufficient area suited to the crop? or is the average production per acre too low, and if so, can it be increased?

A potato shortage is apt to result in this country any year that weather or soil conditions are unfavorable in our principal producing districts.

We can and must grow more and better potatoes. There are good undeveloped districts that can produce a large tonnage, and by better methods of propagation and cultivation the yield on areas now in the crop can be very greatly increased.

The potato comprises about 25 per cent. of the food of European and English-speaking people. Only the Oriental races exist without it. If the potato crop of Europe should fail, famine would result, as it did in Ireland between 1840 and 1850. More pounds of the potato are produced than of any other food crop in the world. 
The number of pounds of food produced to the acre in the potato crop is large, as compared with some other crops. In a 90 -bushel potato crop there are 5,400 pounds of food; a 14-bushel wheat crop weighs only 840 pounds.

Although good yields are made by some growers in the United States, the average production is only 89.8 bushels per acre, while in Germany the average yield is 197.3 bushels, and in Great Britain 186.4 bushels.

In the United States the average consumption of potatoes per capita is between three and four bushels. In Europe it greatly exceeds this, in some sections being more than twenty-five bushels. The potato furnishes a cheap, wholesome food, and its use could be considerably increased with benefit to the race.

At the Battle Creek Sanitarium in Michigan, under the direction of one of the greatest food experts in the world, 1,000 people consume 7,000 bushels per year - seven bushels per capita.

The use of the potato can and will be very greatly extended. In Europe, especially in Germany, the potato is largely used in manufacturing and for stock food. The price of gasoline and kerosene is kept down by the low price of spirit distilled from the potato. A very high-grade glucose, from which confectionery is made, is a potato product. It is superior to grain glucose. Flour which is used in all kinds of cooking is made from the potato. Potato starch is also made in Germany and in the United States.

It was with the idea of improving potato conditions that the senior author wrote the following letter, dated December 7, 1908, to Secretary of Agriculture James Wilson: 


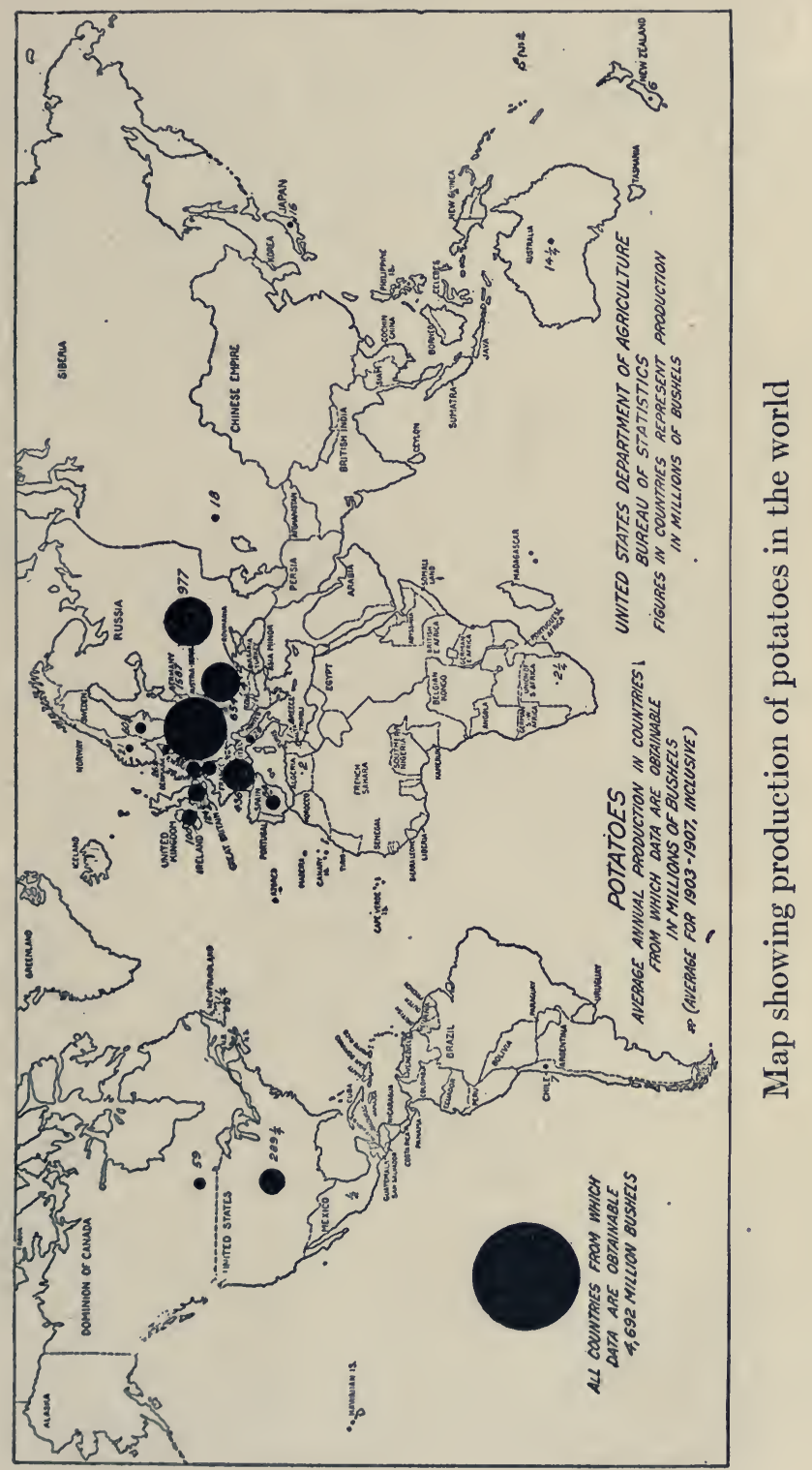



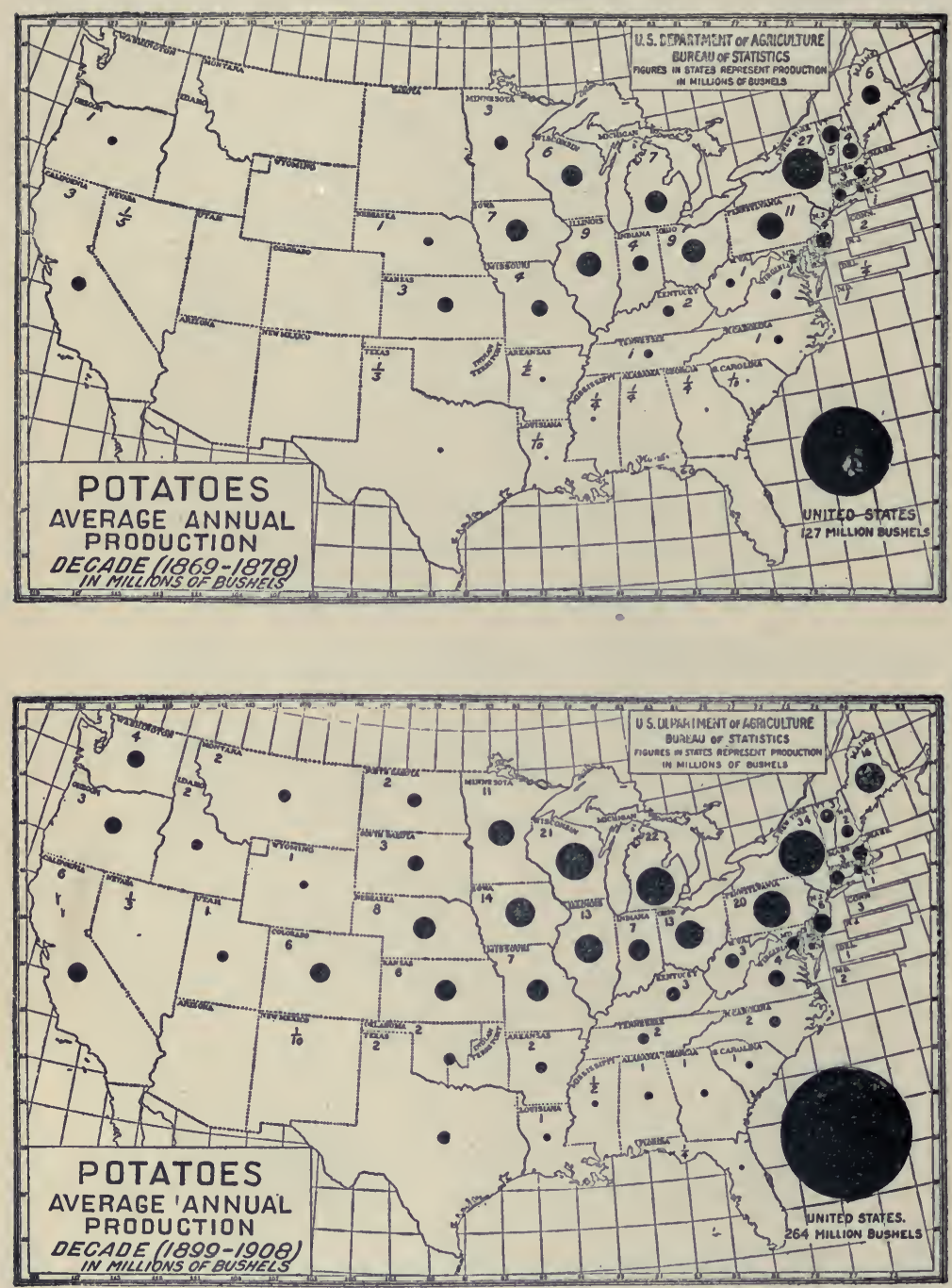

Graphic map showing production of potatoes in the United States 
"It may seem presumptuous on my part to suggest any remedy for the betterment of the present unsatisfactory conditions obtaining in American potato growing, but the more I investigate the subject of potato culture in this country the more I am convinced of the necessity of more thorough and special knowledge of potato growing by American farmers, if they are ever to compete with the vast influx of foreign potatoes to our shores. It seems to me urgent that our Government exert itself to ameliorate, in some measure at least, the present deplorable state of this great and vital industry. We should investigate the causes whereby the foreign potato culturists are able to so considerably exceed our own best efforts of production, and the diffusion of such information among our American farmers would be invaluable and certainly productive of the use of more intelligent methods by them, resulting in a perceptible increase in this great food staple, together with a much needed improvement in quality.

"I am fully persuaded that we imperatively need a more practical knowledge of seed growing and seed selection, of growing special seed stocks, the proper storage of seed stocks during the winter, preparation of seed bed and cultivation, balanced plant foods and fertilization of soil. I know of no acquisition to agricultural knowledge so devoutly to be wished, or that would be so valuable to our farmers.

"If Germany, with an area not more than twice that of Colorado, can and does produce fully two billion bushels of potatoes annually, and the United States, in its entirety, a meagre two hundred and seventy-five million bushels annually 
(which latter is vastly overestimated), we ought to know what it is that produces such marvellous results on foreign soils, which have been cropped for a thousand years."

Since this letter was written the senior author has carefully studied the European potato situation, and the results of his investigations are incorporated in the chapters which follow, being given in detail in chapters XXXVII, XXXVIII, XXXIX and XL.

The attention that is given to this matter abroad, and the esteem in which it is held, are shown by the following extract from a very able address by David Young, editor of the North British Agriculturist, Edinburgh, Scotland, entitled "The Potato Crop." He says:

[ "The potato crop is one of the most important of all in the rural economy of the United Kingdom. The potato is an esculent which is largely used and highly relished as an article of diet by rich and poor alike. The very poorest of the population find it one of the cheapest forms of sustenance they can obtain, and no well-ordered banquet, however sumptuous, would be considered complete without the roti-boeuf and the poulet being flanked by the pommes de terre.

"The potato crop is practically the one farm crop grown primarily for human food of which the United Kingdom can in ordinarily favorable seasons supply the wants of its teeming population." 


\section{CHAPTER II}

\section{THE POTATO AS FOOD}

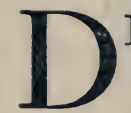

EFINITE knowledge in regard to the world's greatest food crop is very meagre. This is true not only of the mass of consumers, but even doctors and cooks, who should be well informed on every subject pertaining to food.

One of the greatest authorities on food in the world is Dr. J. H. Kellogg, superintendent of the Battle Creek Sanitarium, Battle Creek, Mich. He has spent a lifetime in the study of the various articles of food, his investigations covering all possible sources of information, not only in America, but in Europe. The following article on "The Special Dietetic Virtues of the Potato," by this foremost authority, is one of the best ever written about the potato:

"Soon after the potato was introduced into Europe in the sixteenth century the ridiculous notion somehow got afloat that the use of the potato was the cause of leprosy, which at that time was quite prevalent in most European countries. The prejudice which was thus created against this most valuable of all garden vegetables has never been quite overcome. Various malicious libels against the good name of this most innocent and wholesome of foodstuffs are still afloat. Multitudes believe the potato to be difficult of di- 
gestion. Even physicians often prohibit its use on the supposition that it is likely to ferment in the stomach - a mistaken notion, as the writer will show. The belief is quite general that the potato especially promotes fat-making, and hence that its use must be avoided by persons who have a tendency to obesity. This is also an error. All foods tend to produce obesity when taken in excessive quantity; that is, more than the individual needs to maintain his nutrition on equilibrium. No foods produce excess of fat when limited in quantity to actual daily bodily needs.

"The potato is truly a most remarkable product. It contains within its aseptic covering a rich store of one of the most easily digestible of all forms of starch. The observations of Mossé, Von Noorden and others have shown most conclusively that the starch of the potato is more easily digested and appropriated by the body than the starches of wheat, corn, and most other cereals. In laboratory tests made by the writer it was found that potato starch digested in less than one sixth of the time of cereal starches. The experience of hundreds of physicians in the treatment of diabetics has shown that in many cases the starch of the potato is more easily assimilated or better utilized than other forms of starch.

"Potato gruel made from specially prepared potato meal or the pulp of baked potatoes has been found in Germany of very great service in the feeding of infants and invalids. Potato starch is far better for this purpose than cornstarch, arrowroot and similar substances which are pure starch and cannot be properly considered as foods. The long continued use of these starches in the feeding of young infants often results most disastrously. 


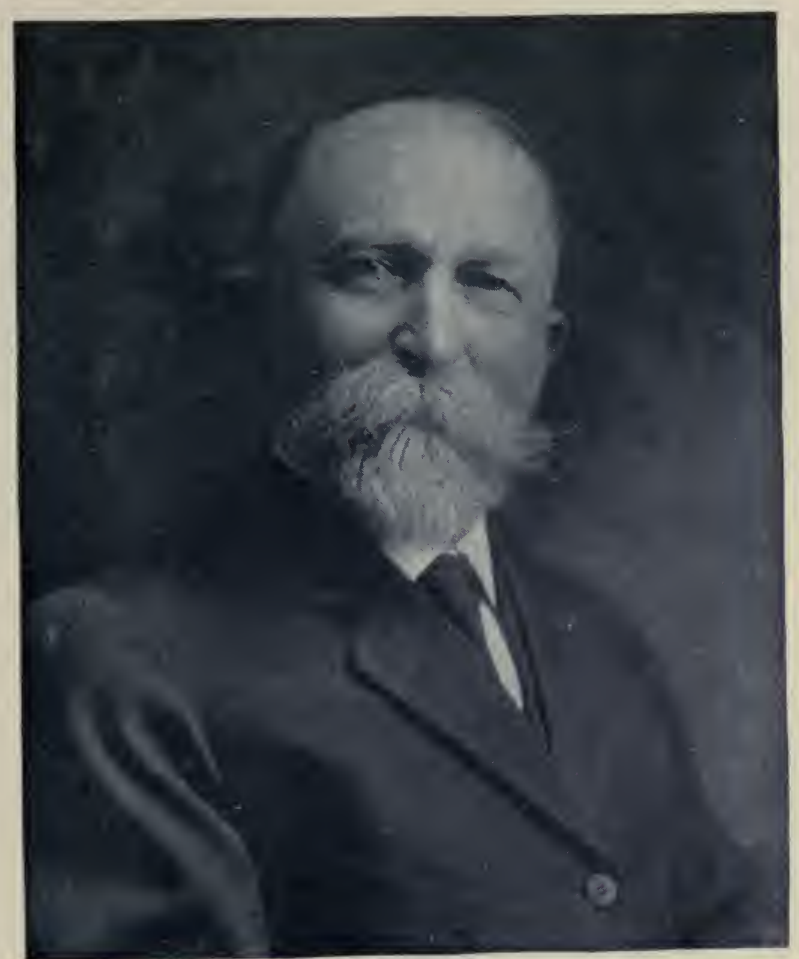

\section{DR. J. H. KELLOGG}

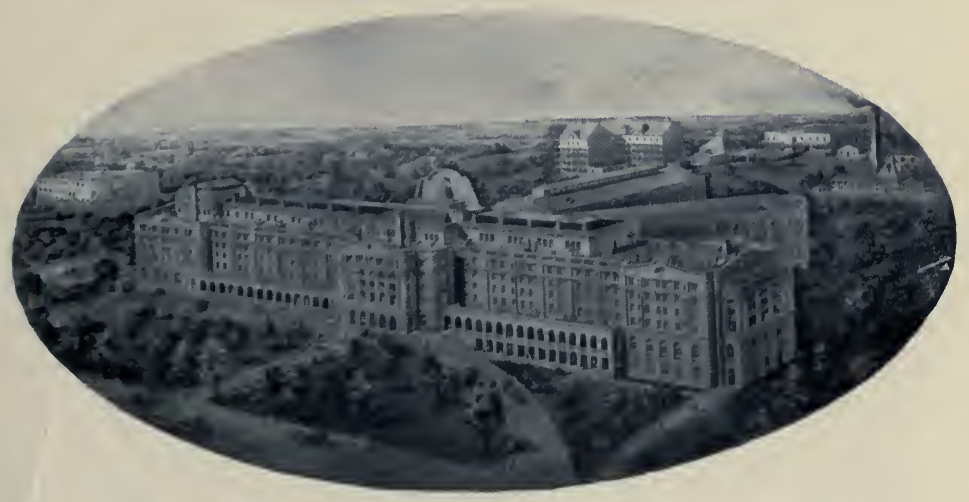

Battle Creek Sanitarium, Battle Creek Mich. 


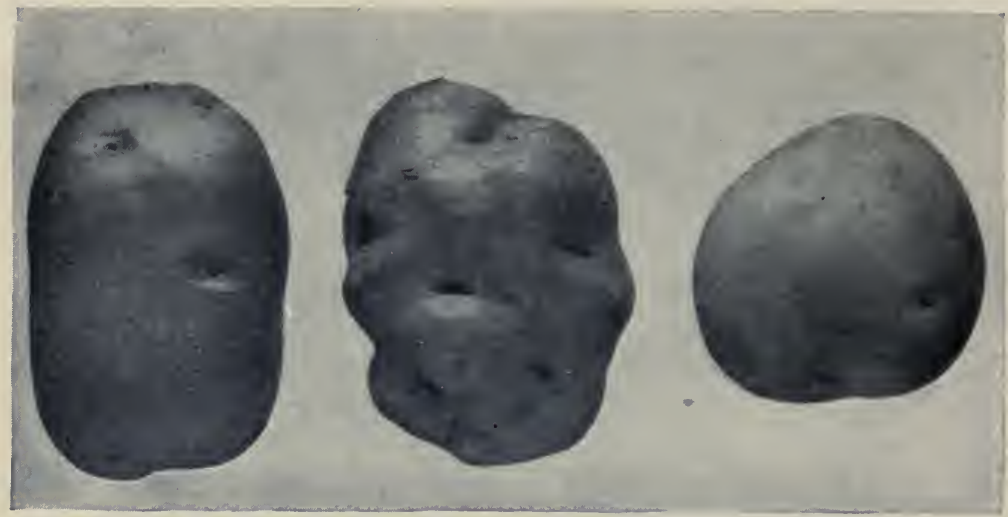

Illustration shows desirable and undesirable types of potatoes before paring

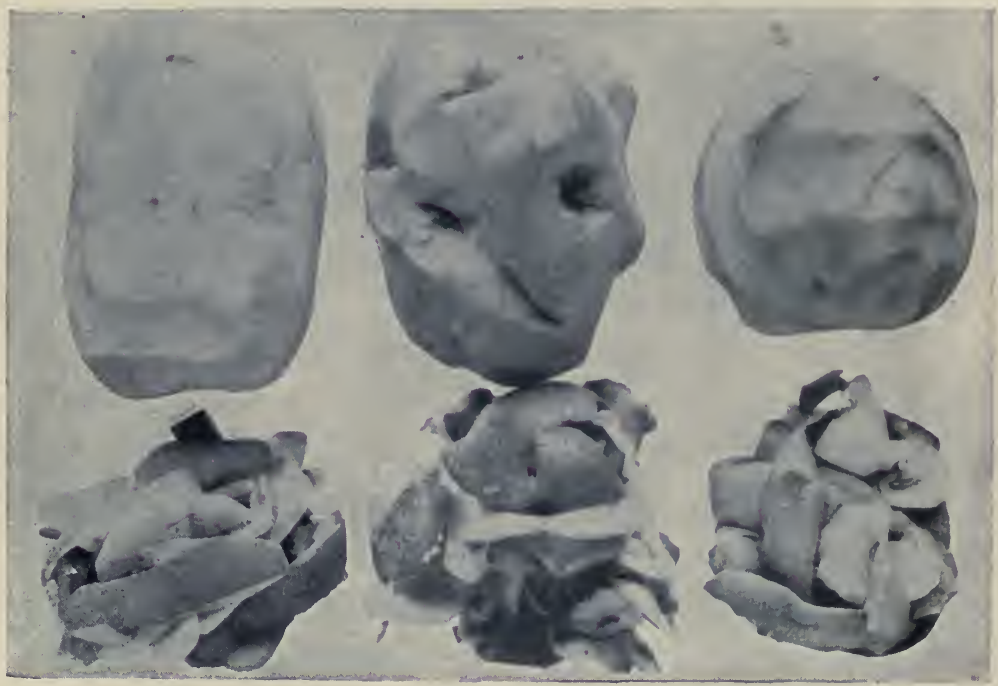

Same potatoes after paring. At the left is shown Dalmeny Challenge potato. The unpared tuber weighed $13.4 \mathrm{oz}$. and the parings $1.7 \mathrm{oz}$. or $\mathbf{1 2 . 6}$ per cent. In the centre is shown the McCormick potato. The unpared tuber weighed $13.9 \mathrm{oz}$. , and the parings $3.2 \mathrm{oz}$, or 23.2 per cent. At the right is shown Red Peachblow potato. The unpared tuber weighed $9.5 \mathrm{oz}$, and the parings $1.2 \mathrm{oz}$, or 12.4 per cent. 


\section{THE POTATO}

"The potato is not only an easily digestible foodstuff but possesses much higher nutritive value than is generally supposed. According to Gautier, about one fourth of the weight of the potato is food substance, consisting chiefly (nine elevenths) of starch. Of the remainder, three fifths are protein, the tissue-building element, and two fifths alkaline salts in combination with citric and malic acids, the acids of the lemon and the apple.

"From a dietetic standpoint, the potato is perhaps slightly deficient in protein, though this statement would be disputed by some physiologists whose experiments appear to demonstrate that the amount of protein contained in the potato is quite sufficient for ordinary bodily needs.

"The potato is certainly deficient in fats, of which it contains almost none, because of the fact that it is not, like so many of our vegetable foods, a seed, but a curiously modified and enormously fleshy tuber. This deficiency in fat must always be remembered in the use of the potato, and the lack must be made up by the addition of cream, butter, or some other foodstuff rich in fat.

"What the potato lacks in fat and protein, however, it makes up in salts, which constitute nearly 5 per cent. of its dry substance and are perhaps its most characteristic quality from a dietetic standpoint and one of its chief excellences. These salts consist chiefly of potash, and in the ordinary form in which they are supplied do a most important service in maintaining the alkaline condition of the blood, which is essential to good health and resistance to disease. Meats contain a very great excess of acid-forming elements and tend to acidify the blood. Cereals have some tendency in the 
same direction. The lowering of the alkalinity of the blood by acid-forming foods, especially by the free use of meat, is unquestionably one of the chief causes of the rapid increase in chronic diseases, the mortality from which has doubled within thirty years, causing a loss annually of 350,000 more lives than would occur if the average citizen was as healthy as he was thirty years ago. This is probably also one of the chief causes of arteriosclerosis, or hardening of the arteries, gout, rheumatism, Bright's disease, apoplexy, and other degenerative maladies. The alkaline salts of vegetables are needed to balance the dietary. If the consumption of potatoes in this country could be quadrupled, the result would undoubtedly be the saving of many thousands of lives annually and an incalculable amount of suffering from disease.

"The great nutritive value of the potato, notwithstanding the fact that it is three fourths water, may be best shown by comparing it with other known foods. A study of the nutritive value of various common foodstuffs shows that one pound of baked potato is equivalent in total nutritive value to the quantities of various foods shown in the following table:

\section{Food Equivalent in Total Food Value to One Pound of Baked Potato}

\footnotetext{
$1 \frac{f}{5}$ pounds of boiled potato

$5 \frac{7}{8}$ ounces boiled beef

1 pound of chicken

$1 \frac{1}{2}$ pounds of codfish

$2 \frac{1}{4}$ pints of oysters (solids)

4 pints of clams (in shell)

$4 \frac{1}{2}$ pints of beef juice

10 pints bouillon or beef tea

$1 \frac{1}{2}$ pints whole milk
} 
3 pints skimmed milk

8 eggs

9 ounces baked beans

7 ounces bread

$1 \frac{3}{4}$ pints oatmeal or corn meal mush

$1 \frac{1}{3}$ pints hominy (cooked)

1 pint boiled rice

1 pound of bananas

2 pounds parsnips (cooked)

1 pound green peas (cooked)

3 pounds beets (cooked)

4 pounds boiled cabbage

4 pounds radishes

5 pounds tomatoes

5 pounds turnips (cooked)

$6 \frac{1}{2}$ pounds cucumbers

"From the above table it will readily appear that the potato is one of the most nourishing of our common foods. Its value is still further emphasized by the fact that steamed or mashed potato digests in two or three hours, whereas roast beef requires four to five hours, or double the time (Gautier).

"As already noted, the potato is not rich in protein, although the amount of this element in the baked potato reaches the Chittenden standard of 10 per cent. of the total nutritive value, a proportion which in feeding many thousands of persons, those in health as well as invalids, at the Battle Creek Sanitarium, we have found amply sufficient. The writer adopted personally a very low protein standard in early life and has adhered to it for more than forty-six years, and with great benefit. Nevertheless, if a larger amount of protein is required, it may easily be obtained by the addition of milk or eggs, substances which while increasing the proportion of protein also add the fat necessary to render the potato a com- 
plete food. Half a pint of rich milk will thus balance a pound of baked potato; or an equally good balance may be made by adding to a pound of potato two ounces of white bread (two ordinary slices) and an ounce of butter.

"Bungé, the world's greatest authority on the chemistry of foods, has called special attention to the importance of the alkaline salts that are found in vegetables, and in a much larger proportion in the potato than in any other vegetable used as food, the potato containing nearly forty times as much of this useful element as some cereal foods. No farmer would think of feeding his horses or cattle on grain alone. Cereals of all sorts contain a considerable excess of acid-forming elements. Grass and herbage of all sorts, as well as fresh vegetables, contain an abundance of alkaline salts, and hence are a necessary part of the diet of animals. Human beings, as Bungé has clearly shown, require such vegetables for the same reason, and the potato is the most valuable of all known foods as a source of these essential elements. This is perhaps the reason why the potato is an almost invariable accompaniment of meat dishes. Meat contains an enormous excess of acid-forming substances, which are to some extent neutralized and antidoted by the basic salts of the potato.

"Graham bread with butter, or beans with butter, however, are much better combinations with potato than meat, for the reason that both meat and potato are lacking in lime. The body requires about thirteen grains of lime a day. Meat contains but half a grain of lime to the pound. The potato contains only about a grain and a half to the pound. Wheat flakes and other whole wheat preparations contain four grains of lime to the 
pound, and peas and beans contain eight grains of lime to the pound. Cow's milk contains fourteen grains of lime to the pint. The American people are losing their teeth, and bone diseases are increasing, as a result of this deficiency of lime. Professor Sherman of Columbia University declares that half the people of the United States are suffering from lime starvation. This is in part because of the meat diet and free use of cane sugar. Less meat, a larger proportion of potatoes, combined with wheat preparations and other cereals, beans, peas, and cow's milk would help to check this degenerative tendency.

\section{THE POTATO AS A FOOD REMEDY}

"The potato is of immense service as a food remedy in the treatment of a large number of diseases. It is especially valuable in cases of chronic intestinal auto-intoxication or 'biliousness.' It affords bulk for the intestine to act upon, and so antagonizes constipation. The large proportion of starch and other carbohydrates encourages the growth of friendly bacteria in the intestine, thus preventing putrefaction. For the same reason the free use of potatoes combats rheumatism and gout, which are results of chronic intestinal poisoning.

"The potato is valuable in the treatment of anemia, because it combats the growth in the intestine of the germs which produce blooddestroying poisons. The death rate from diabetes, according to the mortality statistics of the United States Census Bureau, has increased nearly 50 per cent. in ten years. The freer use of potatoes as an article of diet and the lessened consumption 
of meat would perhaps do more than any other one thing to suppress the alarming increase of this fatal malady.

"Arteriosclerosis, or hardening of the arteries, a disease which causes apoplexy and is associated with Bright's disease and various forms of heart disease besides being the cause of premature old age, is most often directly the result of chronic poisoning, the source of which is the putrefaction of undigested remnants of animal substances which have been eaten, which undergo decay with the absorption of poisonous products. The free use of the potato as an article of diet in place of the excessive consumption of meat and fish, a practice widely prevalent, would unquestionably check the alarmingly rapid development of this disease, which, according to the United States mortality reports, has increased 400 per cent. in the last ten years.

"The potato, buttermilk, and oatmeal diet of the Irish has developed one of the most sturdy and enduring races of men to be found anywhere. The proportion of centenarians in Ireland is more than ten times as great as in England. There can be no doubt that the free use of potatoes by the Irish is in large measure responsible for the remarkable longevity of this nation.

"The idea that the potato is difficult of digestion and thus gives rise to fermentation in the stomach is entirely erroneous. The fault is not with the potato but with the manner of eating. When acted upon by the saliva, the starch of the potato is converted into maltose and dextrin, which Pawlow of St. Petersburg has shown to be powerful stimulants of the glands of the stomach. Properly cooked and well chewed, the potato is 
thus not only a good food but an aid to the digestion of other foods. In persons whose stomachs have a tendency to produce excessive acid the stimulating effect of the potato may be so great as to produce the symptoms characteristic of hyperacidity, heartburn, tenderness of the stomach, regurgitation of gas with acid liquid, and other well-known symptoms. This difficulty is not at all due to fermentation but to an excessive amount of acid and the resulting spasmodic contraction of the pylorus, so the stomach is stimulated to violent contraction. The gas contained in the stomach cannot be forced downward in the proper direction, and so escapes upward. This difficulty is not likely to occur, however, except when chewing is neglected. The gastric juice has little action upon the potato. Coarse particles of potato may remain in the stomach many hours, causing excessive acid fermentation, irritation and eructations. In eating potato every morsel must be chewed until reduced to a smooth paste in which no coarse particles can be detected by the tongue.

"The remedy is simple. Pawlow has shown that fats lessen the activity of the stomach in the secretion of gastric juice. Hence, it is only necessary to increase the amount of fat eaten with the potato. In extreme cases the potato should be eaten in the form of a puree with the addition of butter or rich cream. This difficulty is especially noticeable in persons who have habitually eaten large quantities of meat when they undertake to change their eating habits, taking less meat and more cereals and potatoes. With a change in eating habits, the unpleasant symptoms usually disappear in a short time. 
"Some persons find it necessary to avoid the use of tomatoes and acid fruits with potatoes. The apparent disagreement of the potato with acid fruits is chiefly due to neglect to thoroughly masticate the food. If the potato is eaten in the form of a puree or well mashed, and if the fruit is also in the form of a purée, or if pains is taken to masticate it very thoroughly, inconvenience from the combination will be rarely, if ever, experienced."

In Chapter XXIII the potato as food is discussed further by Mrs. E. H. Grubb and many valuable recipes for preparing the potato for the table are given. 


\section{CHAPTER III}

\section{CLIMATIC REQUIREMENTS}

7 HE potato grew wild and now grows to perfection in southwestern Colorado; in the Rocky Mountains, and under similar conditions in the Andes Mountains in South America. In these districts the winters are cold, and the ground is generally covered with snow from early fall - before the ground freezes - until late in the spring. There is often a heavy blanket of snow until May. In the growing season there are 100 to 110 days between killing frosts. During this period the nights are cool, but there are twelve to fifteen hours of bright, intense sunshine during the day. Occasional light showers of a few minutes' or hours' duration occur, but the total summer rainfall is very small in comparison to the total for the year.

Nothing but the strongest plants and animals live under these conditions, but such grow to the highest perfection and strength. The air is vitalizing and invigorating. Vigorous, healthy people choose it, while debilitated people of low vitality prefer more mild conditions.

Long hours of bright sunshine make the potato in its native home free from disease; and where the tuber is grown under less favorable conditions the ingenuity of man has supplied as nearly as possible the things that nature has furnished in the Rocky Mountain region referred to. 
At Prospect Farm, at Redstone, on Crystal River, in the coal fields of western Colorado, potatoes were grown for the camp during the early '80's. This farm was maintained for eight or ten years, then abandoned. Potatoes have grown in this neglected field from year to year without replanting, ever since that time. Under the conditions in this natural home of the potato the growth of the plant is checked by the frosting of the haulm, or top, in the early fall. This stops the rank, watery growth and the tuber ripens in the dry soil. This growth checking seems an essential in the growing of the highest class product, and where frost does not come in time the same effect has been secured by mowing off the tops.

Since potatoes have been grown commercially under similar conditions to those in the home of the wild potato, it has been found that varieties last longer there without "running out" or "changing seed." Old varieties that have become less valuable each year in other districts are revitalized and restored to their original perfection when planted there. The places referred to are the Carbondale district in Colorado; the Twin Falls country and other sections along Snake River in Idaho; and an instance of this reinvigoration is the success of the "Perfect Peachblow" at Mt. Sopris Farm, Carbondale, Col. At Dalmeny Farms, Edinburgh, Scotland, conditions are similar in some particulars, and potatoes live over winter in the ground and produce crops the next year.

While the potato grows best and with the least care from man in its native habitat, it has been adapted to a wide range of climatic conditions. It is successfully grown in practically every country in the temperate zone and in some places under 
very unfavorable conditions. The potato culturists of Europe have originated and adopted cultural methods and moulded varieties to conditions in a most scientific, skilful, and practical way. Potatoes are grown successfully on shifting sands so light that they are thatched with straw to keep the soil from blowing away, and on clay lands so heavy that they require close tiling (underdraining with tiles forty to sixty feet apart) and the most careful, watchful cultural methods.

It is true that there is no place in the temperate zone where potatoes cannot be grown by adding artificially to the natural conditions those things necessary to make the soil and climate approach the natural environment. It necessarily follows, however, that in selecting a place to grow potatoes under ideal conditions some of the mountain valleys of the Rocky or Andes Mountains would be chosen, other things being equal. Latitude and altitude are synonomous as far as they relate to potato conditions when other requirements are the same. There are good districts north at low altitudes and good potatoes grown at high altitudes south or at low altitudes south at sea level where nights are cool and the air is moist.

Maine, New York, Michigan, Wisconsin, and Minnesota are examples of low altitudes north, the Snake River country, the Greeley and Carbondale districts of high altitudes south, and Santa Rosa, Lompoc, and Salinas on the Pacific coast in California, and southern Great Britain and the Channel Islands of low altitudes at sea level.

These statements as regards north and south refer to the north temperate zone and would be reversed for the south temperate zone. 


\section{THE POTATO}

The sweet potato is another consideration and is described in another chapter.

It is possible that the change in temperature each day, which approximates 30 to 50 degrees, has something to do with the vitalizing of plants, the same as man is apparently invigorated and restored daily in these mountain districts where such changes occur. 


\section{CHAPTER IV}

\section{POTATO SOILS}

D

RAINAGE is the most important requisite in a potato soil. It must either be present naturally or supplied artificially.

So important is this subject considered that a chapter on tile drainage is being included (Chapter V).

As in the subject of climatic requirements, much regarding the soil requirements of the potato may be learned from a study of the soil conditions in the home of the wild potato. In its native habitat the potato grows in loose, friable, welldrained, easily worked, perfectly aerated soil.

The physical or mechanical condition of a potato soil is a more important factor than the fertility, although any plant requires a rich soil for its greatest development.

For the uniform, perfect development of all parts of the potato plant there must be a constant supply of air and oxygen, moisture and fertility. It is impossible to grow good potatoes in a waterlogged soil.

Where soils are infected with disease it is found beneficial to turn out the furrow in which the potatoes are to be planted, allowing the sun and air free access to it. European growers who practise this believe that they lessen liability to infection.

In the Twin Falls country in southern Idaho one of the best potato growing sections in the world 
- the soil is called lava ash, is very mellow and friable, does not bake, can be worked at almost any time in the year, is rich and well drained both by a natural slope and by deep coulees running through it to Snake River.

At Greeley, Col., some of the soil in which potatoes are grown is a medium desert loam, drained by an underlying strata of coarse gravel; other soils are heavier.

The soils at Carbondale are a reddish granite formation and very mellow. The country is very steep. It is drained by the Crystal River, a rushing mountain stream with an abrupt fall. This gives ample drainage to the more level mesa or table lands on which potatoes are grown.

In Wisconsin, Michigan, and other Middle Western States many of the best potatoes are grown on river sands and sandy loams - soils that are very well drained naturally.

In the Salinas and Lompoc districts in California the best potato soils are friable, sandy loams.

In Aroostook County, Maine, the soil is rolling, well drained, of lime-shale formation, and easily worked at all times.

Large quantities of potatoes are now being grown in the Red River Valley, in Minnesota and North Dakota, on the big grain farms. The soil is a rich alluvial deposit.

Potatoes are grown on well-drained sandy soils in Great Britain, but also on heavier soils perfectly drained. The soil in some places in Europe has been made suitable to the crop, even when not naturally so. There are places where sand to a depth of five inches has been hauled on and incorporated with heavy clay. Other heavy soils are 
kept filled with humus by cover cropping and the use of barnyard manures.

These experiences show that districts not generally considered capable of growing potatoes like the territory around Denver and some parts of California - can be made to produce the crop if proper methods of soil treatment are used.

The opinions of various authorities as regards potato soils are very interesting; because each is based on local conditions and experience. While there may seem to be differences of opinion, all really agree on the essentials - drainage, aeration, and easily worked, mellow, porous soils.

Wm. D. Hurd, of the University of Maine, says:

"In its native state the potato is found growing on high, dry plateaus. One of the first essentials then is a well-drained soil. The kind of soil and proper drainage influence yield, cooking quality, liability to disease, and keeping quality of the tubers. 'Virgin soils' grow potato crops of the finest quality because they are usually free from diseases which affect the crop and have an abundance of organic matter and available plant food. The most desirable potato soil is a deep, free, easy working loam. Loams which are inclined to be sandy are usually too poor in plant food and dry out readily, while those inclined to clay may be too hard and apt to retain too much moisture. A proper supply of humus is very important in potato growing. The humus content determines to a great degree the moisture content of the soil. The potato is a crop which uses considerable water in making its growth. Much moisture is, of course, lost by evaporation from the soil, but aside from this it is estimated that a yield of 225 
bushels of potatoes to the acre takes $1,420,000$ pounds of moisture from the soil. Unless humus has been supplied in the application of stable manure to previous crops, green crops such as rye, oats, clover, etc., should be turned in to supply this."

David Young, editor of the North British Agriculturist, Glasgow, Scotland, says:

"The potato crop is not at all fastidious as to the soil in which it is grown, provided the soil be properly cultivated and manured, and in practically all classes of soil, excepting the stiffest clays, this crop may be successfully grown."

Professor A. R. Kohler, Assistant in Horticulture, University of Minnesota, in "Bulletin 114," says:

"A sandy loam soil usually produces potatoes of better quality than a heavier soil does. It also has the advantage of remaining in a more mellow condition during the growing season, thus giving the tubers a chance to become more shapely, and making it easier to dig the crop. A heavier soil will sometimes produce a larger yield because it is often more fertile, but brown rot of the tubers is apt to be worse on such soils. New land is the best for large yields, or sod land which has been in clover or meadow. Sod land is sometimes infested with white grubs and wire worms which may do much damage. These pests are not likely to be present in sufficient numbers to do very extensive injury unless the land has been sod for some years." 
In a treatise on "Early Potato Growing" for the Department of Agriculture and Technical Instruction for Ireland, Matthew. G. Wallace says:

"Soils have considerable influence on earliness. Sandy loams are best, red or gray. It is wonderful what can be done even with poor sand under favorable circumstances and with generous treatment. Here again Rush (a district) may be cited. Much of the soil there appears to be drifting sand, and farmers have to resort to an expedient of lacing it with straw and seaweed to keep it from blowing away and laying bare the potato sets. Still it bears good crops of potatoes. Black lands, or bogs, are not suitable for early potatoes, as the frost seems to grip more keenly there, and, besides, the sample is not so nice, nor is the quality so good."

Walter P. Wright and Edward J. Castle, in "Pictorial Practical Potato Growing," say:

"Potato soil is a loam with an inclination to heaviness rather than sandiness, but cultivation will do much to bring either a clay or a sandy loam into line."

Organic matter, or humus, is a great factor in potato soils. It tends to hold light, drifting soils and makes them more retentive of moisture.

When properly worked, loams, sandy soils, alluvial silt soils, lava ash soils, granite soils, limestone soils, and many others are good for potatoes.

The following by Lord Ogilvy, from the Denver (Col.) Post, is interesting to the student of potato soils: 
"A Greeley farmer said the other day that his soil was a good one, especially for potatoes, if he kept it built up so that it would not blow. This soil, twenty years ago, was considered about worthless, except to grow alfalfa, and there was considerable difficulty in securing a stand. Even in this unfavorable season (1910) the output of potatoes is $\mathbf{1 2 5}$ sacks to the acre."

"This particular farmer moved off a very rich bottom farm, which was a heavy producer of all crops except potatoes, on to the land he occupies to-day. I remember that his neighbors said he was foolish for moving, that the bottom land had twice the productivity of the other tract.

"The man who moved said that they were right in a general way, but that he had always made his money with potatoes, which blighted on the bottom lands and were only of moderate quality, and that the nature of the subsoil made their irrigation a matter of chance.

"I have myself seen water turned on at one corner of a field in such lands, come bubbling up forty or sixty rods away, having in some places sub-irrigated considerable areas to the point of saturation, in others passing through contracted channels, leaving the surrounding soil as dry as a bone.

"The man who moved and the man who succeeded him on the bottom farm have both done well by specializing (the latter growing sugar-beets) somewhat on the crops their lands were'adapted to, but the potato man has made his money easier, has had less help than is entailed in growing beets, and has been able to make good with the help of his own family; in other words, has had the more self-contained business venture. 


\section{THE POTATO}

"By the use of plenty of alfalfa, mostly fed on the place, he has added to his sandy soil the element it needed by increasing its organic and humus content, and the sand seems to contain those other elements necessary to the growth of good, clean potatoes."

The value of aeration is very convincingly illustrated by digging into a hill of potatoes grown on heavy, poorly drained and aired soil. The deeper into the hill that tubers are found, the rougher and more diseased they are. It is also a notable fact that the exhibit potatoes from an average field are those that develop close to the surface. 


\title{
CHAPTER V
}

\section{DRAINAGE}

\begin{abstract}
T $\mathrm{N}$ ATTEMPTING to accomplish the object sought in this work - i.e., that of embodying 1 in one publication as nearly as possible all that is available and valuable information in the potato field - the subject of drainage is held to be of such importance that considerable space is devoted to it. The following article is made up of extracts from "Bulletin 199" of the Agricultural Experiment Station of the University of Wisconsin and is by E. R. Jones, one of America's foremost drainage experts:
\end{abstract}

"Of the several conditions which influence the growth of crops none is more important than the amount of water in or on the soil. While water in a thin film around the soil grains is absolutely essential to plants, an excess is as bad as a deficiency. The removal of this excess is known as land drainage. Surface drainage deals with the surface runoff, and under-drainage with the water which occupies the spaces between the soil grains. Most land has some natural drainage, but many acres have it to such a limited degree that an improvement therein is found profitable.

"Too much water is detrimental because:

"1. It makes areas so soft that they cannot be cultivated. When these soft areas are long and narrow in form, they cut the upland into ir- 
regular pieces that cannot be cultivated conveniently.

"2. It delays cultivation, particularly in the spring.

"3. It makes soils cold: (a) because in the spring more than half of the heat that the soil receives is used to warm this unnecessary water; (b) because its evaporation consumes heat that the soil could otherwise retain; and (c) because its presence in the soil prevents the entrance and downward movement of rainwater, which in the spring is usually warmer than the soil.

"4. It crowds out the oxygen from between the soil grains, thus hindering the necessary decomposition of organic matter in the soil.

" 5 . It prevents all crop growth where it stands on the soil to a sufficient depth. Where it stagnates only a few inches from the surface of the soil it prevents healthy root development below that depth. The shallow root system thus developed limits the depth from which the plant may get water, and with it plant food material.

"The occurrence of an excess of water in a soil or on an area is an indication that some source supplies water faster than it can be removed. The water is either coming too fast or it is going too slowly. Areas at the foot of uplands from which numerous small or large springs run during the greater portion of the year owe their wetness to the excessive seepage from the upland; while retentive clays, due to the fineness of the soil, and flat muck or peat marshes, due to lack of fall, are too wet primarily because the water is very slowly removed from them.

"It is evident that the drainage conditions on an area may be improved either by hindering the 
entrance of damaging water upon one side, or by facilitating its removal from the other. To accomplish one or both of these improvements drains must be constructed which will give gravity a better opportunity to remove surplus water.

"When the drainage needs of our lands are analyzed it is evident that those that have good drainage owe it to:

"1. Some natural condition that prevents the entrance of an excessive amount of water;

"2. A valley or ravine to serve as an outlet for the water that does enter;

"3. A surface slope to allow the escape of surface water to the outlet, or

"4. A subsoil sufficiently porous to admit of some under-drainage.

"Consequently, improvements in drainage conditions consist of:

" 1 . Protection ditches in the absence of natural protection;

"2. Outlet ditches where there are no valleys or ravines;

"3. Surface ditches to aid the limited slope in removing surface water, or

"4. Covered under-drains to facilitate the removal of damaging water from wet subsoils. Some areas need only one of these types, while others need them all.

"When water oozes into the dead furrows and shallow ditches until they are kept wet almost continually it is an indication that the land needs tiling. The water table, instead of extending horizontally from a tile, bends upward at a slope that increases with the retentiveness of the soil. It is evident that laterals may be farther apart in sand than in clay, and that the deeper the laterals 
are the farther apart they may be. Four rods is a common interval in clay subsoils and eight rods in open subsoils. In muck or peat it is frequently best to put them eight rods apart at first, and if that does not prove to be close enough together an intermediate line may be put in later in each space, making them eventually four rods apart. In rare cases of springy soils it has been found necessary to have lines of tile two rods apart.

"A single line of tile in a wet sag is frequently sufficient, but if more than four rods wide, two lines are better, each to be located as near to its side of the sag as seems necessary. In this way the centre of the sag, unless it is exceedingly low, will be protected from the seepage of the adjacent upland.

"Mains are generally located parallel to a natural water course - a little to one side if there is danger of washing by the surface runoff. Submains should be so laid out as to give the laterals a sufficient gradient without an excessive depth.

"Instead of permitting each lateral to discharge directly into the outlet ditch, it is best to put in a main perhaps four rods away from the ditch and parallel to it, to receive the discharge from the laterals. The expense is but little greater because of the saving in the length of the laterals, and there is an advantage in having only one outlet - that of the main - to look after.

"The water in an outlet ditch should be enough below the banks to afford an outlet for a line of tile which may be laid to it from any part of the marsh of which the ditch is the direct outlet. This line of tile is entitled to a depth of 3 feet at the 
head, and a gradient of 0.1 foot in 100 feet. On a marsh exactly level and with no part more than half a mile from an outlet ditch, this means that the 3 feet of depth at the head, added to the 2.64 feet of fall in a half mile requires a depth a little more than $5 \frac{1}{2}$ feet deep at the outlet. With an allowance of $2 \frac{1}{2}$ feet for the depth of the water in the outlet ditch, it is evident that, under these conditions, it should be dug 8 feet deep. Where there is a surface slope toward the ditch, its depth may be decreased by an amount equal to the fall causing the slope. Following this rule, the depth may, in rare cases, be reduced to 4 feet. Tile outlets may be submerged for a short time during flood flow without serious results.

"It is impossible to drain too deep for the majority of farm crops. Our upland soils remain moist where the water table is $\mathbf{1 0 0}$ feet or more below the surface. It is true that a drained peat unless compacted with a heavy roller will dry out almost completely to a depth of from 3 to 6 inches. However, below that depth, it is unusual if the peat does not remain moist regardless of the depth of the water table.

"When plants 'dry up' in a peat soil it is an indication that at some time the water table has been so near the surface that only a shallow root system was developed. With deep drainage from the beginning, conditions favor the development of a root system deep enough to reach through the dry layer at the surface into the moist soil below. This is the moisture that must be relied upon during a drought. It is best to prepare for a drought by deep drainage during the wet season of the year.

"Tile laid deep seem to begin their increased 
discharge as soon after a rain as do those laid more shallow. However, the rate of increase does not seem to be so great in the deep tile in retentive clay soils. To this is probably due the fact that deep drains continue their discharge when shallow drains have become nearly or wholly dry. Furthermore, deep drains are effective for a greater distance on each side of themselves than are shallow drains. Generally speaking, tile should be laid deeper in sand, muck, and peat than in clay.

"In narrow wet ravines and in springy spots the demands made upon single lines of tile may require a diameter of five or six inches. With the vast majority of laterals, particularly those in the gridiron systems, this is larger than the diameter actually required if the tile remain entirely unobstructed. However, there should be made an allowance: (1) in sandy soils, for the sand that finds its way into the tile while they are being laid, and before they are properly blinded; (2) in peat soils, for the uneven settling that may take place and cause a tile to 'jog' slightly past the adjacent one; and (3) in all soils, for the empty space that should be maintained in the top half of the tile to facilitate the entrance of water. Laterals are most efficient as collecting drains when they are less than half full. They lose this efficiency when made to discharge under a pressure head. For these reasons three-inch tile should be rarely laid except in retentive clay soils and then in lines less than five bundred feet long. Four inches is the diameter most commonly used.

"Areas requiring drainage are usually so nearly level that it is necessary to make the best possible use of every inch of available fall. The gradient 
of laterals may be increased by laying them shallow at the head and deep at the outlet, sometimes only two feet deep at the head and three and a half at the outlet. The gradient of a main cannot be controlled in this way, because at the head it must be deep enough to receive the discharge from the laterals. However, the diameter of the main may be increased to give it the required capacity. A gradient of a tenth of a foot, or about one and a quarter inches, to a hundred feet is generally considered a minimum gradient for laterals. The gradient in large mains may be decreased to almost nothing, because the diameter of the tile itself may be considered as constituting a gradient.

"With the cost of the main seldom more than $\$ 4$ an acre, and the cost of the labor and tile for laterals fairly constant at about 75 cents a rod, it is the frequency of the laterals that is the chief factor in determining the cost of tile drainage. The cost will range from $\$ 20$ to $\$ 35$ an acre according as the laterals are placed four rods apart or eight rods apart. This frequency should be based upon principles which have been discussed in the preceding pages. It is safe to say, however, that while eight rods is the interval which in some soils may yield the greatest dividend upon the money invested in the improvement, yet there is no danger of eventually getting the laterals too close together.

"Where under-drainage is desired tile are cheaper than open ditches of the same depth. Furthermore, they offer no obstacle to cultivation, take up no surface space, and are more permanent than the ditches. There are tile in Wisconsin that are working as good or better than ever at the end of thirty years, and in some states the life of tile 
has been much longer than that. If tile are laid more than two feet deep, it does not hurt them to freeze if they are empty when they freeze. There should be no sags in a grade line to prevent the tile from emptying themselves. Silt also has a tendency to settle in such sags. At that depth the expansion of the water in the walls of the tile has but little apparent effect upon the tile. Tile exposed to the frequent and sudden freezing and thawing occurring at an exposed outlet or on the surface of the ground may crumble in a single winter.

"There is danger in sandy subsoils of the entrance of soil particles larger than can be removed by the running water. Sand enters with ease, but is carried away with difficulty. Tile laid in sandy subsoil should be 'blinded' or entirely surrounded by and packed with clay, muck, or old grass. This being done, cracks an eighth of an inch wide are permissible.

"A single tile may break some years after being laid, and the earth that enters is apt to render the line useless above that point. Such a place can usually be found with ease. The broken tile should be replaced with new ones, after the earth has been removed from the tile that have been wholly or partly filled.

"On springy areas having a slope sufficiently great that water runs rapidly in shallow ditches the flow of water will invariably indicate the proper direction for main and laterals. On areas less favored with a fall a few preliminary readings with a level are of value to indicate how small the fall is. If less than two feet in eighty rods, none but a surveyor's instrument should be used for the remainder of the work. If greater than that 
amount, a carpenter's level carefully used or perhaps the water's surface in the bottom of the trench will do. Borings made with an auger or post hole digger will show the nature of the subsoil, and the size, depth, and frequency of the laterals should be based thereon." 


\section{CHAPTER VI}

SEED STOCKS AND VARIETIES

VERY frequent question asked by amateurs and others is, "What is the best potato?"

The answer is that there is no universally "best" potato, but that certain varieties have proved best for certain conditions, and as conditions change, or the varieties change, further changes must be made.

There are hundreds of varieties of potatoes, a large number of them good under certain conditions. This must be determined by experiment and test in the locality in question.

The origin of a number of the leading varieties, showing shape and relative size, is shown on the accompanying "Pharo's Potato Chart." The time of maturity is also shown, EE meaning Extra Early; E, Early; Med., Medium, and L, Late.

Practical results seem to indicate that when potatoes are grown under favorable conditions (such as the mountain districts of Colorado, Idaho, and other parts of the West), and when cultural methods are good, they do not "run out" and deteriorate.

Lack of care in selecting seed true to type, use of small whole seed and small cut seed, and storage under conditions that lessen vitality, tend to weaken the plant and the strength and size of root system, all of which result in lessened vitality and an inferior "run out" product. 
It is generally considered that seed grown at high altitudes or well north is superior to lower altitude or southern seed. One reason for this is that the frost checks late growth and the tubers do not fully mature. Partially matured seed keeps better and makes stronger growing plants that are less liable to disease.

Certain districts in Maine, Wisconsin, Colorado, and other states make a specialty of growing seed.

The potato is not propagated commercially from a seed, but from a cutting from the tuber, the tuber being an enlargement of an underground stem. Potatoes grown from the true seed ball of the potato do not reproduce true to type.

An interesting discussion of seed and varieties is contained in "Potatoes," a lecture delivered by Arthur W. Sutton before the Royal Horticultural Society and reprinted by permission from that body and Mr. Sutton. An extract follows:

"There is a misunderstanding arising from the fact that 'seed potatoes' and 'potato seed' are sometimes regarded as synonymous terms. 'Seed potatoes' are grown from perfectly true and reliable stocks, the crops being carefully examined year after year with the special object of insuring the perpetuation, unmixed, of any given variety. Frequently the tubers of an ordinary crop, which are too small for market, are kept back for planting, and dignified with the title 'Seed Potatoes.'

"I need scarcely remind you that potatoes are mere enlargements of underground stems, shortened and thickened, in which starch is stored up in smaller or larger proportion according to the characteristics of the several varieties. Like other underground stems, the tubers possess buds or eyes, 


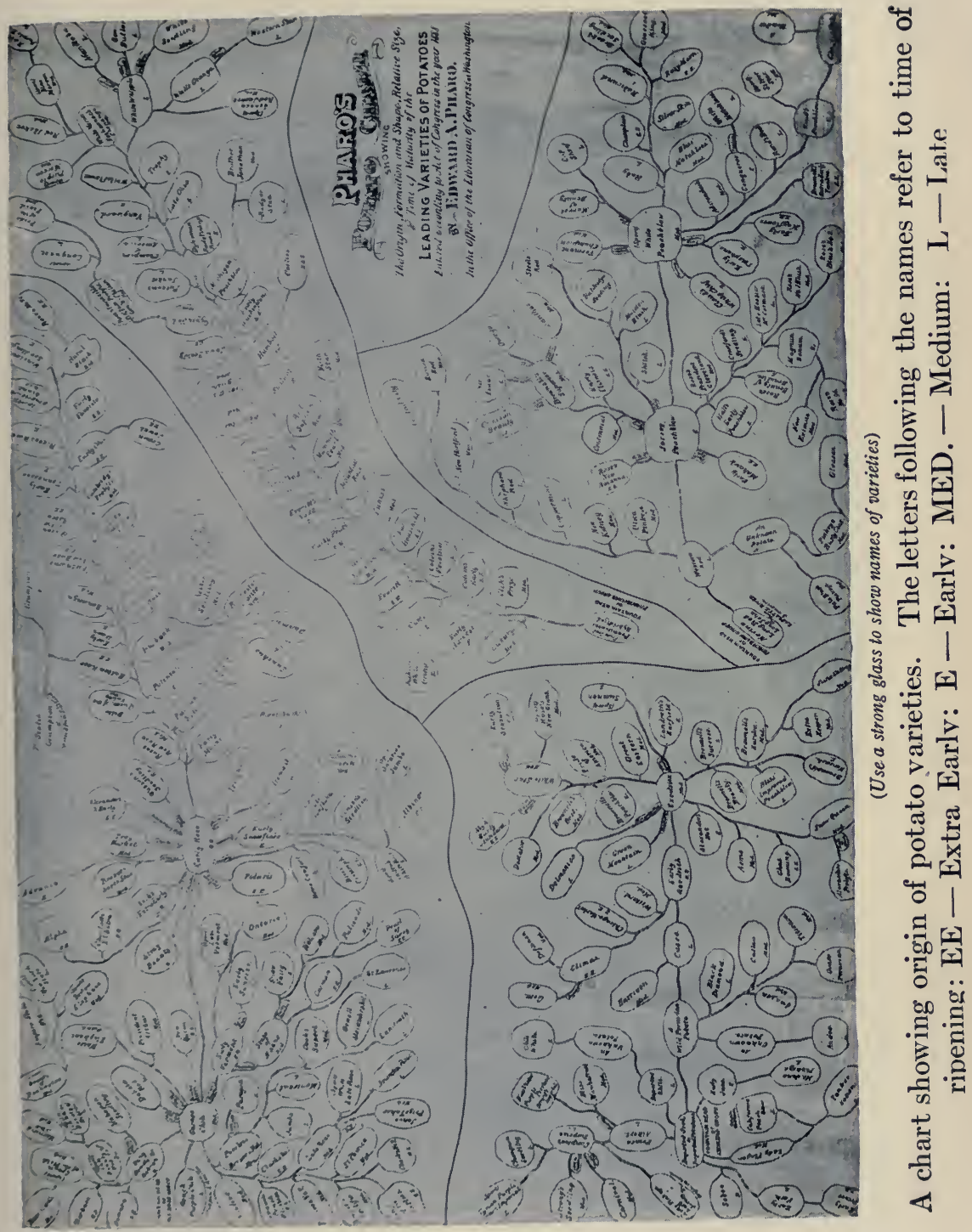



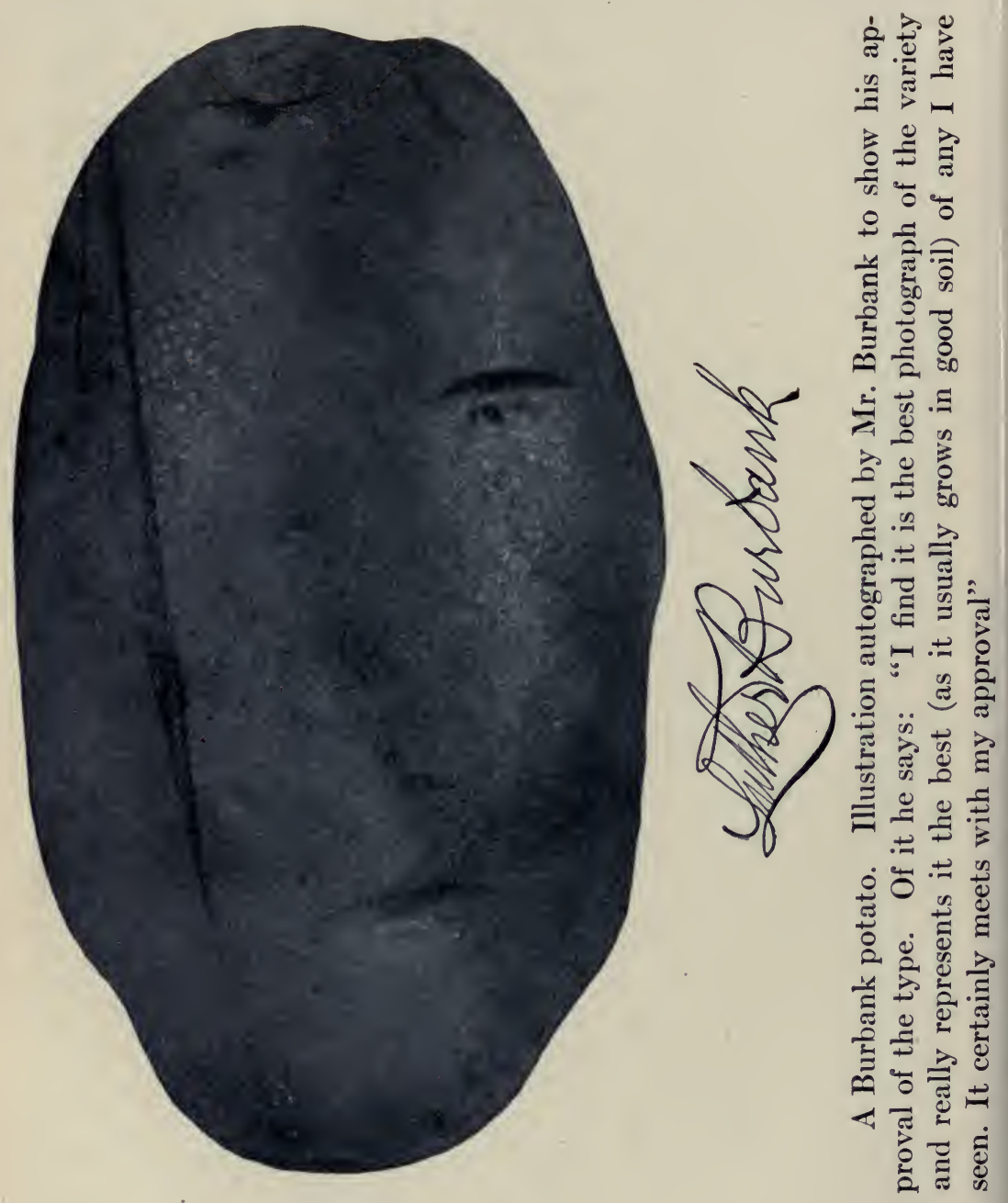
from which, by fresh shoots, the plant is capable of redevelopment; and although the tubers may be preserved through the winter for planting again in the following spring they are neither more nor less than portions of the plant which died down and apparently ceased to exist in the previous autumn. Hence the life of a single potato plant may be prolonged year after year until through weakness or deterioration it comes to an end.

"Potato seed, on the other hand, is totally distinct in every way, being the seeds formed in the potato berries which some, though not all, varieties of potatoes bear freely. A berry may contain from 100 to 300 seeds, the average of five berries examined being 232, and as the parent plant appears able to control but slightly the distinctive character of its progeny, and as all the different seeds from one potato berry may produce plants differing from one another, not only in form, but many of them in color also, it is here we find the great possibilities for improving the race by selection of the better seedlings. Even if no crossfertilization of flowers was attempted, great improvement might be made by the selection of the most promising seedlings during the first few years of their existence; but where judicious crossing of the best known varieties is undertaken, we can in a great measure combine in some of the resulting seedlings the merits of both male and female parents, although even then no two seedlings from the same berry may be exactly alike.

"Those who attempt to raise seedling potatoes must possess abundant patience. Like many other species which are not habitually multiplied by seed, the potato has a remarkable tendency to revert to the wild form. It may be necessary to 
cultivate 100 or even 1,000 seedlings before finding one which is really worthy of a place among the better varieties allready existing. M. Vilmorin says that in France the raising of seed potatoes has been proceeded with in a somewhat haphazard manner; whereas, in England, on the other hand, a more systematic method has been followed, richness in starch, excellence in flavor, power of resisting disease, with little tendency to develop haulm (top), being the characteristics we on this side of the channel generally seek. Unfortunately, he says, they are not always able to profit in France by progress realized in England, because the French have a marked preference for potatoes with yellow flesh; whereas in England, for many years past, there has been a preference for white-fleshed potatoes. On this account even the celebrated Magnum Bonum, which my house had the honor of introducing in 1876, after having enjoyed a brief popularity in the Paris markets, has been almost abandoned as a table variety on account of the flesh being too pale in color. M. Vilmorin remarks that in Germany considerable attention has been given to the raising of seed potatoes, and more particularly with the object of obtaining varieties which are specially adapted for the production of alcohol and starch."

Improvement in the potato comes from a search for the ideal. The Irish Farming World says:

The potato wanted should possess the following essentials:

"(1) It should be a heavy cropper.

"(2) It should have good table qualities.

"(3) It should be a good disease resister. 

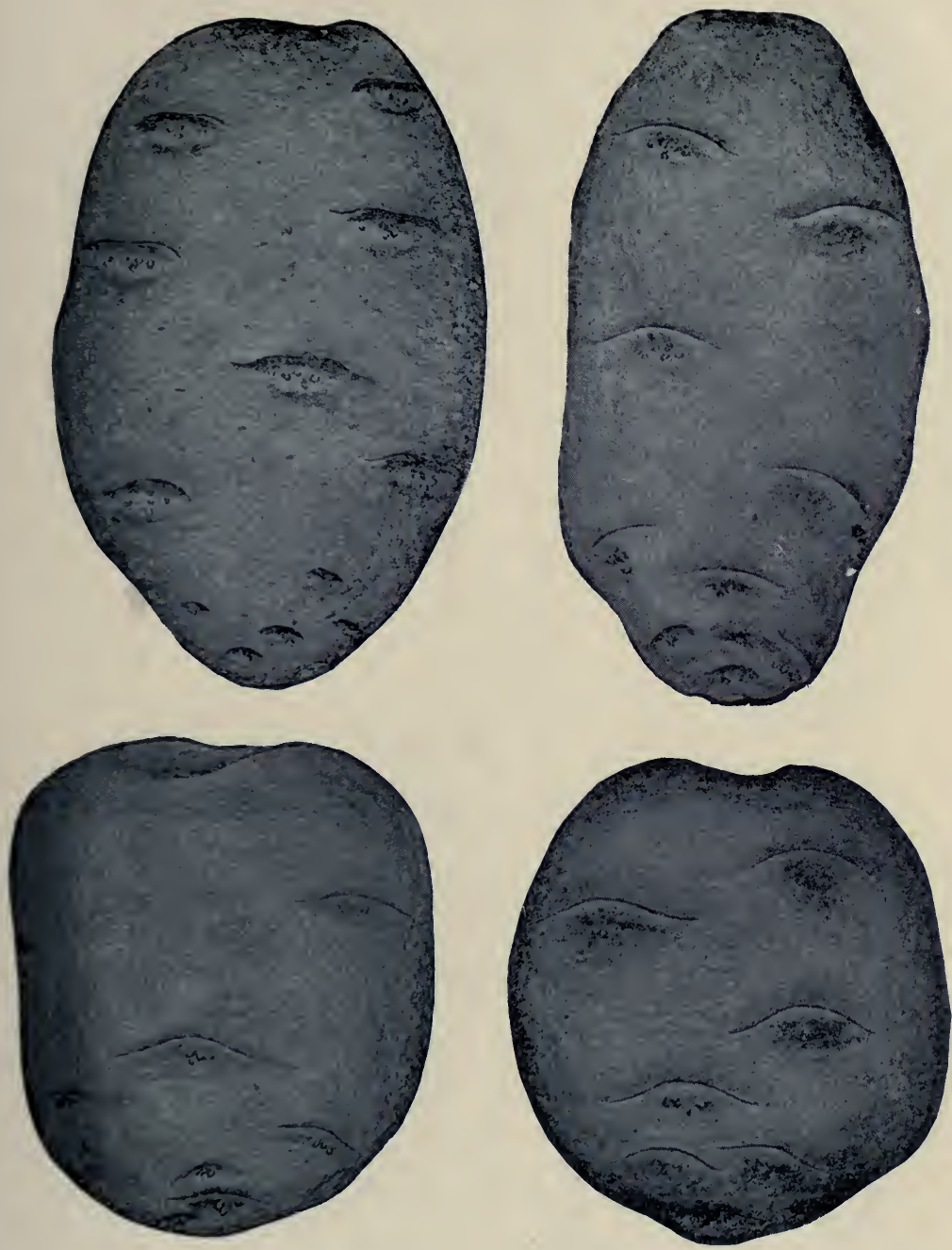

Standard Early Varieties: upper left-hand corner shows Early Ohio; upper right-hand corner shows Early Rose; lower left-hand corner shows Irish Cobbler; lower right-hand corner shows Triumph. The Irish Cobbler is not as yet raised extensively in Wisconsin, but is a standard early variety of the East. - From University of Wisconsin Agricultural Experiment Station Bulletin 

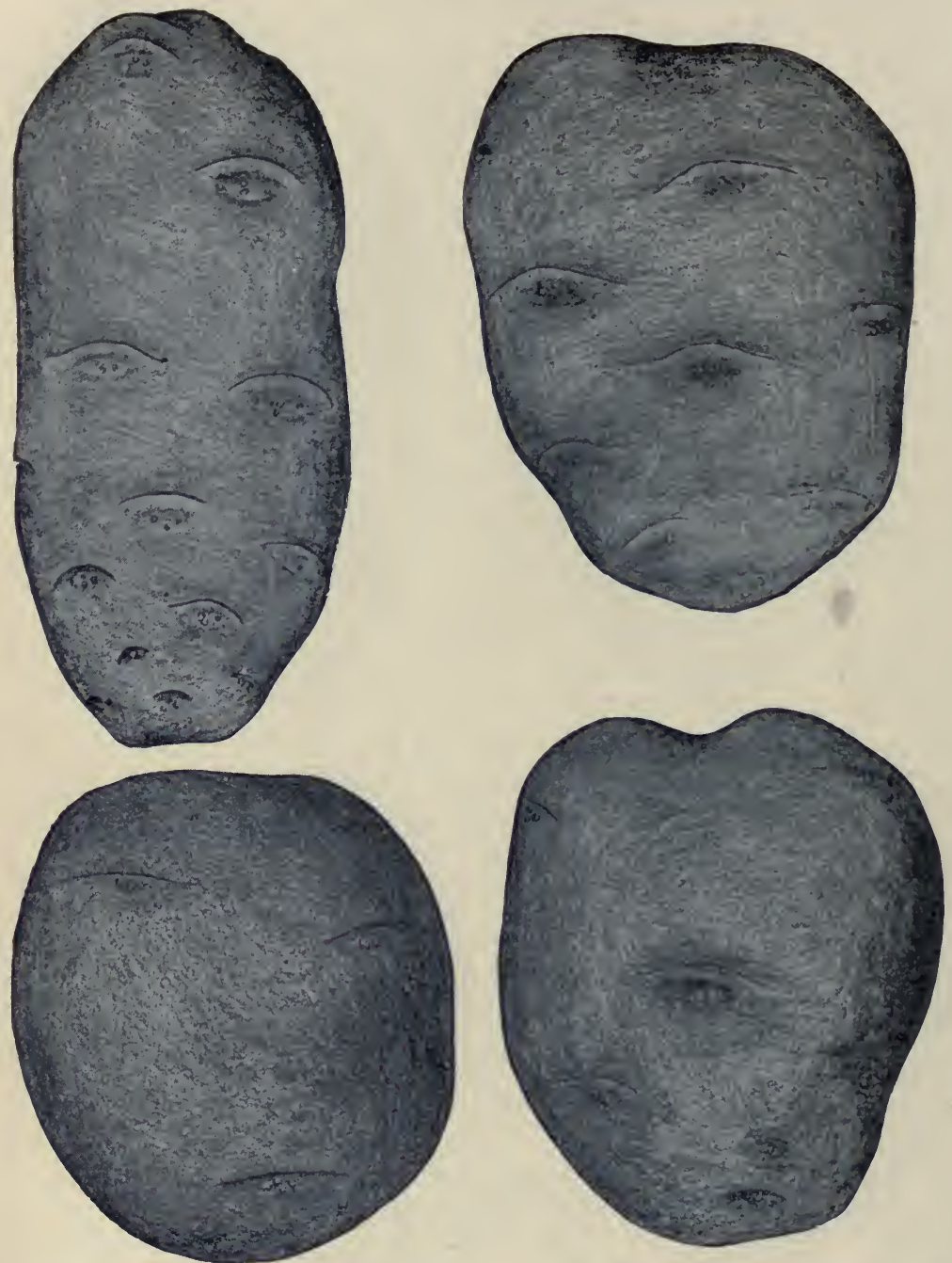

Standard Late Varieties: Upper left-hand corner shows Burbank; upper right-hand corner shows Green Mountain; lower left-hand corner shows Rural New Yorker; lower right-hand corner shows Peerless. These varieties represent typical commercial types. The Green Mountain is not raised commercially in Wisconsin, but is one of the leading late varieties of the East.-From University of Wisconsin Agricultural Experiment Station Bulletin 
" Or, in other words, 'the three R's' of the ideal potato are: Reproductiveness, Relish, Robustness."

It must always be remembered that varieties moved from one locality to another, especially with radical changes of conditions such as European varieties brought to America, must be acclimated before the best results can be expected. It is possible that excellent sorts imported from England have been discarded before they have become thoroughly adapted to our conditions.

In Europe potatoes are classed as "soft" and "hard," depending on their texture and keeping quality. When cut seed of the "soft" varieties is used it is apt to decay rapidly.

The experts in the United States Department of Agriculture are doing a great work in breeding and hybridizing potatoes. In 1910 Prof. L. C. Corbett of the Bureau of Horticulture, who is in charge of the Experimental Farm at Arlington, near Washington, was growing 40,000 plants the results of cross-pollinizing almost every known variety. Careful records are kept of every plant. In the experimental potato field over one half million tubers were produced.

This work gives promise of wonderful results for the American potato grower in new varieties that will be greater yielders of a higher class product, stronger growers, and more disease resistant.

The varieties of potatoes in highest favor differ in almost every locality, as has been already noted. In order to give an idea of the varieties being tried, with some views as to their value, quotations will be made from several sources. This information will be of comparative value, only, to the individual 
grower, and must be used more for the purpose of deciding what might be well to try than to follow the suggestions blindly.

\section{NEW HAMIPSHIRE}

In "Bulletin 3" of the New Hampshire Experiment Station is the following:

"As our New England markets demand a round or oblong white potato, we recommend for main crop the planting of such varieties as the Green Mountain and Delaware, or varieties that closely resemble them.

"As seedsmen are each year introducing and selling at fabulous prices new and untried varieties, the most of which are soon dropped from their catalogues and forgotten, we advise growers to depend on standard sorts that have been fully tested and found adapted to their soil and market, and allow their experiment station to test the novelties for them, thus preventing a large annual waste of time and money."

\section{OHIO}

That the Ohio Experiment Station has tested hundreds of varieties of potatoes and is yet continuing this work is reported in "Bulletin 218."

"Many new varieties are constantly being offered by originators, introducers, or dealers in different parts of the country. A few of these prove of value; an occasional one is excellent; many are quite inferior to our already well known and standard kinds. The question of varieties is one that cannot be treated in a general way with equal 
benefit to all potato growers. Each grower must determine for himself those varieties which do best under his particular conditions of soil and climate, and use his own judgment in retaining the choicest of these for home use, or market, or both.

"It has been remarked by certain growers, too, that it is well nigh useless to buy new varieties; for, in many cases, they declare, the alleged new variety proves to be only an old sort renamed and sold at a fancy price. This position tends to confusion and misunderstanding and often unjust criticism of originators, introducers, and dealers in pure seed stock. True, there are cases in which old varieties may have been reintroduced under new names - we are aware of a limited number of such cases - but such deception is more rare than general. Usually the confusion of growers is occasioned by the fact that there are several distinct types, families, or groups of potatoes and that the hundreds of varieties of different origin may be classified in these several groups. Indeed, there are many varieties of separate and distinct origin which follow a single type so closely as not to be readily distinguished from each other, either by habit or growth of plant or character of tubers, even by an expert potato specialist.

"To present in completeness and with absolute accuracy the lists of varieties belonging to the various groups would tax the most careful student of botany. Such exact classification is neither necessary nor advisable in a purely practical treatise of this kind. In the following classification the writer has not only reduced the groups to the least possible number, but mentions only a few of the many varieties which might easily be included in each one. The classification is based 
principally upon similarity of the character of the tubers of the different varieties, without special consideration of the similarity of the plants of each. In many cases, however, there is a similarity of plants as well as of tubers.

"The Triumph Group: Round, white, red or mottled; first early. Bliss Red Triumph (known also as Stray Beauty, Strawberry and Bermuda red), Bliss White Triumph, Norton Beauty, Nott's Early Peachblow, Woods' Earliest.

"The Early Market Group: Round or oval, flattened; white or slightly tinted; very early; good quality, much superior to the Triumph group. Early Market, Early Standard, Early Petoskey, Irish Cobbler.

"Early Ohio Group: Very similar to Early Ohio in various ways. Early Ohio, Early White Ohio, Early Six Weeks, Baker's Extra Early, Peck's Early, Acme, Ohio Junior.

"Early Rose Group: Long or oblong, cylindrical or flattened; pink or white or mottled. Early Rose, Early Roser, Mountrose, Northern Star, Early Fortune, Early Bovee, Early Sensation, Early Northern, Algoma, Miller-Brooke, Early Breakfast (white), Early Michigan (white).

"Green Mountain Group: Oblong to long; somewhat irregular in form; usually white or straw color. Green Mountain, Whiton's White Mammoth, Gold Coin, Ionia, Uncle Sam, Washington, Happy Medium, American Giant, State of Maine.

"Seneca Beauty Group: Long or oblong, smooth; small, very shallow eyes; red, pink or white with pink eyes; quality excellent. Seneca Beauty, Livingston (White Seneca Beauty), Piqua Chief, Pat's Choice.

"Rural New Yorker Group: Round or oval, much 
flattened; few shallow eyes; color usually white; quality variable. Rural New Yorker, Rural Russet, Banner, Carman No. 3, President Roosevelt, Prosperity, Sir Walter Raleigh, Ohio Wonder, Green's No. 21, White Giant, World Wonder.'

\section{MINNESOTA}

The Minnesota Agricultural Experiment Station in "Bulletin 118" furnishes the following information:

"1. The better varieties of potatoes are as follows:

"Recommended for planting: early, Early Ohio, and for southern markets, the Red Bliss Triumph; late, Rural New Yorker No. 2, Sir Walter Raleigh, and Carman No. 3.

"Worthy of trial: early, Acme and Norton Beauty; medium early, Early Bird, Early Michigan, Early Norwood, and Queen of Sweden; medium to medium late, Carman No. 1, Norcross, and New Queen; late, Pingree and California Russet.

"2. Twelve groups of potatoes, more or less distinct, are being studied. The more important commercial groups in Minneosta are the Rural, Ohio, Michigan, Cobbler, and Green Mountain groups.

"The indications are that, whenever a valuable new variety of potato is originated, different dealers put it on the market under different names. Other evidence also indicates that some dealers put well-known and well-established varieties on the market under new names. Many dealers do not seem to be sufficiently careful to keep their 
potato seed stock pure or true to variety name. Some, if they run out of a variety, will substitute the one nearest like it which they have on hand. The result of these pernicious practices is an endless confusion of varieties, which may require years of study and observation to unravel. To the farmer it means that he is never sure of the variety he is getting, unless he knows the general reliability of the firm from which he buys, and that it has a man in charge of its potato department who knows varieties."

\section{COLORADO}

The following is from "Farmer's Bulletin 386" of the U.S. Department of Agriculture, by the senior author:

"Years of experience have demonstrated that comparatively few varieties of potatoes are really adapted to Western or mountain conditions. Among the early varieties none has been so universally successful as the Early Ohio. This potato is of fine quality and uniform in size and shape, though not a heavy yielder. Another good potato, though not so early, is the Rose Seedling.

"For a medium to late variety, the Dalmeny Challenge, a Scotch variety, is being used quite extensively on the western slope of Colorado. For later varieties, the White Pearl, and Rural New Yorker No. 2 are more extensively used at Greeley, in the San Luis Valley, and in the Uncompahgre Valley; and the Perfect Peachblow is the favorite in the upper Grand Valley. The latter variety has been grown continuously by the writer for twenty-five years, and under the system 
of seed selection already described it has become a much better and more perfect type of potato than it was ten, twenty-five, or even sixty-five years ago, when first introduced."

\section{KANSAS}

Secretary F. D. Coburn, of the State Board of Agriculture of Kansas, says:

"Early varieties for summer marketing are planted mostly, and of these the Early Ohio is by all odds the favorite, followed to a small extent by the Early Rose and Triumph, as named. The small proportion of late sorts planted are the Burbank and Peachblow. Even for winter use the early varieties are grown, and left undisturbed in the ground until fall. While some home-grown stock is planted, Northern-grown seed is found best, and each year thousands of bushels are shipped in by planters and dealers, who buy from Minnesota and eastern North Dakota, in the Red River Valley."

\section{WASHINGTON}

In "Popular Bulletin No. 11" of the Washington State Experiment Station A. G. Craig says:

"There are often different strains of a single variety of potatoes which differ from each other in their characteristics - especially yield - more than do the different varieties. Many varieties possess more characteristics in common than do two different strains of the same variety. Hence, the importance of a well-bred strain of any given 
variety for seed purposes. Select only such varieties for late potatoes as will mature early enough to give ample time for digging in the fall under normal conditions. A few of the best of the many hundred varieties which have been grown on the station farm and at other places in the state are described below. They are arranged in groups according to their habits of growth, and in each group the varieties are placed in the order of preference - yield, shape, color, character of eyes, etc., being taken into consideration - as judged by the results of our two years' tests.

"Group 1: Varieties that produce new potatoes early, and mature early in the season: New Queen, White Ohio, White Rose, Pick's Early, Irish Cobbler, New Early Standard, Six Weeks, White Star, King of Michigan, Early Thoroughbred, New Century, New Climax, Early Ohio, Early Rose.

"Group 2: Varieties that produce new potatoes early and mature early in September: Sweet Home, Champion of the World, Early Excelsior, Rural Red, Crine's Lightning, White Victor, Early Hamilton.

Group 3: Varieties that produce new potatoes early but mature late: Burpee's Extra Early, Arcadia, Crown Jewel, Bovee, Algoma.

"Group 4: Varieties that produce good, marketable tubers and ripen early in the fall; promising for localities where potatoes have a tendency to grow too late in the fall: New Burbank, American Wonder, White Lily, Medium, Carman No. 1, Sir Walter Raleigh, Green Mountain, Vermont Gold Coin.

"Group 5: Varieties that yield heavily, maturing late in season: Governor Folk, Ross Favorite, Rural New Yorker No. 2, Snowflake Junior, Car- 
man No. 3, Burbank, White Beauty, White Mammoth, North Pole Easterly, Great Divide, North Pole Stinnett, Harvest King, North Pole.

Group 6: Heavy yielding varieties; undesirable for market purposes, but may be grown for stock feed: Johnson's Seedling, Purple and Gold, Pingree, Red Jacket, Empress of India."

\section{GREAT BRITAIN}

The following letter from Arthur W. Sutton, Royal Seed Establishment, Reading, England, explains the variety situation in Great Britain:

"As regards a list of the best potatoes now grown in Great Britain, I should like to explain that it would be quite easy to double and treble the sorts mentioned in the enclosed list, but you have asked for a list of the best potatoes now grown in Great Britain, and I have therefore confined myself to those I consider the best, and those which at the same time are fairly widely cultivated.

"You are of course aware that whenever a potato is introduced which proves to be of exceptional merit, a great number of other so-called novelties very rapidly appear in commerce under different names, which cannot be distinguished from the original type. This applies particularly to the class of 'Up to Date,' some of the most popular of this type of potato being 'Duchess of Cornwall,' 'The Factor,' and 'Scottish Triumph;' also types corresponding very closely to 'Sutton's Abundance,' such as 'Cramond Blossom,' 'The Provost,' 'Diamond,' and 'The Crofter,' also to 'Langworthy,' which very closely resembles 'Clarke's Maincrop.'"' 
Following is a list of potatoes chiefly grown in Great Britain:

Earlies." Sutton's May Queen: This variety is very extensively grown, especially in the very earliest districts, such as Cornwall, Jersey, etc., and is without doubt the finest and best cropping first early.

Sutton's Ringleader: White kidney, white flesh, the earliest potato grown.

Sutton's Harbinger: A white round, white fleshed variety, an excellent cropper of superb flavor.

Sutton's Epicure: A white round, white fleshed variety. This variety is more largely grown than any other variety in the north, as the northern people prefer a round to a kidney variety. This particularly refers to Ayrshire one of the earliest districts in the United Kingdom.

Sutton's 90-fold: This is a heavy cropping white fleshed kidney, of American texture.

Sir John Llewelyn: White kidney, white flesh, a heavy cropping first early.

Duke of York: White kidney, yellow flesh, an excellent cropper, of good flavor.

Second Earlies. Sutton's Windsor Castle: A white round, white fleshed potato, heavy cropper, considered by connoiseurs to be one of the best flavored varieties in cultivation.

Sutton's Supreme: White kidney, white flesh, heavy cropper, excellent quality.

British Queen: A heavy cropping variety of good flavor, largely grown by farmers.

Sharpe's Express: White kidney, white flesh, excellent cropper, of good flavor.

Late Varieties. Sutton's White City: White kidney, white flesh, handsome shape, perfect cook- 
ing quality, and has withstood the ravages of the "black scab" or "wart disease."

Sutton's Abundance: White round, white flesh, very heavy cropper, of splendid flavor.

Sutton's Superlative: White kidney, white flesh, one of the heaviest cropping main crop varieties grown.

Up to Date: White kidney, white flesh, excellent flavor, one of the most popular varieties.

King Edward VII: Pink mottled kidney, white flesh, heavy cropper, and is largely grown in the Midlands.

\section{SIZE OF SEED AND RATE OF SEEDING}

Growers will be found to recommend the use of seed varying in size from cut pieces having one small eye to whole seed weighing six to eight ounces.

The best growers everywhere - those who are getting the greatest yields - are using larger seed each year, as will be noted in the chapters on Great Britain and the Channel Islands.

A simple fundamental is the reason for it: the furnishing of more nutriment to supply the needs of the young plant.

The rate of seeding is dependent entirely on the size of the seed piece and the distance of planting. Growers use from 300 to 5,000 pounds per acre. The practice of successful growers indicates the best policy to be:

High fertility of soil

Close planting

Whole seed or large seed pieces

Heavy rate of seeding per acre 
At Mt. Sopris Farm it has been found that it is cheaper to grow medium sized seed in large quantities per acre (by planting in rows thirty-two inches apart and hills six inches apart), store it separately and plant whole, than to cut seed. It costs $\$ 5$ to $\$ 6$ per acre to cut seed, and there is greater danger from dry rot with cut than with whole seed.

In "The Potato Crop" Mr. David Young, editor of the North British Agriculturist, of Edinburgh, Scotland, and one of the foremost agricultural authorities in Great Britain, gives the following very interesting information about potato varieties:

"If in the first two centuries (from the time of its introduction) the progress of potato culture was very slow in the United Kingdom, a different state of matters prevailed in the early part of the nineteenth century. By that time the valuable, or rather we should say invaluable, properties of the potato crop had been fully realized, and its culture on a large scale was the order of the day throughout the country. The plan of producing new varieties from the seeds in the 'plums' or 'apples' was well understood also, and early in that century there were numerous different varieties in general cultivation. The famous wholesale seed firm of Messrs. Peter Lawson \& Son, Edinburgh, which still retains its pristine eminence in the Scottish seed trade, was then devoting great attention to potato culture, and in the agricultural museum, which was located in the chambers owned and occupied by the Highland and Agricultural Society, it had specimens of over 100 different varieties on exhibition. 
"It is also interesting to note that the National Agricultural Society of Scotland was a pioneer of progress in potato culture. In 1827 the society awarded a medal to Mr. Richard Lowthian Ross of Staffold Hall, Cumberland, for bringing out a new variety of potato called Staffold Hall, which that gentleman had grown successively on a deep rich soil, approaching clay, for a long period and had never found it to present the least symptom of curl or disease of any kind, either on its foliage or tubers, and its produce per acre he has found in several instances to exceed thirty tons.

"In the premium article by Mr. Peter Lawson on 'The Comparative Value of Different Varieties of the Potato,' published in Vol. IX. of the society's Transactions, it is recorded that the 'Staffold Hall,' or 'Late Wellington,' as it is sometimes termed, was found superior in specific gravity and quantity of starch contained in a given weight of tubers to any of the others there enumerated, amounting to seventy-three. It would rather seem that if a potato answering the description of the Staffold Hall were to be brought out nowadays it would be hailed with universal acclamation as the very kind that potato raisers and potato growers had for many long years been looking for and striving to obtain.

"In the 'Agriculturist's Manual,' published in 1836 by Messrs. Peter Lawson \& Son, 'Seedsmen and Nurserymen to the Highland and Agricultural Society,' there is given a list of 146 different varieties in ordinary cultivation, and full particulars are given respecting each variety under the different heads of 'Habit of growth,' 'Foliage,' 'Flower,' 'Shape of tubers,' 'Color and other peculiarities of skin,' 'Fold of increase,' 'General remarks' and 
'Weight of starch in one pound of tubers.' From these 'General remarks' we learn that some varieties were then marked as 'healthy,' 'pretty healthy, or 'very healthy,' while others were marked as 'unhealthy' or 'very unhealthy,' and quite a number were marked as 'subject to curl,' or 'very subject to curl.' The 'weight of starch in one pound of tubers' was found to vary immensely in the different varieties, the range of variation being from 408 to 903 'grains troy.' Two varieties - namely, the Sawyer's Red and the Late Jersey - were found to show 903 grains troy of starch for one pound of tubers, but both these varieties were branded as 'rather waxy and indifferent in flavor.'

"It is worthy of note also that in those early days the intelligent growers of potatoes were possessed of a good deal of knowledge which is frequently supposed to be the product of modern experiment and experience. Thus we find in the first edition of Johnson's 'Dictionary of Modern Gardening' that the plan of sprouting seed tubers in trays or boxes for the growing of early potatoes was well known and widely practised, particularly in Cheshire, "where they are celebrated for the early production of potatoes.' The same authority was also very emphatic in regard to the importance of using fairly full-sized uncut tubers for seed, and of conserving the first sprout of the seed by way of preventing the loss of stamina inevitably caused by the breaking of the first sprouts; and he was equally emphatic in regard of using potatoes that had been brought from a district that was higher and cooler than that in which it was to be planted. It was also known in those early days that tubers which had been harvested before being 
fully matured were better adapted for seeding purposes than those which had been fully matured before being harvested. When it is added that in those early days the average yield of the crop was eight tons per acre, or quite two tons more than the official estimate of the crop nowadays, it will be seen that these potato growers of seventy years ago were not so very far behind.

"The year 1845 was a fateful one in the history of potato-growing. In that year the dreaded disease Phytophthora infestans (late blight) wrought sad havoc among the potato crops throughout the country.

"'The disease,' as it is called by potato growers - other diseases in potatoes are always indicated by a specific name, but this one is 'the disease'-was by no means a new pest, for, according to numerous old records, it had year by year done more or less damage to the potato crops of the United Kingdom and the Continent. But the disease had rarely, if ever before, been so virulent as it was in 1845. But worse was yet to come, and in the following season, which was wet and ungenial, the disease fell like a pestilence on the crops and practically ruined them. The ruin of the potato crop of that year had one most important permanent effect on the agriculture of the kingdom, for it led torthe abolition of the protective duties which had up till then been levied on all foodstuffs imported from abroad.

"The potato growers of Great Britain suffered heavy financial loss through the failure of the crop in 1846, and for a time they lost confidence in their own ability to fight the battle against the dreaded disease, so that the area under this crop was for some years greatly reduced. But just as a crisis 
of any sort in public affairs usually brings to the front some strong man capable of dealing with it, so this crisis in the history of the potato-growing industry in the United Kingdom brought to the front a man who rendered incalculable service to his country and his fellow-men. This was William Paterson of Dundee.

"As a market gardener and potato-seed grower on a large scale Mr. Paterson had been experimenting for twenty years previously in the raising of new varieties of potatoes; but all the new varieties which he had brought out prior to 1846 had gone down before the disease, like all the others in that disastrous year. But the failure of his exertions in that way only caused him to redouble his energies, with the fixed determination to discover the means of either preventing the scourge altogether or at least of checking its ravages to a material degree. With the zeal of a devotee he set himself to investigate the nature and cause of the disease, while carrying on at the same time his experiments in the way of raising new varieties which should show sufficient constitutional vigor to hold the disease at bay.

"For several years Mr. Paterson worked on with little success and less encouragement, but at length, in the second half of the '50's, he brought out the Paterson's Victoria, which proved to be not only a splendid cropper of excellent quality, but practically immune against the disease. The success of the Victoria was immediate and outstanding, and very soon it was largely grown all over the country. The late Queen Victoria wrote with her own hand a letter to Mr. Paterson ordering a quantity of Paterson's Victorias for planting on the royal farms at Windsor, and that letter is 
one of the most treasured possessions of his family to this day. By way of doing honor to the man whom the Queen had thus delighted to honor, the landowners and farmers of Forfarshire presented him with a solid silver epergne and a claret jug, which are also carefully treasured in the family.

"In his 'Report on Experiments in Propagating New and Superior Varieties of the Potato Plant, for which he was awarded the gold medal of the Highland and Agricultural Society in 1869, Mr. Paterson tells the story of his long-continued and costly struggle to produce a variety which should be distinguished by its heavy-cropping, goodcooking, and disease-resisting qualities. From this report, which is published in the society's 'Transactions' of 1870, we quote the following extract:

"My own conviction regarding the potato blight is that there is no direct cure for it, but that it is entirely owing to atmospheric action in the plant, and that it will be always more or less subject to it. From this time (viz., 1853) I determined on carrying out my original idea of raising and improving seedling varieties from the plum or apple of vigorous and healthy tubers. The initial difficulty was very great. Potatoes in this country had almost ceased to flower, and at considerable expense I imported them from England, the Cape of Good Hope, Australia, America, and Calcutta, from which, as well as from our own standard kinds, I selected the healthiest tubers and planted them in a field of newly taken in land, with reed manure, by the side of a stream where the atmosphere was damp. All produced flowers, and most of them "apples." The experiment was successful, and from the seed or "apple" I produced those new 
and improved varieties which I have given to the public, and which are acknowledged to be at home and abroad of so much benefit to the community.' As already noted, the success of Paterson's Victoria, and several other new varieties raised by him in the way described above, was remarkable and immediate. But the scientific methods of booming new varieties of potatoes were not known in his days, and Mr. Paterson himself was more concerned about doing an incalculable and permanent service to his fellow-men than he was about using even legitimate means of snatching a chance of making a fortune for himself; and notwithstanding all the tokens of public appreciation bestowed on him by the Queen and his fellowagriculturists, he actually was a heavy loser financially through his efforts to bring out a potato which should realize his ideal.

"It is claimed that Mr.Paterson, the raiser of the Victoria, was the first to hybridize or cross-fertilize different varieties of potatoes. It is impossible to say whether that claim be well founded or not, for some of the older writers refer in a vague way to crossing different varieties of potatoes, and Mr. Paterson, in his report to the Highland and Agricultural Society, makes no specific mention of hybridizing. But as the science of botany was well understood in his day, and as he devoted so much attention and skill to the propagation of different varieties, it is quite likely that he followed the principle of cross-fertilization. It may be well, therefore, at this stage to give a brief account of the system which is now so largely followed in the cross-fertilization of potatoes.

"It will be noted that Mr. Paterson in his report to the Highland and Agricultural Society says 
that, before he got on to the line of experiment which led up to the production of the Victoria, "potatoes in this country had almost ceased to flower,' let alone bearing 'apples' or 'plums.' Whether that was due to the loss of constitutional vigor, or to the fact that through the process of selection, the varieties which expend all their energies on the production of tubers and not on the production of 'apples' had come to be the only kind generally grown, cannot now be determined. And here we may note a somewhat remarkable fact in this connection. Many years ago Mr. John Wilson, Chapelhill, grew a variety of potatoes which regularly produced a full crop of 'apples.' Mr. Wilson came to the conclusion that the plants could not possibly produce such a heavy crop as they could otherwise do if a great part of their energy was expended in the production of 'apples,' and by way of experiment he set his 'hands' to snip the blooms off the plants in a few acres situated in the centre of the field. The result was that the part of the field so treated yielded a crop which was quite two tons per acre heavier than that yielded by the same variety in the other parts of the field which were not so treated. But in the evolution of heavy-cropping varieties 'apple'bearing varieties are now very few and far between.

"In the scientific process of hybridizing, the anthers have first of all to be removed at an early stage of the flowering process in order to prevent the pollen produced on them from lighting on the pistil. Care must also be taken to prevent the pollen of any neighboring plants from lighting on the pistil of the plant to be impregnated. Then the pollen collected from the anthers of the plant to be used as the 'male' in the crossing process has to 
be dusted on the pistil which is to be impregnated. Care must also be taken that no other pollen is allowed to get near that pistil. Some hybridizers put a glass vase over the cross-fertilized plant, and others follow the plan of tying a muslin bag over the pistil for the same purpose.

"One difficulty that often confronts the hybridizer is that the plant he wants to use as a 'male' may not be in bloom at the time that the plant he wants to use as a 'female' is ready for the impregnating process. Another difficulty is that, owing to the 'apple'-bearing capacity having been almost entirely bred out of the heaviest cropping varieties, the plant may not produce any 'apples' though the pistil has been duly impregnated. The taking off of all the blooms but the one to be impregnated has a marked effect in the way of making the plant produce 'apples.' Some hybridizers pick away the growing tubers from the roots for the purpose of causing the plant to expend its energy in the production of 'apples' in place of tubers. With all these devices, however, the hybridizer may pollinate twenty different blooms, and consider himself very lucky if he gets 'apples' on one or two of them. When the 'apples' are full-grown they, are gathered and the seed washed out from the surrounding juice, each 'apple' containing from 100 to 300 seed.

"The seed are sown in fine rich mould in a greenhouse in the early spring, and after they have sprouted the young plants are planted out in the garden or elsewhere. Each of these transplanted plants will produce a few tubers, mostly all of small size. The first year's seedlings are not invariably of small size, however. Thus at the first show of the National Potato Society at London in 1904 
the Sir John Llewellyn Challenge Cup for the best collection of potatoes was awarded to Messrs. Sutton \& Sons for a collection of fifty different varieties, which included a selection of seedlings grown direct from the 'apple' seed in the same year, these seedlings being for the most part of quite the size ordinarily obtained from the planting of full-sized 'sets.' Last year also Doctor Wilson, the lecturer on agriculture at St. Andrews University, who has devoted much attention to the scientific hybridizing of farm plants, had an 'apple' seed planted in March which in October showed a yield of six pounds one ounce of fairly full-sized tubers.

"The tubers of the seedlings in the first year from 'apple' seed generally show a great variety of type, and even of color, 'blues' and 'reds' being quite common in first year's seedlings, even from seed produced by the cross-fertilizing of two whiteskinned and white-fleshed varieties. Then the process of selection begins, and has to be continued for several years until the types selected are properly fixed. A vast amount of patience is required for this work, as very frequently a seedling which gives great promise in its second, third, or even fourth year has eventually to be discarded on account of its failing to come up to the promise of its earlier years.

"The Victoria and other new varieties brought out by Mr. William Paterson 'held the field' for a good many years, but in process of time they began to lose their pristine vigor. There were others, however, who took up the work that Mr. Paterson had expended so much zeal upon, and one of the most notable of these workers was Mr. John Nicol, then of the Ochterlony Gardens, 
Forfarshire, who in the early 'r0's brought out the Champion, which was a heavy cropper of fair quality and had great disease-resisting power. In the course of a few years this variety was very largely grown in Scotland as well as in Ireland.

"Early in the '70's also a number of new varieties were imported from America, and from one of these - the Early Rose - crossed with Paterson's Victoria, there was produced the Magnum Bonum, which was brought out by the Messrs. Sutton in 1876. The Magnum Bonum was a capital cropper, of excellent quality and great capacity for resisting disease. In a short time it took the leading place among all the varieties grown in England.

"A series of wet seasons, culminating in the disastrous season of 1879, wrought great havoc among the crops of the country, particularly in England. A departmental committee was appointed to investigate the whole question of producing new varieties, and they recommended that parliament should initiate and subsidize experiments designed to produce new and disease-proof varieties; but this recommendation was never acted on. Lord Cathcart, in commenting on this report, states: 'All potatoes have degenerated in their disease-resisting powers. A variety from seed takes four to six years for its establishment, and under the most favorable circumstances a good variety may be expected to degenerate in twenty years. The production of new varieties is of national importance.'

"Through the influence of Lord Cathcart, Mr. J. G. Baker, the eminent botanist, was led to make an exhaustive study of the genus Solanum, in order to advise as to the relation of the cultivated varieties 
to the various wild species found in the American continent, preparatory to hybridizing experiments in which these wild species might be used. As a result of his investigations, detailed in his 'Review of the Tuber-Bearing Species of Solanum,' he recommended the crossing of the cultivated varieties with the Darwin potato, Solanum Maglia, from the Chonos Archipelago, and the Uruguay potato, Solanum Commersoni. Lord Cathcart furnished specimens of the S. Maglia to the Messrs. Sutton for crossing purposes, but the produce obtained from crossing the best cultivated varieties with the S. Maglia were far behind in appearance, crop, and quality. The cross with the Commersoni was attempted year after year, but without success.

"During these years of investigation and experiment, however, the hybridizer, like the schoolmaster, had been abroad. Many excellent new varieties were brought out by the Messrs. Sutton, whose name is synonymous with excellence and quality in every department of farm and garden seeds. Numerous other enthusiasts in the same line added their quota to the national stock, but all through the '80's the Champion and the Magnum continued to hold the leading places. But in England in particular the crops were often very disappointing. The English growers had not then learned the lesson so well known by the early Scotch growers of getting a change of seed from the colder and later climate of Scotland.

"In the end of the '80's public attention began to be attracted to the new varieties raised by Mr. Findlay, then of Markinch, Fifeshire. His first success was the Bruce, which gave excellent results for a time. Later on he followed with the 
Up-to-Date and the British Queen, both of which were excellent varieties. At one time it seemed as if both these varieties would have to be discarded on account of disease, but they seemed to recover their vigor and reputation. In fact, the Up-to-Date, though it has now been before the public for some fourteen years, is still probably the variety most largely grown throughout the country. Shortly after it was brought out it was grown on a large scale on Lord Rosebery's home farms at Dalmeny, and the enormous crops of Dates then produced - which certainly were grown on exceptionally excellent and lavishly manured soil - helped greatly to bring the Date into public favor. The Langworthy, brought out by Mr. Niven of Madderty, Crieff, about the same time as the Up-to-Date, is a variety of exceptional cooking quality, but is not so heavy a cropper, though it generally commands a higher price per ton. Other varieties, such as the Scottish Triumph (raised by Mr. Gemmell, Flakefield, Hamilton), the Crofter, and the Factor (raised by Mr. Chapman, Bathgate), the Dalmeny Hero (raised by Mr. John Hunter, F. I. C.), and many others, have their backers as the main crop varieties most approved by them.

"So matters stood at the end of the nineteenth and the beginning of the twentieth century. Then there was brought about the great Potato Boom, which may well take its place in history along with the South Sea Bubble. The circumstances at the time were all in favor of those who worked up the boom, for in 1902, and still more so in the following year, the season was very unfavorable for the potato crop in the United Kingdom as well as on the Continent, so that prices for sound tubers ruled 
high; and those who were fortunate enough to have large and sound crops - as many of the farmers in Scotland were - reaped a golden harvest in each of these years. The methods and agencies by which it (the boom) was worked were those so well known and so frequently resorted to by the Bulls and the Bears of the Stock Exchange. In the centre of the boom were two new varieties, which were declared to be immense croppers and practically immune against the disease. During the winter of 1902-1903 prices for one of these varieties were forced up to an unprecedented level. But at the end of the following season, when the disease was again very prevalent and prices for sound tubers were abnormally high, a perfect frenzy for new varieties seemed to seize upon growers. Day by day and week by week the reading public were informed that some prominent grower or other had bought a tuber of one of these new varieties at $\$ 100, \$ 250$, or $\$ 500$, and as these reports increased the delirium of buyers increased. Some of these reported purchases of tubers at more than their weight in gold were undoubtedly genuine; and in a lawsuit regarding the non-delivery of a stone (14 pounds) of one of these new varieties in the spring of 1904 evidence was led to show that three pounds of that precious stone had been sold before hand at $\$ 800$ per pound! The public appetite for new varieties seemed to be insatiable at the time, and scores of new varieties - most of which were old friends with new names - were rushed upon the market and eagerly snapped up at fabulous prices by growers.

"Even at the termination of the planting season of 1904 the delirium had not subsided. The boomers had still another arrow in their quiver, and 
they shot that shaft with far-reaching aim. Miles of greenhouses were rushed up for the purpose of 'forcing' tubers of the $\$ 800$ per pound variety, and the public was conjured to buy shoots or sprouts of that and other varieties at $\$ 20$ each. Thousands of farmers and gardeners who could not afford to buy a pound of tubers at $\$ 800$ per pound rushed to buy these precious shoots at from $\$ 10$ to $\$ 20$ each. One developer boasted that he had taken 1,000 shoots from a single tuber, so that if he had sold all these at an average of $\$ 15$ each he would have made $\$ 15,000$ off a single tuber, and had that precious tuber left to grow a further crop with.

"But the potato harvest of 1904 found the growers of new and high-priced varieties in a very different frame of mind. The precious shoots which they had bought at from $\$ 10$ to $\$ 20$ apiece had each 'and all of them yielded a caricature of a crop, as the merest tyro in botanical science and farm practice could have told them would be the case. Most of the new, or so-called new, varieties had also proved to be quite as susceptible to the disease as the older varieties. And above all, the general crop of the country was a very full one, so that prices ruled very low. Then there was a rush to sell for seed the stocks which had been bought at fabulous prices, but the demand had gone off and the slump came. The following year - 1905, that is - was also a favorable one for the potato crop, and on account of the heavy yield prices were low. The new varieties rushed upon the market two years before had, as a rule, proved no better than any of the well-tried standard varieties, and some which were undoubtedly new varieties developed a fatal facility for going wrong 
in the pits, though they looked quite sound when lifted. The result is that at the present time potato growers are greatly at a loss as to what variety they should plant, and they are cautious, even to the verge of suspicion, as to the purchase of any new variety whose merits as a cropper and diseaseresister have not been fully proved on a large scale, and for at least a couple of years.

"But while the potato boom was being shot up by scientific and other devices on its rocket-like course, there were scientists in Ireland engaged in experimental work which was destined to be of great and permanent interest to potato growers. The Department of Agriculture and Technical Instruction for Ireland - a Board backed with ample funds and staffed with able and energetic men - had been most successfully carrying on a great work for the advancement of the agricultural and other industries of Ireland. That experimental and demonstration work carried on by the Irish department was destined to be of paramount importance to potato growers in Great Britain as well as in Ireland. The potato crop covers such a vast area in Ireland, and is so staple a food of the Irish peasantry, that the department wisely devoted a great part of its resources toward the development of the potato-growing industry. The chief scientific adviser of the Irish department is Professor J. R. Campbell, a young and very able Scotsman, who was formerly assistant lecturer on agriculture at the Glasgow Agricultural College before being appointed Professor of Agriculture, first at the Lancashire Agricultural College, and afterward at the Yorkshire College. Professor Campbell, while engaged as lecturer on agriculture for the Glasgow Agricultural College, was well acquainted with the 
principles and practice so profitably followed by the skilful and enterprising farmers on the Ayr and Girvan coasts, and other parts of the southwest of Scotland, in the growing of early potatoes for the early market, and on his being translated to Ireland he soon decided to make a vigorous effort in the way of stimulating the Irish growers to take up that same very profitable business, as Ireland, owing to its earlier and milder climate, was even better suited than the seaboard of Ayrshire for the production of early potatoes in the month of June, when prices for new potatoes are always at their highest.

"Knowing full well the outstanding abilities of Mr. Wallace, Terreglestown, Dumfries, as a highly successful grower of both early and main-crop potatoes, Professor Campbell secured in 1900 the services of Mr. Wallace to deliver an annual course of lectures in Ireland, and supervise numerous experimental and demonstration areas for the department in Ireland. This experimental and demonstration work proved a great success.

"The system of sprouting seed tubers of the earliest varieties in boxes during the winter and planting them out early in spring, which was followed in Cheshire in the early part of the nineteenth century and has long been followed in Ayrshire and the west coast of Scotland, produced for the Irish growers a good crop which was ready for harvesting in the early part of June before even the Ayrshire crops were ready, and were all marketed at highly satisfactory prices before the time at which the disease makes its appearance, while a fairly full crop of roots, cabbages, or other produce could be afterward grown on the same ground the same season. This was a new and very profitable 
venture for the Irish growers, and the system is spreading so rapidly in Ireland that the large quantities of early potatoes now annually shipped from Ireland to the British markets are very sensibly affecting the prices and profits realized by the growers on the Ayrshire and west coast generally. The official report of the Irish department showed that the crops of early potatoes in Ireland last year had been all marketed at prices averaging over £30 per statute acre.

"It was probably intended at first that the efforts of the department in this direction should be concentrated on the development of the early potato-growing business. But the experimental and demonstration work of the department broadened out into new fields of far-reaching importance. The crops of the earliest varieties of potatoes, when the seed tubers are sprouted in boxes and planted early in early districts, are usually marketed before the disease begins to make its appearance in the fields. For some years the Irish department had made an exhaustive series of experiments in spraying the late or main crops with Bouille Bordelaise or sulphate of copper solution, and had proved up to the hilt that this system was of incalculable value in either altogether preventing or at least very materially checking the ravages of the disease. Professor Campbell and Mr. Wallace came to the sound conclusion that no variety of potato which was then on the market, or was ever likely to be on the market, was proof against the disease, and that while it was very desirable to give a preference to those varieties which showed the greatest power in resisting the disease provided their flavor and yield were satisfactory, yet the best plan of preventing or check- 
ing the ravages of the disease was to systematically follow the plan of spraying. Mr. Wallace also well knew the old fact which had been stated in the 'Dictionary of Modern Gardening' sixty years before, but had been practically forgotten by growers in the second half of the nineteenth century - namely, that it was not only most desirable to plant good-sized seed, preferably uncut, but it was also of the first importance to preserve the first bud of the seed tuber in order to provide against loss of stamina in the plant through breaking off the shoots. He therefore proceeded to prove by demonstration on the field what he had previously proved in his own practice at Terreglestown, that it was a most profitable plan to have the seed of even the late or main-crop potatoes sprouted in boxes during the winter, as was done in the case of the early varieties for the early market.

"The first Irish experiments in this direction in 1902 were very conclusive, as the crops of goodsized seed tubers which had been sprouted in boxes, and had their sprouts toughened by exposure to light and air before being planted, were not only much larger in yield but were much freer from disease than those which had not been so treated, but had got their first shoots broken off by handling at the time of planting. The department's experiments showed that over all the numerous fields on which these tests as between boxed and unboxed seed had been conducted, the average increase in yield obtained from the boxed seed was over 100 bushels per acre. A similar experiment conducted in the following year at the Yorkshire College farm showed precisely similar results, and attracted much attention in England. Year after year similar experiments were conducted in Ireland 
by the department, and in every year the results have been practically the same.

"Further experiments conducted by the department proved that not only was there a great increase in yield obtained from boxed as against unboxed seed, but that the system of spraying with the sulphate of copper solution, if efficiently and timeously carried out, had not only a most marked effect in preventing or checking disease, but that it had also a most marked further effect in prolonging the growing period of the crop, and in that way increasing the yield. Mr. Wallace unhesitatingly and emphatically declared his settled conviction that, when once the Irish growers had learned to box and spray, the Green Isle, with its potato area of 600,000 acres and its relatively small population of $4,250,000$ souls, would be able not only to supply the wants of its own people, but would also be able to regularly export enormous quantities to the British markets instead of requiring to import large quantities, as had often been the case in former years. The Irish department has therefore concentrated its efforts on stimulating and encouraging the Irish cultivators to box and spray, and the Irish growers have been quick to learn a lesson which promises to be so very profitable to them.

"Last year the Irish growers who had learned to box and spray had very heavy and sound crops and the total output of potatoes in the Green Isle was so heavy and plentiful that it is having a most decided effect, and keeping prices at a very low level in this country. There seems no reason to doubt that as more and more Irish growers are led to box and spray, the crops grown on the vast area under potatoes in Ireland will be heavier year by 
year, and the effect of that on the prices in the home market will be keenly felt by British growers.

"Within the last few years also another great change, which promises to increase the total average yield of the potato crops of Great Britain, has been taking place. The change in question was due to what may be called the rediscovery of a fact which was well known to the gardeners and other growers of potatoes more than half a century ago - namely, that in getting seed potatoes it was always desirable to get them from a colder and later district and climate than that to which they were taken. In comparatively recent years many English growers frequently obtained potato seed from Scotland, and found that in almost every case the seed tubers grown in Scotland yiclded much better crops than those obtained from the use of seed grown in England. The great yield of crop obtained through the use of Scotch-grown seed was, however, generally ascribed to superiority of variety, as the tubers taken south to England for seed were generally of a different variety from those previously grown. That, however, was not the correct explanation. Certain it is that, as a general rule, seed tubers grown in the colder and later climate of Scotland give much better results than tubers grown in the warmer and earlier climate of England. Several reasons may be adduced in partial explanation of this fact. For one thing, owing to the climate of Scotland being colder and later than that of England, the potato crop in Scotland is not usually so fully ripened when it is harvested as the potato crop in England is when harvested, and it is an old but recently rediscovered fact that potatoes harvested before being fully matured are much better for seeding purposes 
than potatoes which have, in a way, exhausted their vitality in ripening. For another thing, again owing to the climate of Scotland being colder and later than that of England, seed tubers taken from Scotland to England for seeding purposes are not usually so much sprouted as those in the warmer south at the same time of year, and consequently do not lose so much of their stamina and vitality through the breaking of sprouts in handling.

"But over and above these considerations there is undoubtedly in the potatoes grown in the colder and more bracing climate of Scotland some subtle force which makes for greater constitutional vigor and habit of growth than is characteristic of those grown in the warmer and more relaxing climate of England.

"In 1903 Professor Seton, at the Yorkshire College farm, carried out an experiment on this point, and found that seed grown in Scotland, when planted in Yorkshire, showed an increase of crop to the extent of two tons per acre, and was much freer from disease than the adjoining crop of the same variety grown from native seed. Much attention was attracted to these findings at the time; but since then they have been very fully confirmed, not only by the experience of hundreds of English growers, but also by scientific and careful experiments at practically all the agricultural colleges in England. At the Cambridge University farm Professor Middleton found that the crop from Scotch-grown seed was so vastly heavier than the crop from native seed of the same variety that he was fairly staggered at the result, and half inclined to doubt the accuracy of his own findings. At the Northumberland County Council farm of 
Cockle Park, Professor Gilchrist found similar results, but found that these were only in accorddance with the experience of growers seventy or eighty years ago.

"At date of writing, the latest series of experiments recorded in this connection is a most exhaustive one from the Lancashire County Council farm, where four different tests, all in duplicate, were carried out with wonderfully uniform results, which led the experimenters to draw the following conclusion - viz., seed potatoes brought from a northern to a southern latitude give a larger crop than those from a southern to a northern latitude, the difference, according to this experiment, being on the average about one hundred bushels per acre.

"If the English growers not only learn to box and spray as the Irish farmers are learning to do, but also learn that seed potatoes brought from a northern to a southern latitude give a crop of three tons per acre more than English-grown seed, that will all make for a greatly increased average yield per acre in England and a comparatively lower range of prices per ton.

As already noted, there is no variety of potato on the market which is not more or less susceptible to the disease, though undoubtedly some varieties show much-greater capacity for resisting the disease than others. It is also a notorious fact that many of the new varieties of potatoes which have been put on the market within the last few years at fabulous prices, as being practically immune against the disease, have proved to be quite as liable to succumb to the attack of the dreaded fungus as any of the well-proved standard varieties which have been before the public for a dozen years or more. Judging from the experience of the 
past century, it is not at all likely that a potato of good quality that will be disease-proof for any considerable number of years will ever be brought out.

"It was reported from France last year that, after many unsuccessful efforts, a cross between the cultivated potato and the wild potato Solanum Commersoni - had been brought out and gave every promise of high disease-resisting power, but that it was not well adapted for table use, as its cooking quality left much to be desired. It seems clear enough, therefore, that growers need not rush wildly after any so-called disease-proof new variety for protection against the Phytophthora infestans, but that they should follow, the lead of common sense and science in the prevention of the disease.

"Planting good-sized tubers, whose first sprouts have been carefully preserved, is a most important matter in the way of maintaining the constitutional vigor of the plant. As a matter of course also, preference should be given to those varieties which show the greatest capacity for resisting the disease - that is to say, if their cropping powers and cooking qualities are up to the mark. For those who farm in the warmer and earlier climate south of the Borders, it is also a most important fact, as was urged upon the attention of growers seventy years ago, that seed potatoes should be brought from a colder and later climate than that in which they are to be planted. Seed tubers that have been harvested before being fully ripened are also to be preferred." 


\section{CHAPTER VII}

SEED-BED PREPARATION AND PLANTING

Go MUCH depends on the conditions in the $\checkmark$ different districts, that seed bed preparation and planting methods differ somewhat.

The fundamentals, however, are the same everywhere. These are whatever cultural methods are necessary to make a deep, mellow seed bed or root nest. The success of the crop depends on the size and vigor of the root system.

The seed should be planted sufficiently near the surface to get the benefit of the heat of the sun, and deep enough that the root system be in contact with the moist earth.

The seed bed must be sufficiently firm that the rootlets come immediately in contact with the soil particles, yet open enough that they readily penetrate.

Humus - decayed vegetable matter - from every source is an essential in a good potato soil. Legumes and barnyard manure are valuable, and decayed turf, from meadows or pasture, is ideal for potato culture. It seems to "clean" the soil from injurious diseases, and because it has grown in it is thoroughly incorporated in the entire soil. All vegetable matter should be plowed under the fall previous to the cropping season.

The cover crop, or green manure-a mass of vegetation turned under in a green state - has a wonderfully beneficial effect on soils, both for the 
fertility it furnishes and the bettered mechanical condition. Some of the best cover crops are the clovers and alfalfa, peas, vetch, rye, and Italian Rae grass.

If the manager of an agricultural proposition knows the conditions necessary to accomplish a required result, his problem is to bring about these proper conditions. When Prof. F. H. King, one of the world's greatest soil authorities, was at the head of the Soil Physics Department of the Agricultural College of the University of Wisconsin, his slogan was "Learn to know why - for this teaches how and when."

The philosophy of seed-bed preparation for potatoes and the planting of the crop is simply this:

First. The soil must be loose and mellow to a sufficient depth to make it possible for the root system to spread freely, and for the tubers to form readily and develop uniformly and normally.

Second. The soil must be sufficiently firm that the rootlets may come in contact with the soil particles from which the nutriment for the plant is taken.

Third. There must be sufficient moisture, but not too much.

Fourth. There must be sufficient fertility, and it must be in such available form that the plant can use it readily.

Fifth. The soil must be warm enough at planting time to start the plant vigorously and rapidly.

All of these conditions in the nearest possible perfection are necessary for the production of the most profitable crops. A deficiency in any one will mean loss.

Thorough seed-bed preparation kills weeds and 
disease germs. The killing of weeds before the seed is planted makes the cultivation of the growing crop easier, and the constant stirring and working of the soil that kills the weeds aerates and makes possible sun action that kills spores and germs of disease.".. On Mt. Sopris Farm the soil is often worked six, seven, and eight times before planting. When the good results that are accomplished in the preparation are continued by deep cultivation closely following planting, a splendid crop is, in most instances, assured.

Where soils are badly infected with disease germs it is best to rotate the potato crop with grains and grasses. George Sinclair, farm manager of the Earl of Rosebery's Dalmeny Farms, a prominent British agriculturist, says that one year in grain and three in sod will free soils of most potato diseases, and that this practice will make possible the continual growing of big crops.

When crops are to be grown in succession it is found advantageous to open up the furrows in which the potatoes are to be planted and let the sun and air disinfect them for a day or longer before planting.

In the Twin Falls country in southern Idaho, or elsewhere throughout the mountain valleys of the Northwest, potatoes make the greatest yields on alfalfa or clover sod. It is always best to grow them in a crop rotation so that not more than two crops are raised in succession on the same land. Growing potatoes puts ground in excellent tilth for grain, because the thorough cultivation makes large quantities of plant food available for the rootlets of the grain plants. One of the most successful crop rotations practised by the best growers is three years of alfalfa or clover, the last cutting 
of the hay the third year being plowed under ten inches deep in the fall; two years in potatoes, and one year in grain, reseeding to grass with the grain.

Good crops are raised on both spring and fall plowing, but the latter has several advantages. The ground can be plowed to a greater depth, making a deeper seed bed and a larger storage capacity for moisture. The weathering through the winter makes fertility available, so that the same soil, if turned up, unweathered, in the spring would contain less food in shape to be used by the plant. Fall plowing for potatoes should be deep, at least eight inches, but ten is better.

Fall plowing in north latitudes or high altitudes makes possible the storage of heat from the sun's rays. Land that has been fall plowed is often eight to ten degrees warmer at planting time than land plowed deep in the spring (thereby turning up a cold subsoil). Fall plowing, in this way, lengthens the growing season, where seasons are short, and often eliminates fungous development that might be damaging to tender potato sprouts. Fall plowing should generally be followed by another plowing in the spring.

In the Channel Islands the potato land is plowed eighteen inches deep every four years.

When alfalfa or clover sod is turned under, the plow should be sharp enough to cut the roots; otherwise it is not all killed and the grass may come up later and bother in cultivation.

If manuring is done, it should be in the fall. Probably the best time to apply manure is to the crop that precedes the potatoes - on the clover or alfalfa sod. In this way there is no possibility of the fermenting or rotting manure making a breed- 
ing place for disease that might affect the potato. If manure is not applied, similar results in restoring vegetable matter and fertility to the soil are obtained by the turning under of the last crop of alfalfa or clover, should either of these crops precede the potatoes. The freezing and thawing of the average winter help to incorporate the vegetable matter in the soil.

In the spring the ground should be thoroughly disked and harrowed, making a fine, firm seed bed.

Small acreages (five acres or less) of potatoes may be planted by hand if a horse planter is not available. Good potatoes have been raised by dropping them in every third furrow when plowing the field, letting the next furrow cover the seed to the depth of four to six inches.

Any larger acreage of potatoes, either on one farm or in a neighborhood, is best planted with a modern planter. With any of the standard twohorse planters five or six acres a day can be planted. In many places in the West potatoes are planted one piece in a place in rows thirty-six inches apart, and the pieces dropped eight to fourteen inches apart in the row. Planted twelve inches apart in the row makes 14,500 hills to the acre. If conditions were perfect, and each hill produced ten marketable potatoes weighing ten ounces each, a yield of nearly 1,500 bushes per acre would be secured. This is entirely possible. Fifteen years ago R. A. Chisholm of Del Norte, Col., grew 847 bushes to the acre, winning a gold purse offered by the Orange Judd Farmer for the best measured acre of potatoes in the United States.

Potatoes that are infected with any disease should never be used for seed. They frequently are, however-often when the grower is not aware of their 
presence. When disease is present, it can be carried from a diseased potato to a healthy one by contact ir the bin, in the sack or in a planter. The knife 1 sed in cutting seed pieces is capable of spreading a disease throughout an entire lot of seed, and the "picker" on a picker planter may do the same thing. Disinfecting potatoes, as indicated in the chapter on diseases, is a good practice for skin diseases, but does not kill internal germ disease.

In southern Idaho potatoes are planted from May 1st to July 1st. Some early potatoes are planted as soon as April 1st. If these escape the late frosts they make big money, generally selling locally at from three to five cents a pound. If the frost catches them the ground may be planted to a later crop, so that some gamble on a few early potatoes to the extent of the price of seed and labor. There is always a possibility of a killing frost during the first two weeks of April.

From May 10th to June 10th is generally considered the best time to plant the main crop of late potatoes in the inter-mountain West.

With the horse planters a furrow two to four inches deep is opened by a pair of disks, and a ridge about two inches higher than the level of the field is turned up, putting the seed piece under about four to six inches of earth.

The amount of seed used by different potato growers varies from 600 to 3,000 pounds per acre. The growers who get the biggest yields plant the most seed. The largest crop ever grown in the country was with whole seed, using nearly 3,000 pounds per acre. Good yields are secured by using seed cut in two to four ounce pieces and having one to two eyes. Commercial seed potatoes weigh from two to ten ounces. The small seed is not cut 
the larger generally cut about four times. These work well in the planter and contain sufficient reserve nourishment to give the plant a good start. It is important that any plant to give the best returns in yield should start strong and vigorous. When potatoes are planted twelve inches apart in the row with rows three feet apart, if a perfect stand is secured and four ounce seed used, 3,630 pounds of seed per acre is required. With smaller seed and an ordinary stand, which is far from perfect, about 1,200 to 1,500 pounds of seed is used. The big seed starts a plant capable of making a big root system. The size of the root system bears a close relation to yield. With a large number of roots in the feeding area the greatest possible amount of food can be secured by the plant. Extremely large yields are secured by close planting.

Lawrence G. Dodge, in "Bulletin 365" on "Farm Management in Northern Potato Growing Sections," says:

"The general methods of potato culture in use have developed during the past fifteen years, or a little more, and are followed with considerable uniformity throughout the section. The rotation is a simple one, but is undoubtedly the foundation of the success of the growers. Potatoes are grown on any piece of land only one year as a rule and are followed by one crop of oats or spring wheat, with which are sown clover and timothy for hay. This crop is cut for hay one year by many of the best farmers and plowed in the fall for a new potato crop. The furrow is usually turned to a depth of seven or eight inches, and on most of the farms this work is done with a reversible sulky plow, an 
implement admirably adapted to working on side hills. Some growers like their hayfields to stand a second year before plowing, but rarely longer than that, for the land is in too much demand for potatoes to continue it in grass more than two years.

"The sod, usually containing a large amount of clover which was plowed the previous fall, is harrowed in the spring as soon as the season permits, usually being worked over thoroughly four times in all with a disk harrow followed by a springtooth harrow.

"Planting is done from the 15th or 20th of May to the 1st of June, using about five barrels of seed to the acre - that is, thirteen or fourteen bushels. The seed is cut by hand into pieces containing about two eyes and of such a size as to feed readily through a planter, and is dropped by the planter in rows about thirty-three inches apart and from twelve to fifteen inches apart in the row, so that the ground is entirely occupied with the crop, and the vines in midseason meet in the rows.

"There are two prevailing types of planter, in one of which the seed pieces are distributed by steel forks or pickers, and in the other by pockets in a revolving disk. Both types are two-horse machines, the former being operated by one man and the latter requiring a second man to attend to the seed distribution. Either type will plant about five acres per day. The planter at the same time distributes the fertilizer, from 1,200 to 1,500 pounds per acre usually being applied. This amount of fertilizer can be safely used directly in the drills. The fertilizer commonly used contains about 3 per cent. of nitrogen, 7 or 8 per cent. of phosphoric acid, and 9 or 10 per cent. of potash." 
Chas. D. Woods, Director Maine Agricultural Experiment Station, in an address before the New Jersey State Board of Agriculture, said:

"While potato growing is somewhat a matter of soil and climate, it is even more dependent upon the ability, knowledge, and energy of the man who is trying to grow them. This fact was very clearly demonstrated in Aroostook County, Maine, in the season of 1907. Aroostook County is perhaps the richest agricultural county in the United States, and the potato is the money crop. Upward of eleven million bushels of potatoes were shipped from the crop in 1906, besides all that went into starch. The shipments from the crop of 1907 were less than half that of the preceding year. And yet the good farmers had as large, and in some instances larger, crops than in 1906. The season of 1906 was favorable for a large crop, and everybody that planted potatoes succeeded in growing and harvesting a good crop. The season of 1907 was unfavorable, and only the good farmers had good crops. The men that thoroughly prepared the seed bed on well selected soil, planted only what they could properly care for, who used fertilizer liberally, cultivated all the season, and who sprayed early and often against insect and fungous enemies, and harvested as soon as the crop was ready, not only had a large yield per acre, but because of the high price of potatoes after the poorly grown early ones were marketed, brought it about that with many Aroostook farmers the season of 1907 was the best for years. On the other hand, the farmer that planted illy adapted and slovenly prepared land, of larger acreage than he could well care for, who neglected to spray because 
the weather was not good for spray to adhere, who had so many acres he could not get them harvested before the unusually early freezing of the ground (over 11,000 acres of potatoes were frozen in Aroostook County in 1907), found the year a disastrous one. In many instances the crop harvested was not sufficient to pay the fertilizer bills.

"By practising the methods of the good farmers of Aroostook County, many men in other parts of Maine are successful with potatoes as a money crop. There is no reason why men in other states may not grow the potato at fully as good a margin of profit as the farmer in Maine.

"At the annual meeting of the Massachusetts State Board of Agriculture in 1901 the writer (Doctor Woods), in answer to a question, said in substance: 'If a Massachusetts farmer plants a few potatoes, there is not one man in twenty but will allow something else to crowd in and cause him to neglect his potatoes. The one great reason they grow better potatoes in Aroostook County than elsewhere in Maine is that it is the farmer's business to grow potatoes. He does not allow his stock or other farm duties to lead to the neglect of his potato crop. He makes it his first duty to take care of his field of potatoes, and the field will have from twenty to fifty or more acres in it. One man and a pair of horses work on twenty acres from spring until the fall, and the one man and pair of horses will care for the twenty acres, and he will not be taken off to do anything else. This is one of the reasons they grow potatoes better - because they are growing them for business. They are not thinking of the dairy cow or the breed of sheep; I wish they were, but they are not. They are thinking about growing potatoes. When I used to live 
in Connecticut, up and down the Connecticut valley were men that ate, drank, and slept tobacco. And so there are men that eat, drink, and sleep potatoes down in Aroostook County, Maine.'

"The potato is so generally and extensively grown, we are so familiar with its qualties and the various methods of culture, that most farmers are very positive as to the best methods of growing this crop. During the past twenty-five years hundreds of experiments have been made at experiment stations and by practical growers, and the results from experiments in propagation and culture are so conflicting that the careful student will be very slow in drawing conclusions. While he will be convinced that there are ideal ways of treatment under certain conditions, he will be equally convinced that under different conditions very different practice will be necessary to insure the best crop. In potato growing, as with most farm operations, the soil and atmosphere are such determining factors that there is no best way. Each farmer who would grow potatoes to the best advantage must be sufficiently intelligent to understand the conditions of the soil on his own farm. The methods of preparation of soil, of planting, cultivating and fertilizing the crop depend largely on the character and condition of the soil and the season.

"The successful growing of the potato crop demands careful and conscientious work from start to finish. There are many details which, if neglected, mean partial failure, and which must be complied with in order to insure the fullest success. It is not practicable in a short paper to hint at more than a very few factors which enter into successful potato growing. Among the most im- 
portant are the selection, the preparation of the soil, including application of fertilizer; the seed and the care of the crop during the growing season.

"A soil to grow potatoes well must be in an excellent state of tilth, sufficiently mellow to make a good seed bed and place for the tubers to develop. Abundant plant food must be supplied, and the land must be so situated that it will not suffer from excessive rain and will be well adapted to stand drought. If not naturally well drained, it must be under-drained. If it is not of good water-holding capacity, this must be secured by increasing the humus by green manuring or the use of liberal quantities of stable manure.

"There is no farm crop that is more easily, speedily and greatly affected by the supply of moisture than is the potato. It has been found by experiment that it takes about 425 tons of water to grow a ton of dry matter of potatoes. A crop of 200 bushes per acre would therefore require approximately 650 tons of water, equivalent to a rainfall of nearly six inches. Because of its need for large water supply, and its remarkable susceptibility to climatic conditions, it follows that the average potato yield is affected more by water supply than by lack of plant food. The selection of soil and methods of culture must be with this fact in view, if success is to be had. The liberal applications of fertilizers or the presence of large amounts of readily available plant food will prove of but little value if the moisture supply is deficient. It is also true tr.at too much water will check the growth as quickly and effectually as too little.

"Too much attention to the fitting of the soil for the crop can hardly be given, for no amount of after tillage can overcome neglect in preparation. 
Deep and thorough plowing and harrowing, so as to make a perfect seed bed, not only establishes an earth mulch so as to prevent the loss of moisture of the spring rains, but it so fines the soil that the plant food contained in it becomes accessible to the growing plant. The conservation of moisture by frequent tillage is not understood or practised as it should be. The old notion that potatoes should be hilled and that tillage should cease as soon as the potato is in bloom, is wrong for most situations. Hilling is frequently practised so as to keep the tubers from becoming exposed to the sun; that is not necessary if the soil is properly prepared. On hard, compact soil the potato will, because of less resistance of the soil, push out of the ground. This will not happen in deeply worked land.

"The proper preparation of a soil for the potato crop is a matter of years and not a single season. A soil, in order to do the best must be in excellent state of tilth and a high state of fertility. Such conditions can only be obtained by careful forethought and planning. Frequently soil is not plowed deeply enough. It is very common for people to speak of plowing seven, eight, or even nine inches, but most men would be surprised if they were to apply a rule to see how much short of this depth the plow actually goes below the actual level of the field. Many men who think they are plowing seven or eight inches deep are only plowing five inches. If this shallow plowing has been practised it is bad management to suddenly deepen the plowing, as this brings too much of the subsoil to the surface in a single plowing.

"Good potato land may be handled in a three or four year rotation - potatoes, grain, grass one or two years, and then potatoes again, in some such 


\section{THE POTATO}

way as the following: Land which is used for potatoes should, immediately after harvesting of the crop, be treated to a liberal application of farm manure, if it can be obtained, and plowed with lap furrow. The plow can well run an inch deeper than it did the preceding year when the land was prepared for potatoes. In the spring the soil will have crumbled by the frosts, and should then be thoroughly worked by frequent harrowings with some such tool as a disk or spading harrow. It should then be smoothed with an Acme harrow, or some other tool, and seeded to grain. If it is designed to grow only a single crop of grass, it is best at the time of seeding to sow clover with the grain. If, however, it is designed to remove two crops of grass, it can be seeded with a mixture of clover and timothy. The grain crop will be harvested the first year; the second season the crop will be chiefly timothy; the third it will be timothy and clover, and at the end of the two or three years, whichever plan is followed, there will be in the field in the fall a good stand of second growth clover. This should not be cut or fed, but should be plowed under, and this is all the more important if the piece has not been treated with farm manure. This fall plowing should be with lap furrow and the following spring it should be thoroughly worked with the disk and smoothing harrows in order to get ready for planting.

"It may in many situations be desirable to follow the grass crop with corn, and then follow with potatoes. The same thorough preparation will be of advantage to the corn crop. The land for the corn should be liberally fertilized. Farm manure will be again used in this part in the rotation to advantage. The corn must be overfed in every 
way so that the land will be in a higher state of fertility at the end than at the beginning of the season. If corn enters into the rotation, fall plowing should be again practised, and the following spring the land should be thoroughly worked. The best possible seed bed should be prepared, so that the soil will be light and thoroughly pulverized to a depth of five or even six inches. In a soil thus prepared the planter will run easily.'

In the senior author's trip to Europe in 1910 he found all of the best growers in Great Britain and Germany using nothing but whole seed. He did not visit a grower abroad who used cut seed. He secured a shipment of a ton of very select seed the from Earl of Rosebery's Dalmeny Farms, and George Sinclair, the farm manager, advised planting them whole, even though they cost $\$ 200$ a ton laid down at Carbondale, Col.

In cutting seed, especially where soils are apt to be infected with fungous disease, the "armor" of the potato is broken in cutting and the tender tissue is exposed.

"Farmers' Bulletin No. 92" of the United States Department of Agriculture contains the following:

"As a recent bulletin of the New York Cornell Experiment Station shows, the average yield of potatoes in the United States is far below what it should be. This bulletin states that 'the average yield of potatoes throughout New York is not more than one half what is should be and what it would be were better methods practised.' This low yield is not due, as a rule, to poverty of the soil, because 'all soils of ordinary fertility contain sufficient potential plant food to produce abundant 
crops,' and a part of this potential plant food can be made available for the use of plants by tillage, and drainage, if necessary. The experiments of the Cornell station, which have now covered four seasons, were planned with a view to learning what superior tillage and care would do in the way of unlocking the hoarded fertility of the soil and increasing the yield of the crops.

"The soil on which the potatoes were grown has been continuously under crop without fertilizers since the winter of 1893-94, except that cover crops of rye, crimson clover, or wheat, to be turned under in the spring, have as a rule been grown. But the growth of these has necessarily been so small and the cropping so intensive that the soil is beginning to show a deficiency of humus, indicated by its tendency to become hard and compact under beating rains; for 'in order to keep a soil permanently in good physical condition, it is absolutely necessary that organic matter be returned in some way, either by green manuring or the use of barn manures.'

"Notwithstanding this fact, the yields in the Cornell experiments have been much above the average each year. This was as true of 1898 as of previous years, in spite of the additional fact that the latter season was one of severe drought and the soil used in the experiments 'is gravelly and porous and especially subject to injurious effects from drought.'

"It is probable that frequent and deep plowing has done much to bring and keep the land productive. So far as the plowing is concerned all plats have received the same treatment. The land has been turned from two to three times each year, and the pulverizing which has resulted there- 
from has liberated sufficient plant food to mature large crops. In addition to the plowing the land has been frequently harrowed and cultivated and the intensive culture which has been given has liberated all the plant food that could be used by the growing crops with the amount of moisture that was present.

"A fact clearly brought out by these experiments is that 'success with potatoes depends largely upon the preparation given the soil before the potatoes are planted. Plowing should be deep, and at the time of planting the soil should be mellow and loose.'

"Only first-class marketable potatoes should be used for seed. These should be cut into pieces averaging two strong eyes. 'Seed should not be cut for any considerable period before planting. If it becomes necessary to delay planting for some considerable time after potatoes are cut, the cut pieces should be dusted with plaster and spread out in a moderately moist, cool place.'

"Early planting has usually given best results, but this necessitates careful spraying with Bordeaux mixture and Paris green to protect the plants from diseases and insects. Early and deep planting and frequent and level tillage are especially important in soils like that used in these experiments, which are likely to be seriously affected by drought.

"The methods of planting and cultivation used at the Cornell station in 1898 were as follows: 'The pieces were dropped in the furrows directly after the furrows had been opened, one piece being put in a place and at distances fourteen inches apart in the row. A furrow was opened (with a shovel plow) in the middle of the space left when the first 


\section{THE POTATO}

furrows were opened. This served to cover the potatoes, the earth being ridged up directly over the potato row. The planting was done on May 10th. The soil was then left undisturbed until May 28th. The ridges which were left over the seed potatoes covered them to a depth of about eight inches. By May 28th the weed seeds which were in the surface soil had germinated and the whole surface was covered with tiny weeds. A spike-tooth harrow was fitted with a piece of $2 \mathrm{x}$ 4 scantling placed diagonally across underneath the frame and held in place by the harrow teeth. The harrow thus rigged was used upon the potato plats, being first run lengthwise of the rows and then crosswise. The weight of the driver upon the harrow was necessary in order to make it do the leveling as required. The benefit derived from this treatment was very marked. All weeds were destroyed, the surface crust was broken, all clods and stones were removed from above the row and deposited in the centre of the space between rows, the surface was leveled, and in every way the conditions were made favorable for the rapid growth of the potatoes, and they appeared above ground in three or four days.

"In general it may be said that 'on soils which are not well drained, either naturally or artificially, and on clay or clay loam soils, potatoes may be planted somewhat shallow and slight hilling may be practised with benefit.'

"If planting is done very early in the spring the ridges may be permitted to remain for ten days to two weeks before harrowing down. If planting is done somewhat late the ridges should be harrowed within one week after planting. In the case of the early planting there is usually enough moisture 
present so that the ridging may temporarily prove a benefit by enabling the soil to become warm. In the case of late planting all the moisture should be conserved, and this is best done by leveling the ridges.

"Harrowing the soil before the plants appear above ground, followed by from six to seven cultivations during the season, is recommended."

Thoroughness and care are qualities that must be given attention in seed-bed preparation and seeding, for with these operations well done the crop is well on its way toward success. 


\section{CHAPTER VIII}

\section{CULTIVATION}

7 HE objects sought in cultivating the potato are: First, keeping the soil in the seed bed loose and retaining moisture for the crop, and, second, keeping down the growth of weeds, which, if allowed to grow, not only rob the potato plant of moisture but also of available fertility.

Moisture is taken from the ground into the air by capillary action. By cultivation the surface of the soil is broken and the evaporation checked.

Disease germs find it difficult to live and develop in soil that is exposed to the sun and air, providing there is thorough aeration and consequently plenty of oxygen.

It is not possible to farm by definite rules. Conditions change daily, sometimes hourly, so that a farmer must know what result he desires to obtain and use judgment in the time and frequency of such operations as cultivation and irrigation, and be governed by circumstances.

In an irrigation district, if ground is dry before planting, it should be irrigated well, so as to make the soil and subsoil a reservoir of moisture to be drawn on by the starting and growing plant. Some growers maintain that potatoes should not be watered after this "before planting" irrigation until the tubers are well set; that the moisture must be conserved by cultivation. Conditions may arise, however, such as a long dry spell with winds that 
draw the moisture from the soil, that would make irrigation advisable sooner.

In the irrigated West the crop should be cultivated deeply, soon after planting making a loose, deep seed bed. Cultivator shovels fourteen working inches long and about four inches wide, two on each side of the row, are valuable for this work. If this deep cultivation just after planting turns up the soil rough, a harrow may follow to fine the surface in order to hold moisture. The second cultivation can come when the plants begin to show. The number of cultivations depends on the condition of the soil, weeds, and number of irrigations or rains. Cultivation after the tubers are set should not be so deep nor so near the hills, because a potato torn off while in the forming stage is lost. Tearing off feeder roots or rootlets at this stage also reduces yields.

Ditches between the rows for irrigation are made with a double shovel plow attachment fastened to one beam and a two-horse cultivator. The best potatoes and the heaviest yields have been produced where deep ditching and heavy ridging have been practised. Ridges must contain plenty of dirt to protect the tubers from the sun and to prevent greening, but growing in fairly loose, wellaired soil into which the moisture comes up from the bottom has proved best. The bulk of the roots of the plant go deeper, but the tubers have the benefit of forming and developing in a favorable environment.

Flat cultivation, stirring the surface only, so as not to destroy the surface roots, is advocated in potato growing in some sections of the rain belt. There, all moisture is applied evenly over the surface in the form of rain, and it is necessary that 

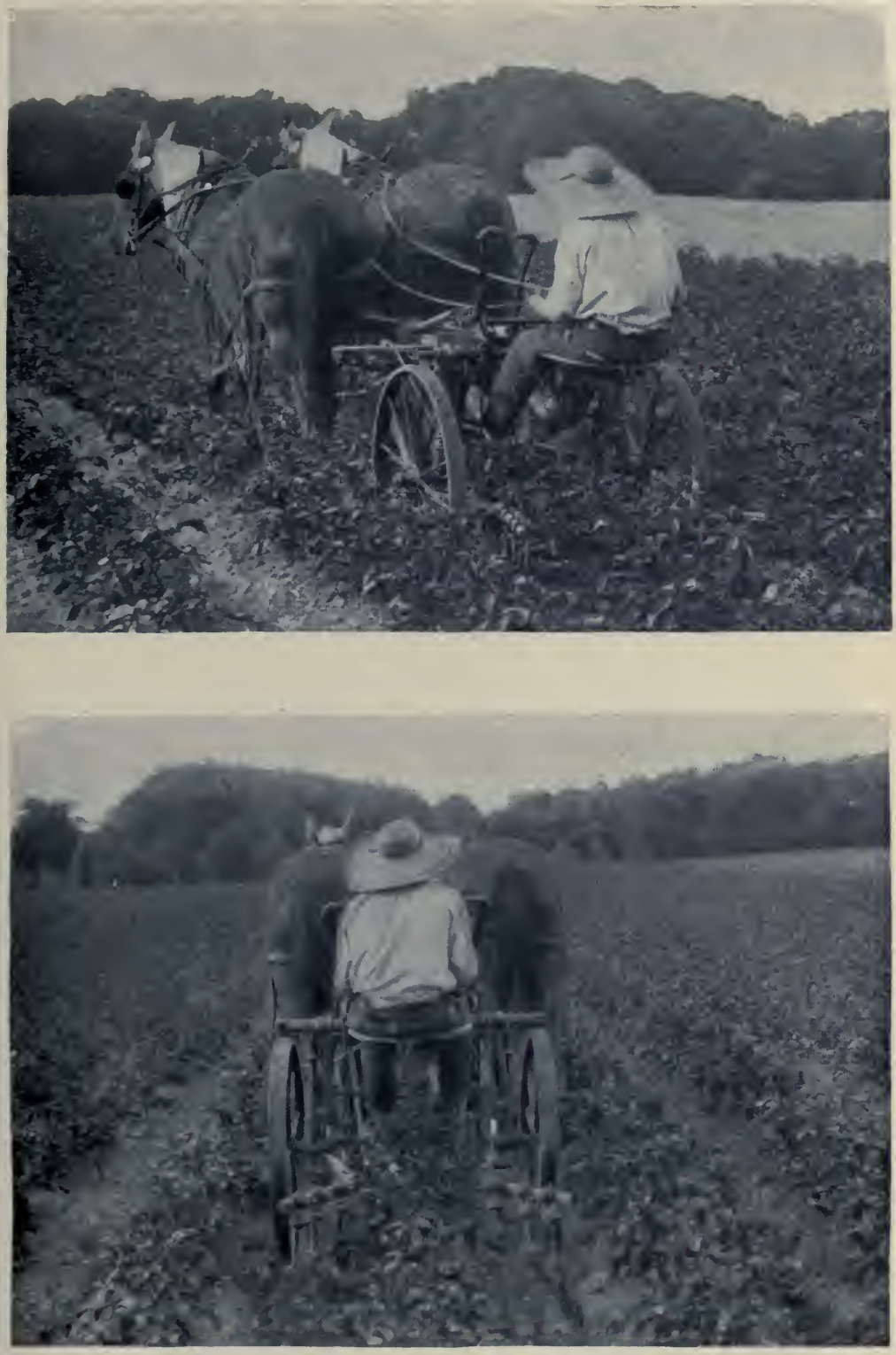

Two views of Iron Age Cultivator at work 


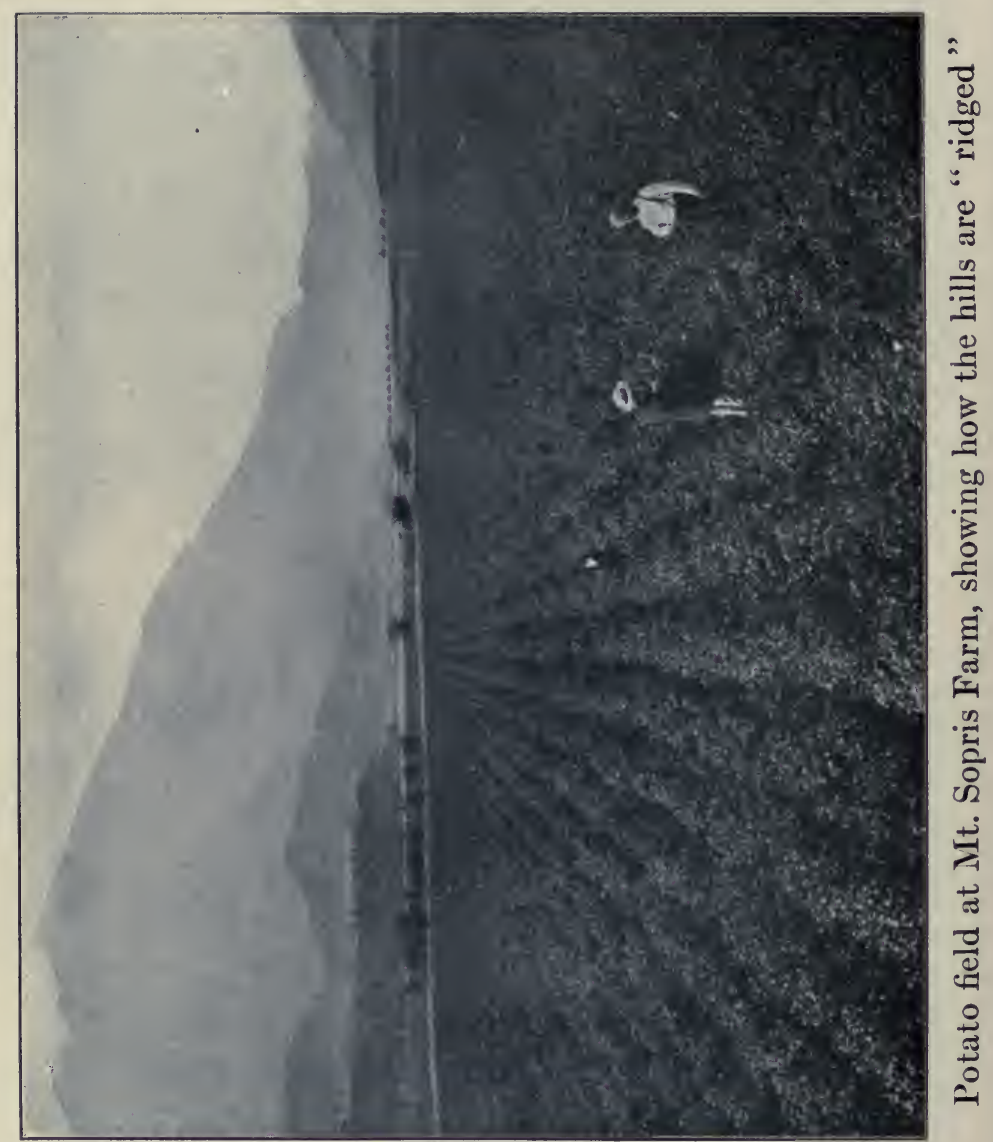


moisture be carefully conserved for fear of drought at some time during the growing season. The available plant food is also more largely in the first few inches of surface soil than in the more loose desert soils that have had the action of the elements for ages without the packing and leaching heavy rainfall.

It is important to run the irrigation water low in the furrow to keep from solidifying the soil and soaking the tubers. The root system seems to go deeper and adapt itself to the conditions as long as the irrigation water is supplied evenly and the soil is rich. Each of these conditions is under control where the water is abundant and the soil fertile.

Irrigation is followed by cultivation, and by irrigation again as soon as necessary. This is determined by examination of the soil and the color of the leaves of the plants. If the soil about the roots is so dry it will not remain moulded with the imprint of the hand when a small handful is compressed, it is too dry and needs water. This cannot be taken too literally, but some judgment must be used even in making as simple a test as this. One novice, making this test, found that the mould he formed stood all right, but on being touched crumbled away. Literally, as he understood the rule, the test showed sufficient moisture. Actually, the ground was getting dry and.needed irrigation.

When potatoes require water they indicate it by the dark green, almost black, color of the leaves. When watered too heavily they get too light green, almost yellow. The characteristic healthy medium green of a potato plant in good condition and doing well must be seen to be appreciated. but these things are easily learned. 
Good potatoes are grown with one to five irrigations, the last one not much later than August 20 th, to give forty to sixty days for finishing growth and ripening. Some of the best growers irrigate alternate rows at each irrigation, taking two waterings to go over the entire field.

There is good reason why irrigation conditions are ideal for the production of potatoes. The value of this crop, as of many others, depends on a right amount of moisture at the right time, the demand for moisture being heavy while the tubers are forming and developing. In Wisconsin it is assumed that the eighteen inches of water generally counted on during the growing season is sufficient to mature a maximum crop. In ten of the past twenty-one years the amount of rainfall during the growing season has been fourteen inches or less. Prof. F. H. King, the soil expert, found at the Wisconsin Experiment Station that the addition of two acre inches of water by irrigation increased the yield of marketable potatoes 100 bushels per acre. In the Twin Falls country in Idaho and some other places in the Rocky Mountain country the moisture supply is under absolute control, making, with an ideal soil, a sufficient and legitimate reason for the production of the most perfect potatoes.

It requires from 270 to 500 pounds of water to make one pound of dry matter in the vine and tuber of the potato plant.

The best growers favor several rather light irrigations to fewer heavier applications.

In "Bulletin 132" of the Maryland Agricultural College is given the result of an experiment to ascertain whether deep or shallow cultivation would produce the best potato crop. The summary follows : 


\begin{tabular}{cccccc}
\multicolumn{2}{c}{ Surface } & \multicolumn{2}{c}{ Medium Deep } & \multicolumn{2}{c}{ Deep } \\
Bu. & Bu. & Bu. & Bu. & Bu. & Bu. \\
Primes & Culls & Primes & Culls & Primes & Culls \\
127.3 & 30.0 & 137.9 & 30.3 & 141.6 & 28.2
\end{tabular}

And also the average of yields as affected by frequency of cultivation, disregarding depth:

Five Days

Bu.

Primes Culls

$126.5 \quad 27.4$
Ten Days

$\mathrm{Bu}$.

Primes

132.4
$\mathrm{Bu}$.

Culls

27.6
Fifteen Days

$\begin{array}{cc}\text { Bu. } & \text { Bu. } \\ \text { Primes } & \text { Culls } \\ 147.5 & 33.2\end{array}$

In discussing it the Maryland people say: "The above figures seem to clearly indicate that the deep and infrequent cultivation was most profitable, there being a difference of more than fourteen bushels per acre in favor of the deep over the shallow cultivation, and of twenty-one bushels in favor of infrequent working. It would seem, therefore, that the practice of farmers who usually cultivate with such tools and at such times as will keep the crop free from weeds is about all that is necessary to produce a good crop under the conditions prevailing here. The result may have been different if the same experiment had been conducted in the arid West. It is only at rare intervals that the rainfall in Maryland is so slight that it is practicable or necessary to work for a 'dust mulch.' What is really important is to destroy the weeds and stir the soil fairly deep to aerate, and at the same time dry it and make it loose and friable."

In an essay by Dr. Chas. D. Woods of Orono, Maine, in the fifty sixth annual report of the Massachusetts State Board of Agriculture is the follow- 
ing: "All through the growing season the field should be kept free from weeds. The exaggerated ridge culture which is so common in Aroostook County could be better replaced in Massachusetts by a less pronounced ridge, or as level culture as is practicable. Suitable potato land is naturally or artificially so well drained that it does not suffer from excessive moisture, and with the high-ridge culture there is danger even in a moderately dry season of the crop suffering from lack of water. The frequent running of the cultivator not merely keeps down the weeds, but it lets the air into the soil and prevents excessive loss of moisture from evaporation, and in every way seems to be beneficial to the crop. This should be kept up until the vines pretty well cover the ground. If weeds are appearing in the drill, these should be removed by hand."

By the foregoing it will be seen that much depends on the individual, who must study his conditions and adapt practice accordingly. 


\section{CHAPTER IX}

\section{IRRIGATION}

$\mathrm{F}$ gated farm.

At first thought it was intended to preface this chapter with a note to the effect that the ideas which follow will pertain only to those parts of the earth where crops can be grown only with irrigation.

The practice of irrigation, however, is simply that of supplying a plant the quantity of moisture required to bring about its most perfect, normal development. There are times when an application of water to the soil of what is called the "rain belt" would be of great benefit and result in profit to the grower.

The practice of irrigation is sure to increase as the productiveness of the acre must continually be made greater.

It cannot be made too plain that irrigation is easy as long as the operator keeps in mind the moisture needs of the plant.

The following interesting article on irrigation is from the "Irrigator's Hand Book," which is a compilation of suggestions on various agricultural subjects written in 1909 , primarily for the settlers on the J. S. \& W. S. Kuhn irrigation projects in southern Idaho by the authors of this work 
in collaboration with other members of the Agricultural Department of the Twin Falls North Side Land \& Water Company, and published by H. L. Hollister of Chicago. C. J. Griffith, one of the foremost agriculturists in America, and at present Director of Agriculture for the company mentioned above, prepared the following:

"Irrigation is the artificial application of water to land. It is necessary in arid regions in order that profitable crops may be grown; and it is useful in semi-arid regions to increase their production. Although most useful in arid regions, it is often practised in localities of heavy rainfall, for instance in the rice-growing districts of the South, where the annual rainfall is from forty to sixty inches.

"The practice of irrigation is older than the Pyramids of Egypt. The valleys of the rivers Nile and Euphrates have an unbroken historical record of more than 4,000 years.

"In a great many places in this hemisphere there are ruins of irrigation works that antedate any written history, and the civilization of the race that built them is only surmised.

"The irrigated area of all the nations of the world does not exceed 100,000,000 acres, or a land area of less than twice the acreage of the state of Idaho. Of this area India has 53,000,000 acres, and in that country may be seen some of the most expensive irrigation works in existence.

"There are only 13,000,000 acres of irrigated land in the United States, and the greatest systems yet developed are in the Twin Falls country.

"The preparation of land for irrigation consists in: First, putting the land in condition for farm- 
ing; and, second, a proper surface grading for the even distribution of water.

"There is nothing that pertains to irrigated farming that pays better than proper leveling or grading of the land. It is the key to the whole situation, and when once done it is done for all time.

"It is not always necessary to change the general grade or lay of a piece of land, but it is absolutely essential to take off high places and build up low ones.

"There are several implements with which to do leveling and grading; among these are Fresno scrapers, buck scrapers and land graders of different makes. Each one has a special use, some being for heavy cuts and long hauls, and some best for short hauls. The character of the work to be done will be the determining factor in the implement chosen. After the grading is done, in order to get surface smoothness, a home-made leveler or jointer made of plank should be run over the land to take out all small unevennesses. This leveler or jointer should be used every time a field is plowed. It firms and fines the soil. On some land this leveler is the only implement needed for leveling.

"No hard and fast rules can be given for the laying out of the ditch system for a new tract of land, but there are a great many essential points to be considered in order to have satisfactory results. It is desirable to bring the water to the highest point on the farm, so that every part can be reached. The 'farm supply ditch' should be as short as it is possible to make it in order to lessen seepage, evaporation and maintenance. It should ordinarily be made on a grade of 1 foot (1.2 
inches) to 0.2 feet (2.4 inches) fall per hundred feet, according to the firmness of the soil through which it is made. Ditches that carry over three or four second feet of water should have less grade. Whenever the current of the water picks up and carries sediment, the ditch will give trouble, because the sediment will be dropped in places where the current is slower and eventually this will choke up the ditch and cause a break. Especially in sandy soil should care be used to get an even and light grade, which should not exceed $\mathbf{1 . 5}$ inches per hundred feet. Where it is necessary to take a farm supply ditch down a heavy grade, drop boxes should be put in to take care of the excess grade. Farm supply ditches should be so located, if possible, to avoid dikes and flumes. A dike where absolutely necessary should be made of stiff soil, the banks should be made wide and high, and the dirt for it should not be taken closer than four feet from the toe of the bank on each side. When water is put through it for the first few times, it should never be allowed to run all night, because the soil thus thrown up is loose and readily fills with water. After a few hours' run, the water begins to seep through the banks, and until the dirt in the fills has repeatedly soaked up and settled there is always danger of it breaking. As soon as the dikes are firm and solid, the banks should be seeded to some grass that makes a good sod. Kentucky blue grass and Brome grass (Bromus Inermus) make good sod for holding ditch banks. Sandy soil makes a very unsatisfactory dike, as it never hardens like a stiffer soil. Flumes are unsatisfactory unless well made. Galvanized iron flumes give good service. Farm supply ditches should have ample capacity. New 
ditches lose a great deal by seepage, and until they become silted up they do not carry as much water as their size would indicate. New land in an arid district takes more water the first year than it ever requires thereafter. For an 80-acre tract of new land the supply ditch should be made with a slip scraper and it should generally be at least one foot deep in the solid ground, to say nothing of the height of the banks made by the dirt scraped out.

"Care should be used to run the distributing laterals on a light grade, because water must be taken out of them for the corrugations or checks, and if they have a heavy grade it is a difficult thing to do, because it requires so many checks in the laterals. These laterals can be made with a plow and a go-devil, or a regular ditch plow. The corrugations should be run in the direction of the greatest fall.

"The best method of irrigation to be followed is dependent upon the character of soil and the slope of the land. The corrugation system is suitable for land that takes up water readily and that has ten feet of uniform slope per mile (a trifle more than one inch per fifty feet) or more. Corrugations may be placed as close together as is necessary. Usually twenty inches apart is the minimum width and three feet apart the maximum. The furrows are made about four inches deep and should be made immediately after seeding or before the seed germinates. In old alfalfa fields the corrugations can be renewed when it becomes desirable with an iron corrugator that has sharp, plow-like points.

"Sub-laterals are made parallel with the laterals. For corrugation or furrow irrigation in Idaho 
a sufficient head of water is taken from the lateral to supply about twenty corrugations. This is run into the sub-laterals, and from these distributed to the corrugations. This breaks up the head of water into small streams that can be more easily handled. A controlling device to regulate these small heads of water may be made from $1 \times 4$ inch stuff nailed together, making a box four inches square outside measurements and about three feet long. This box is placed between the lateral and sub-lateral low enough to intercept the flow of water. The sub-lateral is generally a plow furrow with the dirt thrown down hill. Dirt dams are placed in it at proper intervals (about every twenty corrugations) to force the water out to the corrugations.

"It is sometimes necessary to place checks immediately below the diversion points in the lateral in order to raise the water level high enough to force the water into the corrugations. These checks are boxes or gates put in ditches or laterals through which the water is made to pass. The height of water maintained above the check is regulated by building up the opening (with narrow strips beginning at the bottom) through which the water passes. Canvas dams can also be used as checks when they are properly made. Sacks filled with dirt can also be used for diversions.

"The corrugation or furrow system is the method best adapted for the watering of all root crops. Potatoes show the bad effects of even a break between the furrows and consequent flooding. For potatoes the furrows are made quite large, the rows being ridged and furrows made between the rows. Sometimes the best method for 
the crop and the most economical in the use of water is to irrigate only alternate furrows at each irrigation. Water should be on the ground until it is sufficiently wet, sometimes from twelve to twenty-four hours. If the soil is very mellow and readily permeable, then four to eight hours is generally sufficient. The irrigation should continue until the moisture 'subs' between the furrows until it meets. Orchards are commonly irrigated by the furrow method. Care should be taken to keep the water away from the trees, as it is found that they thrive better when the water does not touch them but percolates into the soil and reaches the roots. When all the ground between the trees is moistened the roots spread uniformly. Grain and alfalfa may be irrigated with corrugations and in this section it is the most common method. By its use water is evenly distributed over the fields, is absolutely under control all the time, and where the land is in proper shape the work is quite rapid and probably less expensive than any other method except by the border system.

"The flooding system of irrigation can be used for watering grain and alfalfa. The laterals are most commonly run parallel to the slope, water being taken out from only one side of the lateral and extending to the next one. Sometimes on nearly level land they are run down the steepest slope, the irrigation water being taken out from each side and extending midway to the next lateral. Under this method the distance between laterals should not be over 200 feet and it is better to have them closer together, not over 100 feet. These laterals may be either permanent or made over each year, as in the case of grain crops. 


\section{THE POTATO}

This method is in general suitable for medium slopes, soils which do not bake, grain pasture and hay crops, and where lands are not of great value, such as meadow lands at high altitudes. One man can irrigate from two to five acres a day. As a rule the irrigation by this method is more uneven than with the other system.

"Some system to care for waste water is a necessary part of an irrigated farm. Especially where the ranch is bordered by other irrigated tracts or by public roads it is essential to have an adequate system of waste ditches that will receive and care for whatever water is not used by the irrigation. It often happens that draws or coulees are so located that they will carry away the waste water and in such cases no further attention is necessary. The amount of waste water is so variable that it is seldom satisfactory for any one else to try to use it for irrigation, and because of the fluctuations in its flow is not best to waste the water into another farm ditch.

"The term 'duty of water' as used in irrigation is accepted to mean the acreage of land that a certain amount of water should sufficiently irrigate. The standard measurement for running water is in cubic feet per second - that is, a running stream is measured by the number of cubic feet which pass a given point per second. In Idaho a miner's inch of water is one fiftieth of a cubic foot per second. The amounts used in irrigation are commonly spoken of in acre feet or acre inches. This is the amount covering an acre of land one foot deep or one inch deep as the case may be.

"The amount of water needed to grow and mature a crop is dependent on a great variety of 
conditions, some of which fluctuate even on a given farm from year to year. The composition of the soils, the subsoil, the annual rainfall, the humidity of the air, temperature, the time of seeding and many other things have appreciable effects upon the amount of water necessary for a given crop for maximum results. It is a question of knowing how little instead of how much to use. The soil can retain only a certain amount, and whatever is applied more than this is lost by percolation into the subsoil and beyond the food gathering area of the roots of plants. An appreciably large per cent. of irrigation water is lost in this way. New land will take more water the first year than thereafter, and for the third year less is required than for the second. The time to apply water is when the crop needs it and not before. This is determined in alfalfa by a darkening in the green of the leaves. The moisture content of the soil should be closely watched, and by the exercise of a little good judgment no serious mistake in applying water need be made. Too little as well as too much moisture in soils injures plants. The amount of water to be put on at one application is dependent on the crop and the soil, but generally about five acre inches is sufficient for an irrigation. On sandy loam, and making allowances for some loss as waste and evaporation, this amount will wet the soil about as deep as plant roots go.

"In localities where water for irrigation is scarce, fall or winter irrigation is often practised. It has a number of things to commend it besides the principal fact that if the water is not stored in the land it is lost. By using the water in this way, where there is a scarcity, additional land can be farmed and made to yield remunerative crops. 
Enough moisture can often be stored in the soil during the fall or winter to grow a crop of grain or potatoes. Cultivation usually plays quite a prominent part in raising such crops. It too often happens that where water is plentiful irrigation is substituted for cultivation. Where water is scarce it is an advantage to get the seed in the ground just as early in the spring as is possible so that the crop may be shading the ground before warm weather comes on. This prevents evaporation." 


\section{CHAPTER $\mathbf{X}$}

\section{HARVESTING}

7 HE bulk of the potato crop of the world is grown in what may be called "short season" L territory, and by that is meant that there is danger to the crop from frost at both ends of the growing period.

Because of this the main harvesting care is "weather." The potatoes must be out of the ground and cared for before the heavy freezes.

Potatoes that are not fully matured at the time in the fall of the year when frost threatens must be dug green.

Practically all large acreages of potatoes are now dug or "lifted" by machinery. There are several excellent horsepower potato diggers. These have a projecting "snout" or flat shovel which runs under the row, lifting the entire mass of dirt which contains the tubers to an apron made of iron rods. The dirt falls through these iron rods and the potatoes are passed along - to be finally dropped on the top of the ground.

The process of harvesting potatoes has passed through the same evolution as other farm operations. At first the tubers were dug by hand with a hoe or shovel, or "plowed out" with an ordinary moldboard walking plow. Then a pronged fork took the place of the hoe and shovel, and a flat nosed plow with wide double moldboard made of iron rods was used. With this sort of digger 
the dirt fell through and the potatoes were carried over.

To make a field trial of a machine in the particular character of soil it is to be used in is a safe way to select a digger.

Green, heavy tops clog a digger. Some pull the tops and haul them off the field in order to make digging easier. A simpler way to remedy this difficulty is to run a harrow over the field -in the same direction that the digger will run. This straightens out the tops and they make less trouble. A long spike tooth harrow, with teeth slanted back, should be used.

An essential in digging potatoes is to let the tubers lie on the top of the ground for two or six hours to dry out any dirt clinging to them and toughen the skin. In this way the potato is less liable to bruise in the after handling and much less dirt is carried from the field.

Some potato digging machinery manufacturers have been trying to perfect a device for sacking as well as digging potatoes. It would seem that the "drying out" in the sun, previously mentioned, is of such importance as to make this attachment impractical.

In the districts in the western part of the United States potatoes are picked by hand into pails or baskets and deposited in "half sacks." Regular potato sacks are half filled and pickers are paid a stated price for filling into each one bushel. Half sacks are used to make handling easier. (Filled and sewed, the sack holds about two bushels, or 120 pounds.) The usual price is three cents per bushel for picking.

These small sacks are hauled from the fields to the cellar and there the potatoes are spread out 
in thin layers. These layers gradually become thicker as the cellar is filled, but it is best not to fill any one part of the cellar too deep at one time.

Sometimes potatoes are run over a sorter in the field and the marketable ones either taken direct to the shipping point or stored separately in the cellar. Potatoes marketed from the field weigh 10 per cent. more than those taken to the cellar and rehandled. If weather conditions are urgent, and help scarce, this can often be done to better advantage in the cellar.

A machine digger will handle four to six acres a day.

Irrigated districts, where there is no rain during the growing and digging season, have a considerable advantage in the ability to turn out a product free from mud. This is emphasized by a study of the potato bulletins of the Eastern States and Europe, where the grower is admonished to "lift early," and in dry weather if possible.

Potatoes should always be dug when the vines die - frost conditions must indicate how long before that time. As long as the vine is green, the tubers are growing. One experiment shows that one third of the merchantable part of a crop was made (developed) in the last thirty of the 120-day period from planting to digging.

Careful handling pays at every stage of the harvesting process. A cut or badly bruised potato decays readily and every tuber lost reduces the profits.

While the toughening described is beneficial especially as regards bruising in handling - the potato must not be left too long in the sun or it will turn green and be unfit for food. 
In gardens, "grabbling" is sometimes practised, especially in Germany. This is to dig carefully into the sides of a hill of potatoes and remove the largest tubers for early use or market. If carefully done this will cause no injury to the smaller tubers.

An excellent description of handling potatoes in the field in the East is given by Alva Agee, in "Bulletin No.105" of the Pennsylvania Department of Agriculture. It follows:

"In great potato-growing sections years ago it was a common practice to pour bulk potatoes into wagon-beds, and to shovel them out into baskets when unloading. This primitive method was laborious, and did injury by bruising the tubers. Potato boxes have now come into common use in many districts. They are made of light material, preferably basswood or similar wood. The boards for sides and bottom should be three eighths inch in thickness, and the ends one half. The size of box should be such that it will contain 2,688 cubic inches, level full. The legal bushel measure for grain contains 2,150.4 cubic inches, and in measuring roots or potatoes the rule is to heap the half-bushel measure sufficiently to add one level peck to the two level half-bushels. Five level pecks, or 2,688 cubic inches, are the equivalent of two rounding half-bushels and of a level potato box rightly made. The following dimensions are the ones used by a leading manufacturer of these boxes: Twelve and one half inches deep, thirteen and one half inches wide, and sixteen inches long. This gives exactly 2,700 cubic inches. This size probably is more convenient than any other that could be devised. The length 
of two boxes is near the width of the ordinary wagon-bed, leaving only room for the hands when putting them into position, and, when empty, one box can be placed inside of two others, economizing space. With high sideboards on the wagon-bed, it is convenient to tier up sixty bushels when drawing from the field to the cellar or to market, but the extensive grower may prefer a long platform that will hold twenty or more boxes in a single tier.

"The home-made box is usually less satisfactory. It is rarely made of the best light material, and when one takes into account the number of times the boxes must be handled, he may see the advantage of having the very best. Manufacturers furnish solid boxes that weigh only seven pounds, are exact in size, trim in appearance, and will last for fifteen or twenty years, if cared for properly. Other boxes, slatted on ends and sides, are furnished at a less price, and are less substantial. The boxes, bought in crates of a dozen, cost about 18 cents apiece for the solid ones and 14 cents for the slatted.

"The potatoes are picked up after the digger and placed in the boxes, the unmerchantable tubers being left on the ground. When a load is ready, the boxes are handed up to the driver of the wagon, and while he takes the load to the car, cellar or other place of storage another load is made ready by the pickers. Returning, the driver puts his empty boxes out, takes on his load of full ones, and the work proceeds with a minimum amount of handling. If the potatoes are drawn directly to consumers, neat boxes for handling them are a good advertisement as well as a means of saving labor, time, and injury to the stock. 
"When good seed, cut to two eyes, has been planted in good ground, and the tillage has been right, the number of unmarketable potatoes usually is small, and many years we do not pick them up. It is the practice of some growers to pick up all sizes together and then to sort out those that are not merchantable, using the best of these for planting and the remainder for stock feed. The small tubers are not the most desirable for use as seed. If there is a considerable proportion of the crop that is too small for market it should be gathered from the ground after the merchantable potatoes have been taken up."

The practice of washing potatoes is not common, and there is a general idea that it is detrimental, but the Wisconsin Farmer says editorially:

"A good deal may be said in favor of the practice of washing potatoes, provided they are thoroughly ripened before being dug. We know of one instance where a shipper of early potatoes refused to fulfil his part of the contract on account of a customer having washed his early potatoes. He said that washing greatly impaired the keeping quality of early varieties. However, in the case of mature potatoes, if for any reason they are dug at a time when the dirt adheres to them, it will undoubtedly pay to give them a good washing. Nevertheless, it is highly important that they be thoroughly sun-dried before they are stored in the cellar or cave or before they are placed in sacks. It is reasonable to suppose that dried mud adhering to potatoes will carry a certain amount of germ life, and it is not strange if some of this form of life tends to induce decay, One 
grower informs us that he makes a practice of thoroughly washing his potatoes every year, after which they are stored in bushel boxes. The claim is made that by this method the highest market price is obtained on account of the fine, clean appearance of the tubers, and also on account of the splendid condition in which they keep stored in this fashion."

An Iowa grower believes in the practice of washing potatoes, and says in the Wisconsin Farmer:

"According to my experience, too much cannot be said in favor of throughly cleaning potatoes as soon as they are dug. The finest crop I ever saw was rotting in the ground on account of the weather being hot and moist. As soon as they were dug the spray-pump was started and the potatoes thoroughly washed. They were then allowed to dry before being housed, and after being sorted not a solitary tuber decayed. I had another experience that tends to corroborate this practice. Over a year ago I bought some potatoes, but when they were delivered they were covered with dry mud. These potatoes when cooked had a nauseating taste, and in several instances had a sickening effect. I came to the conclusion that when potatoes were left in this dirty condition germs of disease were present, and it is my opinion that the law should prohibit the marketing of potatoes in this condition. Not only are they unwholesome, but they are much more apt to decay, than if they are thoroughly cleaned by washing."

Another grower condemns the washing of the tubers and says: 
"All any one need do to know whether it spoils them or not is just to try it. Cook some that have been washed a week or two; then cook some that have been dug when the ground was in condition - the more fresh dirt among them the better - and see how much better and more mealy and palatable they are than the washed ones. Potatoes that are to be kept over winter should be left in the ground as long as possible, until there is danger of freezing them. Then dig when the ground is in condition, not when the mud will stick to them, and the more fresh dirt the more brittle and fresh they will come out in the spring."

The natural, normal way to take potatoes from the ground and store them is when the soil is dry. When this is the case no washing is necessary.

Whether harm comes with washing depends on the drying and after care, and the need of washing depends on the amount of mud adhering to the tubers when they are dug.

Good, hard headed, common sense is required in all harvesting operations, and no rules can cover all conditions. 


\section{CHAPTER XI}

\section{POTATO MACHINERY}

D

URING the past decade great improvements have been made in agricultural machinery. The up-to-date farmer of to-day is not content with old methods or tools, if there is no better reason for their use than that his father or grandfather used them. Every machine that will do work more cheaply or better finds a welcome on the strictly modern business-farmer's place.

The senior author has been intensely interested in the betterment of machines that will render farm operations more effective. Over forty years ago he made plows and agricultural machinery in a plow factory in Illinois, and appreciates the situation more than one less conversant with the details of the machinery business both from manufacturer's and user's standpoints.

It is true of makers of potato machinery that it is their desire to make an implement that will do the greatest possible service for the user, and they welcome suggestions from practical growers for improvements.

During the past twenty-five years the senior author has been responsible for a great many improvements to machinery now in use.

The increasing interest in farm machinery, or farm mechanics, is indicated by the fact that practically all of the leading agricultural colleges now have departments devoted to this subject. 
It is the intention of the authors to present in this book descriptions and illustrations of a large number of implements used satisfactorily in the potato industry. This will enable the reader to form an opinion as to those best suited to his conditions.

\section{THE IRON AGE MACHINERY}

The following machines are made by the Bateman Manufacturing Company, Greenloch, N. J.:

\section{Iron Age (Improved Robbins) Planter}

This planter feeds the seed automatically. It shakes the seed out into the pockets of an elevator wheel, which in turn drops it through a short spout to a horizontal feed wheel, also provided with pockets. This wheel makes one complete revolution in front of the boy or man on the rear seat; when he finds a pocket that has no seed in it, he supplies a piece from a pile within reach; if a pocket gets two seed pieces, he takes one out. The result is that you get one seed piece in every space and one only. You can understand what this means if you will consider a few figures. If a normal average for a perfect stand were 150 bushels (and this is very reasonable) 5 per cent. skips would mean a loss of seven and one half bushels, or $\$ 3.75$ per acre at an average price of 50 cents. It costs no more to cultivate, spray, and fertilize a perfect stand than it does one with skips here and there.

\section{Iron Age Riding Cultivators}

Cultivators should have all of the necessary adjustments for narrow or wide rows, deep or 


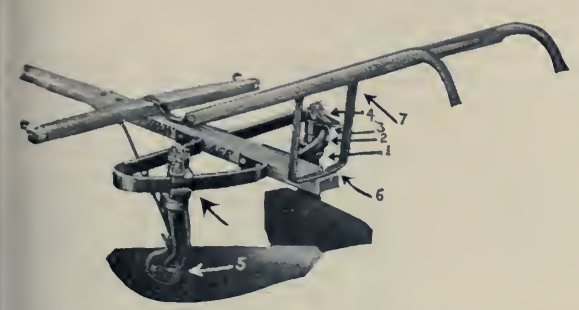

Iron Áge Potato Hoe or Ridger

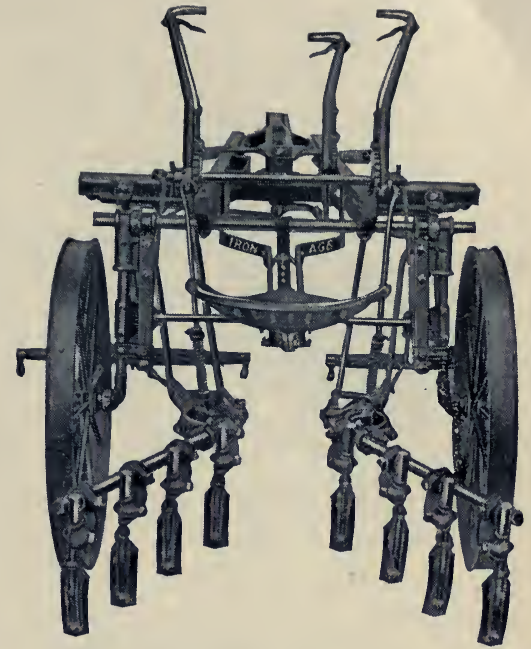

Iron Age Riding Cultivator

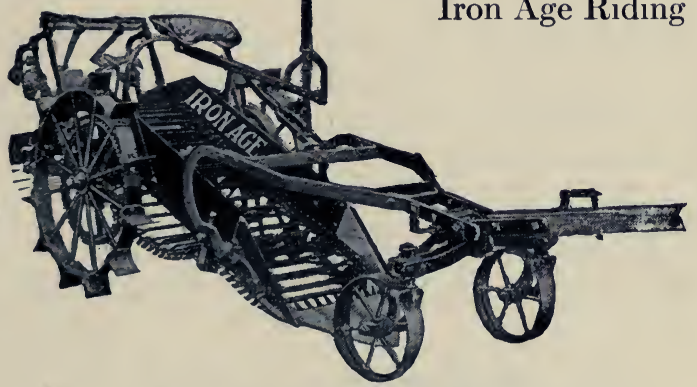

Iron Age Potato Digger

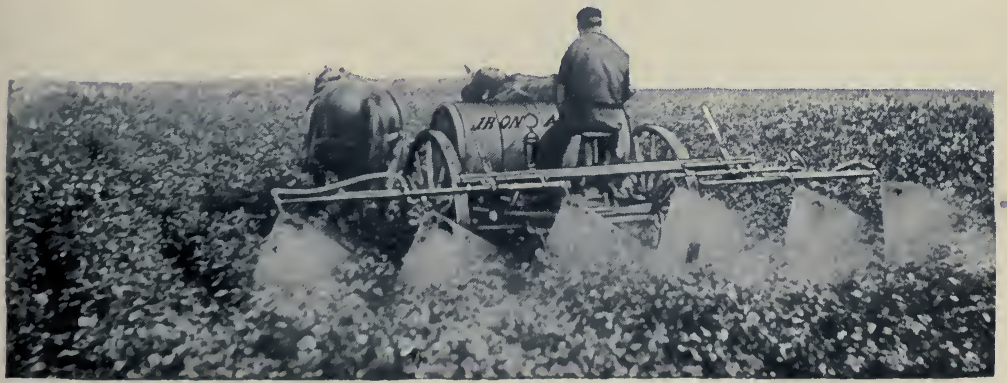

Iron Age 'Traction Sprayer 


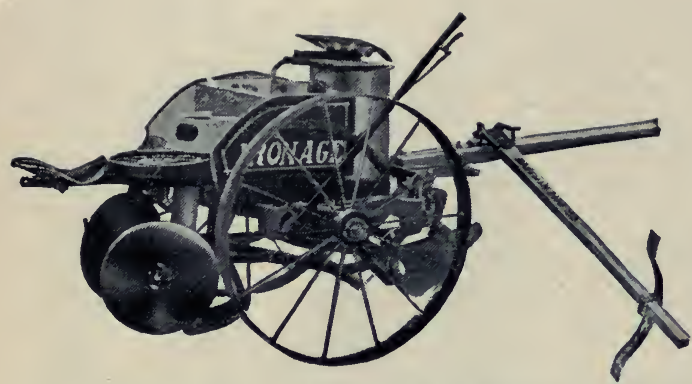

Iron Age (Improved Robbins) Potato Planter

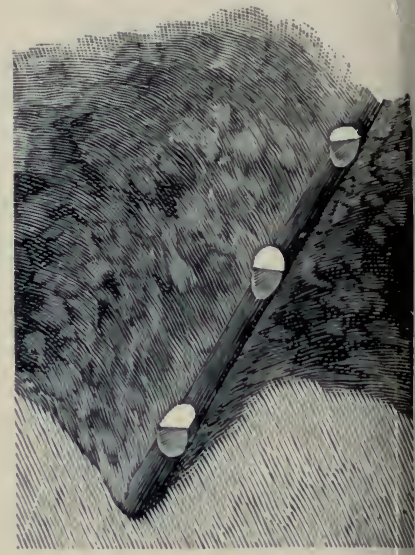

Seed pieces in place in the furrow opened by the Iron Age Planter

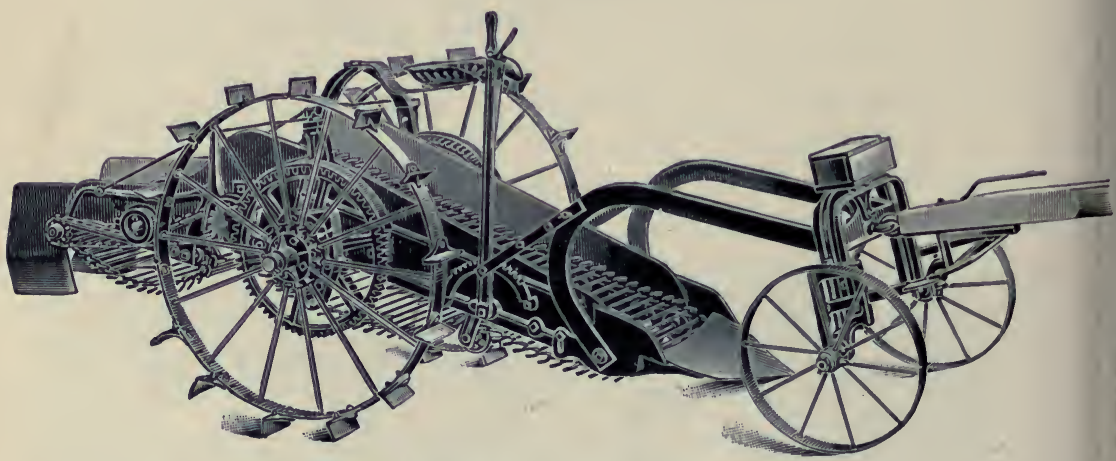

Dowden Potato Digger 
shallow cultivation, and the teeth changed quickly to any position in the row while the team is in motion. All of these necessary adjustments are found on Iron Age cultivators. They are of many styles and combinations to fit the varied conditions of ground and cultivation desired. Pivot wheels are used on three styles - they make guiding easy. High or low wheels - six or eight hoes for one or two rows, break-pin hoes, spring hoes, or spring teeth can be furnished. The hoes are kept in the ground by spring pressure; thorough cultivation is the result. Disk, plow, ridging, and other attachments are furnished.

\section{Iron Age Traction Sprayers}

The Iron Age sprayer drives from the centre, has a perfect working relief valve and a big air chamber, is thoroughly protected against corrosion, and is easily shut off from the seat. It is furnished in four, six, or seven row sizes, with 55 or 100 gallon wood or 55 gallon steel tanks, and revolving mixer, single or double action pumps. It is made for one or two horses.

\section{Iron Age Potato Hoe or Ridger}

These tools are adjustable at any position on the frame by simple eccentric levers. They are also adjustable for angle of the blades, position of the handles, etc. Made with plain steel blades, or with detachable shoes for stony ground, or with twenty-inch disks.

\section{Iron Age Potato Diggers}

The Iron Age line comprises four machines: No. 125 is a rotary disk, low down machine for light, sandy soils; No. 127, same digger with 
elevator and shaker attached; No. 150, medium size elevator and twenty-eight-inch wheels; No. 155, large elevator, thirty-two-inch wheels, and kickers for heavy conditions, as to ground, grass, vines, etc. They have steel spurs on the wheels, and are designed so that wearing parts can be easily and cheaply replaced. They can be thrown in and out of gear from the seat. The plow is adjustable so as to get all of the potatoes with as little cutting as possible and as little soil, and so that draft will not be too great.

\section{THE JOHN DEERE MACHINERY}

The machinery described in the following paragraphs is made by Deere \& Company, Moline, Ill.:

\section{John Deere Two-Way Sulky Plow}

A fine plow for potato growers and truck farmers. It turns all the soil one way, leaving no dead furrows or back-furrow ridges. In irregular fields it leaves no crooked dead furrows - and all furrows are straight. When used in arid climates, harrowing and planting can be kept up with the plowing. In this way evaporation is checked and seed is planted in moist soil.

\section{John Deere Model "B" Flexible Disk Harrow}

No tools equal a good disk for finely pulverizing the soil. One or two diskings make a nice, deep, mellow seed bed for potatoes.

Spring pressure enables this harrow to penetrate and cultivate an even depth the full width of cut. Third lever controls spring, hence operator can set the disks for thorough work in all conditions. Either solid or cutaway disk blades may be had. 


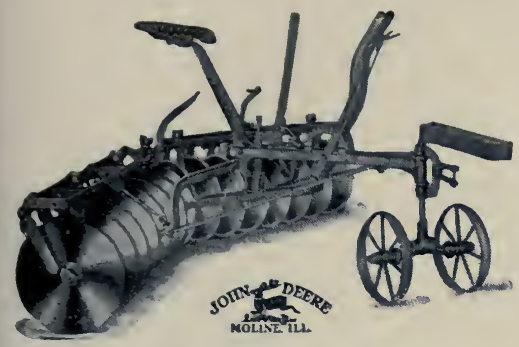

Deere Disk Harrow

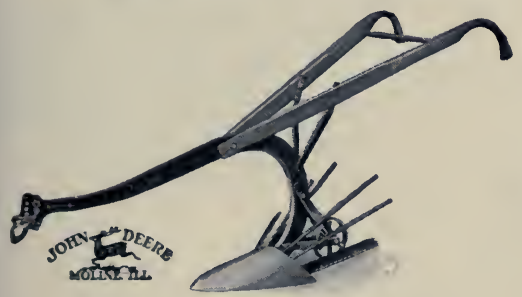

Deere Potato Digger

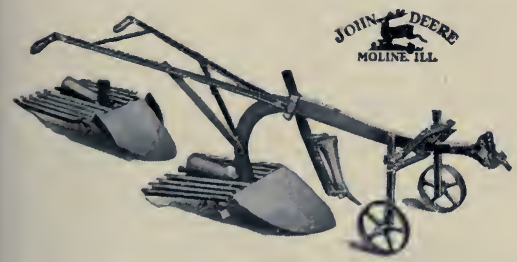

Deere Shaker Potato Digger
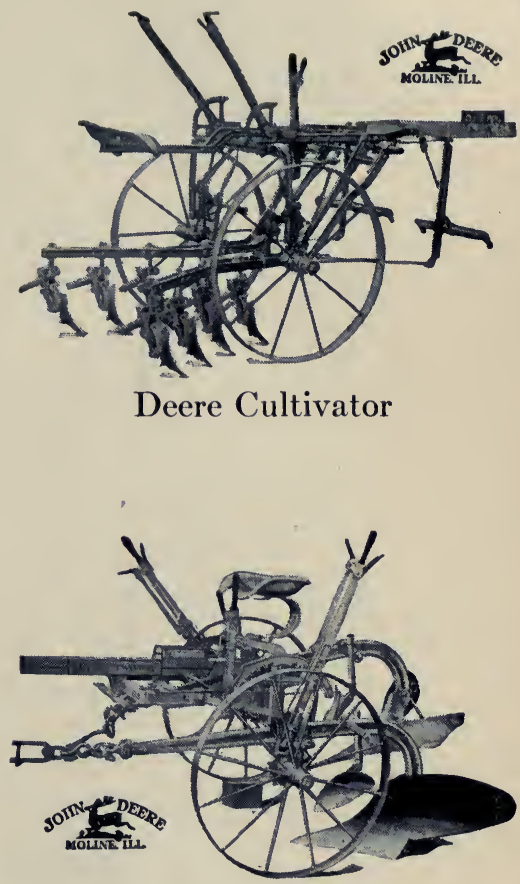

Deere Two-Way Plow

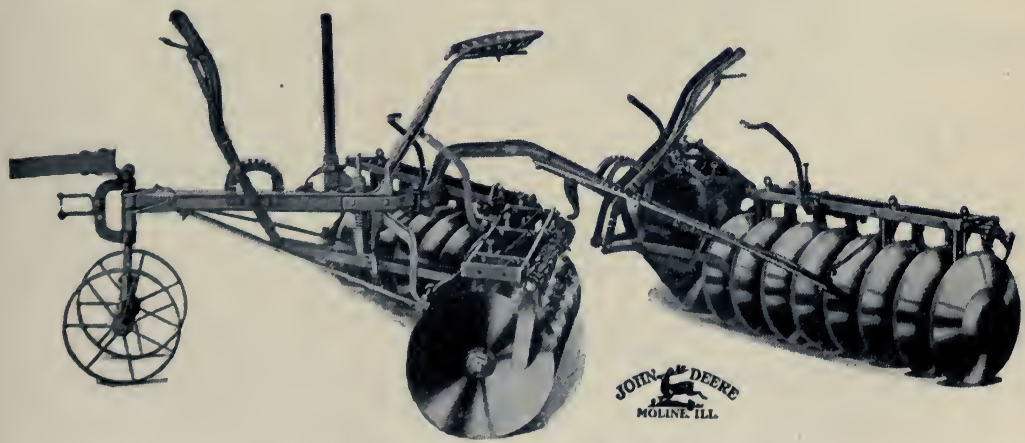

Deere Double-Action Disk Harrow 


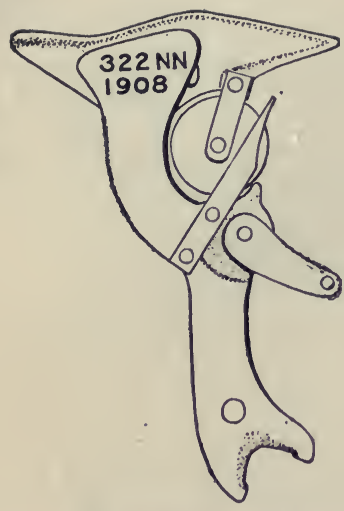

"Picker" in Aspinwall Planter

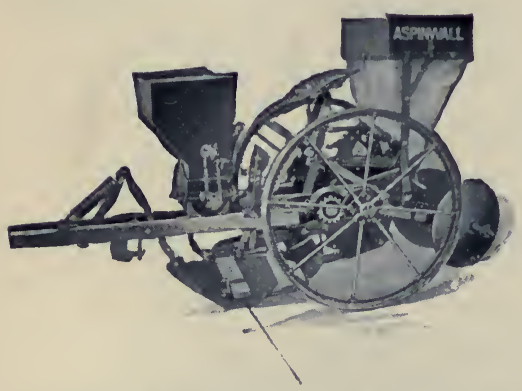

Aspinwall Planter with Fertilizer Attachment

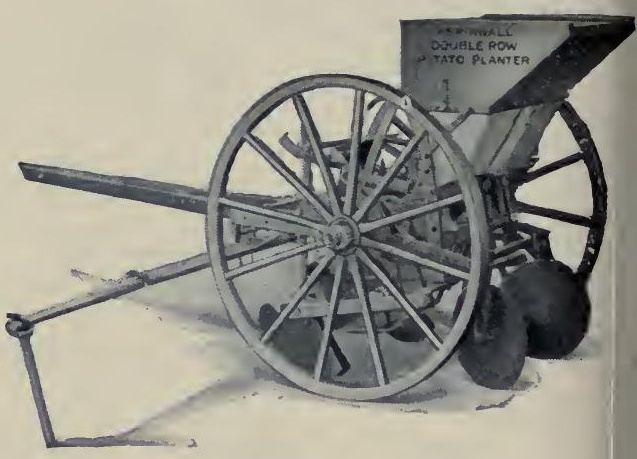

Aspinwall Two-Row Planter

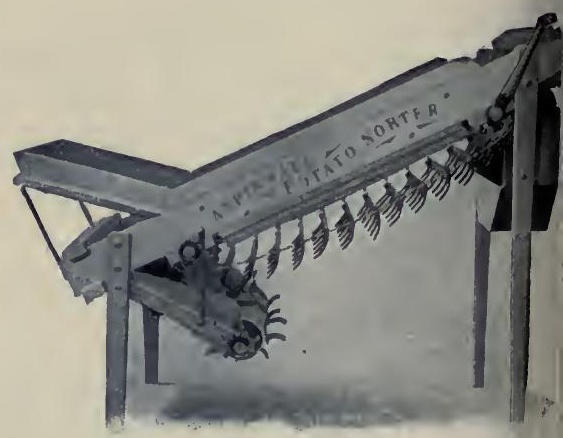

Aspinwall Potato Sorter 


\section{John Deere Double-Action Disk Harrow}

Double disking saves one half in time and labor, and secures better results than two single diskings, because the soil, freshly broken by the first selection, is pulverized by the second section without giving any opportunity for drying out and hardening. Front section is out-throw, rear, in-throw, leaving the land surface level. Furnished with both solid and cutaway disks.

\section{John Deere KA-Pivot Axle Cultivator}

This machine is especially good for cultivating potatoes, because it will work in wide or narrow rows and rigs can be spaced to suit lean or bushy rows. Wheels are shifted by foot pedals which make it easy to guide cultivator and dodge plants out of line with row. Spring tooth rigs, disk or moldboard hillers can be used on a John Deere KA cultivator. It is equipped with spring trip or pin break rigs. Longer, narrow shovels are also used on this cultivator in some districts in the West where extra deep cultivation is required.

\section{Deere Potato Digger}

The Deere potato digger has been in successful use for many years, and is equal to any requirement that may be made on it. It works with very light draft and throws the potatoes out of the ground without cutting, leaving the ground in good shape. The gauge wheel regulates the depth and helps to steady the digger.

\section{John Deere Shaker Potato Digger}

An ideal implement for the man who grows a limited area of potatoes. Sprocket, which runs on 
ground, gives hinged grating and up-and-down motion. This shakes out the dirt and leaves the tubers in a clean, compact row. Weed fender clears away weeds and vines ahead of blade. This digger is inexpensive and can be owned by any one. A wing shovel and extra bars to widen grate are furnished for sandy soils.

\section{THE ASPINWALL MACHINERY}

The Aspinwall Manufacturing Company, Jackson, Mich., makes the machinery which is described in the following:

\section{Aspinwall Potato Planter No. 3.}

'This planter is entirely automatic. The picker represents the automatic action of the hand in planting, and is mechanical, but six of these hands are employed for all distances of planting. The distance is regulated by gears instead of change in number of pickers.

With the Aspinwall potato planter the fertilizer attachment is used largely in the East.

\section{Aspinwall Two-Row Planter}

By using this machine there is a saving of time and labor, one man and team doing double the work of the single row. The two rows are absolutely equal in distance apart, which is of great advantage when using a two-row cultivator, as it permits of very close cultivation. The draft of the machine is but slightly more than the single row. The large wheels and narrow furrow openers reduce the draft and compensate for the increased size of the machine. Centre draft. The hopper capacity enables planting one half mile without refilling. 


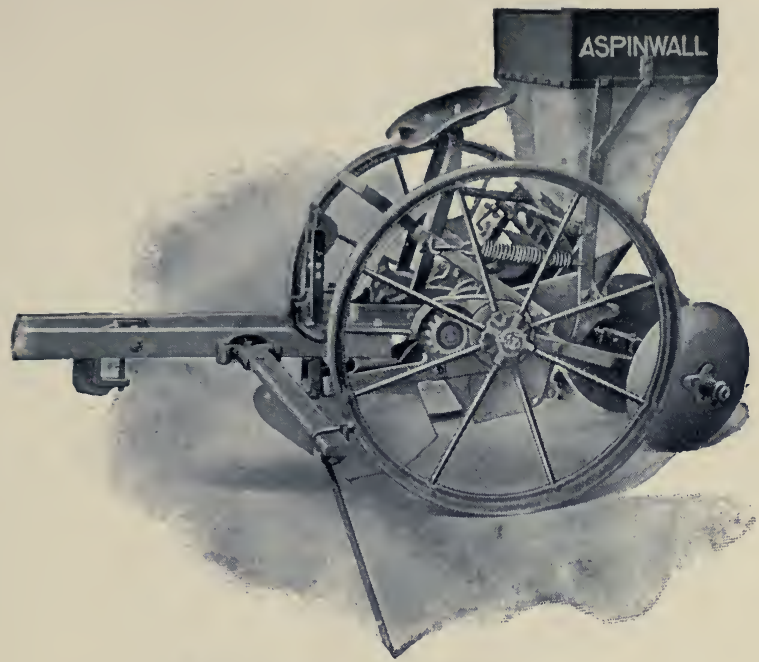

Aspinwall Potato Planter

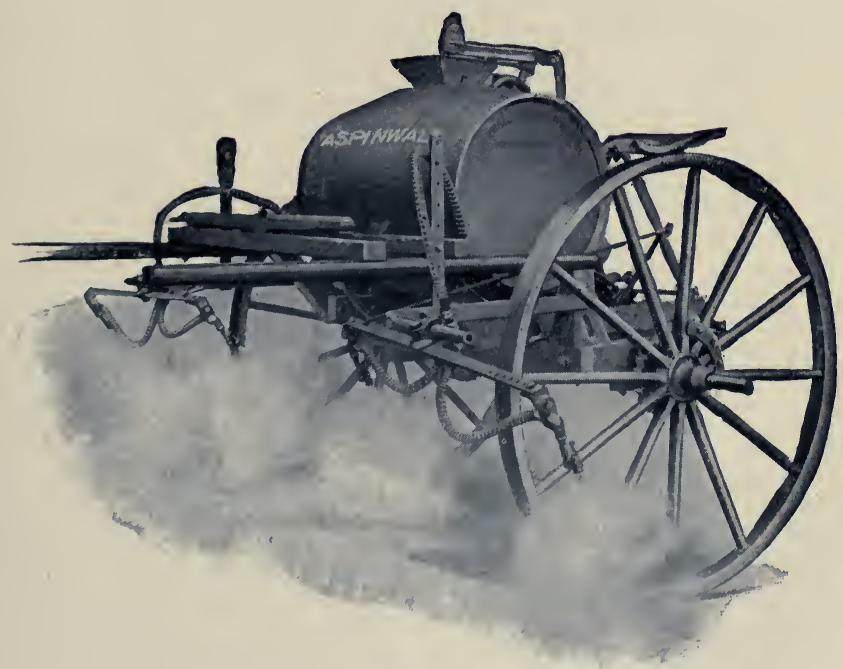

Aspinwall Sprayer 


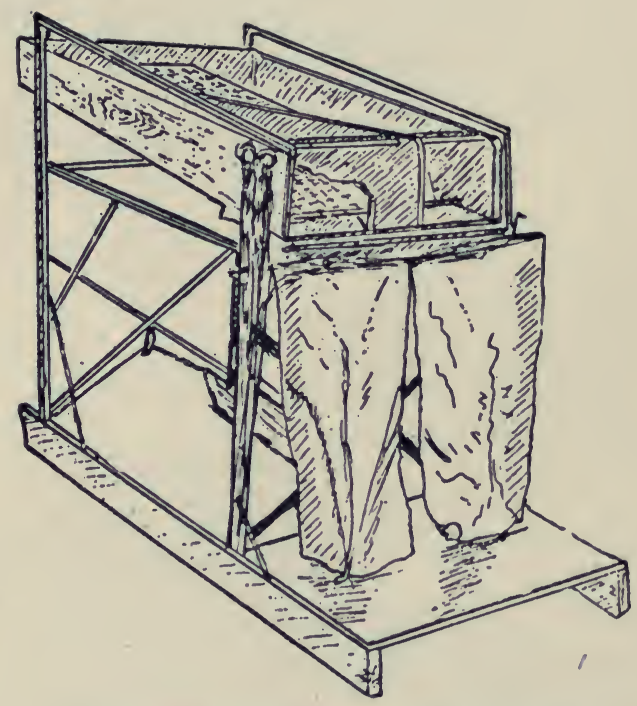

Thompson's Greeley Potato Sorter 
Distance of planting between the rows is adjustable to suit requirements. The furrow openers are very narrow, which insures planting in straight lines. The disk coverers are set inside of the furrowers and close the earth into the individual furrows with a single disk.

\section{Aspinwall Potato Sprayers}

These machines are made with attachments for all purposes, including orchard attachment and attachments for the various crops grown by truck gardeners. They are equipped with nozzles in front, adjustable by pedals which the driver can guide so as to deflect the spray and overcome any tendency of the wind to drive it from the rows of potatoes. The spraying capacity is four rows in one operation, or twenty acres per day. Pressure is from 60 to 120 pounds and adapted to spray Paris green, Bordeaux mixture, or sulphate of iron used with the broadcast attachment for grain fields.

\section{Aspinwall Potato Diggers}

The Rotary potato digger is intended to dig potatoes under various conditions. In operating the machine it is best to work around a number of rows or drills of potatoes the same as in plowing or mowing, discharging the potatoes constantly to the right side of the machine. This machine is not illustrated.

\section{Aspinwall Potato Sorter}

The manufacturers state that this machine will sort from 500 to 1,000 bushels per day, and work is superior to hand work. The low-down hopper makes easy work when shoveling and feeding the machine. It may be run by hand or power, as rẹ- 
quired. The entire work is under the control of the operator and any potatoes which are decayed or ill-shaped may be removed while the work is progressing. The sorting or separation divides the potatoes into three sizes.

\section{THOMPSON MACHINERY}

The Thompson potato sorter is made by James Thompson, Greeley, Col., and is largely used in the West. Mr. Thompson also makes bag holders and potato baskets. The sorter is operated by rocking back and forth the part into which the potatoes are emptied, the small potatoes dropping through the screen and being conveyed into one sack, the larger ones going over the screen and into the other sack. It is used both in the cellar and field.

By laying a burlap sack over the upper end of the screen there is less bruising of the potatoes as they are shoveled or emptied on the sorter. The sack may cover one quarter to one third of the top surface of the sorter.

\section{THE DOWDEN MACHINERY}

The Dowden potato digger, made by the Dowden Manufacturing Company, Prairie City, Iowa, weighs 1,140 pounds and is drawn by two or four horses, although made strong enough that six may be used, if required.

The point, or "snout," of the digger goes under the rows, elevating the potatoes over an apron made of rods spaced far enough apart to let the dirt fall through, but close enough together to carry the potatoes over and deposit them on the top of the ground. 


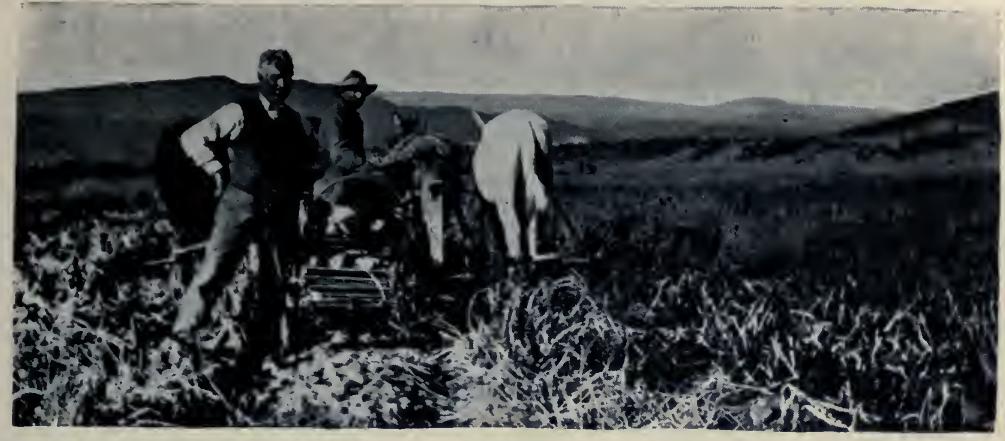

Dowden Potato Digger at work on Mt. Sopris Farm

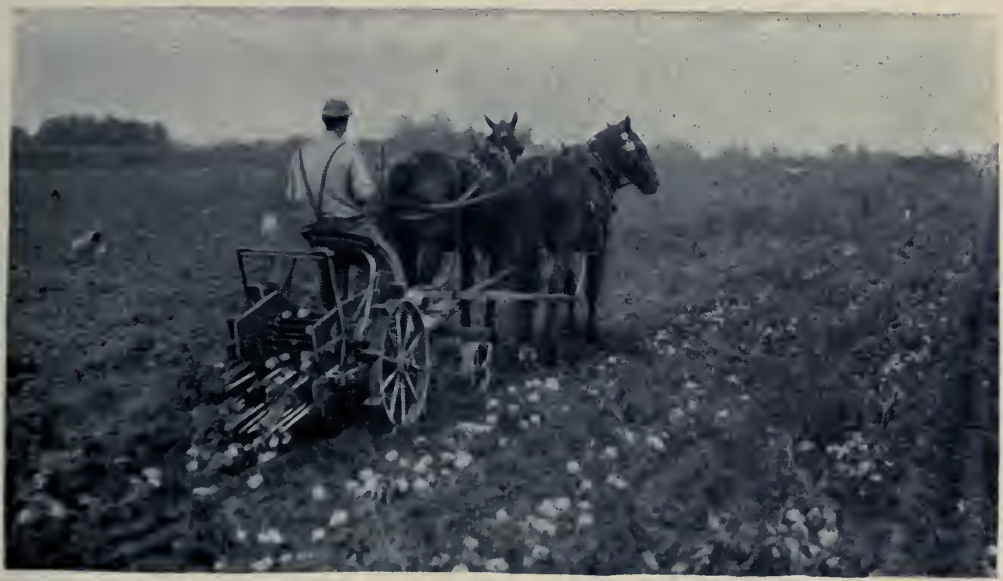

Iron Age Digger at work

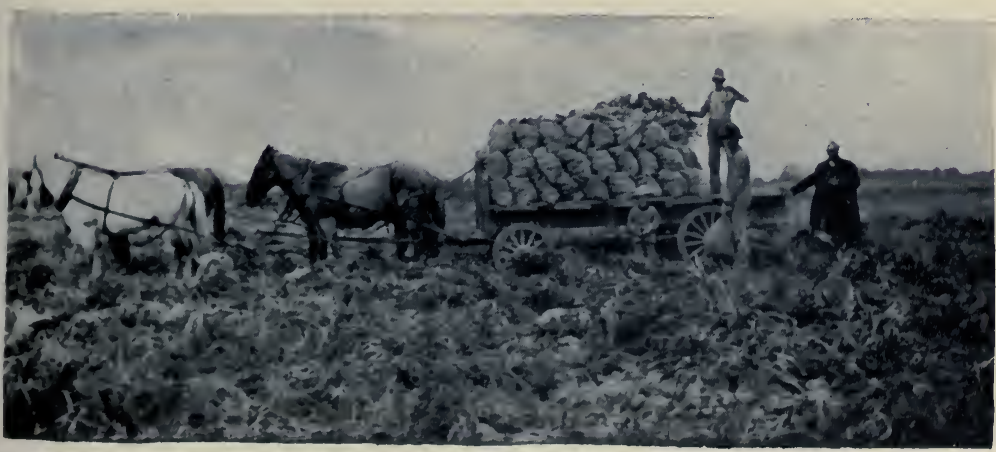

Hauling potatoes to storehouse in "half-sacks" - Mt. Sopris Farm 


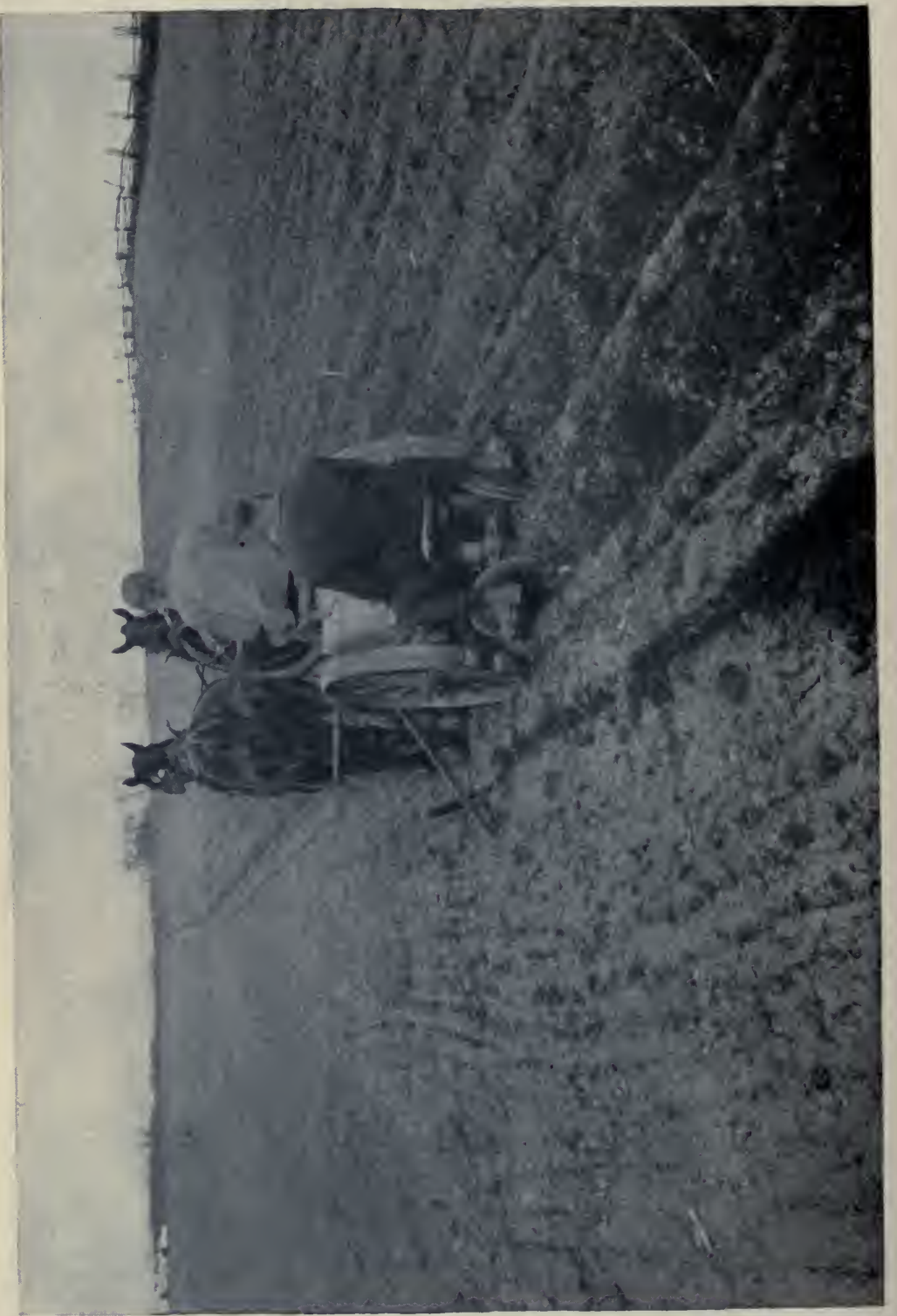

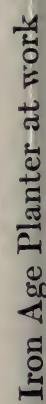




\section{CHAPTER XII}

\section{SELLING AND STORAGE}

D OES it pay to store potatoes or sell direct from the field to the dealer, and if storage pays what sort of structure is best?

The answer to the first must be made by the individual grower. The element of chance enters very largely into this problem, to a greater degree, perhaps, than with any other farm crop.

Statistics show that this statement is true viz., that the farmer who has favorable conditions for potato growing and can practise a good rotation, who will grow the same acreage of potatoes each year for ten years, selling half at digging time and storing the balance, will show a nice annual profit on his ten years' operations.

To say that prices will be good this year or next, or that it will pay to sell or store this fall or any later single fall, is simply making a guess.

The Government reports showing acreage and condition of crop during the season and a comparison with other seasons give some idea of what to expect. In addition to this the grower should know what other districts besides his own are in position to compete with him in his natural markets, and the condition of their crop is another fact on which to base his guess. Figuring the average production in the United States at about ninety bushels per acre, the per capita consumption four bushels, and the population of the country. 
at $90,000,000-360$ million bushels, or over three million acres, are required to meet the demands. When the acreage is short or the per acre yield low, the price will be high. In the appendix is given a table showing averages. These facts are interesting in this connection.

Table of Chicago prices, per bushel, follows:

\begin{tabular}{|c|c|c|c|c|}
\hline \multirow[t]{2}{*}{ Year } & \multirow{2}{*}{$\begin{array}{c}\text { December } \\
\text { Low }\end{array}$} & \multicolumn{3}{|c|}{ May of following yea } \\
\hline & & High & Low & High \\
\hline $1886 \ldots \ldots \ldots \ldots \ldots \ldots \ldots \ldots$ & 44 & 47 & 65 & 90 \\
\hline $1887 \ldots \ldots \ldots \ldots \ldots \ldots \ldots$ & 70 & 83 & 65 & 85 \\
\hline $1888 \ldots \ldots \ldots \ldots \ldots \ldots \ldots$ & 30 & 37 & 24 & \pm 0 \\
\hline $1889 \ldots \ldots \ldots \ldots \ldots \ldots \ldots$ & 33 & 45 & 30 & 60 \\
\hline $1890 .{ }_{1} \ldots \ldots \ldots \ldots \ldots \ldots \ldots$ & 82 & 93 & 95 & 110 \\
\hline $1891 \ldots \ldots \ldots \ldots \ldots \ldots \ldots \ldots$ & 30 & 40 & 30 & 50 \\
\hline $1892 \ldots \ldots \ldots \ldots \ldots \ldots \ldots \ldots$ & 60 & 72 & 70 & 90 \\
\hline $1893 \ldots \ldots \ldots \ldots \ldots \ldots \ldots$ & 51 & 60 & 64 & $08+2>>2>$ \\
\hline $1894 \ldots \ldots \ldots \ldots \ldots \ldots \ldots$ & 43 & 58 & 40 & 0 \\
\hline $1895 \ldots \ldots \ldots \ldots \ldots \ldots \ldots \ldots$ & 18 & 24 & 10 & $z$ \\
\hline$\ldots \ldots \ldots \ldots \ldots \ldots \ldots$ & 18 & 26 & 19 & 2( \\
\hline$\ldots \ldots \ldots \ldots \ldots \ldots \ldots$ & 50 & 62 & 60 & 8 \\
\hline 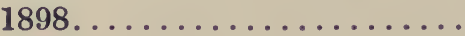 & 30 & 36 & 33 & 5 \\
\hline$\ldots \ldots \ldots \ldots \ldots \ldots$ & 35 & 46 & 27 & 3 \\
\hline$\ldots \ldots \ldots \ldots \ldots \ldots$ & 40 & 48 & 35 & 6 \\
\hline .............. & 75 & 82 & 58 & 100 \\
\hline$\ldots \ldots \ldots \ldots \ldots \ldots$ & 42 & 48 & 42 & 6 \\
\hline$\ldots \ldots \ldots \ldots \ldots \ldots \ldots$ & 60 & 66 & 95 & 116 \\
\hline$\ldots \ldots \ldots \ldots \ldots \ldots \ldots$ & 32 & 38 & 20 & 2 \\
\hline $1905 \ldots \ldots \ldots \ldots \ldots \ldots \ldots$ & 55 & 66 & 48 & \\
\hline$\ldots \ldots \ldots \ldots \ldots$ & 40 & 43 & 55 & 7. \\
\hline$\ldots \ldots \ldots \ldots \ldots$ & 46 & 58 & 50 & 8 \\
\hline 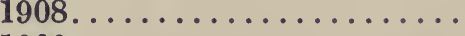 & 60 & 77 & 70 & 15 \\
\hline & & 58 & .. & \\
\hline
\end{tabular}

Various other price statistics are shown in the tables.

A large part of the potatoes of the world grow in countries of freezing temperatures, and whether stored by the farmer or by the dealer, that part of the crop which is not consumed before the main 
Average farm price of potatoes per bushel in the United States.

\begin{tabular}{|c|c|c|c|c|c|c|c|c|c|c|c|c|c|c|c|c|c|c|c|}
\hline \multirow{2}{*}{$\begin{array}{l}\text { State, Terri- } \\
\text { tory, or } \\
\text { Divlsion. }\end{array}$} & \multicolumn{4}{|c|}{$\begin{array}{l}\text { Price December } \\
1, \text { by decades. }\end{array}$} & \multicolumn{9}{|c|}{ Prlce December 1, by years. } & \multicolumn{6}{|c|}{ Price blmonthly, 1909.} \\
\hline & 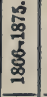 & 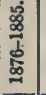 & 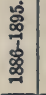 & 灾 & 1900 & 1901 & 19021 & 1903 & 19041 & 19051 & 1906 & 1907 & 1908 & ¿̊ & में & $\stackrel{-\dot{0}}{\stackrel{g}{g}}$ & हैं & $\begin{array}{l}-i \\
\dot{s} \\
\delta\end{array}$ & मूं \\
\hline $\begin{array}{l}\text { Malne......... } \\
\text { N. Hampshire.. } \\
\text { Vermont........ } \\
\text { Massachusetts. } \\
\text { Rhode Island... } \\
\text { Connecticut.... } \\
\text { New York...... } \\
\text { New Jersey..... } \\
\text { Pennsylvania.. }\end{array}$ & $\begin{array}{r}\text { Cts. } \\
50 \\
51 \\
39 \\
65 \\
70 \\
67 \\
50 \\
68 \\
59\end{array}$ & $\begin{array}{r}C t s . \\
55 \\
56 \\
50 \\
70 \\
74 \\
72 \\
54 \\
70 \\
56\end{array}$ & $\begin{array}{r}C t s . \\
55 \\
58 \\
49 \\
69 \\
70 \\
67 \\
49 \\
61 \\
54\end{array}$ & $\begin{array}{r}C t s . \\
56 \\
63 \\
52 \\
73 \\
75 \\
72 \\
54 \\
64 \\
56\end{array}$ & $\begin{array}{r}C 6 . \\
49 \\
53 \\
40 \\
66 \\
70 \\
70 \\
15 \\
60 \\
53\end{array}$ & \begin{tabular}{|r|} 
Cts. \\
67 \\
79 \\
64 \\
90 \\
93 \\
91 \\
71 \\
85 \\
76
\end{tabular} & $\begin{array}{r}C t s . \\
65 \\
69 \\
58 \\
81 \\
75 \\
73 \\
59 \\
61 \\
57\end{array}$ & $\begin{array}{r}C t . \\
56 \\
65 \\
50 \\
71 \\
82 \\
78 \\
56 \\
69 \\
62\end{array}$ & $\begin{array}{r}C t s . \\
48 \\
56 \\
47 \\
71 \\
76 \\
72 \\
54 \\
61 \\
54\end{array}$ & $\begin{array}{r}\text { Cts. } \\
61 \\
72 \\
71 \\
84 \\
89 \\
91 \\
70 \\
75 \\
65\end{array}$ & $\begin{array}{r}C t s . \\
50 \\
60 \\
55 \\
65 \\
80 \\
72 \\
49 \\
66 \\
57\end{array}$ & $\begin{array}{r}C t s . \\
50 \\
67 \\
53 \\
84 \\
93 \\
77 \\
57 \\
74 \\
67\end{array}$ & $\begin{array}{r}C t s \\
61 \\
73 \\
67 \\
8.5 \\
80 \\
90 \\
75 \\
89 \\
80\end{array}$ & $\begin{array}{r}C t s \\
64 \\
77 \\
72 \\
92 \\
95 \\
90 \\
77 \\
85 \\
80\end{array}$ & $\begin{array}{r}\text { Cts. } \\
73 \\
80 \\
77 \\
99 \\
99 \\
97 \\
83 \\
95 \\
88\end{array}$ & $\begin{array}{r}\text { Cts. } \\
85 \\
90 \\
97 \\
110 \\
103 \\
105 \\
89 \\
101 \\
96\end{array}$ & $\begin{array}{r}\text { Cts. } \\
85 \\
92 \\
90 \\
107 \\
104 \\
108 \\
85 \\
90 \\
95\end{array}$ & $\begin{array}{r}C t s . \\
50 \\
71 \\
54 \\
84 \\
78 \\
85 \\
65 \\
85 \\
76\end{array}$ & $\begin{array}{c}\text { Cts. } \\
47 \\
64 \\
44 \\
79 \\
80 \\
83 \\
50 \\
82 \\
65\end{array}$ \\
\hline
\end{tabular}

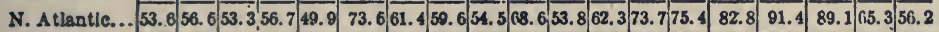

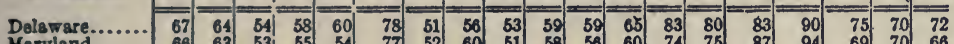

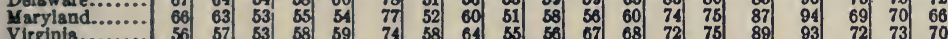

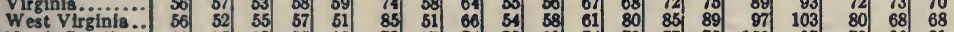

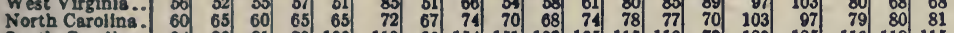

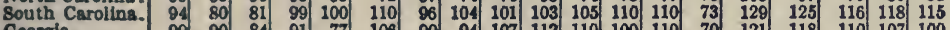

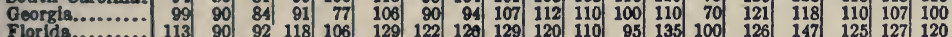

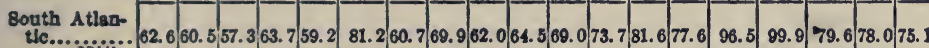

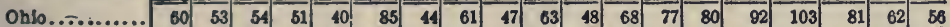

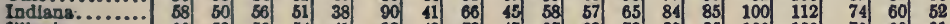

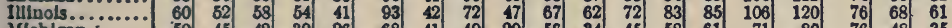

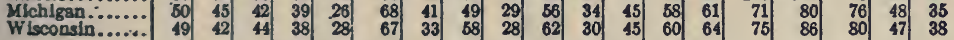

\begin{tabular}{l} 
N. C. E. of \\
Kiss. River. 55.848 .750 .5 \\
\hline
\end{tabular}

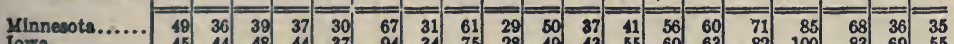

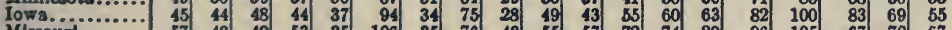

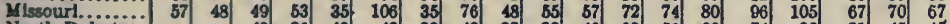

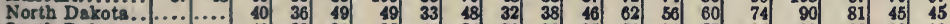

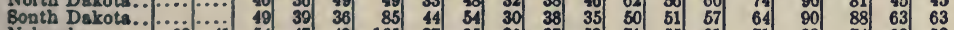
\begin{tabular}{r|r|r|r|r|r|r|r|r|r|r|r|r|r|r|r|r|r|r|r|r|r|r|r|} 
Niebraska........ & 63 & 41 & 54 & 47 & 49 & 105 & 27 & 65 & 26 & 37 & 52 & 70 & 55 & 61 & 71 & 92 & 74 & 68 & 60 \\
Kansas......... & 65 & 64 & 63 & 58 & 48 & 104 & 45 & 85 & 56 & 69 & 70 & 88 & 83 & 86 & 110 & 134 & 85 & 82 & 79 \\
\hline
\end{tabular}

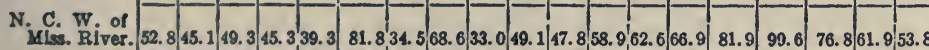

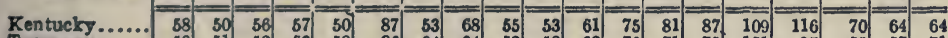

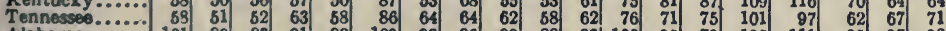

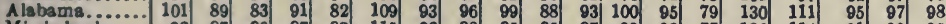

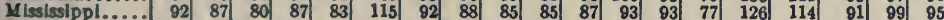

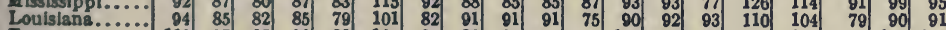

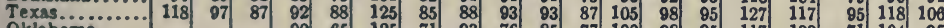

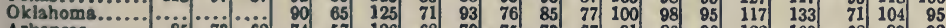

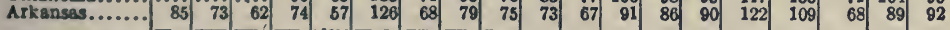

8outh Central. 66.9 (30.2 61.3 73.9 61.9 108.1 69.1 79.2 74.0 73.6 73.0 90.2 88.9 77.9 117.6 113.4 77.9 91.8

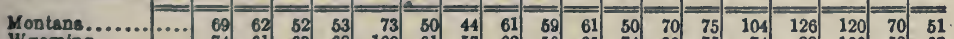

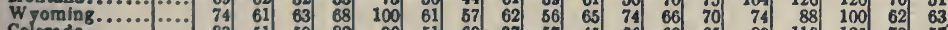

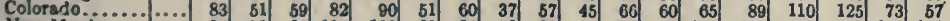

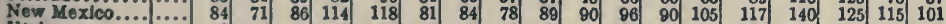

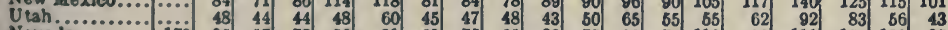

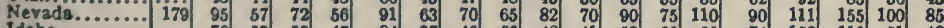

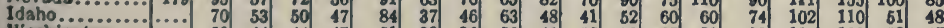

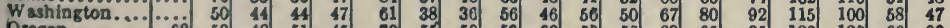

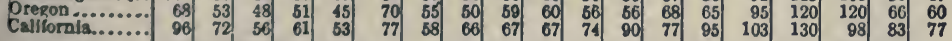

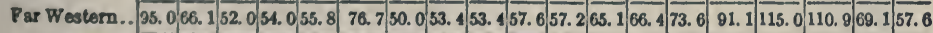

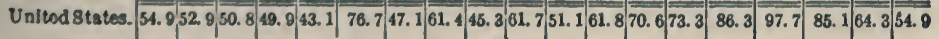


Wholesale prices of potatoes per bushel, 1896-1909.

\begin{tabular}{|c|c|c|c|c|c|c|c|c|}
\hline \multirow{3}{*}{ Date. } & \multirow{2}{*}{\multicolumn{2}{|c|}{ 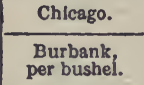 }} & \multirow{2}{*}{\multicolumn{2}{|c|}{$\frac{\text { Milwaukee. }}{\text { Per bushel. }}$}} & \multirow{2}{*}{\multicolumn{2}{|c|}{$\begin{array}{l}\text { St. Louis. } \\
\text { Burbank, } \\
\text { per bushel. }\end{array}$}} & \multirow{2}{*}{\multicolumn{2}{|c|}{ Cincinnati. }} \\
\hline & & & & & & & & \\
\hline & Low. & High. & Low. & High. & Low. & High. & Low. & High. \\
\hline 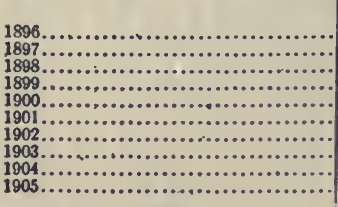 & \begin{tabular}{|r|} 
Cents. \\
10 \\
18 \\
29 \\
26 \\
25 \\
30 \\
30 \\
38 \\
31 \\
18 \\
\end{tabular} & $\begin{array}{r}\text { Cents. } \\
31 \\
62 \\
87 \\
75 \\
50 \\
125 \\
100 \\
85 \\
122 \\
72\end{array}$ & $\begin{array}{r}\text { Cents. } \\
10 \\
15 \\
25 \\
15 \\
20 \\
25 \\
\ldots \ldots \\
35 \\
20 \\
10 \\
\end{array}$ & $\begin{array}{r}\text { Cents. } \\
35 \\
100 \\
90 \\
90 \\
80 \\
185 \\
\ldots . . .90 \\
90 \\
120 \\
70\end{array}$ & $\begin{array}{r}\text { Cents. } \\
20 \\
21 \\
30 \\
25 \\
27 \\
18 \\
41 \\
40 \\
36 \\
27\end{array}$ & $\begin{array}{r}\text { Cents. } \\
45 \\
65 \\
85 \\
75 \\
54 \\
140 \\
105 \\
125 \\
125 \\
175 \\
\end{array}$ & $\begin{array}{r}80.60 \\
.80 \\
1.25 \\
1.10 \\
.32 \\
.30 \\
.90 \\
1.20 \\
1.20 \\
.25 \\
\end{array}$ & $\begin{array}{r}11.35 \\
4.75 \\
3.75 \\
6.00 \\
.57 \\
1.20 \\
3.00 \\
3.00 \\
1.80 \\
.80 \\
\end{array}$ \\
\hline 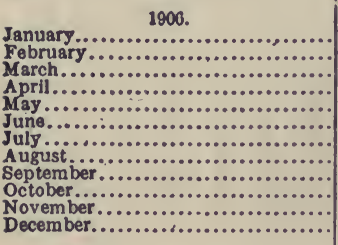 & $\begin{array}{r}55 \\
17 \\
43 \\
47 \\
48 \\
40 \\
60 \\
\cdots \cdots \cdots . . . \\
\cdots \cdots \\
45 \\
40 \\
41 \\
40\end{array}$ & $\begin{array}{r}66 \\
57 \\
68 \\
63 \\
63 \\
73 \\
87 \\
\ldots \ldots \ldots . . . \\
\therefore \ldots \ldots \\
58 \\
47 \\
48 \\
843\end{array}$ & $\begin{array}{l}45 \\
35 \\
35 \\
60 \\
15 \\
50 \\
40 \\
85 \\
85 \\
25 \\
25 \\
25\end{array}$ & $\begin{array}{l}58 \\
50 \\
62 \\
62 \\
75 \\
80 \\
87 \\
50 \\
65 \\
40 \\
10 \\
10\end{array}$ & $\begin{array}{l}58 \\
53 \\
31 \\
65 \\
60 \\
65 \\
35 \\
37 \\
43 \\
43 \\
45 \\
40\end{array}$ & $\begin{array}{r}82 \\
61 \\
70 \\
68 \\
88 \\
125 \\
75 \\
60 \\
62 \\
36 \\
85 \\
46\end{array}$ & $\begin{array}{l}.35 \\
.45 \\
.45 \\
.60 \\
.35 \\
.80 \\
.75 \\
.58 \\
.35 \\
.30 \\
.45 \\
.45\end{array}$ & $\begin{array}{l}.65 \\
.62 \\
.75 \\
.85 \\
.75 \\
1.05 \\
.90 \\
.80 \\
.60 \\
.60 \\
.38 \\
.47\end{array}$ \\
\hline Year................. & 10 & 87 & 25 & 87 & 35 & 125 & .45 & 1.05 \\
\hline 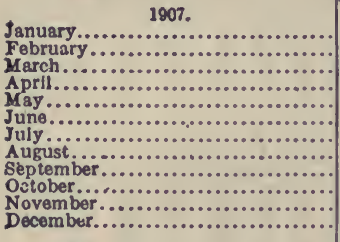 & $\begin{array}{l}34 \\
37 \\
33 \\
33 \\
65 \\
32 \\
30 \\
30 \\
30 \\
45 \\
45 \\
46\end{array}$ & $\begin{array}{l}45 \\
48 \\
17 \\
61 \\
75 \\
70 \\
50 \\
\dddot{60} \\
65 \\
63 \\
58\end{array}$ & $\begin{array}{l}25 \\
25 \\
25 \\
25 \\
40 \\
30 \\
35 \\
30 \\
45 \\
40 \\
40 \\
40\end{array}$ & $\begin{array}{l}45 \\
45 \\
45 \\
60 \\
70 \\
70 \\
90 \\
90 \\
75 \\
75 \\
65 \\
65\end{array}$ & $\begin{array}{l}43 \\
51 \\
43 \\
63 \\
74 \\
60 \\
50 \\
60 \\
45 \\
55 \\
53 \\
85\end{array}$ & $\begin{array}{r}53 \\
56 \\
35 \\
68 \\
75 \\
78 \\
125 \\
95 \\
72 \\
70 \\
65 \\
64\end{array}$ & $\begin{array}{l}.45 \\
.48 \\
.50 \\
.40 \\
.70 \\
.60 \\
.25 \\
.70 \\
.60 \\
.50 \\
.50 \\
.50 \\
\end{array}$ & $\begin{array}{l}.30 \\
.33 \\
.33 \\
.80 \\
.80 \\
.70 \\
.85 \\
.80 \\
.85 \\
.62 \\
.65 \\
.65 \\
\end{array}$ \\
\hline Year.................................... & 30 & 75 & 25 & 90 & 43 & 125 & .25 & .85 \\
\hline 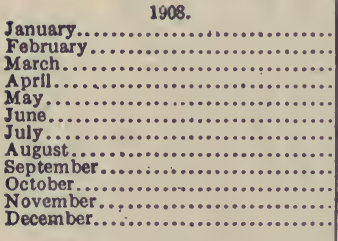 & $\begin{array}{l}52 \\
58 \\
62 \\
60 \\
50 \\
33 \\
70 \\
58 \\
58 \\
50 \\
57 \\
60\end{array}$ & $\begin{array}{r}65 \\
73 \\
75 \\
77 \\
80 \\
150 \\
110 \\
90 \\
78 \\
81 \\
71 \\
77\end{array}$ & $\begin{array}{l}53 \\
65 \\
63 \\
65 \\
58 \\
68 \\
55 \\
60 \\
60 \\
54 \\
58 \\
64\end{array}$ & $\begin{array}{r}75 \\
70 \\
70 \\
80 \\
80 \\
150 \\
110 \\
85 \\
80 \\
80 \\
70 \\
70\end{array}$ & $\begin{array}{r}62 \\
67 \\
71 \\
73 \\
65 \\
100 \\
\cdots \ldots . . . \\
\cdots \cdots . . . \\
72 \\
67 \\
69 \\
69\end{array}$ & $\begin{array}{r}\mathbf{6 9} \\
77 \\
78 \\
78 \\
78 \\
74 \\
105 \\
\cdots \cdots \cdots . . . \\
\cdots \cdots \\
72 \\
70 \\
72 \\
75\end{array}$ & $\begin{array}{r}.60 \\
.65 \\
.70 \\
.70 \\
.60 \\
.60 \\
1.10 \\
.85 \\
.75 \\
.65 \\
.65 \\
.65\end{array}$ & $\begin{array}{r}.68 \\
.82 \\
.80 \\
.85 \\
.85 \\
1.35 \\
1.35 \\
1.15 \\
.85 \\
.80 \\
.75 \\
.80\end{array}$ \\
\hline Year.......................... & 50 & 150 & 53 & 150 & 62 & 105 & .60 & 1.35 \\
\hline 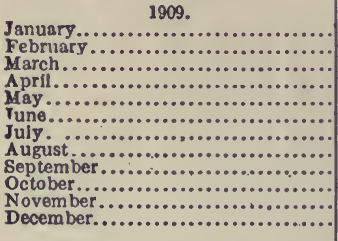 & $\begin{array}{r}60 \\
65 \\
80 \\
85 \\
170 \\
20 \\
15 \\
38 \\
42 \\
35 \\
15 \\
20\end{array}$ & $\begin{array}{r}79 \\
95 \\
93 \\
110 \\
150 \\
145 \\
125 \\
66 \\
65 \\
55 \\
50 \\
58\end{array}$ & $\begin{array}{l}60 \\
60 \\
70 \\
70 \\
80 \\
30 \\
20 \\
40 \\
45 \\
40 \\
30 \\
30\end{array}$ & $\begin{array}{r}72 \\
88 \\
95 \\
115 \\
135 \\
105 \\
100 \\
90 \\
65 \\
60 \\
50 \\
50\end{array}$ & $\begin{array}{l}73 \\
80 \\
89 \\
92 \\
85 \\
40 \\
40 \\
35 \\
45 \\
42 \\
40 \\
40\end{array}$ & $\begin{array}{r}83 \\
93 \\
98 \\
108 \\
102 \\
140 \\
110 \\
62 \\
72 \\
56 \\
52 \\
50\end{array}$ & $\begin{array}{l}.72 \\
.75 \\
.85 \\
.95 \\
.95 \\
.90 \\
.50 \\
.70 \\
.55 \\
.55 \\
.30 \\
.30\end{array}$ & $\begin{array}{r}.80 \\
.90 \\
.95 \\
1.15 \\
1.00 \\
1.20 \\
.95 \\
.75 \\
.70 \\
.60 \\
.60 \\
.48\end{array}$ \\
\hline Year.......................... & 15 & 150 & 20 & 135 & 35 & 140 & .30 & 1.20 \\
\hline
\end{tabular}



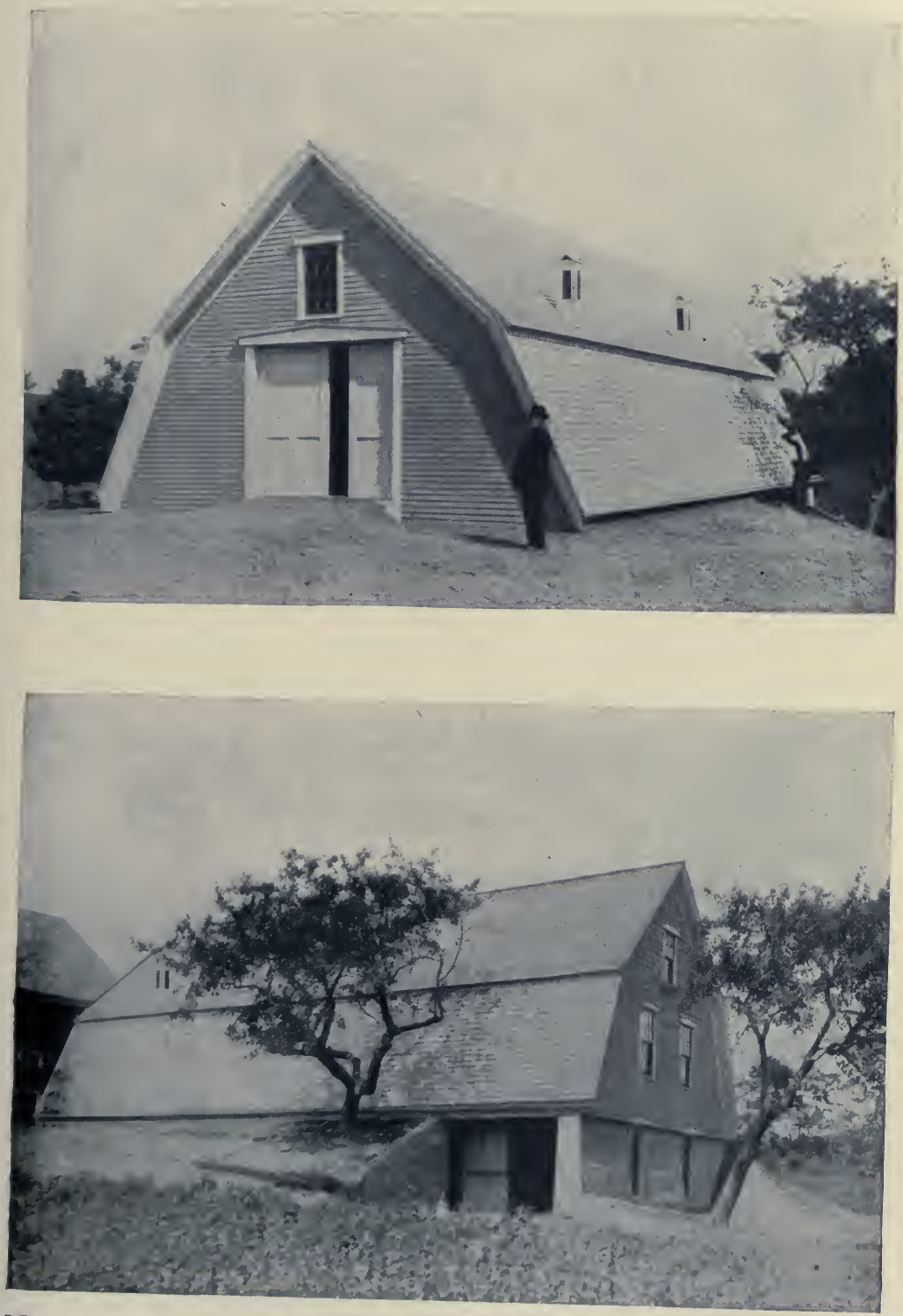

New potato cellar of Commissioner of Agriculture A. W. Gilman, Foxcroft, Maine 

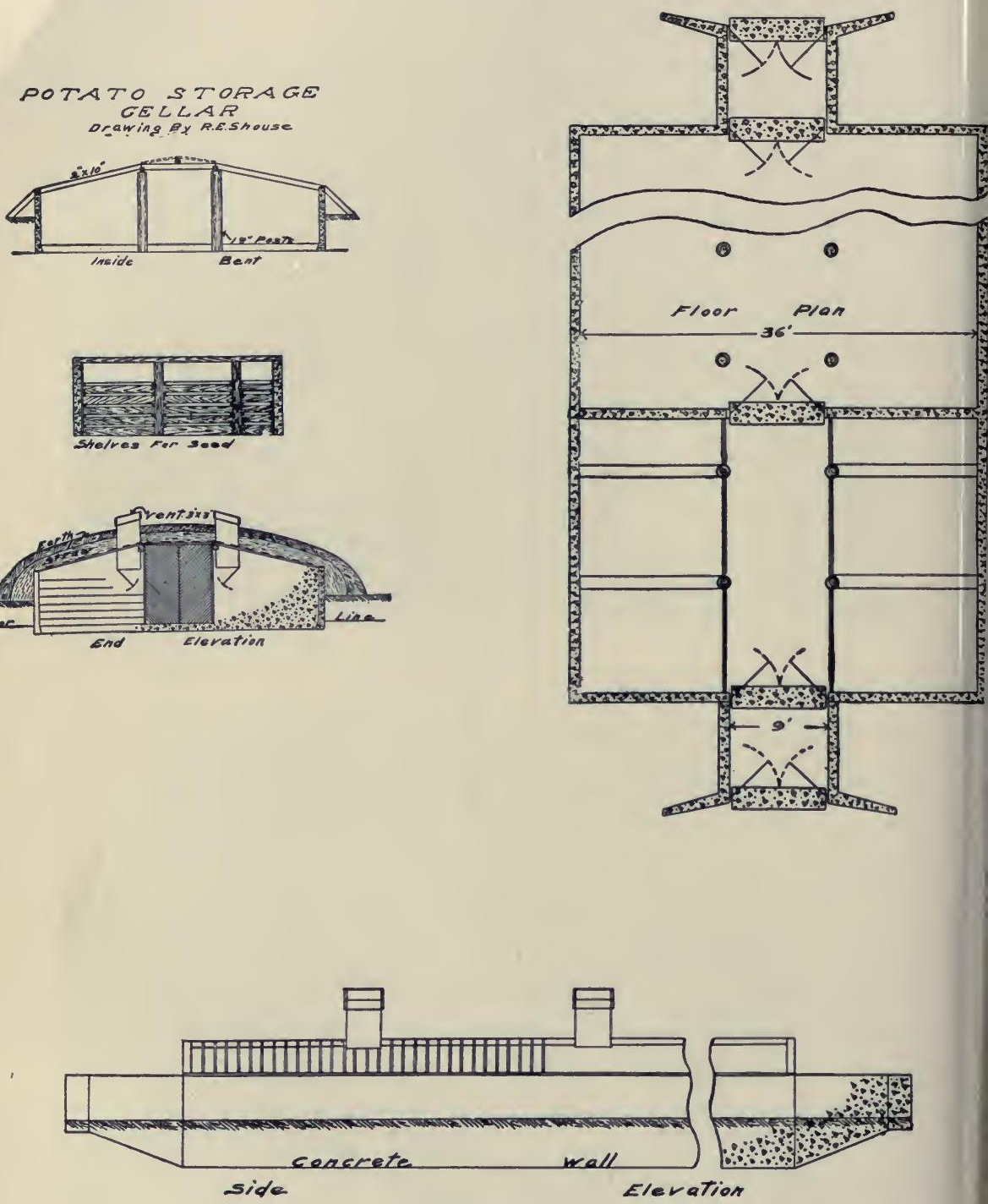

Potato storage cellar plans 
Average farm price of potatoes per bushel, monthly, 1908-9.

\begin{tabular}{|c|c|c|c|c|c|c|c|c|c|c|c|c|c|c|}
\hline \multirow{2}{*}{ Montb. } & \multicolumn{2}{|c|}{$\begin{array}{l}\text { United } \\
\text { States. }\end{array}$} & \multicolumn{2}{|c|}{$\begin{array}{l}\text { North } \\
\text { Atlantic } \\
\text { States. }\end{array}$} & \multicolumn{2}{|c|}{$\begin{array}{l}\text { South } \\
\text { Atlantic } \\
\text { States. }\end{array}$} & \multicolumn{2}{|c|}{$\begin{array}{l}\text { N. Cen. } \\
\text { States East } \\
\text { of Miss. } R \text {. }\end{array}$} & \multicolumn{2}{|c|}{$\begin{array}{l}\text { N. Cen. } \\
\text { States West } \\
\text { of Miss. R. }\end{array}$} & \multicolumn{2}{|c|}{$\begin{array}{l}\text { South } \\
\text { Central } \\
\text { States. }\end{array}$} & \multicolumn{2}{|c|}{$\begin{array}{l}\text { Far West } \\
\text { ern States. }\end{array}$} \\
\hline & 1909. & 1908. & 1909. & 1908. & 1909. & 1908. & 1909. & 1908. & 1909. & 1908. & 1909. & 1908. & 1909. & 1908. \\
\hline & $\begin{array}{l}\text { Cts. } \\
72.0\end{array}$ & $\begin{array}{l}\text { Cls. } \\
63.4\end{array}$ & $\begin{array}{l}\text { Cls. } \\
74.5\end{array}$ & $\begin{array}{l}\text { Cls. } \\
64.9\end{array}$ & $\begin{array}{l}\text { Cls. } \\
83.2\end{array}$ & $\begin{array}{l}\text { Cis. } \\
76.0\end{array}$ & Cls. & $\begin{array}{l}\text { Cts. } \\
55.5\end{array}$ & Cts. & $\begin{array}{l}\text { Cls. } \\
62.5\end{array}$ & Cts. & $\begin{array}{c}\text { Cls. } \\
92.7\end{array}$ & Cls. & $\begin{array}{l}\text { Cls. } \\
62.7\end{array}$ \\
\hline $\operatorname{arch}$. & 80.0 & 69.0 & 77.2 & 73.0 & 90.3 & 84.2 & 77.1 & $\ddot{59.7}$ & $\begin{array}{l}60.9 \\
72.3\end{array}$ & 66,0 & $\begin{array}{r}87.9 \\
118.2\end{array}$ & 100.0 & $\begin{array}{l}73.6 \\
83.5\end{array}$ & $\because \ddot{64}$ \\
\hline pril.. & 86.3 & 70.4 & 82.8 & 73.0 & 96.5 & 85.8 & 83.2 & 64.8 & 81.9 & 67.2 & 117.6 & 104.9 & 91.1 & \\
\hline & 97.3 & 73. & 93.6 & 79.2 & 101.3 & 80. & 97. & 66.8 & 94 & 67.3 & 119.5 & 104.8 & 100 & \\
\hline & 97.7 & 71.3 & 91.4 & 72. & 99. & 86. & 94. & 67.7 & 99. & 68.3 & 113.4 & 94.4 & 115.0 & \\
\hline & 91.0 & 77.8 & 91.2 & 76.4 & 94. & 80.6 & 79. & 80.6 & 91.8 & 75.9 & 93.0 & 86.0 & 115.1 & 68 \\
\hline agust & 85.1 & 83.6 & 89.1 & 93.2 & 79. & 74.9 & 77. & 85 & 70. & 73.4 & 77.9 & 80.8 & 110.9 & 69 \\
\hline 8 & 71.5 & 78. & 77. & 87 & 76 & 75. & 59. & 77 & 65. & 64 & 84. & 82. & 81. & \\
\hline Octobe & 64.3 & 74.8 & 65.3 & & 78. & 74 & 54. & & 61. & 64.0 & 91. & 87.1 & $69 . \hat{1}$ & \\
\hline Novem & 57.8 & 69.2 & 58.5 & 71. & 76.7 & 76. & 47. & 67. & 56. & 61.1 & 89.0 & 88.2 & 58.0 & 67 \\
\hline Decembe & 54. & 70.6 & 56.2 & 73.7 & 75.1 & 81. & 44.4 & 67. & 53.8 & 62.6 & 86.3 & 88.9 & 57.6 & 66.4 \\
\hline
\end{tabular}

crop is dug, or a few days thereafter, must be stored in frost-proof buildings or pits.

Potatoes grown in southern climates may be stored in dark warehouses or in straw-covered piles in the field.

The normal losses in storage from October to May amount to 5 to 12 per cent. of the total bulk. This does not include losses due to disease or sorting.

It has been estimated that of the total storage loss 75 per cent. is due to loss of moisture and 25 per cent. to respiration. The potato tuber does not die when taken from the ground and placed in a cellar, but it lives by using some of the food material stored up in its cells. The material used is in the form of sugar, which a ferment forms from starch. Respiration is practically stopped when the tuber is frozen and the sweet taste of frozen potatoes is due to accumulation of sugar.

The important points to be considered in potato storage are:

Conditions to keep a temperature as low as possible without freezing;

Conditions to keep the air as dry as possible, and a place where potatoes may be kept dark. 
While mining at an altitude of 1,000 feet in Colorado, a good many years ago, the senior author of this work met a prospector who was going to leave the country. He said that in an old tunnel would be found some supplies, including twelve sacks of potatoes which had been put there two years before. These the prospector gave to him. The condition of these potatoes was apparently the same as when they were dug; they were not shriveled, no shrinkage was apparent, they had not started to sprout, and when cooked they were just as edible as when dug out of the ground. There had been an airshaft constructed at the end of the tunnel and through the tunnel was a good current of dry air. The temperature was uniformly about 40 degrees $\mathrm{F}$., being in a rock tunnel 200 feet below the surface of the ground. In building a potato cellar he tried to get as near those conditions as possible.

The cellar illustrated is about 50 by 200 feet. At each end there is a dead-air space ten feet square in the form of a vestibule between the outer and inner doors. This affords protection from freezing. There is a driveway clear through, with bins on either side, skylights and ventilators being placed every ten feet. The temperature of the cellar may be lowered by opening the doors and letting a current of air pass through. When it is too cold for this, the ventilators at the top may be opened. The best ventilation is always secured by building the cellar in line with the direction of the prevailing air currents. During the winter the temperature should be kept as near 32 degrees F. as possible; it is best when it does not go below 30 degrees nor above 36 degrees. A temperature of 28 degrees $\mathbf{F}$. for one or two hours will 
not freeze potatoes when in large quantities. In a cold country some means for providing artificial heat should be provided. In the spring of the year, when the weather becomes warm, the cellar doors are kept open at night and closed in the daytime.

The plans submitted give a general idea of a satisfactory cellar, and can be modified to suit conditions. In planning the size of the structure it is safe to estimate one bushel at one and one fourth cubic feet.

In a small cellar built with a driveway this space need not be wasted but filled with potatoes or other vegetables after the bins at the side have been filled.

One important point in the storage of potatoes is to reduce the temperature to as low a point as possible directly after the product is stored. Put about one foot of potatoes on the cellar floor, and by the time the entire floor is covered to that depth the heat from those potatoes is pretty well carried off by the air currents. Then add another layer, thus properly regulating the temperature as the storage progresses. Ordinarily, when the cellar is filled, the potatoes are piled about five feet deep.

There are many types of potato cellars, each suited to individual conditions and factors which control size, material used, and construction. In Maine, steam-heated, double-wall stone masonry warehouses are used. In some sections of the West poles and timbers are used largely in construction and the storage space is largely under ground. Cellars built entirely under ground are used in some other localities.

Pits, covered with straw and earth, are used 
to store thousands of bushels of the world's crop. The principal objection to these is the absence of control over conditions during the coldest weather. In zero weather they cannot safely be opened to haul the crop to market, or for sorting if the tubers are rotting. Heavy rains may cause damage to pitted potatoes. A grower with one acre can afford to have a ventilated storehouse, even if this is only a well-covered underground cellar.

Sorting potatoes that have started to rot from freezing or disease requires a cellar that can be lighted when desired. Careful growing to prevent disease, and careful handling for the same purpose, may cost a little more than slipshod methods, but the probability of marketing a crop without the expense and loss of rehandling rotten potatoes warrants the expense.

Ventilation devices, such as open partitions, may be used to advantage when large quantities of potatoes are stored in bulk.

Sacked potatoes corded in piles keep well in a good cellar, and when sprouts start in the spring the growth of these may be checked by moving the sacks. A bruised sprout dies.

When the floor is of dirt, it is well to use some sort of material, preferably strips of wood, between the dirt and the potatoes, to prevent rot.

It is important that potatoes be free from dirt when taken from the field to the cellar. Dirty potatoes do not keep well, because of the dirt that adheres to the individual tubers, and that which falls off and fills up the air spaces between the potatoes, preventing free ventilation.

A very satisfactory place to build a cellar is on a knoll, thus insuring perfect water drainage and a good circulation of air. 
There is no limit to the ingenuity of the builder in providing conveniences in the way of sorting rooms and divisions in a potato cellar.

It is hard to conceive a well-planned, diversified farm anywhere in the temperate zone that is complete without a storage cellar for potatoes and other vegetables. A "hoed" crop, requiring deep, thorough cultivation, is an important factor in a rotation of crops, and a business farmer is not living up to his possibilities when he grows a crop that for lack of storage facilities he must sell in a short time after its maturity, thereby placing himself at the mercy of the middleman and retailer.

In the well-regulated farm we have in mind a fairly definite proportion of the farm would be in potatoes and roots each year, one part of the potatoes to be sold at digging time, the balance held for later marketing; and a quantity of roots always stored for livestock feeding. This system makes a storage cellar as important a factor as the stock barns.

Following are specifications for the potato cellar illustrated:

To be built with eight-inch concrete walls with six-inch footing, one foot below floor line. Inside width thirty-six feet, making twenty-seven feet storage space and a nine-foot driveway. Length to accommodate the amount of potatoes to be stored. Height of side walls seven feet from floor line, three and one half feet underground level, centre ten feet from floor line. Heavy posts to be set every ten feet along each side of driveway. Round posts would answer for this purpose as well as the more expensive sawed lumber.

On top of these posts is run a ten-inch by ten- 
inch stringer or girder the length of the building. It rests on the concrete of each end. This is the support for the rafters; all rafters two inches by ten inches.

Two-inch by six-inch plate is bolted to the top of the concrete wall for the rafters to be nailed to.

A portion of the cellar can be fitted with shelves, or drawers for tray storage of different kinds of seed potatoes.

The yield of potatoes in this country can be very greatly increased by more careful selection and storage of seed. Growers in Europe find it profitable to store selected potatoes, to be used whole for seed, in trays. This is especially desirable for early potatoes. With this system, stubby strong sprouts are grown on the seed tubers before they are planted.

On top of rafters wire netting is placed. On this is placed fifteen inches to twenty-four inches of straw; then well covered with earth. Straw is a good insulator and absorbs moisture. Any kind of tight, rainproof outer covering may be used above the earth if conditions make this necessary.

Ventilators are placed every twenty feet, with tight fitting cover on top and hinged sash on bottom.

Doors to be made of three-fourths-inch flooring, to be of a double thickness, with heavy building paper between the boards.

In places where cement is much more expensive than lumber, this building could be built by setting posts and making a frame wall.

The Colorado Agricultural College built a cellar sixty by eighty feet at a cost of about $\$ 1,150$. Piled five feet deep and with the driveway filled this 
would hold about 19,200 bushels. It is estimated that a farmer could build a cellar of like capacity for a cash outlay of $\$ 900$. They estimate the cost of a cellar at from 7 to 30 cents per hundredweight of potatoes stored - depending on the permanence of the structure.

Where large quantities of potatoes are to be handled, it is well to have a switch run to the cellar and load direct from the cellar to the car by use of a small engine and belt to carry the filled sacks.

Potatoes for seed in Europe are stored in crates, insuring more uniform conditions for each tuber.

Keeping potatoes in the South is a problem. It is very desirable to keep those grown in the spring for fall planting. In a Bulletin of the Florida Experiment Station, J. F. Mitchell says:

"The method that has proved uniformly successful at the station has been to take a slat crate, place a layer of pine straw needles in the bottom, then a layer of potatoes, covering them with a layer of pine straw, and continue the process until the crate is filled. Finally, the crate is covered with a layer of pine straw and stored in the barn without further attention. On taking the potatoes out in the fall they have been found to be sound and fresh in appearance and there has been no difficulty as to their sprouting when planted. Fall planting at the station has just been completed. The potatoes cared for as above described were in prime condition; in fact, they were as good as, if not better than, seed potatoes shipped from the North.

Storing potatoes in oat straw proved a failure on account of the tendency of the potatoes to decay. Spreading the potatoes on a board floor 
was unsuccessful, as the potatoes turned green and shriveled, being then unfit for either shipping or planting. On trying a mixture of lime and dry sand, in the proportion of one pint of lime to a bushel of sand, it was found that, while the potatoes did not decay, they were no longer viable, the lime apparently killing the eyes and thereby preventing them from sprouting successfully. Dry sand alone produced better results."

In "Bulletin No. 2, Volume 8," of the Commissioner of Agriculture of the State of Maine, is given the following description of a potato cellar built by Hon. A. W. Gilman, Foxcroft, Maine, the Commissioner:

"This house and plan are recommended to any who intend to grow potatoes for a series of years. This building is located on a side hill, and is fifty feet long by thirty feet wide, and serves both as a storehouse for potatoes and for the housing of farm implements.

"The bottom is concrete, the walls are of grout coated on the outside and inside with cement to prevent the moisture soaking through. They are eight feet high, eighteen inches wide at the bottom, ten inches at the top. The plates which are used for sills and set on these walls are chambered an inch and a half both on the outside and inside. These pieces are filled with cement to keep the cold air out. The sleepers on which the floor is laid are six inches square. These are boarded on top with a double floor with tar paper between, and single boarded underneath, thus giving a dead-air space of six inches. The rafters are nine feet long, coming up nearly perpendicular, giving 
more storage space. The second rafters are fifteen feet long, forming the roof.

"The part that forms the cellar proper is thirtyeight feet long, the remaining twelve feet making a room for sorting and packing potatoes. The cellar is divided by two partitions, making three bins each ten feet wide. Each bin has trap doors in the centre of the floor covering that bin. Each trap is about five feet long by eighteen inches wide, with three feet between each trap.

"The potato bins, each thirty-eight feet long, are partitioned off from the sorting room. Both sides of the partition are boarded up with matched boards. A double door leads from the sorting room into each bin. These doors are closed in the coldest weather. The sorting room has two windows for light and air.

"If the potatoes begin to sweat in storage or need ventilation, the trap doors can be raised, and the doors from the bins into the sorting room can be opened, giving a perfect system of ventilation, which soon dries the potatoes off.

"The potatoes are removed fom the storage house through the sorting room, the floor of which is on a level with the road outside, thus saving much labor.

"Bill of material for this storage house. (Estimates furnished by W. L. Brown, Foxcroft, Maine):

\begin{tabular}{ccc}
$\begin{array}{c}\text { No. of } \\
\text { pieces }\end{array}$ & \multicolumn{1}{c}{ Size } & Lengths \\
16 & $4 \times 6$ Posts for cellar partition & $8 \mathrm{ft}$. \\
6 & $6 \times 6$ End and cross sills & $30 \mathrm{ft}$. \\
5 & $6 \times 6$ Side sills & $20 \mathrm{ft}$. \\
40 & $2 \times 6$ Floor timbers & $20 \mathrm{ft}$. \\
20 & $2 \times 6$ Floor timbers & $12 \mathrm{ft}$. \\
60 & $2 \times 5$ Rafters & $9 \mathrm{ft} .6 \mathrm{in}$.
\end{tabular}


No. of

pieces

$602 \times 5$ Rafters

Plates

$202 \times 6$ Beams

$502 \times 4$ Studding for gables

$8 \mathrm{M}$ Boards P.I.S. includes double floors matched and beaded pine for doors
Size

Lengths

$13 \mathrm{ft}$.

250 lin. $\mathrm{ft}$.

$22 \mathrm{ft}$. $12-16 \mathrm{ft}$.

15 squares Neponset waterproof paper for floors.

$5 \mathrm{M}$

$22 \mathrm{M}$ Sheathing for cellar, ceiling and cross partition.

22

500 feet XI Shingles with four rolls sheathing paper, or 600 feet Pine finish.

$69^{\prime \prime} \times 3^{\prime \prime}$ 12-lighted windows and frames.

1 M Brick for chimney.

All timber is spruce. If of fir add one inch to depth of all sills and floor timbers.

Grout wall (150 lin. ft. $8 \mathrm{ft}$. high) and cement floor would cost about $\$ 250 . "$ 


\section{CHAPTER XIII}

COST OF GROWING POTATOES - YIELD PRICES - PROFITS

7 HE yield of a crop of potatoes, the cost of growing and the consequent profits, vary - not only with conditions, but with individual operators under similar conditions. In common with every other phase of agriculture, and everything else in the world, the individuality of the man in charge is the most potent factor.

The price is a proposition that the individual grower has no control of and varies with the world's supply and demand.

Average yields do not represent the possibilities of the business, and are not fair to the industry. The best growers always produce crops far in excess of the average for a district or a community. The average producer of potatoes is not a potato grower in the strict sense of the term-he is simply a farmer growing potatoes and giving little, if any, thought or study to the "reasons why" for various operations.

The estimates and figures which follow regarding prices of the various operations and the profits in potato growing show the possibilities and probabilities in various sections. The best grower may make larger profits than some of these-poor growers much less.

In the Twin Falls country in southern Idaho the yield of potatoes is from 100 to 700 bushels. 
per acre. The cost of producing a 150-bushel crop is estimated as follows:

Plowing .

Harrowing . . . . . . . . . . . . $\quad .75$

Floating . . . . . . . . . . . . 1.00

Seed, a verage planting 700 lbs. at 2c. . . . . . 14.00

Planting . . . . . . . . . . . 2.50

Irrigating first year . . . . . . . . . 5.00

Cultivatıng three times at 50c. . . . . . . 1.50

Digging . . . . . . . . . . . . 1.50

Picking - 150 bu. at 4c. . . . . . . . . 6.00

Sacks -75 at 7c. . . . . . . . . . . 5.25

Hauling to pit . . . . . . . . 2.00

Total . . . . . . . . . $\overline{\$ 44.00}$

If potatoes are worth 50 cents a bushel, this crop would sell for $\$ 75$, leaving a profit of $\$ 30.50$ per acre, not deducting rent or interest or taxes.

If, however, the grower produces a 600-bushel crop, the cost of producing (figuring twice as much seed and increased cost of the operations) would be about $\$ 95.75$. The crop would sell (at 50 cents a bushel) for $\$ 300$, leaving a profit of $\$ 204.25$.

In their work on "Potato Culture" (published by A. I. Root Co. Medina, Ohio), T. B. Terry of Hudson, Ohio, and A. I. Root of Medina, Ohio, estimate the cost as follows:

Plowing . . . . . . . . . . $\$ 2.00$

Harrowing with Thomas and three horses . . . 33

Rolling . . . . . . . . . . . 25

Eight bushels seed at 50 cents average . . . 4.00

Cutting to one eye . . . . . . . . . . $\quad .1 .50$

Planting with planter. . . . . . . . . 1.00

Harrowing three times . . . . . . . . 45

Harrowing four times with weeder : . . . . 80

Cultivating eight times, once in a row . . . $\quad 3.36$

Bugs . . . . . . . . . . . . . 2.00

Hand pulling or cutting weeds 


\section{THE POTATO}

Digging with four horses . . . . . . . . 2.50 Picking up and storing . . . . . . . . . 3.00 Marketing three-mile haul . . . . . . $\quad 6.00$ Manure . . . . . . . . . . 5.00 Interest on value of land $\$ 100$, at 6 per cent. . $\quad 6.00$

$\$ 38.94$

If the crop makes 250 bushels and sells for 40 cents a bushel, the profit will be as follows:

250 bushels at 40 cents . . . . . . . $\$ 100.00$

Cost of production . . . . . . . . . 38.94

$\$ \longdiv { 6 1 . 0 6 }$

Lawrence G. Dodge, scientific Assistant in the Bureau of Plant Industry, gives, in "Farmers' Bulletin 465" of the U. S. Department of Agriculture, the following:

"The accompanying table represents the usual expense of growing an acre of potatoes in Aroostook County, Maine, and in many parts of Michigan and Wisconsin. In fact, the second column of figures will represent the expense put into growing the crop in most localities where potato growing is carried on, on a less expensive and throughgoing basis:

\begin{tabular}{|c|c|c|c|c|c|}
\hline $\begin{array}{l}\text { Cost of supplies and } \\
\text { labor with rent } \\
\text { of land }\end{array}$ & Maine & Wisconsin & $\begin{array}{l}\text { Cost of supplies and } \\
\text { labor with rent } \\
\text { of land }\end{array}$ & Maine & Wisconsin \\
\hline Plowing & $\$ 1.50$ & $\$ 1.25$ & Cultivating & $\$ 3.50$ & $\$ 1.90$ \\
\hline Harrowing & 50 & 25 & Spraying. & 3.00 & $* 80$ \\
\hline Fertilizer. & 24.00 & & Digging . . & 6.00 & 2.10 \\
\hline Seed . & 5.00 & 2.50 & Rent of land. & 15.00 & 5.00 \\
\hline Cutting . & 75 & 60 & & & \\
\hline Planting. & 75 & 60 & 'Total & 60.00 & 15.00 \\
\hline
\end{tabular}

*For beetles only 
"The more expensive method of growing potatoes usually gives a yield of 275 bushels or more to the acre. Unless an application of barnyard manure is made in addition to the expense estimated, at an added cost of from $\$ 5$ to $\$ 10$ per acre, the less expensive method rarely produces more than 125 bushels per acre and in a great many instances decidely less than 100 bushels per acre. The increase in yield as a result of the more costly method is sufficient to more than pay the difference in cost, supposing potatoes to sell as low as $33 \frac{1}{3}$ cents a bushel. One hundred and twenty-five bushels per acre grown at a cost of $\$ 15$ per acre and sold at $33 \frac{1}{3}$ cents a bushel yield a net profit of $\$ 26.66$ per acre. Two hundred and seventy-five bushels per acre grown at a cost of $\$ 60$ per acre and sold at $33 \frac{1}{3}$ cents per bushel yield a net profit of $\$ 31.66$ per acre. The second profit is $\$ 5$ more per acre than the first.

"A farmer in Van Buren County, Mich., states that his potato crop, mostly marketed in the fall, sold at an average price of 44 cents a bushel for a period of ten years. At the latter price the more expensive method of culture would yield a profit of $\$ 61$ per acre, against $\$ 40$ from the cheaper method. Furthermore, some of the leading potato dealers of the North have stated emphatically that a better quality of potatoes is normally obtained with large yields than with small."

The dean of the College of Agriculture of the University of Maine, Dr. William D. Hurd, says:

"Many questions are asked as to the cost of growing an acre of potatoes. So many things, different circumstances, facilities for carrying on 
labor, kind of season, etc., enter into the problem of cost in such varying proportions that it is almost impossible to give statistics which will prove of much value to others. From records for several years on the college farm at Orono, the cost of growing a ten-acre field of potatoes is about as follows: Man and team labor are reckoned at $\$ 3.50$ per day, extra men at $\$ 1.50$ per day.

\section{Ten-acre field}

Plowing at $\$ 2$ per acre . . . . . . . . $\$ 20.00$

Harrowing five times, $\$ 3.50$ per acre $: \quad . \quad 17.50$

Fertilizer (home mixture) $\$ 30$ a ton . . . 225.00

Seed -130 bushels, 75 cents a bushel . . . 97.50

Disinfecting seed (labor and material) $\quad . \quad 3.00$

Cutting seed (by hand) at 6 cents per bushel $\quad 7.80$

Planting, team and two men three days, $\$ 5$. 15.00

Harrowing or weeding before crop is up, four times 10.50

Cultivating crop eight times at $\$ 3.50$. . . $\quad 28.00$

Spraying six times ( $\$ 1$ per acre each application) . $\quad 60.00$

Hand hoeing and pulling weeds once (if necessary) $\quad 15.00$

Digging and hauling to storehouse or station at

$\$ 15$ per acre . . . . . . . . . 150.00

Rent of land (5\% on $\$ 50$ per acre value) 10 acres $\quad 25.00$

Depreciation of implements, (plows, harrows,

planter, sprayer, digger, etc.) value $\$ 250$ esti-

mated at $10 \%$. . . . . . . . 25.00

$\$ 699.30$

Value of crop, 225 bushels to acre ( 2,250 bushels at 50 cents) . . . . . . . . . . $\$ 125.00$

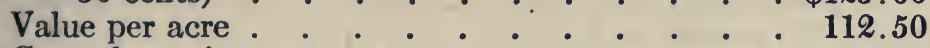

Cost of growing per acre . . . . . . $\quad 69.93$

Net profit per acre . . . . . . . . . $\$$. $\$ 42.57$

The E. L. Cieveland Company of Houlton, Maine, one of the largest growers and dealers of seed potatoes in America, makes the following estimate of the cost of growing an acre of potatoes: 
Commercial fertilizer $1,500 \mathrm{lbs}$. to 2,000 Preparing ground for seed . . . Seed 600 pounds -7.00 Planting 2.50

Cultivation $: \circ \quad \cdot \quad \cdot \quad 3.50$

Gathering or harvesting . . . . . 7.50

Preparing for market . . . . 50

Wear and tear on implements . . $\quad 50$

Rent of land (tenant farmer pays) . $\$ 10.00$ to $\$ 20.00$

Bordeaux mixture . . . . . . 4.00

Paris green . . . . . . . 50

Hauling to market . . . . . . 3.50

Average yield of product per acre . . $220 \mathrm{bu}$.

Average value of product per acre . . $\$ 88.00$

Average size of fields . . . . . 15 acres

Average value per acre of land growing such crops

Profit per acre

75.00 to 100.00 17.00

"Much depends on the weather conditions as to the cost of applying Bordeaux mixture, Paris green, cost of cultivation, labor and general net results.

"The above estimates may be regarded the average for a series of years."

Mr. L. F. Shanklin of Lompoc, Cal., estimates the cost of producing an acre of potatoes as follows:

Use of land (will rent for) . . . . . . . $\$ 30.00$ Seed 400 pounds at $1 \frac{1}{2}$ cents . . . . . . . $\quad 6.00$

Plowing and preparation . . . . . . . . 5.00

Cultivation twice - hoeing once . . . . . 1.00

Digging and picking . . . . . . . 3.00

Sacks 5 cents, sacking 5 cents (100 sacks per at) $\quad 10.00$

Hauling . . . . . . . . . . . . 1.00

$\$ 56.00$

His average crop is: 
70 sacks firsts 115 lbs. to sack at $\$ 1.30$ per 100. $\$ 80.50$ 30 " seconds 120 lbs. to sack at $\$ 1.00$ per 100.36 .00 30 “ cow feed or waste at 10 cents per 100 .

3.00 $\$ 119.50$

Profit $\$ 63.50$

The cost of producing one acre of potatoes on the farm of W. Dennis \& Sons, Kirton, Lincolnshire, England, is:

Seed per acre 2,600 pounds . . . . . . . $\$ 16.00$

Rent . . . . . . . . . 15.00

Rate Tax (special Government income tax) . $\quad 2.50$

Eight tons barnyard manure . . . . . . 13.75

Commercial fertilizer (phosphate nitrate, potash) $\quad 15.00$

Planting . . . . . . . . . . . 1.25

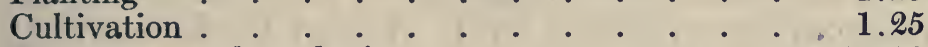

Harvesting and marketing . . . . . . 15.00

Plowing and preparation after planting . . . $\quad 1.20$

Ridging and covering in .. . . . . . . 2.50

Spraying . . . . . . . . . . . 5.00

Hauling . . . . . $\div \frac{5.00}{93.45}$

Average cost . . . . . . . . . . $\frac{.993 .45}{5195.00}$

Total average revenue $\quad . \quad . \quad . \quad . \quad . \quad . \quad . \quad \$ 125.00$

Profit . . . . . . . . . . . . \$31.55

W. Dennis \& Sons grow 3,000 acres annually and these figures are an average for that acreage. Prof. L. A. Merrill of the Utah Agricultural College reports that the cost of growing according to Mr. W. F. Harper of Smithfield, Utah, is as follows:

Plowing, harrowing and leveling the land . . . \$5.00

Fifteen loads of manure at 25 cents per load . . $\quad 3.75$

Hauling manure at 75 cents per load . . . . 11.25

Seed.

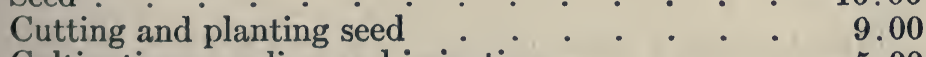

Cultivating, weeding and irrigating . . . . 5.00

Picking and sacking . . . . . . . . . 10.00

Loading on car .

4.50 
To this should be added interest on the money invested in the land which would vary with the price of land, and also taxes on the land; these two items will probably average $\$ 10$.

The profits will range from $\$ 20$ in the poorer potato sections to $\$ 125$ per acre in good potato districts. Mr. Harper reports a net profit of the latter sum from his potatoes in 1910.

The cost of producing the acre of potatoes that won the first prize in 1910 Burley Contest (prize of $\$ 500$ cash given by D. E. Burley, General Passenger Agent, Oregon Short Line Railroad, for best measured acre in territory tributary to that railroad) is estimated by L. A. and W. L. Snyder, Twin Falls, Idaho, the growers, as follows:

Plowing alfalfa to kill the plants

$$
\begin{gathered}
\text { No. of } \\
\text { horses used }
\end{gathered} \begin{gathered}
\begin{array}{c}
\text { No. of } \\
\text { men }
\end{array} \\
\begin{array}{c}
\text { No. of } \\
\text { days }
\end{array}
\end{gathered}
$$

(crowning or plowing three inches deep with sharp plow)...

Disking in spring. ...........

Harrowing $. . . \ldots \ldots \ldots \ldots . .$.

Corrugating.............. 2

Irrigating before plowing....... 0

Plowing.............. 4

Planking................ 2

Cultivating first time........ 2

Cultivating second time........ 2

Hilling first time............ 1

Hilling second time.......... 1

Irrigating............. 0

Digging.............. 3

Planting................ 2

$\begin{array}{lll}3 & 1 & \frac{3}{4} \\ 3 & 1 & \frac{1}{2} \\ 2 & 1 & 1 \\ 2 & 1 & \frac{1}{5} \\ 0 & 1 & \frac{1}{4} \\ 4 & 1 & \frac{3}{4} \\ 2 & 1 & \frac{1}{10} \\ 2 & 1 & \frac{1}{2} \\ 2 & 1 & \frac{1}{2} \\ 1 & 1 & \frac{1}{3} \\ 1 & 1 & \frac{1}{3} \\ 0 & 1 & 1 \\ 3 & 7 & \frac{2}{3} \\ 2 & 2 & \frac{1}{2}\end{array}$

This makes a total of 18 horse days - or about 18 horses working 1 day; and about 12 man days. Estimating the horse time at $\$ 1$ a day and the man time at $\$ 2$ a day, the labor bill is: 
Horse work, 15 days at $\$ 1$. . . . . . . . $\$ 15.00$

Labor, 12 days at $\$ 2$. . . . . . . . . . 24.00

Additional charges are as follows:

Twine . . . . . . . . . . . 75

Sacks 350 sacks at $6 \frac{1}{2}$ cents each $\quad . \quad . \quad . \quad . \quad 22.75$

Hauling . . . . . . . . . . . 13.80

1,750 pounds of seed at 2 cents per pound . . . $\quad 35.00$

Twelve loads of manure at $\$ 1$ per load $. \quad . \quad 12.00$

Rent of land (6 per cent. on valuation of $\$ 200$ per acre)

12.00

$\$ 125.30$

The yield was as follows:

Gross weight . . . 38,685 pounds 644.75 bushels Less Culls . . . 4,150 pounds

Marketable . . $\overline{34,535 \text { pounds }} \overline{575.5 \text { bushels }}$

Estimating the returns from the crop at $\$ 1$ per hundred, or 60 cents a bushel, the marketable potatoes are worth $\$ 345.35$, a profit of $\$ 220.05$ without figuring the waste potatoes. With waste potatoes at $\$ 5$ a ton, the total revenue is $\$ 10.40$ more, or $\$ 230.45$.

Ashel Smith, a successful grower and exhibitor of potatoes of Ladner, British Columbia, says that he pays $\$ 25$ an acre per year rent for land in sod, and that some sod land would be worth a rental of $\$ 50$ for growing potatoes.

When land that has been in sod from three to ten years can be secured, no commercial fertilizer is used. The sod is thoroughly disked to a depth of six inches (even if six diskings are required) before plowing.

Where sprouted whole seed is used the earliness of the crop is increased three weeks as compared 
with cut seed. They are planted thirteen inches apart in rows thirty-six inches wide.

Seed stock is graded by numbers according to the diameter. For instance, No. 2 seed weighs about ten ounces, and No. 7 is about one inch in diameter.

The per acre cost of production is about as follows:

Rent of land . . . . . . . . . . . $\$ 25.00$ 1,400 pounds of seed . . . . . . . . $\quad 21.00$ Seed bed preparation . . . . . . . . 8.00 No spraying is required

Cultivation five times . . . . . . . . . 3.50 Digging . . . . . . . . . . . . . 14.40 Sacks . . . . . . . . . . . . 14.40 Storage . . . . . . . . . . . . . 6.00

$\$ 92.30$

The yields run from 200 to 400 bushels, with an average of about 245 bushels per acre.

Potatoes usually bring about $\$ 1$ per hundred or 60 cents a bushel.

A yield of 9 tons (18,000 pounds or 300 bushels) at $\$ 20$ a ton ( $\$ 1$ per hundred) would bring $\$ 180$. This would make:

Returns from crop . . . . . . . . . $\$ 180.00$ Cost of producing . . . . . . . . . . 92.30

Net profit . . . . . . . . . . $\$ 87.70$

In the Hastings district in Florida, F. E. Bugbee gives the following cost and revenue for an acre of potatoes:

"Where the common methods described above are used, the figures are about as follows: 
Fertilizer . . . . . . . . . . . . $\$ 30.00$

Seed . . . . . . . . . . . . . 14.00

Barrels . . . . . . . . . . . 12.00

Rent. . . . . . . . . . . 15.00

Digging and delivering $\quad . \quad . \quad . \quad . \quad . \quad . \quad 10.00$

Cultivation . . . . . . . . . . . 7.50

$\$ 88.50$

Revenue 40 barrels at $\$ 3.25$. . . . . . . $\$ 130.00$

Cost . . . . . . . . . . . . . 88.50

Profit . . . . . . . . . . . \$31.50

"Where land is tiled with three-inch tiles eighteen inches deep, with lines of tile forty feet apart, with a device for closing tiles at outlet so as to control moisture content of land greater revenue is made. The cost of tiling is $\$ 30$ an acre.

"On tiled land there is no waste from open ditches and more seed and fertilizer are required. More seed is required because hills are planted closer together.

"Following are figures on tiled land:

Fertilizer

Seed

Barrels

Rent

Cultivation

Digging .

$$
\begin{array}{r}
\$ 40.00 \\
25.00 \\
30.00 \\
30.00 \\
7.50 \\
20.00 \\
\hline \$ 147.50 \\
\$ 390.00 \\
147.50 \\
\hline \$ 242.50
\end{array}
$$

Revenue 120 barrels at $\$ 3.25$

Cost

Profit

The cost of growing an acre of potatoes in Kansas is given by Secretary F. D. Coburn, of the 
Kansas State Board of Agriculture, in a consensus of the detailed statements of forty representative growers, reporting from thirty-two different Kansas counties the crop averaging 122 bushels:

Average cost of plowing . . . . . . . $\$ 1.20$

Harrowing : . . . . . . . . . . . 54

Seed . • . . . . . . . . . . . 7.25

Planting . . . . . . . . . . . . 1.35

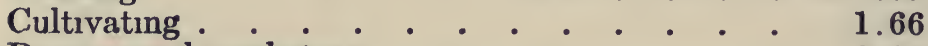

Digging and marketing $\quad . \quad . \quad . \quad . \quad . \quad 8.85$

Wear and tear of tools and rental of land or interest

on its value . . . . . . . . . 4.42

Total cost per acre, or 122 bushels . . . . . $\$ 25.27$

Averages of other items, gathered from those furnishing the forty foregoing reports, are as follows:

Average number of years each of the forty reporters

has raised potatoes in Kansas . . . 18

Average number of acres raised by each annually : $\quad 26$

Average quantity of seed planted per acre (bushels) 9

Average yield per acre (bushels) . . . . . . 122

Average value of potato land per acre $\quad . \quad$. $\quad \$ 60.00$

Statements of ten of the growers reporting who are most extensively producing potatoes for commercial purposes, in the Kaw Valley, average as here shown:

Average cost of plowing . . . . . . . . $\$ 1.45$

Harrowing . . . . . . . . . . . 51

Seed . • . . . . . . . . . . . 8.05

Planting . . . . . . . . . . . 65

Cultivating . . . . . . . . . . 1.46

Digging and marketing $\quad . \quad \therefore \quad . \quad 11.00$

Wear and tear of tools and rental of land or interest on its value . . . . . . . . . 6.85

Total cost per acre, or 154 bushels . . . . $\$ 29.97$ 


\section{THE POTATO}

Range of price per bushel $\$ 0.14$ to $\$ 1.15$ per bushel. Average price per bushel Kaw Valley on board cars is about

Average number of years each of these ten reporters

has raised potatoes in Kansas . . . . . 18

Average number of acres raised by each annually : 80 Average quantity of seed planted per acre (bushels) 10.4 Average yield per acre (bushels) $\quad . \quad$. . . . 153.7 Average value of potato land per acre $\quad . \quad$. $\$ 105.00$

Incidentally, by these forty reports it is noted that the number of times the ground is harrowed. ranges from one to four and in one it is given as eight; in some cases the ground is disked also; and in the Kaw Valley it is not uncommon for some of the more extensive growers to plow their potato ground twice.

Likewise, in the more western counties, in cases where the crop is mulched with a covering of straw or hay where irrigated, the cost of cultivating, which includes these items, is proportionately higher, owing to extra labor in the first instance and more frequent cultivating in the second.

In the item of planting, the cost to Kaw Valley growers is lessened by the quite general use of machine planters. 


\section{CHAPTER XIV}

\section{MARKETS AND MARKETING}

7 HE marketing of high-class farm products in attractive packages, to special trade 1 is a department of agriculture that has a most promising future.

Farm marketing has been too much like other farm operations - slipshod and easy going - with little or no system. There has been too little care as to the quality of the product.

The demands of the market to be supplied should be the first consideration. If a white potato is the popular one - the best possible white potato of the size and shape desired should be grown - selecting to that type consistently each year - making a product that so much excels the bulk of the offerings that it always demands a premium. An instance of this is the Salinas Burbank on the Pacific coast and the Mt. Sopris Farm or Carbondale Peachblow on the Denver market and for the dining car trade. Both of these are products of exceptional quality, smooth, even, and good cookers, but the former is a long white potato, the latter round and red.

In the fruit trade, where selection and package have been given careful consideration by up-todate growers in the western part of the United States, the marketing of all grades and sizes in the same package is no longer considered good business. The best and most select are packed in 
separate packages and often under separate brands. During the 70's, potatoes were shipped on boats and cars in bulk, now the crop is handled in bags, boxes and barrels.

It pays to sort the crop carefully - offering only sound, clean tubers for human consumption, feeding all refuse to stock. Then the sound, clean potatoes should be sorted as to size; large, medium and small for different requirements. Potatoes of uniform size cook most evenly. Each size should be put up in clean, new packages. Barrels and sacks are acceptable for the large users hotels, restaurants and dining cars, but crates or cartons make attractive packages for the retail trade. It may not be good business on the part of the average purchaser of supplies for the household, but it is nevertheless doubtless true, that 75 per cent. of the potatoes consumed by city and town people, pass over the counter of the retail grocer in small lots. For such trade," five, ten, and fifteen pound cartons would be very attractive.

The potato for this high-class trade should be packed on the farm a short time only before being retailed, and go in an original sealed package to the consumer. There would be no bruising and the potato could go to the table free from disfigurement. This should bring the grower a considerable premium for his work.

Quality and flavor in the potato receives more attention in Europe than in the United States. The early crop can be lower in quality than any other because it is not kept so long. A low quality crop, however, causes a falling off in consumption, as in 1907. On the other hand, an increase in quality greatly increases consumption - the aver- 
age per capita demands could be greatly increased by attention to this detail.

W. C. Brown Presiident of the New York Central Lines, says that since eating scientifically irrigation grown potatoes from Mt. Sopris Farm, where the moisture content supply is controlled, his family eat four times as many as when they got the ordinary run of the market. The same report has come from many other epicures.

Ninety per cent. of the potatoes used in hotels, dining cars and restaurants are pared. Economy in the cost of producing food of high quality for the table is a question that the modern chef and manager give the utmost consideration. For this reason his ideal potato would weigh fourteen to sixteen ounces, be smooth and even and was the smallest possible percentage in paring. Of course all cannot be this size, but the smaller ones are used for baking. The ideal potato would be a little smaller than the hotel man likes to pare, and would weigh twelve ounces, have smooth, clean skin, shallow eyes, smooth eyebrows that do not protrude, and as nearly as possible the shape and size of a turkey egg. Potatoes that weigh eight to sixteen ounces are those most highly valued for the best trade.

Several years ago, at the beginning of his dining car trade, the senior author of this book went to Mr. John F. Smart, superintendent of dining cars of the New York Central Railroad, with a sample of the smooth, even potatoes Mt. Sopris Farm produces. By actual demonstration he was able to show that these potatoes at double the prevailing market price, would make a saving because of their evenness and smaller percentage of waste in paring and preparing for the table. At least 20 
per cent. of the total weight of ordinary potatoes was being thrown out the dining car windows as waste. This consisted of small, cut, diseased and rough potatoes.

The business of growing and marketing potatoes should not be unlike any other manufacturing enterprise, both the producing and the marketing are very important. A modern manufacturer would not think of sending a shipment of goods to a customer, a part of which shipment was culls and of no use - and expect to hold his trade. Yet the potato grower will sack for the consumer 10 to 25 per cent. of absolutely useless potatoes cut, diseased, rotten and frozen - for the buyer to pay for and pay freight on and then discard.

At one time the farmer or grower of produce of all kinds held it to be good business to deceive the buyer. The best berries and apples were put on top - the culls beneath; rocks were weighed in loads of grain and bad eggs sold for fresh ones. The modern apple grower of the Northwest, markets train-loads of fruit of uniform quality, the apple in the centre of the box in the centre of a car being as good as any in the entire shipment. This practice has made money. Western apples often sell for more per one bushel box than Eastern apples per three bushel barrel. One reason for this is that the barrel is often faced at the top and bottom with good fruit and has the bottom filled with comparatively poor.

The average potato grower has not yet risen to the same plane as the best fruit men. Putting good ones on top is an old trick. It was common practice in Colorado a short time ago to put good potatoes at the bottom of the sack, fill the centre with the poorest, and put good ones on top. This 
was to fool the buyer if he opened the bottom instead of the top of the sack. The broker and dealer got around this by slitting the side of sacks for a sample. This led to the stovepipe method of filling. A few good potatoes would be placed in the bottom of a sack, a section of stove pipe inserted and the culls dropped in this, surrounding the pipe by good potatoes, withdrawing the pipe and filling the top with extras. Every kind of deception in marketing is poor business - and must sooner or later be stopped.

In some districts growers have formed associations and potatoes are marketed under a brand insuring quality. This will in time cause potatoes carrying this brand to command a premium.

Every employer of labor in potato work will find it hard to get men to be careful in sorting, no matter how strict the instructions. This was found to be the case at Mt. Sopris Farm, where a select trade has been built up by marketing potatoes on the same basis and method as the apple business at Hood. River - upon honor. The fact that there has never been a complaint is an indication of how well the plan has succeeded. "Do not put a potato into a sack for market that you would not be proud to serve on your own table" - this is the instruction to the employees in the potato cellar that makes it most easy to accomplish the result.

A great many growers make a practice of planting their entire acreage to the same class of potatoes and marketing all at one time. For instance, it may be all Earlies, or second Earlies, or Later, and all marketed from the field - or in the case of the late crop, all held for the winter or spring trade. 
A modification of this policy is suggested. This is to lengthen the planting, harvesting and marketing season by planting some acreage to an early variety or varieties; some to later sorts and the balance to late varieties. This makes it possible to do the work with less help at the "rush" time, keeping the fewer extra help required for a longer period. It makes it possible to market a portion of the crop from the field, saving rehandling. Some money is brought in early to pay the season's expenses. By reason of getting a part of the crop out of the way and off the farm early, the proportionate loss from shrinkage and possible loss in the storage cellar in the entire crop is lessened, while enough of the crop is carried over to get the benefit of possible high prices the coming spring. This plan has been adopted at Mt. Sopris Farm and is working out very satisfactorily.

The potato shrinks its greatest percentage during the first ten days after digging - probably 10 to 12 per cent. Potatoes clipped by the digger are usable at digging, while if put in the cellar they decay, and cause decay in the tubers with which they come in contact.

Greater economy in grading is possible in America. The common market requirement is to discard as culls, all potatoes that will not pass over a two-inch screen or riddle. In some places those passing through the screen are thrown away, not even being used for stock food. Some of these small potatoes are perfectly good for human food and should be put up in packages - graded to size and sold at a discount. They are quite as good as any for making soups and are all right baked. They can be easily and thoroughly cleaned with brushes. They do not require paring and can 
be used down to a size as small as one inch in diameter. Crops often run from 10 to 33 per cent. of potatoes under two inches in diameter, and the difference between profit and loss is contained in this part. The economy of the world's food supply seems to demand that they be utilized.

Potatoes that can be marketed at home, without incurring transportation, middlemen and retail expense, make the most net money for the grower. Local market places where seller and buyer could meet would be a benefit to both. The net price at the farm - after deducting charges above the cost of growing - often leaves the producer only 25 to 75 per cent. of the retail price. When a potato farm is a long distance from market or railroad shipping point and the roads are bad, the wagon haul is a large item of expense because of the great per acre weight of the crop.

Following are some interesting marketing ideas from "Farmers' Bulletin 386": "Potato Culture on Irrigated Farms of the West," by E. H. Grubb, transmitted December 30, 1909: "In deciding what.kind of potatoes to plant, the grower should study the conditions and demands of the market. He should grow a medium-sized potato. On rich land the potatoes planted eight inches apart in the row will yield not only a great tonnage, but tubers of more desirable size. There are few markets, except in the South, that will pay a high price for large potatoes. Our methods of packing and marketing potatoes have been and are yet for the most part, more crude than those used with other products. By the time they get to the consumer they are more or less bruised or crushed. The writer has thought of crating potatoes and developing that idea in Denver and New York. 
At the present time he favors a forty-pound crate. This size may be increased or decreased to suit the market. The grower should cater to the demands of the most particular and exacting consumers. He should try to educate the public to appreciate the delicacy of a first-class potato. The grower need not be afraid of freight bills if he can furnish better potatoes than anybody else. Hood River has a reputation for apples that makes them cost more to the consumer on the eastern market than the eastern apples by two or three times. This reputation was gained by packing apples that did not have an imperfect specimen in a car. Do not put in a package a potato that you would not serve to a guest at your own table."

J. G. Milward of the Horticultural Department of the University of Wisconsin is doing a great work for the potato growers of that state. In a circular issued by him in May, 1911, he says:

"The growing of miscellaneous types not adapted to competition on the leading markets, causes difficulty in sorting and grading at the loading stations. Growers in several sections have responded to a plan to establish community centres where uniform car lots of one variety can be handled. An important step toward the development of this plan will be to secure the best seed raised in the state in car lots, and reserve it for Wisconsin planting. The Agricultural Experiment Station through its Agricultural Extension Service has secured hearty endorsement, from growers, commission men, buyers, of a practical plan to disseminate the best seed raised in Wisconsin on the basis of a community centre 
plan. If the majority of growers in these centres select one standard variety adapted to their soil conditions the following advantages will be gained: 1. Reputation on the market as a variety centre; 2. Possiblity of handling straight, uniform car lots; 3. Easier disposal of stock during periods of depressed prices; and 4. Better prices under close competition.

"Many sections in northern Wisconsin have become important commerical potato centres. Northern fields under the direction of this Station are being planted largely to the standard varieties: Rural New Yorker, Burbank, Peerless, Early Rose, Early Ohio and Triumph. Market stock of a high standard can be produced on the good potato soils in this section. Coarse, undesirable types are being planted too often on land which will produce standard stock of high grade. This Station has been in touch with the leading commission houses of the West, and all these firms complain of the mixtures and substitutions of type in Wisconsin shipments. In addition they emphasize the need of closer attention to sorting and grading.

"During the past ten years Wisconsin has ranged from third to fifth in the rank of states in potato production. Available records show that there are thousands of acres of developed and undeveloped potato soils in this state adapted to produce stock of as high quality as any of the other famous potato centres of the country. Notwithstanding these possibilities for development there has been a falling off in many sections in the standard of both seed and commercial table stock. This circular is designed to urge improvement in uniformity and quality of car shipments. In ac- 
cordance with this need this Station does not assist in the dissemination of any but recognized standard market types. In some of the northern counties the Burbank, Rural New Yorker or Triumph predominate. In relation to market conditions these sections have recognized the advantage of a community industry. The potato industry in this state will be benefited by the elimination of coarse imitative types, novelties and local varieties and a return to straight car lots of the standard varieties, notably Burbank, Rural New Yorker, Peerless, Early Rose, Early Ohio and Triumph."

It is possible that many do not realize the scope of the potato business in a single market. The following interviews with the senior author in the Chicago Tribune in December 1910, is very interesting:

"Chicago as a market is next to New York in the number of bushels of potatoes consumed and distributed. A vast area, comprising among others, the states of Wisconsin, Michigan, Minnesota North and South Dakota, Colorado, and Idaho, ships its product to Chicago to be marketed.

"About 24,000 cars of potatoes are handled in Chicago annually, making an average of a little more than sixty cars daily. Many of these potatoes are consumed within the city and the rest supplies vast territories where the growing of the vegetable is practically unknown.

"As in all products of the farm, the crop and cost of potatoes is dependent largely upon the season. This year the price of potatoes has been high, due to the drought, and the market is just 
beginning to assume a normal tone. The market price determines to a great extent whether or not potatoes grown in states near Chicago will be shipped here for marketing. When the Chicago price is not sufficient to allow a fair return for the product and the New York price is higher, the shipper does not hesitate to send his potatoes to New York. And the same is true of potatoes grown in the East.

"But the United States nowhere near equals foreign countries in the growing of potatoes. There are three or four times as many potatoes grown per acre in Europe as in this country. Regular shipments of European potatoes arrive in New York and occasionally reach the Chicago market. In 1908, when there was a shortage of potatoes throughout the country and the prices were high, a large proportion of potatoes sold in the Chicago and Missouri River markets were grown in Europe. Potatoes ordinarily are cheaper in October than any other month. October is the month for harvesting the great crops from the Northern States, although it is true that new potatoes begin to arrive as early as September 1st. It is, however, possible to secure new potatoes in Chicago the year round. Bermuda furnishes potatoes in January and February. Florida furnishes them a little later. Potatoes in the spring come from Texas, and following northward, the market is supplied with a certain number of new potatoes in all seasons, but those which come from the Bermudas and Texas command fancy prices and go only on the tables of the wealthy or of the high-class restaurants.

"People of the laboring class eat more potatoes than those in other walks of life, and potatoes are 
valued especially by them because of the nutriment they supply, and their cheapness as compared with other food.

"Fifty cents a bushel is a fair price for the large commission men who handle large quantities of potatoes to pay, but by the time they pass through the hands of the jobber and the retailer a bushel of potatoes for which the commission man paid only 50 cents arrives on the table of the ultimate consumer at a cost of 80 or 85 cents or more a bushel."

Potato dealers are not unlike all others on a city market. There are many tricks in the seed trade. It is so hard for the amateur or the old practical dealer or grower to tell the difference in varieties, and there are so many so similar that a buyer can almost always be accommodated, no matter what stock is on hand. Instances are common where a half dozen different varieties have been supplied to as many different customers from a single shipment of a single variety. In the early spring it is common to see small old potatoes washed and sold for new potatoes at fancy prices.

It is probably true that the American or European potato grower will find his greatest future market in the increase in population at home, yet there are sections both in the Arctic and Tropical zones, where the Irish potato does not grow, that can be exploited for special long keeping and generally heavy skinned varieties at high prices. Some of these are Alaska, Gulf States, Old Mexico, Panama, Orient, and Philippines. There seems to be a good future in the preparation of dried or desiccated potatoes for this trade.

The potato market is very uncertain, the grower reaping a handsome profit one year, a loss the next. 
No one seems to be able to forecast or guess the future - even one season ahead. The "intermittent" potato grower may make big money or go broke, but the one who grows a stated acreage every year for ten years makes a nice average annual profit.

As is true of all crops that make food for the human race, the ultimate future of the potato crop for the intelligent grower is certainly very bright. No market is so panicky and so subject to rise and fall in price. This is true in both Europe and America. This is one of the phases of the business that should make the grower alert and watchful of crop and market conditions. It requires more than ordinary judgment to know when to hold or sell.

There are several ways of loading potato cars for shipment in cold weather to prevent freezing. At Carbondale a foot of straw is put on the bottom of the refrigerator car and a foot around the sides as the potatoes in bags are laid in tiers. After the car is fully loaded, oil stoves are put in, the temperature raised to 80 degrees, the stoves removed and the cars tightly sealed. This generally insures the car going through in good shape.

In Maine, a false bottom and false sides are made in the refrigerator car, leaving a two-inch air space all around. This frame is covered with building paper. The air space serves the same purpose as the straw. About 300 sacks of a little over 100 pounds each - or about 30,000 pounds is the weight usually loaded per car, although double this tonnage is sometimes loaded. 


\section{CHAPTER XV}

ENEMIES OF THE POTATO

7 THE potato is less subject to diseases and pests in the higher mountain country where it grows wild, than in any other part of the world.

Thousands of tons of tubers - the bulk of the crop of the world, in fact - are produced where the grower must fight many kinds of fungous and insect enemies.

The large amount of work being done along the line of securing disease resistant varieties - either by selection or hybridizing - has resulted in the production of some varieties of market value for the disease infested regions, and doubtless more will be produced.

The enemies of the potato may be divided into two classes; diseases and insects.

The diseases include:

Blights,

Scab,

Rot of various kinds,

Black leg,

Black scab or European wart disease.

Among the insect enemies are:

Flea beetles,

Colorado potato beetle,

Potato bug, . 
Potato worm,

Potato stalk weevil,

Potato eelworm.

One of the diseases of the potato that is attracting much attention abroad is the wart disease and steps have been taken to prevent its introduction into America. Following a discussion of this, the various blight, scab and rot diseases are described.

WART DISEASE

In "Leaflet 105" of the Board of Agriculture and Fisheries of the British Government, (information and illustrations from this source are used by permission of the Controller of His Britannic Majesty's Stationery Office), this disease is described as follows:

"The disease known as Wart Disease (Syncnytrium endobioticum Percival), formerly known as Chrysophlyctis endobiotica, Cauliflower Disease, Canker, 'Fungus' or Black Scab, attacks the tubers and haulms of potatoes, giving rise to large and irregular outgrowths which suggest a resemblance to pieces of cauliflower. In bad cases these 'warts' may appear at the surface of the soil and can be detected at the base of the haulm as yellowish green masses.

"Warts or wrinkles appear at first in the eyes of the young tuber, and later several warts by growing together form a brown spongy scab, which finally rots and becomes black. This scab has no connection with ordinary potato scab and does not resemble it in appearance, but as both are fre- 
quently found on the same plant they are sometimes confused.

"The disease has caused most damage in gardens or allotments where potatoes are grown every year, but in a few cases there has also been serious loss in potatoes grown on farms worked on a fourcourse rotation.

"The occurrence of the wart disease in the affected districts is similar to that of the Fingerand-toe disease which, on certain soils and in some seasons, causes serious damage to turnips. Although in the first instance only a few plants may show the wart disease, it is almost sure to spread, and the disease must be treated as a dangerous enemy, which, if neglected, may entirely prevent the profitable culture of potatoes where it occurs. Land may be unfit for potato growing for as long as six years after infection, and possibly for a much longer period.

"The diseased tubers or haulms contain numberless 'spores' (the 'seeds' of the disease), which are not only capable of infecting healthy potatoes the following season, but appear to be able to lie dormant in the soil for several years.

"The diseased tuber is the usual source of infection and the spread of the disease from one holding to another is mainly to be attributed to the planting of infected sets.

"When disease appears it may, if neglected, spread over a farm and render the soil useless for potato growing in the course of a few years. It is spread by manure, by the decay of affected haulms, tubers and runners in the soil, and it may even be carried from one field to another on implements and boots.

"Diseased potatoes must always be well boiled 
before being given to cattle or pigs, for infection is very readily spread by manure if raw diseased tubers are fed to stock. For the same reason diseased haulms must be burned and never be thrown on the manure heap; this should be done as soon as possible after the crop is lifted, as the 'warts' rot very quickly and further contaminate the soil. Dung which has been contaminated in any way should not be used for potato growing. If practicable, it should be applied to land under permanent grass.

" 'Seed' potatoes from a diseased crop or from a field in which disease is known to have occurred within six years should be avoided. If 'seed' potatoes are purchased in a district in which the disease is common, they should be bought as soon after harvest as possible, so that they may be kept under observation; the sets should be freely sprinkled with sulphur (four to five pounds will dress a ton) and should then be stored in boxes or pits until required.

"Tubers only slightly diseased may be easily overlooked, and may cause widespread infection when planted. Potatoes from an infected crop may appear to be perfectly sound when lifted, but after storing they may develop warts. It is important, therefore, that seed should be carefully examined before planting. As minute warts are difficult to see, a grower would be well advised to reject any seed potatoes among which diseased tubers have been found.

"In the case of a disease, like wart disease, which infects the land gradually, it is necessary to detect and stamp out the fungus as soon after infection as possible. When discovered the entire plant affected should be carefully removed, the useless 
portions burned, and the tubers boiled without delay. If possible the surrounding soil should also be removed and burned, or at least heavily dressed with gas-lime. Further, when the field is next planted with potatoes the piece of ground where the disease appeared should be fallowed and dressed with gas-lime at the rate of four to five tons per acre.

"If the attack has occurred in a garden required for frequent potato growing, the occupier should dig out and burn, not only the affected plant, but a considerable quantity of the surrounding soil so as to ensure that every fragment of the diseased plant is destroyed. Gas-lime should then be applied to the soil.

"If fields worked on the four-course rotation have become generally infected, farmers should replace the potato by some other crop, so as to let eight years intervene before the next potato crop is planted. The sets should be dusted with sulphur before planting, as recommended above.

"In gardens and allotments in which the disease has appeared, potatoes should on no account be planted on the same piece of land next season, and one of the following methods of treatment may be adopted:

"(a) The ground toward the end of April, should be covered with gas-lime (two pounds to the square yard), which may be forked into the surface soil to a depth of three inches. After lying fallow until the end of June it should be dug and prepared for cabbages.

"(b) If the soil be deep, two pounds of gaslime per square yard may be applied at the end of March, and a month later the soil should be in- 
verted by deep trenching. Any crop except potatoes may be grown.

"Whichever of these methods may be adopted it is desirable, when potatoes are next planted in the garden, that the sets should be dusted over with sulphur, and as they lie in the drills should be freely sprinkled with sulphur before they are covered in. Before the potatoes are earthed up, the surface of the soil round the haulms should be sprinkled with sulphur.

"Gardens in which even a single diseased potato has been found, the course recommended in the foregoing paragraphs should be adopted; but if no other land for growing potatoes is procurable, and occupiers of gardens and allotments are obliged to grow potatoes on land on which disease has been seen, they should apply gas-lime in autumn or early winter at the rate of three pounds to the square yard. After the sets have been placed in the drills they should be freely sprinkled with sulphur. Before the plants are 'earthed up' the ground should again be sprinkled with sulphur.

"Some varieties of potatoes are not affected by wart disease, or are very slightly affected. The varieties known as 'Snowdrop,' 'Conquest,' 'Abundance,' 'Langworthy,' 'What's Wanted,' and 'Golden Wonder,' have escaped infection, when such other sorts as 'Up-to-date,' 'Northern Star,' 'British Queen,' 'Royal Kidney,' 'King Edward VII.,' 'Epicure,' 'Express,' 'Ninety-fold,' and 'May Queen,' planted in the same soil have been severely attacked. Early potatoes often escape attack the first two or three years, i. e., until the soil gets badly infected.

"If an early potato be required 'Snowdrop' or 'Conquest' should be planted; if a late variety, 

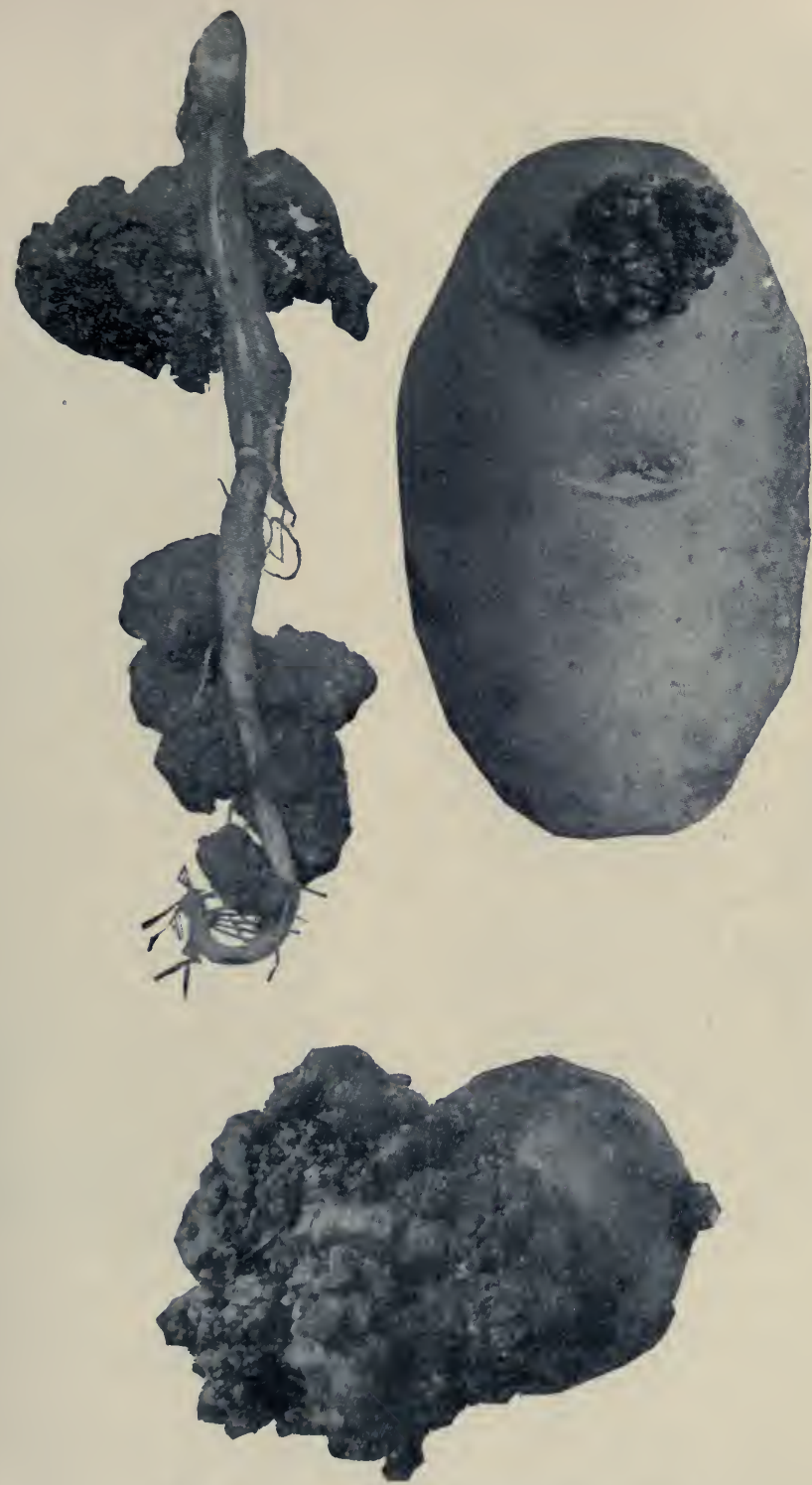

WART DISEASE OF PO'TA'TOES

Upper left-hand figure shows affected stem. Upper righthand figure shows tuber slightly attacked. Lower figure shows tuber badly attacked. Illustration from circular of British Board of Agriculture and Fisheries 


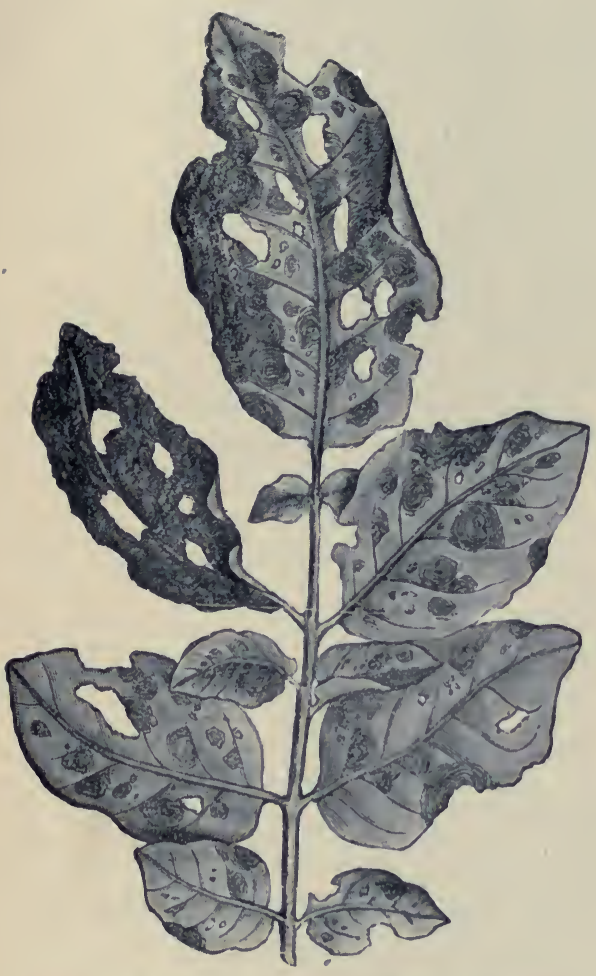

Early Blight. Characteristic appearance of badly blighted leaf

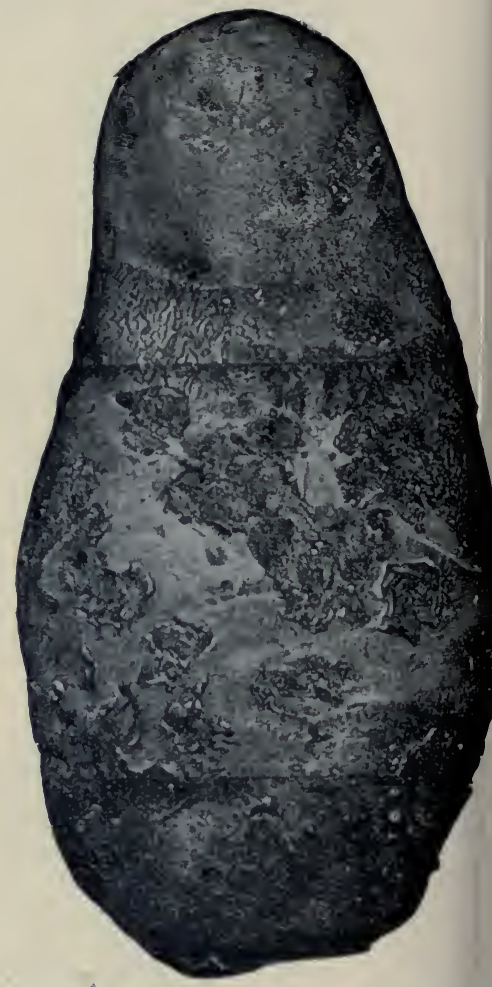

Potato Scab. From Farmers' Bulle 91, U. S. Department of Agricultt 
preference should be given to 'Langworthy.' This variety is commonly cultivated in the potatogrowing districts of the east of Scotland, and reliable seed is easily procurable. It does not yield so heavily as 'Up-to-date,' but is less liable to ordinary potato disease, and the cooking quality is much better, so that even in districts where wart disease has not appeared it is a variety to be recommended. It requires rather a long period of growth, well-tilled soil, and a free use of manure. Those who wish to grow it successfully should give attention to the following points:

"(1) Cultivate the land deeply: shallow soils should be subsoiled, or in the case of gardens, trenched to a depth of fifteen inches.

"(2) Apply dung liberally. In the case of fields, fifteen to twenty tons per acre, and supplement this dressing with a mixed artificial manure.

"(3) Sprout the tubers before planting, and plant early.

"Sulphur suitable for the purposes indicated above should be procurable at from $9 \mathrm{~s}$. (\$2.25), to 11s. (\$2.75), per cwt., or 1s. 3d (31 cents), to $1 \mathrm{~s}$. $6 \mathrm{~d}$. (37 cents), per stone (fourteen pounds). Sulphur has been recommended because, of many remedies tried for dressing soil during the growing season, it seems to be the best. It occasionally does good, especially in light soils, but it cannot be relied upon to protect potatoes planted in badly affected soils. Its good effect seems to be enhanced by using black sulphur and mixing it with an equal quantity of quicklime.

"Wart Disease (Synchytrium endobioticum), is scheduled as a notifiable disease under the Destructive Insects and Pests Acts, 1877 and 1907, and occupiers of land on which the disease occurs must 
at once report it to the Secretary, Board of Agriculture and Fisheries, 4 Whitehall Place, London, S. W. In reporting an outbreak, occupiers must state their names in full and their postal address, and it is desirable that specimens for identification should be sent to the Board. Neglect to report renders the owner liable to a penalty not exceeding ten pounds $(\$ 50) . "$

\section{EARLY BLIGHT}

Potato Leaf Blight (Alternaria Solani). The following description is from "Bulletin No. 71" of the Wyoming Agricultural Experiment Station:

"This disease has probably been long in existence. Our knowledge of it, however, is exceedingly recent. So long as the real nature of potato diseases were not understood, the different kinds of such diseases were not discriminated. They were all classed under one name, if named at all. Our first definite knowledge of the early blight was worked out in this country in the early ' 90 's, though references to it occur somewhat earlier in the nineteenth century in European literacure. It had been overlooked or confounded with the late blight, but it is now fully understood that the parasitic organism causing it is wholly different from the one causing the late blight in structure, in method and time of development, as well as the conditions under which it occurs.

"The fungus, like most other plant parasites, lives within the tissues of the host, spreading its mycelium through the intercellular spaces of the leaf. It consists of slender threads (hyphæ), more or less branched, which tend to become aggregated 
in certain areas, the tissues of which die, producing the characteristic brown spots. While in full growth and while the tissues of the host are supplying an abundance of food, there are few, if any, reproductive bodies (spores) produced. When the leaves become partially exhausted and dry, spore reproduction takes place freely and the characteristic several-celled spores, formed in chains, occur abundantly.

"Since the early blight has only recently attracted attention in this state, it is not generally known to our growers. It may, however, be readily recognized and easily distinguished from the late blight and the other potato diseases. Early blight begins to show itself about the time that the blossoms appear, which, with us, is usually in July. More rarely it attacks plants scarcely six inches high. The first indications are relatively small grayish brown spots, which, as they become larger, are marked with faint concentric circles, giving a target-like appearance to them. The spots may increase in size until several of them run together and form large patches of dead tissue. In the course of a few days these spots become brown and withered, while the rest of the leaf takes on a yellowish, sickly color, though the stems may remain green. Sometimes the disease progresses quite slowly and the vitality of the plant is only gradually reduced. In any case, however, the tubers either stop growing entirely or remain so small as to make them of little value. The death of the vines in this way is often mistaken for early ripening and it then occasions a surprise to find that no tubers of value are present.

"Any injury to the foliage, such as insect bites 
or bruises from hail, seems to furnish the condition for the entrance of the fungus into the leaf. Likewise any decline in the vigor of the plant seems to invite attack. Drought, poor soil, delayed development due to cold weather, excessive heat tending toward wilting or sun-scald, all make the plants less able to withstand the attacks of this blight. In other words, the more nearly perfect the plant and the more vigorous its growth the less likely it is to suffer from this parasite.

"But little is known concerning the source of the disease. The tubers seem to be wholly free from attack, and there is therefore no reason for suspecting that the seed potatoes carry the disease over from one year to the next. Certain it is that somewhere the several-celled black spores winter over and start the disease again the following season. That this might happen where the dead tops are not destroyed, but are scattered about over the field and farm, is easily understood.

"Satisfactory treatment for this disease has not yet been found. Many experiments, however, have shown that the effects of the disease may be greatly reduced by two or three thorough sprayings with Bordeaux mixture. The spraying must be thoroughly done and the first application must be made previous to the appearance of the blight. After the leaves have become filled with the mycelium and the spots are beginning to show, it is too late. Prevention must be the aim, and this is accomplished by putting the leaves in such a condition by the application of the Bordeaux that the spores cannot germinate upon the leaf surface." 


\section{THE LATE BLIGHT}

The Late Blight (Phytophthora infestans) is a very serious disease. The following is from "Bulletin 71" of the Wyoming Experiment Station:

"Though this disease had not been fully worked out until in comparatively recent times, yet there are references in literature to potato epidemics which devastated the fields of Europe at intervals during the nineteenth century, which were undoubtedly due to it. The first recognizable description occurs first in 1845. Its life history, however, has now been known for some time, though as late as the ' 80 's and '90's this trouble was still confused with the early blight. For a considerable time it was not known that the rot which usually follows an attack is also due to the same parasite. While probably of rare occurrence in the Rocky Mountain states, late blight is feared more than any other disease in the potato districts of the Eastern States. It is estimated that the loss in New York alone sometimes amounts to $\$ 10,000,000$ a year.

"Though this fungus resembles the early blight in many respects, yet it is easily distinguished from it by its mode of growth, the effect it produces on the leaf tissues, and especially by the spores and the way in which they are produced. It finds entrance into the potato leaf through the stomata, and the mycelium once having found entrance spreads by numerous branching hyphæ through the leaf among its cells, from which the fungus draws its nourishment. After the leaf has become filled, as it were, with the mycelium, the fruiting period of the fungus is reached. Some of the hyphæ then grow out through the stomata, 
branch, and produce small pear-shaped bodies on the tips of the branches. These latter structures, known as sporangia, serve to spread the disease to other parts of the field. They are very readily detached from the filament upon which they are grown and then fall upon the soil, or are carried far by the wind. If they happen to fall upon a potato leaf they will begin to grow just as soon as a little moisture either from rain or dew is present. This growth consists either in the formation and discharge upon the surface of the leaf of several free swimming spores, capable of infecting the plant, or in the direct formation of a filament which enters the leaf through a stoma and develops again a mycelium. From this mycelium other similar reproductive bodies are formed, in turn, to further infect the field.

"During the time that the fungus is spreading its mycelium through the tissues of the leaf there is little to indicate its presence. When the fruiting stage is reached it soon becomes evident enough by the formation of brown spots, which grow gradually larger and larger, finally turning black and a little later decomposing and emitting a disagreeable but characteristic odor. If one of these.infested areas be examined closely it will be found to be bordered by a grayish white mildew. This latter, under examination with a lens, is seen to be the branched fruiting hyphæ bearing the sporangia described in the preceding paragraph.

"For the development of the mycelium-that is, for the growth of the fungus within the potato plant-moderately cool weather seems the most favorable. For this reason this disease rarely proves troublesome where high temperatures prevail for considerable periods of time. Spore pro- 


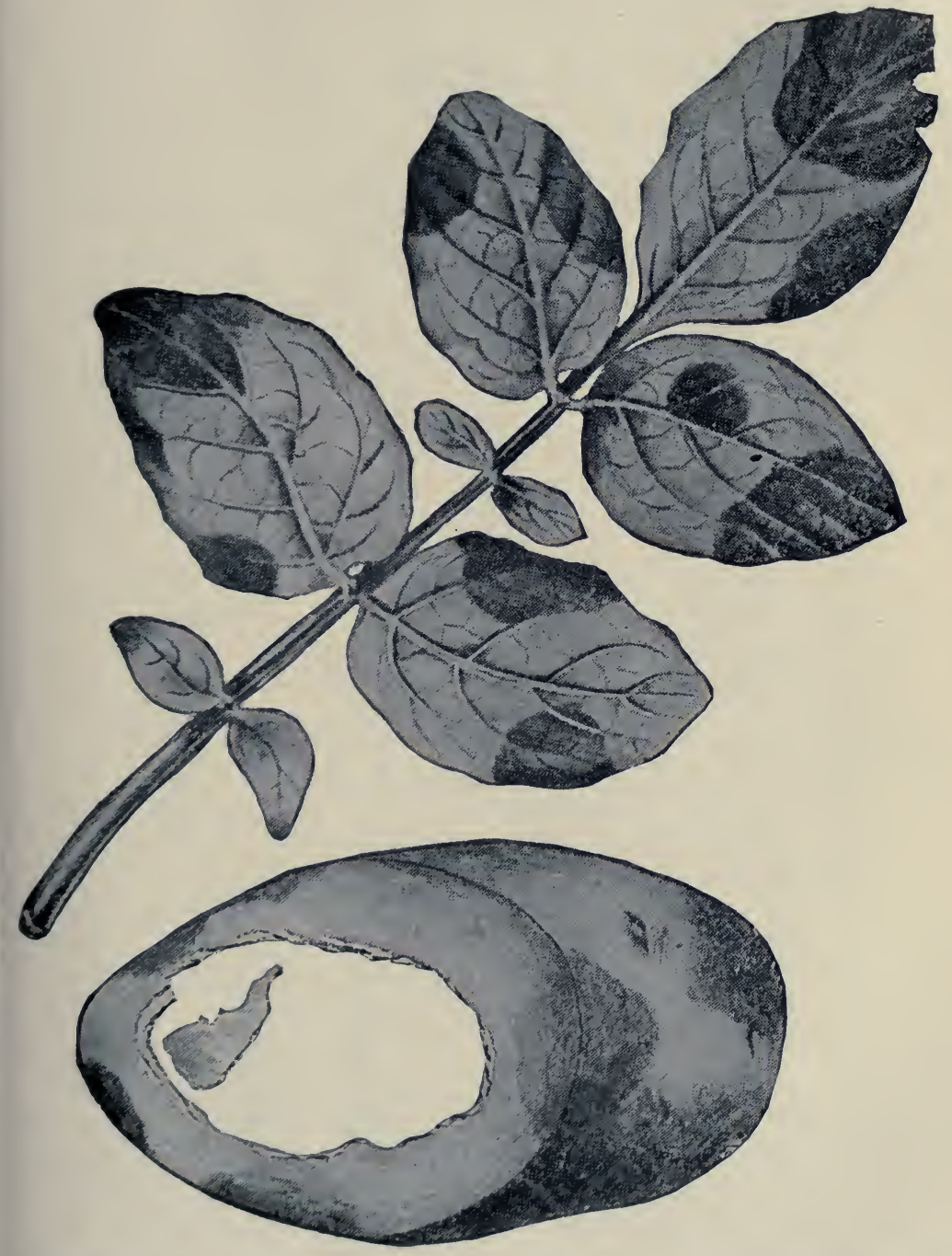

Late Blight Diseased leaf and tuber of potato. From the Journal of the British Board of Agriculture and Fisheries 


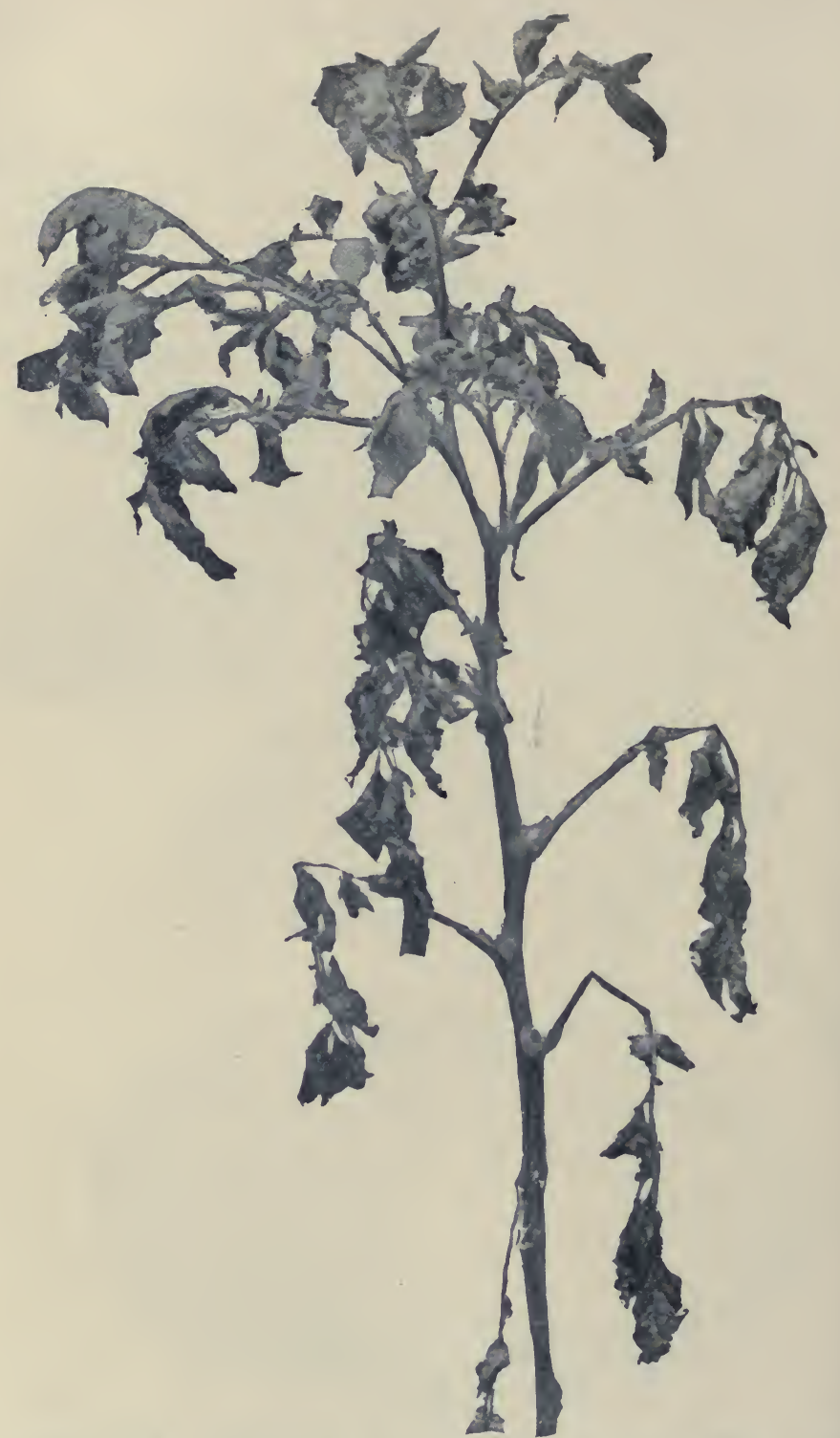

Late Blight. The last stages of the disease. When this is reached the field looks as if fire had swept over it. (From the New York Experiment Station. Geneva, Bulletin 241). 
duction, however, seems to be hastened and enormously increased when a few days of warm, cloudy and muggy weather alternate with the longer, cooler periods. Under such conditions a field showing but slight infection may in a few days look as if it had been swept by fire or frost. It rarely attacks early potatoes, mostly appearing upon the late varieties during the tuber-forming period.

"Various experiment station workers have tried different remedies for holding this disease in check. At some stations these experiments have been carried on for many years. While several have given results which were of value, no treatment has been as uniformly successful as the application of Bordeaux mixture. The universal experience is that spraying with this fluid will so nearly control the late blight as to make it possible to secure a crop even in those years when this disease is most prevalent. It requires, however, that the spraying should be begun in time and continued at intervals throughout the growing season. As already stated, it must be a precautionary measure. If not begun until after the blight is evident in the field only partial control can be expected. If the spray is applied thoroughly from the beginning, not only will the blight be controlled, but the rot of the crop which usually follows a severe attack is altogether prevented.

"It has been almost conclusively proved that the rot of the tuber which follows an attack of late blight is really due to the infection of the tuber by the spores which have fallen upon the soil and which, in the course of the season, are carried by rains or irrigation waters into contact with the tuber itself. Here it may begin growth at once or. 
it may develop after the potato has been dug and stored. Sometimes a large portion of the crop is thus lost even after it has been harvested. Thorough spraying of the vines will, at the same time, impregnate the surface of the soil with the copper-sulphate solution. Thus not only is the formation of any considerable number of spores prevented, but the spores that do happen to reach the soil are destroyed.

"It is believed that the spores of the fungus do not live through the winter. If that be true the mycelium of the fungus must either live over in the dead tops that are left strewn about the field, or else the tubers carry the disease over from one season to the next. The latter is thought the more probable, as it has been seen that the blighting of the tops (if not checked by spraying) is very likely to be followed by rot of the tubers, either before or after digging. Of course, no one would think of planting badly rotted potatoes, but those that are but slightly affected may escape notice. These, if planted, will be sufficient to start the infection the next year, and once started it soon goes over the field."

This disease is very serious in Europe. In "Leaflet 23" of the Board of Agriculture and Fisheries of Great Britain is the following:

"This disease, well termed by agriculturists the 'potato disease,' has in the past been the cause of immense loss, and is even at the present day the chief trouble with which potato growers have to contend.

"The first sign of this disease is the presence of yellowish spots on the leaves. These spots grad- 
ually increase in size and become brown, this condition being followed by the curling of the leaves. If the under surface of a diseased leaf is examined with a magnifying glass, the fruiting branches of the fungus will be seen forming a delicate white mold.

"The spores of the fungus are exceedingly numerous and minute, and are scattered by wind, or by ground game and other animals running amongst the plants. When it is stated that every spore brought into contact with a damp potato leaf is capable of starting a new centre of infection, the rapid spread of the disease under favorable conditions will be readily understood. The disease develops and spreads with the greatest rapidity during damp, warm weather, such as often occurs in July.

"Spores that fall to the ground are washed through the soil by rain and may infect young potatoes, especially those growing near the surface. It is probable, too, that the mycelium of the fungus passes down diseased stems into the young potatoes. If the season be wet and warm the mycelium present in the potato continues to grow, soon causing brown spots to appear, and ending in the rotting of the tuber. On the other hand, if potatoes that are infected be kept dry, the mycelium in their substance may remain stationary until the following spring, when it may commence growth and infect the new crop, afterward appearing in the fruiting condition on the leaves.

"Preventive and remedial measures suggested are:

"1. Potato disease is propagated and carried on from season to season in the sets. It is therefore 
of the utmost importance that sound crops only should be kept for seed, and that sets should be stored under the most favorable conditions. In an ordinary way seed potatoes should be carefully selected, all those being rejected that show the least sign of taint; they should be allowed to get thoroughly dry before clamping and should be stored separately.

"2. Diseased haulm should be removed and burned before the potatoes are lifted. If the disease appears late in the season when the tubers have attained a fair size much benefit may be derived by pulling the haulm at once.

"3. Potatoes are found to become less resistant to disease the longer they have been in cultivation, and therefore a good, new strain is to be preferred to an old stock; but most of the new varieties offered for sale are more susceptible to disease than old stocks of the best kinds, and growers are warned against relying on the disease-resisting power of a potato merely because it is a recent introduction.

"A change of seed is desirable if sets from a sound crop can be obtained, because of the increase in the total crop of sound tubers which is likely to follow, but it must not be supposed that changing seed will enable the plant to withstand disease. On the contrary, it is often found that the luxuriant growth of haulm which may result from changing seed renders the crop more susceptible, and that the percentage, though not the actual weight, of sound tubers is reduced.

" 4 . The rows of potatoes should be well 'earthed' or 'banked' up, as the thicker the layer of soil the less chance is there of the spores of the fungus reaching the young tubers. 
" 5 . Neither the planting of vigorous varieties nor cultivation can be trusted to ward off the disease in a wet season, but spraying with Bordeaux mixture has been found effective and is now a part of the regular routine of cultivation in humid districts. Even in dry seasons when no disease is apparent the treatment is found to be beneficial, producing a longer period of growth and an increased yield. 'This is so generally recognized that spraying has become general in several potatogrowing districts, whatever the season promises to be. As the disease does not as a rule make much headway before the end of July, spraying is seldom wanted for the first early sorts, the leaves of which will be dying down before any great harm is done.

"Bordeaux mixture may be prepared as follows:

Sulphate of copper or bluestone......... 12 lbs.

Freshly burnt quicklime............... 8 lbs.

Water................... 75 to 100 gals.

"In order to obtain good results from Bordeaux mixture, careful attention must be given (1) to the materials employed, and (2) to the preparation.

"1. Materials: Copper sulphate of 98 per cent. purity should be obtained, 'Agricultural' copper sulphate, which usually contains iron sulphate, must be avoided. Iron sulphate or copperas is valueless for this purpose.

"An easy test for the presence of iron in the copper sulphate is to dissolve a little in water and add ammonia with constant stirring until a deep, blue liquid forms; any quantity of brown flocks floating about in this blue liquid indicates the presence of so much iron that the material should be subjected to a proper analysis previous to use. 
"The lime used should be white 'fat' lime from the mountain limestone or chalk, the kind of lime which is used by plasterers. 'It must be freshly burnt.' If of good quality eight pounds will be required to neutralize twelve pounds of copper sulphate, but the weight of lime required depends upon the quality, and while as little as six to seven pounds might be sufficient in one case, as much as ten to twelve pounds might be required in another.

"2. Preparation: The copper sulphate and lime must always be diluted with a large quantity of water before being brought into contact, otherwise a very inferior mixture will result. When making a small quantity the best plan is to dissolve the copper sulphate in about one half of the water, mix the lime with the other half and then bring the two together; but when a large quantity of spray has to be prepared it is usually much more convenient to make a somewhat concentrated mixture and to dilute immediately before application to the crop. Under no circumstances, however, should the first mixture be made too strong, and when twelve pounds of copper sulphate and eight pounds of lime are to be employed, the first mixture should fill a forty-gallon cask. To make the mixture, proceed as follows: Run into cask about thirty gallons of water. Crush twelve pounds of copper sulphate, tie up in a piece of sacking and suspend just below the surface of the water; or, if preferred, dissolve the bluestone in boiling water and pour into the cask. Next moisten and slake eight pounds of lime; the lime must be allowed to swell and crumble slowly; when it has been well slaked, work it down first into a thick cream and gradually dilute to four or five gallons. The milk of lime must next be strained through a fine sieve or piece 
of sacking to remove grit; it should then be further diluted with water to about ten gallons and poured slowly into the cask containing the solution of copper sulphate. As the two fluids mix they must be thoroughly stirred. If the lime has been slaked slowly and the whole process has been carried out as indicated, a gelatinous precipitate forms in the cask - that is, the water becomes filled with starch-like flecks; these remain in suspension for a long time. On the other hand, if too little water has been employed, or if the lime has not been properly prepared, or if stirring has been neglected, a comparatively coarse powder forms in the mixture and soon settles, so that after standing for an hour or two the fluid in the upper part of the cask is quite clear. The starch-like precipitate, when once it dries on foliage, adheres closely for months, whereas the coarser powder, which results from careless preparation, washes off readily, so that the leaves lose much of their protection after the first heavy rain, and spraying does little or nothing to check disease.

"When Bordeaux mixture has been made it should be diluted if necessary and used without delay. One or two days' supply only should be made at a time, for although well-made Bordeaux mixture will keep fairly well for several days, it is best used within forty-eight hours.

"For spraying potatoes under favorable conditions the mixture, if made in a concentrated form, should be diluted to 100 gallons, but when spraying must be done in damp weather it should be diluted to from seventy-five to ninety gallons. Before pouring into the sprayer it should be stirred thoroughly. If possible, a sprayer provided with a dasher or other contrivance for keeping the mix- 
ture agitated should be used. If no mechanical contrivance is available, stirring should take place frequently while the work is in progress.

"The amount to be applied per acre varies with the quantity of haulm in the crop to be treated, but is usually from 100 to $\mathbf{1 5 0}$ gallons where the foliage is fully developed. The plants must be sprayed from underneath as well as from above, so as to reach the fungus on the under side of the leaves. Machines can be obtained which spray the plants from below.

"The cost of a single spraying need not exceed \$2 per acre, and, with certain horse machines, thirty acres can easily be treated in a day. Bordeaux mixture does not begin to work until several days after it has been applied, and it must, therefore, be used some time before any symptoms of disease are to be expected, say, toward the end of June, or early in July, according to the locality and season. The crop should be sprayed twice at least. The first spraying should take place as soon as there is a good development of haulm, the treatment being repeated about three weeks later when the growth is complete. If only one spray. ing is given it should take place about the middle of July."

\section{POTATO SCAB}

Oospora scabies is one of the most common potato diseases.

In "Bulletin 71" of the Wyoming Experiment Station it is described as follows:

"This fungous disease is too well known to need any description. All who use as well as all who grow potatoes know the familiar, irregular, sore- 
like blotches which sometimes are so numerous as nearly to cover the whole potato. Only the surface may be affected or the fungus may have penetrated and broken down the tissues almost to the centre. While probably not wholly preventable, yet it is the potato disease that is most readily held in check. With clean or properly disinfected seed, if one puts it into clean ground (free from the fungus) the crop should and will be essentially clean. It is well known that once the fungus gets into the soil it will live over winter and infect the next crop more completely than the former. Just how many years may be necessary to completely rid the soil of the fungus is not definitely known, but it is certain that another crop of potatoes should not follow scabby potatoes for two or three years and probably better not for four or five. Other crops on this land are not attacked, which points anew the safety and desirability of a scheme of crop rotation extending over several years.

"Having decided upon the variety to be planted -and this choice must rest upon many characteristics, such as quality, shape, period of ripening, resistance to disease, marketableness, etc., - then select those that are the freest from scab of any that you can find. It is well to remember that the absence of the characteristic surface markings is not conclusive evidence that the potatoes are free from the fungus. They may have been in contact in the bin with scabby specimens, as a result of which they are infected abundantly with the scab spores. Unless you are sure of the condition of the seed it will pay as a precautionary measure to treat (disinfect) the seed.

"The old method is quite largely in use in the state and must still be regarded with much favor. 
The new method, however, has some very practical advantages. Both are given below, so that if the ingredients for one are not at hand, the other may be used.

"Corrosive Sublimate Treatment. - Dissolve two ounces of corrosive sublimate (bichloride of mercury) in two gallons of hot water. When the corrosive sublimate is dissolved, add cold water until you have fourteen gallons in all. Having put the potatoes in a gunny sack, place the sack in the solution and leave it there for one and one half hours. Then empty the potatoes out upon the floor to dry before cutting and planting. If they can be left thus exposed to the light and air for a few days they will grow all the better.

"Caution. - If taken internally corrosive sublimate is a violent poison, hence all animals must be kept away from the solution and the treated seed. On account of its action on metals the solution must be prepared in wooden vessels, a barrel, for instance. See that the potatoes are clean. Put them into a coarse gunny sack and place it in the solution. The vessels and all objects in contact with this poisonous solution must be destroyed or thoroughly cleaned.

"Formalin Treatment. - Formalin (or formaldehyde) may now be secured at moderate cost at any drug store, or can be secured from the larger drug firms (by expréss) at 50 cents (or less) per pound. Since this treatment is at least as effective as the other, most people will prefer to use it for the following reasons: (1) It is easily prepared; (2) any kind of vessel may be used; (3) it is not poisonous to handle.

"Method. - Soak the seed potatoes for two hours in a solution of fifteen gallons of water and one 
half pint (half pound) of formalin. Smaller or larger quantities in the same proportion. Dry the soaked seed, cut and plant as usual.

"It is well to remember that disinfected seed will be reinfected if it is put back into the dirty sacks or boxes from which it was taken. If to be used again, disinfect the sacks and boxes also."

It will be interesting to note how this subject is handled by the Board of Agriculture and Fisheries of Great Britain. Their "Leaflet 137" says:

"At the present day Oospora scabies is one of the most widespread of diseases affecting the potato. The fungus usually attacks the tubers while young, forming scattered rough patches or scabs on the surface; these patches gradually increase in size and number, and not infrequently, when the tuber is full-grown, its surface is more or less completely covered with scab.

"The injury is confined to the surface of the tuber, the skin being broken up into fragments over the diseased patches. Although the market value is much depreciated when scab is present in quantity, the quality of the potato is not in the least impaired for eating.

"Prevention and Remedies. - (1) If scabbed potatoes are used for 'seed' without having been sterilized, the resulting crop will almost certainly be diseased, and in addition the fungus will pass into the soil, where it is capable of living for several years. Scabbed potatoes may be used for 'seed' without the slightest danger of spreading the disease if they are immersed for two hours in a solution consisting of one pint of commercial for- 
malin (formaldehyde 40 per cent.) mixed with thirty-six gallons of water. The potatoes should then be spread out to dry, when they may be cut and planted in the usual manner. Great care must be taken after potatoes have been treated as above that they are not placed in sacks or hampers that have contained scabbed potatoes.

"(2) Land that has produced scabbed potatoes is certain to be infected with fungus, and should not be planted with potatoes for several years afterward; beets, Swedes, carrots, and cabbages are also attacked by the fungus. Cereals may be sown with safety on infected land.

"(3) In the case of gardens and small allotments, where potatoes are of necessity grown every year, the trenches in which the potatoes are planted should be sprinkled with powdered sulphur.

"(4) Lime favors the development of the fungus in the soil; the same is true of stable manure, nightsoil, etc. Acid manures only should be applied to land that is infected.

"(5) Peelings from infested potatoes, unless they have been boiled, should not be given to pigs. Burning is the safest, and in the end the most economical method of dealing with them."

\section{TIP BURN, LEAF BURN OR SCALD}

"This disease of the leaves occurs in many parts of the country and is often confused with early blight," says B. T. Galloway in "Farmers' Bulletin No. 91." "The tips and edges of the leaves turn brown and these discolored areas soon become hard and brittle.

"The burning or scalding may occur at any time and as a rule is the result of unfavorable con- 
ditions surrounding the plant. Long-continued, cloudy and damp weather followed by several hot and bright days is very apt to result in the burning of the foliage. This is especially the case on soils carrying a comparatively small percentage of moisture. When the weather is cloudy and damp the tissues of the potato become gorged with water and this has a tendency to weaken them. If the sun appears bright and hot when the leaves are in this condition there is a rapid evaporation of the moisture stored up in their cells. The evaporation may be faster than the supply furnished by the roots, and if this continues for any length of time the weaker and more tender parts first collapse, then die, and finally turn brown and dry up. Tip burn may also occur as a result of protracted dry weather.

"Little of a specific nature can be said on the treatment of this trouble. Numerous factors are involved in the matter, so that only general statements are possible. Every effort should be made to keep the plants in good growing condition, for if they become checked through lack of proper food or cultivation, or both, they are more apt to burn. It is a fact that where the Bordeaux mixture is used for other diseases burn is less apt to occur, and this furnishes another instance of the remarkable properties of the fungicide. Briefly, therefore, the plants should be kept as vigorous as possible by good cultivation, plenty of available food, and the application of Bordeaux mixture as recommended for early blight.

"In many sections where Paris green in water is applied to potatoes, injuries are produced which cannot be distinguished from early blight by an ordinary examination. It frequently happens, 
therefore, that farmers are led to believe that their potatoes are affected with early blight and other diseases when the trouble has been brought on by themselves through the improper use of Paris green. Injuries resulting from the use of this substance are very apt to occur where flea beetles have eaten the foliage. The arsenic attacks the tissues at such points, and as a result more or less circular brown spots are produced, having for their centres the holes eaten out by the flea beetles. By combining the Paris green with Bordeaux mixture, as already described, these injuries may be wholly avoided.

"The cost of the work of spraying, as described here will depend to a considerable extent upon the kind of machinery used and the price paid for labor. With suitable apparatus, and labor at $\$ 1.50$ per day, potatoes may be sprayed six times for about $\$ 6$ per acre. This estimate is based upon experiments extending over several years, and includes the cost of chemicals as well as labor. The cost of treating scab is mainly in the labor involved in dipping and drying the seed, and seldom exceeds 15 cents per acre. Much attention has been given to the effects of Bordeaux mixture on the growth and yield of potatoes aside from its value in keeping parasitic foes in check. It has been shown conclusively that it pays to apply this preparation if for no other purpose than to induce a more vigorous growth. Three or four applications of the mixture have in many cases increased the yield of potatoes 50 per cent., so that no matter where the crop is grown, or whether diseases are present or not, the writer feels warranted in recommending the application of the mixture, on the ground that its use will yield a handsome return." 
DRY ROT

Dry rot, due to Fusarium oxysporum, has been known in the potato world for a good many years, but the real cause was not understood until recently. A great deal of research work has been done in Germany.

This dry rot is a fungous disease that attacks the potato plant through the root system, which not only destroys the root hairs and secondary roots, but penetrates the main roots, the tubers, and later, when the plant is practically destroyed, the stem is wilted. It also causes dry rot in potatoes in storage.

The disease is well distributed over the potato districts of practically all potato producing countries.

A vast amount of experimenting has been done with the idea of finding the best way of combating the pest. In "Bulletin 229" of the Ohio Agricultural Experiment Station Thos. F. Manns summarizes the results of their work. The things he says about Ohio apply to any similar conditions:

"1. The dry-rot fungus (Fusarium oxysporum, Schlecht) of potato proves to be a field trouble common in Ohio, which causes a blight and wilt of the crop.

" 2 . It produces a sick soil condition in potato districts.

" 3 . The field symptoms are characterized by a cessation of growth, a yellowing of the foliage, with an upward and inward rolling of the upper leaves, accompanied by wilt during the heat of the day. "4. The sick soil conditions may reduce the yield to 50 per cent. or more of an average crop. 
" 5 . The casual fungus is carried within the tubers.

"6. The internal infection is characterized by brown or blackened areas usually in the vascular ring; occasionally it specks the flesh in other areas.

" $\%$. Internally infected tubers are the chief means of distributing the disease.

" 8 . The presence of the disease in the tubers may be made known by cutting knife sections from the stem end.

"9. The infection may be removed from slightly infected seed by clipping away the stem end and following by external treatment with formaldehyde.

"10. No attempt should be made to use deeply infected seed, as the infection cannot be cut away.

"11. Slightly infected seed will not materially reduce the yield the first season. It is a means, however, of infecting the soil, which may later result in sick fields.

"12. Spraying will not control the disease.

"13. Proper storage prevents the progress of the disease as a dry rot.

"14. Careful inspection of the seed should be made before placing it in storage. Cellar storage under dwellings should be avoided when seed is infected. Proper pit storage will give better results.

"15. A seed plot on non-infected soil planted with carefully selected healthy seed will offer a means of getting a sound seed supply.

"16. Sick fields should not be planted in potatoes again for at least five or six years, and even longer time may be required to work the parasitic fungus from the soil. Grass and grain crops will undoubtedly eliminate the fungus from 


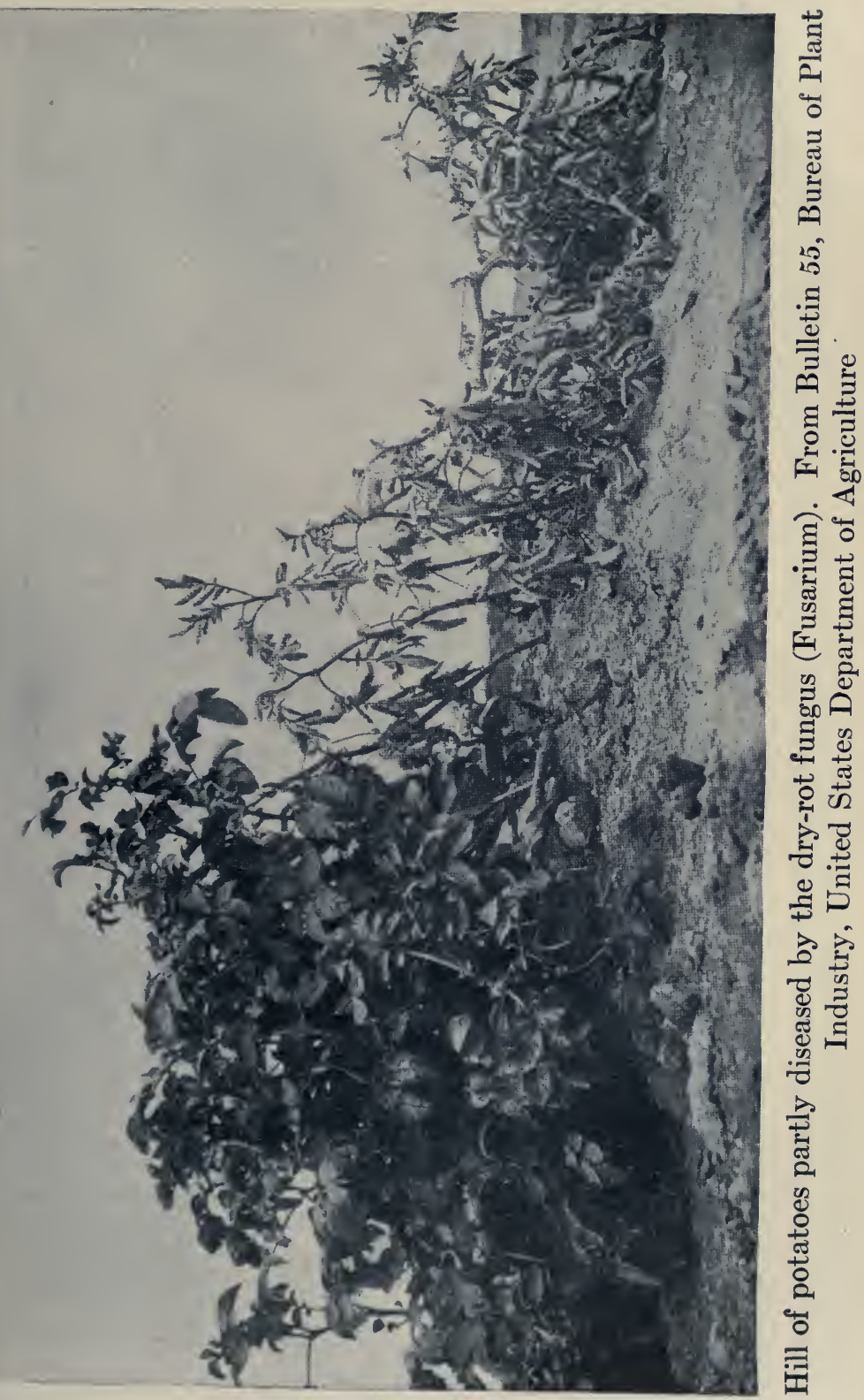



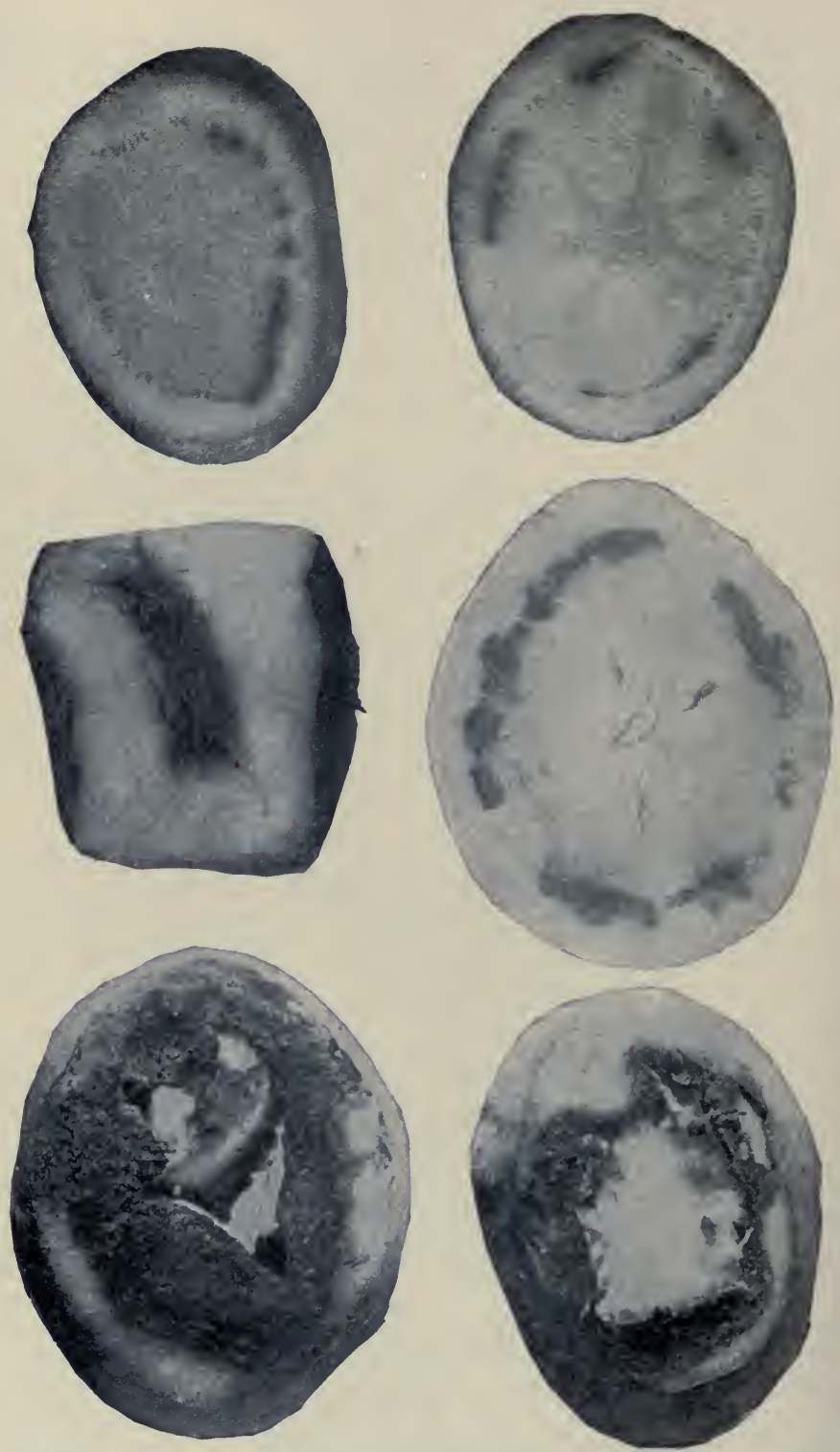

Various stages in destruction of potato tubers by Fusarium. From Bulletin 55, Bureau of Plant Industry, United States Department of Agriculture 
the soil quicker than will manuring and cultivated crops.

"17. Longer than a three-year potato rotation should be practised.

"18. Storage litter and sick seed should not be allowed to reach the manure pile, as this will be a sure method of distributing the disease and infecting the fields.

"19. The disease demands further study. The Department of Botany invites coöperation with potato growers. Examination of seed potatoes and plants will be made and the results reported.

"This Department, in coöperation with the Bureau of Plant Industry of the U. S. Department of Agriculture, has the franking privilege on diseased plant material; the franks will be sent to those having diseased material to be forwarded."

Prof. B. O. Longyear of the Department of Botany and Forestry of the Colorado Agricultural College says:

"One of the most widespread and common diseases of the potato caused by fungi is that commonly known as the Fusarium disease, or Fusarium blight. This trouble first manifests itself in the field by the wilting and yellowing of the lower leaves of plants that have reached the height of ten to twelve inches. In bad cases the entire foliage appears to suffer as though the plant were not getting sufficient moisture. Later on, the tips of the leaves turn brown and dry up, leading to the trouble commonly known as tip burn. The edges of the leaves commonly roll inward during the heat of the day, although they may partially revive during the night. 
"Badly affected plants will be found to have the root hairs and rootlets rotted away and often the larger roots appear sickly. Cross sections of the main root often appear brownish in the region of the vascular bundles or woody part. Under the microscope thin sections of such roots and of the lower part of the stem will show the delicate filaments of the fungus which pass upward through the water-conducting tubes of the plant and eventually clog them to such an extent that the flow of sap is greatly obstructed. This is what causes the wilting and eventual drying of the foliage of the plant.

"The fungus also passes into the tuber-bearing stems under ground and frequently enters the stem end of the tuber for some distance. In bad cases the stem end of the tuber may be rotted away and the presence of the fungus deeper in is indicated by the browning of the vascular ring shown in a cross section of the tuber. The fungus may also enter the tuber from the soil through any bruise, crack, or other break in the skin. Attacks of insect larvæ upon the tubers are often followed by this disease through the wounds which the 'worms' produce.

"Under conditions of plenty of moisture and high temperature, this disease makes its most rapid progress and may reach its culmination at about the time when the tubers are ordinarily half to two thirds grown. When a plant once shows the infection to any marked degree, all further growth ceases. The plants seem to stand still and eventually wilt down entirely or else struggle along in a dwarfed and sickly condition for some time.

"A common source of infection in newly planted fields is through the use of tubers for seed that already contain the fungus. Another common 
source of the trouble is from planting the potato in fields that have previously shown the disease within two or three years. Such soils are said to be 'sick.'

"A second period of destruction due to this disease comes during storage. Tubers infected in the field when stored under conditions of moderate temperature are apt to show a high percentage of dry rot. In such cases the fungus causes a blackening of the tuber, with a final outbreak of a whitish mold, and may serve to infect the wounds in other tubers.

"In the control of this widespread and destructive disease much emphasis should be placed upon the use of tubers free from the disease. ('Bulletin 229,' Ohio Agricultural Experiment Station.) Experiments have been tried with diseased tubers which indicate that if the diseased portion is largely cut away and the tubers treated with formaldehyde solution in water such seed will give nearly as good results as tubers from healthy plants. Potatoes should not be grown on the same soil immediately following a crop of the same kind which showed the disease. Experiments along this line indicate that even a three-year rotation is too short to make it safe.

"Storage of the tubers is also an important matter. It has been found that storing in outdoor pits is preferable to cellar storage, as a rule, and the lower temperature at which the tubers are kept under this method usually prevents, to some extent, the spread of the dry rot. Being a soil fungus and capable of living for several seasons in the soil of an infested field, no spray which can be applied to the part of the plants above ground is effective in controlling the disease." 


\section{RHIZOCTONIA}

This disease of the potato is sometimes known to growers as "Little Potatoes," "Stem Rot," and "Rosette."

Considerable research work in regard to rhizoctonia was done by Prof. F. M. Rolfs when he was at the Colorado Agricultural College. Prof. A. Nelson also presents some interesting facts in "Bulletin 71" of the Wyoming Experiment Station. In the information which follows these two sources have been consulted freely.

This rhizoctonia fungus attacks the underground portions of the plant. It is a true parasite, living either in the internal tissues or upon the external parts. It attacks the stem at or just below the surface of the ground, destroying the bark in whole or in part. If the attack be a severe one it may result in the death of the plant, but if less severe it may induce a wet rot and thus result in the death of the plant, but if still less severe it may simply girdle the stem, the plant continuing to live and often producing as a result of the girdling an enlarged and apparently vigorous top. Owing to the fact that the girdling will prevent the return of the elaborated sap on the underground portions, there can be no tubers formed, or if formed they will be few and small. In many instances when the plant is thus prevented from forming the underground tubers it will throw out from the stem at points above the injury many short tuber-forming stems. These tubers are small and green, and of no value.

The tubers are also attacked by the fungus, and on the surface of these small, hard knots of mycelium, known as sclerotia, are produced. These 


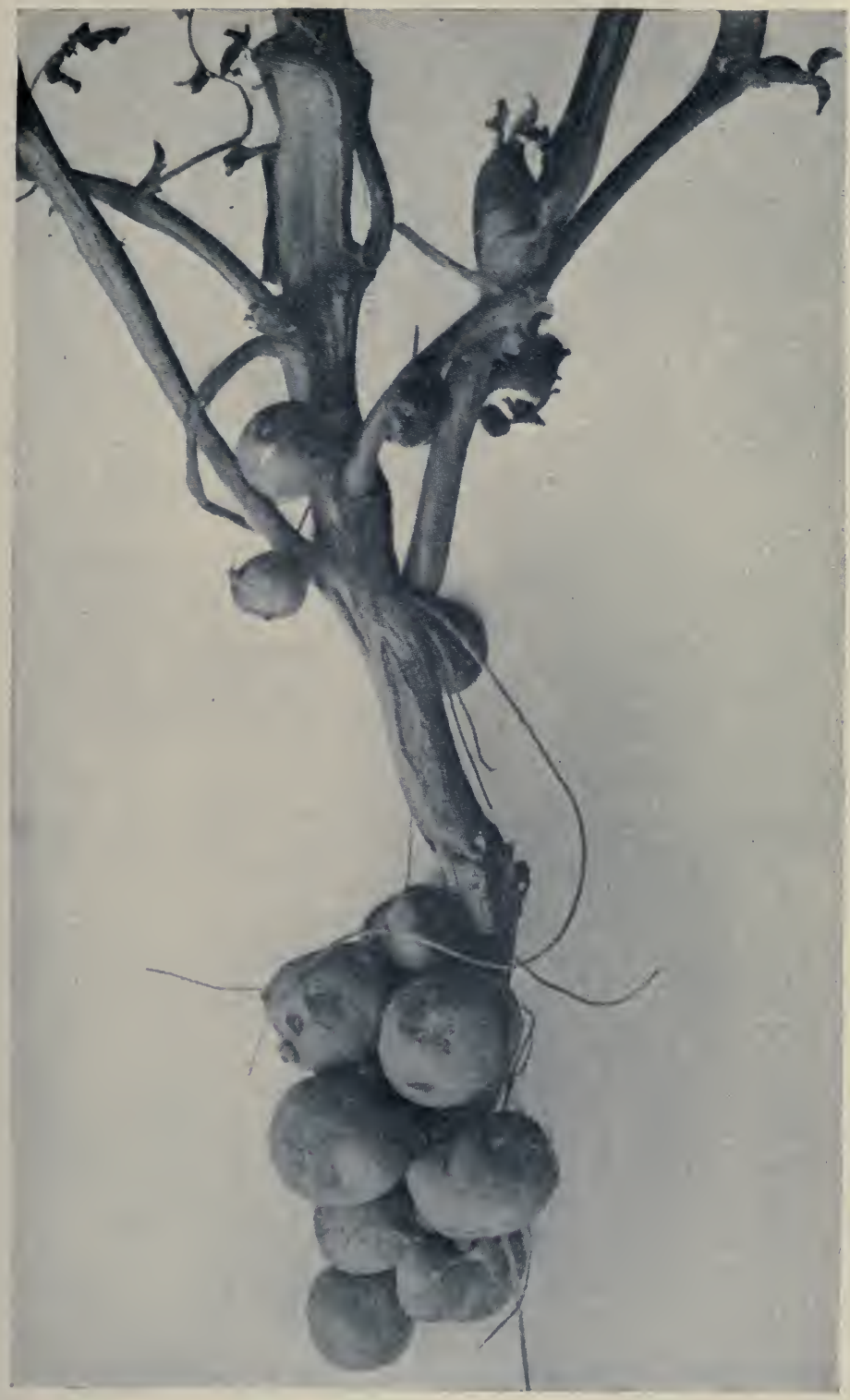

Rhizoctonia. Showing development of "little potatoes" on the branch because of the effort of the plant to form tubers above the point of injury. - From Bulletin 70, Colorado Experiment Station 


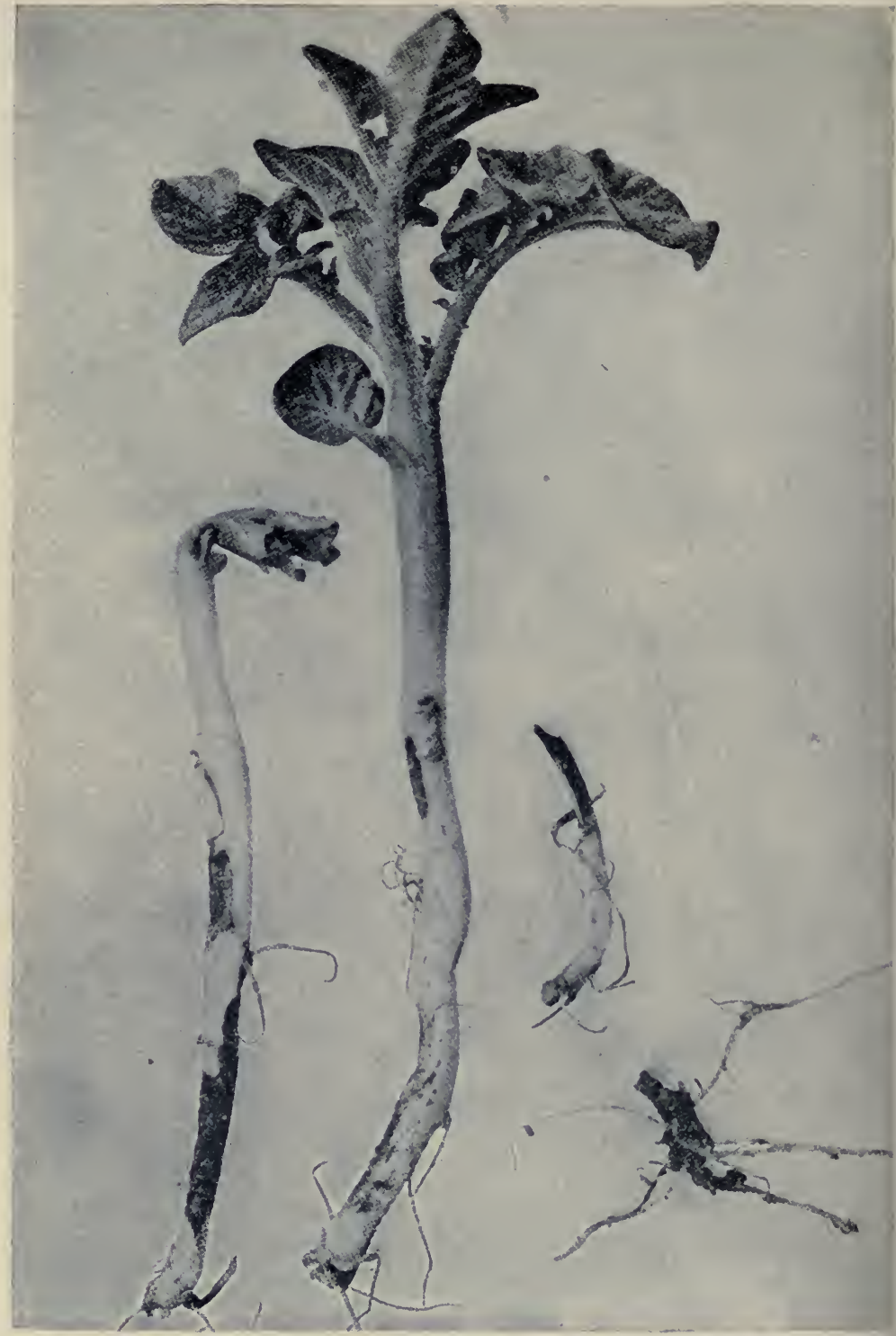

Rhizoctonia. The illustration, from Bulletin 70 of the Colorado Agricultural Experiment Station, shows stems of a young potato plant that has been affected from the seed. 
appear as dark brown bodies, irregular in outline and varying from a mere speck to the size of a grain of wheat. These spots resemble dirt, but do not wash off readily.

Prof. F. M. Rolfs found three distinct stages in the development of the disease in Colorado, as follows:

1. Rhizoctonia stage - the first or growing (vegetative) stage. Two kinds of hyphæ occur the light colored ones in the inner tissue of the host, which, if abundant, produce wet rot; dark colored ones in the outer tissues forming a close web of felted covering, which constitutes merely a girdle or band. If the last only is present, the plant is not killed, but may seem unusually healthy.

2. The Corticium stage. It had been supposed that the fungus produced no spores, but was perpetuated solely by the sclerotia, which are the closely compacted masses of the mycelium forming the dark scale-like or grain-like bodies on the tubers and stems of the host plants. At one stage in its development, however, spores are formed on short lateral branches arising from the hyphæ of the rhizoctonia stage. These are so readily dislodged that their presence is easily overlooked when a microscopic examination is made. It is probable that the spores serve merely for the rapid dissemination of the disease during its vegetative period.

3. The Sclerotium stage. This is the period when provision is made for the perpetuation of the fungus. The sclerotia on the tubers of an infected crop, on the stems of the potato and weeds, carry the disease over from year to year.

To stamp out the disease the sclerotia must be killed, and this is done by the use of clean seed, 
rotation of crops, and treatment of infected seed the same as for scab.

Following is a description of some of the insect enemies:

\section{THE COLORADO POTATO BEETLE}

The following is by S. Arthur Johnson, in "Bulletin 175" of the Colorado Agricultural Experiment Station:

"This insect (Leptinotarsa decemlineata) is a native of a strip of country which lies just east of the Rocky Mountain range and includes eastern Colorado. In its native state the beetle lives upon the wild weeds of the potato family. The chief of these is the buffalo bur, but the beetle is quite a general feeder on plants of this group, including not only potatoes, but tomatoes, eggplant, tobacco, and pepper.

"The adult beetle is oval in shape, about three eighths of an inch in length and a trifle narrower than long. The ground color is yellow and the wings are marked by ten black lines running lengthwise. There are also black markings on the thorax. The eggs are bright yellow when fresh and are generally laid on the under surface of the leaves in patches containing from ten to fifty each. The young are dark red or brown grubs with black heads. The color becomes lighter as the grubs mature.

"The adult beetles live over winter usually in the ground at a depth of from four to six inches. Where the ground is loose they frequently go much deeper. When the ground becomes warmed by the spring sun the beetles emerge and seek food plants 
on which they may feed and lay eggs. They are more or less abundant every year and do considerable damage to early potatoes. The late crops in Colorado generally escape because most of the adult beetles die off before the potatoes appear above ground.

"The eggs hatch in from four to eight days, depending on the temperature. The larvæ feed at first on the surface of the leaf where they hatch, but soon migrate to the top of the plant and eat the tender young leaves which are just unfolding. The young reach full growth about three weeks later. Soon eggs are laid again and the second generation hatches. Ordinarily, two broods are all that we may expect.

"The best and most practical remedy is spraying with some arsenical poison. In commercial fields the best machine is a power sprayer drawn by horses. In garden patches a hand sprayer does very good work. Arsenate of lead, altogether the best poison, is a white paste which must be carefully mixed in a little water before it is poured into the spray machine. It should be strained through a fine screen in order to remove all lumps which might clog the nozzles. Apply the poison at the rate of six or eight pounds to a hundred gallons of water. The proper time to spray is when the grubs begin to appear at the tops of the stems. Arsenate of lead does not kill as quickly as Paris green, but it sticks to the leaves much longer and the benefits can be seen for weeks, even after rains. Paris green is the old standby, is cheaper for a single application, and is still the most used. This poison is mixed with water at the rate of a pound to seventy-five or one hundred gallons. There is danger that this substance will burn the foliage 
of the potato, and to avoid this it is well to add the milk from two pounds of slaked lime to each hundred gallons of water used. While spraying either of these poisons the contents of the spraying machine should be kept well agitated. Sometimes the pest is confined to small areas. In such cases the insects are often controlled by the use of dust sprayers, which either blow the Paris green out in fine clouds, or dust out the same poison when it has been mixed with flour or carefully screened airslaked lime."

THE POTATO FLEA BEETLE

The facts about this insect (Epitrix cucumeris) which follow were written by S. Arthur Johnson for Colorado Agricultural Experiment Station, "Bulletin No. 175":

"When tomatoes are first set out or potatoes first come up there may often be found on them tiny black beetles which jump when alarmed. They are called the flea beetles because of this habit, though they are not closely related to the flea.

"The adult insects live over winter and appear during the latter part of May and first of June. They get their living by eating tiny holes in the surface of the leaves of plants of the potato family, and often attack cucumbers and beans. The insects often congregate in such numbers that the leaves of the plants appear almost black with them. Newly set tomato plants and young potatoes frequently have their leaves so badly eaten that they shrivel and the tomatoes may die. Ordinarily, the stand of the potato crop is not seriously injured in 


\section{THE POTATO}

this way. Their greatest damage to potatoes in Colorado is done by the larvæ, which live under ground. These larvæ are tiny white grubs which attain a length of about a quarter of an inch. The first brood is to be found during June or early July. They frequently cut into and destroy the young tuber stems of the potatoes, thus preventing a regular setting of the crop. The second brood of larvæ appear during August and September. This brood bores into the flesh and under the skin of the potatoes, causing a pimply or scabby development, which may cause great waste in preparing the tubers for the table and seriously depreciate their market value.

"No satisfactory remedy for this pest is known. The leaf injuries to young potatoes and tomatoes may be largely avoided by spraying the leaves thoroughly with Bordeaux mixture to which Paris green is often added. The insects appear to avoid the parts of the plant covered with these disagreeable substances and to seek fresh tissues upon which to feed. It is not certain where the insects hibernate, but they are found often in the fall in large numbers feeding on stray potato plants or pieces of tubers which have been left in the fields. It is well to clear up the fields immediately after the crop is gathered. These insects are seldom, if ever, found on new ground, and are much worse where potatoes are planted in succession."

\section{GRASSHOPPERS}

Grasshoppers are not often counted as an insect enemy of the potato, but their ravages in eastern Colorado have been such that growers have lost heavily. S. Arthur Johnson in "Bulletin 175" of 
the Colorado Agricultural Experiment Station describes the insect as follows:

"There are many kinds of grasshoppers, but the species that become injurious have life histories which are very much alike. The eggs are laid in the fall in packets in the ground, containing from thirty to a hundred eggs. Their position is about an inch below the surface of the soil. The insects appear to select places which are comparatively dry in which to deposit the eggs, and we have found most of them this year in patches of weeds and grass under fences, and along ditch banks and roadsides. The young hatch rather late in the spring and do not become full-grown until midsummer or later.

"Grasshoppers frequently injure potato fields by invading them from the borders, but this is not one of their favorite food plants. The most serious relation of grasshoppers to the potatoes is indirect rather than immediate. Potato growers depend on alfalfa to renew and enrich the soil. The presence of grasshoppers in the fields newly sown to alfalfa is disastrous, for they quickly destroy the little plants and it is impossible to obtain a stand. This prevents a proper rotation of crops.

"The best remedy to employ during fall and spring is the destruction of the eggs. The first step in this work is to locate the eggs. Inspection should be made everywhere in the surface of the soil for the pods of eggs. When the infested areas have been located they should be plowed deeply to bury the eggs, or disked or harrowed very thoroughly to break up the pods so that they will be exposed to the ravages of birds and animals or dried out before they have time to develop. 
The earlier in the fall that this remedy can be applied the more satisfactory will be the results. It is better not to trust to one treatment, but to work over these places several times at short intervals. When young, or even when full-grown, grasshoppers may be caught successfully in a hopper pan. If this is set on wheels a few inches above the surface of the ground and driven over the alfalfa when that is a few inches high, great numbers may be caught. The best time to do this is in the early morning when the hoppers are on the tops of the stems and somewhat numbed with the cold. A third remedy is arsenic-bran mash. This substance is made by mixing white arsenic with bran at the rate of one pound of arsenic to twenty of bran. After the substances are thoroughly mixed add sufficient water to make a sticky but not too sloppy material. Some add a little anise or syrup. The mixture should be scattered late in the afternoon or early in the morning so that the hoppers will get it before the hot sun has dried it up.

"In the Greeley experiments of 1910 the potatoes were sprayed with Bordeaux mixture to test the value of this substance as a repellent to grasshoppers. The results appeared to be favorable as to keeping off grasshoppers, but indecisive as to the prevention of flea beetle injuries to potato tubers."

\section{THE POTATO EELWORM}

The Potato Eelworm (a thread worm, Heterodera Radicola) is about one twenty-fifth of an inch long, and works in the mature tuber. It has been found in Nevada potatoes shipped to California. The following is from Nevada Experiment Station "Bulletin 76". 
"The accompanying photograph shows the external appearance of badly diseased potatoes. The surface of the potato is more or less wrinkled, and dotted with circular or oval pimples somewhat smaller than a pinhead, or with more irregular and larger nodules. The nodules are of grayish or brownish color, more or less depressed in the centre and sometimes surrounded by a slight furrow. In early stages the potato may be full and firm and the pimples so inconspicuous that they may easily be overlooked. When the disease is more advanced the nodules are more prominent, the specimen more or less shriveled and of softer consistency than normal. The easiest way to determine whether a suspected tuber is diseased or not is to cut off slices. If diseased, the cut surface will show several dry, brownish spots somewhat smaller than the head of a pin and extending from a sixteenth to a quarter of an inch into the flesh. They are usually circular or oblong in shape and consist of a brownish ring enclosing a central, whitish, pulpy core. Beneath the pimples there is a similar brown dry rot-like area which may or may not connect with the interior spots or worm burrows. Sometimes the burrows are so numerous and close together as to form an irregular continuous mass like a number of small shot close pressed together. More rarely the burrows may extend deeper into the flesh.

"Badly diseased potatoes may shrivel up to one half the natural size, are softer and less nutritious than normal and of course are not desirable for human food. The burrows afford entrance for the bacteria of decay, so that infested potatoes will not keep as well as healthy ones.

"If a portion of the pulpy centre of one of the 

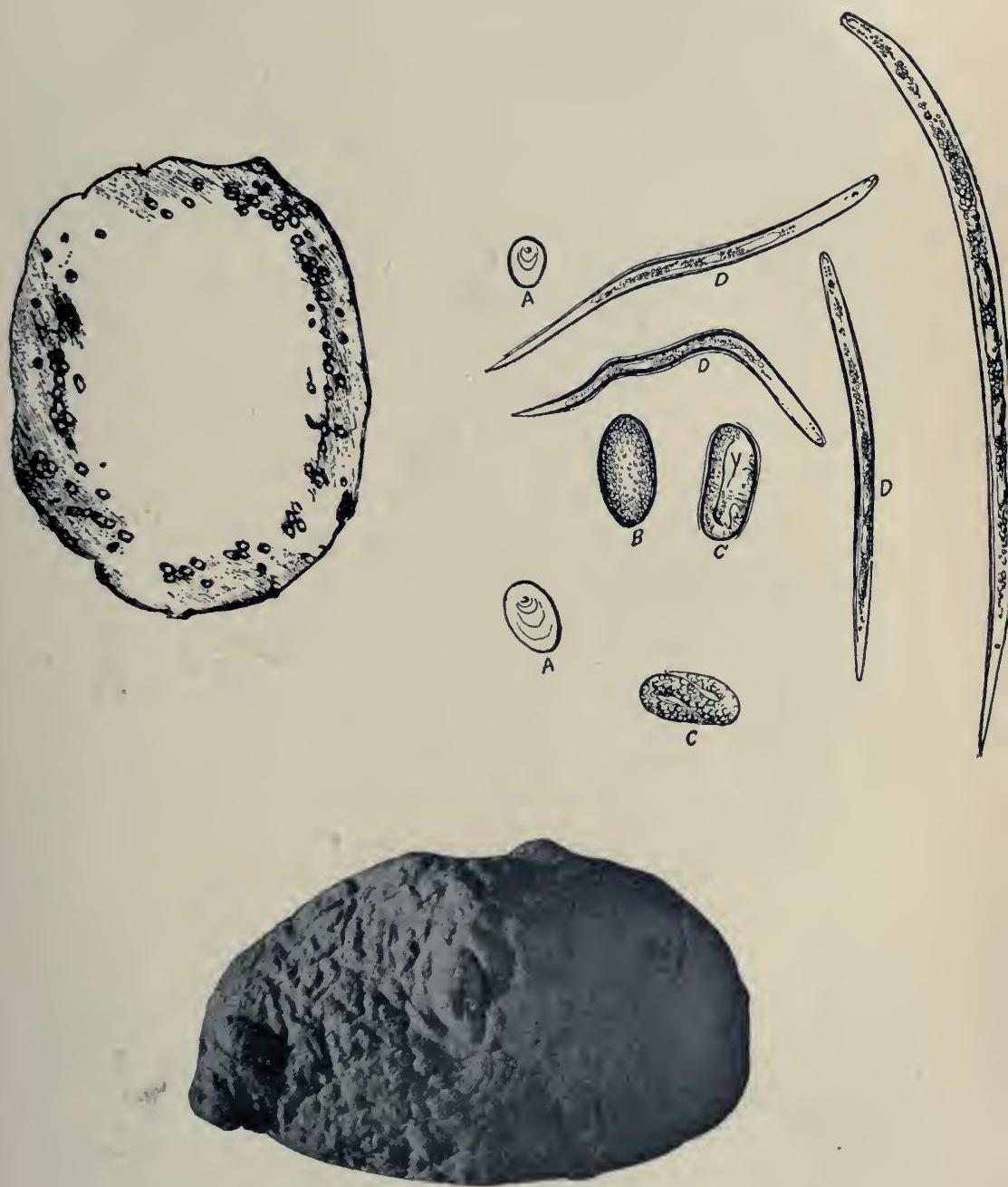

The Potato Eelworm, showing eggs, worms, and infected potato. - From Bulletin 76 of the Agricultural Experiment Station of the University of Nevada 


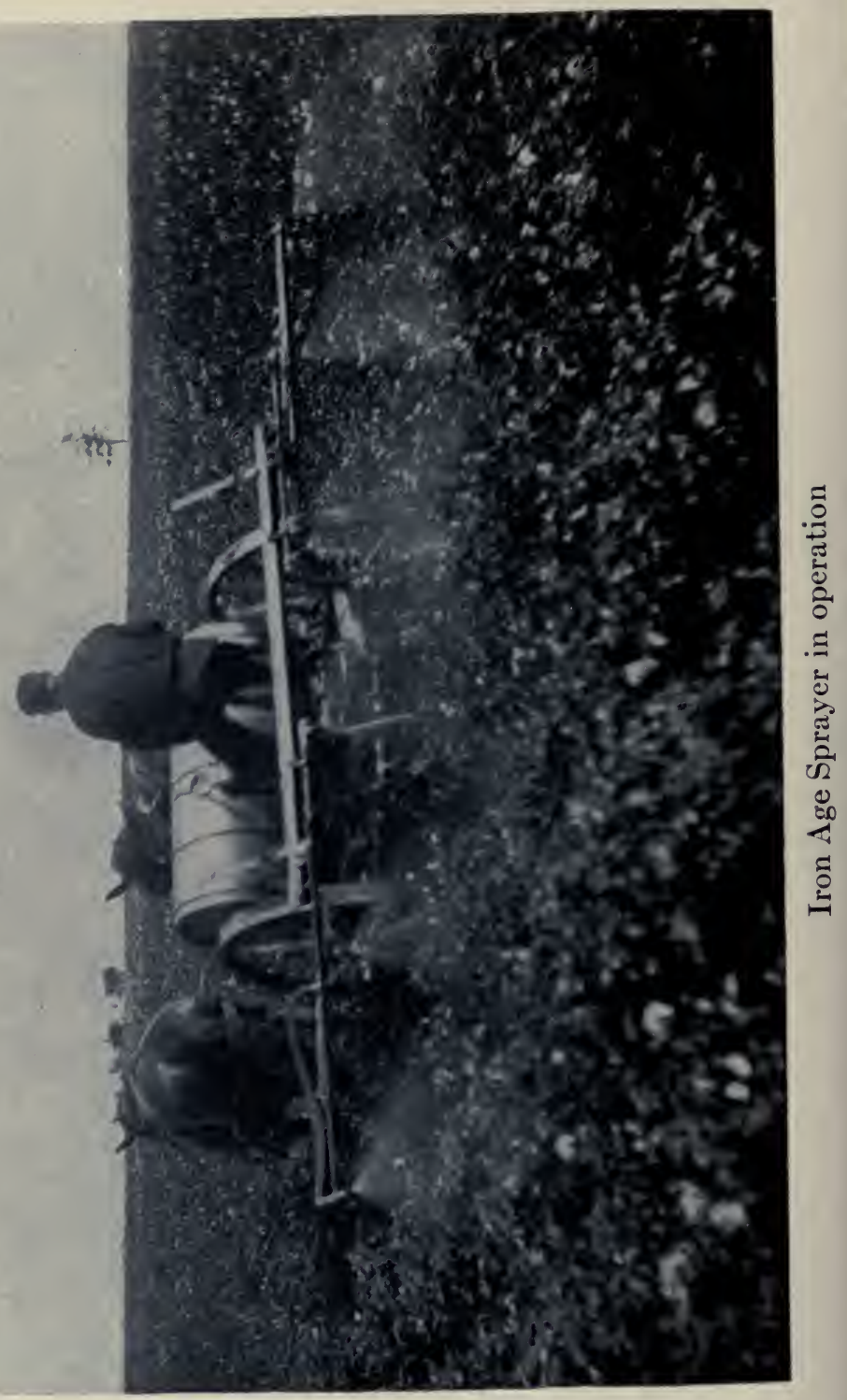




\section{THE POTATO}

burrows is scraped out and examined with the microscope, it will be found to contain numerous eggs, larvæ, young and adult worms like those figured in the illustration. The potato cells have broken walls and the starch grains are fewer in number than in healthy tissue and those present are of smaller size.

"The disease is spread by planting infested seed potatoes. We do not know to what extent the worms may live and multiply in the soil itself or how long a soil may remain infected. This important point can be settled only by careful observation and experiment.

"How to free infected soil from the parasite is a question which the knowledge at present at our command will not permit us to answer satisfactorily. Sterilization or disinfection on so large a scale is not practicable. Possibly deep plowing, letting the ground lie fallow for a year, or, where feasible, covering the fields with water during the winter months, may prove to be effective. The best advice for the present, it seems to us, is to plant infected fields with some other kind of crop, preferably grain or alfalfa rather than a root crop, such as sugar-beets, which might be attacked by the same pest." 


\section{CHAPTER XVI}

DINING CARS, HOTELS, AND RESTAURANTS

7 THERE are no keener students of the food problem than the best hotel, restaurant, 1 and dining-car men.

Two vitally essential things appeal to them quality and economy.

Such men as J. F. Smart of the dining-car service on the New York Central Lines; Sam Dutton of the Albany Hotel, and Col. Morse of the Brown Palace. Hotel, Denver; Ford Harvey and A. T. Hilliard of the Fred Harvey Eating Houses and dining cars on the Santa Fé, and K. L. Eagan, formerly of the North Side Inn, Jerome, Idaho, know more about potatoes than 95 per cent. of the growers.

It would be a splendid thing if growers could meet occasionally with these large critical buyers and users. The caterer to great numbers of critical people is willing and anxious to pay for superior quality in a product, for in the case of potatoes the best and highest priced will often be the cheapest. He would tell the grower that the smooth, even, medium-sized potato, could he get quantities of them for the entire annual supply and be sure that entire sacks and shipments would be all alike, would be worth 25 to 50 per cent. more than the product now purchased.

The hotel man wants a potato of good quality a tuber that has been evenly and uniformly grown to maturity with no check at any time, then well 


\section{THE POTATO}

ripened and stored. When the potato plant experiences drought, the development of the tuber is stopped. Moisture following this starts a second growth, generally watery and waxy - and to the detriment of the part developed before the dry time. A good potato is firm and crisp, with tissues sound and plump and cells well filled with starch. This cooks evenly and is both nutritious and delicious.

Flavor in potatoes is receiving more attention than ever before. The flavor of the tuber is supposed to depend on the mineral matter, citric acid and other substances dissolved in the juice. Flavor is influenced both by variety and the conditions under which the plant is grown.

There is as much difference in the flat and tasteless or bitter and biting flavor of the potato of low quality and the rich, nutty flavor of the better sorts as there is between rancid and good butter.

Potatoes sell in hotels and dining cars at from 5 to 75 cents an order, and a tuber of one pound weight or a little less is an ideal order. There should never be any trouble in selling potatoes at approximately this size for one cent each. This would be 60 cents a bushel, or $\$ 1$ a hundred, a good price if it could be assured.

In every local territory some grower or set of growers should be able to work up a good trade with hotels and restaurants. If a superior product can be furnished regularly, the caterer will be glad to give prominence to the name of the farm on which the potato is produced, or to the variety and locality, thereby helping the individual grower and locality and the whole industry.

Buyers for dining-car service on American railroads were among the first to make cooking tests of the crop before purchasing. 


\section{CHAPTER XVII}

\section{FERTILIZERS}

7 HE object of fertilizing is to have available in the soil a sufficient quantity of all the

1 elements the plant needs for making a maximum crop.

It is also necessary that the soil be in such perfect mechanical condition that plant food may be made available, and that the roots and rootlets of the plant may be able to easily and readily take up this available plant food.

Theoretically, in order to determine the amount of fertilizer a crop should require, it would only be necessary to have a chemical analysis and know the tonnage of the crop, and have an analysis to show the amount of fertility in the soil. Practically, these analyses constitute only one of a combination of factors that should be used in estimating what fertilization is necessary.

The crop indicates whether or not the fertilization is right for immediate returns, but the analyses should be a guide to the grower in estimating what should be done to maintain large crops continuously.

A great many formulas for fertilizing have been worked out by growers and experiment stations both in America and Europe. A number of these will be given - not that they should be used simply because they have been successful under 
other conditions, but that they may be used as a guide for experimenting.

There is removed in a 600-bushel crop of potatoes approximately:

$$
\begin{aligned}
& 160 \text { pounds of nitrogen } \\
& 60 \text { “ “ } \\
& 160 \text { “ " phosphoric acid }
\end{aligned}
$$

An acre of soil eight inches deep weighs about $2,375,000$ pounds. (This varies somewhat and this estimate is for soil on the Twin Falls North Side Irrigation Project, Jerome, Idaho.) The elements of fertility vary, but, as an example, the soil at Jerome, Idaho, contains:

$$
\begin{aligned}
& .47 \text { per cent. of potash } \\
& .11 \text { per cent. of phosphoric acid } \\
& .06 \text { per cent. of nitrogen }
\end{aligned}
$$

This would be a total of

$$
\begin{aligned}
& \text { Nitrogen .........1,425 pounds } \\
& \text { Phosphoric acid.. 2,612.5 pounds } \\
& \text { Potash.........17,692.5 pounds }
\end{aligned}
$$

Even though it is not possible for plants to use all of this, if proper cultivation methods are used there is food enough to last for a great many years.

The three elements of fertility that are called the "essential elements" are nitrogen, phosphoric acid and potash. At least ten other elements enter into the plant and are important and necessary for the production of plants. All but these three are used in small quantities and it is generally considered by students of the soil that the seven magnesium, sodium, chlorin, sulphur, iron, silicon and calcium - are present in most soils in sufficient quantities to supply the needs of crops 
almost indefinitely. The one exception to this is lime, and its use is generally considered to be more to make conditions right for the making available of other elements than as an element of plant food itself.

The potato plant-leaf, vine, stem, root, and tuber - is composed of elements taken from the soil and air. The plant is started from stored-up nutriment in the tuber or part thereof that is planted. After the start, the rootlets take water (hydrogen and oxygen), nitrogen, the phosphates, potash and the other mineral elements from the soil. These are taken up by the movement of sap to the leaves. The leaves take carbon and oxygen from the air through the stomata or breathing pores on their under surface; the various elements are transformed by the sunshine, heat, protoplasm and chlorophyl, and water (hydrogen and oxygen) and carbonic acid gas are given off by the leaves. The food which is manufactured or transformed is deposited throughout the plant. A large part of it goes to the storehouse of the enlarged underground stem or tuber.

An average plant is made up somewhat as follows:

Phosphate, potash and other minerals (from

the soil)
Nitrogen (from the soil and air) Hydrogen (from water) . $^{\circ} \quad$. $\quad 6.5$ per cent. Oxygen (from water and air) . . . 42.0 per cent. Carbon (from air) . . . . . 45.0 per cent.

From this it appears that Nature is lavish in its supplies, and that the soil, the condition of which is more or less under the control of man, contributes a comparatively small share in the plant's economy. 
This part is very important, however, so much so that in many instances success or failure depends on how it is looked after.

In stating the part the elements have in the growth of the plant it must be considered that the statements are relative and not absolute.

Nitrogen is largely instrumental in providing growth in plants, heavy, luxuriant stems and leaves being credited to a liberal supply of this element in available form. A deficiency is shown by weak, yellow growth. The elements of plant food in the soil are transformed or manufactured in the leaves in combination with sunlight and the gases of the air into the substances that form the edible tubers. In order that these processes be carried on with the best results there must be a strong, healthy manufacturing establishment - the plant.

Phosphoric acid hastens the maturity of crops and influences the production of seeds in fruits. In the potato it is supposed to influence the production of starch.

Potash is supposed to influence yield, and be a factor in the formation of starch.

Like many other things concerned with the production of crops and the working of the various elements in nature's laboratory, the exact offices of potash and phosphoric acid are not known, but can only be judged and estimated by experiments and results. In general, it is known that nitrogen is mostly concerned with growth of plants, and phosphoric acid and potash with the fruit or crop.

Nitrogen is obtained from the following sources:

(1) Organic - Natural products in which nitrogen is combined with other elements such as 
carbon hydrogen and oxygen, decaying or decayed vegetable matter, dried blood, dried meat, tankage, fish, garbage, tannery waste, cottonseed and linseed meal, guano, animal manures.

(2) Inorganic (chemical forms)-Ammonia in combination with other elements, nitrate of soda, and nitrate of lime or nitrolin (a new Swedish product).

Phosphoric acid is supplied in the form of phosphates of lime, iron, and alumina. Some of the materials used are bone phosphate (phosphate of lime), raw bone, bone meal, steamed bone, bone black or animal charcoal, bone ash, South Carolina, Florida, Canada and Tennessee rock phosphates, iron phosphate, a by-product of the manufacture of iron phosphatic iron ores, and superphosphates (a product made by treating some of the foregoing elements with acid to make readily available or soluble phosphoric acid).

Fertilizers should be purchased on a per pound basis for the amounts of the elements actually contained. The fertilizer that costs the most per ton may be the cheapest. The following table shows the relative amounts of the elements in various combinations and is used in checking up guarantees:

To convert the guarantee of

Multiply by

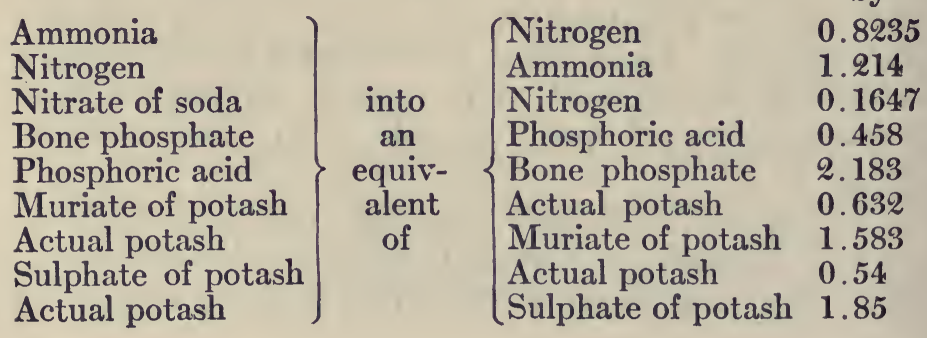


It is often best to buy the elements singly, and with a guarantee as to the contents of available plant food. There are ways of manipulating mixtures so as to puzzle the buyer, and at the same time permit the seller to keep within the law. In buying combined fertilizers the cost of mixing, handling, and advertising must always be added and paid for by the buyer.

In order to maintain and build up virgin fertility and soil condition a grower should be continually adding stores of vegetable matter and such mineral or organic elements as will probably be depleted first. The latter can be applied in forms that are available at once or in less soluble forms where the usable fertility becomes available gradually.

In the countries of Europe where the best results are obtained, and in this country where growers have given the most careful attention to the business, the highest importance is placed on the use of the decaying root systems of strong growing plants for fertilizing material and for keeping the soil in good condition. Sir John Lawes, the eminent British farmer and experimenter, said: "It is the physical condition of the soil, its permeability to roots, its power of absorbing and radiating heat that is of more importance than its, strictly speaking, chemical composition."

An interesting article on the value of green manures is given by $R$. W. Thatcher in "Bulletin 32" of the Washington Agricultural Experiment Station. It follows:

"Soil is a mixture of inorganic material-i. e., rocks or mineral substance broken down into more or less fine particles-with organic matter -i. e., decayed or decaying material which has once been 
living vegetable or animal tissue. The inorganic particles usually compose the greater portion of the soil (95 per cent. to 98 per cent. of sandy or gravelly soils, 80 to 95 per cent. of loams and clayey soils, less than 80 per cent. of muck or peaty soils) and supply the necessary mineral elements of plant food. The organic portion of the soil furnishes the supply of nitrogen, a very necessary element of plant food, without which no crop can make any growth; supplies also the other elements which were taken up in the growth of the plant or animal and which by their decay are returned to the soil in a form readily available for plants; helps to render the mineral elements of the soil available by the action upon the inorganic matter of the acids produced in the decay of organic matter; affects very beneficially the physical properties of the soil, increasing its ease of tilth, moisture holding capacity, capacity to absorb heat, and decreasing the tendency to 'puddle' when wet or 'bake' when dry. Too much organic matter usually results in a soil which dries out very rapidly and which is likely to be 'sour' from the excess of organic acids which it contains. Very few, if any, well-drained lands contain an excess of organic matter, however.

"It is apparent, therefore, that the maintenance of a proper balance between the organic and the inorganic or mineral portions of the soil is one of the first essentials to fertility and to proper physical condition of the soil. Many of the so-called 'wornout' soils have only had their store of organic matter depleted by improper methods of cropping and can be restored to fertile condition by the plowing under of some additional supply of vegetation to decay. 
"Any farm crop which is grown for the sole purpose of plowing it under to increase the supply of organic matter in the soil is known as a "green manure.' Green manures affect the soil beneficially in many ways. Some of the possible benefits are: (1) The addition of vegetable matter or 'humus,' with its attendant beneficial effect upon the physical and chemical properties of the soil. (2) Increasing the nitrogen content of the soil by fixation of nitrogen of the air, when leguminous crops are used as the green manure. (3) Using surplus available plant food which might otherwise be lost. (4) Plant food from lower depths may be brought nearer to the surface and made available for subsequent crops.

"The kind of crop which may best be used as a green manure depends upon which one or more of these beneficial effects is most desired. If the addition of humus, or an increased supply of decaying vegetation, is the only necessity, then any rankgrowing farm crop may be used. The more succulent or juicy plants are best, as they decay much more quickly and are more easily incorporated in the soil. If, however, the supply of nitrogen in the soil is small and its increase is either the chief necessity or a desirable addition to the increased humus content, then some leguminous crop must be used, as no other farm crop has the power of utilizing atmospheric nitrogen or of returning to the soil any essential element of fertility which it did not draw from it. If it is desired to bring up from below some of the mineral plant food which is present in deeper layers of soil, then a deeprooting crop should be used.

"The legumes, or leguminous crops, are a group of plants which are characterized by growing their 
seed in pods and by having peculiar knots or nodules on their roots. These nodules are formed by the action of a certain group of bacteria, immense numbers of which are found in each nodule, which have the peculiar property of being able to use the gaseous nitrogen of the air for their own growth, and supplying this element as they die and decay to the host plant on whose roots they are located. Included in this group are alfalfa, all the clovers, vetches, peas, beans, etc. No other group of plants or animals, so far as is now known, is thus able to make use of atmospheric nitrogen. Legumes may grow in soils which are rich in available nitrogen without the presence of the nodule-producing bacteria, deriving their nitrogen supply directly from the soil as do other crops, but have the distinctive power of being able to flourish in soils poor in nitrogen if the proper bacteria are present to grow upon their roots and supply them with nitrogen from the air, and when so grown to increase the supply of soil nitrogen when plowed under as green manures."

The potato growers of the Jersey Islands use the following mixture at the rate of one ton per acre in addition to animal manures, etc.:

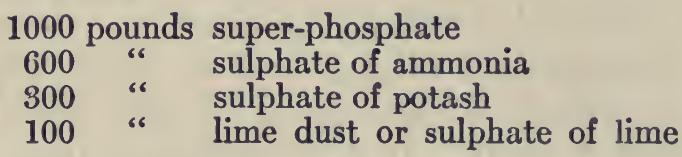

2000 pounds

William D. Hurd states that in Maine "the most common and popular commercial fertilizer used for potatoes has been the one analyzing 4 
per cent. ammonia, 6 per cent. available phosphoric acid, 10 per cent. potash, and costing $\$ 37$ to $\$ 39$ a ton. The following materials for a home mixture would duplicate the above formula:

150 pounds nitrate soda (15 per cent. nitrogen).

800 " tankage (7 per cent. ammonia, 15 per cent. total, 10 per cent. available phosphoric acid). 300 acid phosphate (15 per cent. phosphoric acid). 400 " sulphate potash.

1650 pounds (equivalent of a ton).

"The above material can be purchased f.o.b. Boston at the following prices: Nitrate of soda $\$ 50$ per ton, tankage $\$ 27$ per ton, acid phosphate $\$ 16$ per ton, sulphate potash $\$ 48$ per ton.

"The cost of this mixture would be as follows:

150 pounds nitrate soda at $\$ 50$. . . . . . $\$ 3.75$

800 " tankage at $\$ 27$. . . . . . . 10.80

300 “ acid phosphate at $\$ 16$. . . . $\quad 2.40$

400 “ sulphate potash at $\$ 48 . \quad . \quad . \quad . \quad . \quad 9.60$

Cost of material f.o.b. . . . . . . . . $\$ 26.55$

Labor of mixing, waste, sacking, etc. $\quad . \quad$. $\quad . \quad 75$

Total . . . . . . . . . . $\$ 27.50$

"To this must be added the cost of freight. At most Maine points this would not be over $\$ 2$ to \$2.50 for the above quantity. A saving then of about 25 per cent. can be made by home mixing.

"Many Aroostook County growers have abandoned the 4-6-10 fertilizer and are now using one analyzing 5 per cent. ammonia, 8 per cent. available phosphoric acid, and 7 per cent. potash.

"This sells at $\$ 41$ to $\$ 42$ a ton in Aroostook 
County. Such a mixture can be made from the following materials, using the same grade as in the 4-6-10 mixture given above:

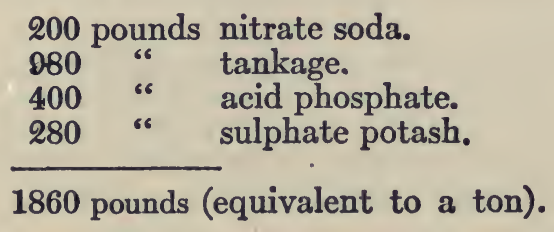

Cost f.o.b. Boston, $\$ 28.15$. Cost of mixing, same as before. Freight extra." 


\section{CHAPTER XVIII}

THE FARM ROTATION

7 HE rotation of crops is a fundamental practice in good farming operations. The 1 potato is one of the most useful crops in a cultivation required, as well as the preliminary deep plowing and the digging, puts the soil in excellent mechanical condition.

The object of rotating crops is to grow a uniform maximum product. All crops benefit by a change. The fertility requirements of no two are exactly the same. A soil is benefited both mechanically and in its store of fertility by the changing of crops. For instance, a soil may have plenty of the essential mineral elements of fertility to last for generations, but the amount of those elements available for the use of a certain plant might be exhausted by a few years'continuous cropping. Another crop would require different elements or different amounts or forms of the same elements. By the time the first crop considered would be grown again on this land, the fertility that was exhausted would either be replaced or made available by different methods and conditions. On farms where rotation is practised diseases are avoided, checked, or controlled.

The maintenance and replacing of nitrogen is one of the most important soil cultural conditions. Humus or decayed vegetable matter is a source of 
nitrogen. Alfalfa, clovers, peas, and other legumes grow so luxuriantly in many localities, and place and leave such large amounts of fertility in the soil, that the nitrogen problem consists simply of growing legumes in the rotation. The keeping of livestock and the return of manure to the land replace some of all of the elements to the soil in a good combination.

A rotation of crops, and their arrangement as far as location on the farm is concerned, is a matter that must be worked out for the requirements of the individual holding.

The farmer is a manufacturer. He directs the growing of meat and dairy products, the fruit, grain, and vegetable crops from the soil and other elements. To get all the returns from the business, he must have no waste, and the by-products must be manufactured into some marketable form. His unmarketable potatoes must be utilized for feed and his unmarketable fruits must be made into cider, vinegar, or jelly. The farmer who makes the greatest success is the one that produces a pound of beef, a pound of pork, or a pound of butter the cheapest. To do this he must know the value of the grain and the hay he uses in producing them. He must know on how much less food a year-old animal makes a pound of gain than a twoyear-old animal. He must know how much food it takes for a pound of gain for a steer and how much for a hog. He must know how to market to the best advantage the products that he raises on his farm, whether directly from the fields or as meat, dairy' products or poultry, or as draft horses, pure cattle, hogs or sheep.

There is no "best" breed of horses, no "best" breed of cattle, and likewise no "best" kind of 


\section{THE POTATO}

farming. Successes have been made in every line and successes will continue to be made in every line repeatedly. No farmer cares to pursue exactly the line followed by his neighbors nor is it necessary. Individuality is just as marked here as elsewhere. To have and to pursue one ideal is the essential thing, and to know all there is to be known about it is a large part of the equipment. Success follows knowledge and application.

The diversified farm is a farm that, having a ruling central idea, grows a rotation of crops to maintain fertility, supports enough and the proper kind of livestock to best utilize those crops, and furnishes as much as is profitable of the products necessary for maintenance of everything on that farm. Any one of the component parts that make up a diversified farm is capable of being a specialty, but the combination and the utilization of the waste ends make diversity. 


\section{CHAPTER XIX}

\section{EARLY POTATOES — SPECIALTIES}

7 HE early potato, like all other early vegetables and fruit, is an "out of season" or 1 "semi-out of season" product, and consequently brings a fancy price.

Extraordinary conditions, either natural or artificial, are required for its production.

The early potato is a specialty suited to the colder part of the season in semitropical countries, such as California, Mexico, Florida, and Texas.

With artificial conditions of sprouting and starting the crop, a large industry has been developed in Great Britain and the Channel Islands during the past ten years.

Protection from early frosts is a prime consideration in sections where the climate is other than strictly semitropical. There are great possibilities for the industry in the Sacramento Valley and other sections of California.

One great advantage of an early crop is that it is matured and harvested before the time (August and September) when the blights and other diseases may ruin the late crops.

Some work has been done by American experiment stations in investigating the business. In "Farmers' Bulletin 114" of the United States Department of Agriculture is the following: "A difference of two or three days or a week in the placing of a crop on the market often makes a dif- 
ference between profit and loss, and the prices obtained for extra-early crops have stimulated cultural experiments with every kind of fruit and vegetables. Some interesting results along this line with potatoes have recently been reported by the Kansas and Rhode Island stations.

"At the Kansas station seed tubers of four different varieties of medium-sized potatoes were placed in shallow boxes with the seed ends up in February. They, were packed in sand, leaving the upper fourth of the tubers exposed, and the boxes were placed in a room with rather subdued light, having a temperature of 50 degrees to 60 degrees F. Vigorous sprouts soon pushed from the exposed eyes. The whole potatoes were planted in furrows in March in the same position they occupied in the boxes. The same varieties of potatoes taken from a storage cellar were planted in parallel rows. The sand-sprouted potatoes took the lead from the start in vigor and strength of top and produced potatoes the first of June, a week earlier than the storage-cellar potatoes. At the final digging they showed better potatoes and gave a 10 per cent. larger total yield.

"In another experiment part of the potatoes was treated the same as in the first test, except that the sand was kept moistened and the other part was placed in open boxes and kept in a light room having a temperature of 50 degrees $\mathrm{F}$. The tubers placed in sand developed strong sprouts and nearly all rooted. When planted in the field they outstripped both the tubers sprouted in open boxes and the storage-cellar tubers in vigor of growth. The tubers started in the open boxes gave earlier yields than were obtained from the storage-cellar tubers, but not as early as the 
tubers sprouted in moist sand. The tubers sprouted in moist sand produced table potatoes from seven to ten days earlier than the storagecellar seed.

"At the Rhode Island station medium-sizec! whole potatoes sprouted on racks, in a fairly warm: and light room, gave a 27 per cent. better yield at the first digging than potatoes kept in a cold cellar until planting time, and this was increased to 40 per cent. at the final digging. The percentage of large tubers was also greater at each digging with the sprouted tubers.

"The results of these experiments are suggestive. The handling of seed potatoes in such manner as to secure strong, stocky sprouts before the tubers are planted out is shown to be an important factor in increasing both the earliness and the total yield of the crop. By planting only well-sprouted seed a full stand is assured.

"One of the objections to this method of growing potatoes is the large amount of space required for exposing the tubers to the light for sprouting. This objection has been overcome in part by the use of trays and racks. At the Rhode Island station the rack used held nine trays. Each tray was three and three fourths feet long and one and one half feet wide, and would hold about one bushel of potatoes when spread out in a single layer for sprouting. The bottoms of the trays were made of pieces of lath placed about one inch apart. Nine trays were placed in a rack over each other, leaving about nine inches of space between each tray. This method of arrangement has the advantage of securing a very uniform distribution of light, heat, and air for all the trays. It greatly facilitates the handling of the potatoes 


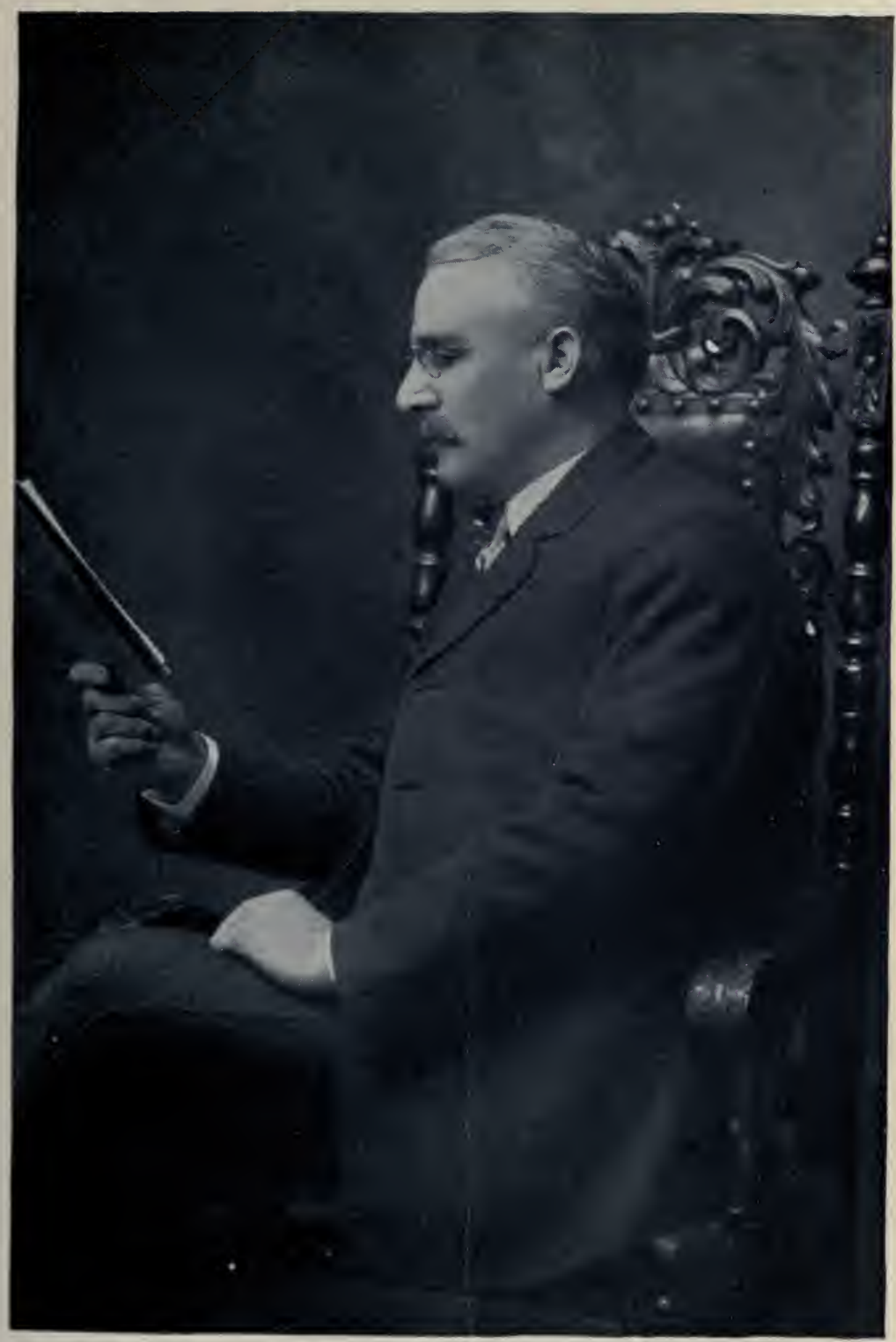

E. L. Cleveland, Houlton, Maine 


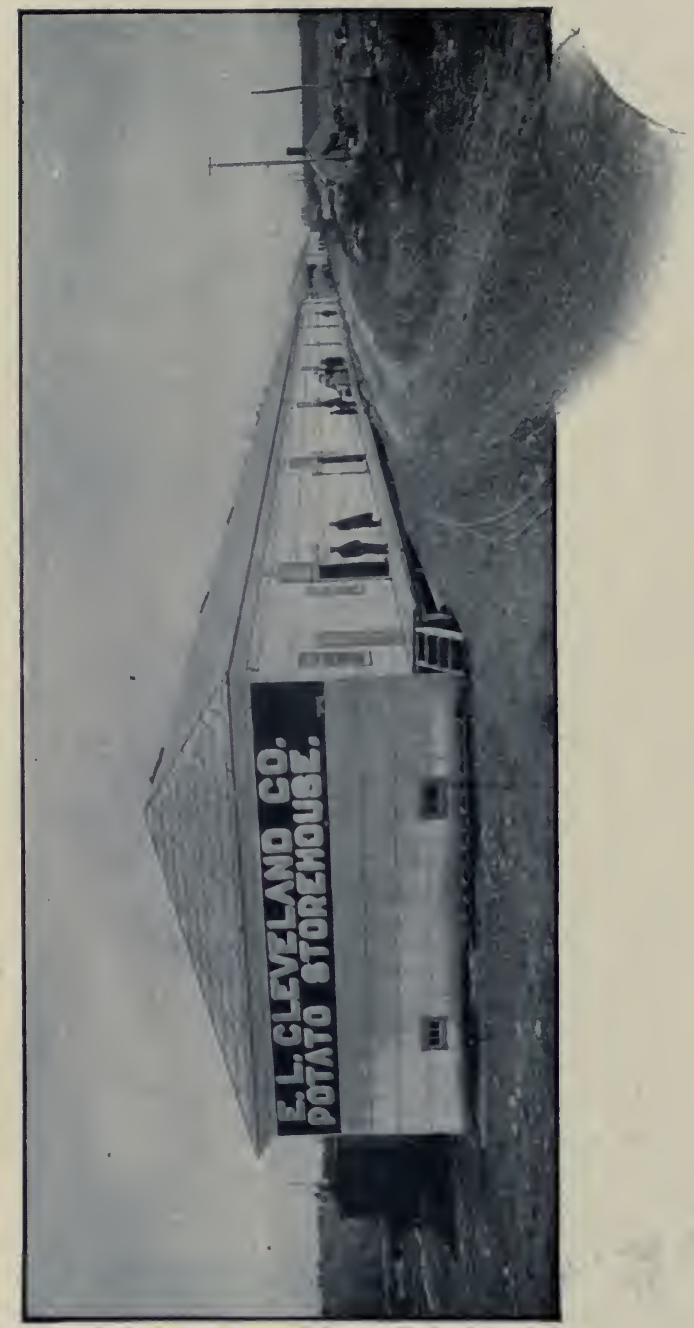


and lessens the danger of breaking off the sprouts when transferring to the field for planting."

Where it is desired to grow potatoes on heavy lands or without cultivation they are sometimes ni.nted under straw.

In a Nebraska Experiment Station publication R. A. Emerson says:

"Potatoes are a cool weather crop. It is because of this that they succeed so well in the far north. Moreover, potatoes require for their best development fairly uniform conditions, especially as regards soil moisture and soil temperature. This being the case, why should not potatoes grown under a litter mulch be especially well developed and therefore make strong seed? The soil beneath a mulch not only has a moderately low temperature during summer, but its temperature is also exceptionally uniform, varying not more than a degree or two between day and night and only a few degrees from day to day. The soil moisture beneath a good mulch is also more abundant and much more nearly uniform in amount than in case of bare ground, even though the latter is given good tillage.

"The value for seed purposes of tubers grown under a little mulch has been tested during two seasons at the experiment (Nebraska) station. In 1904 a plat of potatoes was mulched with straw and an adjoining plat was given careful cultivation. The soil of the two plats was practically uniform and the seed planted on the two plats was taken from the same lot of tubers. Seed was saved from the mulched and cultivated plats separately, kept under the same conditions during 
winter, planted on adjoining plats in the spring of 1905, and given identical cultivation during the summer. In 1906 the experiment was repeated with seed grown in mulched and in cultivated ground the year before. The same precautions were observed as in the first test. Uniform seed was used to start with in 1905 . The seed saved from the mulched and from the cultivated plats was taken as it came, without selection, and was kept over winter under the same conditions. Both kinds of seed were cut in the same way, planted in the same way, on adjoining plats, and treated alike as regards tillage, spraying, etc. Under these conditions any constant differences in yield between the two plats must be ascribed to the effect of the methods of culture employed the previous season. The yields obtained from the mulched and from the cultivated seed were as follows: Cultivated seed, 384 pounds in 1905; mulched seed, 563 pounds in 1905; cultivated seed, 123 pounds in 1906; mulched seed, 174 pounds in 1906.

"The use of seed that has been grown under a mulch the preceding year increased the yield of potatoes 47 per cent. in 1905 and 41 per cent. in 1906. If further tests confirm the results reported here it would seem that mulching might be used for the production of high-grade seed potatoes at home. Moreover, mulching usually results in increased yields if properly handled. Mulching potatoes on a large scale is, of course, impracticable, but most farmers could easily mulch enough of their potato field to produce the seed that they would require the following year, and in doing so they would not necessarily increase the cost of production per bushel." 
"The growing of Irish potatoes as a truck crop at the South has assumed large proportions," says L. C. Corbett, horticulturist in charge of Arlington Experimental Farm and Horticultural Investigations of the Bureau of Plant Industry, U. S. Department of Agriculture, in "Farmers' Bulletin 407." "Thousands of acres are annually planted to early varieties of potatoes which are harvested as soon as they have reached suitable size, regardless of their maturity, and immediately transported to Northern cities for distribution and consumption. This industry extends along the Atlantic seaboard from the southernmost terminals of railway transportation to the vicinity of the great centres of consumption, Florida producing a large annual crop of early potatoes, followed by Georgia, South Carolina, North Carolina, Virginia, Maryland, and New Jersey in turn. The great early-potato-producing sections of Florida are centred around Hastings; in Georgia the sections are largely confined to the vicinity of Savannah; in South Carolina a large acreage is cultivated in the trucking region about Charleston; in North Carolina a very extensive crop is planted in the vicinity of Wilmington; while Norfolk, Va., probably outclasses all other regions along the Atlantic coast so far as acreage and yield are concerned. This vicinity is one of the oldest and largest early-potato-producing sections of North America. Besides this belt of country devoted to this industry there are isolated regions along the Gulf coast and in northern Texas, Kentucky, and Missouri where potato growing has been established and has proved quite profitable.

"It is impossible to give accurate statistics in regard to this crop, for it changes annually with 
the markets of the preceding year, those who engage in the industry, particularly in the West, being influenced very decidedly by the previous year's return. This is an exceedingly unfortunate condition, as the growers should determine their planting, not by their previous year's experience, but by the condition of the crop at the North. The crop of so-called winter potatoes produced at the North has more influence upon the price which will be received for the early crop than any other single factor. The truck farmer should therefore keep a very careful record of the crop at the North preceding the year his planting is to be done. The quantity, quality, and price of the held-over Northern crop are factors which decidedly influence the price of the new crop when it reaches the market. A market which is well stocked with old potatoes which have been kept in fairly good condition means a very low price for the early crop when it comes in competition with such stock. As this new crop cannot be retained long in the soil at the extreme South without rapid deterioration, neglect on the part of the owner to determine the quantity of old potatoes in sight at planting season, as compared with the normal supply, may mean a very meagre profit, if any, or a very heavy loss if the crop cannot be moved at the proper season at a very satisfactory price.

"In growing early potatoes, perhaps more than any other single crop, the sources from which the seed is obtained influence the resulting crop. The practice which is almost universally followed is to plant tubers of early varieties which have been grown for several seasons at the North. The demand by truck farmers for Northern-grown seed 
has developed a very considerable industry in some of the potato-producing regions, notably Maine, Michigan, and Wisconsin. Early varieties which are especially adapted to truck work at the South are in these Northern regions planted extensively for the purpose of producing seed to be used in the South. The crop is harvested and placed in storage houses either at the North or at the South, where it can be made available to the growers at the South early in the spring to meet the demand for seed for early planting.

"Within recent years there has been a marked increase in the use of second-crop potatoes for seed throughout the Southern potato-growing sections. This crop is frequently grown on the same land from which the first crop of potatoes was harvested. In most instances, however, it follows beans or cucumbers, as the seed for this second potato crop is not usually planted until July or August. The seed for this crop is, as a rule, saved from the early crop, the small tubers being stored in a well-ventilated shed, where they are protected from the direct action of the sun and from storms until about ten days or two weeks before the time of planting, when they are spread thinly upon the ground and lightly covered with straw or litter to partially protect them from the sun. Under these conditions the tubers quickly 'green' and all those suitable for seed will develop sprouts. As soon as the sprouts are visible, and before they are large enough to be rubbed off in handling, the potatoes are ready to plant. The product of this planting gives a crop of partially matured tubers which are held over winter for spring planting. This practice gives excellent results in many localities and is found to' 
be more economical than the purchase of Northerngrown seed. To what extent it is safe to follow this practice without renewing the seed from the North by the use of fully matured tubers has not been determined.

"A novel practice for securing quick growth from second-crop seed has been developed by a successful potato grower in Texas. Mr. Morrell has developed an idea which is closely akin to the practices of the potato growers of the Channel Islands. The method consists in storing the tubers of the second crop in a tight building, which by the use of artificial heat can be kept frostproof. At harvest time the tubers are placed in slatted crates and the temperature of the storage house held as low as practicable without freezing until four to six weeks before planting time, when the temperature is raised to 68 degrees or 70 degrees F. This temperature is maintained until the eyes of the potatoes show activity. The sprouts should not be allowed to develop to any considerable length before planting the tubers, on account of the danger of breaking them in the necessary handling at planting time. If the sprouts are one eighth of an inch or less in length there should be little loss from handling. If the house can be well lighted at the time the temperature is raised the sprouts which develop will be much stouter than those developed in the dark. This plan provides a congenial temperature for the germination of the tubers and makes it possible to delay planting until outside conditions are generally favorable for the rapid growth of the plants, and to use for seed only those tubers which are actually viable. With good preparation and cultivation this method should give a perfect 
stand and a decidedly increased yield, together with the early maturity of the crop.

"This plan has been used for Northern-grown seed, but it is found that the mature Northerngrown seed responds more quickly to a given heat stimulus and consequently does not require to be placed in a warm room more than ten days to two weeks before planting.

"The practice on the Channel Islands accomplishes the same results in a slightly different manner. The tubers are placed one layer deep on germinating trays which are arranged on racks or are provided with corner posts a few inches long so as to admit air and light. The tubers are induced to germinate in the trays, and at planting time only those with well-developed sprouts are used for planting. As the work is all done by hand there is little danger of damage to the seed from breaking off the sprouts. In all sections of the South where hand planting is practised this method of procedure is perfectly practicable, and would entirely obviate losses from poor stands resulting from uncongenial conditions due to cold, damp spring weather, and inferior seed. Planting could be delayed until conditions were favorable and poor seed would be detected before it was planted.

"Early potatoes grown as market-garden or truck crops and intended for immediate consumption are, as a rule, harvested as soon as they have reached marketable size, regardless of the maturity of the crop. Because of the immature condition of the tubers it is essential that the crop be handled carefully and quickly. The tender tubers are easily bruised and damaged in appearance; consequently care should be exercised 
in the conduct of all operations connected with the harvesting of this crop. As a further safeguard to loss from bruising at harvest time or during transit the growcrs and the trade have determined upon the red-skinned varieties as best adapted to withstand these misfortunes. Scars and bruises show less on red-skinned than on white-skinned sorts.

"The varieties in most common use among truckers are known as Irish Cobbler, having a white skin, and Bliss Triumph, a red-skinned sort.

"Notwithstanding the fact that red-skinned sorts handle better, the smaller yield usually obtained from such varieties has led all growers except those located at extreme distances from the market to use white-skinned sorts. Red varieties are not employed extensively along the Atlantic coast, although they make up the bulk of the crop grown in the Gulf Coast States.

"While the harvesting of early Irish potatoes grown for home consumption is largely carried on by hand, in some localities improved implements, such as potato diggers and potato sorters, are brought into service. The truck farmers along the Atlantic coast, however, adhere largely to the simpler methods of handling the crop, as suggested in figures 9 and 10. This is undoubtedly accounted for by the fact that labor is more abundant and not so well trained in the use of improved machinery as in the more northern and western districts. In digging early potatoes in the Atlantic coast district ordinary one-horse turning plows are used. Laborers follow the plows and gather the potatoes from the soil and throw them, four or six rows together, in piles, after which they are sorted and put into barrels for shipment. In the potato 
regions of Louisiana and Texas, where early potatoes form a crop of considerable importance, improved machinery is largely depended upon for harvesting.

"The packages for early potatoes are determined partly by custom and the demands of the market, but largely by the local timber supply. In regions where timber is plentiful and barrels and crates figure largely in the shipment of other truck crops, potatoes are chiefly shipped in barrels. In other localities burlap sacks are chiefly employed, as is the case in most regions growing late potatoes.

"Up to the present time no standard measure, barrel, or bag for the handling of potatoes has been adopted. Recently certain states have passed laws requiring that these packages should come up to a given standard, usually 170 pounds net for a barrel, and that all short-measure packages entering their markets should be so marked. The barrel used by the trucker of the Atlantic coast region during past years holds about 11 pecks and weighs from 155 to 165 pounds net. These barrels cost the grower about 22 cents each, including the burlap cover. The bags used for the handling of the crop grown in the southwestern region cost the grower about 5 cents each in lots of 1,000 or more. These packages are used but once and are not returned to the grower.

"The grading of early potatoes is quite as important as the grading of fruits. Large and small tubers should not be mixed in the same barrel. The pickers should be taught to gather the large and merchantable tubers in one basket and the small or seed potatoes in another, and these if placed upon the market should go in separate receptacles and be clearly marked so as to repre- 
sent the grade. If a mechanical sorter is used this work will be more effectively accomplished than if left to the pickers.

"The type of grade usually used is similar to that employed in some sections for grading apples and peaches, although the common type of potato grader is a rotary screen which separates the earth from the tubers and allows the small tubers to fall through the large meshes of the screen before reaching the general outlet which carries away those of merchantable size. The objection to a mechanical grader of this type is that it bruises the immature tubers and renders them somewhat less attractive than when not so handled and probably also shortens the length of time they can be safely held on the market." 


\section{CHAPTER XX}

\section{THE BURBANK POTATO}

\#OR several years the authors of this book have looked upon their occasional visits to Luther Burbank at Santa Rosa, Cal. as bright spots in their year's work. Each visit brings a greater love for the genial, kindly, wonderful man and a greater admiration for his marvelous work in plant breeding - the like of which the world has never before known. He is both a genius and a philanthropist, and the value of his life work to the world will probably never be given a correct rating.

The Burbank potato is in a class by itself on the Pacific coast. In discussing the potato situation in California, Mr. Burbank said:

"I suppose the Russians, who had a trading post on the coast of what is now Sonoma County, may have grown potatoes, but the first potatoes in the state of which we have any record were those brought by sailors from Chile, South America. That it was possible for them to be used on the slow-sailing vessels of seventy-five years ago shows that they were good keepers.

"This Chilean potato was grown on the shores of Bodega Bay in Sonoma County and came to be known as the 'Bodega Red.' It was a red potato, with heavy eyebrows and deep eyes, and when piled in the field and covered with vines would keep for 
two years. It was very subject to blight, however, and a field of growing potatoes might be wiped out by the disease in a few days. At that time it was thought that potatoes could not be grown in the interior valley of California."

It was not until the introduction of the Burbank that large acreages of potatoes were grown in California.

On one of our visits to Mr. Burbank he told us the story of the Burbank potato, and although busy with the thousands and thousands of plants involved in the bringing out of new and improved varieties, and with the writing of the history of his life's work, he has written the following for this book:

"In the summer of 1871, after I had had several years of amateur experience in raising seedling potatoes, I was on the lookout for some potato which did not reproduce itself almost exactly from the seed in form, size, color, and all other particulars, as did most of the potatoes then known. While searching for such a variety, I happened, that autumn, to find on my place a single seed-ball on an Early Rose potato vine, and was immediately impressed with what later proved to be the fact, that this must be something valuable, as the Early Rose very seldom bears seed-balls. It was watched with the utmost care until nearly ripe, my attention being upon it daily. When it was about mature and ready to pick, the patch was visited that morning with that intention, but to my great consternation the coveted fruit had disappeared, and the pain and disappointment were intense when, after a careful search, I was unable to find 
any trace of it. However, believing that it might be somewhere in the vicinity, day after day the place was visited, and the most diligent search made, moving the vines about and leaving nothing undone that might disclose it. At last it was found a number of feet away from the original vine, no doubt removed either by a bird or some animal passing rapidly through the field.

"From this single seed-ball twenty-six distinct new varieties were obtained. The seed was planted out of doors, as one would plant beets or cabbages, and not grown in boxes under glass and transplanted as seedlings of potato and tomato plants usually are. The ground had been prepared with as much care as could be bestowed upon it, and each seed was placed about a foot from its next neighbor in the rows. To-day I would not think of planting valuable potato-seeds in this way because the risks would be too great; but it turned out, perhaps from the unusual care given them, that they all grew well, and from that lot of seedlings varieties were obtained entirely distinct from any which had before been seen. There were two sorts with long, white, beautiful tubers, the most shapely, most uniform in size, of any that had yet been developed. One of these was afterward named and introduced as the 'Burbank' by that pioneer seedsman, Mr. J. H. Gregory of Marblehead, Mass. The other white one was almost as good, but by careful test proved to be somewhat less prolific. This, and all the others except the 'Burbank,'are now lost to cultivation, and let us hope without loss to the cultivator.

"Besides the two seedlings above mentioned, one varicty was bright red, not very productive, and most of the tubers decayed shortly after they 
were dug. Another was a round, white potato; still another was pink; a second pink variety was characterized by its white eyes; another pinkish variety had eyes so prominent that the long, slender tubers seemed to be all eyebrows, the eyes reaching quite to the centre of the potato. Probably seedlings raised from some of these might have produced varieties of great importance, but soon after, in moving to California, the seed was lost. I have raised more than ten thousand seedlings from the 'Burbank' potato since coming to California, but have never obtained one that was equal in all respects to the original.

"Over eight million bushels of the Burbank potato were produced on the Pacific coast alone during 1906, and probably nearly as many each year for fifteen or twenty years past. It is the standard tuber on this coast to-day from Alaska to Mexico, and almost invariably brings the highest price of all potatoes. It thrives as well here to-day as it did in Massachusetts thirty-five years ago. This is one of the proofs that varieties do not run out if grown under suitable environments." 


\section{CHAPTER XXI}

\section{THE SWEET POTATO}

7 HE article which follows consists of extracts from "Farmers' Bulletin 324" of the

1 United States Department of Agriculture, and is by W. R. Beattie of the Bureau of Plant Industry:

"With the passing of each year the sweet potato is becoming of greater importance as a commercial truck crop in the United States. During a long period it has formed one of the principal sources of food for the people of the Southern States and of tropical America. As a commercial truck crop the sweet potato would be included among the five of greatest importance, ranking perhaps about third in the list. As a food for the great mass of the people living in the warmer portions of our country the use of this crop is exceeded by hominy and rice only. In many of the islands of the Pacific, especially in the Philippines, the sweet potato is the principal vegetable food for large numbers of the lower classes, at certain seasons being almost the only food available.

"The sweet potato industry in this country is readily divided into two classes of production: (1) For home use and (2) for market. A quantity sufficient for home use can be grown under a wide range of conditions, while production on a commercial scale is somewhat restricted by climate and 
soil and also by market and transportation facilities. The larger Eastern markets are now well supplied, but there are sections where the people have not as yet become accustomed to the use of sweet potatoes in large quantities. The field for the production and use of sweet potatoes is very broad, and this crop promises to become of more general farm importance.

"In view of the constantly increasing interest in sweet potatoes it is the purpose of this bulletin to give simple cultural directions covering their production both for home use and for market, including the soil and its preparation, the propagation of the plants, planting, harvesting, storing, and marketing, together with the uses of sweet potatoes for stock feeding and for similar purposes.

"The sweet potato is of a tropical nature, its original home probably being the West Indies and Central America. The true sweet potato, as we have it growing in the United States, belongs to the morning-glory family, its botanical name being Ipomoea botatas. Throughout the Southern States the sweet potatoes having moist flesh are commonly known as 'yams' and those having dry flesh as sweet potatoes. The name 'yam' is misleading and properly belongs to a distinct class of plants that are confined almost entirely to the tropics.

"Owing to the tropical nature of the sweet potato it naturally thrives best in the South Atlantic and Gulf Coast States, but it may be grown for home use as far north as southern New York and westward along that latitude to the Rocky Mountains. The areas suited to commercial production extend from New Jersey southward and westward to Texas, and are found again in the central valleys 
of California. In the Mississippi Valley the commercial area extends as far north as the southern part of Iowa, Illinois, and Indiana. The region around Louisville, $\mathbf{K y}$., is noted for excellent crops of sweet potatoes.

"Sweet potatoes thrive on a moderately fertile sandy loam which does not contain an excess of organic matter. They are frequently grown upon almost pure sand, especially where the subsoil is a yellow clay. Soils containing considerable calcium or underlain with limestone are well adapted to the growing of the crop. The sweet potato is exceptional in that a fairly good crop can be grown upon soils that are too poor for the production of the majority of farm crops. Sweet potatoes yield a fair crop on the 'wornout' tobacco and cotton lands of the South, especially when used in a rotation including some leguminous crop for increasing the humus in the soil.

"The more common varieties of the sweet potato have for a great many years been propagated by cuttings, or sets, taken either from the potatoes themselves or from growing vines, and as a result the plants have ceased to flower and produce seed. The greater portion of the commercial crop is grown from sets, or 'draws,' produced by sprouting medium-sized potatoes in a warm bed.of soil. In the Southern States the seed potatoes are frequently cut into pieces in the same manner as Irish potatoes and planted in the row where they are to mature. Where several plants appear in one hill they are thinned, and those removed are used for planting other land. In the South Atlantic and Gulf Coast States the sweet potato is frequently propagated by making vine cuttings. A comparatively small bed of seed potatoes is planted quite 
early and the sets so produced are used to plant a small patch from which vine cuttings are taken later by the cartload for planting large fields. In the southern parts of Florida and Texas and on the South Sea Islands the potatoes may remain in the soil from year to year, being dug only as required for use, those remaining over producing the sets for the following season's planting.

"In the warmer portions of the sweet-potatogrowing district the seed should be bedded when danger of frost has passed. In the northern portion of the area the seed should be placed in the hotbed from the 20th of March to the 10th of April, after the temperature of the bed has fallen to 80 degrees or 85 degrees $\mathrm{F}$. and become regular.

"As a general rule sweet-potato plants are set in the field shortly after a rain. In order to avoid delay in planting, the hands should begin to get out the sets as soon as the rain ceases falling and place them in crates or baskets ready for transportation to the field. The sets are not all produced at once, and only those that have formed good roots are 'drawn,' the others being left until later. In 'drawing' the sets the seed potato is held down with one hand while the plants are removed with the thumb and finger of the other hand. It often happens that five or six plants will cling together at the base, and these should be separated in order to avoid loss of time in the field. Where plants are to be set with a transplanting machine it is essential that they should be in the best possible shape in order that they may be handled rapidly by the boys who feed the plants into the machine. The roots should all be kept in one direction, and if the tops are long or irregular they may be trimmed off even by means of a knife. 
"While 'drawing' the sets it is a good plan to have at hand a large pail or a tub containing water to which there has been added a quantity of clay and cow manure which has been stirred until it forms a thin slime. As the plants are pulled from the bed they are taken in small bunches and their roots dipped into this mixture. This process, termed 'puddling,' covers the roots with a coating which not only prevents their becoming dry in handling but insures a direct contact with the soil when they are planted in the field or garden.

"The success of the crop depends largely upon the way in which the plants start after being removed from the bed and set in the field or garden. Practical growers always plan to set the plants during a 'season' or period when the conditions are suitable to a quick start into growth, either just before a rain or as soon afterward as the soil can be worked. The method of setting will depend entirely upon local conditions and the acreage to be grown, the essential features, however, being to get the roots in contact with moist earth and the soil firmly pressed about the plants.

"The use of water around the roots of the plants is desirable under most circumstances, as it not only moistens the soil but assists in settling it about the roots. A large quantity of water is not necessary, one half pint to each plant being generally considered sufficient.

"Where level culture is practised, the plants are set from 24 to 30 inches apart in each direction. On the eastern shore of Virginia the greater portion of the crop is planted 24 inches apart each way, requiring about 11,000 plants to an acre. By planting 30 inches apart each way, only about 7,000 plants are required to set one acre. Where 
the crop is grown on ridges it is customary to have the ridges from 36 to 42 inches apart from centre to centre and to place the plants 14 to 18 inches apart in the row. By this method an acre will require from 8,000 to 12,500 plants. An acre of good sweet potato land will readily support 9,000 to 11,000 plants, and the number most commonly planted by the several methods will fall within these figures.

"The machine transplanters are provided with a spacing device which indicates the distance between plants; also with a row marker to show the location of the next row.

"Where a few hundred plants are to be grown for home use, or if only an acre or two are to be planted, the hand method of planting will answer every requirement. A trowel or a dibble is used for opening the soil to receive the plant, and the earth is closed about the roots by a second thrust with the implement, or the heel of the shoe is used to press the earth about the plant. For hand planting, the plants are dropped ahead of the 'dibblers' by boys and girls. Seven thousand to ten thousand plants, or an acre, is an excellent day's work for a planter when everything is in good condition. Where a few hundred plants are set in the garden it is always desirable to water them before closing the earth about the plant.

"Under reasonably favorable conditions a machine will plant from three to four acres a day. In addition to being labor savers, these machines do the work better and more uniformly than it is ordinarily done by hand. The plants can be set without the use of water, but the results are more satisfactory where the water is used.

"The methods of handling a crop of sweet pota- 
toes do not differ materially from those employed with ordinary farm and garden crops.

"Aside from planting and harvesting, the work of caring for a crop of sweet potatoes can be done almost entirely by the use of ordinary farm and garden tools.

"The sweet potato is subject to injury from a number of diseases. Those diseases causing rot and decay are most prevalent and result in the greatest loss during the period that the crop is held in storage, Occasionally, however, the crop may be lost before harvesting, and one form of rot, known as black-rot, destroys the young plants, attacks the potatoes while they are in the ground, and causes them to decay while in storage. The spores that are responsible for the several forms of rot affecting sweet potatoes may remain in the soil from year to year, or they may be carried over winter upon the seed. Diseases are generally introduced with affected seed or plants, and when once established in the soil, the storehouse, or the propagating bed it is doubtful whether they can be eradicated except by the adoption of the most thorough methods.

"A disease known as stem-rot causes the stem of the plant to begin to die at the surface of the ground. This decay gradually extends downward to the potatoes and frequently kills the entire plant.

"The diseases known as soft-rot, dry-rot, and white-rot are all similar in their method of attack to the black-rot. One form, known as soil-rot, causes the loss of the crop while it is in the field. Each of these diseases is caused by a particular fungus, but has received the common name suggested by its general appearance or some marked 
characteristic. Any one of the diseases of the sweet potato may be present without causing severe loss provided conditions are unfavorable to its development, and growers should be constantly on their guard to prevent the spread and development of diseases.

"A system of crop rotation by which the land will not be planted to sweet potatoes oftener than every four or five years is the first step toward disease control. Care in the selection and keeping of potatoes intended for propagation is of importance, while clean cultivation and proper handling at the time of harvesting are essential. Diseases will generally make their first appearance upon cut, broken, or bruised potatoes, and all that are in any respect injured should be stored separately from the seed and perfect stock. The storage house should be cleaned and fumigated with sulphur or formalin before storing begins, and all crates or baskets used for handling the crop should be in the house during the fumigation.

"It is very apparent that some varieties are more subject to the attacks of diseases ithan others. The Big-Stem Jersey and the Jersey group generally are especially subject to disease, while varieties of the Hayman group, such as Southern Queen, are seldom affected.

"The sweet potato is reasonably free from the ravages of insects. Cutworms frequently destroy the young plants after they are set in the field, especially when the land has been in grass the previous sea'son. The sweet-potato borer, which works in the roots, is widely distributed and causes considerable injury in the Gulf Coast States. A small insect known as thrips works on the under side of the leaves during the hot and dry weather of 
midsummer, but as a rule the real damage caused by this insect is slight.

"The harvesting and marketing of sweet potatoes direct from the field begin about the middle of August and continue until the crop is all disposed of or placed in storage for winter marketing. During the early part of the harvesting season the yield is light, but as a rule the prices paid are good. The supply for home use and those potatoes that are to be kept in storage should not be dug until just before frost. In the localities where frosts do not occur until quite late in the season the sweet potatoes ripen and the vines show a slight tinge of yellow when ready for handling.

"The foliage of the sweet potato is very tender and is easily injured by frost. A light frosting of the leaves will do no harm, but should the vines become frozen before digging they should be cut away to prevent the frozen sap passing down to the roots and injuring them.

"In sorting sweet potatoes preparatory to packing, about four grades are recognized - i. e., fancy, primes, seconds, and culls. Those packed as fancy include only the most select, both in size and shape. The primes include all those adapted to general first-class trade, while the seconds include the smaller and more irregular stock which goes to a lower-priced trade. The culls are not marketed unless good stock is exceedingly scarce, and as a rule are used for feeding to hogs.

"Sweet potatoes are usually shipped in barrels holding eleven pecks each. Some markets require that the barrels be faced and headed, while for others the tops are slightly rounded and covered with burlap. Small lots of extra-fancy sweet potatoes are sometimes shipped in one-bushel crates 
having raised tops; also in patent folding crates. Throughout the process of handling care must be exercised to see that the sweet potatoes do not become bruised, for upon this their shipping and keeping qualities greatly depend.

"Unlike most perishable products, the sweet potato requires warmth and a dry atmosphere while in storage. The method of storing will depend both upon the locality and the quantity of potatoes to be cared for. The temperature and conditions of a rather cool living room are admiràbly adapted for keeping sweet potatoes intended for home use in the North, while in the South they may be placed in pits or stored in outdoor cellars. The home supply may be placed in crates and stored in a loft over the kitchen part of the dwelling. Sweet potatoes should not be stored in bags or in barrels without ventilation.

"Where large quantities of sweet potatoes are stored for winter marketing, the method employed in the Southern States is to place them in outdoor pits and cellars, while at the North some form of heated storage house will be required. Whether the storage be in pit, cellar, or house, a dry, warm atmosphere with ventilation is essential to good keeping.

"Of the large number of varieties of the sweet potato there are not more than ten that are now of great commercial importance in the United States. For the markets that require a dry, mealy-fleshed potato those varieties belonging to the Jersey group are suitable. For the Southern trade and where a moist-fleshed potato is desired those commonly designated as yams are in demand. Among the Jerseys that are extensively grown are the BigStem Jersey, the Yellow Jersey, and the Red Jer- 
sey. The principal varieties of the yam group are the Southern Queen, the Pumpkin Yam, the Georgia, the Florida, and the Red Bermuda. Of the varieties mentioned there are a large number of special strains known under many local names.

"In the selection of varieties for home use one must be governed largely by locality. As a rule those of the Jersey group will thrive farther north than those of the so-called yam types. For market purposes the particular variety or strain grown in the vicinity should first be selected, and afterward other varieties may be experimented with in a small way.

"The following brief descriptions of a few of the leading varieties may be of assistance in selecting those best adapted to various conditions of soil and climate:

"Big-Stem Jersey. - This variety is the most popular among growers who are supplying the Northern and Eastern markets. It is a form of the Yellow Jersey, having been selected for its productiveness and dry, yellow flesh. The vines are slender and long; the potatoes are of spindle shape and inclined to grow rather large; color of potatoes yellow; color of flesh light yellow or deep cream. While this variety yields heavily, it is unfortunately a rather poor keeper, and its flesh is inclined to become dry and 'punky' toward spring. It will thrive well toward the north, but is better adapted for use as a commercial variety than for home consumption.

"Southern Queen, or Hayman.- The vines of this variety are strong and vigorous; the potatoes are large, thick, and blunt at ends or of short spindle shape; the color is white or light cream, while the flesh is of cream color, becoming darker 
in cooking, moist, and very sweet. This variety is most extensively grown for market purposes where a sweet, moist-fleshed potato is demanded. The Southern Queen yields well, is an excellent keeper, and is adapted for both marketing and stock feeding and for home use in the South Atlantic and Gulf Coast States, but it does not mature when grown in the extreme North.

"Red Bermuda.-The Red Bermuda vines are large and vigorous. The potatoes are usually large and overgrown with heavy ridges and veins. The color of the potatoes is rose red; flesh, creamy; quality fair but not so sweet as Southern Queen. This variety is a heavy cropper and suitable for feeding to stock. It is one of the few so-called yams which thrive in the northern portion of the sweet potato area.

"Black Spanish, or 'Nigger Choker.' - The Black Spanish vines are very long, vigorous, and dark purple in color. The potatoes are long, cylindrical, crooked, or bent; dark purple in color, with snowy white flesh and poor quality. This variety is grown mostly for stock feeding.

"Shanghai. - The vines of the Shanghai variety are large and vigorous; the potatoes long, cylindrical; the outside color almost white. The flesh is creamy white, becoming darker in cooking. When baked the flesh is somewhat dry and mealy and the flavor rather poor. This variety yields fairly well and is adapted for use as stock food in the Gulf Coast States.

"The cost of growing an acre of sweet potatoes will vary with the cropping plan and the extent to which the crop is grown. On an average the cost of growing an acre of sweet potatoes in the regular commercial district is about as follows: Rental of 
land, $\$ 8$; plowing and fitting, $\$ 5$; fertilizers, $\$ 20$; 10,000 plants, $\$ 10$; planting, $\$ 5$; cultivating, $\$ 5$; digging and marketing, $\$ 25$; total, $\$ 78$. An average yield of sweet potatoes is at the rate of one barrel to 100 hills, or 100 barrels to an acre. The price per barrel paid the grower is seldom less than $\$ 1.25$, and $\$ 2.50$ or $\$ 3$ is not uncommon. During good seasons the net profit from one acre of sweet potatoes is about $\$ 75$. While occasionally the net returns are from $\$ 100$ to $\$ 150$ an acre for a single season, there are seasons of crop failure or overproduction when very little, if any, profit is realized.

"The sweet-potato growers on the eastern shore of Virginia as a rule plant about ten acres in sweet potatoes, and this constitutes their money crop. The remainder of the cleared portion of their small farms is devoted to corn, pasture, and hay, all for home use. Here the sweet-potato crop is grown almost entirely without the aid of hired help, and the cost of production does not exceed $\$ 40$ an acre. Where the crop is stored the gross returns are greater, but the cost of production is increased proportionately." 


\section{CHAPTER XXII}

\section{LEGISLATION}

7 THE control and eradication of all disease - human, animal, and vegetable-is a problem in which all of the people in a country or a state are vitally interested. Consequently, laws designed to accomplish this must be made by the highest legislative bodies. No matter how well the individual grower may do his part, unless there is concerted action, enforced by the law, little headway can be made in preventing or combating contagious diseases.

As an industry gains prominence either by its growth or the ability and public-spiritedness of the men interested in it, it is better able to secure such laws as are necessary for its protection.

An example of this is the result of the work of the Commissioner of Horticulture in California. The men interested in the fruit industry in this state demand protection from foreign insect and fungous pests that may be introduced to be a menace to the fruit interests of the state, and inspectors are stationed at every port of entry to inspect importations.

The potato industry in various sections needs similar protection. The Colorado beetle has not yet been introduced west of the Rocky Mountains. The states or parts of states that are now free from this pest should take steps to prevent its introduction. 


\section{THE POTATO}

A very bad pest is now prevalent in Europe the wart disease (black scab). There should be a law to prevent this from getting a foothold in America. The following letter was written by the senior author to Secretary of Agriculture James Wilson from London, England, May 28, 1910:

"I am getting along very well, and am securing information invaluable to the American potato grower about the various stages of potato production.

"There is little or no manufacture of farina from potatoes in Great Britain; all waste and low priced potatoes are cooked and fed to meat making livestock, but I have information that Germany is making flour from potatoes, and later I shall visit there.

"I am in very close touch with the Department of Agriculture here, the seed potato breeders and growers, the commercial growers, and the market men.

"I am sending you a leaflet from the Department of Agriculture of Great Britain on the black scab disease of potatoes. Some of the office men tell me that it is inconsequential, that the disease has been prevalent for fifteen or twenty years, and it has affected potato growing to but very little extent. Some of the field men tell me that it has been developing very rapidly in the last two years, but especially so the last year. They regard it as a very dangerous, if not the very worst, menace that the potato industry has ever had.

"We spent a day with the potato work at Sutton \& Sons, Reading, England, with Mr. Lasham, a Scotchman. He has been their expert and potato specialist for thirty years. They are doing 
more in the way of breeding new types and growing more seed potatoes, and selling and exporting more, than any other firm in the world.

"Mr. Lasham showed us samples of potatoes in the various stages of black scab disease. When I looked at the potato and then when they were cut open it made me shudder with horror. Mr. Lasham considers it more damaging and far reaching in its results to the potato industry than anything of its kind that has ever appeared. He says it takes eight years of grass crops to eradicate it from the soils when the fungus once invades it.

"Mr. Rogers of the Department of Agriculture in London says they do not regard it as very serious, as it is not breeding very rapidly, but calls the attention of the potato growers in the bulletins of the Department of Agriculture of Great Britain to the heavy penalties for not reporting it to the Department. There are penalties for shipping any such diseased potatoes, however. Mr. Rogers admits that they have it in Newfoundland, and that it is developing quite rapidly the last year or two in Germany, Belgium, Roumania, Hungary, and other potato districts of Europe. A few instances are known in Scotland, but it is the worst in Wales.

"Mr. Rogers very kindly invited me to go with their experts throughout the infected districts during the month of August, when the disease makes its greatest development.

"In my judgment it has not been given very wide publicity in Europe, as it would endanger the export trade. I believe the disease is much more malignant than we have a knowledge of, and that it will be a greater menace to the American farmer if once established in the United States or on the 
farms of our country than any of the infectious or contagious diseases of the livestock industry. Steps should be taken before this year's crop is harvested to prohibit the importation of potatoes to America from any of the infected districts of Europe. All of the vessels plying between Europe and the United States use foreign grown potatoes, and it would be very easy for those potatoes to get ashore, and it is also easy for emigrants to take seed stocks with them.

"I feel that I am your personal representative over here in the potato industry, and I am sure that with this full information you will do all in your power to protect the American potato grower from the chances of the introduction of this disease, just as you have protected the livestock grower from the animal diseases of the countries of Europe."

Following up this important work the senior author brought the matter to the attention of Senator Guggenheim of Colorado, who, on April 6,1911 , introduced the following bill in the Senate of the United States:

"To enable the Secretary of Agriculture to more effectually suppress and prevent the spread of diseases of potatoes known as black scab and wart disease, and for other purposes.

"Be it enacted by the Senate and House of Representatives of the United States of America in Congress assembled, That in order to enable the Secretary of Agriculture to effectually suppress and extirpate diseases of potatoes known as black scab and wart disease, and to prevent the spread of such diseases, the Secretary of 
Agriculture is hereby authorized and directed, from time to time, to establish such rules and regulations concerning the importation from foreign countries to the United States and transportation into and through any state or territory of the United States, including the District of Columbia, as he may deem necessary, and all such rules and regulations shall have the force of law. Whenever it shall appear to the Secretary of Agriculture that any potatoes grown in an infested country, district, department, or locality, outside of the United States, are being or are about to be imported into the United States, or the District of Columbia, and such potatoes are infested by wart disease or black scab, he shall have authority to quarantine against such importations from said country, district, department, or locality, and prevent the same until such time as it may appear to him that any such wart disease or black scab has been exterminated, when he may withdraw the quarantine.

"Sec. 2. That when any shipment of potatoes imported or brought into the United States is found to be infested with wart disease or black scab the entire shipment shall be destroyed in such manner as the Secretary of Agriculture may direct.

"Sec. 3. That upon complaint or reasonable ground on the part of the Secretary of Agriculture to believe that any potatoes grown with- in the United States and likely to become subject to interstate commerce are infected with wart disease or black scab, the Secretary of Agriculture shall cause the same to be inspected by a qualified expert, and, if need be, placed 
under quarantine until such infection is removed.

"Sec. 4. That the Secretary of Agriculture shall have authority to make such regulations and take such measures as he may deem proper to prevent the introduction or dissemination of black scab and wart disease in potatoes from a foreign country into the United States or from one state or territory of the United States or District of Columbia to another, and to seize, quarantine, and dispose of any potatoes so infected coming from an infectd foreign country, district, department, or locality to the United States, or from one state or territory or the District of Columbia in transit to another state or territory or the District of Columbia whenever in his judgment such action is advisable in order to guard against the introduction or spread of such diseases.

"Sec. 5. That any person, company, or corporation knowingly violating the provisions of this Act, or the orders or regulations made in pursuance thereof, shall be guilty of a misdemeanor, and on conviction shall be punished by a fine of not less than one hundred dollars nor more than one thousand dollars, or by imprisonment of not more than one year, or by both such fine and imprisonment.

"Sec. 6. That the sum of twenty-five thousand dollars, to be immediately available, or so much thereof as may be necessary, is hereby appropriated, out of any moneys in the Treasury not otherwise appropriated, to carry into effect the provisions of this Act."

It is a sad commentary on American legislative 
affairs that this bill was not made a law. The part which applies to potatoes was attached to an omnibus bill covering all parts of nursery stock.

The bill was opposed by importers of nursery stock, who do not want to be bothered with an inspection that will protect the American grower from foreign pests.

As drawn up by the attorney for the Department of Agriculture, a trifling mistake occurred - so that when it was read Congressman Mann of Illinois made a funny speech calling attention to this error. The bill was then held up, and the American potato grower is without protection.

The legislative end of farm affairs has been badly neglected in the past, but with increasing interest in agriculture this should be remedied in the immediate future.

Following up this matter during the winter of 1911-1912, further consideration was secured in Congress, and a bill prohibiting the importation of all kinds of diseased farm produce and nursery stock has been introduced.

During this past winter, however, many millions of bushels of potatoes from Europe have been imported, and a bulletin has been sent out warning against the use of these foreign potatoes for seed. 


\section{CHAPTER XXIII}

COOKING THE POTATO

TN CHAPTER II the potato as food is discussed by Dr. J. H. Kellogg.

In this chapter the food value of the potato and special recipes are given by Mrs. E. H. Grubb, and valuable recipes are also given by Miss Lenna F. Cooper and Mr. Emil Tenthorey.

The following is by Mrs. E. H. Grubb:

"There are many varieties of potatoes, and tastes differ as to a choice. In America and Great Britain the white fleshed, mealy varieties are preferred. In Continental European countries many yellow fleshed varieties are in great favor, such potatoes being especially valuable for soups, ragouts, salads, and hash, as they are of a waxy texture and retain their shape better when cooked than those of a mealy texture. The yellow fleshed potato is said to contain more protein in proportion to the starch content than the white fleshed and is therefore richer in flavor.

"The potato is a food rich in starch, which supplies the body with fuel for keeping up warmth and provides it with energy necessary for muscular activity.

"The food value and composition of rice and potatoes are very nearly the same, the difference being that potatoes contain a larger percentage of juice, while the rice is dry and concentrated. 
Potatoes are so easily and quickly prepared and may be served in such a variety of ways that they add variety to the daily meal. Their mineral matter is valuable in the processes of digestion. They are easily grown and yield abundantly, and their keeping qualities are excellent. These advantages place them at a price within the reach of all in the localities where they can be grown. Often, when old potatoes are out of the market, new ones are so high in price as practically to be out of reach of those of ordinary means. It is well known that so much of a necessity is the potato considered that many families sacrifice to obtain them at the exorbitant prices new potatoes bring in Northern markets; also in the South the same condition occurs later in the season when potatoes are scarce and high priced. These facts go to prove the popularity of potatoes in the diet. "As dried or evaporated potatoes become better known they will supply the poorer people with this much-prized vegetable at a cost within their reach. The composition of such evaporated potatoes is much the same as the original. While the flavor and in some cases the appearance does not equal that of fresh potatoes, they may be prepared in all the appetizing ways of the fresh ones, and are most acceptable when the fresh potatoes are too high in price to be easily obtained. Evaporated or dried potatoes should be as common in our markets as the dried fruits that are such a welcome addition to our supply of food when the fresh ones are high priced or out of the market. Even in some of our largest potato-growing states, especially in the Mississippi Valley, potatoes often have very poor keeping qualities, and the average farmer finds himself short or entirely without this 
vegetable, and the city people of moderate means must inconveniently economize in the use of potatoes or do without this article of diet. At such times a heavy demand would be made for desiccated or evaporated potatoes were they common in our markets.

"Potatoes for storing for future use should be firm and crisp when cut open with the knife. The quality can only be definitely tested by cooking. This test is best made by boiling in the skins or baking. After removing from the fire hold in a napkin and squeeze lightly, then break open, and if the starch is abundant, you have a white, flaky, uniform mass somewhat shiny and crystalline in appearance. If the starch is scanty it will be soggy and may have a watery core. This condition may be discovered in the raw potato by cutting a thin slice transversely from the middle of the tuber. Hold it up to the light, and if the core is large and many large arms branch out into the outer section, and the outer ring, known as the cortical layer, is thin, such a potato is not likely to be light and flaky when cooked. There is another quality of the potaio which is neither soggy nor mealy, and which is very agreeable to most tastes, and is commonly described as waxiness. This quality is found in the immature tubers or early spring potatoes. In point of flavor there is as much difference as in texture. The immature potatoes contain a larger proportion of albumenoids that gelatinize in cooking, giving this moist consistency, and the larger proportion of acids and mineral matter gives the richness of flavor. In selecting potatoes for the table it is a very difficult matter to judge the quality by the outside appearance. A good, firm potato of 
fine, smooth skin might not be superior in quality to one of rough and uneven character. It is unusual for the purchaser to be fastidious in regard to flavor and quality, and yet these are elements worthy of more attention than color, size, or form. Very large potatoes have a large watery core, or, as is said in the kitchen, a bone, in the centre. They are apt to be coarse grained and lacking in flavor.

"Excepting in cases of necessity no one lives upon potatoes alone. They are under ordinary circumstances eaten with meat, fish, eggs, butter, milk, and cheese, and digestive experiments prove that in these combinations their nutritives are very completely utilized in the body. Their abundant mineral matters are valuable aids in the process of digestion, and are supposed to be a preventive of scurvy. So well recognized was this property during the Civil War, and before the nutritive value of foods had been scientifically learned, that potatoes sliced and pickled in salt vinegar were sent by orders of physicians to supplement the soldier's diet of white flour, fat meat, beef, and beans. The same conditions were noted in the early Klondike days. Potatoes were regarded as necessities and were used regardless of their excessively high cost.

"The early Spanish explorers found the Peruvian natives stocking their boats for long voyages with a plentiful supply of this wholesome tuber.

"Potatoes are easy to cook, not requiring the expensive process in labor and fuel that bread making does. They may be prepared in such a variety of ways that they make many agreeable changes in the food supply during the winter months. They are easily grown, yield abundantly, 
and supply a starchy food at a price within the reach of all. They are especially rich in starch or energy supplying food, are preëminently the food of those who work at physical labor, and it is said that those who work never tire of potatoes. When we consider all these advantages, it is surprising that more potatoes are not used in the United States.

\section{NOTES ON COOKING POTATOES}

"The potato is in such universal use, and is so highly nutritious, that above all other vegetables it would seem that it should be cooked in perfection. However, it may be in reality that no other vegetable is so carelessly cooked. The proper cooking of the potato has much to do with its nutritive value. It is a starchy food; the microscopic starch grains are intermingled with the watery juice, which contains the albumen, gelatine, minerals, sugar, and acids. All of these elements are highly valuable as food or stimulants, but by careless and unscientific methods in preparing and cooking they may be partially lost and wasted. How often do we hear epicures criticising our best hotel cooking, remarking the impossibility of being served with mashed potatoes of a good quality? Where food must be prepared in such large quantities the potatoes are pared and soaked in water for from twelve to eighteen hours before being boiled, thus losing a high percentage of the agreeable flavors, the nutritious starch and albumen and valuable mineral matter.

"In preparing potatoes for cooking, by clumsy, awkward paring large quantities of the edible portion are wasted, one fifth on the average and as 
high as one fourth, when by careful measurement the crude fibre or true skin of the potato is less than one half of 1 per cent. of the whole. When potatoes are pared and soaked in water and then boiled the loss has been found to be as high as 7 per cent. of the food value, the albumen and mineral matter being the elements most largely lost.

"The different methods of cooking potatoes are baking, boiling, steaming, and frying. Each of these methods may be so conducted as to retain practically all of the food material. When potatoes are cooked in the skins they lose nothing of the food value, but a slight loss of water is noted. When fried there is no loss of nutrients and the toasted or browned starch flavor is relished by many. Baked potatoes have been found by scientific experiment to be more quickly digested than those cooked in other ways, but it seems that in healthy individuals the time of digestion of food is not material so it is normally digested. A potato cooked in the skin, either baked, boiled or steamed, then peeled and mashed and seasoned with plain milk, has a richness of flavor, from the conserving of the elements of flavor, that no amoun $i$ of high-priced artificial seasoning such as butter and cream can give. This does not argue against the use of cream and butter, but only calls attention to the fine, smooth consistency and good flavor that can be secured by conserving the cortical layer instead of paring it away. Chemical analysis has shown that as much albumen, the flesh-forming food, is thrown away or needlessly wasted in paring fifty pounds of potatoes as is contained in a pound of sirloin steak; besides this loss of nitrogenous food, that of the carbohydrates or starch is still more. 
"It is evident from all tests that if it is desired to cook potatoes with as little loss of flavor and food material as possible, they must be cooked with the skins on."

The following formulas for cooking potatoes are given as examples of methods by which all of the nutrients are conserved:

\section{Boiled Potatoes}

Place in deep kettle with perforated pan in bottom of kettle, and cover with sufficient water to cook them, but not to immerse the potatoes in the boiling water, as the skins are liable to burst, and thus the food be wasted in the boiling water. Cover very closely. When very well done take in towel and squeeze each one lightly and break the skin; this allows some of the moisture to escape and leaves the flesh in a light, fine, mealy condition. If the potatoes are not in this condition it is because of immaturity or watery quality which is characteristic of tubers grown in soils and climate not well adapted to potato culture.

\section{Baked Potatoes}

Place in moderate oven for thirty minutes or more, then increase to quick heat to finish. When done take in a towel and squeeze lightly, enough to crack the skin, which should not be baked until a thick crust is formed, as by so doing the cortical layer, which adds so much to flavor and nutrition, is lost. Potatoes thus treated may be served immediately or will keep well for a short time if placed in a warming oven.

\section{Mashed Potatoes}

Boil or steam potatoes in their skins until very thoroughly done. Peel and mash in a hot kettle, seasoning with hot milk, adding butter and cream according to taste. Many like the added flavor of a little grated onion or finely minced chives.

The secret of having these in perfection is in mashing and beating thoroughly with a wire beater until they are light and creamy. 


\section{Special Baked Potatoes}

Pake as for ordinary baked potatoes. When cooled sufficiently to be handled without burning the hands, cut skin from one side, scoop out contents into a hot kettle, mash and beat very thoroughly, seasoning carefully as for mashed potatoes. Fill shells, place a small piece of butter in top of each, and brown in quick oven. Grated cheese over the tops while baking is a welcome addition for many tastes.

\section{Harvest Home Potatoes}

Take smooth medium-sized potatoes, cut a thin slice from one side, scoop out contents. Mince finely, seasoning with salt and pepper and minced parsley. Place in shells and cover with very thin slices of bacon so arranged that, in cooking, the fat from the bacon may run down into the minced filling. Finely chopped celery may be added to the mixture.

Buttered bread crumbs may garnish the tops, if liked, instead of bacon.

Cracker crumbs and milk may be added to the filling. In fact almost any number of variations may be invented.

Place in hot oven and bake until thoroughly done. Set in warm oven for fifteen minutes or more before serving; this gelatinizes the filling, giving it a rich, creamy texture.

\section{Potato Soup}

Boil, steam, or bake potatoes until thoroughly done, then peel and mash very finely, adding while mashing a spoonful of flour for each good-sized potato.

Season with salt, pepper, minced celery, chives or grated onion as liked. Add milk to make desired consistency.

This is one of the most highly nutritious soups.

\section{COOKING RECIPES BY A FAMOUS CHEF}

The following recipes were compiled for this book by Emil Tenthorey, chef at Hotel Colorado, Glenwood Springs, Col. In polite society potatoes are only admitted "en robe de chambre," - that is to say, in their jackets - to the midday meal and 


\section{THE POTATO}

then not on formal occasions. At such times the following are used:

\section{Potato Georgette}

Special recipe of M. Joseph, chef of the Café Paillard: Take a potato and hollow it out, filling the hollow with a salpicon of shrimp tails drenched in a bisque sauce made from the heads and pounded bodies of the shrimps. Cover the potato with some of the mashed insides and bake very well done and serve hot.

\section{Pommes de Terre aux oeufs}

From the recipe of a famous French chef: Put a good sized lump of butter into the pan, as soon as it is hot, and brown some onions in it. Cut some cold potatoes, which have been boiled in their skins and afterward peeled, into slices. Throw these into the pan, spread over them the well-whipped yellow of two eggs. Salt, pepper and serve when the potatoes have taken a nice brown color on each side.

\section{Potatoes Hangraise}

Slices of cold boiled potatoes and onions fried together, then baked in the oven with a little grated cheese thrown over it and garnished with finely chopped parsley.

\section{Potatoes à la Maires}

Potatoes cut in rounds, boiled until barely done in salted water, drained and put in cream which has been reduced to a state of condensed richness by evaporation in a steam vessel. The reduction of the cream to one half its volume is the special and essential feature of this recipe.

\section{Potatoes Hashed in Cream}

Cut three warm boiled potatoes into small even pieces, add them to half a pint of boiled cream and a salt spoonful of salt.

\section{Potatoes Anna}

Specialty of Delmonico's, New York: Cut very thin slices from across the largest potatoes, lay the slices in flat layers on a small plate; spread fresh butter freely over the potatoes, then add another layer, and so on until the po- 
tatoes are about four inches high. Bake until the potatoes are tender (about one half hour) in a quick oven.

\section{Potatoes à la Bonne Bouche}

Slice some boiled potatoes, chop a blade of shallot, also a little parsley very fine. Place in a stewpan with a small piece of butter and a pinch of mixed sweet herbs. Let simmer slowly for five minutes, then put in the potatoes, sprinkle some seasoning over them and let simmer slowly for ten minutes, occasionally stirring to prevent burning. Just before serving squeeze the juice of a lemon over the potatoes.

\section{Potato Croquettes}

Dry boiled or steamed potatoes with butter, salt and egg yolks, all mashed together, rolled into cone shape, breaded, or rolled in cracker dust, and fry in hot lard.

\section{Potatoes Duchesse}

Large slices of raw potatoes cut in fancy shapes, sprinkled with salt, dipped in eggs and baked.

\section{Potatoes Victoria}

Same as croquettes, dipped in egg and baked to a light brown color.

\section{Potatoes Gastronome}

Potatoes raw, cut in shape of bottle corks with tube cutter, boiled barely done in salt water, drained, and finished in hot lard, dust with salt and chopped parsley.

\section{Potatoes Monico}

Raw potatoes cut size and shape of a half dollar, cooked barely done in salt water, drained and finished in hot lard. Dust with chopped parsley and paprika.

\section{Potatoes Julienne (Shoestring Potatoes)}

Cut raw into very fine shreds like straws, cook quickly in hot lard, dust with fine salt.

\section{Between the Acts Potatoes}

Same as Julienne, only cut about twice as large. 


\section{THE POTATO \\ Potatoes à l'Anglaise}

Boiled potatoes in skins, peeled, cut in quarters, shaken up with soft butter, salt and chopped parsley.

\section{Potatoes au Gratin}

Boiled potatoes sliced in cream sauce with Parmesan cheese and cracker dust on top. Bake to a golden brown in oven.

\section{Potatoes au Lard}

Stewed potatoes with finely minced bacon in the sauce.

\section{Potatoes Sauté}

Boiled potatoes cut in slices, fried in pan in hot lard or butter.

\section{Pommes Nouvelles d̀ la Crême}

New potatoes peeled and stewed in cream.

\section{Potato Queuelles}

Potatoes boiled or steamed, then mashed with salt, butter and egg yolk, rolled in balls, well breaded and fried in very hot lard.

\section{Potato en Surprise}

Bake large potatoes in the skins until three quarters done. Make a tubular opening in the end and hollow out the end. Tightly roll a thin strip of bacon, insert in the opening, close the end and bake until done.

\section{Potatoes Brétonne}

Cold boiled potatoes cut in cubes. Fry with onions and brown sauce.

\section{Potato Colbut}

Same as Brétonne. Add chopped parsley.

\section{Potatoes Natarroise}

Potatoes cut in cubes, parboiled and fried to a light color in oil.

\section{Potatoes Régente}

Same as potato croquettes - hollow out and fill with pattie mixture of lobster. Replace end and stand upright. 


\section{THE POTATO}

\section{S'aratoga Potatoes}

Cut into very thin slices, wash and steep in water for the starch to settle. Fry in hot lard. Dust with salt and pepper.

\section{HOTEL POTATOES}

The following list is from the breakfast bill of the Brown Palace Hotel, Denver, Col.:

Potatoes, French Fried....15 Potatoes, Baked........15 Potatoes, Saratoga Chips. .20 Potatoes, Julienne.......25

Potatoes, O'Brien .......30 Potatoes, Sauté.......15

Potatoes, Hashed Brown. .20 Potatoes, Parisienne.....25

Potatoes, Sweet..........25 Potatoes, Lyonnaise. . . . 20

Potatoes au Gratin.......25 Potatoes Stewed in Cream.25

Potatoes, German Fried. . 20

\section{BATTLE CREEK RECIPES}

The following recipes, which are in daily use at the Battle Creek Sanitarium, have been furnished by Miss Lenna F. Cooper, director of the Battle Creek Sanitarium School of Health and Household Economics:

\section{Peanut Potato Soup}

$1 \frac{1}{3}$ cups potatoes

1 cup cream

1 pint milk

Cook two medium sized potatoes and put through a colander. Add water, if necessary, to make $1 \frac{1}{3}$ cups; heat and add hot milk and cream; salt and serve. This makes one quart.

\section{Potato Chowder}

1 cup milk

1 cup cream

$\frac{1}{2}$ small sliced onion

$\frac{3}{4}$ pint sliced potatoes

1 pint boiling water

$\frac{1}{2}$ teaspoonful salt 
Put two thirds of the potatoes to cook in the boiling water; when tender, put them through a colander and add the remaining sliced potatoes, the onion and salt. Cook till all are tender; heat the milk and cream in a double boiler and add to the cooked potatoes. Add water to make one quart.

\section{Potato Soup}

1 cup raw sliced potatoes

$1 \frac{1}{2}$ teaspoonfuls butter

1 teaspoonful celery salt

2 cups water

Steam the potatoes and put through a colander. Add water to make two cups; season and serve.

\section{Potato Cakes}

2 cups hot riced potatoes

2 tablespoonfuls butter

$\frac{1}{2}$ teaspoonful salt

$\frac{1}{2}$ teaspoonful celery salt

$\frac{1}{2}$ teaspoonful onion juice

Yolk of 1 egg

Mix the ingredients, shape and bake in cakes; when almost done, brush the cakes with cream to glaze them.

\section{New Potatoes in Cream}

1 pint cooked potatoes

$\frac{1}{2}$ cup cream sauce

1 cup cream

\section{Lentil and Potato Loaf}

$1 \frac{1}{3}$ cups lentıl purée

2 tablespoonfuls butter

$\frac{1}{4}$ cup cream

1 teaspoonful salt

$\frac{1}{3}$ teaspoonful sage

2 cups riced potatoes

$\frac{1}{2}$ cup cream

$\frac{1}{2}$ teaspoonful butter

$\frac{1}{2}$ teaspoonful butter for brushing

Mix the first five ingredients and place in the bottom of an oiled baking dish. Whip together the hot potatoes and 
the remaining ingredients. Place this mixture on top; bake in a quick oven; serve with tomato sauce.

\title{
Creamed Baked Potatoes
}

\author{
12 medium-sized potatoes \\ $\frac{1}{2}$ cup cream \\ 1 cup milk \\ $\frac{3}{4}$ teaspoonful salt
}

Pare the potatoes and place in the bottom of a pan; cover with the milk and cream; add the salt; cover the pan and place in the oven; keep covered until the potatoes are almost done; then remove the corer and allow the milk and cream to cook down until they are somewhat thick.

\section{Creamed Potatoes and Peas}

3 pints steamed or boiled potatoes

1 can peas

1 cup cream

1 cup milk

2 tablespoonfuls flour

1 tablespoonful butter

Thicken the milk and cream with flour, braided with a little milk saved out for the purpose; add the butter; cook fifteen minutes; put the peas in and pour over the steamed potatoes.

\section{Potato and Onion Hash}

1 cup boiled onion chopped

2 cups cold boiled or steamed potatoes

2 tablespoonfuls butter

1 teaspoonful salt

Chop ihe potatoes and onions together; add salt and butter, and heat in the oven.

\section{Potato Loaf}

1 pint freshly mashed potatoes

$\frac{1}{3}$ cup cream

1 egg

1 teaspoonful salt

Mix, and place in oiled baking dish; brown in the oven. 
Savory Potato Meal Gruel

1 cup water, in which is steeped two stalks of celery

$\frac{1}{3}$ cup water

$\frac{1}{2}$ cup strained tomato

$2 \frac{1}{2}$ tablespoonfuls baked potato meal

$\frac{1}{4}$ cup cream

$\frac{1}{4}$ teaspoonful salt

Mix ingredients and heat.

\section{Baked Potato Cream Gruel}

1 baked potato

$\frac{1}{2}$ cup cream

$\frac{1}{2}$ cup water

$\frac{1}{4}$ teaspoonful salt

Mash the potato and add the other ingredients, and reheat.

\section{Baked Potato Gruel}

1 small baked potato

$\frac{1}{4}$ teaspoonful butter

1 cup water

$\frac{1}{4}$ teaspoonful salt

Mash the potato, add the butter, salt and water; hcat to boiling.

\section{Potato Meal Gruel}

$1 \frac{1}{2}$ quarts water

1 cup potato meal

Mix, heat and serve.

\section{Lyonnaise Potatoes}

3 quarts diced steamed potatoes

1 medium-sized raw onion chopped

$\frac{1}{4}$ cup chopped parsley

$\frac{3}{8}$ cup butter

Mix and heat in a double boiler.

\section{Mashed Potatoes}

1 quart mashed potatoes

$\frac{1}{2}$ cup cream or milk

$\frac{1}{2}$ tablespoonful butter 


\section{THE POTATO}

\section{Minced Potatoes?}

1 quart minced potatoes

$\frac{1}{2}$ cup cream or milk

Heat in oven.

$\frac{1}{2}$ teaspoonful salt

\section{Parisian Potatoes}

1 quart steamed potatoes

1 pint brown sauce

Place potatoes in a pan, cover with brown sauce, and bake fifteen to twenty minutes.

\section{Brown Sauce}

$\frac{1}{4}$ cup flour

$\frac{1}{4}$ cup butter

$1 \frac{1}{2}$ cups water

$\frac{1}{3}$ cup cereal coffee (liquid) broth

$\frac{1}{2}$ cup strained tomato

1 teaspoonful salt

\section{Stuffed Potato}

1 medium-sized baked potato

1 teaspoonful cream

1 teaspoonful butter

Remove the inside of the potato with a spoon, mash and mix with the cream and butter. Fill the potato shell with the mixture and put in the oven for a few minutes.

\section{Potato Salad}

1 quart diced potatoes

2 hard cooked egg yolks

Grated onion or celery

Salt for seasoning two cups of mayonnaise dressing; dice cold boiled potatoes; cut yolks in small pieces, season, mix with mayonnaise and let stand one hour before serving. 


\section{CHAPTER XXIV}

MANUFACTURES

T THE potato consists largely of starch and water. Its use in manufacturing comes 1 from the high content of the carbohydrate starch.

In the manufacturing world the potato is made use of for starch, potato flour, glucose, alcohol, and desiccated potatoes.

\section{STARCH}

The starch content in potatoes in Wisconsin is discussed in "Farmers' Bulletin 65" of the United States Department of Agriculture:

"The value of a potato crop to the grower depends mainly upon the yield and the size, form, and healthy condition of the tubers. Perfect tubers find ready sale at the best prices, while the yield in itself has no effect on the transaction, and the chemical composition of the potatoes is, as a rule, disregarded by the buyer, unless they are to be used in starch making. In every 100 pounds of average potatoes there is seventy-five pounds of water. Of the remaining twenty-five pounds about twenty pounds is carbohydrates (starch and sugar, etc.) and two pounds protein. The chief value of the potato for food as well as for starch making lies in the starch which the tubers contain. 
The protein content is low and the carbohydrates high, and, therefore, potatoes are especially valuable for use in connection with foods rich in protein, such as lean meat, eggs, etc., to furnish a well-balanced diet. The subject of the starch content of potatoes is thus seen to be one of great importance, and during recent years it has attracted increased attention from American and European investigators.

"An interesting study of the conditions affecting the starch content of potatoes, begun in 1889, is reported in the Annual Report of the Wisconsin Experiment Station for 1895. In these investigations the starch content was approximately determined by means of the specific gravity of the tubers. Since by far the greater part of the potato tuber is starch and water, and since starch is heavier than water, it is evident that the variation in starch content will affect the specific gravity of the tuber.

"Among the forty-six varieties of the crop of 1889 the variety Zenith showed the highest starch content, 22.9 per cent., and Rural Blush the least, 13.1, the average for all varieties being 16.2 per cent. In 1890 thirty-one varieties, mostly different from those tested the year previous, had an average starch content of 14.3 per cent., Burbank showing the highest, 17.7, and the Kidney, a potato from Germany, the least, 11.4 per cent. All these varieties of potatoes were grown on the same kind of soil and under practically the same cultural conditions. Still, the variation in starch content was as much as $\mathbf{9 . 8}$ per cent.

"The starch content was found to vary with the season with different tubers of the same variety. Pronged and regular tubers of four varieties 
were tested separately, and in each case it was found that the percentage of starch in the pronged tubers was smaller than in the regular tubers. This seems to be one of the causes of the variation in the starch content above referred to.

"A test of different-sized tubers of the same variety proved that there was practically no difference in the starch content of large and small tubers.

"In studying the influence of the depth at which tubers grow in the soil upon the starch content, it was found the first year that in every case the percentage of starch was largest in the deepergrowing tubers and smallest in those growing nearest the surface. When we consider the slight variation in depth at which the tubers grow in the soil these facts are significant. The next year the experiment was repeated with a trial of level and hill culture. The level culture gave higher starch content than hill culture, and the variations with the depth were greater in the hill culture than in the level culture. These facts suggest a possible explanation of the depth influence - viz., that it acts through the temperature of the soil. The deeper tubers are in a cooler medium than the shallow ones, and soil that is hilled is warmer in warm, dry weather than that which is not hilled. The variation of temperature in the deeper and shallower layers would naturally be greater in the hilled soil.

"In experiments in planting at different distances the starch content increased as the distance between the plants decreased. This seems to accord with the results of the tests of depth of planting, since close planting promotes shading of the ground and thus tends to reduce the soil temperature. 
"A test of scabby and healthy tubers of the Delaware variety showed a higher starch content in the scabby tubers than in the healthy ones, thus showing that scabby potatoes are not necessarily poorer in starch than those free from scab."

The manufacture of starch from sweet potatoes is discussed in "Farmers' Bulletin 334" of the United States Department of Agriculture as follows:

"With a view to the more complete and profitable utilization of the sweet-potato crop the South Carolina station several years ago began investigations to determine the starch content of different varieties of sweet potatoes and those most promising for starch making, how much starch can be recovered commerically from the potatoes, and the quality of the starch for commercial purposes.

"As it is usually managed at the present time, only a fraction of the crop is disposed of, all unmarketable potatoes being usually a dead loss, and frequently, through inability to market the crop promptly, great loss is suffered through damage by rotting, etc. Where the crop could be disposed of to starch factories the grower would have the following advantages: (1) All potatoes could be sold, regardless of their size. (2) No barrels or containers would be required in marketing the crop. They could be loaded into a wagon in the field and hauled directly to the factory, or to the nearest railroad and loaded into cars for shipment. (3) Grown on such a large scale, modern machinery could be employed in planting, cultivating, and harvesting the crop, thus 
reducing the cost of growing. (4) Heavier yielding varieties could be grown, which are the ones most valuable for starch production.

"Up to the time when the study of the question of producing starch from sweet potatoes was begun at this station, it was a subject that had received practically no attention in this country. It is true, starch was made from this plant on a small scale in the Southern States during the war, but the starch obtained in this way was a comparatively impure product and intended, only for home consumption.

"It would seem that the sweet potato could be profitably used for this purpose, as it contains a larger percentage of starch than the Irish potato, yields a heavier crop, and can be grown more cheaply. Another advantage it has over the Irish potato is the fact that the vines of the former make a good food for stock - some varieties being very palatable, making good hay and excellent silage. In composition they compare favorably with other forage crops.

"The development of cotton manufacturing in the South has created a demand, which is continually increasing, for starch used in 'sizing' yarn and 'filling' cloth. At present every pound of this starch is brought from other states, principally from the cornstarch factories of New York and Illinois. The experiments which we have had carried out show that for use on cotton goods the starch produced from sweet potatoes is better than cornstarch, and fully equal to the best grades of Irish potato starch. The annual production of sweet potatoes in the South Atlantic and Gulf States is about $60,000,000$ bushels, but this might be easily increased tenfold. The theoretical 
amount of starch produced per acre from a good crop of sweet potatoes is from one and one half to four times as much as from corn, wheat, or Irish potatoes per acre.

"The variety most in demand for a table potato is not necessarily the one best suited for the manufacture of starch. In fact, we can say almost conclusively that it is not, as the variety containing the largest percentage of starch is apt to be dry and insipid. Then, too, for starch production we want a prolific potato, and as a rule the heaviest yields are not of the best quality for the table. These are the most essential requirements: (1) High starch content; (2) prolificness; (3) flesh light, or white in color. The following come nearer possessing these requirements than any we have thus far examined: Providence, Southern Queen, and Triumph. Further work may show that there are other varieties better suited for this work than any of those mentioned.

"The machinery used in the station experiments was similar to that used in making starch from Irish potatoes.

"Four varieties of potatoes were used Southern Queen, Providence, Triumph, and Red Nansemond. The first three were chosen for their high starch content and light color, and one test was made of Red Nansemond to see if the color would interfere with successful starch making.

"The results of experiments carried out for two years in succession show the entire practicability of the manufacture of starch from sweet potatoes, but 'the data accumulated is yet insufficient to make any positive statement as to whether engaging in this enterprise will prove a paying investment.' 
"At the price at which sweet potatoes are sold at the present time their manufacture into starch alone would not be profitable. It must be remembered, however, that, grown on the scale which would be necessary to run one or more starch factories, there are a number of expenses which could be eliminated.

"In the conducting of a factory the following plan suggests itself as a feasible one: The factory to take over all potatoes from the farmer, select the best and even-size ones to be shipped to market for table use, and make starch from the small, over-size, and ill-shaped ones. All operations being controlled in this way by the factory on a large scale, the product could be utilized and marketed to the best advantage. In case of dull market conditions, instead of shipping the potatoes they could be canned, for which there is a great and increasing demand at the present time.

"A successful method has also been devised for evaporating sweet potatoes. In this condition they will keep indefinitely, and, owing to their concentrated form, can be shipped long distances at comparatively small cost. They would, no doubt, be quite popular if better known.

"As is the case in all paying enterprises, it would be necessary to watch carefully the byproducts and utilize them to the best advantage. A method could undoubtedly be devised for collecting the water with which the potatoes are treated in the grinding operation. This would contain the greater portion of the sugars and could be added to the pulp - from which starch has been extracted - and all sugars, starch, and fermentable matter remaining could be converted into alcohol. It has been shown that, theoreti- 
cally, fifty gallons of 95 per cent. alcohol could be produced from the residues from 100 bushels of potatoes.

"It is practically settled that the starch produced from sweet potatoes is of a high grade and suitable for use in many operations where a high grade starch is required. In all of the tests we have had made not a single adverse report has been received.

"In practical tests for laundry purposes, for sizing yarn, filling cloth, thickening colors, etc., the starch gave highly satisfactory results."

\section{ALCOHOL}

The potato is one source of industrial alcohol. In "Farmers' Bulletin 269" of the United States Department of Agriculture H. W. Wiley says:

"The most important of the uses of industrial alcohol as far as the farmer is directly concerned are those included in heating and illumination.

"It is quite certain that the use of alcohol motors on the farm will become quite common as soon as the technique of construction is practically complete and the price of alcohol is sufficiently low. Alcohol can be used for all purposes for which gasoline is employed-namely, the driving of wagons, carriages, stationary motors, water pumps, mowing machines, plows, etc. Very little change need be made in the engine of a motor car designed to use gasoline to fit it for the use of alcohol.

"Alcohol is used very extensively in the manufacture of dyes and other by-products from coal tar. The manufacture of smokeless powder is one 
of the industries in which tax-free alcohol is of the highest importance.

"One of the most important technical uses of alcohol is in the manufacture of varnishes and lacquers, where the gums which are employed are necessarily dissolved in alcohol. The use of alcohol is extremely important and affects a great many industries.

"The ether of commerce, sometimes called sulphuric ether, is manufactured exclusively from alcohol by the action of sulphuric acid and heat.

"Alcohol is used very extensively in the preparation of medicines. That great body of remedies known as tinctures is made by using alcohol as a solvent for the active principle of the herbs and plants from which the tinctures are made. The law, however, does not permit the use of denatured alcohol for 'liquid medicinal purposes.'

"The substance which is known as imitation silk is really a production from cotton or other cellulose material which, in its finished state, resembles silk somewhat in lustre. It is not silk and hence not even artificial silk. It is a textile product which has the promise of a successful future and is therefore of interest not only to the manufacturer and the consumer but to the farmer who produces the cellulose. Imitation silk is in a measure the same substance as smokeless powder, except that after it is made the nitrogenous constituents are removed, so as to restore the finished product again to the condition of ordinary cotton, devoid of explosive properties. In the making of imitation silk a partial nitrification of the cotton is accomplished in much the same manner as in making smokeless powder. The partially nitrated cotton is then reduced to a paste by solution in 
alcohol, ether, or other solvent, and in this condition is forced through small orifices, producing fine fibres of a silky lustre.

"Dilute alcohol, commonly known as low wines, can be utilized for the manufacture of vinegar. For this purpose the dilute alcohol is made to pass over the fresh shavings of beech wood.

"The flavoring extracts of commerce are made largely with alcohol as a solvent."

In "Farmers' Bulletin 268" is the following by the same author:

"'The term 'industrial alcohol' is used for brevity, and also because it differentiates sharply between alcohol used for beverages or for medicine and alcohol used for technical purposes in the arts.

"The process of rendering alcohol unsuitable for drinking is called 'denaturing,' and consists, essentially, in adding to the alcohol a substance soluble therein of a bad taste or odor, or both, of an intensity which would render it impossible or impracticable to use the mixture as a drink.

"The substance should also be of such a character that it is difficult to remove it entirely from the alcohol by any usual process of distillation.

"Industrial alcohol, therefore, is a product which is the joint work of the farmer and the manufacturer. The function of the farmer consists in the production of the raw materials from which the alcohol is to be made. The manufacturer takes these raw materials and converts them into alcohol. This is done under the supervision and control of the Bureau of Internal Revenue of the Treasury Department.

"The number of substances which have been 
mixed with alcohol to denature it is extremely large, and that particular denaturing agent should be selected which is best adapted to the special use to which the denatured alcohol is to be put. Among the substances which have been proposed are the following:

"Gum shellac (with or without the addition of camphor, turpentine, wood spirit, etc.), colophonium, copal resin, Manila gum, camphor, turpentine, acetic acid, acetic ether, ethylic ether, methyl alcohol (wood alcohol), pyridin, acetone, methyl acetate, methyl violet, methylene blue, anilin blue, eosin, fluorescein, naphthalene, castor oil, benzin, carbolic acid, caustic soda, musk, animal oils, etc.

"The materials and the quantities which are employed depend upon the purposes for which the denatured alcohol is to be used. There are many technical uses of alcohol, however, in which the pure alcohol only can be employed, and it is a question to be decided by the Bureau of Internal Revenue whether such use of pure alcohol can be permitted under the existing law.

"The raw materials from which alcohol is made consist of those crops grown upon the farm which contain sugar, starch, gum, and cellulose (woody fibre) capable of being easily converted into a fermentable sugar. Alcohol as such is not used as a beverage. The alcohol occurring in distilled beverages is principally derived from Indian corn, rye, barley, and molasses. Alcohol is also produced for drinking purposes from fermented fruit juices, such as the juice of grapes, apples, peaches, etc.

" The term ' alcohol' as used herein and as generally used means that particular product which is obtained by the fermentation of a sugar, or a starch converted into sugar, and which, from a 
chemical point of view, is a compound of the hypothetical substance ethyl with water, or with that part of water remaining after the separation of one of the atoms of hydrogen. This is a rather technical expression, but it is very difficult, without using technical language, to give a definition of alcohol from the chemical point of view. There are three elementary substances represented in alcohol: Carbon, the chemical symbol of which is $\mathrm{C}$; hydrogen, symbol $\mathrm{H}$; and oxygen, symbol $\mathrm{O}$. These atoms are put together to form common alcohol, or, as it is called, ethyl alcohol, in which preparation two atoms of carbon and five atoms of hydrogen form the hypothetical substance ethyl and one atom of oxygen and one atom of hydrogen form the hydroxl derived from water. The chemical symbol of alcohol therefore is $\mathrm{C}_{2} \mathrm{H}_{5} \mathrm{OH}$. $\mathrm{Ab}$ solutely pure ethyl alcohol is made only with great difficulty, and the purest commercial forms still have associated with them traces of other volatile products formed at the time of the distillation, chief among which is that group of alcohols to which the name fusel oil is applied.

"Starch is a compound which, from the chemical point of view, belongs to the class known as carbohydrates - that is, compounds in which the element carbon is associated by a chemical union with water. Starch is therefore a compound made of carbon, hydrogen, and oxygen, existing in the proportion of two atoms of hydrogen to one atom of oxygen. Each molecule of starch contains at least six atoms of carbon, ten atoms of hydrogen, and five atoms of oxygen. The simplest expression for starch is therefore $\mathrm{C}_{6} \mathrm{H}_{5} \mathrm{O}_{5}$.

"The principal starch producing plants are the cereals, the potato, and cassava. With the po- 
tato may be classed, though not botanically related thereto, the sweet potato and the yam. Among cereals rice has the largest percentage of starch and oats the smallest. The potato, as grown for the table, has an average content of about 15 per cent. of starch. When a potato is grown specifically for the production of alcohol it contains a larger quantity, or nearly 20 per cent. Cassava contains a larger percentage of starch than the potato, varying from 20 to 30 per cent.

"Under the microscope the granules of potato starch have a distinctive appearance. They appear as egg-shaped bodies on which, especially the larger ones, various ring-like lines are seen. With a modified light under certain conditions of observation a black cross is developed upon the granule. It is not difficult for an expert microscopist to distinguish potato from other forms of starch by this appearance.

"The mineral matters which the potato extracts from the soil or from the fertilizers which are added thereto consist chiefly of phosphate and potash. The mean average composition of the ash of the potato is shown in the following table:

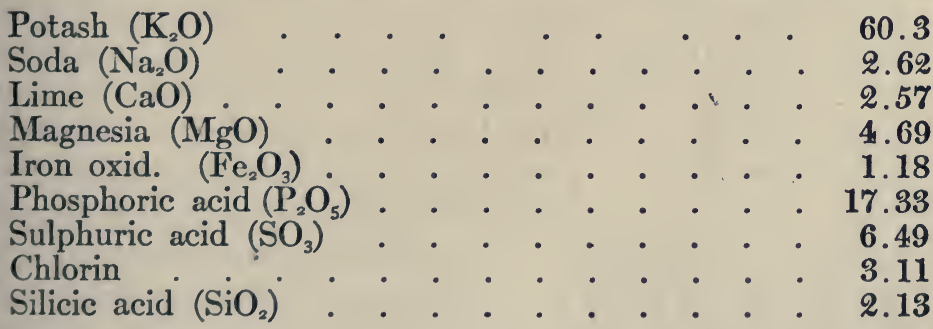

"This analysis was made upon the so-called pure ash, deprived of its unburned carbon, and freed of sand and carbon dioxid. 
"Of all the common root crops, the potatoes, including the yam and the sweet potato, are the most valuable for the production of alcohol, meaning by this term that they contain more fermentable matter for 100 pounds than other root crops. This is shown by the following comparative statement:

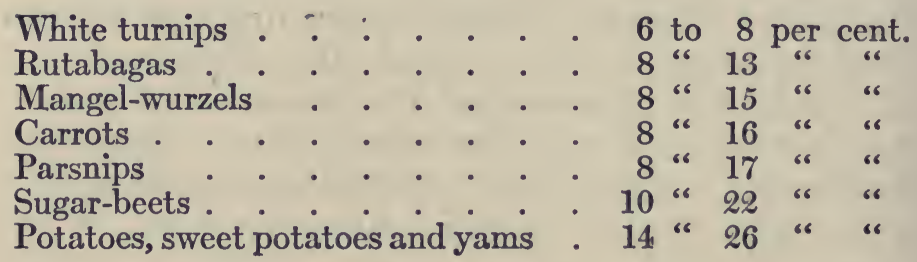

"Under the most favorable circumstances and with potatoes which have been bred especially for the purpose an average content of fermentable matter of about 20 per cent. may be reasonably expected. It is thus seen that approximately ten pounds of industrial alcohol can be made from one hundred pounds of potatoes. If sixty pounds be taken as the average weight of a bushel of potatoes, there are found therein twelve pounds of fermentable matter, from which six pounds of industrial alcohol can be produced, or six sevenths of a gallon. It has also been shown that at the prices quoted in 1905 the amount of Indian corn necessary for the production of a gallon of industrial alcohol costs not less than 15 cents. From this it is evident that the potatoes for alcohol making will have to be produced at a cost not to exceed 15 cents per bushel before they can compete with Indian corn for the manufacture of industrial alcohol.

"The three principal steps in the manufacture of 
alcohol are (1) the preparation of the mash or wort, (2) the fermentation of the mash or wort drawn off from the mash tun, and (3) the distillation of the dilute alcohol formed in the beer or wash from the fermentation tanks. The preparation of mash includes (1) the treatment of the material used with hot water to form a paste of the starch or the sugar, and (2) the action of the malt or ferment on the paste to convert the starch into fermentable sugar.

"The object of the mash tun is to reduce the starch in the ground grain to a pasty, gummy mass, in order that the ferment of the malt may act upon it vigorously and convert it into sugar. If the mashing be done before the addition of the malt the temperature may be raised to that of boiling water. If, however, the malt be added before the mashing begins, the temperature should not rise much, if any, above 140 degrees $F$., since the fermenting power is retarded and disturbed at higher temperature. The mashing is simply a mechanical process by means of which the starch is reduced to a form of paste and the temperature maintained at that point which is best suited to the conversion of starch into sugar.

"The mash, after the starch has all been converted into sugar, goes into fermenting tanks, which in Scotland are called 'wash backs' when the yeast is added. They often have a stirring apparatus whereby the contents can be thoroughly mixed with the yeast and kept in motion. This is not necessary after the fermentation is once well established, but it is advisable, especially in the early stages, to keep the yeast well distributed throughout the mass. In these tanks the fermentations are conducted, the temperature being varied according to the nature of the product to 
be made. For industrial alcohol the sole purpose should be to secure the largest possible percentage of alcohol without reference to its palatable properties."

Consul John H. Grout, Odessa, Russia, says:

"In the alcohol-distilling industry of Russia potatoes are annually increasing in importance. the alcohol produced therefrom exceeding that produced from all other sources.

"Aside from the large quantities of potatoes purchased every year by the factories from peasant producers and estate owners whenever these may have a surplus which they cannot more profitably dispose of, there are large plantations devoted solely to the production of potatoes for distilling purposes, there being also a tendency to increase these plantations.

"The potato crop of 1910 for European Russia was greatly in excess of that of the previous year, which was also a good one, and the quality of the tubers was in most districts better than in 1909 . It is generally supposed that the climate of Russia is favorable for the production of potatoes in vast quantities, and that, with the aid of fertilizers, their production can be increased to meet all demands of distillation, the production of denaturized sprits for industrial and illuminating purposes now being only in its infancy."

\section{DRIED OR DESICCATED POTATOES}

It is the opinion of Secretary of Agriculture James Wilson and other close students of the food supply of the world that there should be some way 
of preparing and preserving potatoes that stocks may be carried over from the "fat" (large producing) to the "lean" (small producing) years. This would balance or equalize supplies to guard against possibility of famine or an approach to it because of crop shortage in densely populated countries.

In the Daily Consular and Trade Reports of the Bureau of Manufactures of the Department of Commerce and Labor, February 19, 1910, Consul Thomas H. Norton, of Chemnitz, describes a process recently introduced by a Prussian firm by which potatoes may be converted into a dry concentrated meal. He writes as follows:

"The potato occupies a relatively more important position in Germany than in other European countries. It is not only employed largely for food for both man and beast, but also for conversion into starch and alcohol. The 1908 crop was estimated at 46,500,000 metric tons $(51,256,950$ short tons), 13,000,000 tons being used for human food and 19,000,000 tons for feeding domestic animals. Starch factories utilized 1,500,000 tons, distilleries 2,500,000 tons, while $5,500,000$ tons were required for seed. There remained $5,000,000$ tons, lost by decay, freezing, etc. German economists have recognized the extent of this national loss, of about $\$ 28,500,000$ in value, especially because the empire now imports annually about $\$ 72,000,000$ worth of cattle fodder. Nearly 40 per cent. of this sum, paid to foreign agriculture, could be saved if the loss by subsequent decay in the harvest potato crop could be prevented.

"Numerous processes have been submitted in response to an offering of prizes amounting to 
$\$ 6,000$. These are based upon two distinct methods of treatment. In the first, sliced potatoes are exposed to the current of hot gases from a furnace; in the second, the flake process, potatoes are more finely divided, and dried at a lower temperature with the aid of steam coils. This last method is costly. The product of the first method, while available for industrial purposes, is not fully satisfactory for use as a fodder.

"A process recently patented and introduced by a Prussian firm seems to have successfully overcome the disadvantages of the earlier systems. The essential features consist in the use of pressure combined with a vacuum for withdrawing the bulk of the water in potatoes, the further drying of the residue by artificial heat, and the isolation of albumen found in the press liquor. This process has been tried with excellent results on an industrial scale.

"The plant employed is comparatively simple. The potatoes are first thoroughly washed in a large vat provided with a stirring apparatus. Thence they pass into a mashing machine, and the pulpy mass is pumped into a reservoir, and from this is fed through a large funnel into the suction machine. The latter is the central feature of the plant and presents a somewhat novel form of utilizing the vacuum principle. It consists of two hollow cylinders, one immediately above the other. The exterior is made of perforated plate similar to that employed in centrifugal machines and filter pumps, and is covered with linen filtering cloth. A pipe connects the interior of each cylinder with an air exhaust. The interior spaces are, however, divided into segments, and the construction is such that the lessened pressure in each segment is 
felt when it is in immediate contact with the companion cylinder. As the potato pulp passes between the two cylinders, not only their pressure, but also atmospheric pressure, removes nearly all liquid. The residual mass falls into a trough and is conducted by a helical conveyor to small cars. These pass into a hydraulic press, where the mass is finally deprived of all water capable of removal by pressure.

"From the press the potato mass is transferred to the drier. This consists of a cylindrical chamber, within which there is a revolving drum, divided horizontally into ten sections. The upper seven sections are heated by connection with a series of steam pipes; the lower three are cooled by means of a similar series, through which water circulates. The pressed potato cake is continuously fed into the top section. From this it gradually descends through openings into the lower sections, one after another, until it finally issues from the bottom compartment and is conveyed to storage rooms. The construction of this revolving drum is such that prongs attached to its axis continually stir up and crumble the nearly dried potato cake, so that it is in coarse grains when it leaves the apparatus. At the same time, by means of properly directed air currents and the aid of the elevated temperature in the upper seven sections, nearly all moisture remaining after the treatment in the press is effectively removed.

"The resultant coarse potato meal has one quarter of the original weight of the tubers employed, and occupies one eighth of the space. It has an odor and taste similar to that of freshly made bread. It may be used or kept in this condition, or can be pressed into compact cakes for 
convenience in transportation. The chemical analysis of potato meal, dried as above described, gives the following percentages: Water, 11.50; fat, 0.31 ; protein, 3.73; ash, 2.06; fibre, 1.71; carbohydrates, 80.69.

"Pressed potato cake is easily broken up by hand, and can be fed to animals, alone or mixed with other forms of fodder, preferably after moistening with a little water, when it is at once softened.

"By the combined processes of pressure and suction nearly three quarters of the weight of raw potatoes are removed in the form of a cloudy liquor. This portion is allowed to stand in reservoirs until all traces of starch have settled to the bottom. The clear liquor is then boiled and filtered with the aid of a vacuum apparatus. A precipitate is obtained of crude protein amounting to about 2 per cent. of the original weight of the tubers. By proper treatment this yields about 80 per cent. of technically pure albumen, which is constantly in demand in German markets.

"The residual liquors from the protein precipitate contain small amounts of sugar, salts, and nitrogenous matter. They can be advantageously used for irrigation purposes on agricultural lands.

"The plant requisite for the treatment of 10,000 tons of potatoes during a season of about eight months costs $\$ 18,000$ to $\$ 19,000$. The machinery alone, without a press for transforming the meal into cakes, costs $\$ 12,000$. For a building, $\$ 3,000$ suffices, and the remainder is needed for pumps, motive power, washing vats, etc.

"The force needed to operate the plant con- 
sists of seven men, and includes one engineer, a stoker, one helper, one workman in the potato cellar, two to attend to the machines, and one to handle the residual liquors. If the final product is to be pressed into cakes, the additional cost of the plant is about $\$ 4,000$, and two more operatives are required. Such an installation can naturally be operated with great economy in connection with a distillery or starch factory.

"In practice it is found that the total cost of preparing unpressed potato meal by the above method (including interest, depreciation, etc.) is $\$ 0.56$ per long ton of tubers. The additional cost for pressing into cakes is $\$ 0.12$ per ton of potatoes. In estimating the cost of the fodder thus produced it is, of course, necessary to deduct a certain sum for the albumen extracted from the residual liquor, as mentioned above. When potatoes are to be raised for supplying regions more or less remote with cattle fodder the advantage of having the nutritive constituents of the tuber in a concentrated form is obvious. Thus, in practice, 3.8 tons of raw potatoes yield one ton of the desiccated product. The freight charges in Germany for transporting (in carloads) the 3.8 tons a distance of 100 kilometers (62 miles) are $\$ 3.07$. The freight charge, under similar conditions, for the one ton of meal would be $\$ 0.81$. Adding to this the cost, 56 cents per ton, of treating the 3.8 tons of raw potatoes, or $\$ 2.13$, the total expense of delivering the fodder would be \$2.94. At the comparatively short distance of twenty-six miles there is then a distinct economy in shipping the meal instead of tubers. With every increase in distance there would be a proportionate increase in the saving. 
"In these days of rising values for all meat products there is a prospect that the newly introduced process will aid materially in decreasing the cost of cattle raising in various sections of the empire, where stock raisers are largely dependent upon fodder transported from a distance."

The manufacture of desiccated potatoes has been started in the United States.

C. F. Langworthy, in "Farmers' Bulletin 295," says:

"Potatoes are so valuable in the diet that many attempts have been made to put them into a compact form in which they can be kept for a long time. This is usually accomplished by drying them, which both preserves them from decay and reduces their bulk. One of the oldest of such preparations is one long used in Peru and known as chunno. To make it, part of the juice is pressed out of the potatoes, which are then dried in the air until they are reduced to about one fourth of their original weight. There is a variety of similar preparations in American and European markets, and although the mode of procedure differs considerably in the various brands the main principle is the same - namely, to check bacterial action. The changes which we call decay are caused mainly by the development of bacteria. These can reproduce only where there is moisture and warmth present. Therefore, if the moisture is removed, their growth is retarded. The fact that the bulk of the potatoes is reduced at the same time is especially advantageous because such dried preparations are used mainly for camping expeditions, long sea voyages, and under other conditions where 
storage space is at a premium. The composition of such desiccated or evaporated potatoes is practically that of the original tubers minus more or less of the water. Of course, if extreme heat is used in the preparation, part of the starch may be changed to dextrin and there may be other minor changes in the chemical composition. There is no reason to believe that these decrease the nutritive value. Various kinds of desiccated potatoes have been studied at the California Agricultural Experiment Station. Their water content ranged from 4.8 to 7.9 per cent. and their total carbohydrates from 77.9 to 80.6 per cent. In fact, their general composition was not unlike that of good white flour. They contained slightly less water, protein and fat, slightly more carbohydrates, and noticeably more mineral matters. Of course desiccated potatoes are supposed to be soaked in water before using and in this way regain somewhat their original characteristics. While their flavor and appearance cannot equal these of good fresh potatoes, they are considered very appetizing and acceptable where fresh ones are unobtainable.

"Chemical substances are sometimes used for improving the color (i. e., 'bleaching') of desiccated potatoes. While a small quantity of these may be harmless, their continued presence in the diet might be very dangerous, and their use is not to be recommended.

"Canned potatoes are on the market and are prepared for use in camps or wherever it is not convenient to cook food. They also may be kept in good condition for a long time. In composition such goods do not differ from similar freshly cooked potatoes." 


\section{MANUFACTURING AT KYRITZ, GERMANY}

During the season of 1910 the senior author made a study of manufacturing potato products in Germany, and his notes follow:

"The manufacture of starch, potato, flour and glucose at this place was started in 1872. It is now one of the largest and most successful manufacturing centres. The factory there claims to produce the best product in Germany. There are from twenty to thirty factories in the country.

"The factory is an immense affair, as large as a million dollar beet-sugar factory in the United States and equipped with the finest machinery. Everything in the factory is kept polished and clean. Germans are noted for this in all their manufacturing plants.

"Potatoes come to the factory in cars in bulk. The factory starts about September 1st, or as soon as starch is developed in the potatoes.

"The company which owns and operates the factory is owned jointly by the growers and business men of Kyritz. It must be operated at a profit. As manager, Mr. Bergmann was anxious to know if there were opportunities for factories in America.

"In the factory every economy that German science and mechanics can invent is employed for the cheap handling of the product, for saving greatest per cent. of high-class products and conserving the by-products.

"One of the most interesting features was a pipe line for carrying the water that had been used in extracting the starch from the sliced or pulped potato to a waste piece of sand land grown 
up to heather, two miles distant. This was reclaiming and building up the fertility of this land. It was seeded to pasture grasses and 200 acres furnished grazing for 300 head of stock.

"The pulp or waste is used for stock feeding, the same as beet pulp from sugar-beet factories, but the Germans prolong its use more than we do by drying it so that it retains its feeding value for a year. It is mostly used for cow and pig feed.

"Farmers who live long distances from the factory manufacture coarse or crude starch on their farms and ship the gross product to the factory for refining and manufacturing, saving the transportation on raw potatoes and keeping the pulp for their stock.

"Potato flour is usually called rough starch. The process of manufacturing has recently been very greatly improved and still greater improvements are now contemplated.

"The price of starch and flour is the same. It is ruled by the price of wheat and sells at about the same price per hundred.

"Rye flour is improved for baking by its addition. Cake makers and confectioners use it mixed with wheat flour. It makes delicious and nutritious puddings and cakes. The usual price is $\$ 5$ per barrel of 200 pounds.

"When the manager was asked why they had so many casks racked up at a starch factory, he replied: 'I had hoped you would not see them or ask me about them. They are casks in which we ship glucose in to the confectioners of London, Paris, Berlin, and other large cities.'

"This glucose is one of the by-products of the factory. It is of the highest quality and brings more money than glucose manufactured from 
cereals. It sells for 75 cents more per 200 pounds than flour.

"This factory uses 250,000 tons of potatoes annually. The price paid for potatoes of 18 to 24 per cent. starch content is 20 to 35 cents per hundred, or 12 to 21 cents per bushel. One of the by-products is 3,500 tons of glucose.

"The farmers in irrigated districts of the West can make splendid incomes for growing potatoes for starch. It can also be done by the farmers of the potato-growing states of the East when they bring their lands up to the productiveness they are capable of.

"The manufacturing of small and waste and rough potatoes every year, feeding the pulp, and making desiccated potatoes in seasons of overproduction, will make the potato industry more stable and make the prices more even.

"With our cheap electric power and coal, as compared with Germany, this manufacturing of potatoes should be more profitable here.

"The manufacture of alcohol from potatoes keeps the price of gasoline comparatively low in Europe." 


\section{CHAPTER XXV}

POTATOES AND POTATO PRODUCTS AS STOCK FEED

N A basis of strict economy as regards the use of the world's supply of foodstuffs, it would probably never be right to feed potatoes fit for human food to livestock.

Granting this, the potato has yet a place of some importance as a stock food. There are thousands of tons of small, cut, bruised and diseased potatoes produced annually in potato districts that should be converted into high-class animal products. In addition to this, there are the by-products of the various manufacturing processes in which the potato is used

The feeding of potatoes and potato products has been practised more in Europe than in America, because the American farmer has had, since the beginning of agriculture in this country, an abundance of cheap grains for stock feeding.

We have undoubtedly seen the last of extremely low-priced grains - so that the heavy cropping, succulent potato, should have a place of increasing importance as one part of stock feed rations.

In "Farmers" Bulletin 79" of the United States Department of Agriculture is the following interesting information:

"A number of French agriculturists have recently studied the desirability of ensiling potatoes." 
A considerable amount of heat is generated by the fermentation of the green material in silos, and it was thought this could be utilized and the potatoes could be cooked as well as preserved.

"In one test the potatoes were buried in a silo filled with crimson clover. They acquired the characteristic color of the plant and the odor developed in fermentation. The tubers were flattened by the heavy pressure to which they had been subjected. When removed from the silo they were comparatively soft. They were examined microscopically and chemically, and it was found that they had been cooked by the heat of fermentation, and that they were rendered more digestible by the process; that is, the percentage of soluble material was increased.

"Another silo was filled by surrounding about a ton of potatoes with corn (whole plant). Upon opening, the corn and potatoes were both found in good condition. The tubers were found somewhat flattened, as in the previous experiment, but were more cohesive. The potatoes were not as thoroughly cooked, since the temperature and pressure were less than in the previous case.

"As shown by analysis, the potatoes ensiled with crimson clover had lost less water than those ensiled with corn. The most striking difference, however, was the high percentage of cooked starch; or in other words the increased assimilability of the potatoes ensiled with clover. The crushed potatoes when removed from the silo lost weight very rapidly on exposure to the air, and formed a hard mass, containing only 15 to 20 per cent. of water. In this condition they could be kept for a long time. When required for feeding purposes they were soaked in water, which they readily 
absorbed and thus regained their softness and digestibility.

"Another investigator ensiled chopped raw potatoes with two pounds of salt per 1,000 pounds of potatoes, under pressure of 2,500 pounds per square yard. The total cost of washing, chopping, putting in the silo, and weighing fifty tons of potatoes was about $\$ 15$. The potatoes were put in the silo in the latter part of November. When the silo was filled the material was five and a half feet deep. Sixty-two days later the silo was opened, and the mass had sunk to a little over three feet. The temperature of the silo when filled was 39 degrees F., and when opened it was 50 degrees. The ensiled potato pulp was white, but became blackened on exposure to the air. Cattle ate this pulp greedily, alone or mixed with cottonseed cake.

"Experiments made at the Minnesota station have shown that while the digestibility of cooked and raw potatoes by pigs was about the same, pigs could be induced to eat larger quantities of cooked potatoes. It was calculated that a ration of fifteen pounds of potatoes and four pounds of shorts would furnish an amount of protein sufficient for maintenance, leaving a margin for growth.

"On the basis of cost, comparisons were made of the value of potatoes and other feeding stuffs. In the investigator's opinion, with foods at the present prices, it is doubtful whether it would be profitable to feed large amounts of potatoes to dairy stock, because cows require more protein than would be supplied by a fattening ration similar in character to that mentioned above. 
"Potatoes cannot be fed to young animals as safely as to more mature ones, since if fed in too large quantities they have a tendency to prematurely fatten the animal. With mature animals when the object is principally the addition of fat to the body, potatoes may be fed to good advantage.

"When the crop of potatoes is large and prices low, a method of storing and feeding potatoes to advantage is desirable.

"A method of preserving potatoes which at the same time cooks them would seem worthy of trial, but it would doubtless be wise to experiment on a small scale first."

John M. Scott, in Florida Agricultural Experiment Station "Press Bulletin 71," says:

"In all feeding experiments it has been found that rations containing a high percentage of carbohydrates (fat and heat producing material) do not give good returns in producing meat; but if sufficient protein (muscle and bone producing material) is added, so as to give the animal a balanced ration (or one nearly balanced) the results are generally satisfactory. It makes little difference in what feeds the carbohydrates are furnished so long as the material is digestible. Since sweet potatoes are a crop easily grown, give good yields, are well adapted to the soils and climate of Florida, and contain a large percentage of carbohydrates, some notice should be taken of them, and they deserve to be studied in order to find out their value as a feed for pork production.

"It has been pretty clearly demonstrated that sweet potatoes when fed alone are a poor feed for 
pork production. This is due to the fact that sweet potatoes contain such a large amount of carbohydrates and such a small percentage of protein. The results of these experiments may be summarized as follows:

"In a feeding test lasting forty-two days, four pigs were fed on sweet potatoes only, during which time the pigs lost in weight instead of making a gain. The pigs in this test were rather small, averaging only twenty-two pounds. In another experiment with older pigs, averaging about one hundred pounds, the results were a little more favorable; yet the gains in weight were not large enough to make it a paying investment to feed sweet potatoes alone. When some other feed was used in combination with sweet potatoes, the results were quite different. In one test lasting for a period of twenty-eight days pigs averaging 150 pounds were fed sweet potatoes and shorts in the proportion of one part shorts to six parts sweet potatoes by weight. The pigs made good daily gains, giving the sweet potatoes a value of about 50 cents per hundred (when pork was worth 5 cents per pound) for pork production.

"This may perhaps seem a very small price for the farmer to receive for his sweet potatoes, but it certainly gives him an idea as to the feeding value of his potato crop. If the market price of potatoes should fall as low as 65 cents or 70 cents per hundred, it would be a question whether or not the farmer could best afford to put his crop on the market or feed it to his hogs."

In "Farmers' Bulletin 410," the analysis of potatoes, potato skins, and potato slop is given as follows: 


\begin{tabular}{|c|c|c|c|c|c|c|c|}
\hline Material & Ash & $\begin{array}{c}\text { Protein } \\
\text { (Nx 6.25) }\end{array}$ & $\begin{array}{c}\text { Ether } \\
\text { extract } \\
\text { (fat) }\end{array}$ & $\begin{array}{l}\text { Sugar as } \\
\text { dextrose }\end{array}$ & Starch & $\begin{array}{l}\text { Crude } \\
\text { fibre }\end{array}$ & $\begin{array}{l}\text { Nitro- } \\
\text { gen free } \\
\text { extract }\end{array}$ \\
\hline I & $\begin{array}{c}\text { Per } \\
\text { cent. }\end{array}$ & $\begin{array}{l}\text { Per } \\
\text { cent. }\end{array}$ & $\begin{array}{c}\text { Per } \\
\text { cent. }\end{array}$ & $\begin{array}{l}\text { Per } \\
\text { cent. }\end{array}$ & $\underset{\text { cent. }}{\text { Per }}$ & $\begin{array}{c}\text { Per } \\
\text { cent. }\end{array}$ & $\begin{array}{c}\text { Per } \\
\text { cent. }\end{array}$ \\
\hline Potato & 4.39 & 10.06 & 0.29 & 1.59 & 70.35 & 2.26 & 10.55 \\
\hline skins & 6.51 & 21.87 & 2.55 & 1.44 & 8.65 & 20.69 & 38.40 \\
\hline Slop & 11.26 & 30.00 & .69 & 2.29 & 2.98 & 6.54 & 46.24 \\
\hline
\end{tabular}

"This table shows that the dry substance in the slop is very different in composition from the potato itself, being a more highly nitrogenous food. The great increase in the amount of protein as compared with the total dry substance in the slop is, of course, due to the fermentation of the starch and sugar, resulting in a concentration of the nitrogenous material.

"Any scheme for the operation of agricultural distilleries, whether small or large, should provide for the utilization of the by-product known as 'slop.' This is the residuum remaining after the alcohol and a small amount of water have been boiled off from the fermented distillery mash; and it contains, dissolved or suspended in the remaining liquid of the mash, all of the constituents of the materials employed except that portion of the sugars and starch which was converted into alcohol during the fermentation. This slop has been found, both in this country and abroad, to be a feeding stuff of high value and should be fed to the stock on the farm that furnishes the raw materials used in the distillery. In this way its full utilization can be secured. First, through the production of flesh, milk, or energy in the stock to which it is fed; and, second, by returning to the soil in the 
form of manure those necessary elements of plant food which were abstracted during the production of the potatoes or other raw materials.

"The large proportion of water contained in all slop has an important bearing in determining the amount of slop solids which can be fed to any animal in one day. It has been customary in this country, where cattle have been fed with slop in sheds on the grounds of large whiskey and alcohol distilleries and not on the farm, to allow each bullock daily the volume of slop corresponding to a bushel of the grain mashed. In other words, a distillery mashing 1,000 bushels daily will distribute its slop among 1,000 head of cattle. Reduced to volume, this would be equivalent to about thirty gallons per head per day. This amount is excessive, even when fed with considerable quantities of hay and other roughage, as is shown by the flabbiness of the stock and the liquid character of their manure. The injurious effect of the slop when fed excessively, as heretofore in this country, is liable in the case of milch cows to result in dangerous contamination of their milk through the great difficulty of keeping their hindquarters clean.

"In Germany, where slop feeding has been practised very successfully on the basis of careful investigations at the agricultural experiment stations, it is customary to feed much smaller volumes. According to Maercker, it is allowable to give from eighteen to twenty gallons per head per day in fattening oxen weighing from 1,300 to 1,400 pounds. More than this amount has been found injurious. Milch cows should not receive more than sixteen gallons daily. It is necessary to feed the slop as hot as possible, and since it is 
especially susceptible to bacterial decomposition it should also be fed when fresh.

"Investigations are needed in this country to determine the composition of rations, suited to American conditions, in which potato slop takes its proper place." 


\section{CHAPTER XXVI}

POTATOES FOR EXHIBITION: SCORE CARDS AND STANDARDS

7 HE interest in exhibits of agricultural products increases yearly. Never before in the history of this country have the most representative and influential people so keenly realized the importance of farming, and this is manifested in the apparent demand for shows at which are displayed the products of the soil.

To see the results of the most advanced work in farming helps the producer, the dealer, and the consumer. The producer is spurred to do his best, and the rivalry between growers makes the product better each year; the dealer is educated as to better sorts, and methods of marketing are improved, and the consumer learns to know and appreciate the best, thereby increasing consumption.

The Old World is far in advance of America in some features of agricultural exhibitions. There, shows are held for agricultural exhibits alone, without the disgusting so-called "attractions" and fake shows that characterize so many American fairs. A change is coming rapidly in this country, brought about largely by the representatives of the agricultural press. These broad-minded, hardworking gentlemen have had and continue to have in a greater degree than ever before a most wholesome and uplifting influence for higher ideals in American agriculture. • 
The selection and exhibition of potatoes is a fine art in England, the potato being one of the principal features in their agricultural shows. Recent shows in this country, notably the Chicago Land Shows in 1909 and 1910 and 1911, and the New York Land Show of 1911, have had most creditable exhibits, and there are plans now under way for displays better and more elaborate than any yet made. During the next decade visitors to American agricultural fairs will see remarkable advances in the modern potato.

Exhibitions of the past have been a factor in increasing the demand for high-class potatoes, and in the future will be an even greater factor in making demand and increasing per capita consumption. These displays show discerning people that there are potatoes and potatoes, the same as other food products, and they teach themselves to distinguish between the good, bad, and indifferent.

The work of preparing potatoes for exhibit should begin with the selection of strong, true-totype seed, and include everything that is correct in cultural methods. A deep, mellow, well-aired seed bed is especially important. This permits the tubers to grow naturally and evenly.

At digging time the potatoes are either carefully dug with a fork, or selected as they are turned out by the digger. The ground should be perfectly dry and every precaution taken to prevent bruising and peeling. This is particularly important when the tubers are not entirely ripe.

As they are gathered they should be allowed to remain in the sun only long enough to dry and harden the skin - probably two or three hours. As soon as thoroughly dry, the potatoes may be 


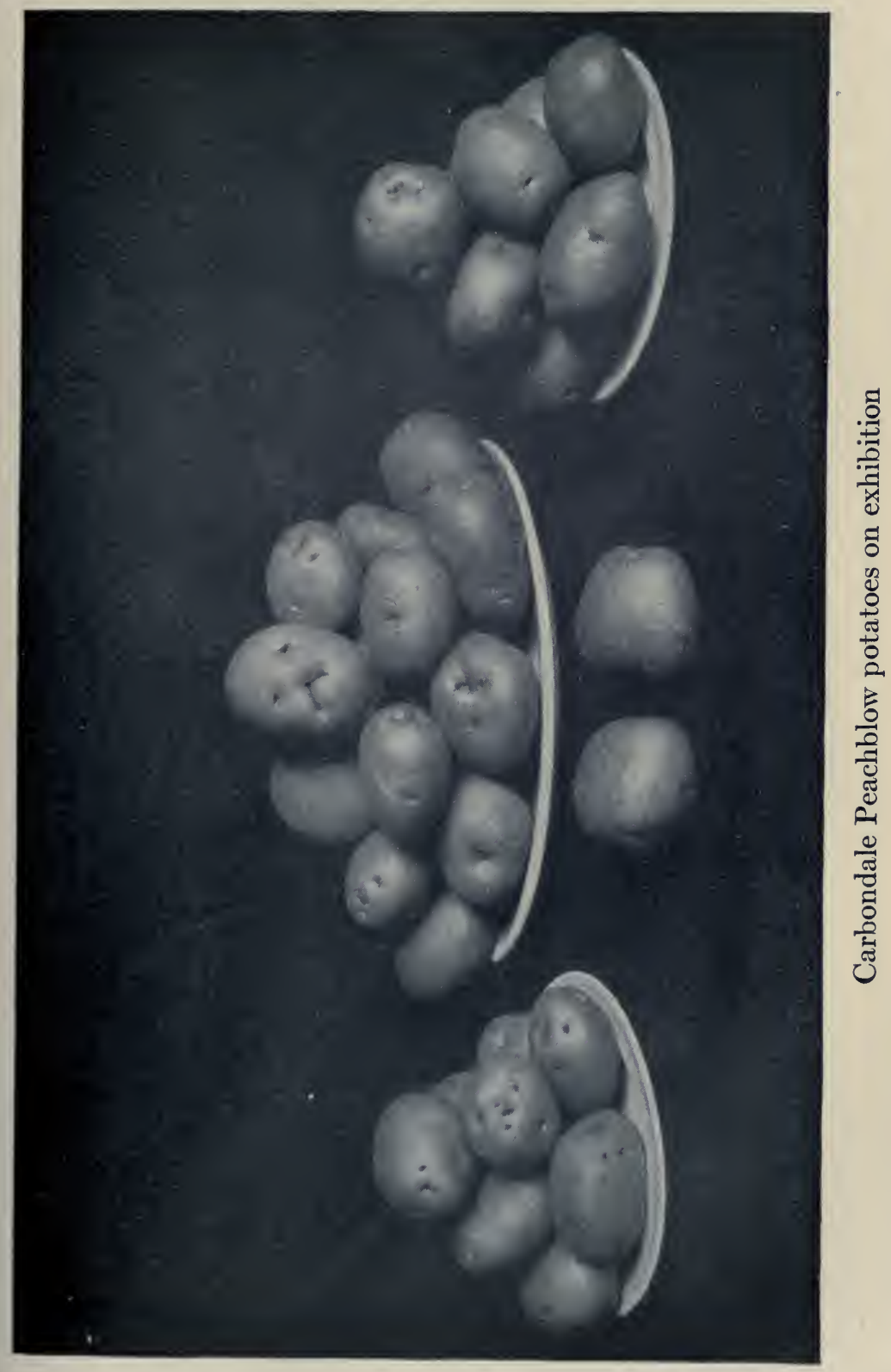




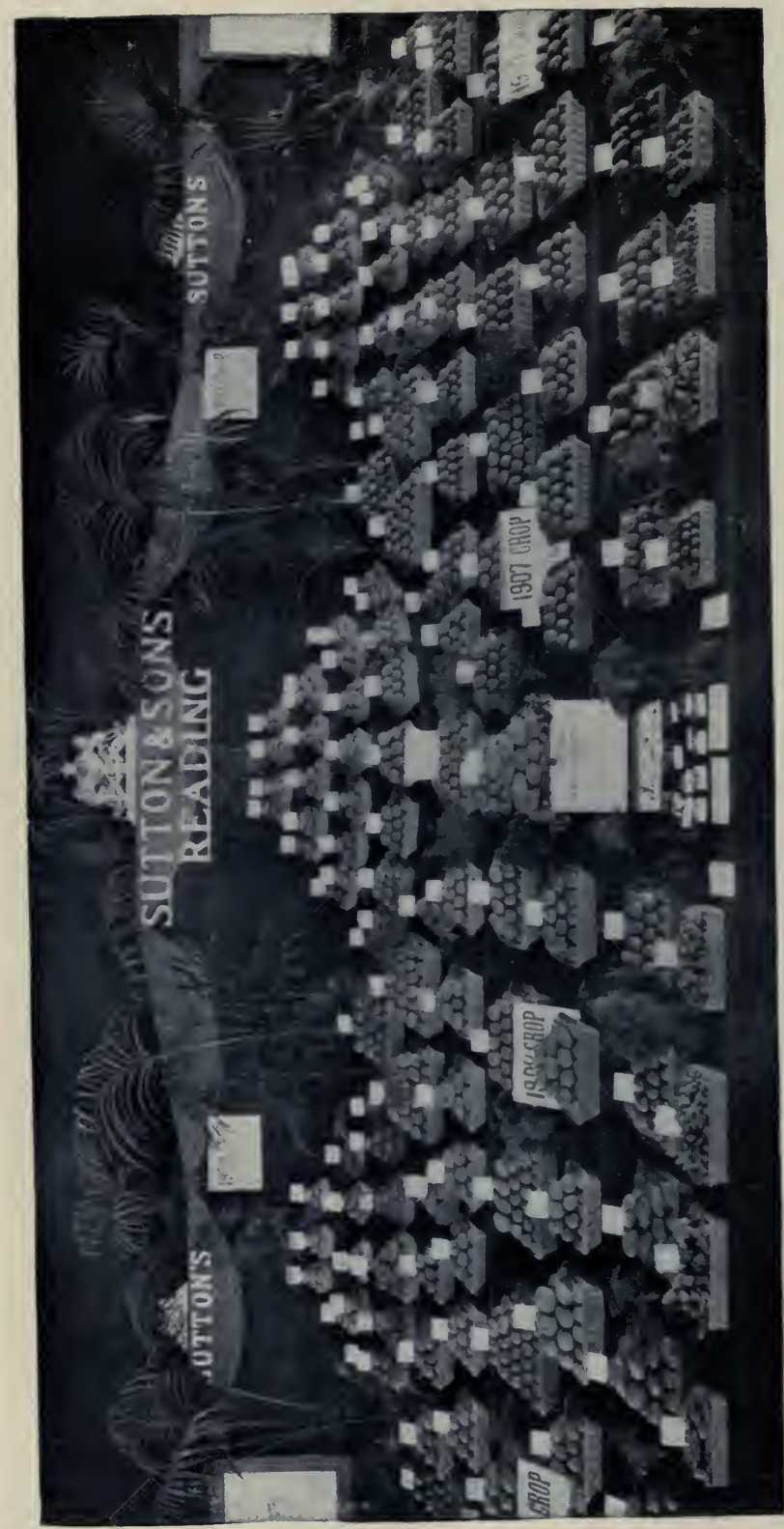

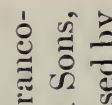

$\approx \Xi$

ย స

†

$\omega \equiv$

荥 $\overrightarrow{0}$

$\geq$ 을

플

$\checkmark \pm$

氝 $\frac{0}{\sqrt{2}}$

.

A 5

글 을

๘

$5 \div 3$

हี

$\forall$ ت

¿ 0

‡ 0

की झु

吾 $\frac{0}{0}$

등 응

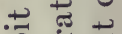

는

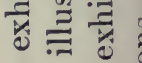

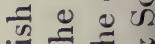

है $E$

길

¿ ¿્త

.

를

$\pm=$

है $=\hat{s} \cdot \frac{0}{\pi}$

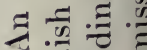

$4:$ 芯 
carefully brushed with a soft brush - to remove all dirt and dust - then wrapped in soft paper and carefully packed in slatted crates. If potatoes are left in the sun too long they turn green.

Exhibition potatoes must be kept in a cool, dry place and should be examined frequently to make sure that all conditions are right. The kind of potato that wins in the shows is one that is of the greatest commercial value - a smooth even tuber weighing ten to sixteen ounces, with clear, diseasefree skin, shallow eyes, and the lustre and bloom that make an attractive appearance. It must be true to the type of the variety, and each potato as nearly like the others as possible.

Shows encourage growers, keep old varieties distinct and bring about the production of new ones of higher quality and usefulness.

The big overgrown potato is no longer a factor . at a show except as a monstrosity.

At the show, the ideas of the exhibitor as regards attractive display make the individuality of the exhibit. The one important thing to keep in mind is that pretty decorations should be made secondary to displaying the quality and uniformity of the potatoes. Bushel market baskets may be used to advantage in display, and plates are sometimes used.

A large quantity of potatoes, displayed in a pile or against a wall, impresses the observer with the idea of plenty, and that they must come from a big, rich country or farm that is well adapted to the production of the crop. Such a display is especially striking when in the same show there are exhibits consisting of only two or three specimens of a variety.

At the English and Scotch shows very fine dis- 
plays are made by the big seed houses. They show big banks of even tubers that are as attractive as oranges or apples. Retail dealers in Great Britain put up potatoes for sale in very much more attractive shape than our dealers, thereby increasing their sales and the consumption of the crop.

Fruit and flower shows have been important factors in increasing the interest in and demand for these, and there are great possibilities both for the grower and exhibitor, and the industry in general in the well-planned exhibitions of potatoes.

For judging potatoes there is no universal scale of points. The following is one used by the Weld County, Colorado, Farmers' Club. Greeley is the principal town in this county:

\section{SCORE CARD FOR GREELEY POTATOES}

Disqualifications: For show or first three market grades. Screen less than one and seven eighths inches in clear. Many knots. Very deep eyes or very irregular shape. For show, any mixture of varieties; for market, more than 5 per cent. of same color or 2 per cent. of different color. Color mottled, splashed, blue or purple. Muddy. Over 15 per cent. scabby or wormy, or 1 per cent. unsound. One fourth hollow. Sacks not neat, strong, uniform in size. Sacks not securely sewed with standard sack twine.

Trueness to name and type required, but judges are instructed to favor improvements in type. No red potato to score as high on color as a white variety; no deep-eyed or long potato to be scored as high on shape as if round and smooth. 
I. Dealers' Scale. External Examination

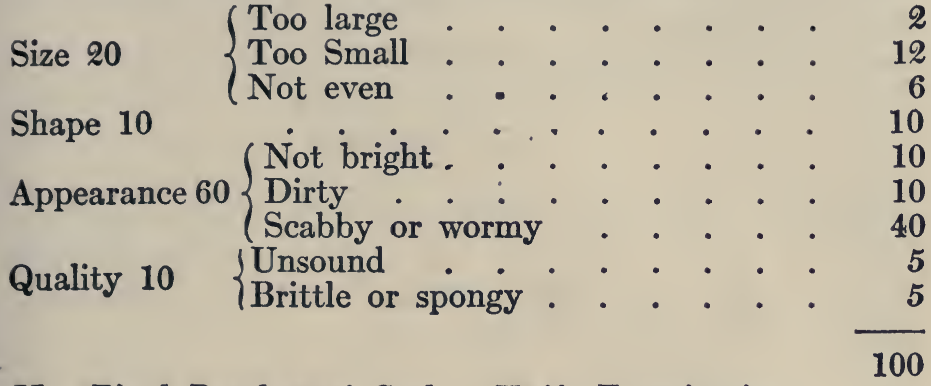

II. Final Purchasers' Scale. Knife Examination

Smoothness

Pares thin

Flesh white

Sound and not hollow

Cortical layer thick

Centres small and not watery

III. Consumers' Scale. Table Quality

Quickness of cooking

Potatoes cook alike

Mealiness

Whiteness

Grain (mashed)

Flavor

$$
\begin{array}{r}
5 \\
. \quad 10 \\
5 \\
\cdot \quad 5 \\
10 \\
15 \\
\hline 50
\end{array}
$$

Four potatoes for cooking test of same total bulk for each lot shall be put into white pots of same shape and size, covered at same time with boiling water, kept boiling evenly until done. Set one potato aside until cold. If it then crumbles on cutting as for rewarming, deduct 1 to 5 points on mealiness. Drain and season alike the three potatoes on each lot with same quantity of salted 
cream, mashed the same number of strokes with same masher.

Total score. Perfect $200 \ldots \ldots \ldots \ldots \ldots \ldots$

\section{MARKET GRADES}

Fancy Potatoes. One variety ripe, sound, smooth, clean, bright, even, run of good size, true to type, not over 5 per cent., but would run over screen two inches in clear:

Choice Potatoes. One variety, ripe, sound, not over 5 per cent. scabby, wormy or knotty; fairly clean, bright and even in size; not over 10 per cent., but would run over screen two inches in clear.

No. 1 Grade. One variety with not over 5 per cent. mixture of same color, or 2 per cent. of other color; fairly ripe for date of shipment; not over 15 per cent. scabby or wormy; not very knotty or muddy; fair size, run over screen one and seven eighths inch in clear.

No. 2 Grade. Not over 50 per cent. scabby, wormy, knotty, or green; not over 5 per cent. unsound or that would go through a screen one and seven eighths inch in clear.

The grower who sorts poorly, or uses a screen less than one and seven eighths inch in the clear, or who does not throw away his poor sacks, or who fails to do that little job of grading and to provide that foot ditch and wasteway, injures his neighbor even more than himself.

\section{THE CHICAGO SCALE}

The scale which follows is used under the Chicago Produce Reporter System:

Fancy Potatoes shall be known as: One variety true to name, ripe, sound, smooth, clean, bright, 
free from disease, scab and second growth, uniform run of medium to large size, correct shape for the variety quoted, with none but would run over a one and three fourths inch screen, and not over 5 per cent. that would run through a two-inch screen for round varieties. For long varieties there may be 20 per cent. that would run through a two-inch screen.

Choice Potatoes shall be known as: One variety with not over 10 per cent. mixture, but all of one color, ripe, sound, not over 5 per cent. scabby, diseased and second growth, fairly clean, good color, medium to fair size and shape for variety quoted, with none but would run over a one and one half inch screen, and not over 10 per cent. that would run through a one and three fourths inch screen for round varieties. For long varieties there may be 20 per cent. that would run through a one and three fourths inch screen.

Good Potatoes shall be the same as Choice, only there may be a 30 per cent. mixture of same color, or 10 per cent. mixture of any color and variety, fairly well matured, according to season shipped, and not over 15 per cent. scabby, diseased and rough, fair to dark color, fair size, with none but would run over a one-inch screen, and not over 15 per cent. that would run through a one and one fourth inch screen, with not over 2 per cent. unsound.

Field Run Potatoes should be practically sound, but unassorted. Dockage, when loading potatoes. In cases where the percentage of dirt, small, inferior, green, etc., potatoes exceeds the allowance in above grades, inspectors may make said stock equal to the grade quoted, or purchased, by such dockage as they consider equitable. 


\section{THE POTATO}

The section from which the potatoes are quoted, and the general quality of that season's crop in that section, should always be considered in connection with grades; not as really changing above definitions, but in close cases inspectors should favor the shipper if that season's general crop is not up to the average quality, or favor the receiver if as good or better than usual." 


\section{CHAPTER XXVII}

POTATO SUPERSTITIONS AND PREJUDICES

7 HERE are a great many superstitions and prejudices in regard to the potato. Some

1 are as old as time but, generally there is no good reason for their existence.

Planting "in the dark of the moon" is a popular fallacy. Some argue, and often can relate, experiences that to them seem to prove that potatoes will not make a satisfactory crop unless planted during that part of the month when the moon does not shine. If planted when the moon shines at night, the belief is that the plant goes "all to top" and will not make tubers. Others will argue that the planting should be done "in the light of the moon" in order to give the plants a good start, because of the additional light. There are experiences to prove that both are right. There is of course no foundation for such notions, and potatoes make good crops if soil and moisture conditions are right, regardless of the moon.

"Cutting off the seed end," or terminal bud, is a practice supposed to result in benefit to the crop. The young potato plant is started and nourished by the plant food stored up in the tuber. To throw away any part of the potato is to destroy food that could be used to advantage. The reason given for doing it is to keep too many eyes from starting, but experience shows that if the seed is strong and has been well stored and handled, the 
sprout from one strong bud dominates and the others remain practically dormant. The terminal bud is the one found first, and European growers consider it the most important part of the seed tuber, and it normally starts first.

"Cutting seed to one eye," or two eyes, or some other number, is supposed by some to carry a mysterious charm that will affect the crop. All there can be of importance in this notion is that the larger the seed piece the greater supply of nutriment available for starting the new plant.

"To irrigate when potatoes are in bloom" is a practice relied upon by growers in some irrigated sections. This may or may not be the right time, depending on the condition of the soil. The time to irrigate is when moisture is required by the plant, regardless of anything else.

"Do not use manure on potato land, it makes scab," is a belief so strong in the minds of some growers that the crop is grown continuously on land without manuring until it becomes impoverished. It is probably true that fresh manure applied to land immediately preceding the planting of potatoes furnishes conditions favorable to the growth of the scab bacteria, but when used in a rotation, as on the grass crop that precedes potatoes, manure, especially when well rotted, is a benefit. Growers in Europe place great dependence on its use.

"To plant potatoes on Good Friday" is believed by some people to insure the crop, regardless of the conditions. If all conditions are right, it would be as well to plant on this day as any other, but no better. Soil and climatic conditions must be the guide for time of planting.

Color and shape are factors that govern some 
markets. For instance, on the Pacific coast the demand is for a long, white potato; Denver and Colorado Springs pay a premium for red potatoes; in England, kidney shaped varieties are in highest favor, and nowhere are blue-skinned varieties popular except in Spain. As a matter of fact, any good potato is good food; there is no more reason for these discriminating prejudices than for white eggs to sell higher in San Francisco than brown, and vice versa in Boston.

"That potatoes grown on irrigated land" are not of good quality and flavor is sometimes believed.

Moisture is one of the essentials in the production of the potato crop, and with irrigation the supply of moisture can be kept even and sufficient to grow a product of the greatest possible uniformity and quality. It depends entirely on the grower. A potato grown from start to maturity without a check is produced under the most ideal conditions. 


\section{CHAPTER XXVIII}

RECENT DEVELOPMENT IN NEW AND OLD DISTRICTS

$7 \mathrm{HE}$ acres of land in the world capable of producing crops can and must produce a 1 greater annual tonnage of food in order to feed the people, unless there be some unforeseen calamity to stop the rate of increase of population.

The production must be increased by better methods in the countries now producing the greatest total crops, and undeveloped and semi-developed countries and districts must be brought up to the limit of their producing possibilities.

That the potato has been and is given very high consideration in Great Britain is very conclusively shown in the article by David Young in the chapter on "Seed Stocks and Varieties."

During the past decade more attention has been paid to the potato in America than at any period. This interest must continue because of the increasing importance to the world of all food crops.

A number of educational factors are at work in this country. Among these are the agricultural colleges and experiment stations, the farmers' institutes and the great transportation interests.

Great good has been accomplished in the development of districts by the railroads. It is true, of course, that the reason for this is the increase in tonnage, but the result has been of great benefit to individual growers. 


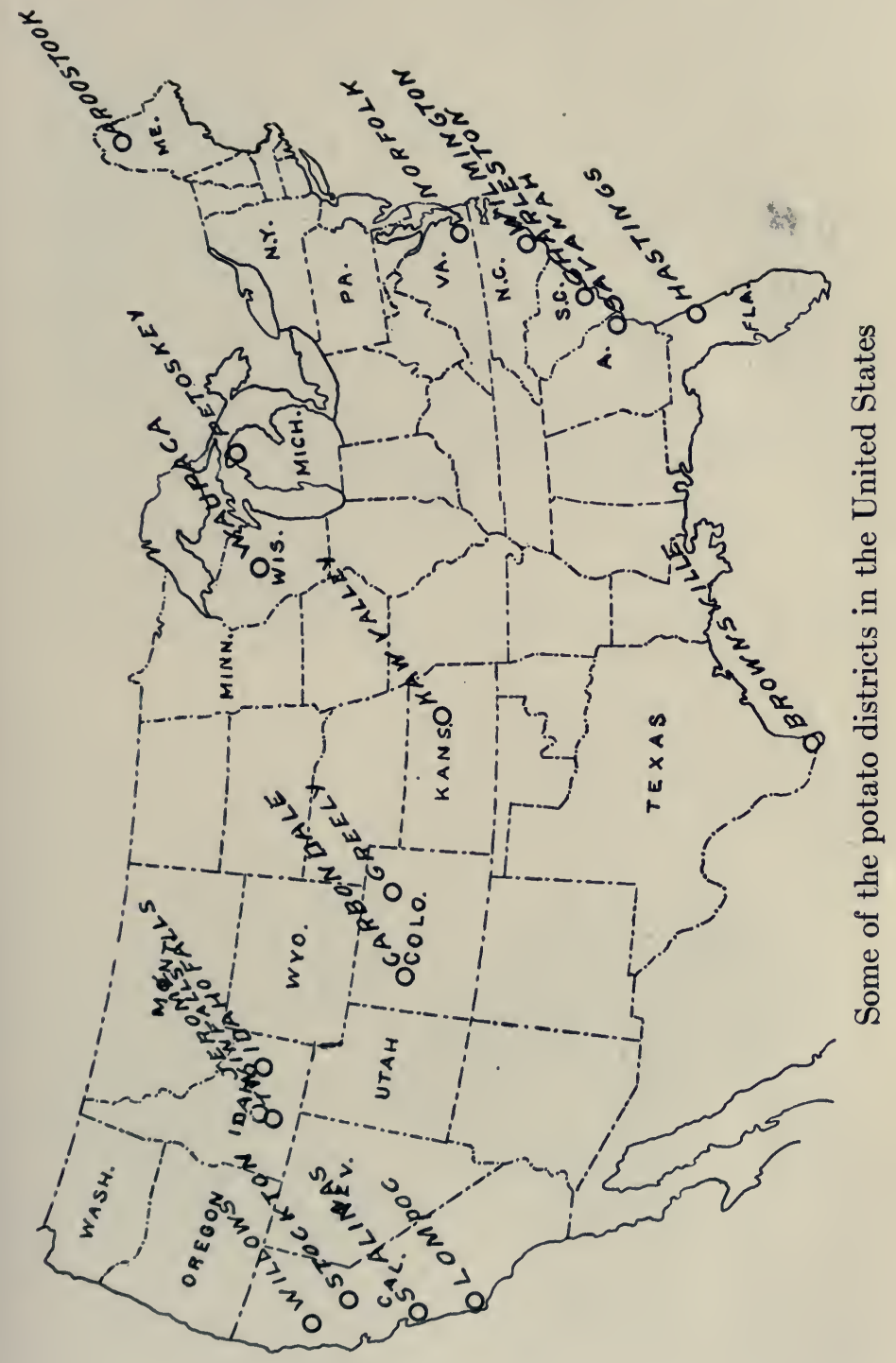




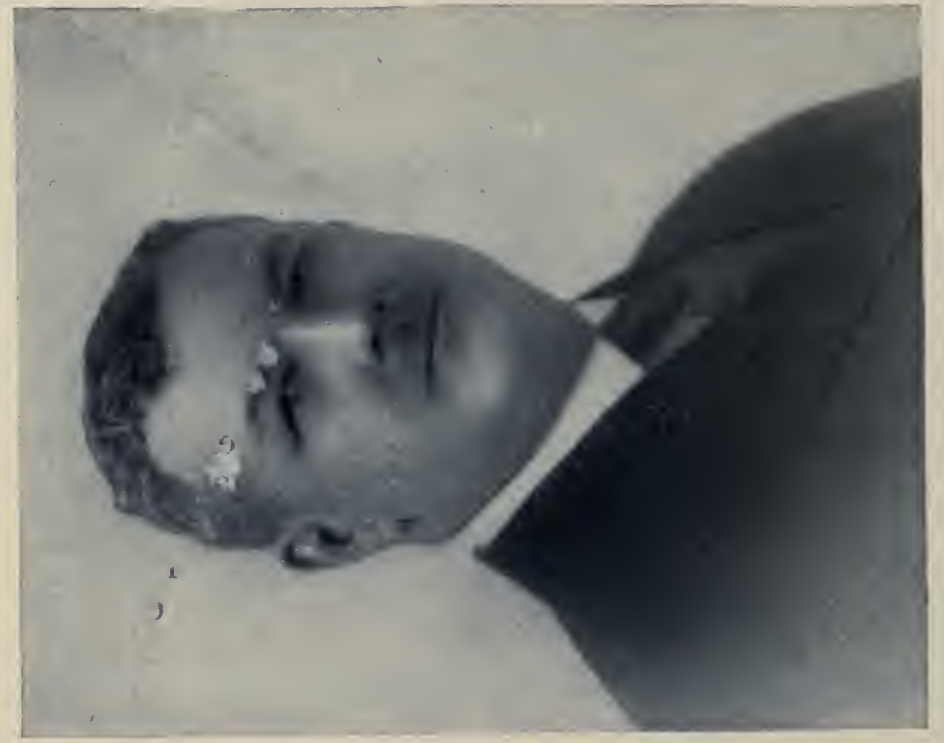

$\sum_{0}^{2}$

$-$

I

ن 응

.ే

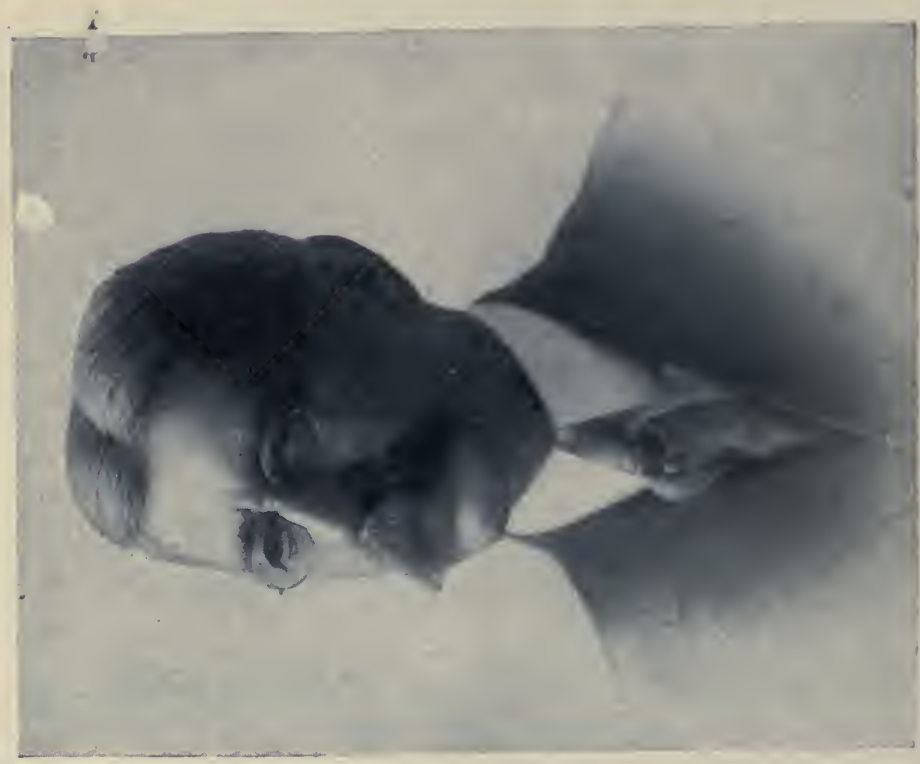

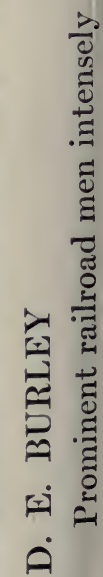


The first railroad to operate a special potato instruction train was the Denver Rio Grande in Colorado. C. H. Schlaacks, now vice-president of the Western Pacific, was vice-president of the Rio Grande at the time of the beginning of this work, and credit is due him for its initiation. He was the first man in America to grasp the great importance of this work.

The first train consisted of five cars, carrying practical growers as instructors, specim 'n implements to improve crop production, and «pproved types of seed. The train travelled over the entire system -1,700 miles. In five years the production of potatoes in this territory was quadrupled.

D. E. Burley, general passenger agent of the Oregon Short Line Railroad, Salt Lake City, Utah, was the first man to put up his own money for prizes for the best potatoes grown in his territo $y$. He also ran a special potato train through Utah and Idaho over 3,500 miles of railroad. This gave great aid to potato growers in a big, undeveloped territory. His work in the interests of agriculture in the Northwest is far-reaching in its effect.

Following are the blanks and other documents used in the Burley contest:

\section{CONDITIONS OF BURLEY POTATO PRIZE CONTEST YEAR 1910}

1. Entries to be filed on or before May 5, 1910.

2. No more than one crop of one variety of potato must be grown on one acre (43,560 feet), and in case grower enters more than one acre, separate blanks must be filled out for each additional acre.

3. The hills or rows must be at least twelve inches from the boundary lines of the acre. 
4. The contest is confined to the four following varieties: Peachblow, Rural Type, Netted Gem, or Dalmeny Challenge.

5. The land must be surveyed by a competent engineer, and satisfactory proof made.

6. "Planting blanks" will be furnished, and must be filled out and sent to D. E. Burley, G. P. A., O. S. L. R. R. Co. Salt Lake City, two weeks after potatoes are planted.

7. D. E. Burley, G. P.A. O. S. L. R. R. Co., Salt Lake City, must be notified ten days before potatoes are harvested.

8. During the growing season inspection of the potatoes may be made at any time by representatives of the contributors.

9. The first prize of $\$ 500$ will be awarded to the acre producing the largest tonnage of best quality marketable potatoes, and the second prize of $\$ 225$ will be awarded to the next best acre.

Prizes are personal contributions of the following:

D. E. Burley, Salt Lake City . $\$ 500.00$

E. M. Heigho, Weiser, Idaho . 100.00

E. H. Dewey, Nampa, Idaho

75.00

H. E. Dunn, Payette, Idaho

25.00

D. C. MacWatters, Milner, Idaho

25.00

ENTRY BLANK FOR BURLEY POTATO COMPETITION, YEAR 1910

Name of Grower

Location

Town

County

State.

Section.

Township

Range.

Variety to be grown

Character of soil.

Probable date of planting. 


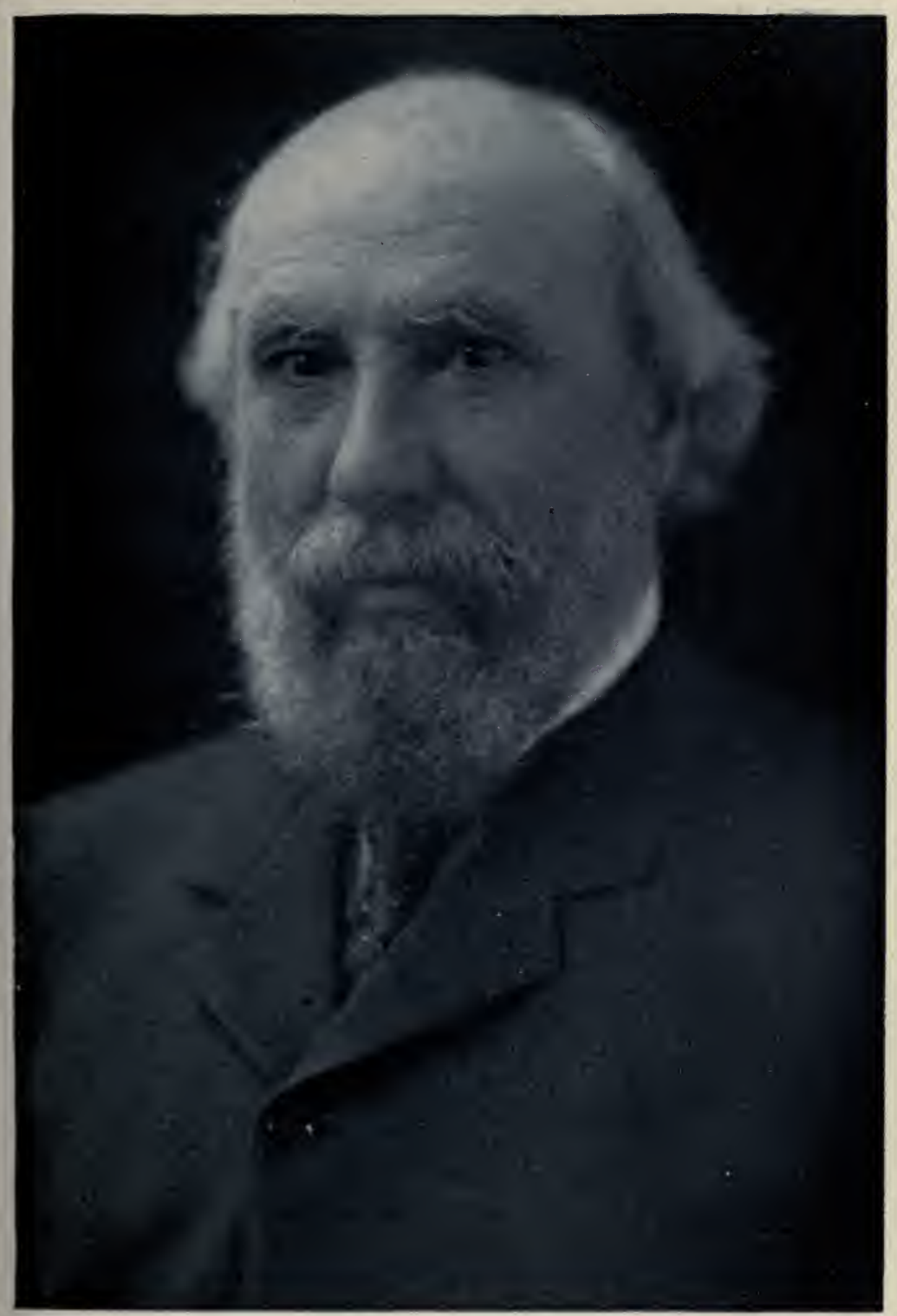

JAMES J. HILL

Photo Copyright by Pach Bros.

An empire builder who early realized the importance of agriculture to transportation interests 


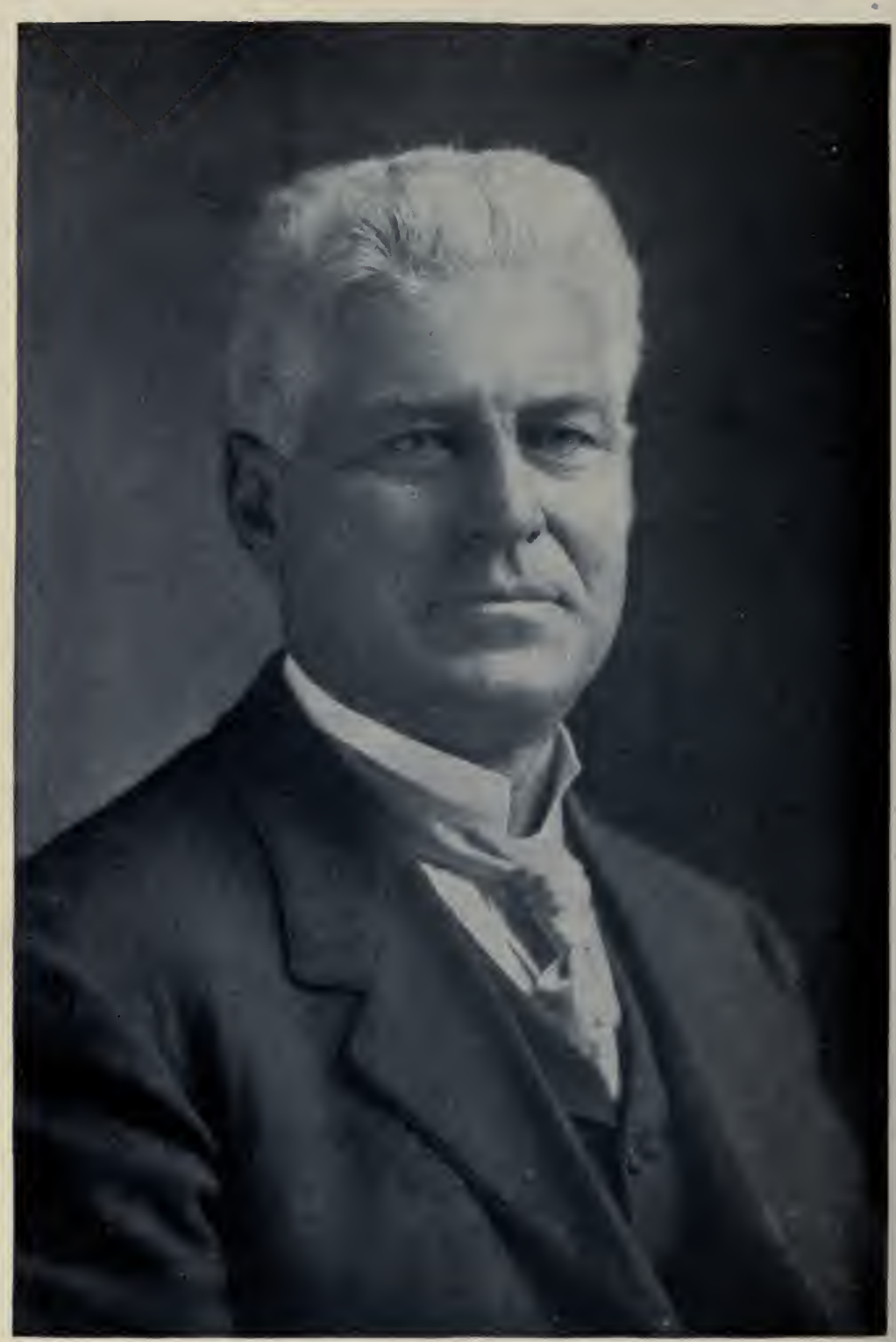

Eugene H. Grubb, who conducted the first potato instruction train in America 


\section{THE POTATO}

PLANTING RECORD OF BURLEY POTATO COMPETITION, YEAR 1910

Name.

Location

Variety to be grown

Character of soil.

Fertilizer used, if any.

Crop in land previous year.

Crop in land second year previous.

Crop in land third year previous.

When was ground plowed.

What was subsequent preparation of land

When were potatoes planted.

How were potatoes planted (by machinery or by hand)....

Depth of planting.

Number of rows planted on acre.

Distance of rows apart.

Distance hills apart in rows.

Number of hills per acre.

Size of seed..

IRRIGATION AND CULTIVATION RECORD OF BURLEY POTATO COMPETITION, YEAR 1910

Name

Location.

Variety to be grown

Character of soil.

When cultivated.

How deep.

Number of times irrigated.

Kind of cultivator used.

When ditched for irrigation.

Date..

How deep.

How high and how wide were ridges made, if any....... 
HARVESTING RECORD OF BURLEY POTATO COMPETITION, YEAR, 1910

Name.

Location

Variety

Plot measured by engineer

Date of harvesting.

How harvested (by machinery or hand)

Yield. .

$\left.\begin{array}{l}\text { State of } \\ \text { County of }\end{array}\right\}$ s.

\section{AFFIDAVIT}

We.................. and

being residents of the county and state aforesaid, hereby certify that on the ..................... day of .1910 , we were each personally present at the digging of one acre of. potatoes planted and owned exclusively by .at or near the city of. . county of and state of...

that the said potatoes were weighed, sacked and sealed in our presence; that they were of a total weight of . pounds and that they were all raised on and taken from one acre of ground only.

We further certify and declare that we are in no way or manner interested financially or otherwise in the outcome of this contest. '

Subscribed and sworn to before me this. day of. 1910. 


\section{THE POTATO}

ANNOUNCEMENT OF AWARDS IN POTATO PRIZE CONTEST

FIRST PRIZE, $\$ 500$

To Mr. L. A. SNyder,

Twin Falls, Twin Falls County, Idaho

Variety, "Dalmeny Challenge"

Gross weight . . . . 38,685 pounds 644.75 bushels Less culls . . . . 4,150 pounds

Marketable . . . 34,535 pounds 575.5 bushels

SECOND PRIZE, \$225

To Mr. W. B. GiLMore,

Payette, Canyon County, Idaho

Variety, "Peachblow"

Gross weight . . . . . . 37,476 pounds

Less culls . • • • . . . 3,920 pounds

Marketable . . . . . . . 33,556 pounds

A description of the methods by which the Snyder potatoes were grown is given in the "Idaho" chapter.

The development of any industry should first follow the lines of least resistance. For this reason, a prospective grower in search of a location would find the opportunities very attractive in the many good valleys throughout the intermountain region of the western part of the United States. As has been indicated elsewhere, the climatic conditions are such that produce the wild potato. In these districts, where irrigation is possible and the soil conditions are right, the highest quality of product can be produced at the lowest possible cost.

In succeeding chapters, the potato industry in various districts, is taken up in detail. 


\section{CHAPTER XXIX}

NORTH ATLANTIC STATES

AEPORT of the potato industry in Maine and New York is given as typical of the states covered in this classification.

The potato is an excellent rotation crop on a general farm in this territory, and there are districts in it that produce as fine seed potatoes as are grown in the world.

\section{MAINE}

The following article is by Mr. E. L. Cleveland, of Houlton, Maine, one of the best potato authorities in America:

“Aroostook County, Maine, covers an area equal to that of the state of Massachusetts, growing and shipping annually approximately 30,000 car loads, or about $18,000,000$ bushels of potatoes.

"By reason of its northern latitude, and the virgin soil in which the potatoes are grown, they inherit those staple and vigorous qualities which make them at once the best and most valuable seed obtainable, as well as the most desirable table potatoes known to the general trade.

"The most improved methods and machinery are here used, and probably no potato-growing county within any state in the Union can show 
such marked prosperity or satisfactory results as those which obtain in Aroostook.

"Some forty different sorts are grown, which, with the exception of the main crop table varieties, Green Mountains, and two or three others, are used almost wholly for seed purposes, and distributed from New England to the Gulf of Mexico.

"The industry of potato growing in Aroostook began to develop in the early '70's, when it was found the soil was especially well adapted to the raising of fine flavored and mealy table potatoes as well as the most vigorous and virile seed, and the demand quickly became general and pronounced.

"The soil in the main is of a rich, gravelly loam, underlying which there is a strata of lime deposit. This gradually disintegrates where near to or exposed to the surface, and thoroughly impregnates the soil, so that it becomes ideal for the growing and maturing of the Irish potato.

"Any up-to-date farmer that practises good farming and adopts improved methods frequently has under cultivation 100 acres or more, and counts on a yield of not less than 275 to 300 bushels per acre, according to varieties used and prevailing local conditions, and it may here be stated that good farming in Aroostook implies proper rotation, and this in turn means to grow potatoes not more than two seasons in succession on the same land, supplying nitrogen with clover, alfalfa, or other nitrogenous plant food as rotation is made, together with a sufficient amount of humus.

"It may here be stated that improved methods of cultivation as well as conservation of soil resources are being sought for and closely followed where proved valuable. Of course commercial fertilizers are still being largely used. They have 
no doubt been used too much in the past, but intelligent farmers are coming to realize that more frequent rotation, together with an adequate supply of nitrogen and humus to be grown on the land with stated periods of rest, is vastly more profitable for a series of years. These matters are being earnestly discussed by the different granges and farmers' clubs, to the end that the best and most approved methods may be practised.

"With the beginning of digging and harvesting of the crop (about Sept. 1st), the potatoes are usually sorted in the field, the merchantable stock being taken direct to the shipping station or to the farmer's cellars, according to his idea of the then prevailing market, and the small and refuse stock, to the starch factories, of which there are some sixty odd in the county. The price obtained for this starch material is of course somewhat elastic, according to the value of the finished product, but at all events there is no waste allowed, and frequently the amount received is such as to materially add to the net profits of the farm operation.

"Where the farmer grows a larger quantity than he has storage for, a part of his crop is hauled direct to the shipping station, where cash is paid on a basis of the prevailing markets, less freight charges, and a fair compensation to the buyer and shipper for the amount of labor required in the marketing and handling of same.

"Such a part of his crop as he decides to hold for later marketing is usually stored in an outdoor farm cellar, built especially for the purpose, and to be hauled during the winter at leisure, according to his idea of what the market may afford as the season advances. 
"The buyer or shipper owns or controls large storehouses at the different shipping stations, and the stock he purchases is promptly forwarded to the different markets in full carloads or held in storage, according also to his judgment and knowledge of the markets, visible supply, and the law of supply and demand, with the result that the immense track storehouses are often completely filled during harvesting, to be gradually emptied according to demand later in the season, artificially heated cars being used as weather conditions demand.

"The construction of these storehouses is such that they are practically frost proof. In fact, some of the more thoroughly built seldom, if ever, use artificial heat.

"Such varieties as are to be used for seed purposes are carefully assorted and placed in large well ventilated bins, the light excluded and temperature kept at as low a point as outside conditions will admit of and be safe.

"The seed shipments begin to move into more southern territory with December, and continue for six months or more, gradually working north with the advance of the season, until the New England States are supplied. In the meantime of course the main crop, or table varieties, are being moved out to the many different markets, this part of the business beginning with harvesting, and continuing for ten months or more. Indeed, shipments are generally made every month in the year, though of course very light in July and August.

"The future of potato growing in Aroostook should be regarded as in no sense problematical. With a large part of the county still undeveloped agriculturally, a soil admittedly almost ideal for 
the production of the Irish potato at its best, improved methods and a quality continually being bettered, a rolling surface well adapted to the use of improved farm machinery, and a product that of itself cannot be matched for either seed purposes or table use, together with competing transportation lines to tidewater, the next decade should see the present output more than doubled."

The following interesting information is from the Bangor Aroostook Railroad, Bangor, Maine:

"Maine has long been famous for its wealth of timber-lands, its summer resorts and great game country. The preëminence of the Aroostook potato is winning for the state new and constantly increasing fame. Because of the remarkable yield and exceptional quality of the crops, the Aroostook potato country has come to be known as the garden spot of New England, and in many ways it is attracting more attention than any other agricultural section of the country.

"The Aroostook potato is known the country over. Millions of bushels are shipped to Boston, New York, and other centres for domestic use, while thousands of carloads are called for from all parts of the country for seed purposes. Wherever it is planted the Aroostook potato varieties retain the characteristics which have made them famous, and they also adapt themselves to conditions of soil and climate supposedly much different from those of Maine. In Virginia, for instance, where the paramount object is to hasten the early crop, the Aroostook potato matures from a week to a fortnight earlier than other varieties.

"The development of the Aroostook country, a 
great area of 4,000,000 acres, has gone hand in hand with the expansion of the Bangor \& Aroostook Railroad, and it is by this road that the potatoes are sent forward to the metropolitan markets. Although the number of new farms increases each year, there are still thousands of acres of desirable land. Aroostook has seen a marvellous growth in the past decade - a growth which bids fair to be even more remarkable within the next few years. Dozens of stations along the line of the Bangor \& Aroostook Railroad are potato shipment points for farmers, while the thriving towns of Houlton, Presque Isle, Caribou, and Fort Fairfield sent out hundreds of potato trains each season.

"The standard size of the Aroostook farm is the regulation 160 acres. At the present time this is considered a large farm. Near any of the business centres of the county, in a locality easily accessible to a railroad shipping point, under good cultivation and with ample buildings, such a farm will range in market value from $\$ 10,000$ to $\$ 20,000$ according to the percentage of good potato producing land it contains. The buildings on an Aroostook farm must comprise, among other things, ample barn room for the storage of hay and grain, a good frostproof potato storehouse capable of holding from 2,000 to 3,000 barrels. The equipment must include all appliances for planting, cultivating and harvesting the potato and other crops, such as seeders, planters, diggers, sprayers, mowing and reaping machinery, etc. Usually from four to six heavy draft horses are required, and the investment outside of the land runs from $\$ 2,000$ to $\$ 3,000$ and many times much more.

"The average price of good, cleared land in Aroostook, well located and under good cultivation 
is not far from $\$ 100$ an acre. The appreciation in value of Aroostook farm land has been steady since the beginning of the potato raising industry, and particularly marked since the opening of the Bangor \& Aroostook Railroad, as has also been the increase in wealth and population in almost all sections of the county. Within fifteen years, or covering the period the railroad has been in operation, many towns have doubled their population and trebled their valuation.

"The phenomenal success of farming in Aroostook from the financial viewpoint has been a strong magnet in attracting the public eye. Numberless instances can be pointed out where successful potato growers have risen from smallest beginnings to possessors of considerable wealth. Statistics show that in no section in the country is the potato yield greater per acre than in Aroostook and also that as a class the farmers are nowhere more prosperous.

"The energetic and enterprising methods of farming in Aroostook County suggest strongly the widely commended Western spirit. Farms are conducted as business establishments. Modern methods are employed and buildings, equipment and paraphernalia are orderly, well-kept and always up-to-date. For the person whose idea of a farm is the depressing picture of the oft talked of 'abandoned' farm, a visit to Aroostook County will be a joyful awakening.

"The Aroostook farmer believes in having every possible city advantage. He believes in making life worth living. His crops make it possible for him to follow this idea. A trip through Aroostook is replete with interest whether it be in the summer when the fields of blossoming potato plants stretch 
far away beyond the reach of the eye or at the harvest time when the farms take on a new activity. The mechanical potato digger has revolutionized the work and the crops are taken from the ground in surprisingly quick time. Potato growing in Aroostook is already a business of big proportions and the constant development promises to make it one of the greatest agricultural industries in the country."

During the winter of 1910 the senior author visited the Aroostook district, and his impressions follow:

This one county is like a Colorado county in area. It is on the northern boundary of Maine and borders on Canada.

Apparently the whole idea of the farmers in the county is centred on the growing of potatoes to the exclusion of all other crops as much as possible. The potato dominates every sentiment and idea. It is the sole topic of conversation where two or more men are gathered together. They are apt to be discussing machinery and wagons for potatoes and the cultivation of potatoes. And you see men hauling potatoes in every direction in barrels to and from warehouses, from farms to markets. They talk of them in the streets, in the offices and in the banks; and, I have no doubt, in the schools and churches, and even in their sleep. At Carbondale and Greeley, Col. they think and talk of other things than potatoes, because their crops are diversified. At Houlton, Maine, the centre of the potato work, is the only place where I have been talked to a standstill on the subject of potatoes. I never met people who were so eager for knowledge in connection with potatoes. 
The yield in this district is three times that of any single district in the United States and quite double that of the irrigated states

Mr. E. L. Cleveland, pioneer and father of the seed potato industry in Houlton, Maine, has for the past thirty years been growing seed potatoes for shipment over the United States, but largely for the Southern market. They are growing sixty varieties of pure seed and their shipments amount to from eighty to one hundred thousand barrels annually:

Their growing season is very short, much shorter than we have in Colorado. It is only about one hundred days between killing frosts from June to September. The first week of April the fields were still covered with snow and it was known as a mild winter and a light snowfall. They almost universally practise fall plowing owing to their short season. They plant their potatoes much closer than we do in Colorado, rows from twenty-eight to thirty inches apart, and the hills from ten to twelve inches apart. This method produces more uniform and smaller potatoes than are grown in the irrigated West. They use about 700 pounds of very small, cut seed to the acre.

The implements for cultivation are very similar to those used in the best districts of Colorado.

Owing to their lack of livestock they have little or no barnyard muck. They place their whole reliance on commercial fertilizers and it is from this and the extravagant use of it that gives them such wondrous results in eclipsing other potato communities, but the cost has been high. They commenced the use of commercial fertilizers twelve or fifteen years ago, using 400 to 500 pounds per acre at a cost of $\$ 7.50$ per acre. They have been com- 
pelled to increase this amount from year to year, and to date they are using 1,800 to 2,000 pounds per acre. This, coupled with the expense of spraying with Bordeaux mixture two or three times in the season and the added expense of combating the potato beetle, brings the expense of growing potatoes to from $\$ 70$ to $\$ 75$ an acre, but a yield of 240 bushels per acre is produced.

These lands are valued at $\$ 80$ to $\$ 120$ an acre, and the tenant farmers pay $\$ 10$ to $\$ 20$ an acre rent for growing potatoes, according to the richness of the soil and distance to railways.

Their proximity to large and populous cities, the cheap and rapid transportation facilities, with the splendid edible qualities of their potatoes (that their natural soil and climatic conditions give), assures them a good business.

The growers of this district can, however, well pay more attention to livestock and diversified farming in connection with their potato work.

\section{POTATO CULTURE IN NEW YORK STATE}

The information that follows is by $\mathrm{Mr}$. T. E. Martin, Superintendent of Demonstration Farms of the New York Central Lines.

"For best results in potato culture in New York State tile drainage is as much of a necessity in soils that contain excess water as is plant food.

"In my personal experience at farming in western New York, thirteen miles south of Rochester, latitude 43 degrees, elevation 550 feet, fifty-seven acres, Dunkirk series of soil, a thorough drainage system of 3,265 rods (over ten miles) was established at a cost of about $\$ 2,000$. This work was 
done under adverse and hostile conditions while carrying a heavy mortgage on unfertile soil much against the proffered advice of self-appointed authorities and established doctrines. However, the drainage has paid for itself several times over.

"As sweet memories of quality and good work linger long after the cost is forgotten, it is therefore essential that only the best thought, effort, and material be allowed to predominate. There is no work of importance in which this truth is more applicable than in tile drainage, because of its permanency, as everlasting as the hills. Often the first crop increase from potatoes repays the entire expenditure, together with handsome annual returns and a heritage imperishable handed down to posterity more valuable the one hundredth year than the first.

"All sewer pipe and round tile were used. No boards under pipe. Mains are two to four inches lower than laterals. Drains are of good length and depth and so placed that the drainage reaches laterally from drain to drain on time. Standing water is fatal to the potato yield. Three-inch lateral drains are placed fifty-five feet apart and four feet deep. Some soils need aeration as much as others require drainage. For such four-inch tile give better efficiency. The drainage usually costs 50 cents per rod, or $\$ 25$ per acre. Intakes are provided with silt basins. Outlets and intakes are established in cement abutments. Special screen pipe prevents animals or trash from entering. Accurate location maps give all data in detail. Horses and an ordinary three-horse plow were used for the opening and closing of drains. Under average conditions a traction ditcher will lessen the cost one third to one half. 


\section{THE POTATO}

We attribute to drainage largely the gradual increasing potato yields of sixty bushels in 1892 to an average of 417 bushels per acre, or 7,510 bushels on eighteen acres in 1906 . No irrigation.

"Crop rotation is a three-year one, growing annually eighteen acres each of wheat, clover, and potatoes. The last of September or early October, after potatoes are harvested, the potato vines are raked and burned to destroy lurking disease, the ground twice disked, leveled with spring-tooth harrow and sown to Klondike wheat.

"The spring following from April 1st to 10th, when certain conditions are present and favorable and the wheat ground is well checked up, one half bushel of high grade medium red clover and alfalfa seed, previously carefully mixed, is sown per acre with a broadcaster, preferably during afternoons, when the surface is dry. Experience only teaches when these conditions exist. The next forenoon a three-section, lever-sets, spiketooth harrow, teeth set straight up and down, is run over the field. Teeth should be sharp. Such valuable seed should be covered as much as garden seeds.

"From 1907 to 1909 six and three fourths bushels clover and two and one fourth bushels alfalfa were sown - a 75 and 25 per cent. mixture; 19101912 four and one half bushels each, equal parts, or 50 per cent. of each has been and will be used; 1913-1915 the mixture will be 25 and 75 respectively, just the reverse of first three-year cycle; 1916 and following, alfalfa only will be grown. No lime or inoculation has been used. The former is dangerous in a short potato rotation. All things being equal alfalfa gives us more hay the following year at first cutting than clover. Second cutting 
has decidedly more alfalfa, and third cutting is all gain. Besides, the alfalfa is richer both as a feed and soil enricher. Roots are larger and go deeper.

"First crop of hay is cut June 15th to 25th, and put up for feeding and sale purposes. Several times the first crop was left on knolls and thin places. If first crop was heavy and hay cheap the second crop was cut August 1st and left on the ground for the following potato crop, and it pays as well as livestock feeding, with little work connected thereto. Third crop is cut middle of September and always left on the land. 'Feed the land and the crop will feed you.' Cutting is preferred, as stray weeds are destroyed. The next crop comes up through this mass of organic matter and it decomposes sooner. Next year as a moisture retainer it has valuable qualities.

"Manure from the stock, four horses and two cows, is made in box stalls and drawn direct to the field and spread on the thin places on the clover and alfalfa. No straw is sold. The surplus is spread and plowed under.

"Potato ground is fall-plowed ten inches deep. In springtime the field is prepared with a fourhorse, double-acting, cutaway harrow, which is run over field four times, lengthwise, diagonally twice, and crosswise lastly, and leveled with the springtooth harrow.

"For available fertility we rely mainly on drainage, preparation, tillage, clover and alfalfa and the farm manure.

"Commercial fertilizers were first used in 1901, increasing from 400 to 1,500 pounds of 4,8 , and 12 per cent. in $190 \%$, costing $\$ 32$ per ton for homemixed goods, using nitrate of soda, blood, tankage, bone, 14 per cent. rock, and sulphate of potash. A 
careful farmer can mix fertilizer constituents as perfectly as the elaborate mixing machinery does in a large fertilizer factory. Home mixing costs about 50 cents per ton, and the saving ranges from $\$ 2$ to $\$ 8$ per ton. A better and purer grade of goods is secured with no filler in them, consequently no worthless stuff. The fertilizer is applied with an eleven-hoe grain and fertilizer drill, preferably between the first and second cutaway work. Tests have been made with the various fertilizer ingredients separately and in combination in varying quantities. On our farm potash paid the best. Fertilizers used in connection with a good supply of organic matter in the soil gives better results.

"If wheat lodges, that is an indication of a lack of potash. Dwarfish growth signifies lack of nitrogen, shrunken grain shows lack of phosphoric acid. However, the only sure way to determine such questions is to test out the fertilizer in plats and let the behavior of the plants and results determine which form of plant food will pay best to invest in. Excessive growth of potato vines with few potatoes represents a shortage of potash.

"The past spring (1911) the fertilizer was cut down to 800 pounds per acre, using the minerals

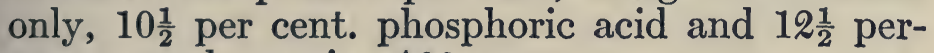
cent. potash, costing $\$ 20$ per ton.

"Good, healthy, vigorous potato seed is one of the most important factors in the growing of the crop; and the simple fact about it is that every farmer can have such first-class seed stock by a little extra study and work; by land digging, for a start, say 500 to 1,000 hills of potatoes, where they are the best in the field, and selecting individual high yielding hills for next year's seed and breed- 
ing. By hand digging and rejecting the low yielding hills next year and years following, a good variety of potato is found to gain both in quality and quantity from 10 to 50 per cent. This is worth looking into. Up-to-date authorities and livestock breeders do not perpetuate the scrubs. If there is an abiding law in the animal kingdom, there certainly is a similar one in the vegetable. Violation of this and similar laws invariably brings disaster.

"Do potatoes run out? They surely do. There is no question about it, but it is man's standard of seed selection and culture that 'runs down and out.' The following are some of the causes of potatoes deteriorating: (1) Wet, infertile soil, (2) half preparation and fertilization, (3) late planting, (4) first sprouts destroyed, (5) diseased stock, (6) low vitality, (7) poor storage.

"Another way is to maintain an annual seed or breeding plat large enough for the requirements. When seed plat potatoes are in full foliage, ten days before they die down, go over them and remove every diseased hill, that such stock will not be a menace to future yields. At harvest time the seed plat product should be carefully handled and put into cold storage. Assort these into two grades specials and selects - enough of the former (ideal shaped typical tubers) to maintain the annual seed plat and of the latter enough to plant the annual crop. Treat the specials with formaldehyde, one pint diluted with thirty gallons of water, and potatoes immersed two hours.

"Potato ground is rolled ahead of potato planter to insure uniform planting depth. Especially important is this if soil varies. At digging time, if season is wet and potatoes are in deep, the digging 
is a sort of horse-killing job even for four strong horses.

"Potatoes are planted 4 inches deep, 11 inches apart in the row, and rows 36 inches apart, 15,840 hills per acre. One pound per hill would yield 264 bushels per acre; two pounds per hill, 528 bushels; twenty bushels of large potatoes are used per acre, cutting to about two eyes per seed piece. Planting is usually completed about May 12th.

"For the cultivation of the crop a riding, pivotwheel, double-row cultivator is used exclusively. Cultivator is started same day or week the planting is finished, endeavoring to get three times over field before potatoes are up. Potato row ridges are fallowed. The row middles should be thorough and deeply broken up. It is safe to cultivate deep at this stage, but not after potatoes are four inches high, as roots extend over halfway from row to row. By deep cultivation at this time roots are torn off, and the potato root system is interfered with, with a corresponding lower yield.

"Next, the walking seven-foot weeder is run twice over field, first crosswise the rows and the last time straight with row, which leaves plants in a narrower row, and aids in closer cultivator work. If storms follow and weeder went crosswise last, the potato row would be wider from being pounded down and elbowing up. For weeder work, dry, hot weather is chosen, if there is a choice, and not starting same until after nine o'clock, as potatoes will stand more abuse when warmed up.

"The cultivator is now adjusted with narrow teeth, one and one fourth inch on the two central ones, and set as close to the row as it is possible to run it; in fact, so close, the operator says, that every time he sneezes out goes a hill of potatoes. 
Go twice over field with cultivator so adjusted. Then cultivator is arranged with a pair of seveninch side steels on the two central teeth, and a small ridge of soil, about three inches high, is thrown on to the potato rows, and twice over field. Up to this time the cultivations number seven. Balance of cultivation, usually twelve to fifteen all told, is done with cultivator, gradually widening apart the side steels as the vines develop. Every cultivation is equal to a light dressing of nitrate of soda - forty pounds per acre. Earth mulch is provided, evaporation prevented, aeration and ventilation of soil is established, and lastly weeds are destroyed. Level culture is the plan, but these frequent cultivations ridge up the field considerably, which ranges around four inches out of level. The more surface the more evaporation. Cultivation is discontinued the last of July. Care is taken to go astride alternate rows at each cultivation. With this construction of cultivator the gang bars are each side of wheels. After vines commence to lop, four teeth are placed forward on gang bars. These teeth raise vines up and prevent damage from wheels and teeth. For stray weeds two hand weedings are given during the middle of July and August.

"Bordeaux mixture is used freely and vigorously. Stock solutions of copper and lime are kept in readiness; 1,000 to 1,500 gallons Bordeaux applied per acre annually, 125 to 150 pound pressure. Arsenate of lead is added to Bordeaux for the potato bugs and larvæ. Nozzle angle should be changed from straight to right and left and go reverse directions at each application. Flank an enemy and he is in a dangerous condition. Bordeaux is a protection insurance only. Only a film 
of it is required. On time and thoroughness are virtues. First application should be made about the last of June, when potatoes are about one foot high. Spraying should be discontinued from September 1st to 15th, depending on the season.

"The results of spraying for 1906 to 1911 follow: This is the net profit, not gain: $1906, \$ 42.07 ; 1907$, $\$ 32.42 ; 1908, \$ 48.80 ; 1909$, $\$ 20.08 ; 1910$, $\$ 24.00$. The total cost of thorough spraying ranges from $\$ 8$ to $\$ 15$ per acre.

"Inside measurements of potato crates are $12 \times 14 \times 15 \frac{1}{4}$ inches. Outside $12 \frac{3}{3}$ inches high, $14 \frac{3}{4}$ inches wide, and 17 inches long. They nest up and fit endwise a three-foot wagon box. They contain 2,562 cubic inches, and hold sixty pounds potatoes level full. Ends are $\frac{7}{8}$-inch pine or whitewood boards, 12 inches wide, cut to length; sides and bottoms are $\frac{3}{8}$-inch basswood. We have 500 crates.

"For harvesting the crop the Hoover digger is used, digging every other row, beginning on lower side of field and digging in divisions of four rows. Four rows of potatoes are picked into two rows of crates. The truck wagon passes to farther end of field, distributing the empty crates. The wagon is loaded on return by driving between the two rows of full crates. One or two men on each side set on to the wagon the crates of potatoes without stopping. The truck wagon platform is $6 \times 19$ feet and only 30 inches above the ground. It holds sixty crates, one crate high. Often 100 to 110 bushels are drawn. In 1906, 1,501 bushels were dug and picked up in one day and over 1,000 bushels drawn one mile and loaded on to cars. Selling direct from field to car is highly satisfac- 
tory. During $1901 \$ 2,013$ worth of potatoes were sold direct from field to car with only the initial handling. Potato crop for 1907 totaled $\$ 2,807.89 . "$

The cost of growing potatoes in these districts will be found in Chapter XIII. 


\section{CHAPTER XXX}

\section{SOUTH ATLANTIC AND GULF STATES}

$\Gamma \mathrm{HE}$ states in this classification grow large acreages of sweet potatoes. This subject is covered in a separate chapter. The Irish potato situation is also discussed in the chapter on "Specialties - Early Potatoes."

The mild climatic conditions make the production of a crop of very.early potatoes - and a later crop - possible, and furnish opportunities for the marketing of an "out-of-season" product at a high price.

There is no reason why the local supply of "white" potatoes for the South should not be grown locally. The fundamental things to be considered are soil, season, and seed.

If the soil in which it is intended to grow the crop is not naturally mellow, easily worked, and sufficiently stocked with fertility to make a crop possible, steps must be taken to bring this about. Heavy, hard lands need cover crops and barnyard manure to lighten their texture; sandy soils require the same things to add fertility.

As far as climate is concerned, it must be remembered that the potato is a "cool-weather" crop, as distinguished from corn, cotton, and the "hot-weather" crops. It must be planted so as to make its greatest growth during the early or late part of the crop season.

Growers of potatoes in warm climates generally 
find it profitable to use Northern-grown seed. Seed from districts where the tops are killed by frost makes the surest and strongest growth. It is only in such places - like Chile and the western slope in Colorado - that potatoes endure without cultivation for centuries. This is a reason for getting seed from these north latitude or high altitude districts, but is no reason why potatoes should not be grown in the South.

Potatoes to be held for use should be stored in a dark place, as cool and dry as possible.

Following is a description of conditions in one district in Florida that has been made quite famous:

The growing of Irish potatoes in the Hastings district in Florida was begun about ten years ago. It has grown steadily until in 1911 the production was 300,000 barrels, or 800,000 bushels.

The conditions that obtain at Hastings are different from anywhere else in the world.

The soil is a very light sand and the subsoil a stiff, impervious clay at varying depths. This sand is claimed to be very low in available fertility, and annual fertilization is necessary. This fertilizing seems to be quite as essential on land just cleared of timber as on that cropped continuously for ten years.

A commercial fertilizer costing $\$ 30$ a ton and containing 4 per cent. nitrate, 7 per cent. acid phosphate, and $7 \frac{1}{2}$ per cent. potash is in common use. It is applied at the rate of one ton per acre, being sown in rows previous to planting the potatoes. Some growers claim that barnyard manure cannot be used for fertilizer because it "poisons" the land and causes potato scab.

Potatoes are planted on what are called "beds," in ridges thrown up with implements similar to a 
"middle breaker" plow or lister, or by a double disk with two small sixteen-inch disks in front, followed by two twenty-four-inch disks that throw the furrows together.

The ridges are forty-two inches apart and about ten inches high; the fertilizer is then put in the furrow and the potatoes planted in this ridge. They are planted two to six inches deep. When planted, the fields have the appearance of a field ridged after the final cultivation in other districts. Very little cultivation is done in this district. Only disk cultivators are used. These cover up the potatoes deeper than they are planted and destroy such weeds as are between the rows.

One grower objected to the use of barnyard manure because it was the cause of many weeds.

The land in the Hastings district is very flat. The heavy rainfall at some seasons of the year makes it imperative that all lands for potato growing be drained. During the dry season irrigation is necessary to insure profitable crops.

This part of Florida is fifteen to twenty miles from the ocean. The St. John's River bounds it on the west. Between the ocean and the river is an artesian water belt. The depth of the wells that furnish this artesian flow is about 200 feet.

At the T. E. Bugbee farm, near Hastings, where land is seventeen feet above sea level, the artesian flow is twenty feet above the surface. At the other end of the farm, two and three fourth miles away, the land is six feet higher and the artesian flow is fourteen feet above the level of the land.

A four-inch well gives a sufficient flow for irrigating forty acres of potatoes. At a cost of $\$ 200$ for the installation, this system affords perpetual irrigation. It is probably the cheapest ir- 
rigation known in the world. All that is necessary to work it is to open or close the valve. The farm homes and barns are supplied with pressure water.

This system of irrigating is similar to that in the San Luis Valley in Colorado. In Florida, however, the sub-laterals or deep trenches are only forty feet apart, while in Colorado they are about 200 feet apart.

The impervious clay subsoil and the flatness of the land permit this system of filling the land with moisture from the clay floor up to the surface or as near the surface as the farmer desires. The top soil is so loose and porous that the soil spaces fill with water readily. These narrow beds in the Hastings district allow the planting of about ten rows of potatoes, forty-two inches apart to the bed. Then, there is about six feet of land required for the trench in which the irrigating water is held until it "subs" or seeps to the centre of the forty-foot bed. This is a waste of land.

Northern-grown seed potatoes are used exclusively. They come from New York or Maine growers. One successful Florida grower says that partially matured seed from Maine gives the strongest plants and growth with less rot in unfavorable cold and wet seasons.

The Spaulding No. "4" Rose, a variety that is regarded as a late sort in the North, is the earliest large yielding sort they have ever grown extensively at Hastings. Fully 95 per cent. of the planting is of this variety. Last year, however, an acre of "Polaris" gave the best yield ever grown.

From ten to twelve bushels of seed are used per acre. From 65 to 90 per cent. of a perfect stand is generally secured, although occasionally a 
whole planting is lost from excessive cold and heavy rains, unless the best possible drainage or ditch facilities are made.

Planting on flat ground without ridging would almost always be a failure because of the heavy rains. This is because the land is so flat and the subsoil so impervious. The water could not be carried off until the crop was scalded by the hot sun, or the seed rotted.

From one to four, generally two to three, irrigations are usually necessary to mature a crop.

The yields are about forty barrels, or 112 bushels, per acre. The range is from 75 to 250 bushels per acre.

The busy harvesting season is from April 10th to June. Harvest hands come long distances to work in the potato fields. The labor is all colored; $\$ 1$ to $\$ 1.50$ per day is the wage paid. Forty to fifty cars a day are sent out during the season. Forty to fifty buyers from Northern cities are on the ground during this short harvesting season. The potato-growing area can be about quadrupled. Considerable capital is required to clear the land of pine trees and stumps - about $\$ 30$ to $\$ 75$ per acre.

Ten days before potatoes are harvested corn is planted in the furrows, and when digging time comes the corn is six to ten inches high. The potatoes are "lifted" or dug by hand. The corn is cultivated once or twice and one and one half bushels of cow peas are sown per acre. The corn is harvested in November and the cow peas cut for hay. The cow peas are cut about eight inches above the ground. The stubble is then plowed under. This makes it possible to grow a crop of potatoes every year. The cow-pea stubble and the root system furnish humus to the soil. 
Land values have advanced in ten years from $\$ 25$ an acre to $\$ 200$ an acre for best improved farms.

Potatoes are graded and shipped in barrels. The No. 1 grade is two and one fourth inches or more in diameter. No. 2, one and one half to two and one fourth inches in diameter. The No. 1 grade usually sells for one dollar per barrel above the No. 2 grade. When the potato crop is short and prices are high, the culls are also shipped. Average prices received by the grower for five years has been $\$ 3.25$ per barrel net. Barrels hold eleven pecks (two bushels and three pecks).

When the potatoes are dug, three rows are thrown into one and one set of pickers pick out the No. 1 grade, another set of pickers follow and sort out the No. 2 grade. This seems a very crude and expensive way.

At the beginning of the harvest, potatoes are only partially matured. They are soft and full of sap and must be taken out of the hot sun within thirty minutes from the time they are exposed. Otherwise, they scald and heat. No sorter or grader has been devised that will grade without bruising the skin.

This season (1912) the best growers are spraying extensively for blight.

The cost of growing potatoes in Florida is given in Chapter XIII.

In a report of Ed. R. Kone, Commissioner of Agriculture of the State of Texas, the following in regard to the Texas potato situation is submitted:

"Potatoes are a profitable crop in Texas. Our soils and climatic conditions appear well suited to 
them. The principal supply of this crop, which goes to the markets of the country, is grown in eastern Texas, though it grows well in much of our soil from the Gulf coast to the northwestern boundary of our state.

"The sweet potato is especially adapted to Texas soils and climate. Usually the yield is much greater per acre than that of the Irish potato. In 'Farmers' Bulletin No. 324' of the United States Department of Agriculture, on sweet potatoes, this crop is placed among the five greatest commercial truck crops, and ranked as third on the list. No truck crop in Texas has increased in volume so much as this. It is one of the great commercial crops and can be grown over as wide a range of territory as any of the other vegetable crops.

"As long ago as 1899 Texas ranked tenth in the value of all vegetable crops grown that year. This is according to the twelfth census report of the United States, 1900. The average value per acre for Irish potatoes for 1899 was $\$ 33.25$, and for sweet potatoes $\$ 38.77$. The average yield per acre for Irish potatoes was 61.5 bushels and for sweet potatoes 75.7. The average value per bushel was 54 cents for Irish potatoes and 51 cents for sweet potatoes. Hence it will be noted that the sweet potato gives the greatest average value per acre, and explains why there has been such a marked increase in the development of the sweetpotato industry in our state during the last tenyear period." 


\section{CHAPTER XXXI}

\section{THE MIDDLE WEST}

LARGE tonnage of potatoes is grown in the states comprised in the territory known as the Middle West.

There is so much similarity in conditions and methods that for the purpose of this work a discussion of two states (Wisconsin and Kansas) is taken as being typical of the territory.

\section{WISCONSIN}

The following very comprehensive information about the potato industry of Wisconsin is furnished by Prof. J. G. Milward of the Horticultural Department of the University of Wisconsin. He is a graduate of that institution and a very capable, earnest worker for the upbuilding of the agriculture of the state. It is the work of such men as Professor Milward that has been one of the principal factors in agricultural progress during the past decade. He says:

"The main or late crop of potatoes in this state is usually planted between the dates June 1st and June 15th. The early potatoes for early market are usually planted May 1st to May 15th. A number of growers in this state who raise early potatoes for seed for southern trucking centres practise planting as late as July 1st and gain what 
is sometimes an advantage of having the vines mature during the cool fall months. The season for harvesting the main crop ranges from October 1st to October 15th. In unusual seasons of drought or blight the late crop may be dead as early as September 15th, in which case the harvesting season is earlier.

"Potatoes are grown in Wisconsin on both the clay loam and sandy loam types of soil. The large potato belt of the state, comprising Waupaca, Waushara, and Portage counties, runs quite largely to the sandy loam type of soil. There is also considerable sandy soil in the newer potato sections in the northwestern part of the state. In this section, where clover grows luxuriantly, the settlers seem able to secure very good yields of potatoes from the lighter grades of sandy soil. The soil in every potato section of the state varies considerably both in mechanical conditions and in fertility, and a wide range of yields is obtained in every section of this state, due quite largely to these varying factors.

"The central potato district of this state comprises Waupaca, Waushara, and Portage counties. The counties of secondary importance in this state are Adams, Juneau, Columbia, and Sauk. The three counties mentioned above rank among the thirteen leading producing counties in the United States. The newer sections in this state, especially under development at the present time, are found in the northwestern part of the state and comprise sections in Washburn, Burnett, Barron, Chippewa, Rusk, and Eau Claire counties. This section is especially adapted to the growing of early varieties, and it is our opinion that northwestern Wisconsin will become one of the leading 
potato sections of the United States. Considerable attention has been given in this section to the development of the seed-growing phase of the industry.

"Most of the potato stock grown in this state is raised from home-grown seed. There has been considerable deterioration in potato seed in the last few years, and there is a great need in this state for more uniformity in varieties grown. Very often the standard sorts in demand on the markets have been supplanted by coarse, imitative sorts. The Wisconsin Experiment Station through its extension service is endeavoring to remedy this matter by encouraging community centres where one variety can be grown. The important commercial varieties in this state are, for late, Rural New Yorker, Sir Walter Raleigh, Carman No. 3, Burbank, and Peerless; early varieties, Early Ohio, Early Rose, and Triumph. A number of growers are becoming interested in the Irish Cobbler, but this variety has not been grown on a wide enough scale to judge its adaptability. The Rural New Yorker, Sir Walter Raleigh, and Carman No. 3 are mixed in car shipments. Most buyers grade potatoes according to type rather than variety, and round white varieties are usually graded together in car shipments. In many localities the standard Burbank has disappeared, and especially on the poorer soils a coarse variety, the Late Pride, has taken its place. This substitution has caused considerable difficulty both at the loading stations and on the markets.

"On the heavy types of potato land in this state fall plowing is often practised. On the sandy loam soil potatoes are usually planted on spring plowed land. Especially in places where a 


\section{THE POTATO}

good catch of clover has been secured spring plowing is satisfactory. The clover is allowed to grow until about May 20th to 25th. The land is then plowed, well disked and harrowed and firmed with a planker, and the potatoes planted fron June 1st to 15th. The most successful growers make an application of manure to clover sod in this state.

"Potatoes are planted usually in drill rows, the rows about three feet apart and the seed pieces fifteen to seventeen inches apart in the row. On the heavier land a number of successful growers practise checking the rows three feet apart each way. Very little difference in yield has been noticed in a comparison of the two systems in this state. In the sandy loam soil the potatoes are planted about four to six inches deep. In the clay loam soil the depth is a trifle more shallow.

"The fields are harrowed well at the time of planting and also about the time the potatoes come up. When the rows are visible the culti-. vator is started and the potatoes are given from three to five cultivations during the season. Level cultivation is practised. Very little hilling is done except to ridge the rows slightly at the last cultivation.

"A good percentage of the potato crop of this state is sold direct to warehouses from the field. If the price is as high as 40 cents per bushel, a large percentage of the crop will go into warehouses and be shipped to the markets during the fall months. The potatoes of this state are handled quite largely through the hands of buyers who ship to commission men in Milwaukee, Chicago, St. Louis, Minneapolis, and St. Paul. All of the large commission houses in Chicago have a number of warehouses in this state. A number of the 
large growers ship direct to commission houses in Milwaukee or Chicago. In some potato sections the farmers have organized and have warehouses of their own. They hire a man at a salary to handle the stock and ship direct to commission houses in the large cities.

"A good many progressive growers in this state have built small storage cellars costing approximately from $\$ 300$ to $\$ 500$. In a good many cases excavations have been made in side hills and arrangements have been made to load the potatoes into these cellars directly through openings in the top, or in some cases provision has been made to back the wagons right into the storage cellars.

"It costs from $\$ 20$ to $\$ 25$ per acre to grow potatoes in this state. Profits necessarily vary considerably, due to the fact that conditions vary so throughout the state. A net profit of $\$ 30$ per acre would be considered satisfactory in sections where an average yield of 150 bushels per acre was secured. In sections where the yield runs as high as 300 bushels the profit should be increased proportionately. There are a good many growers on the light, sandy soils who do not average a net profit of $\$ 25$ per acre.

"Artificial fertilizers are not used to any extent by the potato growers of this state. The best potato growers use the following crops in three or four year rotations: Clover and some grain crop corn, and potatoes. Liberal applications of manure are made on farms where considerable livestock is kept.

"A system of rotation in this state has been found necessary to maintain the fertility on potato farms. Where rotation has been neglected, along with the failure to handle livestock, the 
yields of potatoes have deteriorated in the past ten years both in quality and quantity. There are sections in this state which originally yielded from 200 to 300 bushels per acre which now yield below 100 bushels per acre.

"The largest acreage of potatoes reported in this state on a single farm is 400 acres. In the important potato sections of the state the average acreage would probably run to about ten acres.

"This station (Wisconsin Agricultural Experiment Station) is pushing as hard as possible the extension work along the line of potato improvement. There is a great need in this state for better seed, both in regard to uniformity and conformity to type."

\section{KANSAS}

Secretary, F. D. Coburn, of the Kansas State Board of Agriculture, most admirably sums up the potato situation in that state in "Report 91," as follows:

"The potato is probably more generally grown and utilized than any other vegetable, and every county in the state, with the possible exception of six or eight in the southern and western portions, devotes greater or less acreage to its production. As many conditions within the state's 82,144 square miles of area are widely variant, yields likewise differ; thus the potato grows prosperously luxuriant in the rich, sandy loams of the formerly timbered river 'bottoms' and the upland prairie limestone soils, while flourishing in a more modest degree where altitude, longitude, soil and climate present conditions quite dissimilar yet no less suited to various other crops. However, regard- 
less of adaptability, potatoes, as in the past, will doubtless continue to be grown on practically every farm and in every considerable garden; consequently yields per acre for the state may seem to average low, comparatively; but in the real potato districts in the more favoring seasons returns of over 400 bushels per acre are realized, and an output of 300 bushels or more is not at all uncommon.

"The portion of the state proved most admirably adapted to potatoes as a commercial crop is known as the Kaw Valley potato district, in eastern Kansas, where large quantities are grown and shipped each year. In the main, this consists of sandy loam 'bottom' land, two to six miles wide, adjacent to the Kaw or Kansas river, in the counties of Wyandotte, Johnson, Leavenworth, Douglas, Jefferson, Shawnee, Pottawatomie, and Wabaunsee, and extending westward 100 miles from its joining with the Missouri at Kansas City. Of the total Kansas area planted to Irish potatoes in recent years more than one fourth is in these eight counties, Wyandotte ordinarily leading in acres and production. Nearly a third of the state's crop, or practically all potatoes raised in Kansas for export, is frequently the product of the counties named.

"Early varieties for summer marketing are planted mostly, and of these the Early Ohio is by all odds the favorite, followed to a small extent by the Early Rose and Triumph, as named. The small proportion of late sorts planted are the Burbank and Peachblow. Even for winter use the early varieties are grown, and left undisturbed in the ground until fall. While some home-grown stock is planted, Northern-grown seed is found 
best, and each year thousands of bushels are shipped in by planters and dealers, who buy from Minnesota and eastern North Dakota, in the Red River Valley.

"Kaw Valley potatoes find their market in all parts of the country; early in the season Chicago and northern points claim many, and some go in the direction of New York and Pittsburg, but probably the bulk are sent south and southwest, especially to Texas, and preferably sold at digging-time. "The consensus of opinion of Kaw Valley growers reporting suggests that they consider in the neighborhood of 37 cents a bushel a fair price for potatoes on board the cars, and the range in the past ten years has been from about 14 cents to $\$ 1.15$ per bushel.

"Two striking features of Kansas potato growing as compared with that in other states surpassing her in aggregate yields are absence of need for cxpensive fertilizers and freedom from insects and fungous diseases. Of the Kansans reporting, none mention using commercial fertilizers, although the majority apply more or less manure, or sow some crop such as cow peas or turnips for plowing under when green, thereby enriching the land and increasing its subsequent yields.

"A most interesting and suggestive fact is the possibility of profitably irrigating, in the more western counties, small areas for potatoes, and other vegetables as well, where underground waters are made available by wind or other power. Several correspondents have realized gratifying success by such means. By it the home demand in such territory may not only be supplied with certainty each year, but the markets of nearby cities and towns would offer for any surplus at- 
tractive inducements in prices, usually quite in excess of those realized by growers elsewhere.

"The foregoing pertains to Irish potatoes exclusively, but sweet potatoes are likewise grown more or less in about four fifths of the counties, most extensively and successfully, however, in the valleys of the Kansas and Arkansas rivers. The six counties of Pottawatomie, Riley, Wabaunsee, Shawnee, Wyandotte, and Sedgwick yield annually about one half or more of the state's output, which in the past twenty years has varied from 779,783 bushels in 1889 to 212,468 bushels in 1897."

The cost of growing potatoes in these districts is found in Chapter XIII. 


\section{CHAPTER XXXII}

\section{COLORADO}

$T$ HERE are a number of districts in Colorado that produce potatoes of very high quality.

I Among these are: Greeley and northeastern Colorado, San Luis Valley, the Grand River country, in which Carbondale is located; the territory along the North Fork of the Gunnison River, the La Platte and Montezuma country, and the Routt County territory.

Colorado potato growers have made a name for their product, which is now generally known as "Greeleys" for the section north of Denver and east of the mountains, and "Western Slope" for all the districts west of the mountains.

\section{GREELEY}

Greeley, Col., and vicinity, was settled by a colony of professional and business people who were attracted to the West and to the soil by the forceful writings of Horace Greeley. The early history of the colony chronicles considerable of that element which the Western cow-puncher calls "grief." They had a new business to learn under hard, pioneer conditions. Those who stayed, however, prospered. This has been true of all who have brought to the business of farming trained minds and broad experience.

Many of the advanced cultural methods used 
to-day by the best potato growers originated at Greeley.

The story of the Greeley district is to be told by Senator H. C. Watson, one of Greeley's most influential men and one of the first in the business; by Lord Ogilvy, agricultural editor of the Denver, (Col.) Post, one of the best informed men in agriculture in the world and an old-timer at Greeley; and I. Rothschild, the leading dealer in the Greeley market. Senator Watson says:

"The colonists commenced to arrive here early in May, 1870. I came on the first day of May of that year, and am now the oldest inhabitant in point of continuous residence. The necessity of raising something to feed the people was very apparent, so I hired a man who had a yoke of oxen, to plow up some lots on the higher ground but under the ditch we proposed to dig, and bought some Early Rose potatoes of a merchant in Evans, Col., the town which was, at that time, the terminus of the Denver-Pacific Railroad (now the Union Pacific Railroad), about four miles from Greeley. I paid $3 \frac{1}{4}$ cents per pound; had them planted, but unfortunately for the success of the experiment, I joined a party of men who proposed and did go to the mountains for the purpose of floating logs down the river to supply the very great need of lumber to house the people. The man I left in charge of the crop did not do much, and as a result I did not get much of a crop, although I did demonstrate the fact that we could raise potatoes on the uplands of Colorado, and received enough money from my venture to pay the actual cost of raising. I believe these were (with the exception of some that were raised on the 
Ames place near Fort Collins the same year) the first potatoes raised on the uplands of Colorado.

"In the years following 1870 there were increasing acres planted around here, principally Early Rose. A little later, Morten Whites (these did not make a good potato; they seemed to be lacking in starch and would not cook soft), a few Peachblows, and some Snow Flakes were planted. The latter were the very best eating potatoes, as, in fact, they are yet, but they did not yield heavily enough to be profitable.

"In the course of five years or so we had sufficient potatoes to sell to make it necessary to do something to market them. I was then employed as clerk in a large store here. We built a warehouse on the railroad track, which stands there yet, and went at the business systematically. I had charge of that department and had to make frequent trips to Denver to sell our stuff. On one of those trips I wrote about a column article describing how we handled potatoes in Greeley took them in loose, sorted, and sacked them ourselves. I published this in the News of Denver. The result was that Greeley 'spuds' got a reputation that was of value.

"In the year 1881 I went into business for myself. A part of this business was the handling of potatoes, which by this time had become an industry of larger dimensions and kept increasing every year. In the season of 1886 a number of business men and bankers concluded that the potato business had become so large that it was necessary to organize the selling end, so that we could extend our markets. To that end, the Greeley Mercantile Company was organized with a capital of $\$ 40,000$. Mr. O. P. Gale was president and I 


\section{THE POTATO}

was vice-president. We paid cash and handled our product on its merits, as every business should do. About this time, or in fact several years before, we found that the Early Rose were not growing in paying quantities, and some farmer shipped some seed of the Rose Seedling variety from New York; also some Mammoth Pearls, Carmans, Mammoth Prolifics, and Rurals. All of these varieties were more or less successful, especially the Pearls, which are yet the principal crop raised here. In the summer of 1887 our president died and I was compelled to take charge of the business. We sent a man to Texas and kept him there a whole season at considerable expense, being careful to ship only good stock. We did not make much, but we created a market for the future. That year there were about 1,500 cars of potatoes raised in the territory north of Denver. We found that we had about reached our limit, as the water from the streams would not hold out for late irrigation; that is, in August. This made it necessary to build reservoirs to store flood waters and the winter floods of the streams.

"We were not raising much over 100 bushels to the acre, as the soil lacked humus and nitrogen. A farmer from Iowa by the name of Bliss concluded that he would try turning under alfalfa as they did clover in the East. Now our farmers were of the opinion that you could not get it to rot, as it came right up again, but he managed, by putting chains on the plows, to turn the plant under. The result was astonishing, as it just about doubled the crop, not only of potatoes, but of everything else.

"A number of years ago I conceived the idea that we might increase our crop by shipping in some seed from a non-irrigated country; so we got 
a car of Mammoth Pearl seed from northern Wisconsin. We had some trouble in getting this car sold, as we had to get $\$ 1.25$ per cwt. for it, but we scattered the potatoes over the country - five and ten sacks in a place. The result was a very large increase in the crop and very much better stock. Now our farmers do not object to paying $\$ 2.00$ per cwt. for seed."

\section{Lord Ogilvy says:}

"Whatever claims may be pressed by other sections, it must be remembered that Greeley is one of the best known districts in the potato world.

"The soils in their natural state were not comparable to some of the mountain plateaus and gulches, where grow the wild potatoes, in their adaptability to potato growing. Alfalfa growing and storage of water were necessary before potatoes could be produced to the amount of 10,000 carloads and upward per year.

"There were no popple washes, leaf mould from mountain slopes or accumulation of dead grasses on the plains to furnish stored food for the crop. Cactus of short growth as a rule indicated those pliable rich loams containing granite sand as an enduring base for the welfare of the potato.

"The soil, so rich in mineral elements, was deficient in humus, and it was not until alfalfa had been grown some years that any tonnage was produced except here and there. The breaking up of alfalfa at first gave an excess of humus in that it forced vine and early growth; the tubers set on and matured during the excessive heat of summer. An occasional run or two of river water at the 
right time gave heavy tonnage and indicated what was to be. It became plain that regulated supply of water must be served; that in this district late potatoes must be held back to make their tuber growth during cool weather.

"Even though the first reservoirs of magnitude were completed by the farmers at a time to increase production - which found a light demand during the panic period of 1893 - yet the results were so satisfactory that the building of reservoirs has been continued ever since. Except in those districts where potatoes can be allowed to mature during the heat of the summer, or in those rare instances where the river supply is continuous, reservoirs are a necessity. Once potatoes have set on they must be kept moist so their growth be continuous. If arrested growth takes place and they are then watered the further development will be in the form of knobs that make rough potatoes.

"Those who believe that potatoes must have an exactly suitable soil for successful culture should visit the Greeley district. Not only do the soils vary from heavy clay or adobe to sand, which need entirely different handling, but also the same fields that have raised potatoes for forty years in rotation with other crops are now handled in other ways than were formerly expedient. A rising water table due to pressure from irrigated lands at higher levels has necessitated more aeration by thorough cultivation of the soil.

"Had we been told twenty years ago what was needed to raise good potatoes - brains and hard work - we likely would have quit right there, but we gradually grew into it and perfected the system which can best be studied in all its varieties 
in the Greeley district, where work is thorough and intense; varieties of potatoes studied for their particular adaptations, and the method of culture also made to fit the potato.

"The growing of potatoes begins with seed growing or its purchase. The selection is only partly carried out before the seed is cut, and must continue through that process, rejecting everything that shows badly under the knife. The preparation of the ground has begun years before with the seeding of alfalfa to enrich it with manure, and by its root contents. When the specially built alfalfa plows turn the sod we are nearer the last end of potato growing than the beginning, for we have the seed selected and the medium in which it is to be grown full of stored fertility, the result of forethought.. The good seed is planted at the right moment and the land is not allowed to rest, for the heavy horses in harrowing, leveling, and planting have compacted it too much and lack of air circulation breeds disease. The cultivators at once follow the march left by the planter and should run as deep as a plow sole stirring and aerating the soil.

"From then on clean, absolutely clean, cultivation until the time when the ditches are put in to guide the water through the rows. The depth of these will vary according to the fall of the land, and what is known as the Kersey, a wooden moldboard ditcher, is much used. This has an attachment for distributing earth on top of the rows, to keep potatoes from frost and sun-scald. Just when the water and how much, whether in every other row or all, is something which every farmer must know for himself, for the time will vary according to the condition of the soil, altitude, and 
variety of potato, and it will also vary with the changing seasons.

"Besides the remarkable energy of Greeley people in perfecting their system of potato growing and originating tools and methods of culture, something must also be credited to their system of storage and marketing. Probably nowhere else are such perfect potato cellars to be found upon the farms, or as convenient and large a supply of potatoes along the tracks which can be dispatched at a few hours' notice. Besides this, there is always a large number of cars the routing of which can be changed to meet urgent demands.

"Many varieties of potatoes have been experimented with and discarded, and changes have only been made when a variety has thoroughly proved itself. The Early Rose gave way to the New York, Rural, or Carman group on heavy soils or those with a cool subsoil. Pearls in one form or another are a great standby. The Rose seedling, or, as it is sometimes called, the Greeley Red, fills the demand for red potatoes. The Early Late Ohios are also largely grown, and for all these there is a general score card of perfection in the grower's mind when he has an order to fill, which enables him to satisfy his customers."

There is no one in a district in closer touch with affairs than the dealer. I. Rothschild says:

"There is planted this year (1911) 35,000 acres, and for the past eight years there have been planted 25,000 to 35,000 acres each year, the crop running from six to fourteen thousand cal 'oads each year. 
"Most of our farmers grow potatoes in preference to any other crop, and the only reason more are not grown is because the land is not in just the right condition, and then again it is an expensive crop to grow.

"As to markets, we have Texas first. This is a short haul and quick service; that is, the Texas people can get 'spuds' from Greeley quicker than from any other section and the freight rates are as low and some lower than in a great many of the potato districts. Again, we have onions which we are privileged to ship with potatoes, and the smaller towns which would not use a car of onions will buy the potatoes in order to get twenty or thirty sacks of onions in the car with their potatoes.

"Different localities use a different style of potato. For instance, Chicago wants a rather large, long potato, while St. Louis wants a round, medium size, and Kansas City demands the very largest. Then, there are a few places that will take them mixed, and it all depends on the strength of the market as to whether they will take them at all.

"As to yield, we have one section of the Greeley district that last year averaged 200 bushels to the acre, and another section not fifteen miles away where the average was less than fifty bushels to the acre. Altogether, the average last year was 100 bushels to the acre, and we had one year when they averaged 250 bushels for the entire district.

"Rurals and Pearls are our standard varieties, with 6 per cent. planted to Pearls, but Rurals are gaining. It seems that some of our growers are just learning how to grow Rurals." 
The following table shows the cars sold at various seasons, the price, and total cars produced

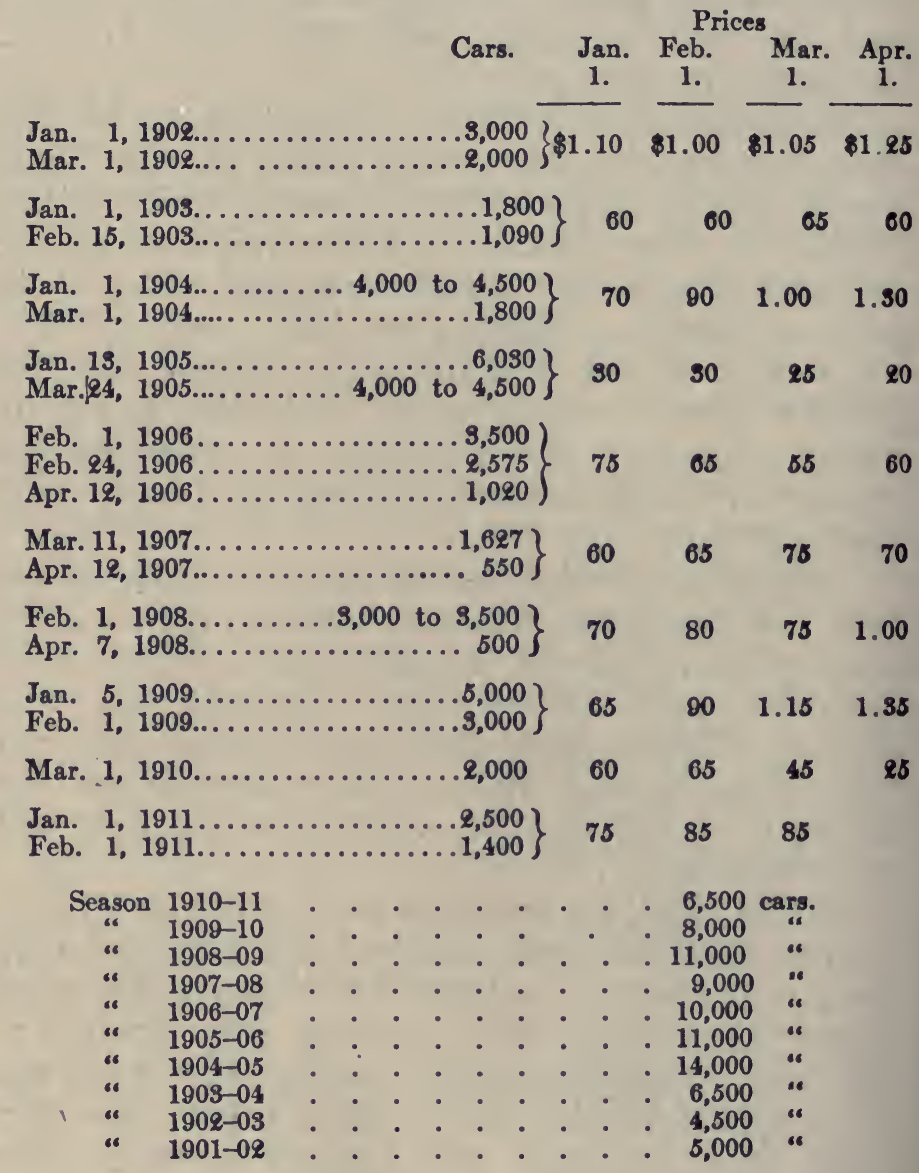

\section{THE WESTERN SLOPE COUNTRY}

The districts that supply the markets with Western Slope potatoes are Carbondale, Rifle, 


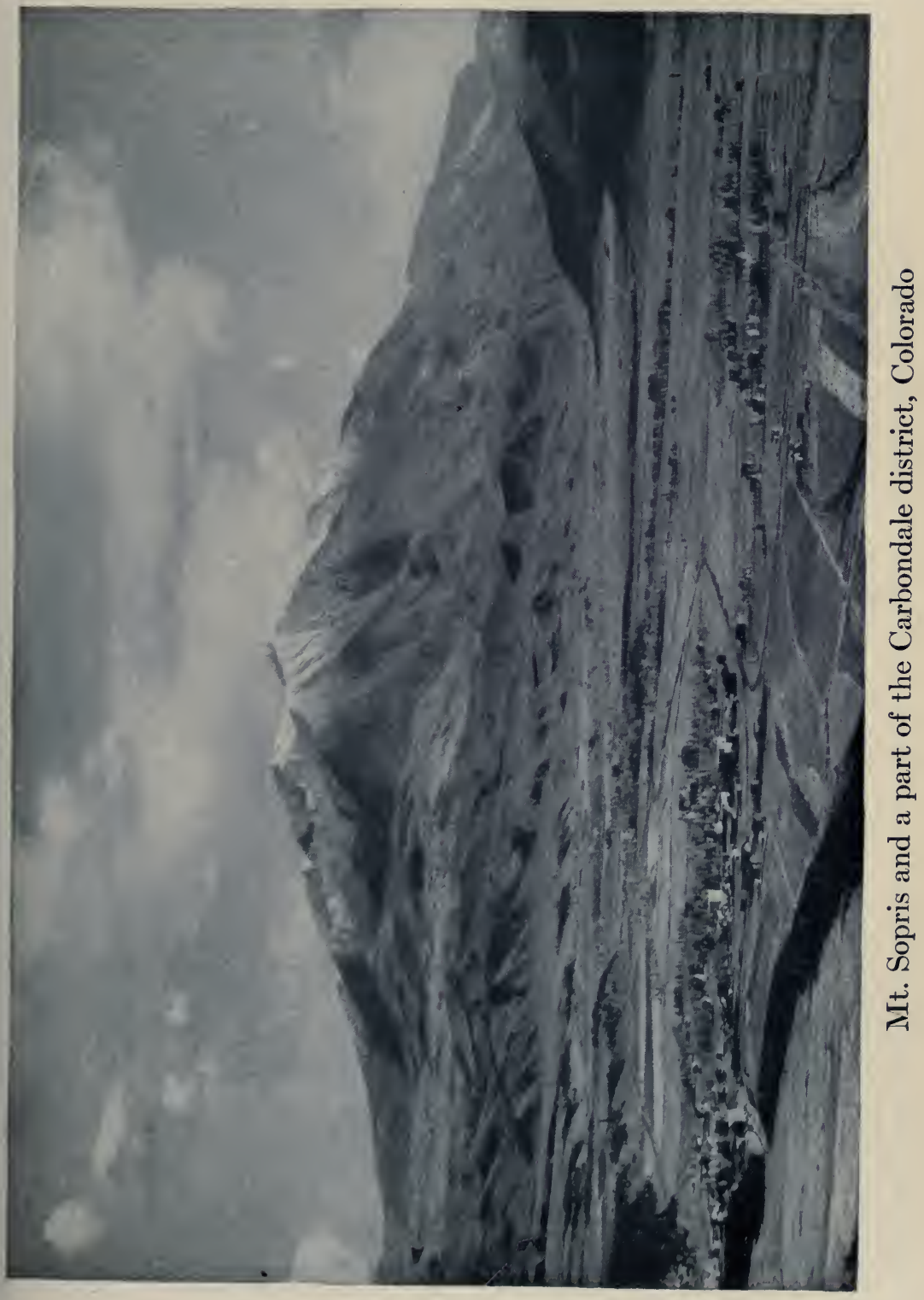




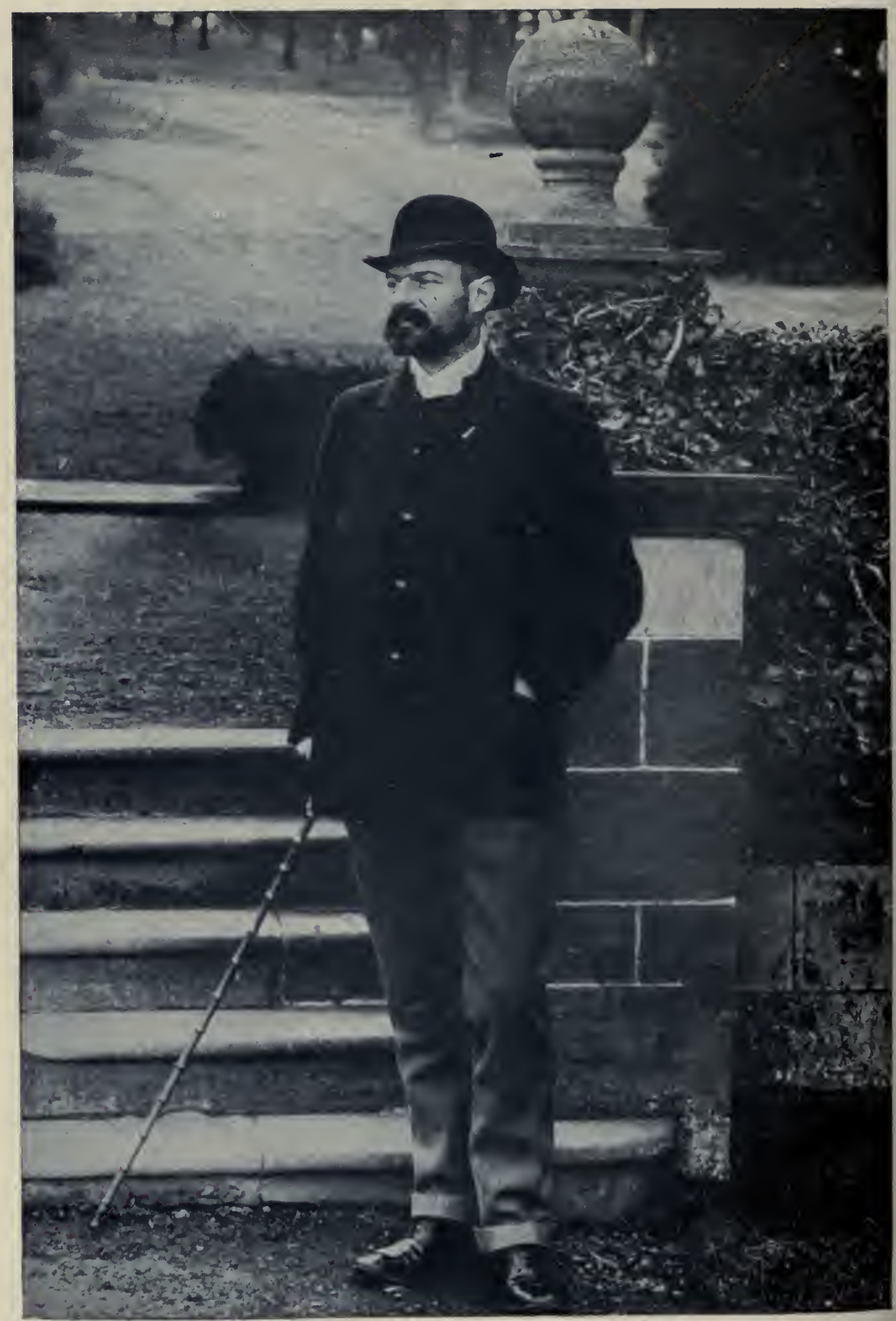

Lord Ogilvy, agricultural editor Denver Post, Denver, Colo 
New Castle, Eagle, Gypsum, Montrose, Delta, Olathe, Grand Junction. The conditions in all of these are very similar and a description of one serves to describe all.

Because it was a leader in making the present popularity of the product, the Carbondale territory will be described most in detail.

Carbondale is just off the Roaring Fork of the Grand River. From the Frying Pan - a small tributary at the head of the Roaring Fork - to Glenwood Springs, where it joins the Grand, the Roaring Fork is about thirty miles long, and the valley is about one mile wide. It is a rough, mountainous country, with an elevation of from 5,000 to 8,000 feet.

The farming land in this valley is not in one continuous body, but in scattered areas along the river and its tributaries and on the bench land adjacent.

It is in this sort of country that the potato is found growing wild. The soil is open and well drained and the native vegetation consists of rich grasses, sage brush, and trees.

The excellence of the potatoes grown at Carbondale first attracted the interest of the particular hotel and dining-car trade. Seven years ago (1905) Mt. Sopris Farm contracted to furnish the New York Central Railroad with potatoes. Baking and cooking tests were made at the farm by the buyer. The business grew, and Carbondale had the first growers' association on the Western Slope. Now this product is known from the Atlantic to the Pacific.

In an interesting publication regarding the country is the following descriptive matter: "Lying within the shelter of high mountains at an alti- 
tude slightly over 6,000 feet, shielded from severe storms and extremes of temperature, with pure, dry, invigorating mountain air and the purest of mountain water, entirely free from alkalies, it is a - natural health resort and an ideal place in which to make a home-an unpeopled valley, luxuriant in wild vegetation and threaded by crystal streams fed by the inexhaustible snows of the giant Mt. Sopris and surrounding ranges, transformed in less than twenty-five years into one of the garden spots of the globe. This, in brief, is the story of the Carbondale district, a story that typifies the highest achievement of natural resources and human resourcefulness and coöperation."

One of the most popular booklets ever published about the potato, if pupularity can be judged by demand, is that issued by Mt. Sopris Farm entitled "A Modern Delicacy." Because that publication is not now obtainable it is being practically reproduced in the following:

\section{A MODERN DELICACY - MT. SOPRIS}

\section{FARM POTATOES}

Next to bread and meat, the most important article of food to the Anglo-Saxon race is the potato. Notwithstanding its importance as a food product, comparatively little attention has been paid to the development and improvement of the potato until recent years. The writer, having spent a number of years in trying to grow varieties of potatoes that would be of such quality and perfectness in economical conformation as to command the highest market prices, and having met with a fair degree of success, is constantly appealed to by growers for information as to methods and by con- 
sumers for a history of the operation in producing the three varieties that I am now growing and which are rapidly attracting the attention of the trade all over the country because of their merit. In order to answer these questions intelligently, I have in this manner explained, as briefly as possible, something of the methods now being successfully used in the Carbondale potato district and on Mt. Sopris Farm, and a history of the principal varieties grown.

In order to produce a perfect specimen of any article one must first have in mind an ideal. We must therefore understand what constitutes a perfect potato, both from the standpoint of the consumer and the trade. The consumer desires a potato that when cooked will be dry, mealy, or, when crushed, like flour. The trade wants a potato that is clean and dry, with a rough skin, not easily bruised or broken, as a broken skin provides the nucleus for rot.

Uniformity. - One of the most important specifications in the production of an ideal potato is uniformity in size. It is, of course, impossible to grow potatoes all the same size, but I make it a point to grade the potatoes before marketing into nearly uniform sizes. In cooking the tuber this is important, as when a small potato is cooked with a large one, either the small one becomes overdone or the large one underdone. With nearly equal sizes, they all cook alike.

Quality. - Potatoes are like fruit in one respect: they are best when fully ripe. A well-ripened potato, matured in proper soil, is a luxury for an epicure when properly cooked. The unripe potato when cooked is wet, soggy and clammy. The starch molecules have not been transformed as 
they should be and the potato is not as digestible. The well-ripened potato cooks dry even in water and crushes into a flaky, powdery mass, with the starch in fine, granulated form.

Conformation. - It is only within recent years that potato breeders have paid much attention to the formation of the potato. The ideal potato must be regular in shape, round or oval, with eyes nearly flush with the surface. Large hotels and restaurants are compelled to use machines for paring. With the old-fashioned, irregular shaped potato, the loss in paring was often equal to a third of the weight of the tuber. The Mit. Sopris potatoes can be handled very economically in a paring machine, the loss being practically nothing but the tough skin. In the matter of economy, therefore, the regular conformation of the potato is highly important.

The original potatoes were found growing wild in the mountain districts of North and South America. In looking for ideal climatic and soil conditions, therefore, we have but to study the environment of the wild potato.

An important effect of the climate is the uniformity in the quality of the product from year to year. Climatic conditions in the mountain sections of Colorado do not apparently vary enough to materially affect the quality of the crop from one year to another, and the crop this year is as good in quality as last year, and will be the same next year. This is highly important in establishing a commercial demand.

My experiments in improving and developing the varieties of potatoes grown on Mt. Sopris Farm cover a period of about fifteen years. My first work was with the Perfect Peachblow. This 
is an improved type of the old Peachblow, a variety grown in this country for over fifty years, and is one of the oldest varieties in existence. Originally it was yellow fleshed, often hollow and bitter of taste. Peter Henderson, a well-known New York seedsman, developed this variety, and in 1883 some of his Perfect Peachblows were brought to Colorado and planted in the Roaring Fork Valley. The perfected variety was of white flesh, never hollow nor bitter, and proved an ideal potato. It was round and slightly flattened on one side, with few eyes and a tough skin. It became a great favorite and is still the leading variety on the western slope of Colorado.

Perfect Peachblow. - My first efforts were in the direction of increasing the tonnage yield of this variety. The trouble most found was that the hills produced one or two potatoes of great size and many small ones. The large potatoes often cracked open and the crop as a whole lacked uniformity. My method was first to plant the size of potato I desired to produce and later to select my seed from hills producing not less than twelve potatoes of uniform type and size. By this method I have been able to secure a crop of uniform and fixed type characteristics. This plan resulted in greatly increased production, but subsequently I found it advisble to sacrifice some of this increased yield to quality. I have succeeded in producing a uniform type of Perfect Peachblow, of fine quality, fixed type characteristic and fairly uniform size.

Dalmeny Beauty. - Several years ago I had an opportunity to see the work being done in type breeding of potatoes on the Earl of Rosebery's Dalmeny Farm in Scotlaná. Since then I have 
imported twelve different varieties of these fine Scotch bred potatoes, but have found only two varieties that proved adaptable to the Roaring Fork district. Of these the Dalmeny Beauty has proved very promising. It is a white fleshed, medium to large potato, oval to oblong, shallow eyed, with a clean and attractive skin. The vines grow from three to five feet high, and it is one of the heaviest yielders known. One stalk in the Carbondale district produced twenty-five tubers weighing eleven and one half pounds. Four acres in the same section produced 307 sacks per acre, 116 pounds to the sack. It is a strong feeder and needs rich soil.

Challenge. - This is another Scotch variety imported from Dalmeny Farm. It is a medium late variety of high quality. It is white fleshed and mealy. The skin is smooth and white. The tubers are oblong, medium to large, with square shoulders. A good cropper. This year one plat of ten acres at Carbondale yielded 277 sacks per acre, 116 pounds to the sack. It is a very high quality potato, and those grown in Carbondale have been used for the past four years on the Vanderbilt system dining cars.

In my opinion the Perfect Peachblow, as developed in the Carbondale district of Colorado, is about as near the ideal potato as has yet been grown. One difficulty most potato growers have had to contend with in other sections is the fact that the various varieties "run out" in two or three years, or, in other words, deteriorate in quality. The Perfect Peachblow is an exception. Notwithstanding the years of injudicious methods in seed selection and cultivation, the variety is as vigorous and healthy as ever and is steadily improving. 


\section{THE POTATO}

It has an astonishingly strong constitution, and seems to easily resist the many diseases that afflict potatoes elsewhere. Much of this is due to the ideal conditions that exist here. It is impossible to grow a firm texture, high quality potato in a hot soil. The soil here is always cool and the tuber has plenty of time to mature.

The consuming public has not yet learned to discriminate in the quality of potatoes. Gradually the demand for the high quality potato is increasing, however, and the time will come when the people of the East will insist upon having the fine tubers grown in the mountain valleys of Colorado. When that time comes Colorado will produce twenty million bushels annually instead of six million, as at present, and the fame of the Carbondale potato will be equal to that of the Rocky Ford cantaloupe.

The important requisite in securing the best results in potato growing is to plant in an open, porous, well-prepared soil. The soil must be well supplied with humus, or vegetable mould, so that it is open and easily accessible to air, as the best potatoes must have air, especially when maturing. Excessive irrigation contracts and solidifies the soil. I practise frequent cultivation, and with special machinery ridge the hills high and wide, with a deep trench for the irrigation. For at least two months previous to maturing I do not irrigate, allowing the tubers to mature in a soil almost dry, the tap and feeder roots providing all the moisture needed for the tubers. By this method the tubers when ripe come from the soil in a clean, bright condition; the skin is tough and the potato keeps better.

The Perfect Peachblow is the best keeping po- 
tato known when grown in this manner, often keeping until the middle of August. It is an ideal potato for the early spring and summer market, being in prime condition.

That a cool, porous soil is largely responsible for the best quality in potato growing was evidenced at the Aspen Fair this year, when the first prize potatoes in a most wonderful exhibition were found to come from an altitude of 8,100 feet above the sea.

Probably the most important item in securing a high quality potato is seed selection. Carbondale growers are now exercising the greatest care. We are trying to secure fixed characteristics, and the seed potatoes from this district will do well in most any potato section where proper conditions can be had, and the crop will be found to possess the uniformity as to size and quality that is so necessary to success.

The proof of the pudding is in the eating. So is the proof of a high quality potato to be found at the table. It must be properly cooked and served, and thus the Carbondale potato will be found one of the delicacies of the world.

Few people know that a potato has a season of best eating quality, the same as an apple or peach. The Perfect Peachblow is best after the first of January. The Dalmeny Beauty is best from the first of November until April. The Challenge is best from September to January.

No part of the world is better fitted by nature for growing potatoes than the mountain districts of Colorado. Those sections where the soil is largely composed of ground granite and sandstone are of course best adapted. The Roaring Fork and Crystal River Valley section of Colorado is as 
nearly perfect in soil conditions as can be found, and the potatoes grown there are not excelled anywhere in the world, and are equalled in but few places. With the requisite climatic and soil conditions, and the use of careful and intelligent methods in seed selection and the maintenance of a uniform type, few crops can be grown that will return better profits for the producer. 


\section{CHAPTER XXXIII}

IDAHO - TWIN FALLS COUNTRY - UPPER SNAKE RIVER

TDAHO is one of the newest states in the Union, both in point of history and agricul1 tural development. As in most of the Western States, mining caused the first immigration.

Lewis and Clark went through the Snake River Valley in 1805, but in 1860 the state was inhabited only by the Nez Perces, Palouse, and Cour d'Alene Indians in the north, and the Blackfoot, Bannock, and Shoshone in the Snake River country.

Irrigation farming is making southern Idaho one of the richest and most famous agricultural sections in the world. The first irrigation was along the small streams where individuals took out ditches to water their small farms and fields. Local consumption took all of the first farmers' produce and more. Even now the people of Idaho import much of their foodstuffs.

The next stage in irrigation was the company or community ditch system, where a few hundred or thousand acres were watered by a number of farmers working together, doing most of the work themselves. All of the work performed in these first two stages of the business was done as cheaply as possible, and comparatively little capital was required.

In the Twin Falls country the first irrigation was along Rock Creek and Goose Creek on the south 
side; along Wood River above and below Shoshone; on Clover Creek on the north; and from springs in the north side of the Snake River Cañon at Blue Lakes and along down the river to the Hagerman Valley. Successful crops of fruit, grain, hay, and vegetables have been raised in these places by pioneer stockmen and miners for forty years.

The great Snake River plains, the most fertile and best drained agricultural section in the state, were undeveloped because millions of dollars was required for large improvements before the settler with ordinary means could find a place.

To I. B. Perrine of Blue Lakes is due the credit for successfully starting the extensive irrigation work in the Twin Falls country. He located the dam at Milner from which water is diverted, and interested capital in the possibilities of the country. J. S. \& W. S. Kuhn of Pittsburgh, Pa., have spent and are spending twenty million dollars in developing the possibilities of this agricultural empire. Five years ago sage brush and coyote reigned supreme; now 40,000 people have their homes in the Twin Falls country.

There are 54,000,000 acres of land in Idaho. Of this amount about 2,500,000 are irrigated. Over 450,000 acres are contained in the irrigation projects already built and being built by the Kuhn interests.

At the present time the tracts reclaimed in Idaho by J. S. \& W. S. Kuhn of Pittsburgh and their associates include the first, second, and third segregations of the Twin Falls North Side Land \& Water Company, embracing 220,000 acres; that of the Twin Falls Salmon River Land \& Water Company, embracing 80,000 acres; and that of the 
Twin Falls Oakley Land \& Water Company, with 50,000 acres; also pumping projects covering 100,000 acres.

The achievements of these organizations are among the greatest in the history of irrigation and agriculture.

To develop in the desert one of the richest agricultural districts in the world is to produce wealth for the state and nation, and make it wonderfully fast.

More development per acre is made in five years under these big projects than was the case in the fertile corn belt in thirty. More capital is being used in developing farms now than ever before, and nowhere is this condition more marked than in this section of Idaho.

The water supply of the greater part of the western slope of the Rocky Mountain system is far in excess of the land available for irrigation. There can never be any question of an abundance of water for the irrigation of all of the lands in southern Idaho if it is properly cared for, and never any possible question about those with the first water rights.

By actual test products grown in the irrigated districts of the West have a higher food value than those of any country where conditions are less favorable for crop perfection. Soil, sunshine and moisture control are responsible for this. For instance, the average weight per bushel of the oats grown in the Middle West and East for 1908 and 1909 was twenty-four to twenty-six pounds. In the irrigated Twin Falls country oats weigh thirty-eight to forty-nine pounds per bushel. A legal bushel is thirty-two pounds. Oatmeal manufacturers have found that oats produced by irrigation contain 7 


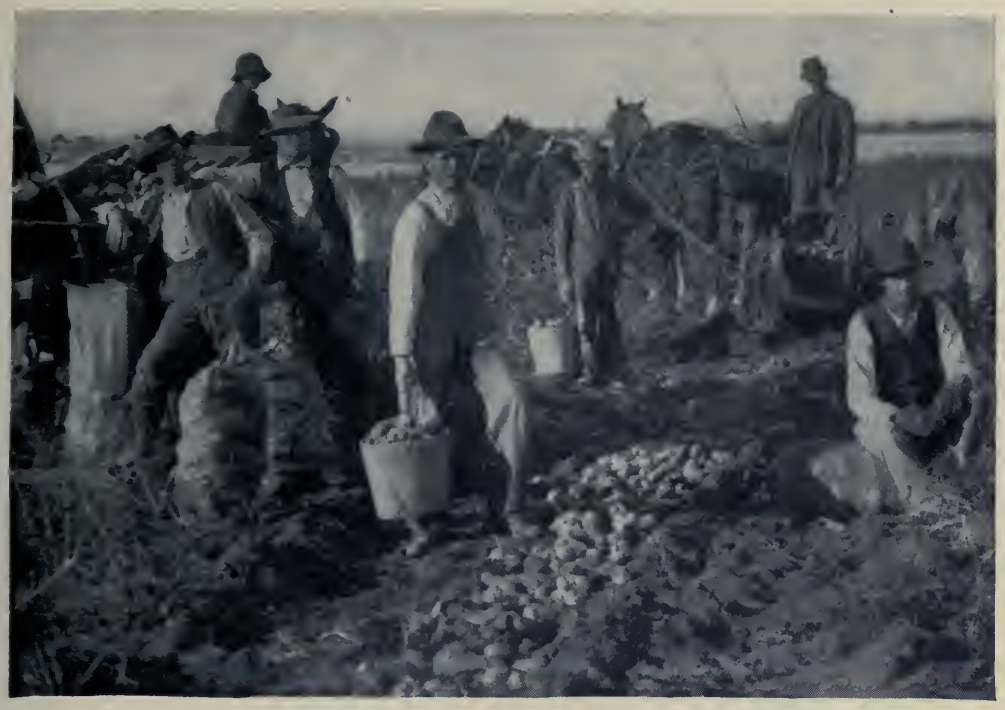

Potato digging near Twin Falls

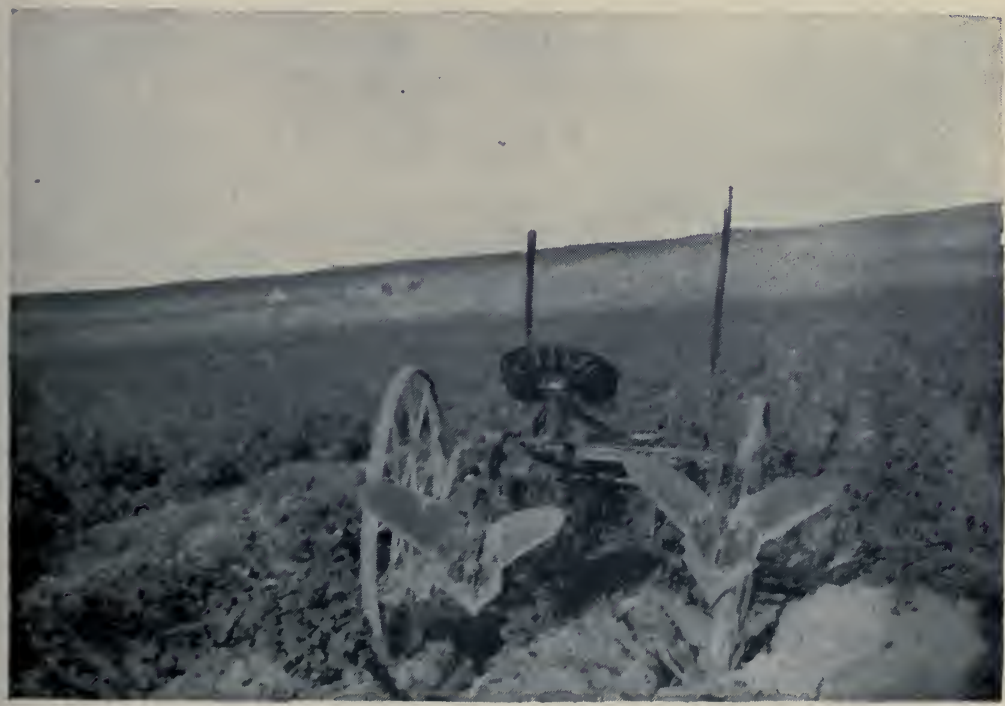

Planet Jr. furrower or ridger for hilling potatoes. These are attached to cultivators. Manufactured by S. F. Allen \& Co., Philadelphia, Pa. 


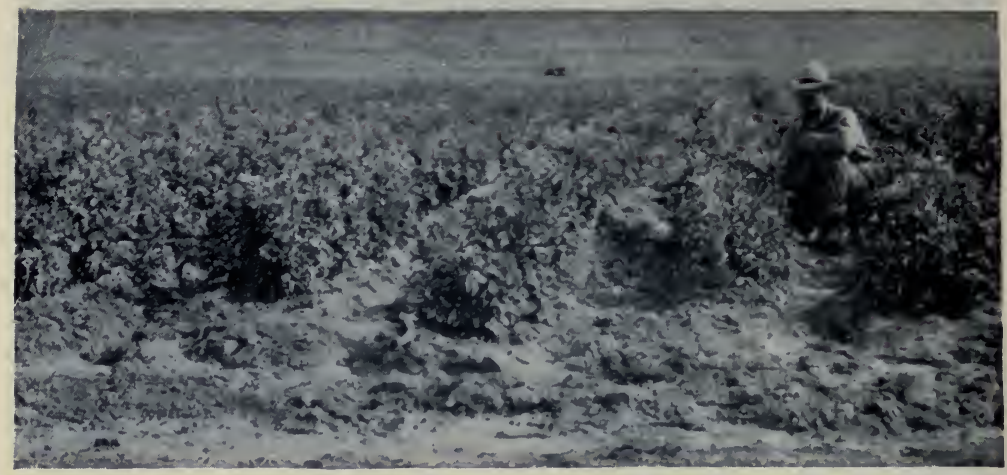

Potatoes near Jerome - junior author in field. Photo taken August 10, 1909

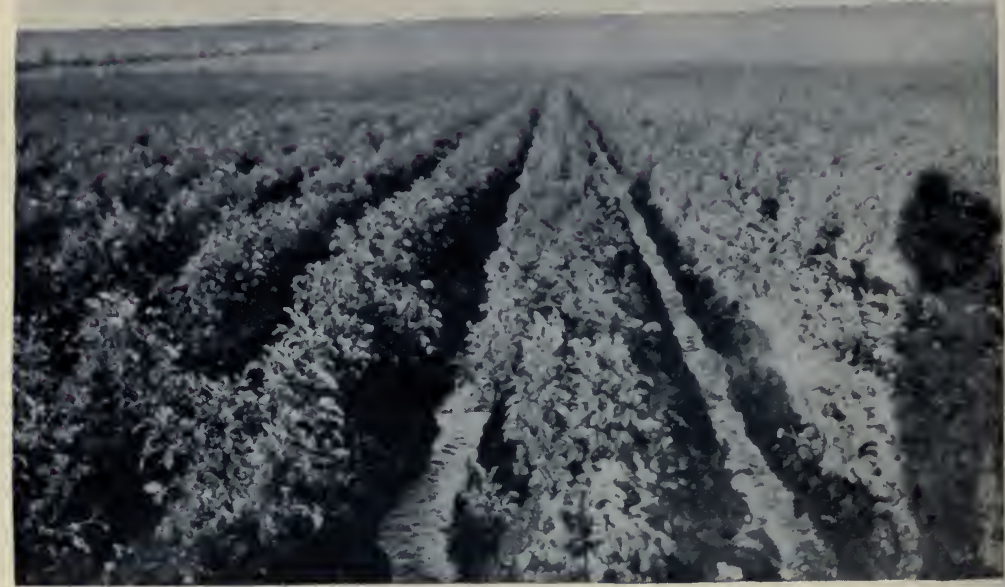

Irrigating potatoes near Wendell

SCENES IN THE TWIN FALLS COUNTRY, IDAHO 
per cent. more meat as compared with hull than any other oats they have milled. Idaho sugarbeets have a high sugar content, and Secretary of Agriculture James Wilson, the father of sugar-beet industry on this continent, has said that it would be possible for Idaho to supply the United States with its sugar. Idaho fruit is high in nutriment and sugar content, because these elements are elaborated by the plant in the presence of sunshine. Its delicious flavor and fine texture are very marked. Meat produced from rich grasses is in turn high in food value.

One of the most important factors in the establishment of a market for all high class agricultural products is the uniform permanency of supply. The conditions are under such perfect control, and the Twin Falls country is of such extent, that this is absolutely provided for.

The Twin Falls country of southern Idaho is in about the centre of what is commonly called the Snake River lava plains. Until the recent application of water to large tracts of land here it has been known as the Snake River desert. It was never a barren desert, however, but covered with a growth of desert plants and grasses, making an excellent winter stock range.

Geologists report that southern Idaho was originally a rough, rocky country, the rocks being granite, rhyolite quartzite, and limestone. The valley of the ancient Snake River was broad and several valleys opened out from it into the mountains to the north and the south. After the river had worn to a deep channel, a flow of lava or a volcanic upheaval obstructed it in the western part of the state, and a lake covering a large part of the Snake River plains was formed. This lake was 
gradually filled up with wash and sediment, and with dust blown from volcanoes. In places this sediment is known to be 1,000 feet deep. Flows of lava from numerous vents, and deposits blown in by the wind, added to the superstructure of the country. The lava flows to the eastward of the lake region have been covered with wash from the mountains, dust blown from the old lake bed and lava dust from old volcanoes. The disintegration of lava rock has also probably added to the present soil. While in one way a plain, the Snake River country is more or less broken, making soil drainage perfect. The valley is surrounded by mountains rising from a few hundred to 6,000 feet above the plains, and 7,000 to 10,000 feet above the sea level.

The lava ash soil of the Twin Falls country is fine in texture. It is classed as an arid or desert soil in comparison with those of the rain belt. Soils found in a country of light rainfall, where irrigation is absolutely essential for the production of maximum yields of most crops, are high in the mineral elements of fertility because the soluble salts have never been leached out by the rains. Muck, peat or sour acid soils are not found in the Twin Falls country. A large number of tests of samples of arid and humid soils shows that the average arid soils contain three times as much potash, thirteen times as much lime, and six times as much magnesia as the humid soils. There is less humus in an arid soil. Humus is one of the chief sources of nitrogen, and nitrogen is one of the principal elements of plant food. The humus of an arid soil, however, contains three times as much nitrogen as the humus of a humid soil. Limestone soils are usually rich in phosphorus, and it is 


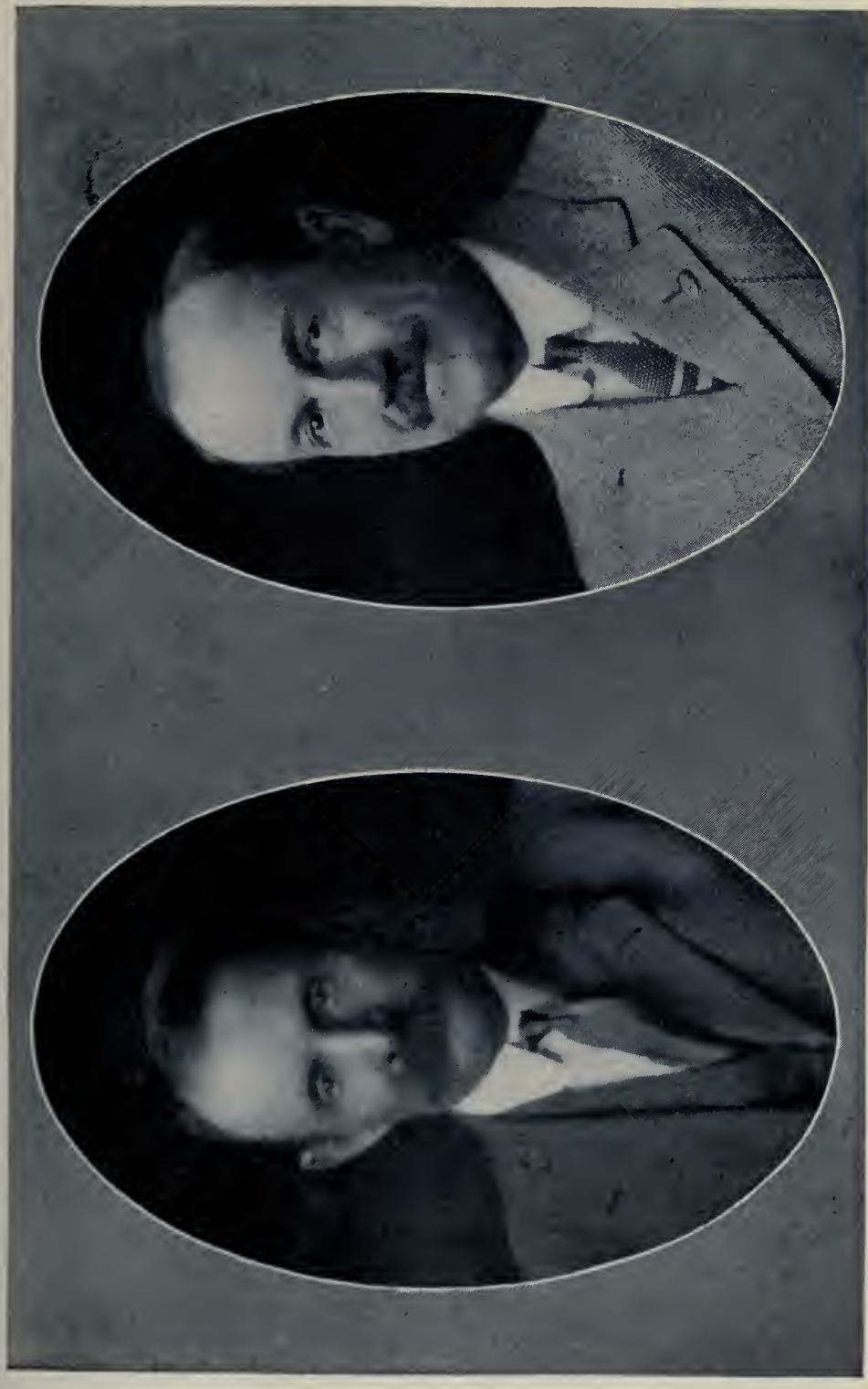

.

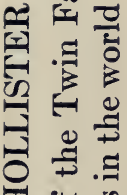

피 눙 홍

; 80.

-

I $=$

ว

을

음

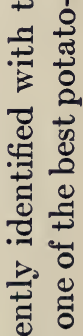

될

䆚

ํํㄹ 을

도 음

다 륭

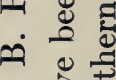

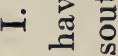

을

్ㅠㅁ

$E$ 

proverbial that "a limestone country is a rich country." The average per centage of lime in clay soils is .617 . In the lava ash soil of the Twin Falls North Side tract there is 4.5 per cent. An acid soil is almost invariably a hard soil to grow crops on. As a general statement, all good soils show an alkali reaction-that is, they contain more alkali salts than acids.

The fact that the soil of the Snake River plains is partly an æolian or wind deposit classes it with the richest soils in the world. It is the deposits of the dust of ages swept from a desert country in addition to the lava dust from volcanic eruptions. The fine particles of soil are those from which the rootlets of the plant obtain their chief food supply. The Twin Falls North Side soil classes as 100 per cent. fine. In the regions embracing these fine, rich deposits there are dust storms while the country is a desert, but after irrigation and cultivation, with the consequent filling of the soil with moisture and vegetation, dust storms do not occur. The great plains of North America, including a large part of the Mississippi Valley, is a wind deposited loess or loam. The fertile loess soil region in northwestern China, which supports a dense population, is of æolian origin. The soil of the Twin Falls country consists of a mixture of the finest particles of the deposits from the disintegration of the rock of the mountains and plains, the wash of the same, and dust blown off the lake deposits to the west and south.

The altitude of the Twin Falls country is from 2,800 to 4,800 feet. It lies just south of the $43 \mathrm{~d}$ degree of north latitude, almost centrally north and south in that section around the globe in which has been made the major part of the world's prog- 
ress. It is about 400 miles east of the Pacific Ocean, 1,320 miles west of Lake Michigan, 432 miles south of the Canadian line, and 700 miles due north of the mouth of the Colorado River at the Gulf of California. Three mountain ranges separate the Snake River Valley from the Pacific Ocean. The main range of the Rockies protects it on the north and east from the moisture-laden winds of the Japan current and from the fury of winds and blizzards that are common in the plains country of the eastern slope. This makes the air dry, and while not free from winds or from some rain and snow, destructive wind is not known. The freedom from blizzards and excessive changes, and the perfect altitude, make possible the greatest perfection in all crops.

The growing season is comparatively long and the combination of cloudless, hot days, rich soil, and irrigation water in the growing season matures crops of quality and great quantity. The annual precipitation is about fourteen inches; the number of clear sunny days average annually 300 ; the highest temperature 101 degrees; and the lowest 12 to 20 degrees below zero. The dry climate makes prostrations from heat unknown. There are some snowstorms in winter, as everywhere in this zone, and in the transformation of the desert wind and dust storms occasionally occur. Almost all of the rainfall is in winter and spring, making the growing and harvesting season practically free from profit losing storms. The last killing frost in the spring is about May 15th, and the first in the fall about September 25th.

Southern Idaho soil has demonstrated that it contains the elements required to make deliciously flavored potatoes, especially where the quality of 
water applied is under absolute control, as with irrigation.

Potatoes grow best in a mellow, deep, easily worked, rich soil, one that does not bake and is well drained. Soils classed as sandy loam and volcanic ash are excellent. Drainage is important, as the water table should be at least three feet below the surface. With the gradual but marked fall of the Twin Falls North Side tract to the south and west toward the Snake River, and the numerous draws and coulees, it is one of the best drained tracts of land in the world.

A light, fine soil is easily worked. It responds more quickly to culture, and the potatoes at digging time come out clean and free from dirt, and keep better. Soil and crop experts, without exception, class the soils on the Twin Falls North Side tract as perfect for the growing of potatoes. It is chemically right, and has produced crops that have never been equalled in quality anywhere. The tubers grown in it are smooth, clear skinned, contain a high per centage of solid matter, are firm, of excellent flavor, and when dry come out of the ground as clean as new dollars from the mint. Besides that, the yield per hill and per acre is very large.

The principal shipping points in this territory are Idaho Falls, American Falls, Rupert, Burley, Turn Falls, Buhl, Jerome, Wendell, Gooding, Bliss, Mountain Home, Pampa, Boise, Caldwell, Payette, and Weiser - all in Idaho.

In the Burley potato contest in 1910, L. A. and W. L. Snyder of Twin Falls, Idaho, won the first prize of $\$ 500$. The production on one acre was 38,685 pounds gross weight. The weight of culls was 4,150 pounds, making 34,535 pounds, or $575 \frac{1}{2}$ bushels, of 
marketable potatoes. The variety was Dalmeny Challenge.

Following is the story of how the first prize potatoes were grown, as told by the growers:

"It will be necessary to give a brief account of our previous experience and observations along this line in order to impress upon the farmer the fact that he can do equally as well if he will use his powers of observation and a little study along with his work.

"We partly owe our success to attending farmers' institutes and demonstration trains, and making a study of the different farmers' bulletins and articles on potato culture by E. H. Grubb and others. We do not mean to infer that we followed any set rules, but whenever we read an article we always compared it with our methods and acted accordingly; so that in reading this, all we expect the farmer to do is to compare it with his conditions and methods. We are confident that our record will be broken within a year or two, still we are pleased to be the first to prove it possible on our soils.

"We came to the Twin Falls tract in the fall of 1905 and have raised a few potatoes each year since. Our first experience was with mixed runout seed, and it kept getting worse each year. We had about decided to quit the potato business when Mr. Grubb shipped in some seed from his farm in Colorado in the spring of 1908. In this car were Red and White Peachblow, Dalmeny Challenge, and Dalmeny Beauty potatoes. The Peachblow had been grown in Colorado for years, while the Challenge and Beauty were imported from Scotland two years previous by Mr. Grubb. We sold 
our run-out stock at 70 cents per 100 pounds and bought some of this seed at $\$ 2.80$ per 100 ; and can say that it was the best investment we ever made in the potato line. The crops raised from this seed were superior in quality and yield; still the yield was far from what was claimed for them in Scotland. In the fall of 1909 we had one patch which yielded 430 bushels per acre. This crop was raised on sagebrush land, which had been cropped twice, but had had a light manuring.

"By this time we were curious to see what we could do on alfalfa land. So in the fall of 1909 we 'crowned' four acres of alfalfa as shallow as possible, plowing with sharp plows to cut alfalfa crowns. This alfalfa was planted in the spring of 1906 . The first two years (including the summer of 1906) it was cut for hay, the next year it was pastured by hogs, about ten head per acre, and the next year it was again cut for hay. We had intended to harrow the crowns to the surface, but we had a wet spell and a freeze immediately after and as a consequence all the crowns were alive next spring.

"When the Burley prize was offered last spring (1910) we decided to enter this contest. We entered for several reasons. In the first place there was nothing to lose; there was a great opfortunity to learn by comparing our methods with those of the winner; and, again, there was a chance to win. In trying to decide how to proceed in order to get the best results, a great many questions confronted us, as for instance: How much manure can we apply without getting scab? How close can we plant without sacrificing the size of the potato and the yield? What size seed will give the best results? How is it possible to get a perfect stand? Realizing that the practical educational value of 
the contest would be lost, so far as a yield crop was concerned, if the winner did all the work by hand on a single acre, we decided to use horses and machinery in all our operations.

"In order to break the crust which had formed over the field during the winter we used a doubleaction disk harrow, which always leaves the surface level, being a marked improvement over the ordinary disk-harrow. This was followed with a drag harrow and was harrowed several times at intervals of one week. By the time we were ready to plow nearly all the alfalfa was dead. All this disking and harrowing had thoroughly mixed the manure with the soil, and had created a dust mulch over the field. Being afraid of scab, we had only applied twelve loads of manure per acre. This was put on in the spring while we were killing the alfalfa. Being so thoroughly mixed with the soil and plowed under so deep, we had no scab, and could have applied more and still have been safe so far as scab was concerned. Before plowing we corrugated and irrigated. We did this for several reasons: First, to help get a better stand; second, to carry the crop as long as possible without any further irrigation, as we have found that the longer the plants can grow and develop without needing any further irrigation the better the results; third, to cause the manure to rot and get in a shape that the plants could use; fourth, to supply enough moisture so that the soil would pack (not bake) after it was plowed. It is always better to irrigate before plowing, as the plowing replaces the air that the water has driven out.

"As soon as the ground was dry enough it was plowed from ten to twelve inches deep. As the surface soil had been worked many times before 
plowing, it was very fine and made a perfect contact with the bottom of the furrow. This is very important and we find it pays to disk before plowing for any crop. After plowing, it was harrowed twice in order to pack the soil and create a dust mulch on top. This harrowing was very beneficial, as a soil which is comparatively compact with a dust mulch on top will hold moisture longer than one which is loose clear to the bottom of the furrow.

"While we were preparing the soil we had been getting the seed ready. The seed was selected true to type, and as near the same size as possible. We cut the seed more to conform with the needs of the planter than to our own ideas. Part of this seed had been hill-selected. We found that the planter planted a piece about the size of a hen's egg to best advantage, so we cut our seed in squares about that size. In cutting a potato we always used as many cuts from the seed end as possible, each piece having one or two eyes. The seed was treated with formaldehyde as per directions.

"As we had decided to do all the work with horses and machinery, we went to considerable expense and delay to get a planter which would plant a perfect stand in preference to planting by hand. An Iron Age Planter was used. Acre No. 1 was planted from four to five inches deep with Dalmeny Challenge, the rows being thirty-three inches apart and the sets eight inches in the rows. Acre No. 2 was planted the same distance, with White Peachblow. Being doubtful as to results of planting eight inches in rows, we planted acre No. 3 with Red Peachblows, the same as acre No. 1, except that the sets were twelve inches apart. The eight-inch planting required 1,750 pounds of 
cut seed per acre and the twelve-inch planting 1,250 pounds.

"The planting was commenced May 21st. The planter was set to ridge the hills quite high. Immediately after planting, the land was 'packed' with a float made from four two-inch planks ten feet long. These planks are nailed together parallel to each other, overlapping about two inches. This float runs over the high ridges in the same direction the planter ran, presses the dirt around the set, and being that it leaves the surface smooth has a tendency to bring the moisture up to the seed. The ground should be harrowed in a few days, or too much moisture will be lost.

"Acre No. 1 yielded 645 bushels, which was over 100 bushels more than No. 2, and was of a superior quality, showing the difference in variety. Acre No. 2 yielded more than No. 3 , which would indicate that planting eight inches in the row was better than twelve inches on this particular piece of ground. The percentage of small potatoes was no greater in the eight-inch planting than in the twelve-inch planting. On the whole, the percentage of small potatoes was less than in the average crop.

"Too much cannot be said of the importance of a good stand. It costs no more to irrigate and cultivate a perfect stand, and the line between success and failure often depends on this point. A more uniform size is produced with a perfect stand, as big, over-sized tubers are more apt to develop where they have too much room."

Seed potatoes from Mt. Sopris Farm have given good results in Idaho. Mr. Alan P. Senior of Twin 
Falls, in a letter to H. A. Stroud, recites the following:

"I purchased from you last year (1908) some seed Red Peachblow potatoes that you secured for me from Eugene $\mathrm{H}$. Grubb of the Mt. Sopris Farm, Carbondale, Col. I planted these potatoes on May 15th, and had a perfect stand. My yield was 530 bushels to the acre. I irrigated twice, the first time when the blossoms were on and the second time about a week later. I believe in thorough cultivation, and went over my potatoes five times. I hilled these potatoes up just as high as possible to get the ridges with the cultivator, and am going to get them higher next year by the use of a machine that will throw the dirt higher than a cultivator.

"I also planted a few of the Dalmeny Beauty and Dalmeny Challenge potatoes, and liked them so well that I intend to try them further next year.

"I took from one row, 1,100 feet long, of Red Peachblows, twenty sacks of potatoes that ran over 100 pounds to the sack - over a ton of potatoes. I sold these potatoes for $\$ 27.40$.

"Any one can raise potatoes in this country potatoes of the highest yield and finest quality. It is only a question of intelligent cultivation and not too much water.

"All of my potatoes and garden produce were grown between rows of young apple trees that I planted three years ago next spring." 


\section{CHAPTER XXXIV}

\section{THE NORTHWEST}

TN THIS classification we have arbitrarily grouped the states of Washington, Oregon, 1 and Utah. Idaho, Colorado, and California are considered separately. Conditions in Wyoming and Montana are very similar to those in Colorado, Utah, Nevada, and Idaho.

There are great possibilities for enlargement of the industry in districts in the states covered in this chapter.

\section{UTAH}

Utah has a comparatively large acreage that is admirably adapted to the growing of potatoes. Both soil and climate are suited to the crop. Prof. L. A. Merrill, agronomist in charge of arid farms for the Experiment Station of the Utah Agricultural College, and Director of Agricultural Extension Work, furnishes the following information:

"The average date of planting potatoes in this state varies from May 1st to 15th, and the average date of harvesting is from September 5th to October 1st, making the length of the growing season about four and one half months.

"Potatoes require for their proper development a deep, rich, sandy loam. We have found that they do not thrive on a heavy clay or lumpy soil, 
neither do they do well on a rocky soil. We have in our state large areas of the very best type of soil for the production of potatoes. In $1910 \mathrm{Utah}$ produced 2,432,000 bushels of potatoes on 16,000 acres, or an average of 152 bushels per acre.

"Most of the potatoes in the state are grown in the following counties and I am giving them in their order of importance as potato-growing sections: Salt Lake, Utah, Davis, Sevier, Weber, Morgan, Cache, Wasatch, Emery, San Pete, Boxelder. The seed is mostly home-grown and is as a rule not well selected. The main factor contributing most to the discouragement of the potato growers of this state is the lack of good seed. In this state this year we have a number of illustrations. On the farm of Mr. H. J. Cannon, West Jordan, Utah, recently I observed a field of homegrown side by side with potatoes grown in Colorado, and it was certainly an object lesson favorable to the imported seed.

"The following varieties are grown: Eureka, Six Weeks, Early Roast, Early Ohio, Royal Duchess, Dalmeny Challenge, Russett, Peerless, Freeman, Twentieth Century, Uncle Sam, Sir Walter Raleigh, Hammond, Maggie Murphy, Peachblow, White Pearl, Majestic, Farmer.

"As a rule the ground for potatoes is prepared by manuring it for winter, plowing it as soon as the land is ready in the spring, harrowing immediately after the plowing. When planting time comes the land is marked off with a marker and a furrow is made some four to eight inches deep with a shallow plow. In this furrow the seed is dropped; it is then covered with the regular plank or log leveler, and usually two harrowings are given the patch before the plant appears above the ground. The field is 
cultivated three or four times after the plants are up, the cultivation being done with a regular horse cultivator and with a small shovel plow. They are usually irrigated four times. During the first two irrigations which are given, one before blossoming and one just after blossoming time, the water is run in every other row, the second time running the water in the row alternately with the rows in which the water was run the first time. The last two irrigations are given as the plants show need of water. As a rule twenty acre inches of water are applied during the season.

"In harvesting I have noted that those who are growing early potatoes use the centre-draft handplow and gather by hand to prevent peeling the thin-skinned tubers. In many localities regular machines for digging are used, and wherever used are giving entire satisfaction.

"Potatoes are stored both in pits and cellars. Pits are made by digging a trench four feet wide and one foot deep and as long as necessary. The bottom of this is then covered with four inches of straw. The potatoes that are being stored are then placed in the pit and covered with about six inches of straw, about six inches of earth is then put on the straw, leaving ventilation holes about every eight feet. These ventilation holes should have an extra whisp of straw in them. A trench is now dug around the pit to insure good drainage. Where cellars are used care is taken that they shall be particularly well ventilated.

"Utah potatoes last year were shipped to Cheyenne, Wyo.; Butte and Helena, Mont.; Denver and Pueblo, Col.; Topeka, Kan.; Kansas City, Mo. Austin, Houston, and Galveston, Texas; San Francisco, Sacramento, and Los Angeles, Cal.; 
Portland, Ore.; Spokane, Seattle, and Tacoma, Wash.

"The potato fields in the state are usually small, ranging from one acre to about thirty. The average size field is about five acres. Around Smithfield the people rotate, planting sugar-beets one year and potatoes the next. This rotation can be practised only when the ground is well fertilized each year. In many places potatoes follow a leguminous crop, generally alfalfa; others have potatoes follow peas or beans, and still others have potatoes follow corn. Potatoes do best when they follow a leguminous crop.

"Potatoes should receive more attention from the irrigation farmers of the state than they do. My opinion is that the potato is destined to become one of our leading crops and is bound to take its place in our permanent rotations for the land under the irrigation canals. We have the fertile soil, good climate, moisture control, and are fairly near to good markets, so that with the good quality which our properly grown potatoes have, the industry in Utah ought to grow and prosper."

\section{WASHINGTON}

R. W. Thatcher, Director of the Agricultural Experiment Station of the State College of Washington, at Pullman, Wash., says that the industry of growing potatoes is a very extensive one in that state, and potatoes are grown commercially at every elevation from below sea level to nearly the snow line; and with every variation of rainfall from so little that irrigation is necessary up to 120 inches annually; and on almost every type of soil known to agriculture. 
"The peculiar climatic and soil conditions of Washington are especially favorable for the production of potatoes," writes A. G. Craig, Assistant Horticulturist of the same institution in 'Bulletin 11.'

"In many large sections of the state the atmosphere is so dry during the summer that conditions are very unfavorable for the growth of fungous diseases on the foliage. We do not have in this state the Colorado beetle (potato bug), which is so destructive a pest in other potato-growing districts. There is little danger of overstocking the market for potatoes here. The Eastern demand for Washington grown potatoes is good and has rarely allowed the price to fall below $\$ 10$ per ton in car lots in the past. In addition to this there is a rapidly increasing market for our potatoes in Alaska. There is no crop now grown in Washington which shows greater variation in yield per acre than the potato. This is largely because of an erroneous idea that the potatoes as a crop do not need much attention. Many farmers give time and care to the potato crop only when there is nothing else to be done, and as a result the potato is neglected. This crop responds to good treatment to as great a degree as any other, and the grower who exercises proper care with his potatoes is always repaid in the yield and quality of his crop.

"There are thousands of acres of land now devoted to summer fallow which might produce good crops of potatoes with very little additional expense, and yet leave the soil in better condition for wheat than it is under the present methods of summer fallowing. The average cost of producing potatoes in eastern Washington is a little less than five dollars per ton. The plowing and harrowing 
which would have to be done on the summer fallow land if potatoes were not grown is included in the cost. Therefore, the potatoes grown in the place of summer fallow can be sold for a very low price and still leave a good balance. If the market remains as high as it has been for many years a net profit of $\$ 15$ to $\$ 20$ an acre from what would otherwise be idle land can easily be secured.

"A deep, friable, mellow loam, rich in humus, is the ideal soil for potatoes. Heavier soils may give good results if well manured or by plowing under a clover or alfalfa sod. If the soil has any tendency to pack, the tubers are restricted in their growth and are often misshapen. Supplying humus to such soils not only remedies this difficulty by making them more friable, but increases their water-holding capacity, thus insuring larger yields per acre. The soil should always be put in good physical condition, as potatoes respond very profitably to good soil conditions. Light soils can be worked earlier in the spring than clay soils and also favor early maturity of the crop. They are, therefore, better for early potatoes. Potatoes should not be grown repeatedly on the same soil, as most of the potato diseases live over in the soil.

"Potato land should be plowed in the fall and allowed to lie rough during the winter. This favors the catching of winter moisture and allows the subsurface soil to settle, and the surface can be worked earlier in the spring. If fall plowing is impossible, the land should be disked in the fall so that the surface may be rough and open through the winter. Deep plowing usually gives better results than shallow. The plowed land should be well harrowed early in the spring and if not immediately planted it should be frequently harrowed in 
order to conserve moisture and kill the weeds which start after the first harrowing. Spring plowed land should be harrowed immediately after the plow, to prevent loss of moisture. In the drier sections, some form of subsurface packer should follow the plow, and this should be immediately followed by the harrow to work up a surface mulch. If the soil plows up cloddy, a plank clod masher may profitably be used.

"The time of planting should be governed largely by the climate and the purposes for which the potatoes are grown. The potato plant needs ample moisture when the tubers are "setting," hence the grower should endeavor to have the plants reach that stage of development at the time when the moisture supply is likely to be favorable. For early new potatoes, the seed should be planted as early in the spring as the soil will permit, on light, warm soil. For late potatoes they may be planted as late as the middle of June, provided the moisture supply is ample and continuous, but where summer rains cannot be depended upon, the earlier the potatoes are planted the better, if danger from frost is guarded against.

"Enormous yields of potatoes have been secured under irrigation, but their cultivation is attended with some difficulty. No other crop is so much dependent upon the skilful use of artificial water. The quality of irrigated potatoes may, or may not, be as good as that of those grown without irrigation. Good varieties, if well grown, will be good in quality either with or without irrigation.

"Winter irrigation may be practised very successfully in potato growing. The fields should be flooded before plowing, and allowed to dry to a tillable condition. This insures perfect condition 
of the soil for working and for the early growth of the potato plants. The ordinary methods of cultivation may then be followed, without further addition of water, until about the time the plants blossom. At this stage of development the tubers are set, and it is then that an abundance of water is needed to give them good growth. After the water is once applied to the soil, it should not be allowed to become dry again until time for the crop to mature. If the soil is allowed to become dry at any time after the first application of water and a subsequent irrigation is given, the tubers are sure to make a second growth and become knobby. Water should not be applied too late in the season, or the potatoes will not ripen properly. In all applications of irrigation water, care must be taken to avoid bringing it in direct contact with the growing tubers, as under such conditions the tendency for the potatoes to become scabby is increased.

"If winter irrigation is not practised, the first water should be applied immediately after the seed is planted. Irrigated potatoes should be hilled, and the water applied between the rows. In ordinary soil, water applied in the middle of rows three feet apart satisfies the requirements of the growing potatoes. The cultivator should follow each application of water.

"Sub-irrigated' lands, when not too wet or too strong with alkali, are most satisfactory for raising potatoes. There are some localities where soils receive just enough seepage from irrigation ditches, or other water supplies, to keep in moist, friable condition throughout the season. These, with frequent shallow cultivation, produce the finest, smoothest tubers, with the least trouble and ex- 
pense. To produce uniform moisture conditions in the soil is the secret of successful irrigation, and this is the absolutely essential condition for the most profitable potato growing under irrigation."

\section{OREGON}

Oregon has earned an enviable reputation for quality of potatoes produced, and Oregon Burbanks are very popular as seed tocks in California and elsewhere.

The following description of Oregon conditions is by Prof. H. D. Scudder, Professor of Agronomy in the Oregon Agricultural College at Corvallis:

"The length of our growing season for potatoes is about seven months. Potatoes are generally planted the first two weeks in April and harvest is completed during the month of October.

"The soils most commonly used for the potato crop here are sandy loams along the river bottoms and silt loams on the valley floor and on the hillsides. Both these types of soil produce a very fine quality of potatoes and, where properly handled, nearly the same yields, the sandy loams, of course, maturing the potatoes earlier and giving a larger yield if anything, as a rule. The silt loams, on the other hand, especially on the red hill lands, prodace a very fine quality of potato.

"The chief potato district in the state is the Willamette Valley, especially at its lower or northern end. The Umpqua Valley and the Rogue River Valley also are potato-growing districts, although of lesser importance.

"All our potato seed is home-grown. The chief varieties are the Burbank and American Wonder, 


\section{THE POTATO}

which are grown as table varieties, and the Early Rose, which is grown as a seed potato and shipped to California. The Garnet and Peerless are also grown to a lesser extent for the same purpose as the Early Rose.

"The preparation of the land here generally consists in early spring plowing, harrowing and disking, then seeding immediately to the potatoes. On the smaller fields the potatoes are generally planted by hand and covered by the plow or with the hoe. In all the fields of any size, however, the planting is done with a planting machine. The more careless farmers give but little cultivation to the potato crop, sometimes merely harrowing the land a couple of times before the potatoes are up. The more successful growers, however, not only harrow the potatoes two or three times before they are up, using the weeder after they are up, but then use a row cultivator two or three times to complete the cultivation. Where such thorough cultivation is given the most excellent results are obtained.

"Irrigation is not required at all for potatoes in western Oregon. They are never irrigated in the Willamette Valley at the present time, although in years to come there is no doubt that the yield may be slightly increased by irrigation when more intensive farming methods require the highest yields obtainable. In the Rogue River Valley the potatoes are sometimes irrigated, but this is not the common practice. Of course, in eastern Oregon wherever potatoes are grown on a commercial scale, at least, irrigation is used, as a rule. Potatoes in eastern. Oregon, however, are grown only, as a rule, in amounts sufficient to supply the local markets. On the dry-farming wheat land in eastern Oregon the farmers are just beginning 
to produce potatoes for home consumption, and they are obtaining very fair yields of very high quality tubers. In fact, potatoes, grown under dry-farming conditions in eastern Oregon on the silt loams, or volcanic ash soils, as they are called, I believe to be the finest flavored and finest quality that I have ever seen.

"Potatoes are harvested in all the large commercial fields by a machine digger, in the smaller fields by hand with the spade, or sometimes merely by plowing them up. Those potatoes which are stored are often merely dumped in bins in an ordinary warehouse, but the best growers, in those cases where they make a practice of storing them, are putting up specially constructed warehouses which are properly insulated with sawdust in the walls and with special ventilation to keep the potatoes in the best possible shape over winter. Practically no protection is required here against freezing, as that rarely occurs with our mild climate. What protection is used is generally merely to maintain equable temperature and humidity.

"The Oregon potato crop is practically all marketed at Portland, Seattle, and San Francisco, all the Early Rose and other varieties raised as a seed crop, being marketed in the last city.

"The cost of growing, of course, varies a great deal, but under good methods it will average from twelve to fifteen cents per bushel in the bin, this figure including interest on the investment. The profit, where the potato crop is grown as a regular part of the rotation, will average $\$ 40$ or $\$ 50$ per acre net.

"No artificial fertilizers are used, the only fertilizer of any kind so far used or recommended being a cover crop of vetch and rye or vetch and oats 
sown in the fall and plowed under when twelve or twenty inches high early in the spring. The vetch, on account of its very high nitrogen content and nitrogen gathering ability, makes, of course, a wonderfully good covering and green manuring crop.

"The size of the farms on which potatoes are grown in Oregon is about 100 acres, and the potato field is anywhere from five to sixty acres in size. A ten-acre field is generally considered a pretty good size field of potatoes, and forty or fifty acre potato fields are only had by those growers who are making a speciality of this product.

"The big growers are beginning to use system in the culture and marketing of this crop, as well as using rotations which will keep the ground in the best condition. One of our best growers is using that old and everywhere very successful rotation of clover, followed by potatoes, followed by wheat, the first crop of clover being cut and left on the ground, and the second crop harvested for seed, the field being plowed early in the spring for potatoes. There are other rotations equally as good, but there are no special ones that have as yet been widely adopted.

"Altogether, potato growing in Oregon is a very profitable industry, especially so where modern methods are employed and rotations are used. Year in and year out the market is high when compared with the potato market elsewhere and as yet no such thing as a potato disease or insect pest is known. As time goes on I think this crop will be more widely and intensively grown and one which will always prove excellent for including in rotations throughout Oregon." 
In a very fine book on Nevada, published by the Homeseekers' Bureau of the Sunset Magazine, San Francisco, Cal., in an article by C. A. Norcross, Commissioner of Agriculture of Nevada, it is stated that the potato is the principal export of the state. The Nevada potato has taken the first award at several fairs, international expositions, and produce shows. It grows evenly, when properly cultivated, of uniform size, clear and healthy skin, firm texture, free from disease, is not watery, and when cooked is dry, mealy, and white as a snowdrift. It is no mean agricultural art to get the best results in potato growing. It requires experience and intelligence to know when and how to plant the crop, how deep the irrigation furrows should be and the precise quantity of water required. But where the art is mastered, the profits from potato growing one year with another are very great. The average yield is about six tons to the acre, or 200 bushels, under any reasonably skilful handling, but the leading potato growers of the state grow from eight to fifteen tons per acre. The average selling price is about $\$ 20$ per ton, or 60 cents per bushel. A net profit of $\$ 200$ per acre on the crop is not unusual in seasons of good prices. 


\section{CHAPTER XXXV}

\section{CALIFORNIA}

OALIFORNIA occupies a similar position on the Pacific coast of the United States to that of the territory lying between Charleston and Boston on the Atlantic coast. There are 158,360 square miles or $101,350,400$ acres within its borders. A large part of this is mountain or desert, but the territory is so great that the total acreage of the arable valleys would make a goodsized eastern state.

The great interior valley in which the Sacramento and San Joaquin valleys lie is about 420 miles long and has an average width of forty-five miles.

California's greatest agricultural asset is its climate. Throughout southern California and the Great Central Valley the growing season is practically twelve months long. During the winter there is some cold weather, but the thermometer rarely registers lower than freezing. Pastures produce feed in the winter season, although less luxuriantly than in summer; oranges ripen, and all kinds of vegetables make satisfactory growth.

Potatoes will live over winter in the ground and make a volunteer crop the next season.

Even though fruit and vegetable growing, dairying, and other lines of agriculture are highly developed in some sections of the state, the resources and possibilities for agricultural pursuit are 
of such magnitude that they can be said to have been hardly touched.

The potato industry has been most largely developed in the vicinity of Stockton in the San Joaquin Valley, and in the Salinas and Lompoc valleys along the coast. The crop is grown everywhere in the state, but not in a large commercial way, except in the places mentioned.

There are splendid opportunities for developing an early potato proposition in the Sacramento Valley and elsewhere throughout the state.

The first potatoes on the market always bring the high prices, and by the use of European methods of storing and starting seed, the crop could be sold four to six weeks earlier than any now produced.

In the following are brief descriptions of California conditions:

\section{THE LOMPOC VALLEY}

The Lompoc (little hills) Valley is a very narrow strip of country that extends up from the Pacific Ocean. The mainland juts out into the ocean somewhat at this point, so that the climate is tempered by the ocean both from the front and sides. The valley is about nine miles long and not over five miles wide at the widest part, having a total area of something less than 15,000 acres. It is in Santa Barbara County, 172 miles north of Los Angeles and 303 miles south of San Francisco. Lompoc (1,500 population), the only town in the valley, is nine miles from the sea on a branch of the Southern Pacific Railroad connecting with the main coast line at Surf.

All of the land in the valley and the surrounding 
foothills was originally embraced in a Mexican land grant. In 1874 this was bought by the Lompoc Valley Land Company, subdivided and the town laid out. The land was sold in comparatively small acreages, principally to people from Santa Cruz - a town farther north on the coast. One of the old Franciscan Missions (La Purissima) is in this valley.

The Lompoc Valley is surrounded by hills 200 to 300 feet high. At the coast, or at the mouth of the valley, the elevation is forty-five feet; at Lompoc, nine miles inland, it is ninety-three feet. Because of the ocean breezes the climate is cool and moist during the entire year. The highest average monthly temperature for twelve years is 75 degrees (for August), and the lowest 44 degrees (for December). The average annual rainfall is eighteen inches, practically all in the winter. There are dry spells some years when irrigation would be beneficial, but good cultivation, in connection with the cool climate and sea breezes and fogs, is generally sufficient to mature maximum crops Grains, potatoes and many seed crops grow to perfection, because there is no excessively hot weather. Mustard (German and English) is grown commercially, and W. Atlee Burpee, the Philadelphia seedsman, selected this as ideal for growing sweetpea and other seeds. A farm, with Edwin Lonsdale in charge, has been started by this concern for growing seeds commercially.

The Pacific Garden of July, 1910, says that the summer temperature is so low that Lima beans do not mature seed. A temperature of 85 degrees is considered very high and 20 degrees very low.

The district is one of small farms, forty acres being an average size. L. F. Shanklin is one of the 
largest potato growers, and he considers fifty acres a good size planting. Many growers have five to twenty acres.

The total annual acreage of potatoes is from 4,000 to 6,000 . The average yield is 75 to 100 sacks (150 to 200 bushels) per acre, making the production about 50,000 sacks (100,000 bushels), or about 165 cars. The other principal crops of the valley, those with which the potatoes are rotated, are:

Mustard seed about 300,000 sacks of 100 pounds each Barley....... about 60,000 sacks of 100 pounds each Beans........ about 125,000 sacks of 90 pounds each Onions....... about 25,000 sacks

There are places in the valley where orchards have been taken out for the growing of potatoes and other field crops, even though with proper care orchards pay well. In other places the Sugar Beet Company has bought land devoted to beans, potatoes and onions, for growing beets. These things show nothing but some of the inconsistencies of American agriculture. It is certainly not economically right that an apple orchard be torn out just because the owner does not like to "fuss" with fruit, or because he has changed his mind about growing apples.

Lompoc is unique in that potatoes of the very highest quality are grown here at a low altitude and a southern latitude. The moist, cool atmosphere and the sea breezes make this possible.

Potatoes have been grown at Lompoc ever since the first settlement, but it is only during the past five or six years that modern methods have been introduced. Now the cultural methods are strictly 
up to date, and improvement in seed work is coming very rapidly.

Like almost every agricultural section in the West, the soils are spotted. Here they range from a very heavy clay, locally called "blue mud," to pure drift sand. In the grades between these are the fine, well-aired, well-drained, fertile, easy-working sandy loams that are known as the "potato lands." The total area of such soils is not over 7,000 to 8,000 acres. The water table on most of this best potato land is about twelve feet below the surface of the ground.

The preparation of land for potatoes is most thorough, three important factors being kept in mind:

'1) Conservation of moisture.

(2) The making of a deep, mellow seed nest.

(3) Killing weeds.

After the crop is off the land in the fall, a heavy growth of volunteer grain and weeds starts up. In January, when this is one to two feet high, it is plowed under, generally eight to twelve inches deep. After this the ground is kept thoroughly worked and free from weeds until May. One of the popular tools for making a mulch and killing weeds is a knife weeder and cultivator, consisting of blades attached under a solid frame. It is a local tool patented at Ventura, Cal. The cutaway disk harrow is also used for this winter working of the soil for killing weeds and conserving moisture. Another local tool is a jointed plank drag filled with harrow teeth.

The plowing in January opens up the soil, permitting the easy absorption of the largest possible quantities of winter rainfall. The almost continuous cultivation following this breaks the 
capillary, holding the moisture in the subsoil, and by killing the weeds keeps them from sapping moisture from the soil. The nettle is a bad weed for this, and growers state that wherever this weed is allowed to grow there is a dry spot the coming summer.

About May 10th the ground is plowed again, this time ten to twelve inches deep. After this the cultivation is continued to keep weeds down and hold moisture. Potatoes are planted May 20th to June 20th. The Iron Age planter with a heavy press wheel behind is now quite generally used, although until the last four or five years the work was done largely by hand. The rows are thirtysix inches apart and the pieces dropped fifteen to seventeen inches apart in the row. Burbank is the only variety grown in the valley, and the best product is a most beautiful potato, absolutely clean and clear-skinned, with a very fine netting that indicates a mature potato of excellent quality. The best growers now want a medium-sized potato, with shallow "eyes" and square shoulders, a "spud" that nicely fills the "fist" of a good-sized man. Some extra large potatoes are grown, and "Peerless" (a big, rough variety here) yields up to 400 sacks per acre.

The seed is almost entirely imported from Oregon. Seed is generally used two years following the introduction before another change is made. The theory is that seed from a cold northern climate is necessary, but L. F. Shanklin believes that the greatest cause of the so-called "running out" of seed is poor selection. The practice is to sell all the best potatoes and select seed from the seconds and culls or "cow feed" remaining on the farm in the spring. He is planning to select his seed from 
staked and selected hills that produce healthy tops and satisfactory hills, then by planting whole seed from such hills he expects to increase yields rather than have them decrease.

Seed is greened with sun and generally cut in very small pieces, sometimes to one eye, about 600 pounds per acre being the average amount used. Because of this the stand is often poor and all of the plants do not always start as strong and vigorous as they would if a larger seed piece furnished more nourishment for the starting of the plant. Mr. Shanklin believes the yield can be increased 30 to 50 per cent. by seed selection and the use of larger seed with the same good cultivation methods now used. From one hill that volunteered from a whole tuber he dug seventeen big potatoes.

Lompoc potatoes are grown by the high ridging system, the aim being to get as high and big a ridge as possible. A heavy soil mulch is kept all over this ridge and there are heavy dews and fogs almost daily. This moist, open, well-aired ridge is an ideal place for the perfect development of the tubers.

The ridging begins with the first cultivation after planting. There are generally two cultivations and the final ridging. This is done with a special ridger which is illustrated.

Potatoes are harvested in November with horsepower diggers, the Douden and $\mathbf{O}$. K. Champion being generally used. A long apron and low wheels on the digger are good things in this very loose soil.

Potatoes are stored in long ricks in the field and in big warehouses in Lompoc. The climate is such that when piled loose in big ricks twelve feet wide at the base, six feet high and often several hundred 
feet long, the potatoes keep with no other protection than mustard straw or some other light covering that simply keeps off the light frosts. It must not mat or shed water, or it will mold. These piles are soaked through repeatedly with the rains and no damage is done thereby to the potatoes. They keep all right until well into the spring; if piled east and west instead of north and south, some potatoes on the north side always frost.

Ten Japanese laborers will pick up the potatoes as fast as one digger will take them from the ground, or six acres per day of eighty sacks per acre. The Japs cost $\$ 1.75$ a day, or $\$ 17.50$ for picking up 480 two-bushel sacks - a little over 3 cents a sack. Potatoes are sacked as fast as dug, but the sacks are left in the field to dry out for a day before being piled in the ricks.

A large part of the crop is sold to brokers at digging time. The quality of the Lompoc and Salinas potatoes is such that they generally bring $\$ 1$ to $\$ 1.50$ per hundred as they come from the field. The crop is graded into firsts, seconds, and "cow feed." The firsts are smooth, even, mediumsized potatoes, the pick of the crop; seconds contain more small and large and the uneven potatoes, but are all sound; "cow feed" includes all cut, bad and very small tubers.

A popular rotation of crops at Lompoc is potatoes, beans, onions, potatoes, potatoes, beans, etc. The soil is naturally very rich, all recent alluvial, and there are frequent overflows from the streams depositing silt. For this reason there has been practically no commercial fertilizer used. Green manuring with legumes is not done (the weather is too cool for alfalfa to do well), and animal manures are not used to any extent. In fact, there is very 
little stock kept in the valley except for work. Of course, range cattle are kept in the hills. It is essentially a special crop valley, but some day fertilization will be given more attention.

The authors are indebted to T. L. Harris, L. F. Shanklin, A. G. Balaam, Secretary Chamber of Commerce, and others for valuable information and many courtesies shown during a visit to Lompoc.

\section{THE SALINAS VALLEY}

In many ways the Salinas Valley is very similar to Lompoc. It is on the coast, between Lompoc and San Francisco.

The maximum temperature is about 91 , the minimum 28, or a little lower. Citrus fruits are not grown commercially.

The principal crops are potatoes, sugar-beets, deciduous fruits, and dairy cow feed.

The methods of cultivation and harvesting are not as good as at Lompoc.

Seed is imported from Oregon every third year by many growers. The seed stock is best the second year, or that following its introduction. The Burbank variety is grown exclusively.

The potatoes grown at Salinas are as smooth as eggs - average from four to twelve ounces in size, and have a beautiful, clear, netted skin.

The best soil is a sort of sandy loam, very mellow and easily worked. There are but a few hundred acres of this character, however, the balance being heavier.

When potatoes are not grown continuously on the land, the system is, grain, potatoes, sugarbeets. No fertilizing is done, and cover crops are not used. 
The land sells for $\$ 100$ to $\$ 500$ an acre when offered, but there is practically none for sale. The entire valley was originally taken up by Mexican land grants and some of these have not yet been subdivided.

The seed stock is stored in straw-covered ricks, and sprouted once or twice before planting.

The land is plowed twice with a three-gang disk plow, ten inches deep; harrowed twice, cultivated twice, and hoed twice. The crop is dug by hand, Japanese labor being used. They do the hand labor for 30 per cent. of the crop.

Growers estimate that it costs $\$ 25$ an acre to produce the crop. Seed cut to two to four ounces is used.

The crop of the valley is about 25,000 sacks. The yield is thirty-five to seventy sacks, of 100 to $\mathbf{1 1 0}$ pounds each, to the acre.

\section{STOCKTON}

The Stockton district is now one of the biggest potato-producing sections in the world, area considered.

The crops are grown in the lowlands in and along the San Joaquin River, in a rich alluvial soil, some of it containing a large percentage of decayed vegetable matter.

The "tule" lands on the islands in the San Joaquin river are made up of the decayed vegetation of many years, and being subject to overflow, this has had some silt incorporated with it. In reclaiming these lands they are surrounded by big levees. Deep drains are cut through the land, with shallower drains emptying into them. These smaller drains are about 40 feet apart. During 
high water time in the river an excess of water on the land is pumped out of the ditches and over the levees by immense electrically operated pumps. When irrigation is needed it can be let through the dikes or the same pumps can be used to pump water from the river back into the ditches. When the ditches are filled the land absorbs the moisture readily. When the land is dry there is danger from fire, and this is very hard to control when it gets into the subsoil. A complete fire fighting force is maintained.

The potatoes are taken to railroad shipping points on boats, and commission men and dealers re-sort before selling to retailers.

Disease develops rapidly in this moist, rich soil. Careful rotation of crops and perfect control of moisture is necessary to control and prevent diseases.

Practically the entire crop in the district is grown by Japanese and Chinese, Portuguese, and Hindus. Large areas are rented at from $\$ 12$ to $\$ 30$ per acre, and sublet in smaller lots to the Japs or Chinese on a share basis, the landlord furnishing land, implements, and seed for 49 per cent. of the crop.

Seed of the Burbank variety from Oregon is universally used. New seed is secured every two years, so that the only home-grown seed used is that produced the first year from imported stocks.

The planting period extends from January 15th to July, and the harvesting is continuous from May to January.

Eight sacks (about 100 pounds to the sack) of cut seed are planted per acre, and the yield is from 80 to 150 sacks per acre.

The potatoes are planted when the land is 
plowed, the seed being dropped by hand in every third row.

The crop is irrigated four to five times and cultivated twice.

The digging is all done by hand.

The men are paid $\$ 50$ per month and board, and they work eleven hours a day.

The rotation of crops practised is potatoes, then barley or onions. Potatoes are never planted twice in succession on the same ground.

The Platt Commission Company of Stockton handles a large tonnage of potatoes. Their chief buyer is a Chinese "boy" who has been with them since 1878. He is considered the most competent buyer in California and draws a salary commensurate with his services.

'Potatoes are often shipped from Stockton before they are fully ripe. They are then loaded in double decks in the cars, but the sacks are set on end instead of being corded up lying flat. By loading on end the air circulates all around the sack. The crop marketed from June to September is handled in this way. It costs $\$ 10$ to fit up a car for this kind of shipping.

Potatoes known as "leaky," kecause when bruised by rough handling, water runs out of them and wets the sacks, are produced in the delta or tule lands. These contain an excess of moisture because they make a rapid, soft growth. These potatoes often turn blue.

The excessive growth of tops that these potatoes make in the field indicates a soil rich in nitrogen, but deficient perhaps in potash and phosphoric acid. The addition of the two elements last named might increase yields and earliness very much and make a firmer, better table potato. 
Closer planting would also increase yields, as would larger seed and the starting of seed, as in the British Isles.

The quality of the tule land potatoes could also be bettered by more perfect control of the water table.

The potato crop in San Joaquin County (on which Stockton is located) was valued at $\$ 2,145,000$ in 1910.

A good deal has been written about a Japanese potato king, Shima, but at Stockton Sing Kee, a Chinaman, is accorded that honor. He grows from 3,000 to 4,000 acres of potatoes every year.

In the following by Forrest Crissey, in the Saturday Evening Post, a description of his methods is given:

"And speaking of potatoes - there is Sing Kee, the real potato king of the Stockton District. His bona-fide Chinese name is Chin Lung, but he is Sing Kee to his American friends. It is passing strange that the publicity men of the railroads and big land companies, who are so eager to prove that the city business farmer is a success when transplanted from the pavement to the soil, should have overlooked Sing Kee, of San Francisco Chinatown. This remarkable Mongolian first slapped his sandals on the pavements of San Francisco about thirty years ago. He slipped quietly into the ranks of the loose-frocked toilers and plodded along for several noiseless years. Then there was a storeopening in Chinatown in which Sing Kee was the central figure. He had saved until he was able to promote himself into the merchant class.

"Sing Kee drove a good trade with his countrymen and built up a respectable following among 
the Chinese farmers and gardeners that came into the San Francisco market with their truck. Having the same inquisitive tendencies as the great $\mathrm{Li}$ Hung Chang, he plied his farmer friends with questions and came to know almost as much about their business as he did about his own. One year trade in Chinatown was depressingly poor. His thoughts then recurred to the tales of farming profits that his customers had brought him, and he was not long in deciding that he could make more money on the soil than he could over the counter.

"Consequently Sing Kee struck out for the soil and carried all his business instincts with him. He made his first big hit in 1889 on 1,200 acres in potatoes. White men had repeatedly gone broke on this very tract of land, owing to their inability to cope with the overflow. But the clever Oriental watched the water with shrewd eyes, and at just the right moment after it had receded he put in his plows. The result was an average of 160 sacks to the acre. At the outset of the harvest season that year the prevailing price of spuds was 50 cents. But his land rental was cheap - only $\$ 7$ an acre - and so was his labor. Even at 20 cents there was a fair profit in the enterprise. But Sing Kee, the merchant, studied the market in his stoical way and looked far ahead. All of his experienced field neighbors were selling their whole crop at this price, but the buyers could get nothing more out of Sing Kee than a shake of the head. Prices went up to 65 cents and from that they eventually climbed to $\$ 1.65$. Between these two points the slant-eyed Oriental merchantfarmer unloaded his bumper crop and made a tremendous profit.

"In spite of the fortune that he realized from 
his single crop of potatoes, Sing Kee is too shrewd a farmer to put all of his eggs into one basket, although he still makes spuds his main crop. An American who is his close business confidant makes this statement of Sing Kee's present farming operations: He has four thousand acres in potatoes; 100 acres in onions; 400 to 600 acres in beans; 560 acres in asparagus; and 300 to 400 acres in seeds. It will be hard to beat that combination.

"No part of his farming operations indicates to the uninitiated the skill and daring of Sing Kee as a cropmaker so much as the simple fact that he has 200 to 400 acres devoted to the production of seeds. Seed-raising may be said to be the supreme test of farming skill. The seed for this part of his operations is sent to him by a seed house the head of which makes this statement in comparing the average American farmer with the alien, and particularly with the Oriental:

"I I should not think of letting a seed contract to many American farmers. Experience has taught me that failure would be the almost certain result. But the men who have been raised in the Old World traditions of intensive cultivation are able to qualify in this highest refinement of field husbandry. I wish that it were otherwise, but it isn't. The average American farmer has more to learn from the alien farmers of every race now represented on our own soil than he can possibly realize or appreciate. The first step toward assimilating the skill and the knowledge that these alien and intensive tillers of the soil have brought to his door is a realization of his lack of their marvelous mastery of plant life, their intimate and almost intuitive understanding of the secrets of plant production.' But Sing Kee isn't afraid to 
put 400 acres into the growing of seeds; and the seed house is not afraid to back this shrewd merchant-farmer in so extensive and difficult an undertaking."

Following is an article from the Stockton (Cal.) Independent of August 26, 1911:

"Stockton, though known to-day throughout the world as a potato centre, is destined to make such strides in tuber cultivation as to make the delta regions adjacent to this city universally famed as one of the leading spud regions of the world, and in many distinctive particulars to stand out in a class by itself in points of merit from a potato standpoint. Such was the general statement made by Eugene H. Grubb, of Colorado.

"While in this section in search of information as to the local product, Mr. Grubb has been the guest of P. E. Platt of the Platt Product Company, and yesterday he visited the delta regions and selected samples of the delta tuber from the Rindge properties.

"Explaining the potato of this section and the crop condition generally Mr. Grubb stated that the one outstanding feature as compared with all the world that signalized the Stockton delta regions was the fact that tubers are in the ground here every day in the year, and that shipments are made from Stockton covering a wide area 365 days continuously year in and year out.

"The continuous crop feature, says Mr. Grubb, is phenomenal and gives Stockton a unique distinction throughout the world in the potato industry.

"Speaking of the improved cultivation of the 
Stockton tuber as compared to five and ten years ago, Mr. Grubb states that the local product has gained wonderfully in point of quality and that its standard to-day is of the highest mark. This, he said, was due to the fact that such shippers as Mr. Platt have come to learn that the trade demands the best obtainable and that anything less than the best is overcome by competition and to that extent unprofitable. The exact conditions imposed upon the shipper by the trade necessitates the shipper holding the grower unrelentingly to the best possible qualities obtainable from the soil.

"Those things which make for quality have been bounteously provided the Stockton delta regions.

"Here, he pointed out, is found the wonderfully rich, fertile, light peat soil so peculiarly adapted to the highest cultivation of potatoes. The sun shines from a growing standpoint every day in the year, the climate is all that could be desired.

"Discussing the local tuber from a distribution and supply phase, Mr. Grubb called attention to the fact that Stockton to-day is shipping practically all points west of the Missouri River and only yesterday shipped two cars to Kansas City, the very centre of a much boasted potato area long since famed among the tuber fields of the country. That the wonderful breadth and scope of Stockton's supply territory might be better emphasized the visitor directed attention to the fact that the Platt Produce Company alone as a single firm ships out of Stockton annually more than one half as large a crop as the noted Greeley district of Colorado. So extensive, says Mr. Grubb, are the fields of patronage for the Stockton product that the Easterner cannot grasp the immensity of it 
all, nor appreciate the vast population fed by the delta regions adjacent to this city.

"Pointing out the merit features of the local spud the distinguished authority on the tuber says that in point of attractiveness, size, shape, smoothness of skin, quality and all that goes to make a potato perfect, the delta regions produce the most nearly perfect tuber known throughout the world. Such potatoes, said Mr. Grubb, could not possibly be grown on a heavy soil nor under general conditions less ideal than characteristic of Stockton.

"Taking up the subject of distribution and supply aside from the quality of the potato itself the visitor pointed out that this section invariably has a normal crop and that for this reason the trade throughout the area covered by the local supply feels that it can always depend upon Stockton for receipts, and places orders here deeming it the most likely of satisfactory delivery. This confidence of the trade is a most valuable asset and goes a long way in establishing Stockton's high standard of reliability as a potato shipping centre. Added to this very important feature is the fact that the local delta regions yield early and at such seasons as famine, so to speak, is characteristic of other tuber districts.

"Of the many variety of spuds grown in this locality the visitor observes that the Burbank is the best adapted to local conditions, and in this connection, Mr. Grubb added, that no section of America is so famed for its Burbanks as are the California potato fields.

"From the standpoint of quantity Mr. Grubb says that Stockton is but a drop in the bucket. Throughout the tuber fields of America there are this season about $300,000,000$ bushels. All Cali- 
fornia will produce but $8,000,000$ bushels. And it is estimated that the local delta regions, which have an acreage planted to potatoes amounting to about 44,000 acres will yield on a general average 100 sacks to the acre. This in dollars and cents will represent about $\$ 5,000,000$ for the total harvest revenue.

"After returning from the delta regions Mr. Grubb met a number of the business and professional men of this city, all of whom heard with delight the announcement that Stockton will become world famous in a greater degree than at this time seems at all probable as a tuber district."

\section{SACRAMENTO VALLEY}

The Sacramento Valley is watered and has been made by the Sacramento River and its tributaries. It is a vast, alluvial plain, comprising over 2,500,000 acres of land.

The annual rainfall in the valley is about eighteen inches, and it comes entirely during the winter months.

Without irrigation the principal crop has been grain - wheat and barley. This is sown in the fall, gets the benefit of the winter rains, and is ripened in early summer. From June until the rains come in October the country is dry and brown.

With irrigation, every crop of the temperate or semitropical zones can be grown.

The Sacramento Valley Irrigation Project of 150,000 acres is the most important undertaking in the valley. Water is taken from the Sacramento River under an Act of Congress.

There are wonderful possibilities for early potate growing on some of the lands in this valley.

The potato being a cool weather crop, in hot 
countries it is grown to the best advantage during the cooler parts of the growing season. For instance - in the Sacramento Valley there are two growing seasons each year: Potatoes planted in February or early in March are dug in July or August and those planted in August are dug late in November. Many failures are recorded when the crop is planted in May or June because of the too intense heat of atmosphere and soil during the period that the tuber should be forming and developing.

This climatic situation makes two crops of potatoes possible where soil conditions are right and cultural conditions are properly managed.

It should be possible to make early potatoes one of the largest per acre revenue yielding crops in the valley because of the possibilities of getting the crop on the market when high prices prevail.

The potato-growing business is a very profitable one now on the bottom lands along the Sacramento and San Joaquin rivers and on the islands and deltas.

The easiest kind of soil in which to grow potatoes is a sandy loam, or one well filled with humus or decayed vegetable matter.

The reason for this is that such a soil is easiest to work; it does not bake when it becomes dry, it takes water from irrigation in sufficient quantity but does not water-log, it drains readily, and is a mellow, friable medium in which the tubers can develop symmetrically and quickly without too great resistance

In order to grow potatoes on heavy clay and clay loam soils, in which the percentage of sand or vegetable matter is very small, it is necessary to do such preparatory work as is necessary to make 
them open and friable; in other words, to better the mechanical condition.

These heavy clay loam soils are among the richest known in agriculture. This is because they have been made of the finer particles that have been washed out of hills and mountains over a large area. The valleys in which such soils are usually found are really the cream of an entire watershed. A soil that is easier to handle may be very much less rich, because the finer soil particles are held apart by coarse sand of little or no fertility, or by large quantities of decayed vegetable matter.

For this reason about the only problem connected with potato growing on the heavier lands in the Sacramento Valley, is to add sufficient vegetable matter to the soil to hold apart the fine soil particles and make it more loose, open, friable and easily worked.

This can be done by growing alfalfa for several years, filling the soil and subsoil with roots and when it is plowed up turn under a big crop of the green alfalfa to further add to the vegetable content.

Another way would be to grow and turn under successive crops of peas, vetch, or other cover crops.

The addition of large quantities of animal manures is another way to loosen up heavy lands.

In Scotland, one large potato farmer has hauled sand onto heavy clay land to a depth of five inches, incorporating this and large quantities of stable manure into the soil.

On a small, intensely cultivated farm in the Sacramento Valley, where large quantities of animal manures are returned to the soil, and alfalfa 
and other deep rooted crops grown, it will be easy to have a plot in fine condition for growing potatoes each year.

The Burbank is the most popular variety of the potato in California. For early planting it would be well to try Bliss Triumph and Early Rose. New early varieties should be experimented with. Only by trial can the most profitable varieties be determined. In a warm climate the best seed is generally that imported from colder or high altitude districts.

Preparation for the early crop of potatoes should begin the year previous to that in which the crop is grown. If stable manure is to be applied this should be done the first or second year prior to the raising of the crop. The presence of too much manure before it is thoroughly decomposed or rotted makes a favorable condition for the development of diseases, like scab.

If the land to be cropped in potatoes has been in alfalfa, it is a good plan to first plow it shallow, with a sharp plow, to cut all the crowns, then plow it ten to fourteen inches deep. Land for early potatoes should be fall plowed.

As soon as the ground is in condition in the early spring, it should be disked and harrowed, to make a good seed bed and to "warm it up" as much as possible in preparation for the seed about to be planted.

A practice not now followed, but one that could be used to advantage, would be to plant nothing but whole seed, and start the sprouts in a greenhouse or sheltered spot, so that there is a sturdy sprout developed on each tuber before it is put in the ground. This will advance the maturity of the crop from twenty to twenty-five days. 
The furrows may be opened up a few days in advance of the planting, so that warm soil will surround the seed when it is dropped. The seed should be dropped by hand and carefully covered with a shovel plow or ridger.

As soon as the first crop is out of the ground, the ground should be thoroughly worked in preparation for the second crop, if another crop of potatoes is to follow. If potatoes are to follow grain or some other crop the ground should be deeply plowed and a good seed bed made. The ground is warm at this time, so that no sprouting of seed is necessary before planting. Seed from the preceding crop, or northern-grown seed that has been kept dormant in storage may be used.

Cultivation should begin soon after the seed is planted. The first cultivation should be deep, to thoroughly open up a deep root nest in which the tubers are to form. On irrigated land the high ridge system of growing potatoes is usually used, because it makes it possible for the potatoes to develop in a loose, open, well-aired soil, the moisture supply coming through the bottom of a fairly deep furrow into the base of the ridge and being drawn up by capillarity.

The number of irrigations, and the number of cultivations, must be determined by the needs of the soil and the growing plant. No fixed rule can be set, because conditions may change daily. Irrigation water must be used with sufficient frequency to furnish all the moisture the crop needs. Too much is as bad or worse than too little. A shortage of moisture makes a short crop. Cultivation is required as often as is necessary to keep the soil open and mellow.

In the Sacramento Valley the first crop starts 
out with a sufficiency of moisture in the soil from the winter rains. Late in the spring one - or perhaps two, irrigations might be required while the potatoes are making the greatest growth. After the tubers are full size they are dug.

After the first crop is taken from the ground (whether this be potatoes, another root crop, or grain) the ground should be thoroughly irrigated before a seed bed is made in which to plant the second crop of potatoes. The irrigation of the second crop, during its early growth, will be more important than the early irrigation of the first crop, because the weather is hot and plenty of moisture must be provided for greater evaporation at this season. Irrigation of the second crop must be discontinued in time to permit the ripening of the tubers in dry ground.

The moisture supply to a potato crop must be constant. If the ground is allowed to become too dry, the tubers begin to mature, and when another supply of moisture is provided, a new growth is started, making little wart-like growths on the already formed tubers.

Practically all of the crop in the Sacramento Valley would probably be sold almost direct from the field, making storage unnecessary. If it was desired to store potatoes, a cool, underground celcar, or a regular cold storage room, should be provided. Heat, rather than cold, is the factor to guard against here.

The potato crop requires deep, thorough preparation and cultivation of the soil; consequently, is a good crop in a rotation. After a crop of potatoes has been grown the soil is in fine mellow condition for a succeeding crop, for in addition to 


\section{THE POTATO}

the fine mechanical "ondition produced, much fertility has been made available.

On heavy soil, small "patches" of potatoes are sometimes grown under straw, or some similar material used as a mulch. By this method the seed bed is prepared (mellow and moist), the seed planted very close to, or just at the top of, the ground, then the whole area is covered with straw to a depth of six to ten inches. This settles down, the plants come through it, and the tubers develop beneath.

When planted this way the crop is not touched from the time the straw is placed until the tubers are dug. 


\section{CHAPTER XXXVI}

\section{THE ISLAND OF CHILOE, CHILE}

TN THE history of the potato there are occasional references to Chiloe. The senior au1 thor and Luther Burbank are planning to go there soon to study conditions.

The following information has been secured through the kindness of Secretary James Wilson of the United States Department of Agriculture, and Alfred A. Winslow, American Consul, Valparaiso, Chile.

" "It is generally understood here that the Island of Chiloe, Chile, is the home of the potato and that it was found there by Pedro Valdivia's expedition in the first half of the fifteenth century, where they were known by the natives as Poni. At that time potatoes served as the principal food of the Indians, who cultivated them to some extent, and where they are still cultivated in a very crude way. "The Chiloe Archipelago is situated off the west coast of Chile between 42 and 46 degrees south latitude, and is composed of many islands of which the largest, Chiloe, is about 100 miles long by 38 miles wide and covers about 2,450 square miles, with a population of about 40,500 persons, mostly Indians or half-breeds.

"The farms vary from 50 to 500 or 600 acres, but the island is covered with a dense forest, save where small patches have been cleared for cul- 
tivation, scarcely ever exceeding fifty acres in area, and the potato patches rarely exceed six to eight acres. According to the best information I have been able to get, no machinery is used in the cultivation of potatoes further than a very crude plow and a spade or hoe. They are planted in rows at irregular distances varying from eighteen inches to three feet apart. On the larger farms the seed is generally planted by dropping whole potatoes into the furrow at distances of from eighteen to twenty-four inches, and covered by dragging a split log over the surface with the face down, or by plowing a furrow on either side of the row.

"As a general rule they are cultivated only once, and then when they are three to four inches high. The weeds are cut out with a hoe or spade, when they are left to take care of themselves until it is thought best to dig them, which may be at any time after they mature until the following spring.

"There are many varieties of potatoes grown in Chiloe, although no special attention is paid to this matter. Each farmer may have his own variety, since no attention is paid to changing seed, for varieties do not seem to run out as at home. I am told that the same variety is planted on the same land year after year, by father and son, without deterioration. No special attention is given to the selection of seed, and still fine potatoes are grown from year to year.

"In general the potatoes are dug by turning the row over with a plow drawn by a yoke of oxen, and the ground poked around with a crooked stick. Of course in this way many are left in the ground, but this makes but little difference, since they are very prolific, and easily raised. 


\section{THE POTATO}

"No special attention is given to storing potatoes in that country. They are generally stored by the producer in a building with a ground floor on a level with the surface of the ground quite open to the air. There are no cellars in that part of Chile.

"There is no way of ascertaining the yield per acre, the cost of production, nor the profit per acre, since no account of such things is kept.

"Potatoes are sold in Chiloe Island by the producer, both to the consumer and the dealer, who may be a grocer, baker, butcher, generally merchant - in fact, almost every business house han dles them." 


\section{CHAPTER XXXVII}

\section{GREAT BRITAIN}

S HAS been indicated elsewhere, the senior author spent the season of 1910 in Europe studying agriculture in general and potato methods in particular.

In the various countries of Europe he found the best growers using very advanced methods, while as in this country the average grower could greatly improve his operations to his own benefit and that of the industry.

In the ultimate analysis of the situation the principles which are responsible for the high yields are simple. They are the essentials of good farming everywhere in the world.

The fundamental reasons for the successes of the best growers of Europe may be all broadly classed as soil culture, but may be classified as follows:

1. Drainage - good, careful, effective farm drainage.

2. The keeping of livestock and the use of animal manures.

3. The use of fertilizers of all forms to make crops produce to the limit of fertility.

4. Seed selection, breeding and adaptation.

Preceding a description of impressions of British agriculture and potato growing by the senior 
author, is the following discussion of the situation in the United Kingdom by Walter P. Wright and Edward J. Castle, taken from their very clever book, "Pictorial Practical Potato Growing," and used with their permission and that of the publishers, Cassell \& Co. of London:

"Ireland has always taken more kindly to the potato than the other countries of the United Kingdom, and she still boasts a larger acreage devoted to this crop than England, Scotland, and Wales combined. From various causes, this acreage has, however, been steadily decreasing for some fifteen years, the decrease being chiefly accounted for by the emigration of potato growers, and changes introduced into the diet of the inhabitants. Still, in 1904, Ireland could boast of 618,540 acres devoted to potato growing, as against 5\%0,209 acres owned by England, Scotland, and Wales. These figures showed a decrease for Ireland, and an increase for the rest of the kingdom, an increase which was augmented to 608,473 acres in 1905 .

"It is gratifying to know that efforts are being made to check the decrease in Ireland, chiefly by the production of very early potatoes for the English market, and of others suitable for seed purposes. Experiments in growing early potatoes on a small scale were made in Ireland in 1901, and proved so successful that each succeeding year has seen an increase in this direction. The climatic conditions of the west coast of Ireland seem exceptionally well fitted to the production of early potatoes, and there are not wanting experts to prophesy that Ireland may yet compete successfully with Jersey and St. Malo. 


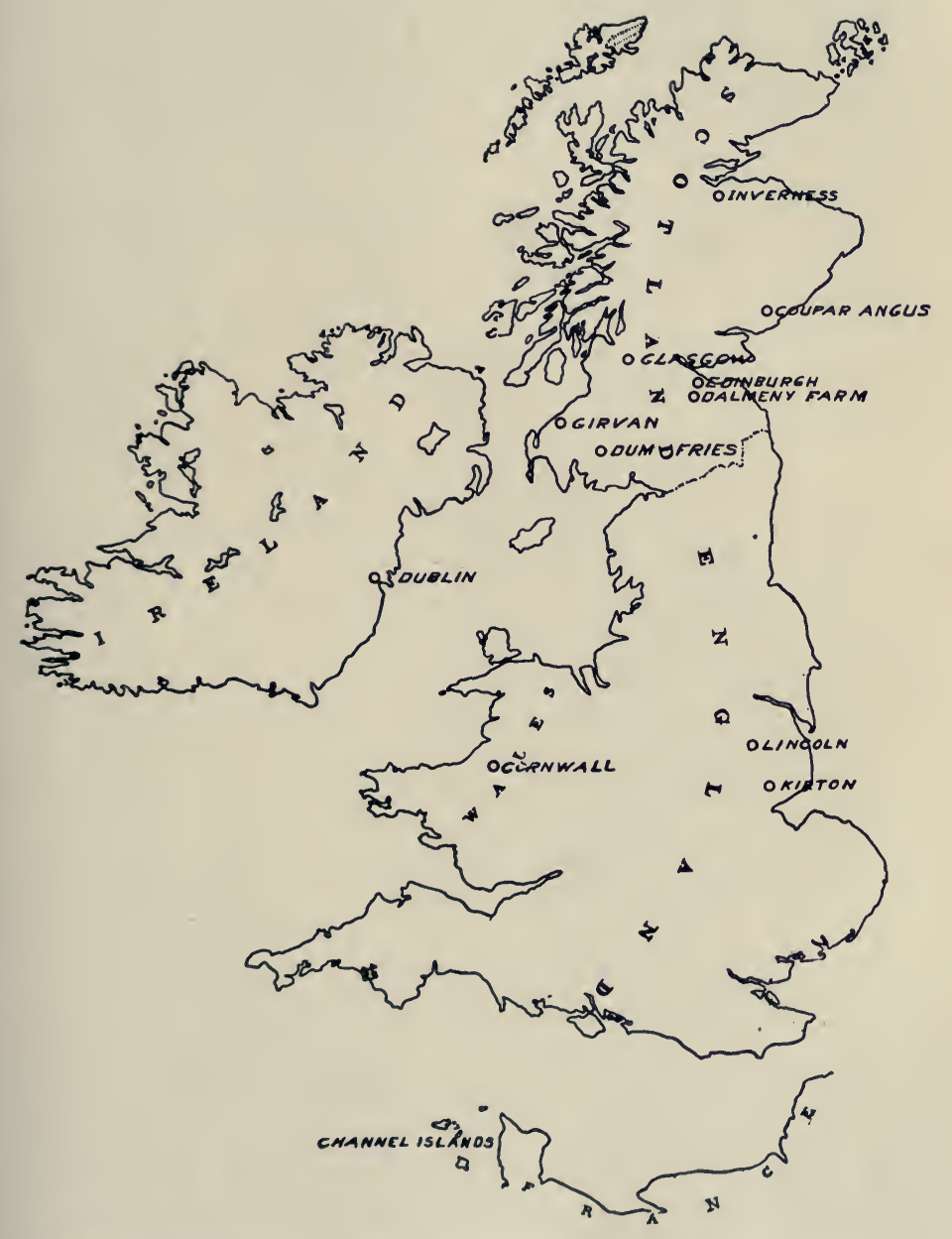

Map showing districts in Great Britain where there are prominent potato farms 

"In the growing of seed potatoes, Irish prospects would seem to be particularly rosy, especially since Mr. J. F. Williamson, of Mallow, has demonstrated that Irish grown seed of the variety Duchess of Cornwall gives better returns than similar seed from other parts of the kingdom. Hitherto the great obstacle to the development of the Irish seed potato trade has been the dogged pertinacity with which the Irish growers adhere to their own type of potato - a type which finds little favor among English growers or consumers. With this obstacle removed, progress may well be expected to be rapid.

"The type of potato, finding chief favor in Ireland is rather ungainly in shape, and possessed of very deep eyes, Champion and Black Skerry being two of the most popular varieties. Both of these cook like balls of flour, and are very white in the flesh, and flaky. As they are cooked and served in their skins in Ireland, shape and appearance matter little, the true criterion of a potato being its flavor. In England, however, where potatoes are generally peeled before cooking, shape is a great consideration, and the deep-eyed, Irish varieties have to yield pride of place to well-shapen, shallow-eyed varieties.

"England is easily next to Ireland in the matter of potato growing, having about three times the area of land devoted to potatoes that Scotland has, and more than fifteen times as much as Wales. Moreover, the acreage of potatoes in England shows a steady increase, it having been 402,725 acres in 1903, 402,760 acres in 1904, and 434,773 acres in 1905 . The average yield per acre is, however, slightly less in England than in Scotland, though more than in Ireland and Wales, the aver- 
age of the ten years 1895-1904 being: Scotland, 5.90 tons; England, 5.84 tons; Wales, 5.36 tons, and Ireland, 3.83 tons per acre (a ton is thirtyseven-and one half bushels).

"The bulk of English potatoes is grown in the counties of Lincolnshire, Yorkshire, Lancashire, Cheshire, and Cambridgeshire. In 1905 the following acreage was under potatoes in the respective counties: Lincoln, 79,564; Yorks, 57,364; Lancs, 47,697; Cheshire, 26,642; and Cambridge, 26,039. Lincolnshire is the centre of the English seed potato industry, and Lincs seed potatoes have a reputation second only to the best Scottish. Cornwall, which has only an area of 4,822 acres devoted to potatoes, has generally the honor of placing the earliest English grown potatoes on the market. These follow the supply from the Channel Islands, the latter, however, being preceded by supplies from Malta and the Canary Islands. The Maltese potatoes reach our shores in November, and have recently become so popular that quite a flourishing trade has been built up.

"In Scotland, the acreage of potatoes has rapidly increased, 144,265 acres being required for the crop of 1905, while 137,735 acres sufficed for that of 1904. This increase is mainly attributable to the enormous demand for Scottish seed potatoes, a demand created largely by the results of experiments conducted by scientists to determine the relative value of seed from various sources. But Scottish ware potatoes also hold their own against the world, the famous Dunbars frequently being quoted at $20 \mathrm{~s}$. $(\$ 4.80)$ per ton above all others. These tubers possess a remarkably bright and taking appearance, combined with high cooking quality, for which the peculiar kind 
of soil in which they are grown is deemed responsible."

The notes which follow were written by the senior author as he visited the various farms mentioned:

\section{NEAR EDINBURGH, SCOTLAND}

Dalmeny Farm, Edinburgh, Scotland, is one of the most famous livestock and plant breeding institutions in the world. It is the home place of of the Earl of Rosebery. A large number of specialists are employed and they have accomplished wonderful results with grains, grasses, vegetables and livestock. The intricate details of breeding have been carefully worked out and the products of the farm go all over the world.

The Earl of Rosebery has bred and raced three Derby winners (thoroughbred running horses), and a great many famous prize winning Clydesdale horses; Aberdeen-Angus and Shorthorn cattle, large Yorkshire and Berkshire hogs and Shropshire sheep.

In the potato world this farm is famous for having produced the largest yield of potatoes ever recorded.

The place is visited annually by many delegations of agriculturists and students from all over the world.

Everything is made to pay. The Earl instructs his factor or manager that unless he makes every branch of the business pay he will be replaced by a man who can.

The crop rotation on the potato lands is: Potatoes, one year; grain, one year; grass, two years. The grass consists of a heavy seeding of rye grass 
or red clover, alone, or rye grass with wheat, oats, or barley as a nurse crop. I saw red clover seeded with wheat. The grain was a very heavy crop, (forty-eight to fifty-six bushels) and the red clover was thick and fully eighteen inches high.

The rye grass meadows are fed off with sheep. Cottonseed and linseed cake and some grain are fed in addition. Then twenty tons of well rotted manure are spread and plowed in during the winter when potatoes are to be grown the following year. Potatoes always follow grass. This system combined with the northern latitude, has always kept the potatoes free from blight and disease. Mr. George Sinclair, the farm manager says: "There is no potato disease in Scotland if the crop is grown only every fourth year, and on turf or sod ground. This keeps the soil open, loose and porous, and full of decayed vegetable matter." The condition of the soil was ideal for potatoes. A special artificial fertilizer mixture that has been adapted to conditions after many years of experimenting by their soil experts and specialists is sown at the time of planting at the rate of six to seven hundred pounds per acre.

Whole seed is always used and increasing the size has given satisfactory results in increased yields. They are now using about 3,300 pounds of seed to the acre. Formerly 2,000 pounds was the rate. I saw as much as 5,000 pounds per acre planted - seed up to three inches in diameter.

In some series of experiments for three years successively with three varieties, 3,500 to 4,500 pounds of seed to the acre gave an average of seven tons per acre greater production than a 2,000-pound seeding.

Late varieties are planted in rows twenty-seven 


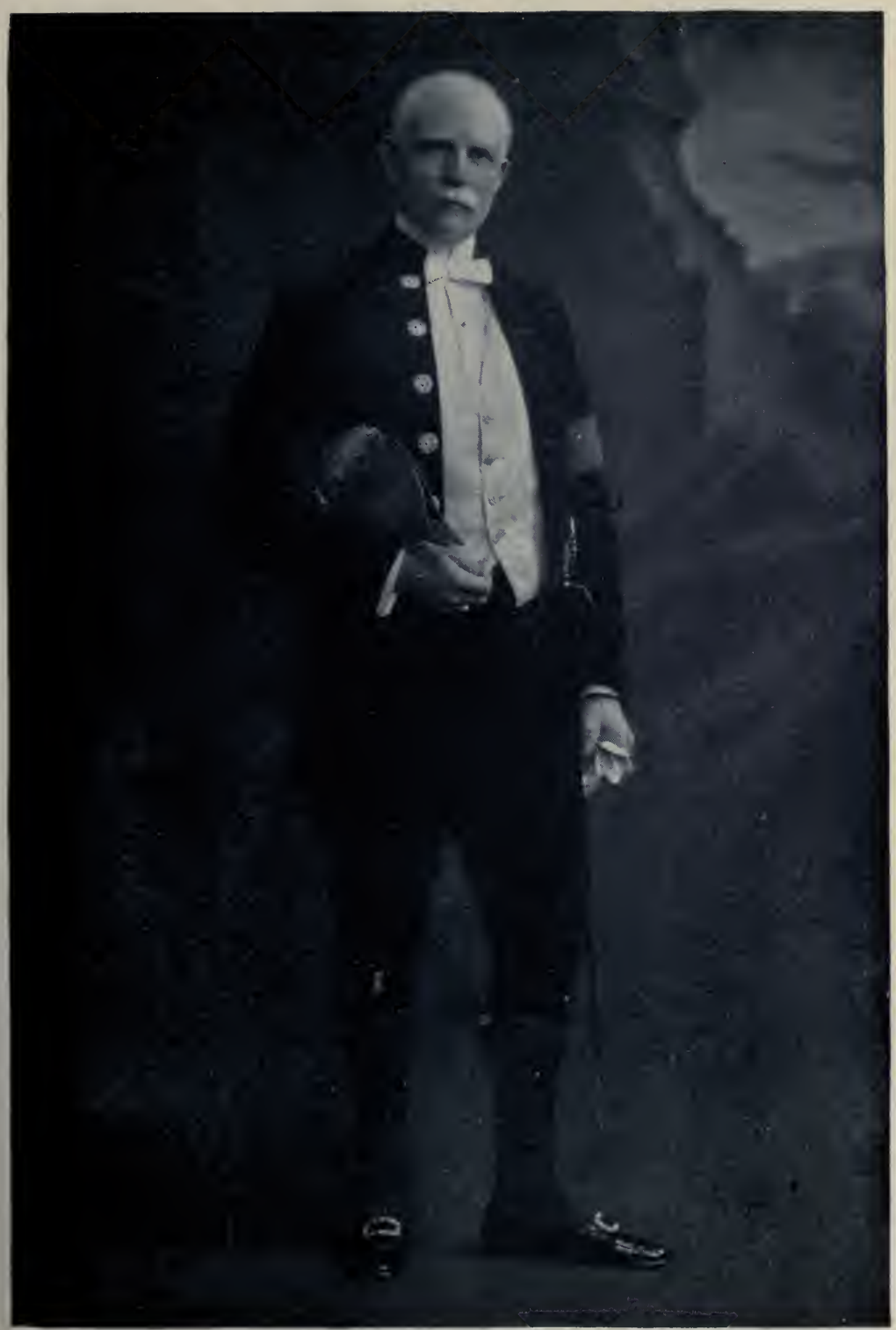

Sir Matthew Wallace - knighted by George V for his work in the interests of the potato industry 


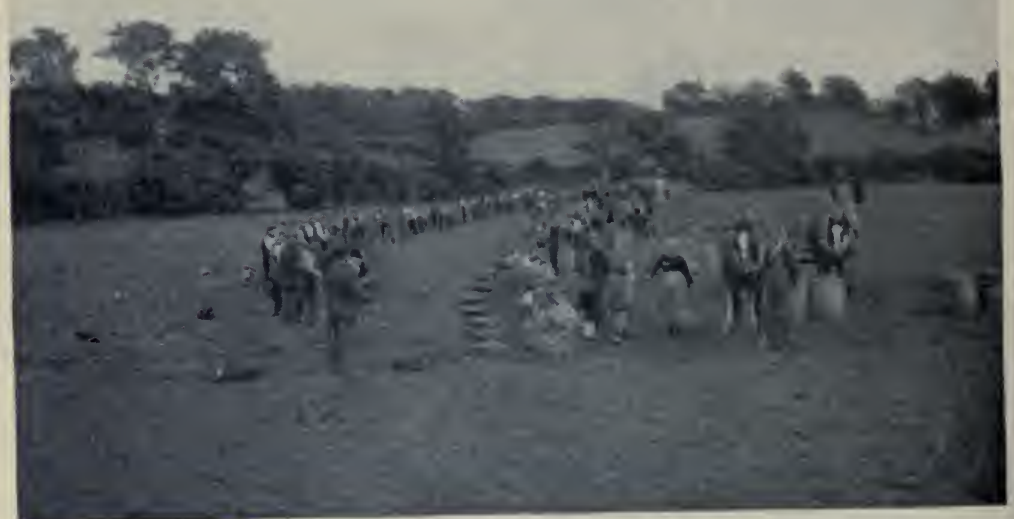

Potato digging in Scotland

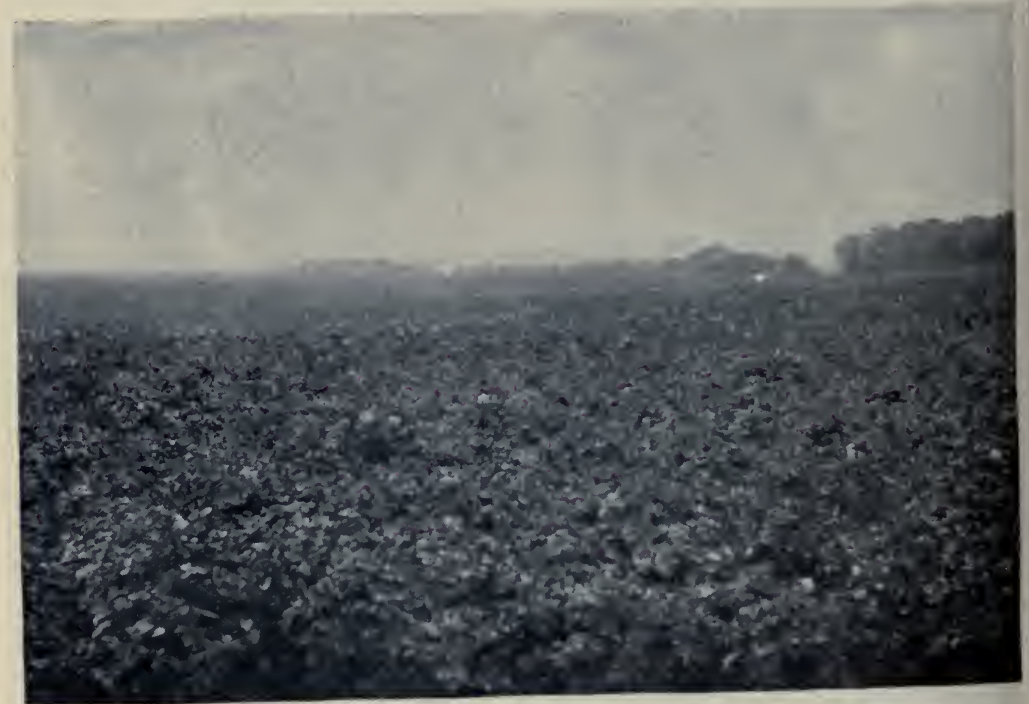

A potato field on the farm of Matthew G. Wallace, Terregleston, Dumfries, Scotland 
inches apart, twelve inches apart in the row. Early varieties are planted twenty six by eight inches. This increases the number of hills per acre, consequently the yields.

Deep cultivation is practised. George Sinclair is the only farmer I have found who advocates extra deep stirring of the soil between the ridges to keep the soil loose, open and porous.

All potatoes for seed are stored in pits. He advises growing as large a crop as possible, rather than digging green, as frost always cuts off the growth sufficiently early to secure strong growing, vigorous seed. There is no special boxing or storing in cellar or houses. Seed is never cut, no matter how high the price. He cannot afford to weaken the plants by dividing the tuber.

Land rents for $\$ 20$ an acre. It cost $\$ 105$ an acre to grow 600 to 675 bushels per acre.

Extra large seed planted whole gives best results for growing seed stocks, as so many more potatoes set to the one big root system, they are slower in growing, more uniform in size and of more suitable size.

\section{IN WESTERN SCOTLAND}

The results of the work of Matthew G. Wallace, Terreglestown, Dumfries, Scotland, in growing potatoes are very remarkable. $\mathrm{He}$ is a tenant farmer, and has been growing potatoes on a 300 -acre farm for the last twenty years. In January, 1911, he was knghted by King George for his services in the interest of the potato industry. This is the first time in history that a man has received such an honor for such service. It is a sign of the increasing interest in agriculture. 
The soil in this section is peculiarly adapted for growing certain varieties of potatoes. It is a very light sandy loam and is naturally well drained. The subsoil is of sand or gravel, and some of the most successful crops are grown where the soil is not more than eight inches deep.

Mr. Wallace's whole work is potato production. His conditions are such that he has grown potatoes every year for twenty years on the same land, and out of a total of 300 acres, 260 are kept in potatoes. The other forty acres are used for pasture and for growing hay and grain for his horses.

On the 260 acres of potatoes he uses annually 5,000 tons of barnyard manure costing $\$ 7,500$ and eighty tons of commercial fetilizer costing $\$ 3,000$. He compounds the latter himself. The manure is applied at the rate of twenty tons per acre.

Mr. Wallace grows only two varieties of potatoes: the Sutton's May Queen and Sutton's Ninety-fold. The former is a capricious variety in its habits and nature of growth. In the soils and weather conditions to which it is adapted it gives maximum yields and endures from year to year. This fact is true of every variety of potato of which $I$ have any knowledge, but it is a phase of the subject that is very little studied by potato growers. One of the strong habits of the May Queen, which grows to perfection in the peculiar conditions at Dumfries, is that it grows very rapidly and strong, and has large leaves and stocks. These are necessarily tender and will not withstand strong winds, which would whip it, weaken the plant, make it apt to blight, and check the growth of the tops as well as the tubers. This variety is not a favorite on the coast where there 
are heavy winds, and it is never grown there. An adaptation of this information can be well applied in districts in western United States, on open plateaus where there are strong winds during the early growing season of June and July.

The May Queen is one of the very best early market sorts for the British markets. On June first I saw one hundred acres that was a beautiful sight because of the healthfulness, vigor and bright green foliage of the plants. Mr. Wallace begins to harvest early in July and the entire crop is harvested during that month.

Potatoes that go over a two and one fourth inch mesh are shipped to market, those between two and one fourth and one and one fourth are sold for seed or kept as seed stocks. When the potatoes are dug they are practically about one half to three fourths grown. They are planted about March 25th and will yield about eight tons when harvested July 8th. When ripe and matured they would make twelve tons over a-one and one half inch mesh.

After being cured in long narrow pits, about three feet wide and thatched with straw, they are shipped to the seed houses for which they were grown.

$\mathrm{He}$ is very particular to keep seed true. The same variety is grown year after year in the same fields so that any potatoes that might winter over and come up as volunteers the next year would not mix with those planted in the spring following. $\mathrm{He}$ is so careful and painstaking that each storage house is labeled with the name of the variety and no other is stored in it.

Potatoes are harvested in July. They are dug with forks and picked up by hand. If no disease 
which they spray to prevent is found, the vines are spread evenly over the surface, plowed under, and three bushels of Italian rye grass sown to the acre.

Heretofore he has imported the rye grass seed from France. It is stronger than the English or Irish grown seed and has given the best results, but this year Mr. Wallace is growing his own seed. He uses an immense quantity of seed. It costs $\$ 1.50$ a bushel or $\$ 4.50$ an acre. The object is to get as large an amount of grass as early as possible, and to get the greatest amount of fibrous roots and turf to plow under later to keep up the humus content and mechanical condition of the soil. Rye grass gives more roots and turf in a shorter season than any other grass they have used. One object of sowing it immediately after the potatoes are harvested is to pick up and hold any or all of the expensive commercial fertilizer that has been used in growing the crop of potatoes. Otherwise it would be leached into the subsoil from the excessive rains. This rye grass is a second crop for the year - following the early potatoes. The grass makes a fairly heavy crop by the end of the growing season.

Manure is piled up and rotted until it is almost like black putty, then it is hauled out and applied to the rye grass crop at the rate of twenty tons per acre and plowed under about nine inches deep in November or December. It has the winter's snow, rain and freezing to decay this green cover crop, to disintegrate the soil and make splendid conditions for growing potatoes the following spring.

His land is thoroughly worked in the spring, and furrowed out in long, straight, deep furrows, six 
or seven inches deep and twenty-seven inches apart. The potatoes are dropped by hand twelve inches apart and covered with a horse plow. This plow has a special form for splitting the ridge and covering two rows of potatoes at the same time.

I consider his seed work, seed storage, and handling the remarkable part of his system and methods. He is without exception using partially grown or partially matured seed. The potatoes that are lifted in July are kept over until the next March for planting. He claims that he gets less disease than when lifted at maturity, the potato throws out a less number of sprouts when planted, it makes a more vigorous growth, and the sprout is stronger. Consequently the crop ripens earlier.

As soon as cold weather approaches in October the potatoes are taken out of the pits and stored in trays of various sizes. These are from fifteen by twenty-four inches to twenty by thirty inches, and about three inches deep, with corner posts six inches high, so that it makes an air space of about three inches for the circulation of air between the layers of potatoes. These trays are corded up to the ceiling in the seed potato storage buildings. These buildings are enormously large and eighteen and twenty feet high. They are made frostproof, with a large part of the roof of glass, so as to give an abundance of light, to keep the potato from developing sprouts. Then when they want them to develop sprouts, the rooms are darkened. When one or two white, tender, delicate sprouts appear at the seed end, these potatoes are taken out into the sun and weather. This must be done a sufficient time before planting so that the sprouts become green and tough to withstand 
the handling in planting. The potatoes in the trays are hauled into the field and dropped by hand by women and boys. This method hastens the crop fully two weeks at both ends of the growing season. It makes it possible to delay planting until the soil is warm, and danger of rotting in cold soil is passed. This can be done with no loss in earliness. The seed is never cut, always planted whole.

Mr. Wallace uses 2,400 pounds of seed to the acre. After this year he expects to use larger seed than ever before. I saw on this farm one twenty-acre field on which was planted five thousand pounds per acre. The potatoes used were as large as a man's hand. This large seed was used this year because the market price of commercial potatoes was very low. He thinks it will make more net money than any acre of potatoes on his farm this year. They were planted next to potatoes where the ordinary amount and size of seed was used with the same soil conditions and culture. The result in the growth of the two crops was very striking and in favor of the large sets. The tops averaged fully 40 per cent. better than the potatoes from the ordinary seed size, and the yield should be correspondingly great.

In growing early potatoes they are very particular never to disturb or break the first sprouts off, or, as some say, to disturb the first intention of the potato to reproduce itself. When not disturbed or broken only one or two sprouts develop. When it is desired to propagate a great many plants from high priced seed, the potato is allowed to put forth sprouts about one half inch long from the seed end. Then the sprout is broken off. The result is that 
all the eyes of the potato develop sprouts of equal vigor and vitality, but none as strong as the first. When only the first develop, the other eyes of the potato remain dormant. When the potato is cut in sections, one eye to a piece, the seed will go much farther and plant a great many more acres, although the crop will be less in yield and fifteen days later in maturing.

On these three hundred acres Mr. Wallace pays about $\$ 5,100$ rent and about $\$ 13,000$ for labor. On this farm it costs $\$ 110$ to grow an acre of potatoes. The annual revenue is $\$ 175$ making a profit of $\$ 65$ per acre.

As near as I could determine in going with him over the several lots, he had (1910) an average of 99.5 per cent. of a full stand.

He pays $\$ 4$ to $\$ 5$ a week and house rent to men with families. Foreman and men handling teams get $\$ 5$ to $\$ 6$ a week.

The potatoes are picked up in small baskets and dumped on a screen, which is placed over the head of a barrel. The dirt and small potatoes go through; the others are put in other barrels. The top is covered with green potato tops and netting. All early potatoes are marketed in barrels, the late or main crop potatoes in sacks.

\section{GIRVAN, SCOTLAND}

Girvan is a town on the western coast of Scotland, on the Firth of Clyde. It is the birthplace of Hon. James Wilson, Secretary of Agriculture of the United States.

It is the earliest potato-growing district in northern Great Britain. It is on the coast where they have no severe late spring frosts, because of 
the protection from the Gulf Stream. Potatoes are planted the first of March and they commence harvesting in June. The soil is a wonderful light, warm, sandy loam. The conditions here are the best I have seen in Europe for potato production.

There are five thousand acres of early potatoes produced annually in this district. They are, without exception, of one variety, Sutton's Epicure. This variety clearly fills all the requisites of the climate conditions in that it is a low, sturdy grower with tough leaves and vines. There are stiff sea breezes and violent storms that come from the sea. These do not injure or damage the plant by whipping and beating. It is an early, strong grower, the tubers form early, it is round and white, and yields well. It is much in demand in the cities throughout Great Britain.

I visited Mr. John Hannah, Girvan, Mains, the leading and largest potato grower of the district. His system varies little from that of Mr. Wallace of Terreglestown. He has the same total acreage of 300 acres, and has continually the same acreage in potatoes - 260 acres. He differs from Mr. Wallace in that his potatoes are all sold for market in June and July, and he does not grow and save his own seed. Every year Mr. Hannah buys his seed in July from other growers in the district. By selecting his seed from the best fields and crops there is apparently no disease whatever, so far as I could learn.

His potatoes are all sold to dealers in the different cities. The same merchants come back year after year and buy the same fields at from $\$ 140$ to $\$ 175$ an acre. The merchants lift (dig) and barrel the potatoes, and Mr. Hannah puts them on the cars. It is surely a novel system of 

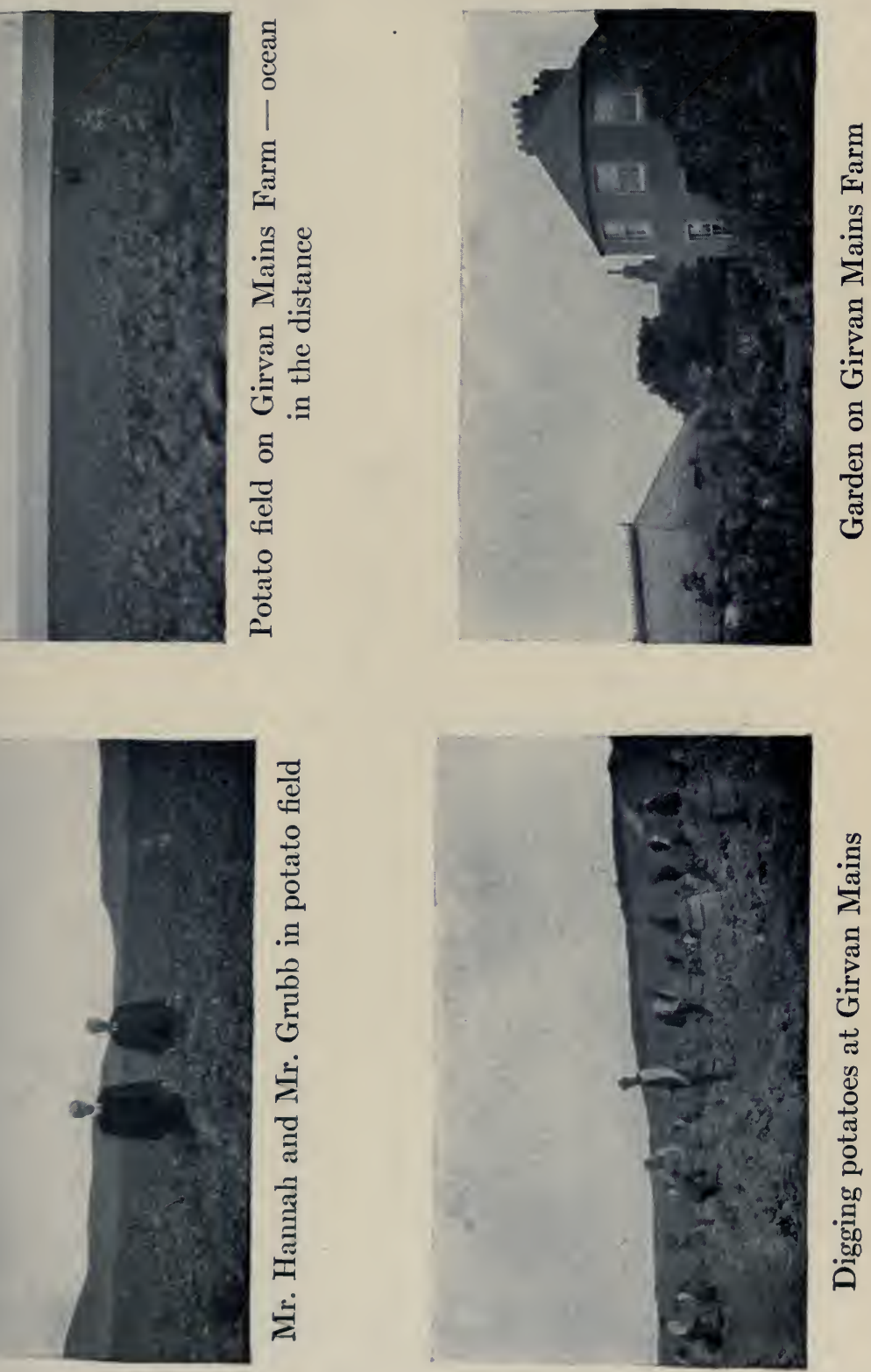

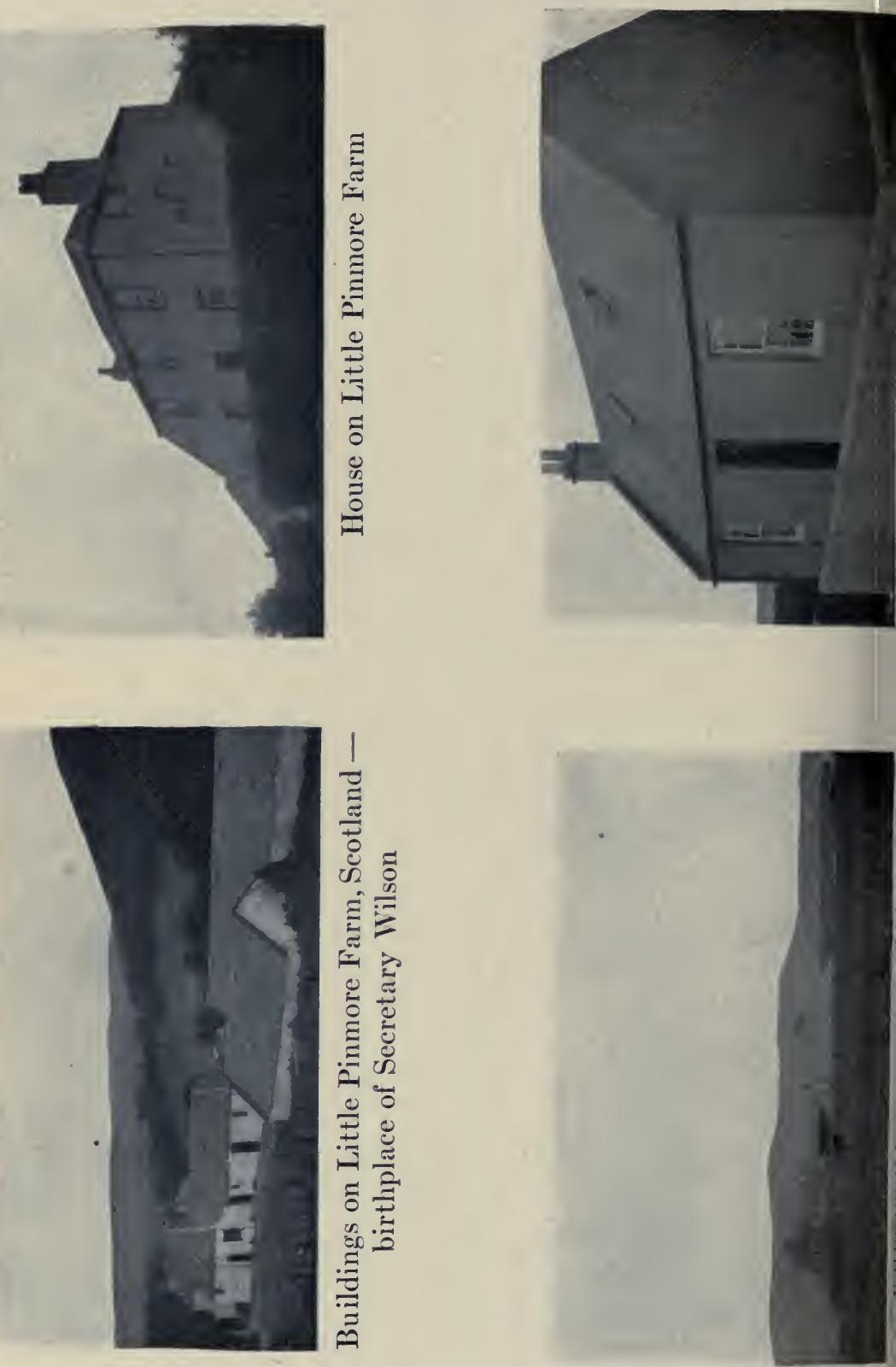
harvesting a crop. These city merchants harvest the crop from day to day as their customers in the various cities require them, and there is no loss in shipping to commission brokers by overstocking and breaking the market.

I had a very delightful time with Mr. Hannah, going over his work and discussing methods. He uses larger sized seed than Mr. Wallace. Mr. Hannah plants 3,000 pounds of whole seed per acre, and, of course, insists that it must be only partly matured when dug. It was very interesting to go over the field, seeing in nearly every hill examined the originally planted seed potato still clinging to the roots as firm and sound as when planted last March. I did not see a single colored leaf or a dying or withered leaf in a field of 100 acres (June 25, 1910).

Mr. Hannah uses seaweed that washes up on the beach for fertilizing. It is gathered and spread on the field in the fall at the rate of forty tons per acre. On the balance of the land he uses twenty tons of well-rotted barnyard manure annually. In fifteen years he has increased the application of commercial fertilizer from some 600 or 700 pounds to about 1,200 pounds per acre, annually. There is a steady increase in the use of commercial fertilizer to keep up the maximum yields.

He had commenced harvesting the day I was there, the 25th of June. The next morning the grass seeder was out ready to start planting. He used three "bushels of French grown Italian rye grass seed per acre and then I think a little more was added for good measure, as he said it cost $\$ 5$ per acre. His 260 acres of potatoes will be harvested in two weeks' time. Instead of plowing the rye grass cover crop under as at Dumfries, 
Mr. Hannah buys 3,000 head of sheep. He usually puts in forty acres of rape, although he can grow rape only about one year in six on account of the finger and toe disease. He would grow more rape than Italian rye grass if it were not on account of this. These 3,000 sheep are started grazing about August first. They cost $\$ 8$ a head. When finished for market they are slaughtered on the farm and the dressed carcasses sent to the London market. Great care is taken that all the offal from the sheep, except what can be sold, goes into the fertilizer heap. Not even the blood is lost. Nothing seems to go to waste on a thrifty Scotchman's farm. The slaughtered sheep give an increase in value of about $\$ 1.75$ per head. No grain or cake is fed - nothing but rape and Italian rye grass pasture. These sheep are pastured in hurdled lots. They are slaughtered once a week until the sheep and pasturage are all gone.

When the grass is fed off, the forty tons of seaweed or twenty tons of manure are spread on the stubble and plowed under in the late fall or early winter.

This farm has been growing potatoes with this same system for thirty consecutive years, the son succeeding his father, and Mr. Hannah sees no change in the yield. This is the most favorable year and the best yield he has ever produced. He sees no reason if this farm has grown potatoes for 100 years why it should not go on forever.

The cost of production is practically the same here as at Mr. Wallace's, Dumfries $-\$ 110$ per acre. He plows about the same depth, nine inches, and has the same system of boxing and sprouting. 
With his peculiar conditions, plowing under the cover crop has given no better results than the growing of forage crops and grazing it off with sheep, and he has the additional profit of $\$ 1.75$ per head for the sheep.

In this northern latitude he is getting two crops a year, one of potatoes, a cover crop of forage, and an increased value in fattening a flock of sheep. Surely this is a fine example of intensified farming, that can well be imitated in many favored districts of the United States.

While I was there a little incident came up that is well worth recording. A golf club wanted Mr. Hannah to release twenty-four acres of his leasehold. He had nine years yet to run on his nineteen year leasehold. After assuming the lease on the twenty-four acres for the nine years, and paying the annual rental to the owner and an additional bonus to Mr. Hannah for the release, they then paid him $\$ 1,000$ for the unexhausted manure that he had applied on the twenty-four acres after removing the crop. A very large part of this land had been tiled to three feet deep, the lines of tile being fifteen feet apart.

Another piece of work he did on a piece of heavy clay land was to cart pure, clean-washed sand and cover ten acres five inches deep with it. He claims that in the increased production and the ease of cultivation it was a paying investment on leased land. This is a good illustration of the great value of the easy working lands of the Twin Falls country in southern Idaho, because it certainly cost a considerable sum of money to have this land covered five inches deep with sand. Mr. Hannah is continuing this work on other land.

It was very interesting to see this scientific, 
practical, money-making potato grower doing experimental and demonstration plot work with the various combinations of fertilizer. Barnyard manure had been applied to all of the plots.

The use of 1,200 pounds of commercial fertilizer in addition to barnyard manure gave an additional yield of seven tons per acre, at an expense of $\$ 22$, or about $\$ 3$ per ton for the excess yield.

Mr. Hannah is a contented, satisfied, tenant farmer. He has made a great success in specialized potato growing for the early markets, on high priced, high rate, rented lands. He is probably worth over $\$ 200,000$, and is living a life of comfort in a beautiful home. He has servants, beautifully kept lawns, parks and gardens, with all kinds of fruits and flowers, and a conservatory for growing hothouse plants and fruits out of season. This is agriculture on ideal lines. The house he lives in is 102 years old.

The popular opinion in America is that it is disgraceful, undignified, and belittling to be a tenant farmer. But here is a tenant farmer who has acquired a quarter of a million dollars as a potato grower, but he is a specialist and he specializes to such an extent that he has more leisure for travel and pleasurable recreation than merchants, mechanics, or professional men, or any well-to-do farmer in America who owns his land, occupies, and farms it.

These tenant farmers are paying high land rentals and for expensive fertilizers, $\$ 5.60$ a ton import duties ôn potatoes into the United States and ocean rates, yet they can successfully compete with the American farmer with all his improved implements and cheap lands. 
IN FORFARSHIRE, SCOTLAND

Thomas Buttar, Corston, Coupar Angus, Scotland, is a very successful breeder of Shropshire sheep and Shorthorn cattle.

Mr. Buttar grows forty acres of potatoes for seed annually for the southern England trade and sells to seed dealers. He fertilizes heavily and grows 370 bushels of seed stock and 110 bushels of large potatoes and waste per acre. He plants large sized seed whole. This gives more tubers per hill and per acre and they are smaller and more uniform in size. It is another corroboration of Mt. Sopris Farm methods and results of planting perfect large tubers for growing seed stocks.

Corston is a large seed-growing section. I met six other large and successful growers. Every one feeds livestock. They grow a very large tonnage of yellow Aberdeen turnips and Swedes, which they feed with oil cake. Each and every one declares they could not farm profitably without grazing, cake feeding for making muck, and the use of artificial manures. Their main reliance is cake made manures and crop rotation, potatoes one year in three, sometimes two years in seven, two years in grass for hay or pasture, usually hay first year and pasture second, then fall plowing after a coat of ten or twelve tons of well-rotted muck or manure has been applied. They have no disease, require no spraying with this system, and it keeps the soil healthy and free from injurious germs. The soil is in splendid physical condition, notwithstanding the fact that there is both drought and excessive rains. It is in such condition that it holds sufficient moisture for 
plants in dry times and drains well to the tiles if there is excessive moisture. All the lands are tiled to a depth of thirty inches with lines of tile twenty-four to thirty feet.

Mr. Leyburn of Kunochtry, Coupar Augus, is another successful grower.

He feeds his land like his bullocks, giving the soil all the barnyard muck and artificial fertilizer it can use. His oats and barley make sixty-four to eighty bushels per acre every year - he has no bad years. He feeds no grain to bullocks or sheep, just roots, chaff, cake, and potatoes. No small potatoes are wasted in Scotland. They are fed to hogs or cattle.

Mr. Leyburn grows the Epicure for early market, and follows with British Queen for second early. King Edward, Ever Good, and Langworthy are the late varieties. Langworthy is not a heavy cropper, but of such quality that it brings $\$ 5$ more a ton for its table quality. There are 300 acres annually in potatoes on a 1,000-acre farm. Mr. Leyburn is a tenant farmer and pays $\$ 13$ an acre rent.

I am sure he feeds his soil all it can utilize from the solid look of the tops. I could not tell the direction of the rows without going into the field. When a hill was lifted eight to fifteen great potatoes would be found. They were not nearly grown and would continue to increase in size for another four weeks.

The Epicure is his favorite for early market. It is not of as good quality as some, but is a strong grower and will stand dry or wet weather well. It is round, of even size, and there are few small ones. They were planted April 1st and harvested July 15th to August 1st. The British Queen is two 


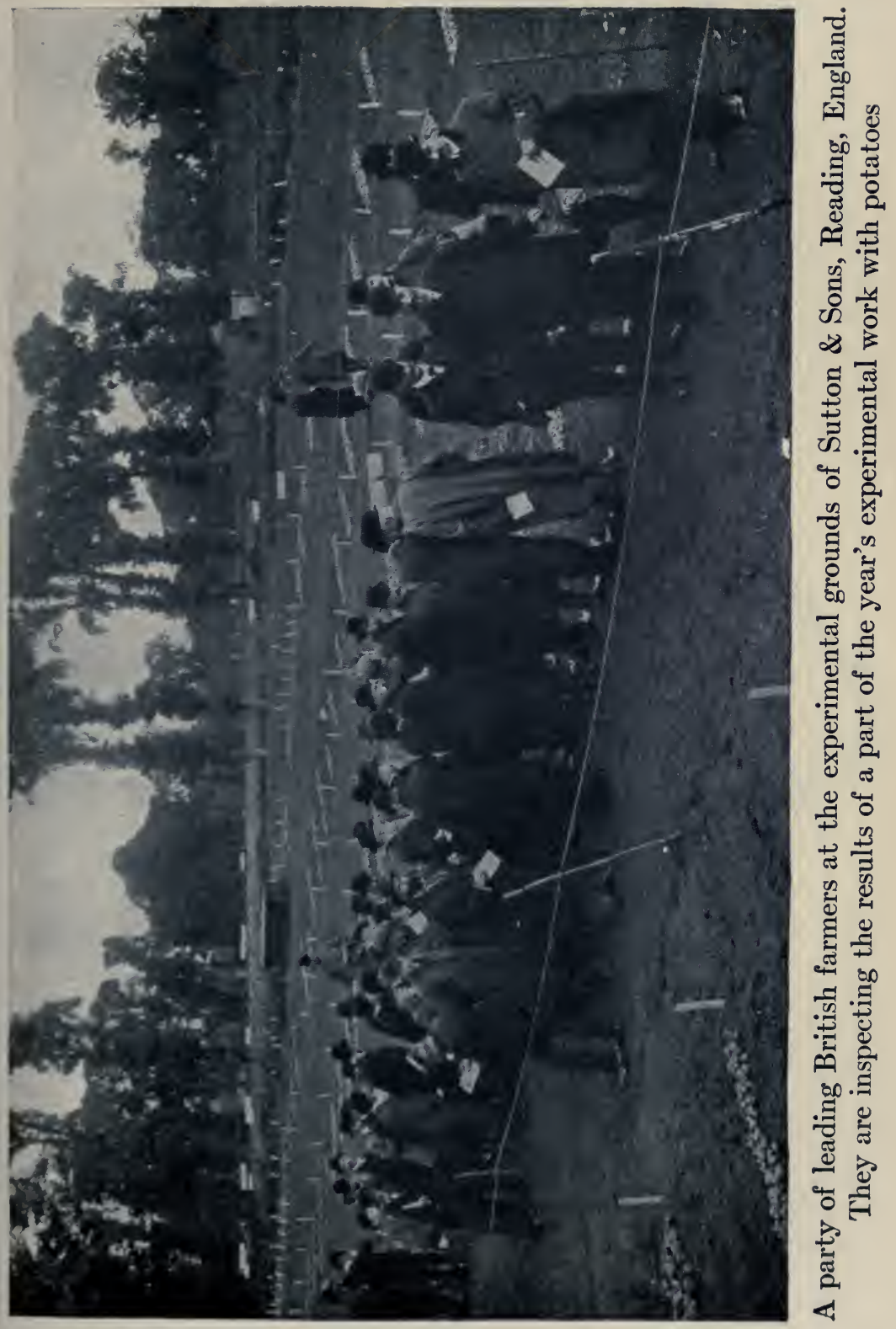




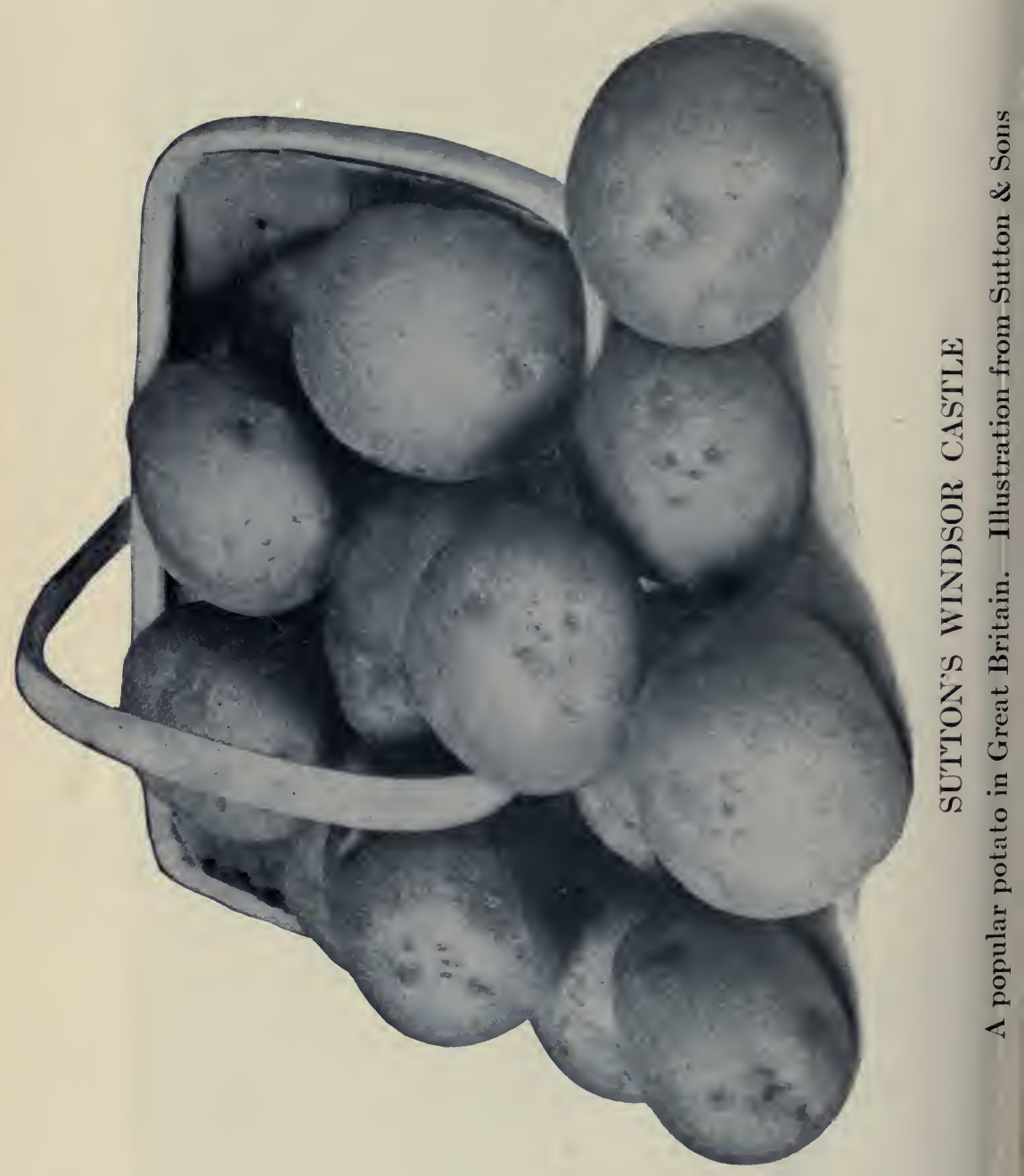


weeks later in marketing. I believe it would be a desirable type for the United States.

Irish women and girls do the digging with forks. Eight women take sixteen rows. They walk backward and fork them out deftly and other women pick them up, two rows at a time. A man empties them into barrels. They are sorted to market size and refuse as picked up. The land is left as smooth and level as if it had been harrowed. The tops from the sixteen rows are put in four winrows. They dig and pick up seventy-five bushels a day at a cost of $\$ 1.20$. They get a cabin, firewood, and what potatoes they can eat. Women work better and sort better than men.

\section{AT DUNFERMLINE, SCOTLAND}

A. Burns and Sons, Dunfermline, Scotland, farm 1,000 acres and crop 300 to 500 acres in potatoes annually.

They grow one variety of early potatoes exclusively, the British Queen. This outsells all other early varieties on account of its extra fine table qualities, good shape and medium size. It is a strong grower and makes large yields. The quality is corroborated by the extra gain of steers fed on the waste of British Queens as compared with softer varieties with less starch, like Epicure and Up-to-Date. Mr. Burns says cattle relish them more, consume more, and they give 25 per cent. more gain on the British Queen.

Mr. Burns grows and saves his own seed. It is screened out of the small potatoes when they are picked up by the harvesters. All the refuse is run over a one and three eighths inch screen. The seed potatoes are boxed and stored in seed stor- 
age cellars if he has time; otherwise they are stacked up outside. They wilt and green in the sun and air and get quite soft. He says this is not advantageous for seed vitality. He uses smaller seed than most growers in Great Britain advise.

He sows rye grass (two bushels per acre) and rape seed (twelve pounds per acre) as soon as the potatoes are lifted. He grazes this off with sheep from August 15th to December 15th. He feeds cake to the stock he is pasturing. Cake is his great reliance for keeping up soil fertility. He applies twenty tons of well-rotted manure in December and plows under as deep as possible. He has grown potatoes successively this way for fifteen years. Potatoes are sometimes followed with wheat or Swedes. The roots get the same treatment as the potatoes. He grows thirty-five to sixty-five bushels of wheat per acre and from thirty-five to forty-six tons of Swedes. There is nothing sold off the farm but finished cattle and sheep, potatoes and wheat. All roots, straw, rye grass, hay, oats, and small potatoes are fed in covered sheds for making muck. No fertilizer is used the year he grows wheat, but 1,200 pounds of ground lime is plowed in. Lime costs $\$ 3.50$ a ton.

He uses 2,300 pounds of seed potatoes per acre, planted whole. They are boxed and sprouted. All potatoes are harvested before they ripen and are sent to market from July 15th to August 15th. If any of the crop is matured it makes 600 bushels per acre. The average when marketed unripe in July and August is 375 bushels.

Mr. Burns uses 1,200 pounds of commercial fertilizer. This is 10 per cent. ammonia, 12 per cent. potash, 25 per cent. phosphates. The secret 

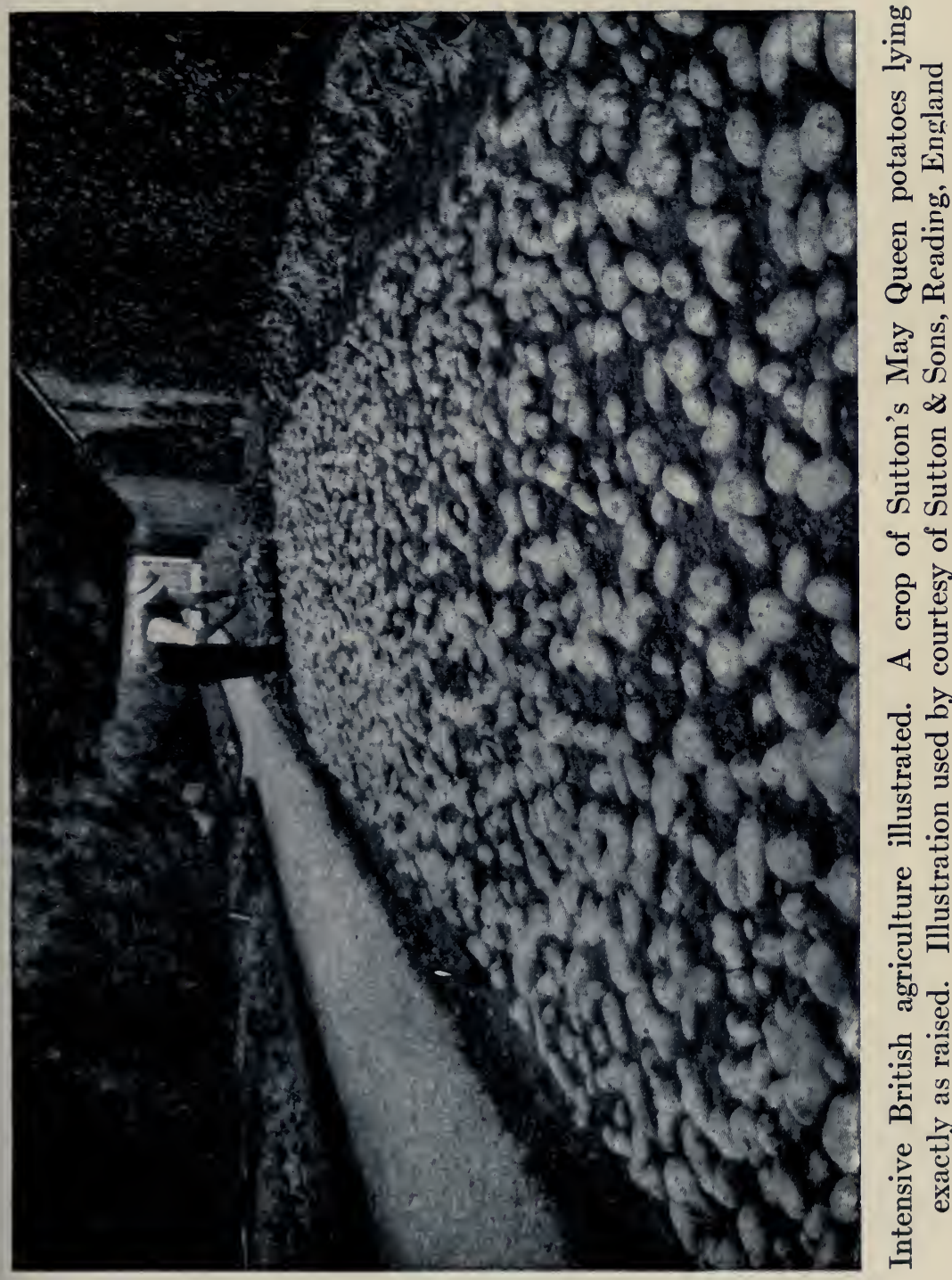

of his success in fertilizing is in getting the proper proportion of barnyard muck and artificial fertilizer.

The crop is cultivated twice and hoed once.

The head lands in the fields are not planted, so it leaves room at the ends of rows without trampling the crop.

The seed is stored in stone buildings. There are windows in the roof and sides that can be fully opened and there are large doors in the ends.

The potatoes begin to throw out sprouts about December. He keeps these from developing too rapidly by opening doors and ventilators. He says the sprouts will not grow if there is a circulation of air at 45 degrees to 50 degrees $\mathrm{F}$. When the sprouts are one and one half inches long he checks their growth, and greens and toughens them by circulation of air and light. One of the great problems of early potato growing is to hold back the development of the sprouts until the time of the planting. Another great secret imparted by Mr. Burns is that if seed potatoes are boxed at once and put into storage before withering or greening, and if only partially matured when dug, only the terminal bud or eye develops. One sprout gives the best crop, and it is ten days or more earlier. There is no disease and no spraying. He had the best 300 acres of wheat I have seen, except an irrigated crop. It was as heavy as would grow without lodging. For this crop he used from 180 to 200 pounds of seed per acre, and it will make a sixty-four-bushel yield.

He has Irish help for harvesting - 100 of them now ( at time of visit). It costs $\$ 11$ an acre to dig and pick up. They commence work at 4 A. M. and work ten hours. 
He feeds 400 bullocks a year in stone-wall stables, under cover, bedded every day with straw and peat moss to hold the liquid manure. They are fed from 100 to 160 pounds of small waste potatoes and ten pounds of cottonseed cake per day with rye grass, hay or straw. He has 100 bullocks on feed. They weigh about 1,040 pounds and cost $\$ 100$ each. He says that in forty days they will weigh 1,200 pounds and bring $\$ 125$. He never grazes steers, but always feeds oil cake, potatoes, Swedes and roughage in close pens. He values potatoes at $\$ 7.50$ a ton for feeding. The manure of cattle fed a ration rich in linseed and cottonseed oil-cake is the reliance and success of his potato growing. The cake and bullock manure with the liquid manure he conserves with the dry bedding of various kinds is worth $\$ 3$ a ton, with city horse manure at $\$ 1.50$ a ton. He gets one and one half tons of manure to a bullock.

Without muck combined with artificial fertilizer, potato growing would be an absolute failure. The advantage of growing early potatoes is that he can grow a crop of rye grass or vetch, before freezing weather, to plow under for green manure or graze off with sheep and cake.

Mr. J. Butterrs, Dunfermline, raises only maincrop potatoes (late) at a cost of $\$ 50$. He grows and selects his own seed, pits it and plants it whole, using from 2,500 to 3,000 pounds of seed to the acre.

He has a special trade direct to consumers, and cannot supply the demand for Langworthy at $\$ 20$ a ton (37.3 bushels) because of the table excellence of this splendid potato.

He gets $\$ 150$ an acre for his crop, making a profit of $\$ 100$. 
He plants 27 by 9 inches. I did not see a weed on the farm. He has grown Langworthy exclusively for eight years, and selects the seed personally. No rogueing (going through field and pulling out other varieties) is necessary here.

\section{IN LINCOLNSHIRE, ENGLAND}

Lincolnshire is one of the largest shires or counties in England. It vies with Yorkshire in its area in production and yields of agricultural products. The lowlands next to the sea are known as the fens. In former years they were bogs that were affected by the tides. They were reclaimed by the Dutch. Now it is one of the most fertile lands for grazing, growing grains and potatoes. It is the largest potato district in England.

The fens are drained by large canals. At one time the drainage water was pumped out by windmills, but now steam power is used. The water is raised ten or twelve feet. In the rainy season the expense of this is much greater, but in some seasons they pump only about four months, just enough to hold the water table from two to five feet below the surface. Some of this land has no fall whatever, while the higher lands are drained by large canals, which empty into the sea. These have a fall of about four feet in six miles. The canals are seventy feet wide, from ten to fifteen feet deep, and from three to five miles apart.

In dry seasons the drainage canals that are not affected by the salt water tide are allowed to fill up to furnish sub-irrigation to the growing crops. From my experience in England with the cloudy weather and excessive rainfall, I would not think there would be any necessity for sub-irrigation 
once in a thousand years. Nevertheless, it is used.

The black fen land produces enormous crops of grass, grains, roots, potatoes, and the most wondrous crops of peas. I saw from forty to sixty acres of peas in a lot and they yield forty to fifty bushels per acre. This year they are bringing very high prices in the city markets. I saw 250 women and children in one field picking the pea pods and sacking them for city markets. At a distance they looked like a great flock of sheep in the long rows.

These lands are now valued at from $\$ 350$ to $\$ 500$ an acre. As the country recedes from the sea it has more drainage and the soil is more of a clay. The lands are tiled. The lines of tile are from ten to twenty yards apart and the tiles are laid four to five feet deep. The original cost of the canals for construction was 75 cents an acre and 25 cents an acre maintenance every four or five years for cleaning and pumping.

Lincolnshire is noted for its specialized breed of livestock. In a week's motoring I saw nothing but Lincolnshire sheep and Lincoln Red Shorthorn cattle. They are all cherry red, and are descended from the old Shorthorn stocks. They are larger than the modern Shorthorn and much better milkers. They are good grazers. I was very much interested in the weight of some bullocks I saw grazing in a pasture, but I could not learn of a single weigh bridge (scales) in the whole of Lincolnshire. I saw 201 thirty-month-old bullocks, all cherry red, sold to a butcher by one firm of farmers, W. D. Dennis and Sons of Kirton. It would have been interesting to have witnessed the deal made, as this was said to have been the largest sale of bullocks from one farm at one time 
in Great Britain. First, the dealer came and looked over the bunch very carefully, then he was entertained at luncheon, where there was a plentiful flow of wine and spirit; and after every one had been put in the best of feeling, the dickering began. I have forgotten just where they started, but it finished £24.15.6 (\$123) per head. The parties guessed at the weight these bullocks would dress. When 200 were counted out at the figure one more broke in, making 201 in the sale. These English farmers are willing to put their judgment against the butchers who are slaughtering and weighing every day. These bullocks had never been on a weigh scale in their lives, and had never been fed a pound of grain. They were largely bred and reared on the farm, and were mostly from pure-bred Lincolnshire cows, 200 of which are kept. Only eight or ten bull calves are kept from the annual calf crop for bulls, and rest are made steers.

I had been so inquisitive in their other farm operations, especially the potatoes, that I refrained from asking one of the sons, who is manager of the cattle department, what one of the bullocks cost. It had been reared from a registered cow, that was valued at $\$ 125$, and was pastured and summered on land that had a valuation of $\$ 500$ an acre. I wanted to know the cost of that calf at weaning time, figuring the interest on the capital invested in the cow and the land she grazed on at $\$ 625$ a year and including the service of the sire, and figuring in the percentage of calves per annum to 100 cows. I simply remarked that I knew of no American farm that could raise steers at a profit on this basis. After weaning, the calves were wintered on straw and roots with a bit of oil cake - a pound a day. The next summer they 
were grazed without cake. The second winter they were carried on straw, clover hay, Swedes and mangels, and four and one half pounds of cake a day until sale early in July. They were a prime lot of killers. The pastures they were grazed on were drained and tiled. There is no history as to when these pastures have been plowed. They will probably be kept for grazing for all time to come.

It would be a great problem to determine just how far and in what way these cattle were a factor in the profitable agriculture of this farm. I am positive that they would not have these fabulous crops were these cattle not raised, as they are necessary in converting the world of straw that is fed and tramped into fertilizer beds of manure every winter. They are just as careful to fertilize their meadows or pastures here as they are their plowed fields. All the manure from the horse stables, pigstys, cow stables, poultry houses, and butcher houses, piles of weeds, and all liquid manure is hauled into the feed lots and conserved.

The Shire is the exclusive horse of this district, as is the white, curly coated Lincolnshire hog. The Lincolnshire sheep are also peculiar to this district.

Mr. Wm. Dennis and his five sons are pioneer growers of large acreages of potatoes. He commenced in 1869 by buying six and one half acres of land at $\$ 500$ an acre. They now have 3,000 freehold acres and lease 3,000 more. They are operating 6,000 acres as follows: 1,500 acres in potatoes, with extra early, early, second early, medium late, and main crop in about equal proportions; 1,500 acres in grain, and 3,000 acres in pasture for grazing. The grass and grazing land 


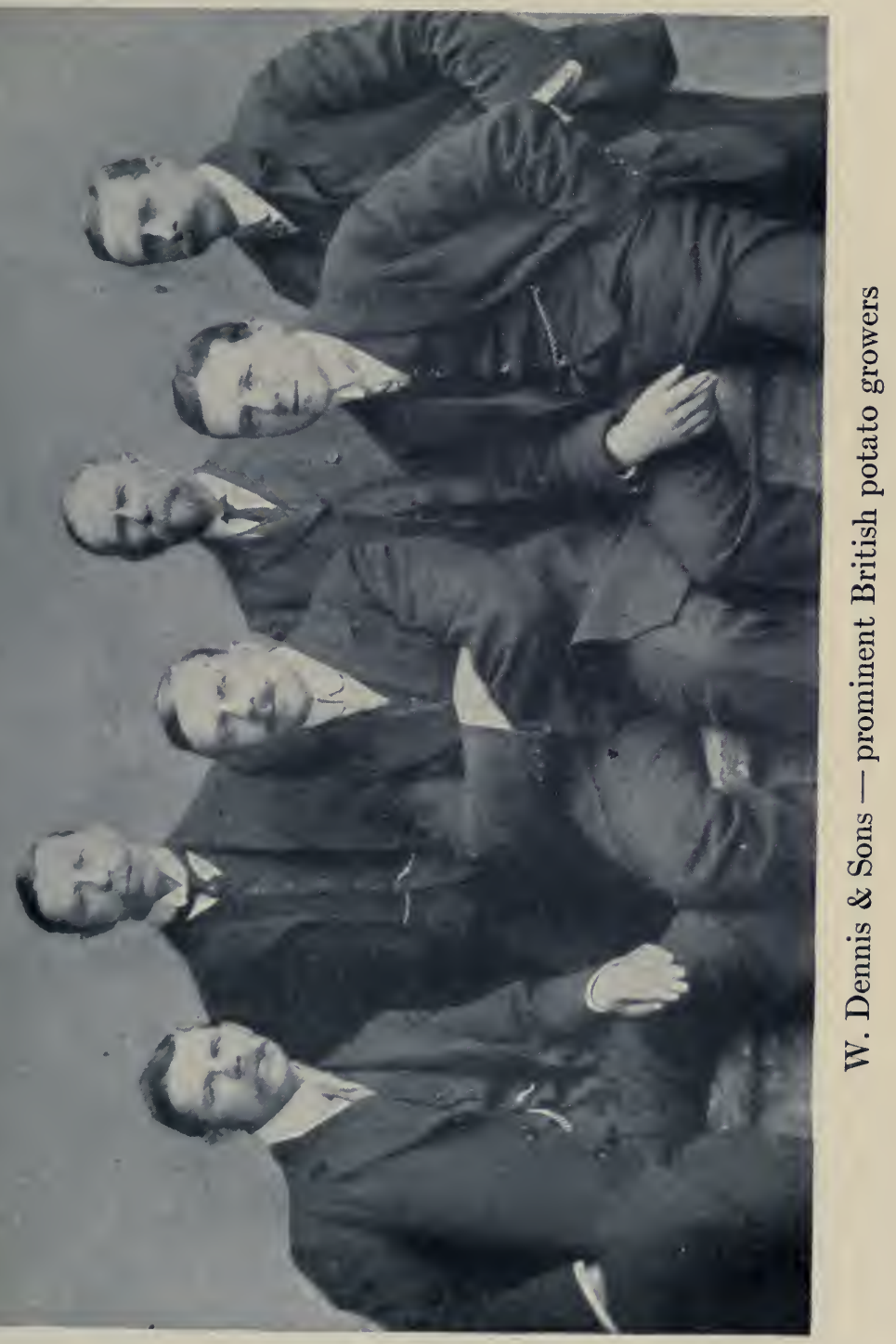




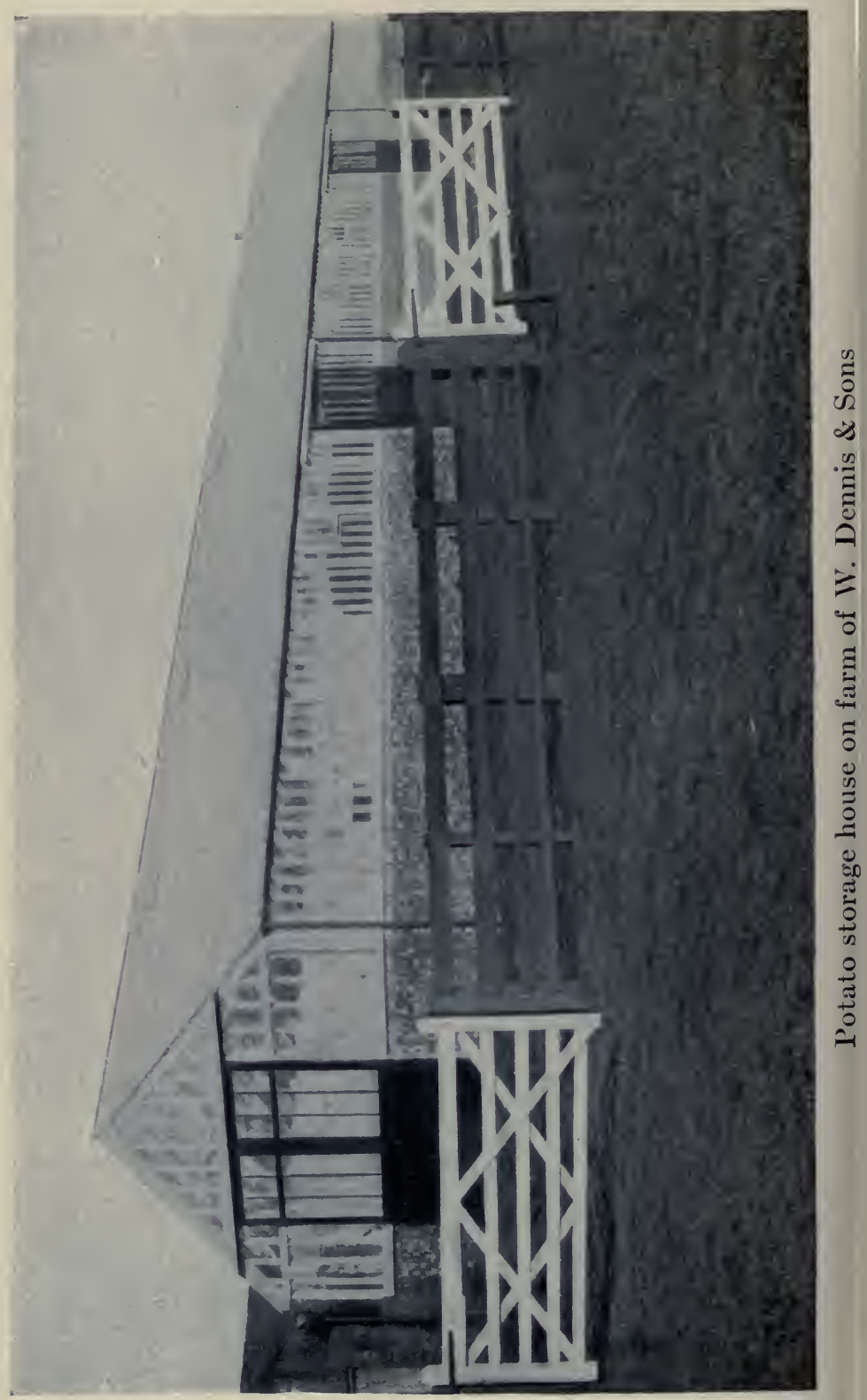


sells for more than plowed or arable land, and it is quite impossible to lease it for the purpose of breaking it up. They run six 1,200-pound bullocks to four acres, always give them a bit of oil cake, and never graze too close.

The older Mr. Dennis tells me that their success, prosperity, and accumulations are all directly due to potato growing, and corroborates the statement that I have made continuously whenever I talk potatoes, that potato growing when given proper attention returns more revenue for capital and labor invested than any other crop.

The Lincolnshire district has used whole seed potatoes for upward of forty years, and their prosperity is largely due to this using of good, sound whole seed, as against cutting the tubers for seed pieces.

Dennis and Sons are also the pioneers in the most successful methods of storing their seed potatoes. They use glass storehouses, and have five on their farms. They are $160 \times 24$ feet and the walls are twelve feet high. The lower six feet of wall is of brick, and the upper six of glass. The roof is all glass. They give the appearance of conservatories or greenhouses. They cost $\$ 2,250$ each and store 200 tons of seed potatoes in crates, giving a total storage capacity of 1,000 tons annually. The balance of their seed stocks is shipped from the north of Scotland. They are large importers of seed.

Mr. Dennis says that no matter how perfect every condition of potato work is made, if seed stock is not perfect, of high germinating power, free from disease, and planted uncut, the grower will lose.

Their home-grown seed is one and three fourths 
to one and seven eighths inches in diameter, but when they buy Scotch seed, the Scotch seed grower furnishes larger sized seed. Their seed stocks are largely selected from the market crops that run through a one and seven eighths inch mesh. They are selected in the field and are immediately put in crates or storage boxes about three inches deep, and stacked up in the open air as long as safe from frost or freezing weather, which is usually about the middle of October. Then they are stored in their glass storage houses for the winter.

Two days before my arrival at Mr. Dennis's, Monday evening, they had sprayed a forty-acre field of May Queen for leaf blight. These were early potatoes they expected to harvest the following week for market. When late that evening they discovered indication of leaf blight, they knew the spraying had been delayed two days too long. That night arrangements were made for thirty or forty men to commence pulling the tops in the early morning. This keeps the disease from attacking the tubers. The potatoes were not much more than half grown. In two days' time the tops had been pulled from this field and thrown in neat winrows. The rest of the crop would be left in the ground for twenty days, then lifted and put in boxes and kept in the open until danger of frosts, then stored for seed. They were too green for market, but would make good seed. To a potato 'grower of the sunny irrigated West this fungous blight in its rapidity of development is frightening, as in three or four days 50 per cent. of the tubers will be diseased. They will have great brown spots, looking like brown blisters. These potatoes had been sprayed some two or three 
times previous, but the weather conditions (continuous cloudy, sunless, rainy weather) made the disease hard to combat. Had the temperatures been high, it would have been a terrible disaster to the British potato industry. The early growing sorts are more susceptible than the more hardy main crops. When the disease strikes a district it spreads with the fierceness of a prairie fire. It is one of the very great problems to contend with where there is such a rank, rapid growth of vegetation. I am inclined to think there is greater danger from their very close planting. The thick, dense foliage completely shades the lower leaves and soil from the little bit of sun that they do have.

As everywhere else in Great Britain, they rely. on barnyard manure, with occasional crops of clover, for humus. The idea is to keep as great an acreage in potatoes as possible and yet keep up their yields and freedom from disease. About one third of their arable lands are kept in potatoes, or potatoes two years out of six, with clover and other grasses one year; and for the other three years wheat, oats, barley, white mustard, mangels, and Swedes for their cattle. I saw some good fields that had grown potatoes twelve years out of eighteen, and one farm that had been in potatoes twelve consecutive years. Here the land was fall plowed as deep as their big three-horse Shire teams with present style plows could turn it. They often plow twice between crops. When this is done one of the plowings will be shallow.

For early potatoes they thoroughly harrow and lay out their lands. The rows are twenty-five inches apart, hills twelve inches apart in the row. Late potatoes are planted $27 \times 14$ inches, and in the fens or peat land, $30 \times 12$ inches. Their peat 
soil is so loose and light that it does not hold its form in ridging so well, so they plant wide to give more soil for better ridging. Up to the present time this soil has required no nitrate of soda or nitrogen, but requires phosphates, lime, and potash.

Whole seed with green sprouts one half inch long are placed in the furrow by women and children. They use light, one-horse cultivators, and practise what we would call shallow cultivation. They depend largely on hand hoeing and hand weeding. It seems to be the only system in the close rows, and these close rows and close planting are very important factors in the large yields in Europe as compared to our small yields in America, where we plant in rows three to four feet wide with hills fifteen to twenty-four inches apart, producing a few large, rough potatoes in a hill and a small number of bushels to the acre.

They spray two to five times per season for blight at an expense of $\$ 2.50$ an acre per spray. Sutton's Epicure is producing nine tons of salable potatoes per acre this 19th day of July (1910) at $\$ 15$ a ton net. They would get thirteen tons matured thirty days later at $\$ 10$ a ton. Their method of harvesting would be very primitive and crude to our potato growers with improved machinery in the United States. Boys and girls first pull the tops in two rows and throw the tops on harvested land. Then the potatoes that were pulled out with the tops are picked up from the surface and the balance are plowed out with oldfashioned shovel plows with rod attachments. Then the potatoes that lay on the surface are picked up by women, boys and girls and carried to a point where they are being sacked. The land is then harrowed twice and picked over again, so 
they will get any potatoes that have been covered up by the inefficiency of the crude digger they have been using. They are thrown into a round sieve thirty inches in diameter that sets on another sieve, and this on top of an empty barrel. The top sieve has a three fourths inch mesh. A man shakes this sieve and the potatoes that do not go through this sieve are pitched into a sack held by a sack-holder. The lower sieve holds the very small potatoes for stock feed. It takes a big, strong man to do this all day. All potatoes over a three fourths inch mesh are marketed as early potatoes. Sacks weigh 112 pounds net. English laws do not allow the weighing of a package or a sack in marketing, as is the custom in America. They do have weigh bridges (scales) for potatoes if they do not for cattle. Every sack of potatoes is sold at the net weight at which it is filled at harvesting time.

The laborers pull the top, dig up and sort, sack, weigh and sew and winrow the tops, going over the field twice, for $\$ 10$ per acre, contract price. The boys and girls make 30 cents a day, the women 48 cents, and men $\$ 1$. All board themselves.

The main or late crop is harvested and handled the same way, and goes direct to market. Those that are stored for late market are put in pits or piled upon the ground six or seven feet wide at the base and coned up at an angle of forty-five degrees. As the weather gets colder they are thatched with straw and dirt is added.

On this farm an economical plan is just being worked out. It is a narrow gauge railway that goes around the outside of a 1,000-acre farm and once through the centre, running to the storage house and railway shipping station. When the 
potatoes are harvested they are pitted or stored alongside this railway. They call these pits "clamps." There are 600 acres of potatoes on this farm that will be harvested and stored in this way, making a pit three miles long. They expect ten tons to the acre, making 6,000 tons of potatoes.

The carting of potatoes in this level peat soil is often quite impossible when they have excessive rain.

Land values in Lincolnshire have changed very greatly in forty years. They are about the same values now as in 1870 . Then Mr. Dennis paid $\$ 500$ per acre for his first purchase. He pointed out to me a 100 -acre farm for which $\$ 500$ an acre was refused in 1870. It was sold in 1908 for $\$ 275$ an acre. Since 1870 the lands that sold as low as $\$ 175$ to $\$ 300$ an acre are bringing from $\$ 400$ to $\$ 500$ an acre.

These lands are now producing up to fifty-six bushels of wheat to the acre, with a general average of a series of years of forty-five bushels. It weighs sixty-three pounds to the bushel. Oats produce up to eighty bushels, weighing forty-two pounds to the bushel. The general average is sixty bushels to the acre. A great deal of the grain of 1909 is still in the stacks unthreshed. They do not thresh their grain until they need the straw. It is kept in thatched stacks instead of in warehouses.

- Growing white mustard is a very profitable industry and it serves as a good change of crops for soils. It often returns $\$ 60$ an acre with very little expense.

A very interesting visit was made to Titus Kime, Marham-le-Fen, Boston, Lincolnshire. In a letter to E. H. Grubb in July, 1911, he gives many facts 


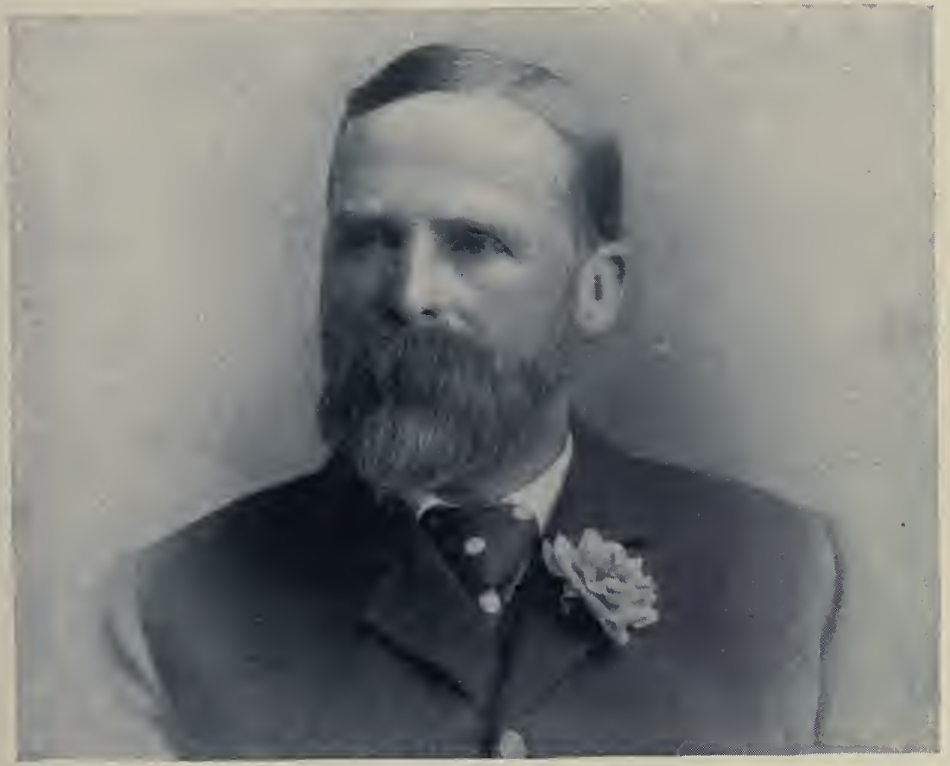

TITUS KIME

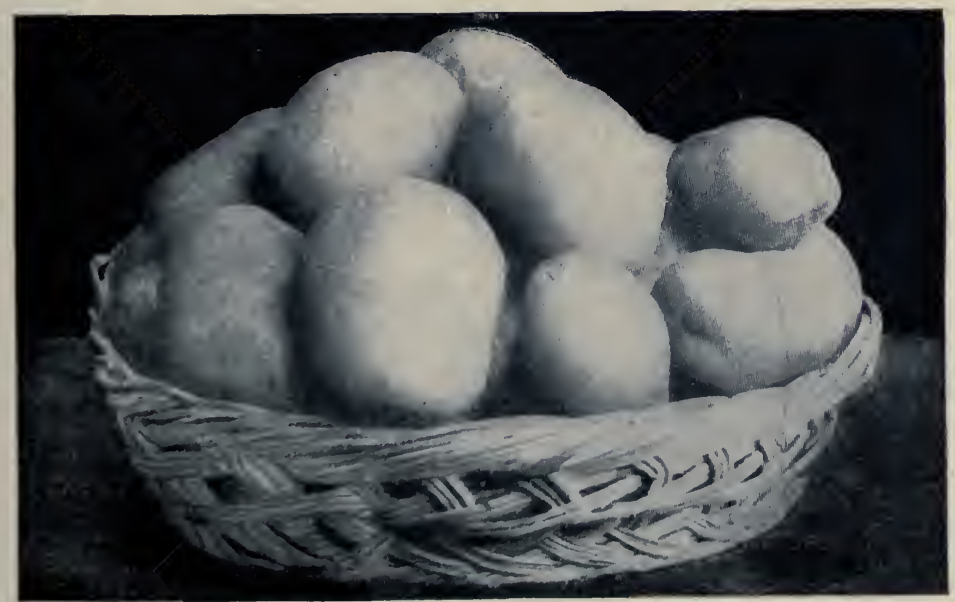

Northern Star potatoes grown by Titus Kime 

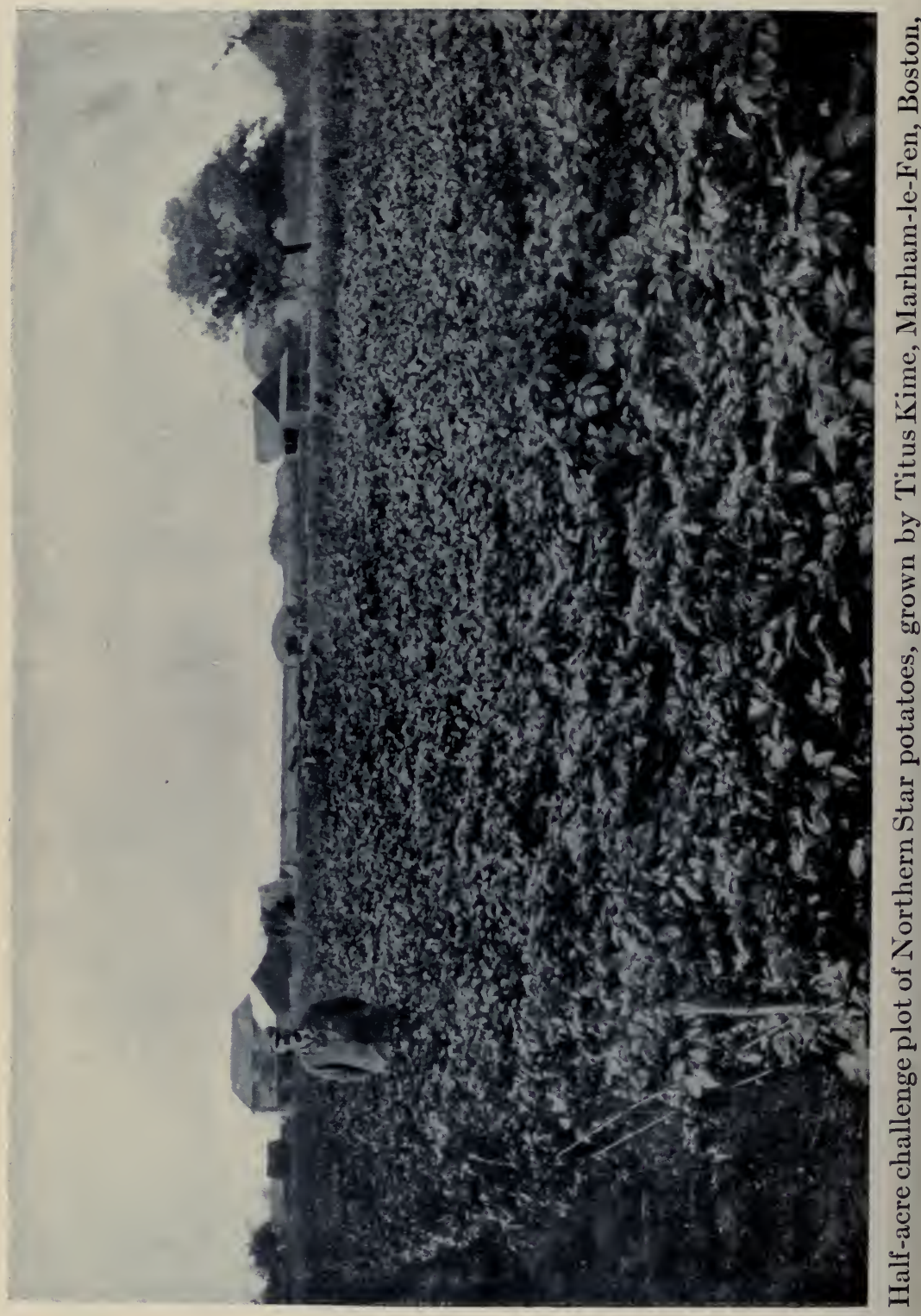

2

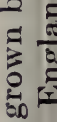

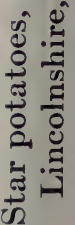

है

4

음 
about his potato and hog business. Extracts from the letter follow:

"This has been the earliest season for potatoes ever known in our neighborhood (Lincolnshire) since we began to send early potatoes in quantity to market. June 11th was the earliest day previously we have ever sent tons to market. This year I sent away on June 6th and 7th three tons twelve hundredweight of Early Puritans (this is an American variety) and they realized exactly $£ 50$ English money (\$250) gross.

"On June 12th I got away a few Eclipse and realized a very good price, and on June 15 th I began to dig Eclipse with a good gang of diggers and pickers. And about these I must tell you a little history which I hope will interest you. On July 26, 1910, I bought two fields of land here near the woods and very poor indeed - well known as being the poorest land in the parish. Perhaps you do not know the old English saying, 'If you want to take land go near the church and far from the wood.' These two fields have an area of exactly fourteen acres. They cost $£ 18(\$ 90)$ per acre; this is, £252 ( $\$ 1,260)$.

"Now perhaps you will excuse me from boasting, but I had potatoes well started in boxes - Eclipse was the kind - and planted on these fields in March. This land is very light, and, as I said, very poor, and I wanted to get it cleared up as early as possible to sow for turnips, as getting a crop of turnips eaten off poor land succeeds splendidly here, makes us sure of a good grain crop (barley or oats) the following year, or, we can take another crop of potatoes. Well, I succeeded in getting all the potatoes off of that field 'green,' as 
we call it, and the land is now ready all in good time for the growing of turnips for this season, with every prospect of a good crop, and the potatoes have realized $£ 276(\$ 1,380)$ - that is more than the purchase price of the land and I am very much pleased and rather proud of the result.

"The cultivation was quite expensive. The field, after barley, had fifty tons of good cowyard manure made under cover and a good deal from feeding linseed and cotton cake, put on before being plowed. Then four hundredweight per acre of kainit was sown broadcast on top of the plowing, and after being ridged ready for planting six hundredweight of Peruvian guano was sown down the ridges, and after the potatoes were well up one hundredweight of nitrate of soda was sown straight down the rows.

"The other field had no cowyard manure, but four hundredweight of kainit per acre was sown broadcast after plowing and then one ton of shoddy waste manure per acre was thrown on and pretty well spread. After ridging ready for potato planting we sowed ten hundredweight per acre of a compound potato manure, analyzing about 4 per cent. ammonia, $3 \frac{1}{2}$ per cent. potash, and 25 per cent. soluble phosphate, and after the potatoes were well up and about ready for ridging up we sowed one hundredweight nitrate of soda straight down the rows.

"You will see from the above that both fields were pretty liberally manured and the crops paid for it, because I find if we mean to dig potatoes early (and every day's delay makes a difference in price) we must be liberal with manure in order to force them along.

"I have about forty kinds of new and old po- 
tatoes this year, and among the new ones perhaps two or three are showing some very good points. One tuber I got from America I am afraid will be of no use here. It has a pale green haulm with white flowers and much too floriferous for a new potato.

"I have two tubers growing which were sent to me by a firm in Scotland, asking me to plant them both whole. I did so, one yard apart, and these two rows make a fine picture. The haulm is splendid, and although the tubers were, as I say, planted three feet apart, the haulms met on July 1st.

"On the other hand, just lately, I had the pleasure of paying $\$ 37.40$ for a few of the new kind that I am afraid are not worth 7 pence-ha'penny. Early Puritan, Duke of York, Sharp's Express, and Eclipse are the best early for earliest market purposes, and the grand old Up-to-Date is still the best main crop we have, but Ever Good, Royal Kidney, and Northern Star are largely grown for main crop in Lincolnshire. The finest quality of all for eating is the old Clarke main crop, now grown under many other names, such as Langworthy, East Anglian, etc. This potato grows well and produces a fairly good yield on good potato land, but on naturally poor land, no matter how well it is manured, it will not do so well.

"My potatoes this year I think look as well as I have ever had them. I have about thirty acres of Eclipse growing from seed direct from Scotland, and I think if you saw them you would say they are a grand sight.

"As to pigs, I still keep my usual quantity, 120 to 150 , and $\mathrm{I}$ am always breeding and always feeding all the year round. I am a member of the 
Lincolnshire Curly-Coated Pig Breeders' Association, but I get up no pigs for showing and make no fancy prices. My pig business is principally feeding. The last two years, when prices have been good, I have sent away on an average of twenty fat pigs, weighing about twenty stone (280 pounds) each, live weight, every six weeks.

"I feed all my waste potatoes to the pigs. I have a boiler which holds about 350 pounds of potatoes, and when we have plenty of waste potatoes, or our ordinary potatoes are making anything under 40 shillings per ton, we cook on an average of nine hundredweight per day. In my valuation I put all waste potatoes down at 15 shillings $(\$ 3.60)$ per ton, but I do not sell any under 20 shillings ( $\$ 4.80)$ per ton.

"As to meal, etc., for feeding pigs: When potatoes are plentiful, we cook liberal quantities and mix in a large cemented brick receptacle that will hold about 200 gallons. Say we shall throw into this about six hundredweight of potatoes and mix up with about four hundredweight of meal, one half barley meal and the other half wheat shorts. If the boiler is not freely employed cooking potatoes we fill up the time by cooking maize previously ground. This makes good food to mix in, and we consider cooked maize very good food for pigs. Also, if beans, peas, and wheat happen to be as cheap, or nearly as cheap, as barley, we grind them up pretty freely and mix with the barley meal. Barley meal, sold as barley meal, is well known to be often by no means ground from barley alone. If lentils or Indian grain are reasonable in price, all in moderation make excellent food for pigs, but sows that have just farrowed and which are suckling their pigs should have very 
little of any kind of meal except (where practicable) fine wheat shorts.

"It is a good plan to begin to feed the young pigs when about four weeks old, by themselves, on a little wheat and shorts mixed with skimmed milk, if you have it. As to the breeding sows, I keep mine now at less than half the cost I used to twenty years ago. I generally have about fifteen or sixteen brooding sows or gilts, and most of these run out summer and winter with the boar in a grass field. In this field they have about five acres to themselves and have rough sheds to lay in. We take them about four buckets - say, about ten gallons (perhaps twelve gallons) per day of slop made of meal and potatoes, and they get plenty of exercise picking up a living from the grass and a few rough roots such as very rough potatoes, mangles and waste grains of any kind when we have them. Sows and gilts in pig, in my opinion, require plenty of exercise and should only be shut up a few days before pigging."

After fully studying and investigating the Lincolnshire farm district, farm lands, livestock, grass, grazing, and potatoes, I cannot see wherein they have an earning capacity equal to the irrigated fertile lands that have a sufficient water supply, like Colorado, Idaho, Utah, and California. The latter exceed them in quantity and quality of everything produced., We (in the West) can and do grow more wheat, more grass, more oats, potatoes, and more hay, with a more healthful climate, and with all kinds of fruit. Lincolnshire is debarred from growing fruits. Above all, our continual summer sunshine enables us to harvest our crops without loss and in good 
condition when grown. I am safe in saying that these lands that are valued at $\$ 500$ an acre on their revenue-earning capacity have an earning ability of 50 per cent. less than good Western irrigated lands.

\section{SUMMARY}

The following practice of European potato growers should be of interest and value to American producers:

1. The use of deep-rooting grasses - rye grass, alfalfa, etc.

2. The use of large quantities of animal manures.

3. The use of immature, northern-grown seed.

4. The careful storage of seed stocks in triys.

5. Selection of seed to type and purity of varieties.

6. Close planting. 


\section{CHAPTER XXXVIII}

\section{THE CHANNEL ISLANDS}

7 TE first early open field grown potatoes of the season for the London markets are

1 from the Canary Islands, southwest of Spain. The next are from the Jersey Islands and arrive in London in April and May. Early potatoes that are marketed previous to that time are grown under glass in the Jersey and Guernsey Islands.

There are so many factors and features of potato work in Jersey that it is really hard to comprehend the magnitude of the industry. In round figures there are 19,000 acres of this fertile little island, of which about one half is cropped continuously in potatoes and has been for a long time, some of it for fifty consecutive years. By the most scientific methods and study they have not only maintained but gradually increased their high yields. All of the potato growers are breeders and growers of Jersey cattle.

A tenant who farms about sixty acres is the largest operator. He is a breeder of cattle, grows twenty-five acres of potatoes annually, and is the most up-to-date, money-making farmer on the island. He pays a rental of $\$ 60$ an acre annually. He values his low grazing land, too low for potato growing, at $\$ 35$ an acre a year for pasture.

The main portion of the crop is planted early in February and harvested in May and June. The 
price received is from $\$ 20$ to $\$ 100$ per ton. The market is very changeable, often varying as much as \$20 a ton in a day, according to the supplies in the London market. They get an average yield on the island of 425 bushels to the acre, but many of these potatoes are sold when only partly grown. A maximum yield of 750 bushels to the acre is considered about the limit for matured potatoes per acre.

They plant very closely. The rows are sixteen inches apart, the hills. twelve inches apart in the row. The potatoes are ridged with hand plows. It is necessary to use hand power in cultivation because the potatoes are planted so close together. They can grow a large number of hills per acre, on account of the great amount of concentrated fertilizer applied to the land.

Only one variety of potato is grown. This is known as the Royal Jersey. It is kidney-shaped and is the smoothest potato I have ever seen. No one seems to know the origin of it, but it is thought that it comes from seed stocks shipped in years ago. It surely would be an acquisition to have a shipment of these potatoes come to the United States, to have them experimented with in the early potato districts. The variety does not seem to be grown any place except on this island.

This calls to mind the wart, or black scab, disease of potatoes. These shrewd islanders are a very careful, exacting class of people in all of their affairs. For a great many years they have not allowed the importation of any livestock, not even for slaughtering on the day of arrival. For this reason infectious or contagious diseases of cattle have never been known on the island. On first 


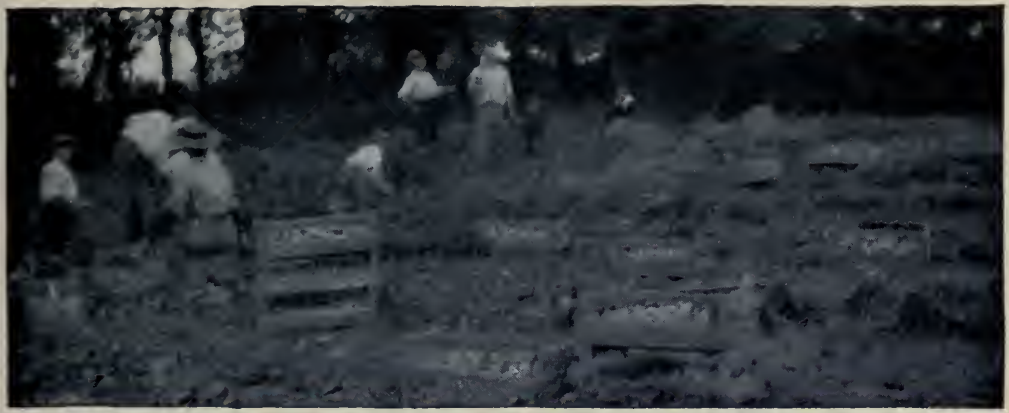

Harvesting early potatoes on the Island of Jersey

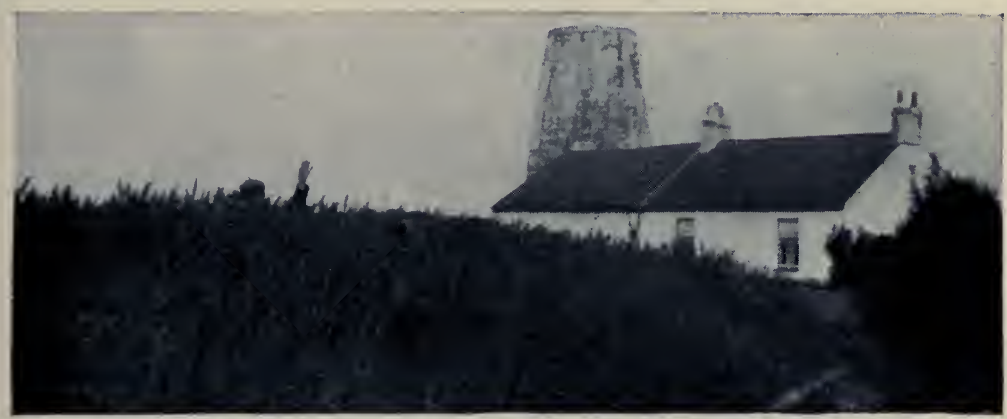

Oats on the Island of Jersey. The senior author is standing in the field and holding up his hand

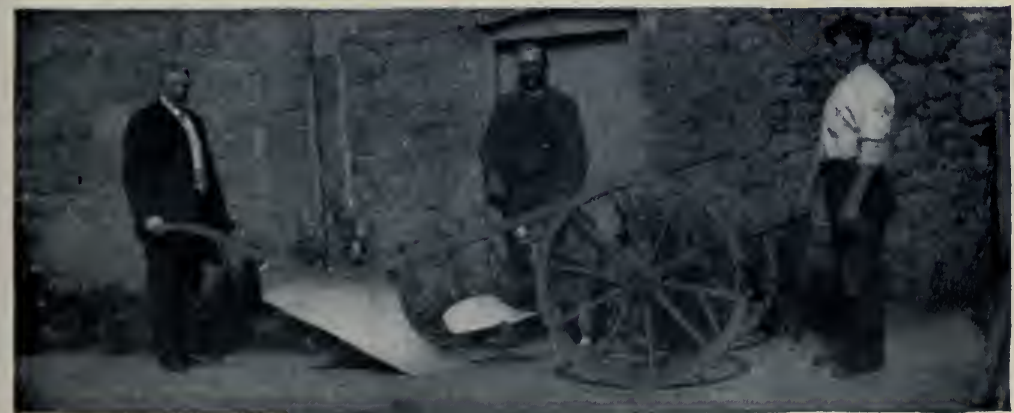

Plow for very deep plowing. Used on Island of Jersey 


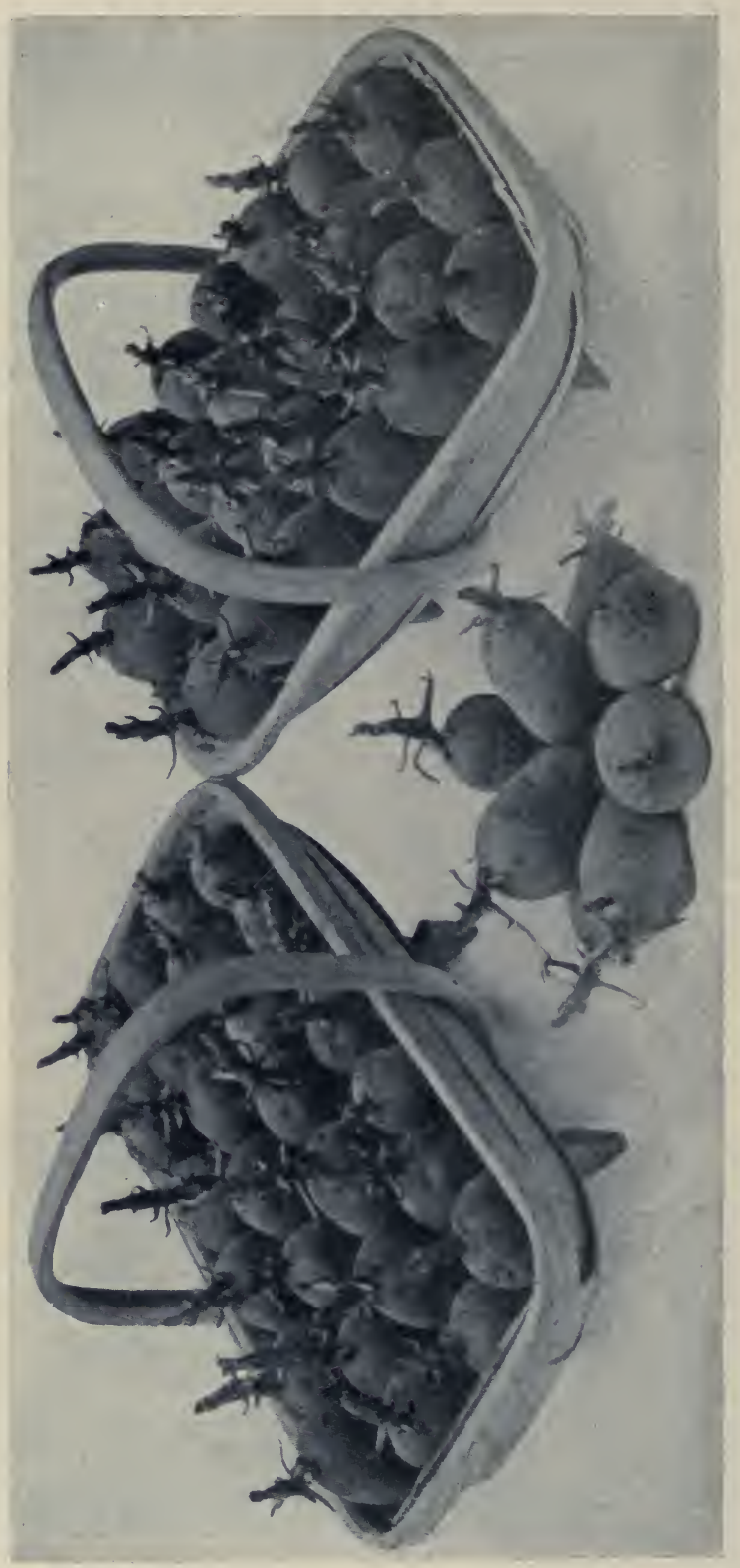

点

品

क्ष

.

三

की

世 थ

च

웅

घี

$\stackrel{0}{+}$

유유

$\frac{2}{n} \cdot \frac{n}{1}$

융

웅

믕

$\rightarrow$

응

栲

on

듕

$\pm$

जิ

4

듕

긴

Е

.7 8

․․․

ह

E 
information of the dread wart disease of potatoes the parliament of the island (which has home rule) quarantined Great Britain against sending any potatoes into the island. They are not even allowed to be brought in for table use. This shows how they protect their most important moneymaking industry. Our national Congress could well pattern after this in the protection of the American farmer and potato grower.

The revenue derived from potatoes per acre is sometimes quite fabulous 'when they get an early crop. They are subject to spring frosts in March, which checks the growth as much as three weeks. One farmer told me he lost $\$ 8,000$ by frost in one morning. The crop often brings as much as $\$ 400$ and $\$ 500$ an acre. One grower received $\$ 2,090$ on one and three fourths acres of the land. This is a remarkable little block of warm, sandy soil, encircled by a stone wall to shelter it from the winds, and sloping to the south at an angle of almost forty degrees. I think it is the finest piece of land that I have ever seen cropped. He took the chances of planting them very early, used an excessive amount of fertilizer, and well-sprouted seed, planted whole. He harvested and shipped them in one day, when the London market was bare of potatoes. This land will readily rent for $\$ 250$ an acre, as it is the earliest piece of land on the island. I saw one twelve-acre farm that rents for $\$ 140$ an acre. In recent years this land, which produces the early crop, has appreciated very much in market value. It is now valued at from $\$ 1,000$ to $\$ 2,500$ an acre. I heard of many small tracts that are being rented at from $\$ 75$ to $\$ 175$ an acre. No wonder that this 19,000 acres of arable land supports a population of 55,000 and 
over, 20,000 domestic farm animals, or three people and one domestic farm animal per acre.

I saw meadow grass - a combination of nearly all of the legumes and other grasses - being harvested. It gave a yield at one cutting of five tons to the acre (2,240 pounds to the ton).

Following this is a second crop to be grazed off by the cattle for fall and winter pasture. This is the result of feeding the soil with liquid manure from the cow barns. It is sprinkled over the meadows from time to time with an apparatus something like a street sprinkler. If this land is kept in grass, say, for three years, it will grow potatoes continuously, year after year, almost indefinitely. Potatoes are often followed with tomatoes. I saw one ten-acre tract the potatoes from which had been harvested in May. On the 6th of July 13,500 tomato plants per acre were in bloom and setting tomatoes. They would give $\$ 600$ to $\$ 700$ an acre as a second crop. Often, after the potatoes are harvested, the land is immediately sown to Italian rye grass for the cows. This gives them the turf and splendid root system of the rye grass to feed the land for the next year's potato crop.

I saw this big sixty-acre farmer, the sixth of July, digging, sorting and putting away his seed for the next year's cropping. The potatoes were lifted by hand with forks; women were picking out by hand the most perfect potatoes for seed stocks and placing them in boxes to be stored in their stone storage houses. They were put in boxes about three inches deep, and were sorted to size. Nothing is wasted on the Jersey Islands. A potato no larger than a hazel-nut is picked up and used for something. 
Three bushels of corn (it looks like American corn) were sown over the field before the potatoes were dug so that the digging of the potatoes would cover the seed three or four inches deep. This grows and is used for pasture and forage for cattle and horses. It is also an aid in feeding the land as a cover crop for the next year's potato growing. They did not lose one hour's time in the use of the land. This corn would be up in four or five days and making rapid growth.

The soil is a disintegrated granite formation.

Sometimes immediately after harvesting the potatoes they sow the land down to rye grasis and clover, and leave it two years. They use it for hay and grazing, sometimes both. The first year after breaking sod they use no barnyard manure; the second and third years they use all the barnyard manure they can secure, twenty-five or thirty tons if possible, with a ton of commercial fertilizer additional to the acre.

They usually spray two to five times during the growing season. The best farmers always spray five times, and they always secure a full crop. I saw two fields adjoining. The conditions were the same. One was sprayed five times and the owner expected a yield of thirteen tons to the acre or more, while the field alongside, sprayed twice, was completely burned up with blight. There was nothing but the black stalks left standing. It costs about $\$ 1.25$ to spray each time, and the work is always done by hand, as they cannot use horses in their closely planted fields.

Their system of using partially grown seed is practically the same as in the early potato-growing districts of England and Scotland. Saving seed in June for the next year's planting is a very 
serious problem. It must be held over during their warm months of summer and fall, and sprouting retarded so as to have the seed in good condition for planting the next February.

Owing to their close planting they require from 3,000 to 4,000 pounds of seed to the acre. They never cut seed.

These potato growers were very much excited on reading the Orchard Heating Bulletin, published by D. E. Burley, general passenger agent of the Oregon Short Line Railroad. This bulletin tells how fruit is saved from frost by the use of heating pots in the orchard. They think frost protection will be very valuable in enabling them to put their potatoes on the city markets of Europe two to four weeks earlier than they ever have before.

I hope to see their great money-making methods for the production of early potatoes adopted in the Sacramento Valley and elsewhere in California. The days of sunshine here are much more favorable for the crop than the chilly winds off the sea on the Jersey Islands, where in the month of July I was not uncomfortable with winter clothing, and where I saw many people wearing their coats in the middle of the day.

The unit of weight which is used in the marketing of farm crops in Jersey is known as the cabot. This is forty pounds. Their potatoes are marketed in willow baskets or small barrels. The potatoes are sold to the dealers in willow baskets. The dealer barrels them. It takes a quarter of a million barrels to handle the potatoes of this little island. The barrels are returned from the markets daily.

There are large numbers of glass houses for grow- 
ing vegetables and crops of all kinds. This gives winter employment and income.

The amount of wheat and oats that grows on this granite soil is wonderful. Much of it was higher than my head and very thick on the ground, and there was not one place where the straw was weak enough to make it lodge. It had the strongest, stiffest straw I have ever seen. They told me the wheat would give an average of sixty-nine bushels to the acre. It did surely look as though no more could grow on an acre, and I have seen upward of seventy-five bushels in the irrigated West.

Referring again to the fertilizing, the Agricultural Society of the island gives prizes for the best conducted and appointed farm. The first requisite in the scale of points, in a total of sixty, is farm buildings, manure and liquid manure tank, five points; if neat and compact, five additional points. There are eighteen other factors for consideration in awarding the prize.

Shiploads of guano and commercial fetilizer are imported and used; great quantities of turf, roots, and cover crops are incorporated in the soil, and every bit of animal manure is conserved. Manure is used at the rate of twenty to twenty-five tons when they have it. That does not mean sticks, fire fanged, coarse manure and straw, but well-rotted barnyard manure which has the consistency of well-ripened sugar-beet pulp.

Their humid, cloudy, sunless climate makes a splendid environment for disease such as blight.

As a plow maker I have contended that it was nearly impossible to make a moldboard plow that would do good work over twelve inches deep, but on the Jersey Island I saw moldboard plows that 
plowed an eleven-inch furrow, eighteen inches deep and turned it well. The moldboard was twentysix inches deep, with a strong steel beam and a pair of ordinary wagon wheels for a front truck to regulate the width and depth of the furrow. It required ten heavy horses to handle it with the turf and manure that was plowed under. A farmer can imagine what a nest or bed this aerated, fertilized soil would make for the root system of the potato or any other vegetable crop. It also makes a fine storehouse for moisture and heat.

On one farm the crop of potatoes from ten acres sold for $\$ 10,450$. Of course, this was a very extreme case, for the potatoes sold for eight cents a pound, or $\$ 180$ a ton. The man farming this land said it would readily rent for $\$ 250$ an acre on nineteen-year leasehold. The man who gave me this information is a leading representative tenant farmer. He told me that he made annually 180 barrels of apple cider and consumed it all on the farm. When he saw me drawing a long breath he led me to the storage cellar and I saw the tanks. He said there was no other beverage used on the farm for his family or help, and I saw great pitchers and mugs of it in the fields where he had thirty men at work.

A great deal of labor is imported from France during potato harvest, the total annual outlay for this item being $\$ 75,000$ to $\$ 90,000$.

The following very interesting account of the Channel Islands potato industry is from "Pictorial Practical Potato Growing," by Walter P. Wright and Edward J. Castle•

"The Channel Islands, as being British territory, and supplying us with our first early 
potatoes in bulk, are entitled to a little consideration here. Guernsey and Jersey are the chief islands concerned in the potato trade, the bulk of the Guernsey crop being raised under glass. Jersey has also taken up glass culture to some extent, but still relies almost solely upon outdoor crops. These are grown everywhere - by roadsides, on railway platform gardens, on the slopes of valleys so steep that one wonders how the soil keeps in position, and even up to the very walls of Jersey's most famous 'lion,' Mount Orgueil Castle.

"Digging begins in the more favored parts, such as L'Etac and St. Aubyn's, at the end of April, an army of Breton peasants, with their wives and families, being imported for the purpose. The potatoes are packed in barrels, and taken to the one Jersey port, St. Heliers, whence they are shipped to England. Prices fluctuate enormously even in a single day, but the returns have averaged some $£ 400,000$ ( $\$ 2,000,000)$ for several years past. The variety grown is the old International Kidney, raised nearly forty years ago by Mr. Robert Fenn, and in its day the leading exhibition variety." 


\section{CHAPTER XXXIX}

\section{IRELAND}

$\mathrm{H}$

ISTORY is responsible for the statement that the first potatoes grown in Great Britain were planted in Ireland, near Cork. The name "Irish Potato" has come into universal use and many believe the tuber to have originated there.

The potato has for generations been one of the principal foods of the Irish peasant, and at the present time potato growing and all other branches of Irish agriculture are receiving great attention. One of the world's best agriculturists, Professor Campbell, is doing a wonderful work in advancing the farming interests of Ireland.

In another chapter considerable history and data concerning Irish potato conditions are given. As stated there, the future of the Irish early potato seems particularly bright. In "Leaflet 19" of the Department of Agriculture and Technical Instruction for Ireland, issued from Dublin, is the following:

"The cultivation of potatoes for the early market is undoubtedly one of the most profitable branches of agriculture, provided the produce can be put on the market at the beginning of the season while high prices still obtain. In May phenomenally high prices are procurable; any time in June the price is usually good enough to insure hand- 
some profits; the first half of July is, as a rule, better than the ordinary late or main crop, and the latter half of July as good as winter marketing.

"With the advent of August, prices often fall to a very low point, and the risk of disease being very great, only those growers who are in favored positions as respects markets and freightage can succeed. It should be borne in mind that the cost of production is much greater than in the case of the late crop, and unless several pounds sterling per acre more is received for the early crop it is not profitable. Within the last twenty years great developments have taken place in this industry. Foreign countries have participated in a trade which was thought impossible to them, and in our own country the crop has been greatly accelerated.

"The season oprens in April with potatoes from Malta and Teneriffe. In May great quantities are poured into our markets from Jersey and Côtes du Nord, France. Strangely enough, the next place in point of earliness is a strip of seaboard, on the west coast of Scotland, where for fifty miles in Ayrshire and Wigtonshire the Gulf Stream exercises a beneficent influence directly through the North Channel, and renders that district singularly immune from spring and May frosts. The Ayrshire season commences generally about the middle of June. Good crops ready to raise at that date are worth $£ 40$ per statute acre, and are sold growing to merchants, who take all further risks and bear the expense of raising, the farmer having no more to do except cart the potatoes to the nearest station.

"Ireland's share in this lucrative industry has hitherto been small, although her physical conditions are extremely favorable. It would not 
be possible to approach the earliness of the Channel Islands, but what can be done in Scotland may assuredly be improved upon in Cork and Kerry, subject to the same ameliorating influences in even greater degree, 200 miles farther south, and possessing ideal soil.

"The east coast of Ireland does not enjoy so mild a climate, but whatever is lacking in that respect is compensated for by contiguity to markets and greater facilities for intensive farming.

"Early potato growing has long been practised in County Dublin, and at one time Scotch markets were largely supplied from there. Even now it is perfectly wonderful what has been achieved at Rush, by a race of shrewd and hardy men, whose ceaseless and laborious industry deserves a better reward. By the adoption of some of the new methods for accelerating the crop they can in some measure recover their lost supremacy, and Ireland generally may to a very large extent participate in the extremely profitable industry of supplying England with early potatoes." 


\section{CHAPTER XI}

CONTINENT OF EUROPE

$\triangle S$ WILL be seen by the graphic map of the world in Chapter I, the aggregate potato 1 production of the countries on the continent of Europe is enormous.

During his European trip in the interest of American potato growers, the senior author spent considerable time in France and Germany and is indebted to Consul-General Frank M. Mason, Paris; Robert P. Skinner, Consul-General, Hamburg; Lutten \& Son, commission merchants, Hamburg; and Baron Kriesheim of Bariskow, for many courtesies and kindnesses.

The manufacture of starch, flour, alcohol, and other products has been developed extensively in some districts. This is described more fully in the chapter on manufactures.

In a report of Consul-General Robert P. Skinner of Hamburg the following facts about the situation in Germany are given:

"A number of causes have combined to bring about the immense German potato crop, which has apparently reached the limit of profitableness, as, in spite of the efforts of the German Government to encourage the industrial use of potatoes, only 4 per cent. of the total crop is taken up for the manufacture of starch and its by-products, and 8 per cent. for the distillation of alcohol. Thus the 
chief demand for potatoes remains the ordinary consuming market, which, because of climatic conditions, looks to a number of foreign countries for considerable quantities of early varieties. There are in this country immense areas of poor agricultural land which yield fairly well when planted with potatoes, and as the crop is valuable for rotation purposes, and the table demand probably greater, relatively, in Germany than in any other country, and the industrial applications numerous, the succeeding years have seen the yield advance steadily to an average which now exceeds $45,000,000$ tons.

"The cultivation of potatoes is indirectly encouraged by the German Government, which confers special privileges upon farm distilleries consuming the products of the land. Consul-General Thackara, in his able report of October 3, 1908, has furnished valuable figures in regard to the production of potatoes and their uses. In respect to the agricultural distilleries, the Imperial Government permits them to produce a certain amount of grain or potato alcohol, the amount depending upon the size and the location of the farms and the annual demand for the product, upon the payment of a revenue tax of marks 1.05 (25 cents) instead of the usual tax of marks 1.25 (29.75) cents per litre. Alcohol distilled in excess of the quantum is subject to the higher rate of tax, and denatured alcohol is not subject to any tax at all. The slops are used for feeding and the refuse is returned to the land.

"At the present time over 200 varieties of potatoes are raised in this country, the most of which are used indifferently for all purposes. Naturally, such varieties as have a small content of water are 
best adapted for the production of alcohol. In some parts of Germany a mealy potato is popular, while in others the watery variety is preferred. The hard, mealy tubers are found to keep better through the winter than the others. A loose and not too heavy soil is preferably chosen for this culture, as in a heavy soil the crop is likely to deteriorate or become diseased. In the proximity of large cities farmers seek to raise favorite table varieties, and in the remote, and particularly the northern, portions of the country the crop goes to a large extent to the alcohol distilleries or starch factories, or to cattle feeding purposes. In portions of the empire where grain is a large crop potatoes are planted every fifth or sixth year. Cabbage also is raised for rotating purposes between wheat and rye, or other cereals. Should the demand for this vegetable be considerably increased there are large tracts of marsh and heath land in northern Germany which could be improved and made to yield potatoes in fair quantities.

"The success of the German farmer with potatoes has largely resulted from the necessity of securing an income from soil which could hardly be utilized for anything else, and upon such soils, in addition to stable manure, large quantities of industrial fertilizers are also applied. In connection with experiments made by order of the Director of the Botanical Garden of Hamburg, the following industrial fertilizers have been successfully used for the cultivation of potatoes:

Kainit. ...... 0.7 tons per hectare (2.47 acres)

Thomas meal.... 0.5 " " "

Chilean nitrate. . 0.3 " 0.3 
"The kainit and Thomas meal were applied in the fall and the nitrate was strewn in the spring. Instead of nitrate, sulphate of ammonia was also used. No mention is made of superphosphates as having been used in these experiments, although farmers employ them to a very large extent. Kainit is a mixture of sulphate of potash and sulphate of magnesia with variable proportions of chlorure of magnesium and marine salt. The useful substance in this combination is the potash which is represented by a proportion of 12.96 per 100. As the chlorure of magnesium is a salt destructive to vegetation, the use of raw kainit is not recommended. As a rule it is sold in prepared form after having been calcined, whereby the chlorure is eliminated.

"Thomas meal is a fertilizer made from basic slag. Concerning Chilean nitrate of soda it is scarcely necessary to speak. In respect to this fertilizer, C. V. Garola says that it is not an indispensable fertilizer, and need not be employed unless it furnishes a pound of azote at a cost inferior to that of other fertilizers containing azote, such as blood, horns, flesh, and, particularly, sulphate of ammonia.

"Mr. Garola, already quoted, in his 'Ten Years of Agricultural Experiments' says in regard to the effect of fertilizers upon the cultivation of potatoes: 'The potato is always very grateful for the manure that it receives. A strong manure, well prepared, is the first condition to a good crop. By using it to an extent of thirty tons (the author does not state over what area) I have obtained an increase of 88 per cent. in the yield; and a small dosing of manure, completed by super-phosphate and nitrate of soda, increased the crop by 105 per cent. 
This confirms what I have already recognized in regard to other crops - that is to say, that manure in moderate doses and with complementary fertilizers is more advantageous than a heavy fertilization of manure alone. The doses of phosphoric acid and potash should be increased in poor soils and diminished in rich soils. They should be buried before sowing. As to the manure, it should be turned under before the winter, if possible. Nitrate of soda should be spread at the time of harrowing.'

"This writer states that upon reduced surfaces he has obtained 550 quintals ( 5.5 tons) of potatoes per hectare (2.47 acres). The maximum yield observed upon a larger scale and upon surfaces of from 7 to 16 hectares ( 17.29 to 39.52 acres) was 410 quintals (4.1 tons). He considered a satisfactory yield, with proper cultivation, to be about 300 quintals (3 tons) per hectare ( 2.47 acres.)

"It is rather doubtful whether American potatoes can be sold profitably in Europe, or, at all events, in Germany, in spite of some rather optimistic discussion of the subject. Wholesale buyers can procure German potatoes to-day (December 22, 1910) at $\$ 2$ per 220 pounds for the 'egg' variety, and $\$ 1.52$ per 220 pounds for the 'Magnum Bonum' variety.

"(Prices on June 28, 1911, date of copy of this report, as follows: Egg potatoes sold out. At present 'long spring potatoes' are on sale and are worth $\$ 2.38$ to $\$ 2.62$ per 220 pounds. 'Magnum Bonum' scarce at present and worth $\$ 2.09$ per 220 pounds. - R. P. S).

"In order to sell American potatoes in Germany, it would be necessary to lay them down in New York at not more than the above figures, less the 
freight to Hamburg, for which my only quotation is 20 shillings (\$4.8665) per ton. It costs only 16 shillings (\$3.8928) per ton to ship German potatoes to America, and perhaps if American ships were available it would not cost 20 shillings to ship American potatoes to Germany, or Europe. From August 1st to February 14th foreign potatoes are admitted free into Germany, but at other times there is an import duty of 60 cents per 220 pounds.

"American potatoes offered for export to Germany, apparently, would not bring more, f.o.b. New York, than 28 cents per bushel of 60 pounds for the 'Magnum Bonum' and 41 cents for the 'egg' variety. The calculation stands as follows:

Price per 220 pounds in Hamburg

Less freight from New York to Hamburg (48 cents)

\section{Magnum Bonum}

$\$ 1.52$

1.04
Egg $\$ 2.00$

1.52

Net price in New York, converting price per 220 pounds into bushels of 60 pounds . . . . . . . . .

"With these figures before them, American correspondents can determine for themselves whether it will be possible to pay freight rates from farm to seaboard, and compete with the prices named. Statistics follow:

\section{Potatoes}

Total importations into Germany: 346,617 tons 329,417 tons From Belgium ............. 53,620 “

Gibraltar, Malta, Cyprus. . . 8,989

France $\ldots \ldots \ldots \ldots \ldots \ldots$. 9,349

Italy $\ldots \ldots \ldots \ldots \ldots \ldots \ldots \ldots, 26,454$

Netherlands.......... 163,311 “ “

Austria-Hungary ....... 16,592

European Russia

63,926

48,462

11,020

6,757

19,579

168,322

29,439

43,540 
Potatoes

1909

1908

Total exportationsfrom Germany: 124,442 tons 115,236 tons

To France.............. 2,120

Netherlands.......... 4,317

Norway ............. 4,931

Austria-Hungary $\ldots \ldots \ldots, \quad 62,969$

Sweden............. 10,108

Switzerland.......... 27,227

Brazil............. 3,078

United States of America.. 1,640

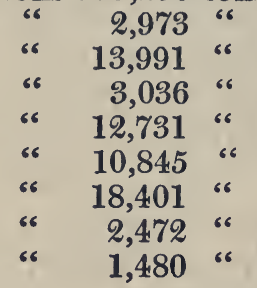

Production in Germany

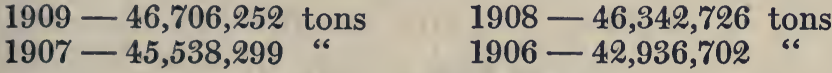

$1905-48,323,353$ tons.

Average wholesale prices in Germany: Cash for prompt delivery. (Per 1000 kilos, 2,200 pounds, exclusive bags):

\begin{tabular}{|c|c|c|c|}
\hline & $\begin{array}{l}\text { Good Early Red } \\
\text { Unassorted distilling }\end{array}$ & $\begin{array}{l}\text { Good Early Red } \\
\text { Sound assorted table }\end{array}$ & $\begin{array}{l}\text { Good sound Silesian } \\
\text { table potatoes }\end{array}$ \\
\hline & Mks. ${ }^{\text {Berlin }}$ & Mks. Berlin & Mks. \\
\hline 1905. & $36.50-\$ 8.69$ & $53.40-\$ 12.71$ & $50.40-\$ 12.00$ \\
\hline 1906. & $20.40-4.86$ & $34.60-8.23$ & $33.20-\quad 7.90$ \\
\hline 1907. & $29.90-7.12$ & $53.10-12.64$ & $40.60-$ \\
\hline 1908. & $32.60-7.76$ & $54.00-12.85$ & $37.70-$ \\
\hline 1909. & $31.80-7.57$ & $49.90-11.88$ & $40.70-$ \\
\hline
\end{tabular}

The market situation in France is given in a report by Consul-General Frank H. Mason of Paris under date of January 27, 1911:

"The shortage in the French potato crop has created a deficit which is being filled by large importations from other European countries, notably Great Britain, Austria, Germany, and Belgium.

"Importations of potatoes from the United States to France had been prohibited since the decree of 1875, which was inspired by fear of the Colorado 
potato bug, until that decree was annulled on October 15, 1910, opening the French markets to potatoes from the United States, provided they are clean, free from the soil in which they were grown, and the packages in which they are shipped contain no stems or leaves of the potato plant.

"As a result of this long prohibition American potatoes are practically unknown in France, and French importers have no acquaintance or established relations with American exporters which would enable the trade to be promptly taken up since the withdrawal of the prohibitory decree. Partly for this reason, and partly because many French people have still a lingering dread of some possible disease in American potatoes and do not even know that the prohibition against them has been withdrawn, they have not yet appeared in any appreciable quantity on the Paris market.

"Meanwhile several letters have been received at this consulate from American shippers who are prepared to offer potatoes to French importers. A careful investigation of the situation has been made, and the names of American exporters given to leading French commission merchants and dealers in potatoes, who have been thus enabled to send direct propositions to the parties who are seeking a market for American potatoes in France.

"The principal mart of the wholesale potato trade in Paris is at the great Central Markets (Les Halles) and the busy streets in their immediate neighborhood. The one recognized wholesale unit or weight or measure for potatoes is the metric quintal of 100 kilos, equal to 220 pounds avoirdupois, and American merchants seeking to find a market here should base their propositions on that unit instead of bushels, bags, or barrels. 


\section{THE POTATO}

"From the statements obtained by personal inquiry among the leading merchants in that line it appears that potatoes are now being delivered in wholesale quantities at 12 to 20 francs per 100 kilos (\$2.31 to $\$ 3.86$ per 220 pounds), according to quality. One firm pays as high as 22 francs $(\$ 4.24)$ for potatoes of the highest class, but this is exceptional and supplies only special and limited demands.

"The ruling price for imported potatoes of good average quality is about 15 francs (\$2.89) per 100 kilos, which would be approximately 82 cents per bushel of 60 pounds. The same potatoes are retailed in the groceries and provision stores throughout the city for about 5 to 6 cents per kilo ( $\$ 1.33$ to $\$ 1.60$ per bushel). Genuine red-skinned potatoes are preferred here, with the white next, and yellow lowest in order of preference.

"The general opinion of dealers is that toward the end of the winter, when the visible European supply is more nearly exhausted, prices of potatoes will be considerably higher than now, and large quantities are at present held in storage at the 'Halles' for this expected advance. New potatoes from Algiers and Tunis reach Paris in February, but they are a luxury, so high in price and so limited in quantity that they exercise little influence on the general potato market.

"Owing probably to the fact that potatoes have not hitherto figured among American exports to France, they are not included among the articles covered by the special arrangement of March, 1910, between the United States and French governments, and are therefore subject, when imported into this country, to the maximum duty of 6 francs per 100 kilos ( 32 cents per bushel) during the months of March, April, and May, and 
3 francs per 100 kilos (about 16 cents per bushel) if imported during the remaining nine months of the year. Potatoes from Great Britain, Belgium, Germany, Austria, and other nations which enjoy the minimum duty rates with France pay 3 francs duty per 100 kilos (16 cents per bushel) from March 1st to June 1st, and only 40 centimes per 100 kilos (or 2 cents per bushel) during the remainder of the year.

"As nearly all potatoes are imported here between June 1st and March 1st, the American product will have to meet this discrimination - an excess of nearly 14 cents duty per bushel above that paid on potatoes from European countries except Portugal.

"Among the offers which have been received here recently is one from an American shipper in Maine who quotes potatoes of high quality grown in that state at $\$ 1.75$ per sack containing 165 pounds, delivered at an American seaport on the Atlantic coast. This, converted into French equivalents, would be about 11 francs per 100 kilos. Adding the estimated freight charges and import duty, cartage and handling, would bring the cost of the potatoes, delivered in Paris, up to about 14.50 francs (or $\$ 2.80$ ) per 100 kilos. As already stated, potatoes at wholesale in the Paris market range from 12 to 20 francs per 100 kilos, according to quality.

"The only apparent chance, therefore, is for American exporters to offer potatoes of the highest grades, clean and free from leaves and stems, such as sell here now for from 17 to 20 francs per 100 kilos, and will undoubtedly be still dearer in late January and February. On account of the change of duty from March 1st, potatoes for France should 
be shipped, if possible, so as to arrive before that date.

"For the Paris market it would be preferable to have potatoes in sacks containing 100 kilos or 50 kilos each, to facilitate valuations and accounts under the French system. This, of course, is not strictly essential, but is an example of one of the wise things which exporters of an unknown article into a new market may judiciously do to 'make things easy for the purchaser.'

"It should be borne in mind that this is the first opportunity which exporters have had for thirtyfive years to offer American potatoes to French consumers. It is therefore worth while this winter, even at the cost of some trouble, to make a serious effort to enter the market here, to make known the high quality of American potatoes, and thus pave the way for an even more prosperous trade in future years.

"There will be a large demand in March for seed potatoes, and for this the best varieties of American origin, free from all taint of disease, should, if properly presented, be especially attractive to French dealers and farmers."

The senior author gives an account of his visit to Baron Kriesheim as describing a typical large estate where potatoes are an important crop. There are many such estates, and the bulk of the crop is probably grown by peasant farmers.

"I am very proud of this most distinguished honor of an American agriculturist coming to me for knowledge in farming," said the big-bodied, massive-brained Baron when he read the letters of introduction of the senior author at the time of his visit. 
The fine condition in which the grounds and parks around the castles in these great estates are kept is a marvel to an American farmer who is used to seeing more or less untidiness about the homes of some of our largest farmers.

The vocation of the wealthy German farmer is certainly alluring not only from the comforts it brings but the pleasure that must come with the accomplishment of results in soil building and crop production.

The farming end of these estates is laid out like a manufacturing establishment - the crops, fertilizers, etc., all planned in ten-year cycles. A four-crop rotation is being used, but a map is made showing just what each field is to do for a ten-year period.

A large amount of vegetable matter in the form of cover crop is returned to the soil; and practically all forage crops are fed on the farm, the manures carefully kept and returned to the land.

Five hundred acres on the Kriesheim estate are kept for permanent pasture for horses, dry cows and young stock. The 100 milking dairy cows are kept in barns constantly and fed green cut grass, beet tops, clover hay, etc.

The land is light, sandy loam, but is valued at $\$ 125$ an acre and rents for $\$ 3$ an acre annually.

The farm hands get 35 cents a day - with cabin, garden and 900 pounds of grain.

The potatoes have been developed for years for high percentage of starch, this quality being especially desired in the manufacture of starch and alcohol. They are coarse and low in quality as compared with British or French varieties.

On the place potatoes have been grown for fifty years without spraying, but this year (1910) the blight was a serious menace to the crop. 
After the land is prepared for planting potatoes, the furrows and holes for the potatoes are opened up with a wheeled implement that opens four furrows. A spade-like affair on the wheel makes a hole four to five inches deep, and the potatoes are dropped in this.

The rows are made twenty-six inches apart and the seed is dropped eighteen inches apart in the row.

The seed is then covered by a horse-drawn "coverer" consisting of two disks, one working on either side of the row.

This system of planting - $18 \times 26$ inches - gives the greatest amount of room for roots possible with close planting. Planting $10 \times 27$ makes the roots of one plant encroach on those of its neighbors.

The entire crop goes to the starch factory, so there is no waste - all cut, green or rough tubers go in. The tubers are harvested by hand and handled in bulk.

A narrow gauge railroad track is run to the potato field to be used in handling the crop. These tracks are in sections and can be moved to any part of the farm. The cars are pushed by hand.

The seed for next season's planting is saved from the main crop.

Whole seed is always planted, but small seed is used so that only about 1,000 pounds per acre are required.

That part of the crop used for table consumption is largely grown on small holdings, while the starch and other factories are supplied from the large estates.

Travelers in Europe complain of the potatoes served at the hotels lacking in flavor and quality. They are mostly served boiled or pared and are 
often very small - about the size of a walnut with the hull on.

The potato is a favorite ingredient for soups and salads, a special soggy potato that does not cook "mealy" being grown for salad making. The Pabst Brewing Company of Milwaukee, Wis., imports some of these every year for their customers. These have been grown at Mt. Sopris Farm. The potato is thin-skinned, yellow, and often seven or eight inches long, tapering at both ends. It is about an inch in diameter, very waxy and holds its form well.

A great may Russians are imported into Germany during potato harvest. They work for low wages, but are required to return to Russia after the harvest season. The German laws rigidly protect local farm labor.

The following about the manufacture of potato flour in Europe is from the reports of the following representatives of the Government of the United States - Consul-General A. M. Thackara, Berlin, Germany, and Vice-Consul D. P. De Young, Amsterdam, Netherlands:

"The great bulk of the so-called potato flour (kartoffelmehl) that is sold at retail in the groceries of Germany for cooking purposes is simply fine ground and sifted potato starch. There is, however, a flour obtained by grinding and bolting dried potatoes that is a comparatively new product.

"In 1901, when the potato crop of the country reached the enormous total of 53,682,010 short tons, efforts were made to discover practical and economical methods of preserving the potatoes, so that the surplus could be stored and utilized in supplying future demands. Prizes were offered and a number of processes were submitted, 
in the more important of which the potatoes are dried by steam, forming what are called "kartoffelflocken," or potato flakes, which can be used for feeding stock, for distilling alcohol, for making starch, and for other purposes for which potatoes are used, or they can be ground and bolted for human consumption.

"In the Tätosin process for the production of flakes, the raw potatoes are washed in a washing machine commonly used in distilleries or starch factories, and then conveyed by an elevator to a steamer erected over the drying apparatus, where they are cooked by means of low-pressure steam, as if the potatoes were to be used for feeding stock. The drying apparatus proper consists of two smooth, hollow, cast-iron revolving drums about four feet long and two feet in diameter, each with a clearance of about 0.039 inch. The drums are supported upon a cast-iron framework, on the top of which there is an iron hopper fitted at the bottom with emasculators, or crushers. The drums are heated by steam of 5.5 to 6 atmospheres led through a pipe passing through their axes. The interiors of the drums are ridged longitudinally. Condensed water is taken from the drums by two small pipes and returned to the boilers.

"The potatoes after being steamed are allowed to fall by gravity into the hoppers and through the emasculators, where they are reduced to pulp, and in this shape are forced on to the drying drum. The drums turn in opposite directions at five revolutions a minute. The heat drives off the moisture of the potato pulp, leaving a firm mass that is scraped off by means of knives set parallel to the main axes of the drums. The dried mass falls into a spiral transporter fitted with revolving 
arms, where it is broken into flakes and conveyed to the packing room.

"In other processes of preserving potatoes used in Germany the tubers are cut into disks or small pieces and dried by hot air. The method described, however, is that most in use. At present there are 436 plants established in Germany for drying potatoes, with an estimated production annually of 110,230 to 165,345 short tons, or $3,674,000$ to $5,511,500$ bushels. Of the above plants, 350 are for the production of potato flakes, and in 86 plants the potatoes are dried by the hot-air processes.

"The prices of potato flakes vary from 14 to 16 pfennigs (3.3 to 3.8 cents) per kilo (2.2 pounds). The estimated cost of the production of the flakes is 6.30 marks ( $\$ 1.50)$ per 50 kilos (110.2 pounds).

"In the production of ground potato flour the potato flakes are ground and bolted. There are but few concerns that manufacture the flour, each having its own process. The flour is a yellowish white product, rich in carbohydrates. According to experiments made by the 'Institut für GärungsGewerbe' (Institute for the Fermentation Industry) in Berlin, the principal constituents of the flour are: Water, 10.69 per cent.; protein, 6.59 per cent.; fatty substances, 0.23 per cent.; nonnitrogenous substances, 78.73 per cent.; raw fibre, 1.1 per cent. and ashes, 2.58 per cent.

"The flour is used principally by bakers for adding to rye and wheat flour in making bread. The proportion for wheat bread is 5 to 10 per cent. of the ground potato flour, and for rye bread the amount can be increased to 15 per cent. It is claimed that the addition of the ground potato flour to the rye or wheat flour gives the bread a good flavor, makes it more digestible, and keeps it 
fresh for a comparatively long time. It is also used to a slight extent in thickening soups and sauces

"There are no statistics available that would indicate the annual consumption of ground potato flour in Germany, but as an industry the manufacture of the flour has not attained large proportions. It is sold principally to bakers. It is known to the trade as 'Walzmehl,' 'Kartoffel Walzmehl,' 'Patent Walzmehl,' and 'Fiddichower Walzmehl.' The prices vary according to the potato crop and the quality, and range from $\$ 4.76$ to $\$ 7.14$ per 100 kilos (220.46 pounds).

"During the last sixty years potato farming has assumed large proportions in the Netherlands, due in great measure to the development of the potato-flour industry. In 1860 the total potato area was 273,318 acres, while in 1908 there were 395,089 acres. The following table shows the production by provinces in 1908 and the area of land devoted to the industry:

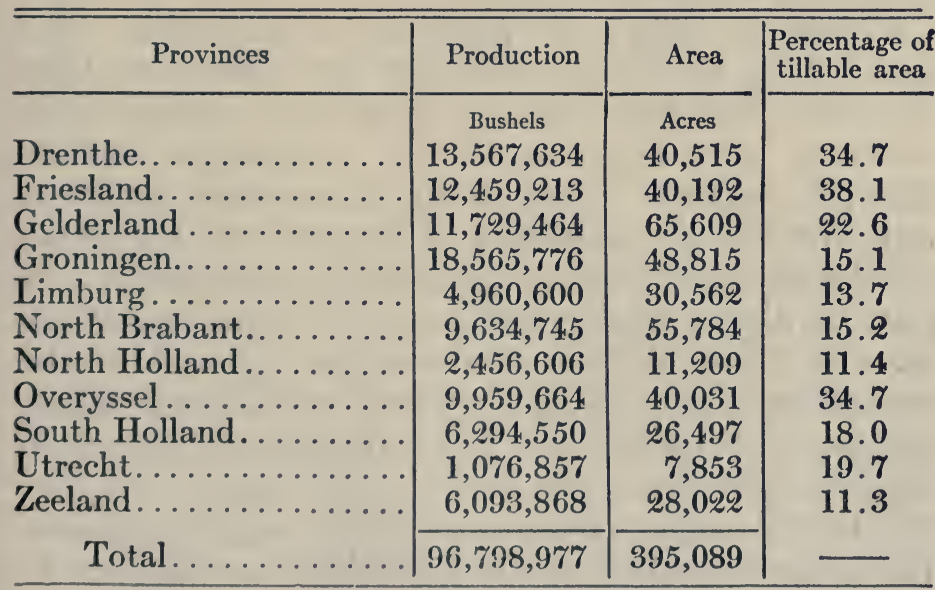


"Seventy-four per cent. of the potato crop is used for food and seed and the remainder supplies the raw material for manufacturing purposes. Three fourths of the manufacturing is done in the province of Groningen, and the remainder is confined to three other provinces. Of the 48,815 acres of potatoes in Groningen; over 37,000 were planted for industrial purposes.

"The scientific fertilization of the soil has become a very important feature of the potato industry in Groningen. Sometimes $\$ 32$ to $\$ 50$ worth of fertilizer is scattered on one hectare (2.471 acres) of ground. The land is valued at fully $\$ 500$ per acre and rents at $\$ 22.50$ per acre per year. The fertilizers consist of about 200 kilos of Chile saltpetre and 700 kilos of superphosphates to the hectare. Potatoes raised on this highly fertilized soil are not very edible, being cultivated principally for their industrial properties. There is a sentiment in favor of using the factory waste for fertilizing, but it has not proved a success as yet.

"The methods of planting, cultivating, and harvesting potatoes have not advanced as they should. Several picking machines have been tried of late, but not to the satisfaction of the planters. They want a machine that will not only dig the potatoes out of the ground, but clean off the dirt and empty them into a sack as well. A potato digger that merely uproots the potatoes, leaving them scattered over the ground to be picked up and sacked by hand, saves little labor, as they still have to be cleaned, sacked, and often shaken loose from the roots and vines.

"In the coöperative potato producing and manufacturing enterprises the packing is usually let to 
contractors at from $\$ 0.09$ to $\$ 0.10$ per row of 140 meters (459 feet). That includes stacking them in piles and covering them with straw. The laborers are also given free potatoes during the picking season. Sometimes these contractors are the heads of large families, but there are also contractors who sublet to individual workmen. They usually pay the pickers $\$ 0.06$ per row. One person is able to pick seven of these rows per day of seven hours. The whole family usually joins in the work, camping out on the potato field during the season. Independent farmers often pick their own crops.

"A great impetus to the potato-flour industry was given by the coöperative method introduced during the last two decades. In fact the introduction of that system has really joined the operation of producing raw materials and manufacturing them into potato flour. It led to the establishment of coöperative experiment stations whose object it is to study the scientific culture and treatment of potatoes for industrial purposes in all practical phases of the industry. Previously there was no organization between planter and manufacturer, which frequently proved disastrous to both.

"The first step toward organization was taken in 1890 by several of the large manufacturers, but arrangements were not completed until 1900, owing to the lateness of some in joining. The factories then announced uniform prices for raw potatoes and the farmers had to sell on their terms. The latter retaliated by organizing coöperative producing societies, which soon developed into manufacturing institutions as well. There are therefore two systems of operating, one in which 
the farmers coöperate to the extent of owning shares in the factory and the other in which the trading is independent and speculative.

"The different coöperative plants are of course still competitive in respect to each other. They have their own trademarks, they sell independently through domestic and foreign agents, and are keen rivals in the production of superior qualities. Of the thirty-four potato-flour factories in the Veenkolonien, eleven are coöperative. The largest independent factory has a capital of $\$ 600,000$ and the buildings and machinery are valued at $\$ 100,000$. This factory has small branches in various sections of Groningen. Some of these mills have a capacity for grinding over 28,000 bushels in twenty-four hours; the smallest, about one fourth of that amount. Three fifths of the total production of potato flour of the country is ground in independent mills. The demand for Dutch potato flour is always greater than the supply.

"The season for manufacturing potato flour is usually about ten weeks in duration - from the middle of September to the last of November. The fine waterway system of Groningen greatly expedites the delivery of potatoes, naturally shortening the season, and in fact accelerating the industry. The great network of canals and other waterways makes it possible to transport the potatoes directly from the field to the factory, the latter always being on canals that accommodate forty to 100 ton vessels. Potatoes are sent in shiploads of 2,000 to 3,000 bushels each. Frequently these ships are owned by the factories, though sometimes by private individuals or transportation companies. 
"It is difficult to set an exact value on the potato used in the potato-flour industry. Some factories buy them by the hectolitre (2.837 bushels) without paying any attention to the quality, while others grade them according to the amount of starch contained. However, it is estimated that at an average of $\$ 0.34$ per hectolitre the value of potatoes ground into flour in one season would be $\$ 3,400,000$. Calculating roughly, one hectolitre of potatoes produces eleven kilos of flour (8.54 pounds to the bushel). A conservative estimate of the total production of potato flour in the Netherlands for one season is 110,000 metric tons of $2,204.6$ pounds. The price per bag of 100 kilos ( 220.46 pounds) has varied in the last few years from $\$ 3.60$ to $\$ 5.20$. An average price of $\$ 4.40$ per bag would bring the total value of the manufactured product up to $\$ 4,840,000$ per season, $\$ 1,440,000$ more than the cost of the raw potatoes.

"It would seem bad business for farmers to pay a rent of $\$ 122.50$ per acre, fertilize to the extent of $\$ 10$ or $\$ 15$, and sell 380 bushels of potatoes per acre at $\$ 0.12$ to $\$ 0.15$ per bushel, but it should be understood that the most valuable land, highly fertilized, produces much more than the average. "The potato flour exported from the Netherlands goes to Great Britain, Spain, Belgium, Italy, the free port of Hamburg, Denmark, and the United States and Canada. The United States imported $\$ 38,000$ worth of dextrin and potato flour from the Netherlands in 1910 . England and Belgium are perhaps the best customers. Exports have grown from 35,933 metric tons in 1898 to 64,000 tons in 1909 .

"There are altogether thirty-two potato-flour 
factories in the Netherlands, of which twenty-four are in the Province of Groningen, two in Friesland, four in Drenthe, and two in Overyssel. In addition to this there are several small factories producing only dextrin or glucose. The total number of men employed in the works is nearly 3,000. Most of the factories are situated on deep canals in the reclaimed swamps of the Veenkolonien, and the tubers are transferred from the boats direct to the mill.

"A disagreeable feature of the potato-flour industry in the Veenkolonien is the waste thrown off and the consequent pollution of the canal water. Just after the milling season the water is so bad that ignitible gases evaporate from it. Often a lighted match thrown into the canal will cause an apparent blaze. The economic loss resulting from this waste is in the eyes of the planters of that region a serious matter. In all it is estimated that the wasted material is worth $\$ 666,432$ per year.

"In connection with the potato-flour industry there are seven dextrin factories in the northern part of the country and two in the province of Limburg. Dextrin is used chiefly for sizing purposes in textile plants. As a consequence, the demand for that product depends largely upon the cotton and linen industries. While there is a flourishing cotton industry in Overyssel, it is not sufficient to consume all the dextrin produced here, the remainder being shipped to Great Britain, United States, Spain, Italy, and Belgium. However, the exports in this line have decreased of late years, owing to both the increased price of the dextrin and higher import duties in many foreign countries. 
"The production of glucose from potatoes in the Netherlands dates from 1875, since which time it has not only greatly increased but the quality has been improved. Eleven factories, some combined with potato-flour establishments and others working independently, produce glucose from potatoes in both the solid and liquid state. From a total production of 9,600 metric tons in 1896 it has grown to 20,000 tons in 1908. Almost all of this glucose is consumed in the Netherlands, especially in confectioneries and cake and jam factories. It is impossible to build up an export trade in this article, owing to the high import duties in other countries and the strong competition it encounters especially from American glucose manufactured from corn. There is a constant fear of overproduction in this article. However, the confectionery industry in the Netherlands is so thriving that domestic consumption may keep pace with the supply for a long time. The high excise tax on the article when consumed in the country - 3.28 cents per pound, American currency - is a great bar to its use. The form in which it will find its most successful outlet, therefore, is in a manufactured state, such as cookies, candies, and other confectioneries, as the excise is withdrawn from such articles if actually exported to another country. It is evidently exported in that form."

"Intensive cultivation" is the lesson to be learned from the European potato grower. 


\section{CHAPTER XLI}

\section{HISTORY}

TN COMMON with many other food plants, the early history of the potato does not appear 1 to be especially authentic; but there are some points on which most writers agree.

The potato (Solanum tuberosum) - French, pomme de terre; German, kartoffel; Dutch, aarappel; Danish, jordepeeren: Italian, patata; Spanish, patatas; American slang, spuds, murphies; English slang, tatties - belongs to the same family as tobacco, belladonna, tomato, egg plant, and capsicum. There are 1,600 species in the family, and but six bear tubers. The wild potato produces seed balls from the flowers, and this is true now of some vines in the valleys of the western slope of the Rocky Mountains. The potato is a native of mountain valleys in South America very similar to, if not identical with, conditions in Colorado and southern Idaho. In its native home it grows at an altitude of 4,000 to 6,000 feet. The potato was probably carried to Spain by returning explorers in the sixteenth century. It was in turn taken to Florida by other Spanish explorers, from there to Virginia, and from that colony to the continent of Europe.

It is reported that when the Spanish discovered South America - Chile and Peru - they found the potato an important article of food.

In "Pictorial Practical Potato Growing," by 
Walter P. Wright and Edward J. Castle, and published by Cassel \& Company, Limited, London, is the following:

"Italy would seem to be the first country to give special attention to the newcomer, an Italian named Cardano being early associated with it. The year 1586 is generally admitted to be the date of introduction to Great Britain, Sir Thomas Herriot, a companion to Sir Walter Raleigh, being its introducer. Some authorities are inclined to give the credit of its introduction into Britain to Admiral Drake, who is stated to have sent planters of Virginia especially to bring over the tubers.

"Be that as it may, it seems certain that the first potatoes known in Great Britain came from Virginia, and it is equally certain that they were first planted in Ireland, near Cork. Switzerland, France, and Germany were the next countries to welcome Solanum tuberosum, but nowhere was it regarded as of particularly high value for food. The famous French botanist, Olivier de Serres, deemed it worthy of a special chapter in a book he published in 1600. To another Frenchman, M. Fraizier, the tuber owes its popular name, it having first been called pomme de terre - apple of the earth - in a book dealing with that gentleman's voyage to the coasts of Chile. This was in 1716 . To a third Frenchman, M. Parmentier, the potato owes its popularization as an article of human food, though the statement that Parmentier had anything to do with its introduction is erroneous. Louis XVI seconded the efforts of Parmentier by ordering a large tract of land to be planted with potatoes, and himself wearing a flower of the plant in his buttonhole. 
"In England the potato at first met with little favor, its relationship to the deadly nightshade causing it to be regarded with suspicion. Sir Walter Raleigh endeavored to interest Queen Elizabeth in the newcomer, and even succeeded to the extent of getting a dish of cooked tubers placed on the royal table. Courtesy forbade the guests to refuse to partake of the new dish, but their dislike was so obvious, and so assiduously did they circulate tales regarding the poisonous nature of the tubers, that we do not read of the experiment being repeated. In Ireland the potato met with a better reception, and its culture was far advanced and understood in that country before England took the matter seriously in hand. Not until 1663 do we read of potato culture becoming at all general in England, but in that year it received a great impetus, owing to the efforts of the Royal Society, which were prompted, it is said, by a recognition of the food value of the tubers in time of famine.

"The original tubers would appear to have been round, and about the size of a large walnut. Herriot called the potato Openwak, and Gerarde, who pictured the plant in his famous 'Herbal' in 1597, gave it the scientific name of Bata Virginia. To Gaspard Bauhin, a celebrated botanist of Basle, belongs the credit of giving the plant its present and universally recognized scientific name, Solanum tuberosum. This was about 1590 , and it does not appear that the name then bestowed has ever been disputed. There are at least six tuber-bearing species of Solanum, but in the opinion of Mr. J. G. Baker, the famous Kew botanist, all the varieties in cultivation have originated from one species $-S$. tuberosum. 
"When once the real value of the potato was recognized its progress into every country of Europe seems to have been very rapid, though Scotland seems to have disregarded it until the middle of the eighteenth century, when famine and great destitution forced the claims of the new improved tuber upon the Scottish farmers. So rapidly did it grow in popularity that in 1747 we read of 700 bushels of potatoes being exported from Carolina, while in 1840, the year of the potato's first appearance in the United States census, the crop is given as 108,298,060 bushels.

"The first real check to potato cultivation was received in 1842, when the now well-known and dreaded potato disease, Phytophthora infestans, (late blight) made its appearance in Germany. Soon after this it was recorded from Canada and the United States; in $\mathbf{1 8 4 5}$ the Isle of Wight, and thence England, felt its presence; and by 1846 it was known almost all over Europe. A famine in Ireland followed, and for a while it looked as though the potato was threatened with extinction. Fortunately, however, the efficacy of sulphate of copper and lime in combating the disease was discovered, and this, under the name of Bordeaux mixture, has greatly helped to preserve the potato as we know it."

Mr. Arthur W. Sutton, Reading, England, in a lecture before the Royal Horticultural Society, presents the following very interesting facts:

"Concerning the introduction of the potato into England, the following extract from 'London's Encyclopedia, published in 1836, is of sufficient importance to find a place in any paper on po- 
tatoes: 'It appears probable that the potatoe was first brought into Europe from the mountainous parts of South America in the neighborhood of Quito, where they were called papas, to Spain, early in the sixteenth century. From Spain, where they were called vattatas, they found their way to Italy, and there received the same name as the truffle, taratoufli. From Italy they went to Vienna, through the Governor of Mons in Hainbault, who sent some to Clusius in 1598. To England the potatoe found its way from North America, being brought from Virginia by the colonists sent out by Sir Walter Raleigh in 1584, and who returned in July, 1586, and "probably," says Sir Joseph Banks "brought with them the potatoe." Gerarde in his "Herbal," published in 1597 , gives a figure of the potatoe under the name of potatoe of Virginia, whence, he says, he received the roots; and this appellation it appears to have retained, in order to distinguish it from the battatas, or sweet potatoe (Convolvulus battatas) till the year 1640, if not longer. Gough says the potatoe was first planted by Sir Walter Raleigh on his estate of Youghall, near Cork, and that they were soon after carried into Lancashire. Gerarde and Parkinson, however, mention them as delicacies for the confectioner and not as common food. Even so late as Bradley's time (1716, in his "Historia Plantarum Succulentarum") they are spoken of as inferior to skirrets and radishes. " "The use of potatoes, however, became more and more known after the middle of the eighteenth century and has greatly increased in all parts of Britain within the last thirty years. It is also very general in Holland and many parts of France and Germany and is increasing rapidly in Russia. 
In Spain and the East and West Indies they are not much cultivated, owing to the heat of the climate; but in all the temperate parts of North America, Australasia, and South America they are grown by the colonists. In China they are cultivated, but not extensively, owing to the slow progress which everything new makes in that country. Indeed, no root hitherto discovered is so well adapted for universal use as the tubers of the potatoe; for, having no peculiarity of taste, and consisting cniefly of starch, their farina is nearly the same as that of grain. Hence, with the flower of potatoes, puddings and such preparations as do not call the gluten of wheat flower into action, may be made equal to those of millet or rice, and excellent bread with a moderate proportion of good wheat flower. Potatoe starch, independently of its use in the laundry and as a hair powder, is considered an equally delicate food as sago or arrow-root. As starch and sugar are so nearly the same that the former is easily converted into the latter, the potatoe yields a spirit equal to that of malt by distillation and a wine or beer by the fermentative process.'

"Monsieur Henri L. de Vilmorin, in his lecture on the best kinds of potato, read before the Agricultural Society of Paris on January 30, 1888, mentions that toward the end of the sixteenth century, the potato was introduced directly into England, where it rapidly obtained a position among the common vegetables of the garden. On the continent, however, its progress was attended with greater difficulty. The prejudices which existed against its general use were, however, combated with energy by certain men devoted to the public welfare, such as Duhamel du Monceau, Inspec- 
tor-General of Naval Construction; Mgr. du Barral, Bishop of Castres, and the Minister Turgot himself. It was reserved, however, to Monsieur Parmentier to succeed where so many able men had failed, and his success was due above all things to his perseverance and the tact with which he used his intimate knowledge of the character of les Parisiens. Instead of trying to convince them by argument, he undertook, with the consent of the King, Louis XVI, to plant potatoes on the plain of Les Sablons, and, surrounding his experiments with an air of mystery, he had the plot guarded by a cordon of troops, and thus succeeded in adding to the curiosity of the population. He then invited a number of scientific and influential men to a banquet where every dish was either composed chiefly of potatoes, or was served up with potatoes as an accompaniment. This proved the most eloquent demonstration possible of the culinary properties of the new vegetable, and his cause was gained. During the end of the eighteenth century and the early years of the nineteenth century the potato made great progress, and when, in 1813, the Central Society of Agriculture undertook to provide, as a basis for study of the culture of the potato, a collection of the varieties then in use throughout the French Empire, it brought together no less than 115 to 120 different kinds.

"Count Rumford in the middle of the last century tells of the trouble he experienced in persuading the people of Munich to use the potato as food, even in a time of great scarcity. Only by his disguising the potato in a kind of soup did they gratefully accept his offering.

"Gerarde, in his 'Herbal,' 1597, wrote as fol- 
lows: 'Virginia potato hath many hollow, flexible branches trailing upon the ground; these are square, uneven, knotted or kneed in sundry places at certaine distances: from the which knots cometh forth one great leafe made of divers leaves, some smaller and other greater, set together upon a fat middle rib by couples, of a swart greene colour tending to rednesse; the whole leaf resembling those of the Winter-Cresses, but much larger; in taste at the first like grasse, but afterwards sharp and nipping the tongue. From the bosome of which leaves come forth long round slender foot stalkes, whereon grow very faire and pleasant floures, made of one entire whole leafe, which is folded or plaited in such strange sort, that it seemes to be a floure made of five sundry small leaves, which cannot easily be perceived, except the same be pulled open. The whole floure is of a light purple colour, striped downe the middle of every fold or welt with a light show of yellownesse, as if purple and yellow were mixed together. In the middle of the floure thrusteth forth a thicke flat point all yellow as gold, with a small sharp greene pricke or point in the midst thereof. The fruit succeeds the floures, round as a ball, of the bigness of a little Bullesse or wild plumme, green at the first, and blacke when it is ripe, wherein is contained small white seed lesser than those of mustard; the root is thicke, fat, and tuberous, not much differing either in shape, colour or taste from the common potatoes, saving that the roots hereof are not so great nor long; some of them are as round as a ball, some oval or egge-fashion, some longer, and others shorter; the knobby roots are fastened unto the stalkes with an infinite number of threddy strings. It groweth naturally in Americus where it was first 
discovered, as reporteth Clusia, since which time I have received roots hereof from Virginia, otherwise called Norembega, which grow and prosper in my garden as in their own native country. The leaves thrust forth of the ground in the beginning of May; the floures bud forth in August, the fruit is ripe in September. The Indians call this plant pappas, meaning the roots; by which name also the common potatoes are called in those Indian countries. We have its proper name mentioned in the title "Potatoes of Virginia." Because it hath not only the shape and proportion of potatoes but also the pleasant taste and vertues of the same, we may call it in English, Potatoes of America or Virginia.'”

The potato is receiving greater attention to-day than ever before in the history of the plant. In the countries where it is most needed for food there has been the greatest development at the hands of man. Single tubers of new varieties in England have sold for fabulous prices, and new, improved sorts are jealously guarded by their originators.

Growers, Government and state experimenters, and other scientific men - in all countries - are now working for varieties that will produce the greatest possible tonnage of the highest class product, and for cultural methods best suited to accomplishing this. 


\section{CHAPTER XLII}

BOTANY, PHYSICAL AND CHEMICAL COMPOSITION OF THE POTATO

7 HE potato (Solanum tuberosum) belongs to the Solanum or Nightshade family. (Sola1 men is a Latin word meaning soothing or quieting.) In Bailey's "Encyclopedia of Horticulture," published by the Macmillan Company, New York, it is technically described as follows:

"Solanum, giving name to the family Solanaceae, is a vast genus of temperate and tropical herbs, shrubs and even trees, but is comparatively poorly represented in temperate North America. Dunal, the latest monographer, in 1852 recognized 901 species, and many species have been described since that time. The genus finds its greatest extension in tropical America. Of the vast number of species barely 25 are of much account horticulturally, and half that number will comprise all the species that are popularly well known. One of these is the Potato, Solanum tuberosum, one of the leading food plants of the human race. The genus seems to abound in plants with toxic properties, although its bad reputation in this respect is probably exaggerated.

"As a genus, Solanum is not easily separated from other genera, but some of its most designative characters are as follows: Leaves alternate: inflorescence mostly sympodial and therefore super- 
axillary or opposite the leaves: corolla gamopetalous and rotate or shallow-campanulate; plaited in the bud, the limb angled or shallow lobed; stamens usually 5 , inserted on the throat of the corolla, the anthers narrower or elongated and connivent and mostly opening by an apical pore or slit: ovary usually 2-loculed, ripening into a berry which is sometimes enclosed in the persistent calyx. The flowers are white, purple or yellow. The species are herbs in temperate climates, but in warm countries many of them are shrubby and some are small trees. Many of them are climbers. Two species bear underground tubers beside the tuberosum. The tuberosum is described as follows:

"'Low, weak-stemmed, much-branched perennial with tender, herbaceous tops, and perpetuating itself asexually by means of thickened or tuberous underground stems, glabrous or pubescent-hirsute: leaves are unequally pinnate; the 5-9 oblong-ovate leaflets are interposed with much smaller ones: flowers are lilac or white, in long-stemmed dichotomous clusters, the corolla prominently lobed: the fruit is a small globular yellow berry, usually not produced in the highly developed modern varieties. It is a native of the temperate Andes of Chile and adjacent regions. There is a form with yellow-blotched leaves (known as var. variegatum) sometimes cultivated for ornament.'

A study of the structure and composition of the potato is very interesting. Dr. C. F. Langworthy, in "Farmers' Bulletin 295" of the United States Department of Agriculture, gives a very full and comprehensive description. It follows: 
"The potato tuber is in reality a modified stem, being shortened and thickened as a storehouse for material held in reserve for the early growth of new plants. The outer skin of the tuber consists of a thin, grayish brown corky substance and corresponds roughly to the bark of an overground stem. If a crosswise section of a raw potato is held up to the light three distinct parts besides the skin may be seen. The outermost one is known as the cortical layer and may be from 0.12 to 0.5 inch in thickness. This layer is slightly colored, the tint varying with the kind, and turns green if exposed to the light for some time, thus showing its relation to the tender green layer beneath the bark of overground stems. It is denser than the other parts of the potato and contains many fibro-vascular bundles, especially on the inner edge where a marked ring of them plainly separates this layer from the next. The interior or flesh of the tuber is made up of two layers known as the outer and inner medullary areas. The outer one forms the main bulk of a well-developed potato and contains the greater part of the food ingredients. The inner medullary area, sometimes called the core, appears in a cross section of the tuber to spread irregular arms up into the outer, so that its outline roughly suggests a star. It contains slightly more cellulose and less water and nutrients than the outer medullary portion. These four parts of the tuber are shown in the illustration.

"As in all other plant forms, the framework of the tuber is made up of cellulose, a carbohydrate or group of carbohydrates familiar in many forms, as, for instance, the fibre of cotton or linen or the bran of wheat. In food and feeding stuff analyses it is usually designated crude fibre. Cel- 
lulose forms the walls of a network of cells, which in turn form the body of the tuber. These cells vary in shape and size in different sections of the tuber according to the part they play in its life. In the flesh they serve mainly for storage, and in them lie the starch grains.

"The interior of the tuber is more or less permeated by water in which are dissolved nearly all the soluble ingredients, including the various soluble carbohydrates. In this connection it is well to recall that the carbohydrates (cellulose, starch, the different kinds of sugars, etc.) are all closely related, and that under the influence of certain acids, heat, or other agency an insoluble form, such as starch, may be changed into a soluble form, or vice versa.

"Cultural varieties of a given plant often have very different habits, appearance and quality, and it is natural that the amounts and proportions of water, carbohydrates, fats, protein and mineral matters which the potato contains should vary with the variety as well as with the character of the soil, the climate, and other conditions under which it grows. Moreover, since the needs of the potato plant vary at different stages of its development, it will provide for them by varying the ingredients stored in the tubers and elsewhere. Taking into account all these factors, it might seem impossible to make any general statements about the chemical composition of the potato, but it may be said that the variations are in degree rather than in kind, and so many analyses and studies have been made, both in this country and in Europe, that the average or general characteristics of the potato are now well established. The following table shows the composition of raw and 


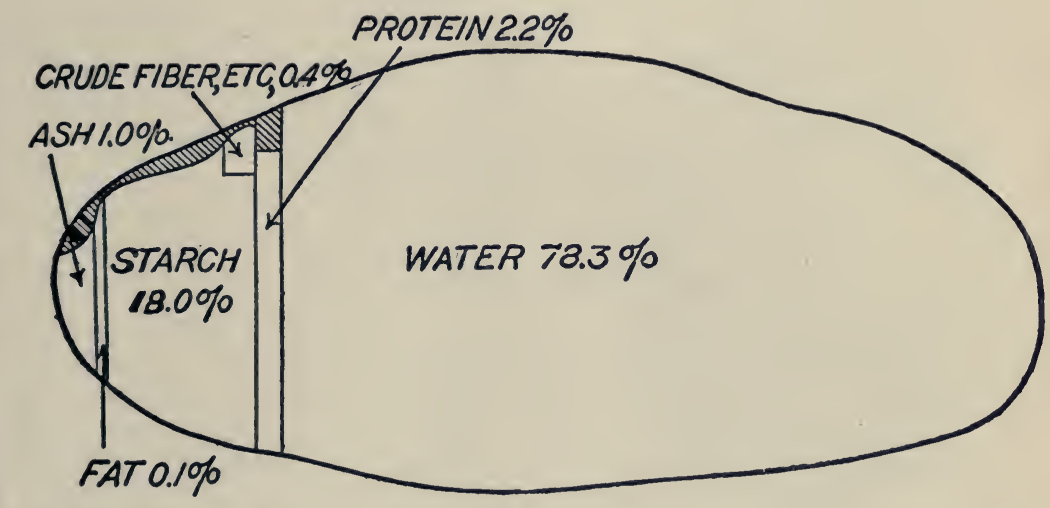

Composition of the potato. The shaded portion represents the average loss of nutrients when boiled 

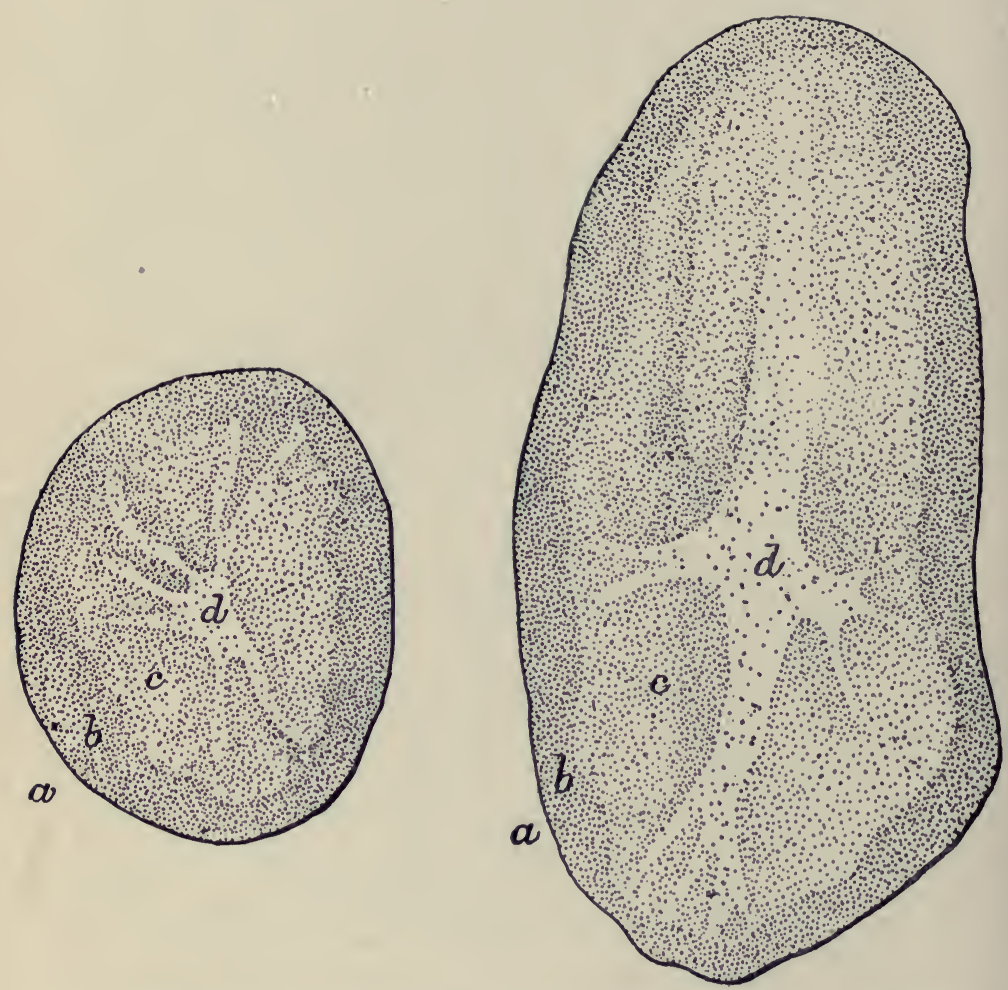

Transverse and longitudinal sections of the potato: $a$, skin; $b$, cortical layer; $c$, outer medullary layer; $d$, inner medullary area. From Farmers' Bulletin 295, United States Department of Agriculture 
cooked potatoes and represents the average of many American analyses. For comparison the composition of white bread is also given.

\begin{tabular}{|c|c|c|c|c|c|c|c|c|}
\hline KIND OF FOOD & $\begin{array}{l}\text { REF- } \\
\text { USE } \\
\text { Per } \\
\text { ct. }\end{array}$ & $\begin{array}{l}\text { WATER } \\
\text { Per ct. }\end{array}$ & $\begin{array}{c}\text { PRO- } \\
\text { TEN } \\
\text { Per ct. }\end{array}$ & $\begin{array}{l}\text { FAT } \\
\text { Per ct. }\end{array}$ & $\begin{array}{l}\text { CARBOHY } \\
\text { Sugar, } \\
\text { Starch, } \\
\text { etc. } \\
\text { Per ct. }\end{array}$ & $\begin{array}{l}\text { YDRATES } \\
\text { Crude } \\
\text { Fibre } \\
\text { Per ct. }\end{array}$ & Per ct. & $\begin{array}{c}\text { FUEL } \\
\text { VALUE } \\
\text { PER } \\
\text { POUND } \\
\text { Calories }\end{array}$ \\
\hline \multirow{4}{*}{$\begin{array}{l}\text { Potato, as purchased } \\
\text { Potato, edible por- } \\
\text { tion } \\
\text { Potato, boiled } \\
\text { Potato, mashed and } \\
\text { seasoned }\end{array}$} & 20.0 & 62.6 & 1.8 & 0.1 & 13.8 & 0.9 & 0.8 & 310 \\
\hline & & 78.3 & 2.2 & .1 & 18.0 & .4 & 1.0 & 375 \\
\hline & & 75.5 & 2.5 & .1 & 20.3 & .6 & 1.0 & 440 \\
\hline & & 75.1 & 2.6 & 3.0 & 17.8 & & 1.5 & 505 \\
\hline $\begin{array}{l}\text { Potatoes fried in fat, } \\
\text { "Potato chips" }\end{array}$ & & 2.2 & 6.8 & 39.8 & 46.7 & & 4.5 & 2,675 \\
\hline Potato, evaporated & & 7.1 & 8.5 & .4 & 80.9 & & 3.1 & 1,680 \\
\hline White bread & & 35.3 & 9.2 & 1.3 & 52.6 & .5 & 1.1 & 1,215 \\
\hline
\end{tabular}

"The corky skin of the potato makes up about 2.5 per cent of the whole, and the cortical layer 8.5 per cent., leaving 89 per cent. for the medullary areas. Theoretically, the skin is the only refuse or inedible material in the potato, but in practice a considerable part of the cortical layer is usually removed with it.

"The edible portion of the potato - i. e., the tuber without the corky skin - holds on an average about 78 per cent. water, and so only about 20 per cent of the whole tuber has a direct food value.

"The illustration shows very plainly that the bulk of the potato tuber is water. The stage of growth and other conditions affect the proportion present, young tubers being more juicy or watery than those which are fully developed.

"The carbohydrates are by far the most abundant of the nutrients. Of the 18.4 per cent. less than 0.5 per cent. is made up of cellulose, yet one 
sometimes hears the statement made that potatoes are indigestible on account of the large quantities of cellulose which they contain. In reality there is as much or more in almost all the cereals and other vegetable foods, and such a criticism of the potato has no warrant of fact.

"The bulk of the carbohydrates which the potato stores for future use is in the form of starch, which is, of course, insoluble in cold water, and small quantities of such soluble carbohydrates as dextrose, sugar, etc. In young tubers there is a larger proportion of sugars and less starch than when they have become mature. As the tuber lies in the ground the starch content increases. When it begins to sprout, however, part of the starch is converted by a ferment in the tuber into soluble glucose. Thus, young or early potatoes and old ones both have a smaller proportion of starch and more soluble sugars than well-grown but still fresh tubers. If the grated potato is mixed with water, starch falls out from the broken cells and settles to the bottom of the vessel, and may be removed in the form of a white deposit. Starch is manufactured to a large extent from potatoes by methods which are similar to the above in principle.

"Other carbohydrates in the potato are the socalled pectose bodies, the substances which cause fruit jellies to stiffen, and when the tubers are large and pulpy pectoses may make up 4 per cent. of the tuber, though they usually occur in much smaller quantities. They are believed to have about the same food value as starch.

"Fat, or ether extract, appears in such small quantities in potatoes that it may be practically neglected in discussing their food value, especially 
as the greater part occurs in the inedible skin in the form of a wax-like body.

"The protein bodies are rather scanty, as compared with those of cereals and such vegetables as peas and beans. Only about 60 per cent. of the total amount present is true protein - that is, in a form which can be used for the building and repair of body tissue. This means that a pound of potatoes furnishes only about 1.3 per cent. or 0.2 of an ounce of true protein, and emphasizes the statement already made that potatoes alone make a very incomplete diet, as the proportion of nitrogenous material would be very small in a quantity sufficient to supply the body with all the energy-yielding material required.

"These potato proteids have been studied by the Connecticut Experiment Station and found to consist of a form of globulin, for which the name 'tuberin' is suggested, and a proteose, part of these nitrogenous constituents being dissolved in the juice and part stored with the starch in the cells, especially in the cortical layer.

"The nonproteid forms of nitrogenous substances in the potato are asparagin and small quantities of amido acids, occurring mostly in the juice. If they have any food value it is indirect and due to the fact that they protect the true proteids from waste during digestion. It is possible that they may aid digestion in some way or serve a similar purpose. There is a larger proportion of protein compounds, and especially of the more soluble forms, in young potatoes than in old.

"The most important mineral matters found in potatoes are potash and phosphoric acid compounds. There are several organic acids (as citric, tartaric and succinic acid), which vary in tubers 
of different ages and account in some measure for the flavor of potatoes.

"If peeled potatoes are exposed to the air the outer surface turns brown, just as does the flesh of many fruits. Such change is due to the action of enzyms or unorganized ferments naturally present in the plants. In the presence of the oxygen of the air they work upon tannin-like bodies in the tuber or fruit in such a way that the latter change color. In the case of potatoes this browning may be prevented by putting the peeled tubers into salted water or even into cold plain water.

"In the condition in which they are purchased potatoes resemble such succulent carbohydrate foods as turnips and beets, with an average water content of 90 per cent., more than they do such dry carbohydrate foods as flour or rice with an average of 12 per cent. The condition in which foods are eaten should also be taken into account, for if the value of a food is judged solely by its chemical composition as it is found in the market a wrong impression may be obtained. For instance, potatoes as purchased consist of one fifth and rice of seven eighths nutritive material. The first inference is that rice is more than four times as nutritious as potatoes. In one sense this is true that is to say, a pound of uncooked rice contains more than four times as much nutritive material as a pound of raw potatoes. But if we take about four pounds of potatoes - that is, the amount necessary to furnish as much nutritive material as the pound of rice - the composition and nutritive value of the two quantities will be just about the same, while from a pecuniary standpoint the advantage would be on the side of the potatoes. The chief difference in the two foods before cook- 
ing is that one is juicy and bulky, while the other is dry, and therefore more concentrated. In cooking rice we mix water with it, and may thus make a material not very different in composition from potatoes. By drying potatoes they can be made very similar in composition and food value to rice. Considering the two articles as ordinarily purchased, 4.5 pounds of raw potatoes and a pound of uncooked rice contain nearly equal weights of each class of nutrients and have about the same nutritive value."

The manufacturing processes of the potato plant are described in "Bulletin 71" of the Wyoming Experiment Station, as follows:

"In order to understand the relation of the leaves to the tubers it is necessary to know that the starches and other food materials which are stored up in the tubers are produced within the leaves through the activity of the contents of the leaf cells when influenced by the action of light. The leaves are green because the cells contain the green bodies technically known as 'chloroplasts.' No plant which lacks ' chloroplasts' is capable of manufacturing starch.

"Leaf structure is essentially the same in all plants. A section from the upper to the under side will show on either side an epidermis of flattened, colorless cells. The cells immediatly underneath the upper layer are elongated and closely packed and are known as the palisade tissue. The lower half of the leaves contain nearly spherical cells, rather loosely arranged, with conspicuous air spaces near the lower epidermis. These communicate freely with the smaller spaces among the 
cells, and are continuous one with the other throughout the leaf. The air spaces are in direct communication with the outside air through tiny openings known as stomata. These openings on the surface often occur on both sides of the leaf, but in most crop plants they are more numerous on the under side, or may be entirely wanting on the upper. They are very important to the plant, since it is through them that the plant food derived from the atmosphere finds ingress to the leaf, which is really the plant's starch factory. They also serve the very important function of allowing the escape of the watery vapor and the oxygen which is released during the period of active starch formation. Necessary as are these openings on the leaf surface, they are also sources of great danger to the plant. The rest of the surface of the leaf is so thickened or waterproofed with the substance known as cutine that water cannot enter nor escape through it, neither can germs from the atmosphere find entrance into the leaf. When germs or other fungi secure admission to the tissues of the plant it is usually either through the stomata or through wounds upon the leaf or other part of the plant. It is for this reason that insect attacks are so often followed by fungous and germ diseases. Similarly wounds which plants accidentally receive or which are made by pruning are also often followed by diseased conditions.

"The crude sap of plants, which is essentially the soil water with the gases and soluble minerals of the soil dissolved in it, is taken up by the roots and conveyed through the stem to the leaves. The air which has been admitted to the leaf through the stomata supplies the carbon dioxide. 
From these ingredients, through the agensy of the protoplasm of the cell and the 'chloroplasts' acting in the presence of sunlight, starch is manufactured. This starch is temporarily stored in the leaf, but at night, when starch formation no longer is going on, the starch is, through the action of a ferment, converted into soluble form and is transmitted from the leaf through the stem to the underground stems, which become gorged with the material thus received. Another ferment now reconverts this soluble form of starch into the insoluble, which is then deposited in the tuber as a permanent part of it. The ultimate size of the tubers, therefore, depends upon the amount of starch that is thus formed by the leaves and transmitted from time to time to the tubers for storage.

"It seems that most of the crude sap passing upward in the stem is transmitted through ducts in the interior tissue, while the elaborated sap (as it is called when it has been acted upon by the leaf and is in condition to be used as plant food) is conveyed downward close to the exterior of the stem, viz., in the interior layers of the bark. It follows, therefore, that any injury to the inner bark or any artificial obstruction in these layers will prevent the downward movement of this elaborated sap. In the case of the potato, an injury to the bark will prevent the formation of tubers, as the sap conveying the soluble starch can no longer reach them. In the event of the elaborated sap being left in the above ground portions, it results either in very marked increase in the size of leaf and stem, through forced feeding, or the plant will attempt the formation of tubers above ground." 
.

y 


\section{APPENDIX}





\section{THE WORLD'S FOOD PROBLEM}

The most important problem in the world to-day is the future food supply - and in this the potato is an important factor. President W. C. Brown of the New York Central Lines has made a very careful study of the agricultural situation all over the world, both as it concerns the producer and consumer. So valuable are his ideas considered that the following very copious extracts are made from his address at the annual banquet of the Rochester (New York) Chamber of Commerce, March 18, 1910:

"We hear much of the subject of the conservation of our natural resources, and it is well that this most important subject should have the most careful consideration.

"I have thought, however, that about 90 per cent. of the discussion of this important question has been directed to about 10 per cent. of our natural resources.

"Husband our coal as we will, economize in its use to the last limit, but the day will come when the last ton will be mined and nothing will remain but the empty holes in the ground.

"The same is true of all the products of our mines; but the fertility of the soil cannot only be maintained, but constantly augmented, and it must be, if this nation or any other nation on the face of the earth is to continue to exist.

"Broadly stated, the great increase in the cost of living is caused by the simple economic fact that consumption is rapidly overtaking production, and a careful analysis of the increased price of farm products, as compared with the increase in price of the products of manufacture, will suggest the wondering inquiry how it has been possible to make the reductions, or to maintain the unchanged or slightly increased prices of the lattei, while the prices of the former have been moving upward so rapidly.

"These figures show conclusively that, in spite of the fact that the great increase in cost of these prime necessaries of life has increased the cost of labor more on the average than 33 per cent., these great manufacturing companies have been 
able, by economics in administration, operation and cost of distribution, to keep their prices down substantially to the level of ten years ago.

"Furthermore, by these same economics, these concerns are year by year increasing their sales in foreign lands, offsetting in great measure the loss in our exports of foodstuffs, which are rapidly diminishing to the vanishing point.

"No more accurate measure of fundamental prosperity can be found than that an individual or a nation produces and sells more than he or it buys - that the aggregate of all transactions results in bringing money in, rather than paying money out; and here occurs another sharp and significant contrast between the products of agriculture and those of mining and manufacture.

"In 1899 we produced more than three and one half billion bushels of corn, wheat, rye, oats and barley, and, including flour and cornmeal, we exported something more than four hundred and seventy millions bushel.

"In 1909 we produced more than four and one half billion bushels of these cereals, but our exports had dropped to less than one hundred and thirty-four million bushels.

"In other words, our exports of these products of the farm in 1899 exceeded those of 1909 by 251 per cent.

"Our exports of beef and its products for 1899 exceeded those of 1909 by 72 per cent., and the exports of the products of pork in 1899 exceeded those of 1909 by 89 per cent.

"Coincident with this falling off in our agricultural exports we imported in 1909 no less than 8,384,000 bushels of potatoes, $3,355,000$ bushels of beans and dried peas, and $6,667,000$ bushels of oats; and during the latter part of January of this year, notwithstanding a duty of 25 cents a bushel, we came within one half of 1 cent per bushel of importing wheat from England.

"The increase in corn, wheat, oats, rye, barley, potatoes, hay, buckwheat, flaxseed, rice, and cotton for 1909, over 1899 , is as follows:

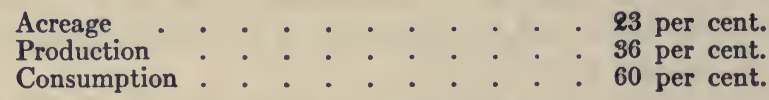

"In this economic evolution we are not following an untrodden path. Other nations have been confronted with the same great question, 'How shall we be fed and where- 


\section{APPENDIX}

withal shall we be clothed?' and upon the wisdom with which the question has been solved has hung the fate of those nations.

"More than a century ago the production of wheat in Great Britain had gone down to about the average of this country to-day - viz., a fraction less than fourteen bushels per acre.

"A royal commission was appointed, which has been in continual active existence ever since. The yield of wheat was gradually brought up to thirty-two bushels per acre, and at that figure it is maintained year after year.

"The story of this campaign for improved agriculture in England is exceedingly interesting, and, in the present juncture, of profound importance to this country.

"The islands of the sea have been swept clean of their rich stores of guano, the accumulation of ages. Phosphates have been imported by the millions of dollars' worth from the United States. The battlefields of Europe were combed, the catacombs of Egypt rifled, and for years the bones of three million men were ground up annually and used to bring the soil of England back to its present fertility.

"Approximately five million dollars' worth of our phosphates are being exported each year. In some way this should be stopped. In the years to come this master fertilizer will be worth more than gold.

"I believe it is well within the bounds of conservatism to say that long before the middle of the present century the phosphates which we export annually, and for which we receive five million dollars, will be worth five hundred million dollars for fertilizing our own land.

"It is safe to say that no country in the world excels the United States in natural fertility of soil, or has a more favorable general climate.

"Notwithstanding these natural advantages, with our careless, uninformed methods - our utter want of method our farms produce an annual yield of less than fourteen bushels of wheat per acre, as compared with thirty-two in England, twenty-eight in Germany, thirty-four in the Netherlands, and twenty in France.

"We produce an average of less than twenty-three bushels of oats per acre, while England produces forty-two, Germany forty-six, and the Netherlands fifty-three.

"Germany, with an arable area of less than some of our 
largest states, produces more than seven times the number of bushels of potatoes that are produced in all the states.

"Experimental farms should be established in every county of every state, where the most modern methods of fertilization and cultivation and the result of such methods can be demonstrated, and where every farmer in the county can see exactly how it is done, instead of being told in books or lectures how it can be done.

"The marvelous extension and development of railroads through the Middle West during the ten years following the close of the Civil War, opening up and making easily accessible empires of this rich land, marvelously stimulated emigration; and each new railroad, each extension of existing railroads, was followed by the location of thousands of settlers and the opening up and cultivation of millions of acres of new land.

"The result that followed was inevitable. The products of the nation's farms soon so far exceeded the demand for them that prices fell far below the bare cost of production.

"I have seen as good corn as the states of Iowa, Kansas, and Nebraska ever grew sell for ten to twelve cents per bushel, and it was a drug on the market at that price. I have seen this corn burned for fuel on the farm, because it was cheaper than wood or coal.

"Is it strange that such conditions resulted in a ruinous collapse in farm values in Pennsylvania, New York, and New England, or that they begot methods or habits of unthrift and improvidence in the cultivation of the soil in the West?

"These conditions prevailed not only in our own country but abroad. Railroads were being built in Russia, Australia, Argentina, India, and New Zealand, and cheap land with its cheap product competed in every market on the globe.

"Fifty-one years ago, in an address delivered before the Wisconsin Agricultural Society, Abraham Lincoln said:

" My first suggestion is an inquiry as to the effect of greater thoroughness in all departments of agriculture than now prevails in the Northwest; perhaps, I might say, in America.

"What would be the effect upon the farming interests to push the soil up to something near its full capacity? Unquestionably, it will take more labor to produce fifty bushels from one acre than it will to produce ten bushels from the same acre; but will it take more labor to produce fifty bushels from one acre than from five?

"Unquestionably, thorough cultivation will require more labor to the acre; but will it require more to the bushel? 
"'If it should require just as much to the bushel, there are some probable, and several certain, advantages in favor of thorough practice.

" 'It is probable it would develop those unknown causes which of late years have cut down our crops below their former averages.

"The thought recurs that education, cultivated thought, can best be combined with agriculture labor, or any labor, on the principle of thorough work, and thorough work again renders sufficient the smallest quantity of ground to each man, and this again conforms to what must occur in a world less inclined to war, and more devoted to the arts of peace, than heretofore.

"Population must increase rapidly, more rapidly than in former times, and ere long the most valuable of all arts will be the art of deriving a comfortable subsistence from the smallest area of soil.

"No community whose every member possesses this art can ever be the victim of oppression in any of its forms. Such community will be alike independent of crowned kings, money kings, and land kings.'

"These words of Mr. Lincoln could not have appealed very strongly to the farmers of Wisconsin or the neighboring states when land and its products were about the cheapest thing in which men dealt.

"Why expend money or especial effort to increase production when the most indifferent farming produced more than could be used and the surplus in many cases would not bring the bare cost of production? Why spend money in building up and enriching the soil when for two thousand miles, from the Mississippi to the Pacific, land as rich and fertile as the best on earth could be had for the asking.

"Fifty years later this admonition, under the changed conditions, comes with the force and significance of prophecy, because it applies now to a vital, burning question in which lie the issues of national life or death.

"When these words were spoken, and for thirty years following, production exceeded consumption, and there was a steady, continuous, heart-breaking decline in the values of the thing produced.

"Now, and for ten years past, consumption is overtaking production with alarming rapidity, and values are rising by leaps and bounds.

"Then, increased consumption could be provided for by increased acreage; now, this is impossible. Increased consumption can only be met by increased production on substantially our present acreage.

"Then, the outlook for agriculture was dark and almost hopeless, the market was limited, prices low, and the tendency was always down. Now, the market is unlimited at liberal and steadily advancing prices." 


\section{POTATO STATISTICS}

The world's production of various food crops for 1908 is as follows:

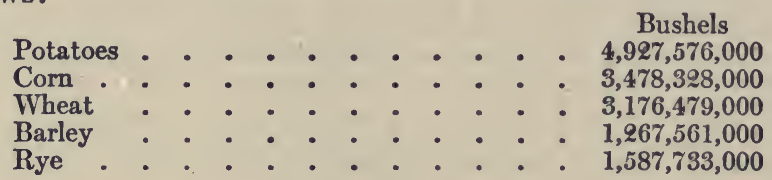

A comparison between potatoes and rice given in pounds:

$$
\begin{aligned}
& \text { Pounds } \\
& \text { Potatoes . . . . . . . . } 334,431,840,000 \\
& \text { Rice . . . . . . . . . 135, } 186,068,000
\end{aligned}
$$

The Year Book of the Department of Agriculture gives the potato crop of the principal potato-growing countries as follows:

(No statistics for Switzerland, Portugal, Argentina, Transvaal, Egypt and some other less important potato-growing countries.)

North America

United States........

Mexico..............

Newfoundland........

Canada.............

Total.

South America

Chile................

Europe

Austria-Hungary.....

Belgium...........

Denmark...........

Finland . . . . . . . . . .

France............

Germany.............

Italy.............

Malta..................

Netherlands.........

Norway...........

Roumania..........

Russia (European)....

Servia...............

Spain..............

Sweden.
Year 1904

Bushels

$332,830,000$

527,000

$1,350,000$

$55,436,000$

$390,143,000$

$6,131,000$

$520,461,000$

$91,632,000$

$24,214,000$

$15,465,000$

$451,039,000$

$1,333,326,000$

$29,000,000$

733,000

$94,421,000$

$17,253,000$

$3,001,000$

$893,908,000$

718,000

$84,000,000$

$51,314,000$
Year 1908

Bushels

278, 985,000 469,000

$1,350,000$

$74,746,000$

$355,550,000$

$8,063,000$

$639,407,000$

$82,846,000$

$29,752,000$

$20,432,000$

$375,000,000$

$1,702,803,000$

$29,000,000$

692,000

$96,695,000$

$28,030,000$

$4,310,000$

$1,060,135,000$

645,000

$84,000,000$

$78,020,000$ 
APPENDIX

POTATo STATistics - continued

\begin{tabular}{|c|c|c|}
\hline Europe & $\begin{array}{c}\text { Year } 1904 \\
\text { Bushels }\end{array}$ & $\begin{array}{l}\text { Year } 1908 \\
\text { Bushels }\end{array}$ \\
\hline Great Britain........ & $133,961,000$ & $146,258,000$ \\
\hline Ireland............. & $98,635,000$ & $119,455,000$ \\
\hline $\begin{array}{l}\text { (Total Great Britain } \\
\text { and Ireland)....... }\end{array}$ & $(232,596,000)$ & $(265,713,000)$ \\
\hline Total.......... & $3,843,081,000$ & $4,497,480,000$ \\
\hline \multicolumn{3}{|l|}{ Asia } \\
\hline Japan.............. & $11,274,000$ & $21,023,000$ \\
\hline Russia (Asiatic)...... & $18,800,000$ & $22,588,000$ \\
\hline Total. ........... & $30,074,000$ & $43,611,000$ \\
\hline \multirow{2}{*}{\multicolumn{3}{|c|}{ Africa. }} \\
\hline Algeria............. & $1,655,000$ & \\
\hline Cape of Good Hope... & $1,942,000$ & $1,304,000$ \\
\hline 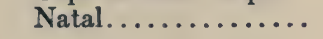 & 451,000 & 405,000 \\
\hline Total. ........... & $4,048,000$ & $3,512,000$ \\
\hline \multicolumn{3}{|l|}{ Australasia } \\
\hline Australia........... & $16,777,000$ & $14,021,000$ \\
\hline New Zealand........ & $7,795,000$ & $5,339,000$ \\
\hline $\begin{array}{l}\text { Total.................. } \\
\text { Grand Total..... }\end{array}$ & $\begin{array}{r}24,572,000 \\
4,298,049,000\end{array}$ & $\begin{array}{r}19,360,000 \\
4,927,576,000\end{array}$ \\
\hline
\end{tabular}

A comparison of the total value with that of other 1909 crops in the United States is interesting:

\begin{tabular}{|c|c|c|c|}
\hline & Acreage & Production & Value \\
\hline Potatoes.... . . . & $3,525,000$ & $376,537,000$ & $206,545,000$ \\
\hline Corn. & $108,771,000$ & $2,772,376,000$ & $1,652,822,000$ \\
\hline Wheat.... & $46,723,000$ & $737,189,000$ & $730,046,000$ \\
\hline Oats... & $33,204,000$ & $1,007,353,000$ & $408,174,000$ \\
\hline Barley. . & $7,001,000$ & $170,284,000$ & $93,971,000$ \\
\hline Rye............ & $2,006,000$ & $32,239,000$ & $23,809,000$ \\
\hline Buckwheat. . . . . . . . & 834,000 & $17,438,000$ & $12,188,000$ \\
\hline Rice........... & 720,225 & $24,368,000$ & $19,341,000$ \\
\hline
\end{tabular}

While of increasing importance in the United States, there are other crops that outclass it here. This is due to the fact that this is one of the great grain-producing countries of the world, and that the potato industry is capable of almost unlimited expansion here. In Europe its relative importance is very much greater than in the United States. A résumé of the potato industry in the United States from 1866 to 1909 shows the increase in its importance and volume: 
Acreage, Production, Value, Prices, etc.

\begin{tabular}{|c|c|c|c|c|c|c|}
\hline Year & $\begin{array}{c}\text { Acreage } \\
\text { planted and } \\
\text { barvested }\end{array}$ & $\begin{array}{c}\text { Average } \\
\text { yield per } \\
\text { acre }\end{array}$ & Production & $\begin{array}{l}\text { Aver. } \\
\text { farm } \\
\text { price } \\
\text { per bu. } \\
\text { Dec. I }\end{array}$ & $\begin{array}{l}\text { Farm value } \\
\text { Dec. Ist }\end{array}$ & $\begin{array}{l}\text { Imports } \\
\text { during } \\
\text { fiscal year } \\
\text { beginning } \\
\text { July I }\end{array}$ \\
\hline 1866 & $1,069,000$ & 100.2 & $107,201.000$ & 47.3 & $50,723,000$ & 198,265 \\
\hline 1867 & $1,192,000$ & 82.0 & $97,783,000$ & 65.9 & $64,462,000$ & 809,555 \\
\hline 1868 & $1,132,000$ & 93.8 & $106,090,000$ & 59.3 & $62,919,000$ & 138,470 \\
\hline 1869 & $1,222,000$ & 109.5 & $133,886,000$ & 42.9 & $57,481,000$ & 75,336 \\
\hline 1870 & $1,325,000$ & 86.6 & $114,775,000$ & 65.0 & $74,621,000$ & 458,758 \\
\hline 1871 & $1,221,000$ & 98.7 & $120,462,000$ & 53.9 & $64,905,000$ & 96,259 \\
\hline 1872 & $1,331,000$ & 85.3 & $113,516,000$ & 53.5 & & 346,840 \\
\hline 1873 & & 81 & & & & 549,073 \\
\hline 1874 & 1,3 & 80.9 & 105 & 61.5 & & 188,757 \\
\hline 1875 & 1,5 & 110.5 & 166 & 4.4 & & 92,148 \\
\hline 1876 & 1,7 & 71.7 & 124 & 1.9 & & $3,205,555$ \\
\hline 1877 &, 000 & 94.9 & 170 , & 43.7 & 74 & 584 \\
\hline 1878 & $1,777,000$ & 69.9 & 124, & 58.7 & 72,9 & $2,624,149$ \\
\hline 1879 & $1,837,000$ & 98.9 & 181, & 43.6 & 79 & 721,868 \\
\hline 1880 & $1,843,000$ & 91.0 & 167,6 & 48.3 & 81,0 & $2,170,372$ \\
\hline 1881 & $2,042,000$ & 53.5 & $100,145,000$ & 91.0 & $99,291,000$ & $8,789,860$ \\
\hline 1882 & $2,172,000$ & 78.7 & $170,973,000$ & 55.7 & $95,305,000$ & $2,362,362$ \\
\hline 1883 & $2,289,000$ & 90.9 & $208,164,000$ & 42.2 & $87,849,000$ & 425,408 \\
\hline 1884 & $2,221,000$ & 85.8 & 190,6 & 39.6 & & 658,633 \\
\hline 1885 & 000 & 77.2 & 175 & 7 & & $1,937,416$ \\
\hline 1886 & & 5 & & & & 2,490 \\
\hline 1887 & & & & 2 & & 8,25 \\
\hline 1888 & & 9.9 & 20 & 2 & & 380 \\
\hline 1889 & 2,6 & 77.4 & 20 & 35 & 72 & $3,415,578$ \\
\hline 1890 &, 000 & 55.9 & 148 & 75.8 & 112, & $5,401,912$ \\
\hline 1891 & $2,715,000$ & 93.7 & 24,000 & 35.8 & 91 , & 186,871 \\
\hline 1892 & $2,548,000$ & 61.5 & 55,000 & 66.1 & 103 & $4,317,021$ \\
\hline 1893 & 2,60 & 70.3 & 189 & 59. & &, 578 \\
\hline 1894 & 2,75 & 68.4 & & 53.6 & $91,527,000$ & $1,341,533$ \\
\hline 1895 & $2,955,000$ & 100.6 & $297,237,000$ & 26.6 & 78,9 & 175,240 \\
\hline 1896 & $2,767,000$ & & $252,235,000$ & 28.6 & & 246,178 \\
\hline 1897 & $2,535,000$ & & & 54.7 & & $1,171,378$ \\
\hline 1898 & & & & & & 530,420 \\
\hline 1899 & & & & & & 155,861 \\
\hline 1900 & & & & & & 371,911 \\
\hline & & & & 76.7 & 143, & $7,656,162$ \\
\hline & & 96.0 & 284,6 & 47.1 & 134,1 & 358,505 \\
\hline & & 84.7 & $247,128,000$ & 61.4 & 151,6 & $3,166,581$ \\
\hline & $3,016,000$ & 110.4 & $332,830,000$ & 45.3 & 150 , & 181,199 \\
\hline 1905 & 2,9 & & $260, ?$ & 61.7 & 160,8 & $1,948,160$ \\
\hline 1906 & $3,013,000$ & 102.2 & $308,038,0$ & 51.1 & $157,547,000$ & 176,917 \\
\hline 1907 & & 95.4 & $298,262,000$ & 61.8 & $184,184,000$ & 403,952 \\
\hline 1908 & $3,257,000$ & 85.7 & $278,985,000$ & 70.6 & $197,039,000$ & $18,383,969$ \\
\hline 1909 & $3,525,000$ & 106.8 & $376,537,000$ & 54.9 & $206,545,000$ & \\
\hline
\end{tabular}




\section{APPENDIX}

The variation in price is worthy of notice, and the fact that the average yield per acre is practically the same now as forty years ago shows the possibilities of advanced work and methods. The acreage has been increasing gradually with the development of the country.

The annual imports from Europe bear a direct relation to the total home production.

The acreage, production, and value of potatoes in the United States in 1909 follow:

State, territory or division

Maine.

New Hampshire........

Vermont.............

Massachusetts........

Rhode Island. . . . . . . . .

Connecticut.............

New York............

New Jersey... . . . . . . .

Pennsylvania........

North Atlantic.... . . . .

Delaware...........

Maryland..............

Virginia............

West Virginia.........

North Carolina.........

South Carolina.........

Georgia.............

Florida.............

South Atlantic........

Ohio.

.

Illinois ............

Michigan............

Wisconsin ..........

N.C.E. of Miss. River..

Minnesota...........

Iowa. ..............

Missouri..............

North Dakota.........

South Dakota.........

Nebraska............

Kansas..............

N.C.W. of Miss. River.
Acreage

130,000

21,000

$\mathbf{8 0 , 0 0 0}$

$\mathbf{3 4 , 0 0 0}$

6,000

36,000

438,000

80,000

$\mathbf{3 0 5 , 0 0 0}$

$1,080,000$

9,000

35,000

60,000

39,000

25,000

$\mathbf{9}, 000$

10,000

5,000

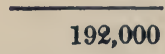

182,000

95,000

164,000

348,000

262,000

$1,051,000$

160,000

145,000

88,000

40,000

50,000

105,000

91,000

679,000
Production

$29,250,000$

$2,730,000$

$4,650,000$

$4,250,000$

750,000

$4,320,000$

$52,560,000$

$7,200,000$

$23,790,000$

$129,500,000$

864,000

$2,800,000$

$5,520,000$

$3,822,000$

$1,850,000$

765,000

810,000

475,000

$16,906,000$

$16,926,000$

$9,025,000$

$14,924,000$

$36,540,000$

$26,724,000$

$104,139,000$

$18,400,000$

$12,905,000$

$7,480,000$

$4,400,000$

$4,000,000$

$8,190,000$

$7,189,000$

$62,564,000$
Farm Value December Ist

$\$ 13,748,000$

$1,747,000$

$2,046,000$

$3,358,000$

600,000

$3,586,000$

$26,280,000$

5,904000

$15,464,000$

$72,733,000$

622,000

$1,848,000$

$3,864,000$

$2,599,000$

$1,498,000$

880,000

810,000

570,000

$12,691,000$

$9,479,000$

$4,693,000$

$9,104,000$

$12,789,000$

$10,155,000$

$46,220,000$

$6,440,000$

$7,098,000$

$5,012,000$

$1,908,000$

$2,520,000$

$4,914,000$

$5,679,000$

$33,643,000$ 
544

State, territory or division

Kentucky...........

Tennessee............

Alabama.............

Mississippi.............

Louisiana.............

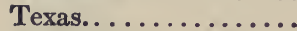

Oklahoma..............

Arkansas. ..............

South Central.........

Montana............

Wyoming............

Colorado............

New Mexico...........

Utah.................

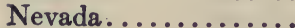

Idaho.

Washington..............

Oregon...............

California.............

Far Western

United States.

APPENDIX

\begin{tabular}{|c|c|c|}
\hline Acreage & Production & $\begin{array}{l}\text { Farm Value } \\
\text { December ist }\end{array}$ \\
\hline 40,000 & $3,680,000$ & $2,355,000$ \\
\hline 30,000 & $2,250,000$ & $1,598,000$ \\
\hline 17,000 & $1,360,000$ & $1,333,000$ \\
\hline 9,000 & 783,000 & 744,000 \\
\hline 16,000 & $1,200,000$ & $1,092,000$ \\
\hline 60,000 & $3,000,000$ & $3,180,000$ \\
\hline 27,000 & $1,890,000$ & $1,796,000$ \\
\hline 33,000 & $2,310,000$ & $2,215,000$ \\
\hline 232,000 & $16,473,000$ & $14,223,000$ \\
\hline 25,000 & $4,500,000$ & $2,295,000$ \\
\hline 10,000 & $1,600,000$ & $1,008,000$ \\
\hline 65,000 & $10,400,000$ & $5,928,000$ \\
\hline 1,000 & 85,000 & 86,000 \\
\hline 15,000 & $2,700,000$ & $1,161,000$ \\
\hline 3,000 & 540,000 & 459,000 \\
\hline 25,000 & $5,000,000$ & $2,400,000$ \\
\hline 41,000 & $6,970,000$ & $3,276,000$ \\
\hline 46,000 & $7,360,000$ & $4,416,000$ \\
\hline 60,000 & $7,8,00,000$ & $6,006,000$ \\
\hline 291,000 & $46,955,000$ & $27,035,000$ \\
\hline $3,525,000$ & $376,537,000$ & $206,545,000$ \\
\hline
\end{tabular}

It will be noted that the states rank as follows:

\begin{tabular}{|c|c|c|c|c|c|c|c|c|c|c|c|}
\hline New York & & & & & & & & & & $52,560,000$ & bushels \\
\hline Michigan . & & & & & & & & & & $36,540,000$ & “ \\
\hline Maine. & & & $\bullet$ & • & • & . & & & • & $29,250,000$ & 6 \\
\hline Visconsin & - & & • & • & - & - & - & • & • & $26,724,000$ & “" \\
\hline Pennsyl & & & & & & & & & & $23,790,000$ & “؛ \\
\hline
\end{tabular}

The importance given Idaho, Colorado, California, and other Western states in this book is because of the quality of their product and the possibilities in developing and enlarging the industry.

The average production of wheat and potatoes in different countries covering a period of ten years is given:

AVERAGE YIELDS IN BUSHELS PER ACRE 1899-I908

\begin{tabular}{l|c|r|r|r|r|r}
\hline \hline & U.S. & $\begin{array}{r}\text { European } \\
\text { Russia }\end{array}$ & Germany & Austria & $\begin{array}{r}\text { Great } \\
\text { Britain }\end{array}$ & France \\
\hline Potatoes........ & $\begin{array}{r}89.8 \\
13.7\end{array}$ & $\begin{array}{r}98.4 \\
9.3\end{array}$ & $\begin{array}{r}197.3 \\
28.7\end{array}$ & $\begin{array}{r}151.4 \\
18.7\end{array}$ & $\begin{array}{r}186.4 \\
32.6\end{array}$ & $\begin{array}{r}118 . \\
20.4\end{array}$ \\
\hline
\end{tabular}




\section{APPENDIX}

The best averages for states for 1909 are as follows:

\begin{tabular}{|c|c|c|c|c|c|c|c|c|c|}
\hline Maine . . & - & - & - & - & & 225 & Bushels & per & acre \\
\hline Idaho . & & . & . & . & & & & & \\
\hline Montana & & . & & & & 180 & “ & “ & “ \\
\hline Nevada & & . & : & . & & 180 & & “ & \\
\hline Utah. & & . & . & . & & 180 & “ & “ & " \\
\hline Washington & • & . & . & . & & 170 & “ & “ & “ \\
\hline Colorado. & & . & . & . & & 160 & “ & “ & “ \\
\hline Oregon . & • & . & . & . & & 160 & & “ & “ \\
\hline Wyoming & & . & . & . & & 160 & “ & “ & \\
\hline Vermont & & . & . & . & & 155 & “ & “ & “ \\
\hline New Hampshir & & . & . & . & & 130 & “ & “ & “ \\
\hline California & & . & 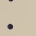 & . & & 130 & “ & “ & \\
\hline Massachusetts & & . & - & . & & 125 & “ & “ & “ \\
\hline Rhode Island . & & . & . & . & & 125 & “ & “ & \\
\hline Connecticut & & & • & . & & 180 & “ & “ & “ \\
\hline New York. & • & . & . & . & & 120 & “ & “ & \\
\hline Michigan . & & . & . & . & & 105 & “ & “ & \\
\hline Wisconsin & • & . & . & . & & 102 & “ & & $1 / 20$ \\
\hline Florida . & & - & - & . & & 95 & “ & “ & \\
\hline Kansas . : & & . & . & . & & 79 & “ & “ & 68 \\
\hline Pennsylvania & & . & • & . & & 78 & “ & “ & “ \\
\hline Louisiana . & & . & . & . & & 75 & “ & “ & \\
\hline Oklahoma & & . & & . & & 70 & “ & “ & \\
\hline Texas & & & & & & & “ & “ & \\
\hline
\end{tabular}

The production of potatoes in every state in the Union can and must be greatly increased. This can be done by the use of better methods, and it is the duty of every citizen of the commonwealth to do everything possible to bring about the desired result. 



\section{The Farm Library}

Each Volume, Net, $\$ 2.00$

Soils : How to Handle and Improve Them. By S. W. FLETCHER. More than roo illustrations.

Farm Management. By F. W. CARD. Marketing; Accounts, Buying Land, etc. Illustrated.

Farm Animals. By E. V. Wilcox. Cow, horse, sheep, and swine are all fully dealt with. Many photographs.

Cotton. By C. H. Burkett and C. H. Poe. The only book dealing adequately with this important subject. Illustrated.

Just The Potato Book. By Eugene H. Grubb. Issued All the facts about the potato and its cultivation in one concise volume.-The most up-to-date, practical and authoritative book ever published.'

\section{Other Books on Ägriculture}

The First Book of Farming. By C. L. Gooprich. A practical, common-sense handbook. Net, \$1.00.

Orchard and Fruit Garden. By E. P. Powell. Embodies the latest information. Net, \$I.Io.

The Vegetable Garden. By I. D. Bennetr. A thorough treatment of the staples with excellent chapters on fertilizers, garden tools, etc. Net, \$I.Io. How to Make a Fruit Garden. By S. W. FLETCHER. I82 illustrations. Net, \$2.00.

How to Make a Vegetable Garden. By E. I. FULlERTON. 250 illustrations. Net, \$2.00.

The Garden Week by Week. By Walter P. WRIGHT. 200 illustrations. Net, $\$ 2.00$.

DOUBLEDAY, PAGE \& COMPANY Garden City New York 
The Country Life Press

Garden City, N. Y.

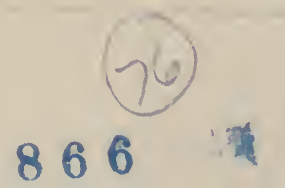







\section{PLEASE DO NOT REMOVE \\ CARDS OR SLIPS FROM THIS POCKET}

UNIVERSITY OF TORONTO LIBRARY

BiolMed 


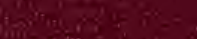

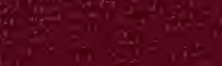

